B-TM-1639

SPECIFICATIONS, PRE-EXPERIMENTAL PREDICITONS, AND TEST PLATE CHARACTERIZATION INFORMATION FOR THE PROMETHEUS CRITICAL EXPERIMENTS

\author{
M. L. Zerkle, M. E. Meyers, S. M. Tarves, and J. J. Powers
}

Bettis Atomic Power Laboratory

West Mifflin, Pennsylvania 15122-0079

April 2006

Prepared for the

U.S. Department of Energy

By Bechtel Bettis, Inc. 


\title{
SPECIFICATIONS, PRE-EXPERIMENTAL PREDICTIONS, AND TEST PLATE CHARACTERIZATION INFORMATION FOR THE PROMETHEUS CRITICAL EXPERIMENTS
}

\author{
M. L. Zerkle \\ M. E. Meyers \\ S. M. Tarves \\ J. J. Powers
}

April 2006

\section{NOTE}

This document is an interim memorandum prepared primarily for internal reference and does not represent a final expression of the opinion of the corporation. When this memorandum is distributed externally, it is with the express understanding that the corporation makes no representation as to completeness, accuracy, or usability of information contained therein. 
B-TM-1639

\section{NOTICE}

This report was prepared as an account of work sponsored by the United States Government. Neither the United States, nor any of their employees, nor any of their contractors, subcontractors, or their employees, makes any warranty, express or implied, or assumes any legal diability or responsibility for the accuracy, completeness or usefulness of any information apparatus, product or process disclosed, or represents that its use would not infringe privately owned rights. 


\section{Acknowledgements}

The authors would like to express their gratitude for the assistance provided by members of the Naval Reactors Prime Contractor Team materials community in the fabrication of the refractory metal and moderator test plates for these experiments. The assistance provided by Steve Buresh (KAPL) and Ross Luther (Bettis) during the specification, procurement, fabrication, and characterization of the test plates was invaluable. The assistance provided by Richard Dean (KAPL) in performing the high precision density measurements for the test plate specimens is gratefully acknowledged. 
B-TM-1639

(Intentionally Blank)

$-4-$ 


\section{Table of Contents}

Table of Contents

List of Figures 7

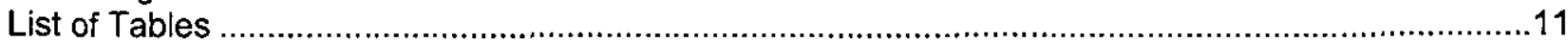

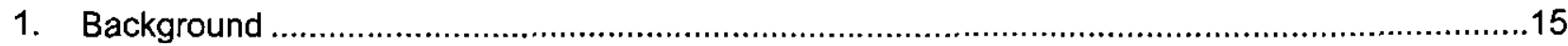

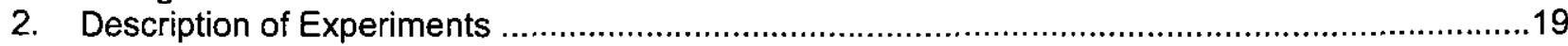

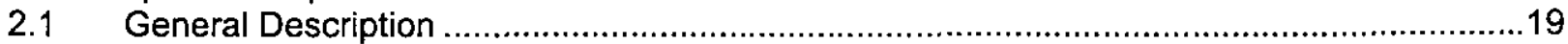

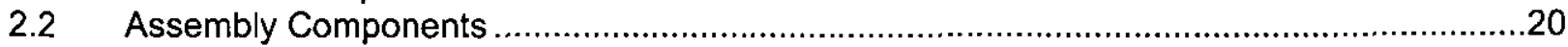

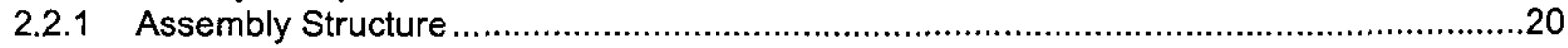

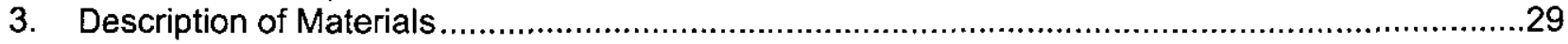

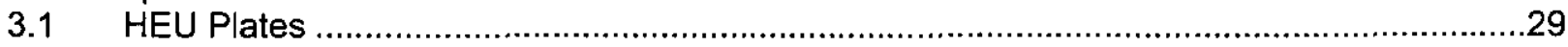

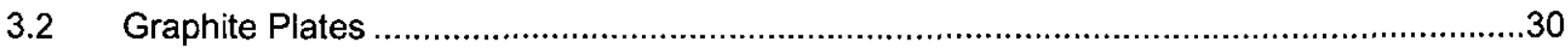

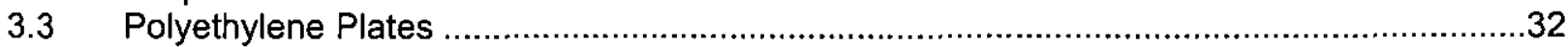

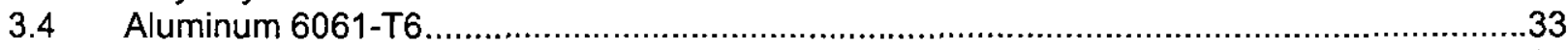

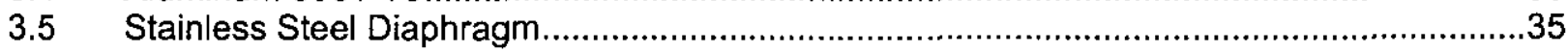

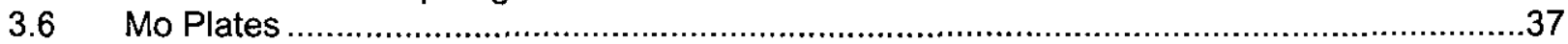

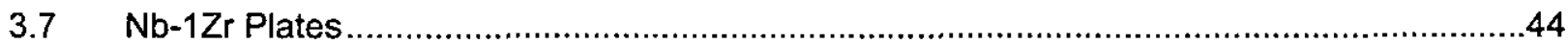

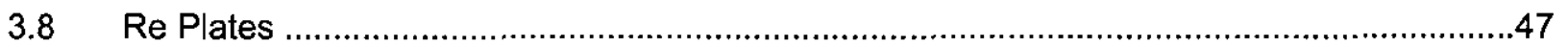

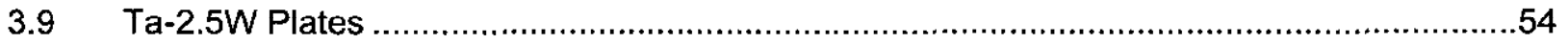

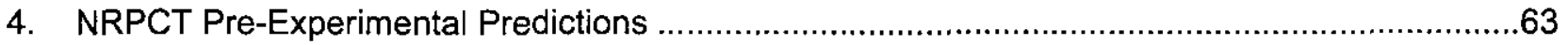

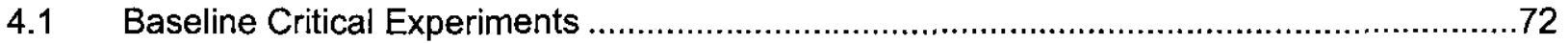

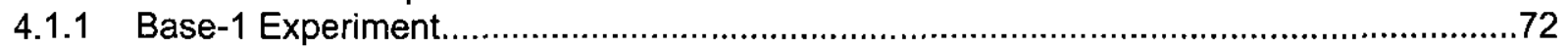

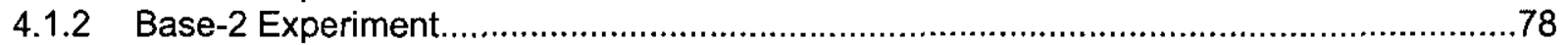

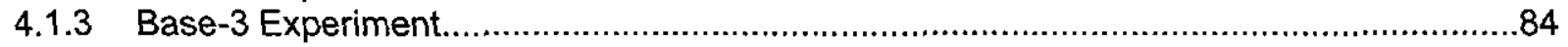

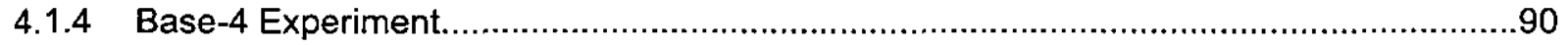

4.1.5 Baseline Critical Experiments Summary and Conclusions ......................................96

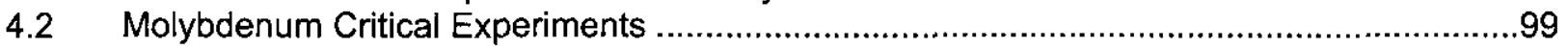

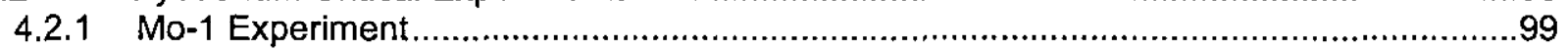

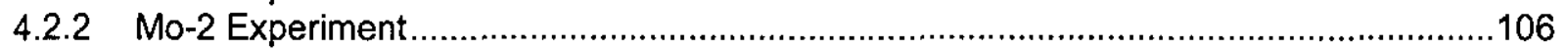

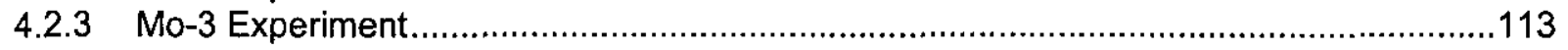

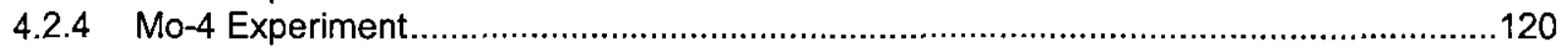

4.2.5 Molybdenum Critical Experiments Summary and Conclusions..................................127

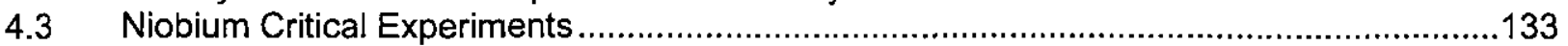

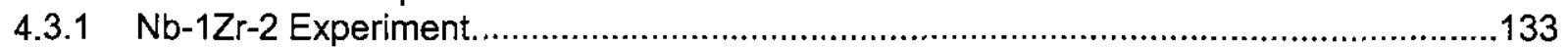

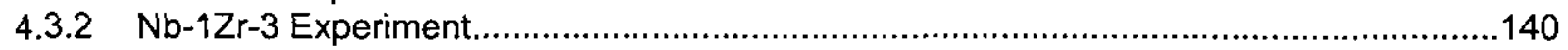

4.3.3 Niobium Critical Experiments Summary and Conclusions .....................................147

4.4 Rhenium Critical Experiments............................................................................... 150

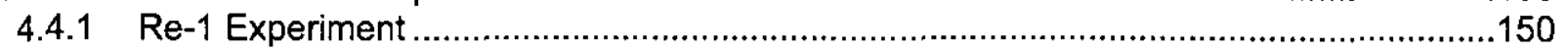

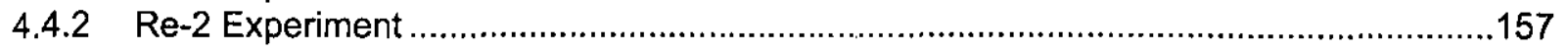

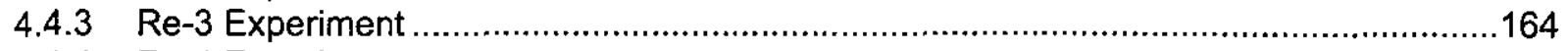

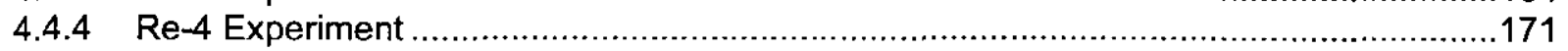

4.4.5 Rhenium Critical Experiments Summary and Conclusions .....................................178

4.5 Tantalum Critical Experiments ............................................................................ 180

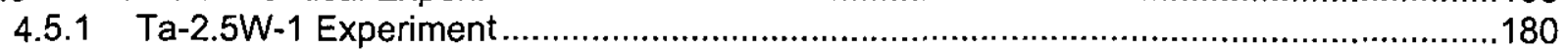

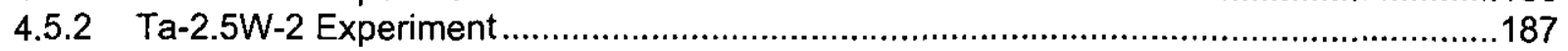

4.5.3 Ta-2.5W-3 Experiment .............................................................................. 194

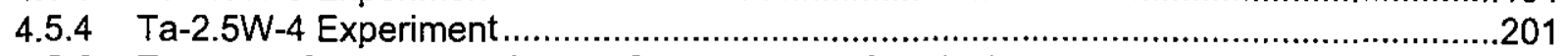

4.5.5 Tantalum Critical Experiments Summary and Conclusions .......................................214

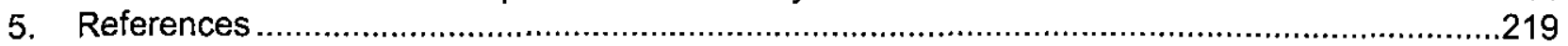

Appendix A Specifications for the Prometheus Critical Experiments ................................... A-1

Appendix B Specifications for the ORNL Nb-1Zr Critical Experiments.................................... 
Appendix C Appendix D Appendix $E$

Predicted

Appendix $F$ Appendix $G$ Appendix $\mathrm{H}$ Appendix I

Definition of SPACE05A Cross Section Library C-1 Material Density Measurements and Uncertainty Analysis ................................. D-1 Impact of the Increased Diaphragm Thickness and Mass Loading Limit on the

Appendix $J$ Critical Configuration of the Prometheus Critical Experiments Mo Plate Dimension and Chemistry Reports

Re Plate Dimension and Chemistry Reports.

Ta-2.5W Plate Dimension and Chemistry Reports

0.1 " Thick Graphite Plate Inspection Reports

Polyethylene Plate Inspection Reports 


\section{List of Figures}

Figure 1. Components of the first $\mathrm{Nb}-1 \mathrm{Zr}$ critical experiment, partially assembled split stack during approach to critical.

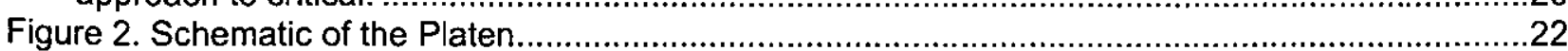

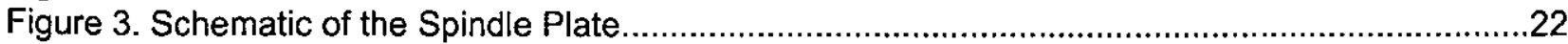

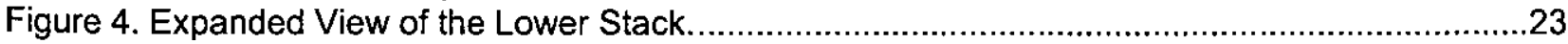

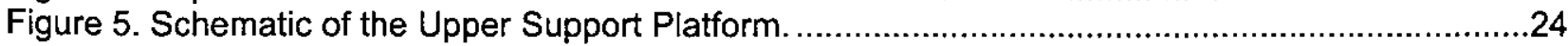

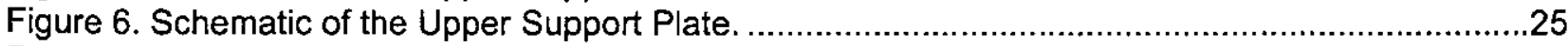

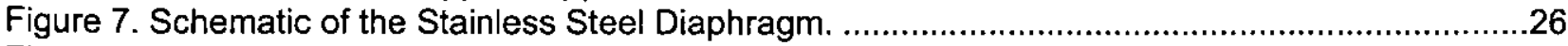

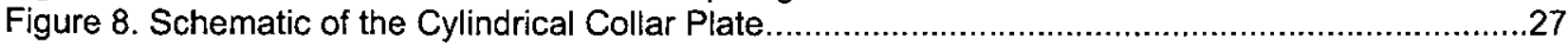

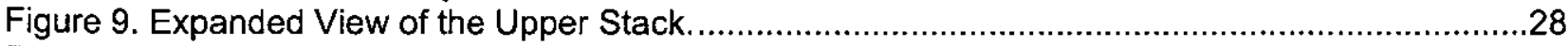

Figure 10. A Nested Pair of an Inner HEU Disk and an Outer HEU Ring .......................................29

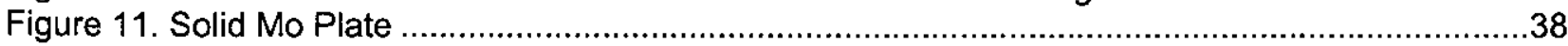

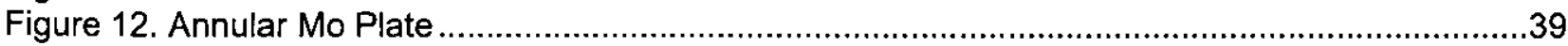

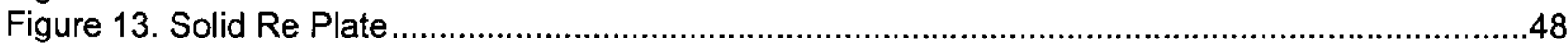

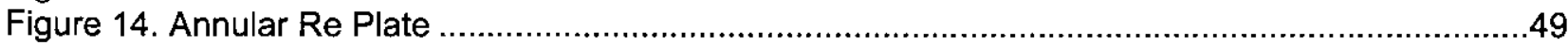

Figure 15. Comparison of Measured and Inferred Re Plate Thicknesses ......................................51

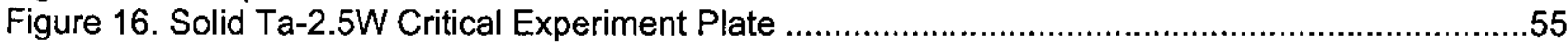

Figure 17. Annular Ta-2.5W Critical Experiment Plate ............................................................56

Figure 18. Overview of the Critical Experiment Configuration ......................................................66

Figure 19. Close-up View of the Critical Experiment Configuration ..............................................67

Figure 20. Close-up View of the Critical Experiment Configuration, without the Upper Aluminum

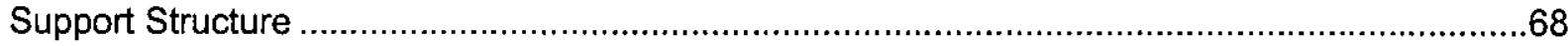

Figure 21. Cross-sectional View of the Base-1 Assembly ........................................................

Figure 22. Cross-sectional Close-up View of the Base-1 Assembly ............................................74

Figure 23. Base-1 Assembly $k_{\text {eff }}$ as a Function of the Number of Stacking Units ...............................76

Figure 24. Base-1 Assembly keff as a Function of the Top Reflector Thickness ................................76

Figure 25. Cross-sectional View of the Base-2 Assembly .......................................................

Figure 26. Cross-sectional Close-up View of the Base-2 Assembly ..............................................80

Figure 27. Base-2 Assembly $k_{\text {eff }}$ as a Function of the Number of Stacking Units .............................82

Figure 28. Base-2 Assembly $k_{\text {eff }}$ as a Function of the Top Reflector Thickness ..............................82

Figure 29. Cross-sectional View of the Base-3 Assembly .......................................................85

Figure 30. Cross-sectional Close-up View of the Base-3 Assembly ...........................................86

Figure 31. Base-3 Assembly $k_{\text {eff }}$ as a Function of the Number of Stacking Units ............................88

Figure 32. Base-3 Assembly $k_{\text {eff }}$ as a Function of the Top Reflector Thickness ...............................88

Figure 33. Cross-sectional View of the Base-4 Assembly .........................................................91

Figure 34. Cross-sectional Close-up View of the Base-4 Assembly .............................................92

Figure 35. Base-4 Assembly $k_{\text {eff }}$ as a Function of the Number of Stacking Units ...............................94

Figure 36. Base-4 Assembly $k_{\text {eff }}$ as a Function of the Top Reflector Thickness...............................94

Figure 37. Comparison of the RCP01 and MCNP5 Fission Rate Spectra for the Baseline Critical

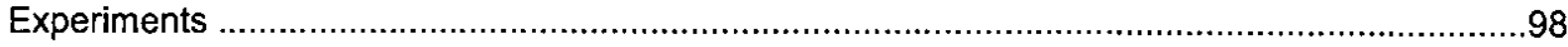

Figure 38. RCP01 Fission CDFs for the Baseline Critical Experiments .....................................98

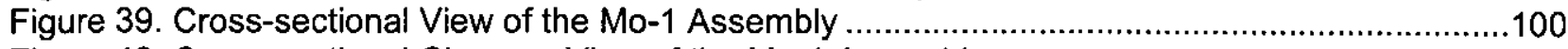

Figure 40. Cross-sectional Close-up View of the Mo-1 Assembly ..............................................101

Figure 41. Mo-1 Assembly $k_{\text {eff }}$ as a Function of the Number of Stacking Units .............................104

Figure 42. Mo-1 Assembly $k_{\text {eff }}$ as a Function of the Top Reflector Thickness ...............................104

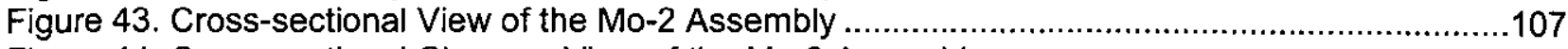

Figure 44. Cross-sectional Close-up View of the Mo-2 Assembly .............................................108

Figure 45. Mo-2 Assembly $k_{\text {eff }}$ as a Function of the Number of Stacking Units .............................111

Figure 46. Mo-2 Assembly $k_{\text {eff }}$ as a Function of the Top Reflector Thickness ................................111

Figure 47. Cross-sectional View of the Mo-3 Assembly .............................................................114

Figure 48. Cross-sectional Close-up View of the Mo-3 Assembly .......................................... 115 
Figure 49. Mo-3 Assembly $k_{\text {eff }}$ as a Function of the Number of Stacking Units ..............................118

Figure 50. Mo-3 Assembly $k_{\text {eff }}$ as a Function of the Top Reflector Thickness ...............................118

Figure 51. Cross-sectional View of the Mo-4 Assembly .......................................................121

Figure 52. Cross-sectional Close-up View of the Mo-4 Assembly .............................................122

Figure 53. Mo-4 Assembly $k_{\text {eff }}$ as a Function of the Number of Stacking Units .............................125

Figure 54. Mo-4 Assembly $k_{\text {eff }}$ as a Function of the Top Reflector Thickness ...................................125

Figure 55: Comparison of the RCP01 and MCNP5 Fission Rate Spectra for the Mo Critical

Experiments

Figure 56: RCP01 Fission CDFs for the Mo Critical Experiments ...................................................129

Figure 57: Comparison of the RCP01 and MCNP5 Mo Absorption Rate Spectra for the Mo Critical

Experiments

Figure 58: Neutron Absorption Cross-Section vs. Energy for Natural Molybdenum (ENDF/BVI.0) and

Isotopically-Combined Equivalent (JENDL 3.2) [20] …....................................................131

Figure 59: Comparison of RCP01 and MCNP5 Mo Absorption Rate Spectra over Ranges of Varying Cross-Section Data

Figure 60. Cross-sectional View of the Nb-1Zr-2 Assembly ..................................................134

Figure 61. Cross-sectional Close-up View of the Nb-1Zr-2 Assembly ........................................135

Figure 62. Nb-1Zr-2 Assembly $k_{\text {eff }}$ as a Function of the Number of Stacking Units ...........................138

Figure 63. Nb-1Zr-2 Assembly $k_{\text {eff }}$ as a Function of the Top Reflector Thickness ............................138

Figure 64. Cross-sectional View of the Nb-1Zr-3 Assembly ................................................141

Figure 65. Cross-sectional Close-up View of the $\mathrm{Nb}-1 \mathrm{Zr}-3$ Assembly ............................................142

Figure 66. Nb-1Zr-3 Assembly $k_{\text {eff }}$ as a Function of the Number of Stacking Units ...........................145

Figure 67. $\mathrm{Nb}-1 \mathrm{Zr}-3$ Assembly $\mathrm{k}_{\text {eff }}$ as a Function of the Top Reflector Thickness ................................145

Figure 68: Comparison of RCP01 and MCNP5 Fission Rate Spectra for Nb-1Zr Critical Experiments

Figure 69: RCP01 Fission CDFs for the Nb-1Zr Critical Experiments

Figure 70: Comparison of RCP01 and MCNP5 Nb-1Zr Absorption Rate Spectra for Nb-1Zr............. Experiments

Figure 71. Cross-sectional View of the Re-1 Assembly

Figure 73. Re-1 Assembly

Fif

Figure 75. Cross-sectional View of the Re-2 Assembly.............................................................158

Figure 76. Cross-sectional Close-up View of the Re-2 Assembly ..................................................159

Figure 77. Re-2 Assembly $k_{\text {eff }}$ as a Function of the Number of Stacking Units ...............................162

Figure 78. Re-2 Assembly $k_{\text {eff }}$ as a Function of the Top Reflector Thickness ......................................162

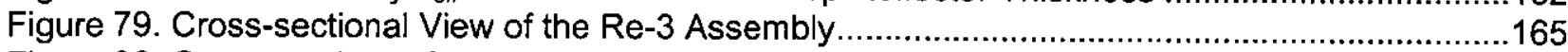

Figure 80. Cross-sectional Close-up View of the Re-3 Assembly ................................................166

Figure 81. Re-3 Assembly $k_{\text {eff }}$ as a Function of the Number of Stacking Units ...................................169

Figure 82. Re-3 Assembly $k_{\text {eff }}$ as a Function of the Top Reflector Thickness ....................................169

Figure 83. Cross-sectional View of the Re-4 Assembly....................................................... 172

Figure 84. Cross-sectional Close-up View of the Re-4 Assembly .........................................173

Figure 85 . Re-4 Assembly $k_{\text {eff }}$ as a Function of the Number of Stacking Units ...................................176

Figure 86. Re-4 Assembly $k_{\text {eff }}$ as a Function of the Top Reflector Thickness ...............................176

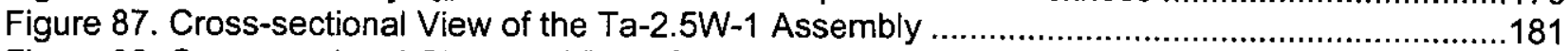

Figure 88. Cross-sectional Close-up View of the Ta-2.5W-1 Assembly ..........................................182

Figure 89. Ta-2.5W-1 Assembly $k_{\text {eff }}$ as a Function of the Number of Stacking Units ............................185

Figure 90. Ta-2.5W-1 Assembly $k_{\text {eff }}$ as a Function of the Top Reflector Thickness .............................185

Figure 91. Cross-sectional View of the Ta-2.5W-2 Assembly .....................................................188

Figure 92. Cross-sectional Close-up View of the Ta-2.5W-2 Assembly ............................................189

Figure 93. Ta-2.5W-2 Assembly $k_{\text {eff }}$ as a Function of the Number of Stacking Units ...........................192

Figure 94. Ta-2.5W-2 Assembly $k_{\text {eff }}$ as a Function of the Top Reflector Thickness ............................192

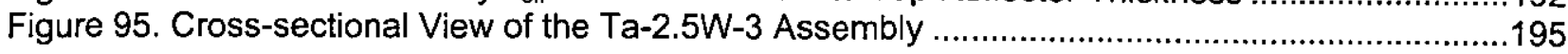


Figure 96. Cross-sectional Close-up View of the Ta-2.5W-3 Assembly .......................................196

Figure 97. Ta-2.5W-3 Assembly $k_{\text {eff }}$ as a Function of the Number of Stacking Units .............................199

Figure 98. Ta-2.5W-3 Assembly $k_{\text {eff }}$ as a Function of the Top Reflector Thickness .............................199

Figure 99. RCP01 Cross-sectional View of the Ta-2.5W-4 Assembly .........................................203

Figure 100. MCNP5 Cross-sectional View of the Ta-2.5W-4 Assembly .........................................204

Figure 101. MCNP5 Cross-sectional Close-up View of the Ta-2.5W-4 Assembly ...............................205

Figure 102. Ta-2.5W-4 Assembly $k_{\text {eff }}$ as a Function of the Number of Stacking Units .........................210

Figure 103. Ta-2.5W-4 Assembly $k_{\text {eff }}$ as a Function of the Top Reflector Thickness ............................210

Figure 104. Comparison of Predicted RCP01 and MCNP5 Ta-2.5W Absorption Rate Spectra for the

Ta-2.5W-4 Critical Experiment

Figure 105. Comparison of RCP01 and MCNP5 Fission Rate Spectra for the Ta-2.5W Critical Experiments

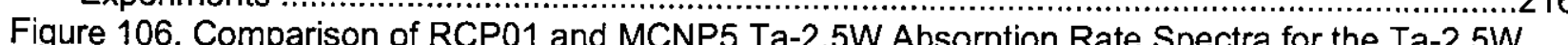
Critical Experiments

Figure 107. RCP01 Fission CDFs for the Ta-2.5W Critical Experiments 216 
B-TM-1639

(Intentionally Blank)

$-10-$ 


\section{List of Tables}

Table 1. Summary of NRPCT Designed Critical Experiments .........................................................17

Table 2. Summary of Test Plates Supplied for Prometheus Critical Experiments ...............................18

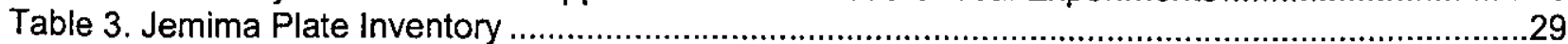

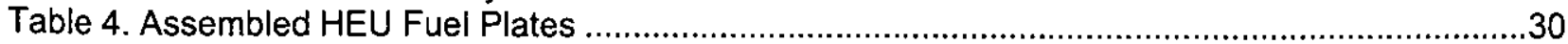

Table 5. Average Isotopic Composition of HEU Fuel Plates ......................................................30

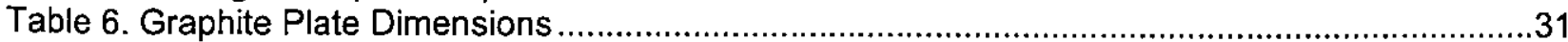

Table 7. As-Built Thickness and Mass Measurements for the 0.1" Thick Graphite Plates ..................31

Table 8. Average Isotopic Composition of the Graphite Plates .......................................................32

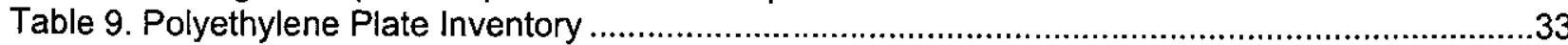

Table 10. Average Isotopic Composition of the Polyethylene Plates ..........................................33

Table 11. Chemical Composition of Aluminum 6061-T6 .........................................................34

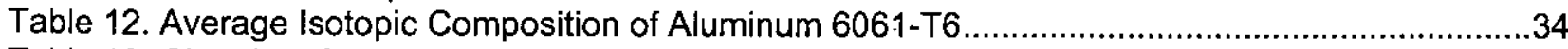

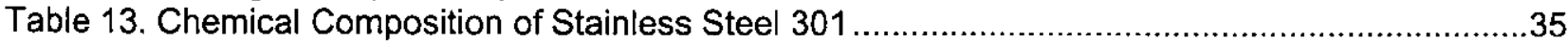

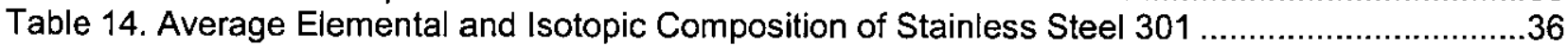

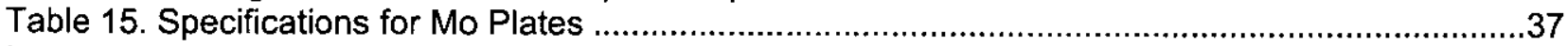

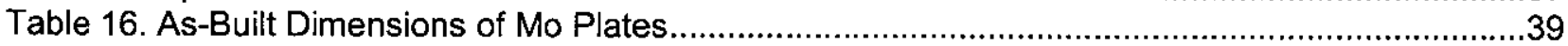

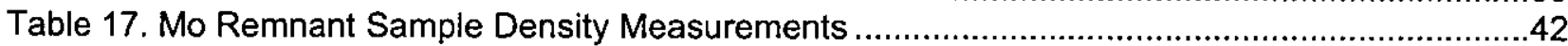

Table 18. Chemical Composition Certificate for Mo Plates .............................................................43

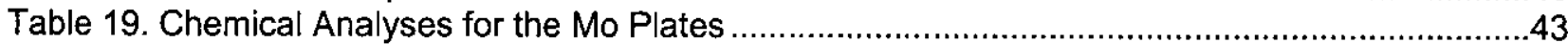

Table 20. Average Elemental Composition of the Mo Plates ......................................................43

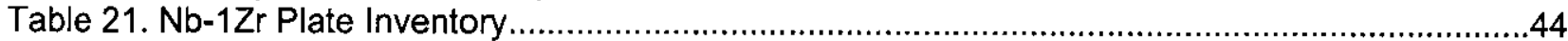

Tabje 22. As-Built and Nominal Dimensions of Nb-1Zr Plates ..................................................44

Table 23. Chemical Analysis for the $\mathrm{Nb}-1 \mathrm{Zr}$ Plates .................................................................46

Table 24. Elemental Composition from the Top of the Ingot of the $\mathrm{Nb}-1 \mathrm{Zr}$ Plates .............................46

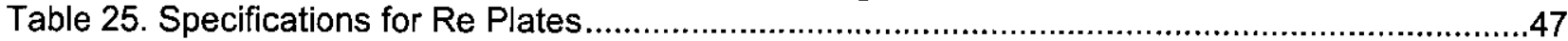

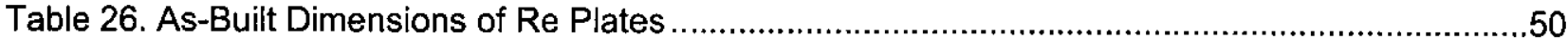

Table 27. Re Remnant Sample Density Measurements..........................................................5

Table 28. Full Spectrum Chemical Analysis for Re Plates ........................................................52

Table 29. Average Isotopic Composition of the Re Plates .......................................................53

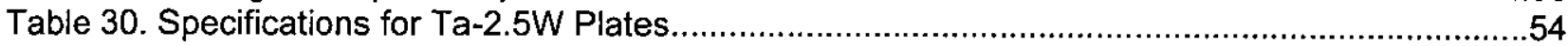

Table 31. As-Built Dimensions of the Solid Ta-2.5W Plates .......................................................57

Table 32. As-Built Dimensions of the Annular Ta-2.5W Plates .................................................58

Table 33. As-built Thickness and Mass Measurements of the Ta-2.5W Plates, Performed by LANL..59

Table 34. Ta-2.5W Remnant Sample Density Measurements .....................................................61

Table 35. Chemical Analyses for the Ta-2.5W Plates ...............................................................61

Table 36. Average Elemental Composition of the Ta-2.5W Plates...............................................62

Table 37. Cross Section Data Sources......................................................................................69

Table 38. MCNP5 with Space Cross Sections Unresolved Resonance Region Treatment .................71

Table 39. MCNP5 ENDF/B-VI.8 Cross Sections Unresolved Resonance Region Treatment ..............71

Table 40. Predicted Critical Configuration for the Base-1 Assembly ..............................................75

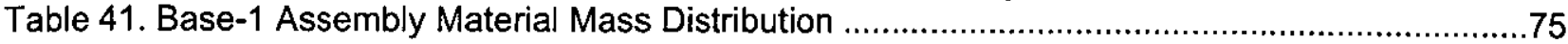

Table 42. Base-1 Assembly $k_{\text {eff }}$ as a Function of the Top Reflector Thickness ................................77

Table 43. Predicted Critical Configuration for the Base-2 Assembly ...............................................81

Table 44. Base-2 Assembly Material Mass Distribution .........................................................

Table 45. Base-2 Assembly $k_{\text {eff }}$ as a Function of the Top Reflector Thickness ..............................83

Table 46. Predicted Critical Configuration for the Base-3 Assembly. ............................................87

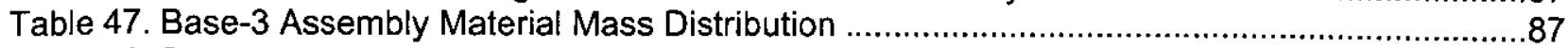

Table 48. Base-3 Assembly $k_{\text {eff }}$ as a Function of the Top Reflector Thickness ................................89

Table 49. Predicted Critical Configuration of the Base-4 Assembly .............................................93

Table 50. Base-4 Assembly Material Mass Distribution ......................................................93 
Table 51. Base-4 Assembly $k_{\text {eff }}$ as a Function of the Top Reflector Thickness .............................95

Table 52. A Summary of the Energy Spectrum Covered in the Baseline Critical Experiments ............96

Table 53. A Summary of the Pre-Experimental Predictions for the Baseline Critical Experiments ......97

Table 54. Predicted Critical Configuration for the Mo-1 Assembly ..............................................102

Table 55. Mo-1 Assembly Material Mass Distribution ..................................................................103

Table 56. Mo-1 Assembly $k_{\text {eff }}$ as a Function of the Top Reflector Thickness ................................105

Table 57. Predicted Critical Configuration for the Mo-2 Assembly ................................................109

Table 58. Mo-2 Assembly Material Mass Distribution...............................................................110

Table 59. Mo-2 Assembly $k_{\text {eff }}$ as a Function of the Top Reflector Thickness ................................112

Table 60. Predicted Critical Configuration for the Mo-3 Assembly. .............................................116

Table 61. Mo-3 Assembly Material Mass Distribution ................................................................117

Table 62. Mo-3 Assembly $k_{\text {eff }}$ as a Function of the Top Reflector Thickness ................................119

Table 63. Predicted Critical Configuration of the Mo-4 Assembly ................................................123

Table 64. Mo-4 Assembly Material Mass Distribution..................................................................124

Table 65. Mo-4 Assembly $k_{\text {eff }}$ as a Function of the Top Reflector Thickness ..................................126

Table 66. A Summary of the Energy Spectrum Covered in the Mo Critical Experiments ..................128

Table 67. A Summary of the Pre-Experimental Predictions for the Mo Critical Experiments .............128

Table 68. Predicted Critical Configuration for the Nb-1Zr-2 Assembly .......................................136

Table 69. Nb-1Zr-2 Assembly Material Mass Distribution ............................................................137

Table 70. Nb-1Zr-2 Assembly $k_{\text {eff }}$ as a Function of the Top Reflector Thickness ...........................139

Table 71. Predicted Critical Configuration for the Nb-1Zr-3 Assembly.......................................143

Table 72. Nb-1Zr-3 Assembly Material Mass Distribution .............................................................144

Table 73. Nb-1Zr-3 Assembly $k_{\text {eff }}$ as a Function of the Top Reflector Thickness ..............................146

Table 74. A Summary of the Energy Spectrum Covered in the Nb-1Zr Critical Experiments.............147

Table 75. A Summary of the Pre-Experimental Predictions for the $\mathrm{Nb}-1 \mathrm{Zr}$ Critical Experiments .......148

Table 76. Predicted Critical Configuration for the Re-1 Assembly...............................................153

Table 77. Re-1 Assembly Material Mass Distribution ..............................................................154

Table 78. Re-1 Assembly $k_{\text {eff }}$ as a Function of the Top Reflector Thickness..................................156

Table 79. Predicted Critical Configuration for the Re-2 Assembly...............................................160

Table 80. Re-2 Assembly Material Mass Distribution ................................................................161

Table 81. Re-2 Assembly $k_{\text {eff }}$ as a Function of the Top Reflector Thickness................................163

Table 82. Predicted Critical Configuration for the Re-3 Assembly...............................................167

Table 83. Re-3 Assembly Material Mass Distribution ..............................................................168

Table 84. Re-3 Assembly $k_{\text {eff }}$ as a Function of the Top Reflector Thickness ..................................170

Table 85. Predicted Critical Configuration of the Re-4 Assembly .............................................174

Tabje 86. Re-4 Assembly Material Mass Distribution ...............................................................175

Table 87. Re-4 Assembly $k_{\text {eff }}$ as a Function of the Top Reflector Thickness................................177

Table 88. A Summary of the Energy Spectrum Covered in the Re Critical Experiments .....................178

Table 89. A Summary of the Pre-Experimental Predictions for the Re Critical Experiments.............179

Table 90. Predicted Critical Configuration for the Ta-2.5W-1 Assembly ......................................183

Table 91. Ta-2.5W-1 Assembly Material Mass Distribution.........................................................184

Table 92. Ta-2.5W-1 Assembly $k_{\text {off }}$ as a Function of the Top Reflector Thickness ..............................186

Table 93. Predicted Critical Configuration for the Ta-2.5W-2 Assembly ......................................190

Table 94. Ta-2.5W-2 Assembly Material Mass Distribution.......................................................191

Table 95. Ta-2.5W-2 Assembly $k_{\text {eff }}$ as a Function of the Top Reflector Thickness ..............................193

Table 96. Predicted Critical Configuration for the Ta-2.5W-3 Assembly. .....................................197

Table 97. Ta-2.5W-3 Assembly Material Mass Distribution........................................................198

Table 98. Ta-2.5W-3 Assembly $k_{\text {eff }}$ as a Function of the Top Reflector Thickness .........................200

Table 99. RCP01, MCNP5 (Space XS), and RACER Predicted Critical Configuration for the Ta-2.5W-

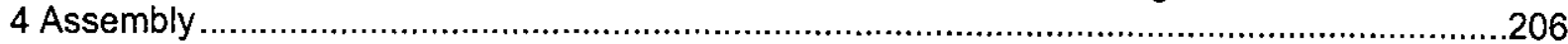

Table 100. MCNP5 Predicted Critical Configuration for the Ta-2.5W-4 Assembly........................208

Table 101. Ta-2.5W-4 Assembly Material Mass Distribution ...................................................209 
Table 102. RCP01, MCNP5 (Space XS), and RACER Ta-2.5W-4 Assembly $k_{\text {eff }}$ as a Function of the Top Reflector Thickness.

Table 103. MCNP5, MCNP5 (Space XS), and RACER Ta-2.5W-4 Assembly $k_{\text {eff }}$ as a Function of the Top Reflector Thickness.

Table 104. A Summary of the Energy Spectrum Covered in the Ta-2.5W Critical Experiments

Table 105. A Summary of the Pre-Experimental Predictions for the Ta-2.5W Critical Experiments ..215

Table D-1. Specimen Density Measurements.

Table D-2. Raw Data from the Specimen Density Measurements. D-9

Table E-1. Sensitivity Analysis for the Rhenium Critical Experiments $E-5$

Table E-2. Sensitivity Analysis for the Tantalum Critical Experiments E-6

Table E-3. Sensitivity Analysis for the Baseline Critical Experiments $E-7$

Table E-4. Sensitivity Analysis for the Molybdenum Critical Experiments E-8 
B-TM-1639

(Intentionally Blank)

-14 - 
B-TM-1639

\section{Background}

This report provides specifications, pre-experimental predictions, and test plate characterization information for a series of molybdenum (Mo), niobium ( $\mathrm{Nb}$ ), rhenium (Re), tantalum ( $\mathrm{Ta}$ ), and baseline critical experiments that were developed by the Naval Reactors Prime Contractor Team (NRPCT) for the Prometheus space reactor development project. In March 2004, the Naval Reactors program was assigned the responsibility to develop, design, deliver, and operationally support civilian space nuclear reactors for NASA's Project Prometheus. The NRPCT was formed to perform this work and consisted of engineers and scientists from the Naval Reactors (NR) Program prime contractors: Bettis Atomic Power Laboratory, Knolls Atomic Power Laboratory (KAPL), and Bechtel Plant Machinery Inc (BPMI). The NRPCT developed a series of clean benchmark critical experiments to address fundamental uncertainties in the neutron cross section data for $\mathrm{Mo}, \mathrm{Nb}, \mathrm{Re}$, and $\mathrm{Ta}$ in fast, intermediate, and mixed neutron energy spectra. These experiments were to be performed by Los Alamos National Laboratory (LANL) using the Planet vertical lift critical assembly machine and were designed with a simple, geometrically clean, cylindrical configuration consisting of alternating layers of test, moderator/reflector, and fuel materials. Based on reprioritization of missions and funding within NASA, Naval Reactors and NASA discontinued their collaboration on Project Prometheus in September 2005. One critical experiment and eighteen subcritical handstacking experiments were completed prior to the termination of work in September 2005. Information on the Prometheus critical experiments and the test plates produced for these experiments are expected to be of value to future space reactor development programs and to integral experiments designed to address the fundamental neutron cross section uncertainties for these refractory metals. This information is being provided as an orderly closeout of NRPCT work on Project Prometheus.

Refractory metal alloys containing substantial amounts of $\mathrm{Mo}, \mathrm{Nb}, \mathrm{Re}$, and Ta were under consideration for use in the Prometheus reactor. An outstanding issue in the nuclear design of Prometheus reactor concepts using substantial amounts of these refractory metals is the lack of prototypical critical experiment data. There are no clean benchmark quality critical experiments containing substantial amounts of $\mathrm{Mo}, \mathrm{Nb}, \mathrm{Re}$, or $\mathrm{Ta}$ in prototypical neutron energy spectra in the international critical experiment handbook [1]. A series of critical experiments using each of these materials and a series of baseline experiments without refractory metal test plates were developed to resolve this issue with the following objectives in mind:

1. To assess the adequacy of existing $\mathrm{Mo}, \mathrm{Nb}, \mathrm{Re}$, and Ta neutron cross section evaluations in neutron energy spectra characteristic of Prometheus reactor designs under normal and accident conditions.

2. To reduce the uncertainty in $k_{\text {eff }}$ for Prometheus reactor designs containing substantial amounts of $\mathrm{Mo}, \mathrm{Nb}, \mathrm{Re}$, and $\mathrm{Ta}$ by performing benchmark quality critical experiments that bracket the neutron energy spectra expected under normal conditions.

3. To perform benchmark critical experiments to identify what improvements are needed in Mo, $\mathrm{Nb}, \mathrm{Re}$, and $\mathrm{Ta}$ neutron cross sections and to provide qualification basis for revised evaluations.

For each material (with the exception of $\mathrm{Nb}$ ), three experiments were designed to bracket the neutron energy spectra expected in the Prometheus reactor under normal operating conditions and one experiment was designed to simulate an accident condition in which the core is flooded with water. Table 1 summarizes the NRPCT designed critical experiments. The -1 series of experiments were designed to approximate the neutron energy spectrum expected in the center of the Prometheus reactor, this series has the hardest spectrum of the four. The -2 and -3 experiments were designed to bracket the average neutron energy spectrum expected in the Prometheus reactor. The -4 experiments were designed to approximate the neutron energy spectrum for an accident condition in 
which the Prometheus reactor is immersed in, and flooded with, water. The $-1,-2,-3$ experiments were moderated and reflected by graphite plates of increasing thickness to adjust the neutron energy spectrum in the experiments. The -4 experiments were moderated and reflected by polyethylene plates. Specifications for the NRPCT designed critical experiments are provided in Appendix A.

Oak Ridge National Laboratory (ORNL) designed a series of four critical experiments using niobium 1 weight percent zirconium ( $\mathrm{Nb}-1 \mathrm{Zr}$ ) and furnished a series of $\mathrm{Nb}-1 \mathrm{Zr}$ test plates to LANL prior to the transfer of responsibility for Project Prometheus to the NR Program. The specifications for the ORNL $\mathrm{Nb}-1 \mathrm{Zr}$ critical experiments are provided in Appendix B for completeness. The NRPCT assumed responsibility for the $\mathrm{Nb}-1 \mathrm{Zr}$ experiments in March 2004 and LANL completed one polyethylene moderated and reflected critical experiment (Mexp 4U) in June 2004. An International Criticality Safety Benchmark Evaluation Project evaluation for the Mexp $4 \mathrm{U}$ experiment is currently under preparation [2]. Following the July 2004 security and safeguards shutdown at LANL, the NRPCT and LANL concluded that it would not be practical to complete the remaining three ORNL designed $\mathrm{Nb}-1 \mathrm{Zr}$ experiments (Mexp 2J, Mexp 2L, Mexp 4Y) and they were replaced by two NRPCT designed $\mathrm{Nb}-1 \mathrm{Zr}$ experiments (Nb-1Zr-2 and $\mathrm{Nb}-1 \mathrm{Zr}-3$ ). No replacement for the Mexp $4 \mathrm{Y}$ experiment was designed.

If significant deficiencies in the Mo, Nb, Re, or Ta neutron cross section evaluations were identifjed by the Prometheus critical experiments, the next step would have been to perform neutron cross section measurements and develop improved cross section evaluations to resolve the experimental discrepancies. The Prometheus critical experiments would then be used to qualify the new cross section evaluations. The ultimate objective of these experiments was the reduction in the uncertainty in $\mathrm{k}_{\text {eff }}$ for the Prometheus reactor.

The principal test materials used in the Prometheus critical experiments include LANL. supplied highly enriched uranium (HEU) plates (Jemima plates), NRPCT supplied Mo plates, ORNL supplied Nb-1Zr plates, NRPCT supplied Re plates, and NRPCT supplied tantalum - 2.5 tungsten (Ta-2.5W) plates. Table 2 summarizes the quantity and nominal dimensions of the refractory metal and moderator/reflector test plates supplied by the NRPCT and ORNL for the Prometheus critical experiments. With the termination of NR Program work on Project Prometheus the NRPCT supplied test plates have been transferred to LANL with the understanding that they would be eventually moved to DAF for use in future critical experiments. Remnant samples from the NRPCT furnished test plates are being retained by the Bettis Atomic Power Laboratory in the custody of Dr. Michael L. Zerkle.

In addition to the Prometheus critical experiments, the NRPCT supported the completion of the formal documentation for the ZPPR-16 and ZPPR-20 series of engineering mockup critical experiments that were performed in the late 1980 s to validate the nuclear design of the SP-100 reactor $[3,4,5]$. The NRPCT also supported the development of three critical experiment benchmark evaluations based on the ZPPR-20 experiments that were added to the 2005 Edition of the International Handbook of Evaluated Criticality Safety Benchmark Experiments [6, 7, 8].

Section 2 of this document provides a general description of the Prometheus critical experiments. Section 3 gives a detailed description of the materials and components to be used in the critical experiments. Section 4 provides the pre-experimental prediction of the critical mass and configuration for each experiment, including the results of supporting analyses. The NRPCT pre-experimental predictions are based on RCP01 [9], MCNP5 [10], MCNP5 using a collection of cross section data sets, collectively referred to as SPACE05A (will be referred to as MCNP5 with space cross sections), and RACER [11] Monte Carlo neutron transport analyses. The RCP01 and MCNP5 analyses were performed by Bettis and the MCNP5 with space cross sections and the RACER analyses were performed by KAPL. The RCP01 calculations used a preliminary version of the SPACE05A cross section set; while, MCNP5 with space cross sections and RACER calculations used the SPACE05A cross section data set (Appendix C). The MCNP5 calculations used ENDF/B-VI. 8 cross sections. 
The specifications for the NRPCT designed Prometheus critical experiments are provided in Appendix $A$ and the specifications for the ORNL designed $\mathrm{Nb}-1 \mathrm{Zr}$ critical experiments are provided in Appendix B. Appendix $C$ contains the definition of the SPACE05A cross section library. Appendix D provides the results of the material density measurements performed on selected remnant samples from the NRPCT supplied refractory metal test plates and provides detailed description of the uncertainty analysis used to determine the experimental uncertainty in the density measurements. Appendix $E$ provides an analysis of the impact of increasing the thickness of the stainless stee! diaphragm separating the upper and lower core assemblies and implementing a mass loading limit of $150 \mathrm{~kg}$ on the diaphragm of the predicted critical configuration for the Prometheus critical experiments. Vendor dimension inspection and chemistry reports for the Mo, Re, and Ta-2.5W plates are provided in Appendices F, G, and H, respectively. Finally, the vendor inspection reports for the NRPCT supplied 0.1 " thick graphite plates and the polyethylene plates are found in Appendices I and $J$, respectively.

Additional technical work was planned to further refine the pre-experimental predictions for the Prometheus critical experiments, as well as eventual detailed post-experimental analyses; however, due to the termination of Naval Reactors Program involvement in Project Prometheus this work was reduced in scope and an orderly closeout of work was begun. This document provides the NRPCT analyses performed for this project to date, but in no way reflects the full scope that would have been undertaken had the Naval Reactors Program continued its involvement in Project Prometheus. Finally, References $[12,13,14,15$ and 16] document the results from the 18 subcritical hand-stacking experiments performed by LANL in preparation for the Prometheus critical experiments.

Table 1. Summary of NRPCT Designed Critical Experiments

\begin{tabular}{|l|l|l|}
\hline Name & Test Material & Test Spectrum \\
\hline Baseline-1 & N/A & Core center spectrum \\
\hline Baseline-2 & $\mathrm{N} / \mathrm{A}$ & Harder than core average spectrum \\
\hline Baseline-3 & $\mathrm{N} / \mathrm{A}$ & Softer than core average spectrum \\
\hline Baseline-4 & $\mathrm{N} / \mathrm{A}$ & Flooded spectrum \\
\hline Mo-1 & Mo & Core center spectrum \\
\hline Mo-2 & Mo & Harder than core average spectrum \\
\hline Mo-3 & Mo & Softer than core average spectrum \\
\hline Mo-4 & Mo & Flooded spectrum \\
\hline Nb-1Zr-2 & $\mathrm{Nb}-1 \mathrm{Zr}$ & Harder than core average spectrum \\
\hline $\mathrm{Nb}-1 \mathrm{Zr}-3$ & $\mathrm{Nb}-1 \mathrm{Zr}$ & Softer than core average spectrum \\
\hline Re-1 & $\mathrm{Re}$ & Core center spectrum \\
\hline $\mathrm{Re}-2$ & $\mathrm{Re}$ & Harder than core average spectrum \\
\hline $\mathrm{Re}-3$ & $\mathrm{Re}$ & Softer than core average spectrum \\
\hline $\mathrm{Re}-4$ & $\mathrm{Re}$ & Flooded spectrum \\
\hline Ta-2.5W-1 & $\mathrm{Ta}-2.5 \mathrm{~W}$ & Core center spectrum \\
\hline Ta-2.5W-2 & $\mathrm{Ta}-2.5 \mathrm{~W}$ & Harder than core average spectrum \\
\hline Ta-2.5W-3 & $\mathrm{Ta}-2.5 \mathrm{~W}$ & Softer than core average spectrum \\
\hline Ta-2.5W-4 & $\mathrm{Ta}-2.5 \mathrm{~W}$ & Flooded spectrum \\
\hline
\end{tabular}


Table 2. Summary of Test Plates Supplied for Prometheus Critical Experiments

\begin{tabular}{|c|c|c|c|c|c|c|}
\hline Material & $\begin{array}{c}\text { Furnished } \\
\text { By }\end{array}$ & $\begin{array}{c}\text { Thickness } \\
\text { (in) }\end{array}$ & Type & $\begin{array}{c}\text { Outer } \\
\text { Diameter } \\
\text { (in) }\end{array}$ & $\begin{array}{c}\text { Inner } \\
\text { Diameter } \\
\text { (in) }\end{array}$ & Quantitiy \\
\hline \multirow{4}{*}{ Mo } & \multirow{4}{*}{ NRPCT } & \multirow{2}{*}{0.060} & Solid & 21.000 & - & 4 \\
\hline & & & Annular & 21.000 & 2.510 & 4 \\
\hline & & \multirow{2}{*}{0.030} & Solid & 21.000 & - & 22 \\
\hline & & & Annular & 21.000 & 2.510 & 22 \\
\hline \multirow{7}{*}{$\mathrm{Nb}-1 \mathrm{Zr}$} & \multirow{7}{*}{ ORNL } & \multirow{2}{*}{0.060} & Solid & 21.000 & - & 8 \\
\hline & & & Annular & 21.000 & 2.500 & 8 \\
\hline & & \multirow{2}{*}{0.030} & Solid & 21.000 & - & 38 \\
\hline & & & Annular & 21.000 & 2.500 & 38 \\
\hline & & \multirow{3}{*}{0.010} & Solid & 21.000 & - & 7 \\
\hline & & & Annular & 21.000 & 2.500 & 22 \\
\hline & & & $\begin{array}{l}\text { Solid Half- } \\
\text { round Disk }\end{array}$ & $\begin{array}{c}10.500 \\
\text { (Radius) }\end{array}$ & - & 29 \\
\hline \multirow{2}{*}{$\operatorname{Re}$} & \multirow{2}{*}{ NRPCT } & \multirow{2}{*}{0.015} & Solid & 21.000 & - & 22 \\
\hline & & & Annular & 21.000 & 2.510 & 22 \\
\hline \multirow{2}{*}{$\mathrm{Ta}-2.5 \mathrm{~W}$} & \multirow{2}{*}{ NRPCT } & \multirow{2}{*}{0.025} & Solid & 21.000 & - & 42 \\
\hline & & & Annular & 21.000 & 2.510 & 42 \\
\hline \multirow{2}{*}{ Graphite } & \multirow{2}{*}{ NRPCT } & \multirow{2}{*}{$\begin{array}{l}0.100 \\
0.100\end{array}$} & Solid & 21.000 & - & 25 \\
\hline & & & Annular & 21.000 & 2.510 & 25 \\
\hline \multirow{6}{*}{$\begin{array}{l}\text { High Density } \\
\text { Polyethylene }\end{array}$} & \multirow{6}{*}{ NRPCT } & \multirow{2}{*}{1,000} & Solid & 21.000 & - & 2 \\
\hline & & & Annular & 21.000 & 2.510 & 2 \\
\hline & & \multirow{2}{*}{0.500} & Solid & 21.000 & - & 2 \\
\hline & & & Annular & 21.000 & 2.510 & 2 \\
\hline & & \multirow{2}{*}{0.080} & Solid & 21.000 & - & 20 \\
\hline & & & Annular & 21.000 & 2.510 & 15 \\
\hline
\end{tabular}




\section{Description of Experiments}

\subsection{General Description}

The Prometheus critical experiments were designed to be assembled on the Planet general-purpose vertical assembly machine at the Los Alamos Critical Experiments Facility (LACEF). The assemblies consist of a cylindrical core region containing interspersed plates of $\mathrm{HEU}$, refractory metal plates, and graphite or polyethylene plates of various thicknesses. The core region is partially reflected by placing graphite or polyethylene axial reflectors on the top and bottom of the assembly. Additional detail on the components and the experimental configurations are provided in later sections.

The assembly is divided into two approximately equal portions. The upper core region and the top reflector rest on a stationary aluminum support platform attached to the Planet machine. The upper segment of the core rests on a thin, cylindrical stainless steel plate, called the diaphragm, which is retained between an aluminum support plate and cylindrical collar plate. The aluminum support plate is attached to the aluminum upper support platform. The lower core region and the bottom reflector are seated on a cylindrical aluminum spindle plate that rests on the aluminum lower platen which is connected to the vertical drive of the assembly machine. The vertical drive of the assembly machine uses a hydraulic ram for coarse positioning and a stepping motor for fine positioning. The lower core plates and bottom reflector are held in position by a central, hollow aluminum alignment tube. A neutron source is placed inside the alignment tube to ensure indication of neutron multiplication. The experiment is conducted by raising the lower portion until it fully closes to the steel diaphragm that supports the upper segment of the core. There are no control or safety rods inside the assembly.

Several neutron detectors (safety monitors) will be placed at varying distances from the assembly to monitor the neutron flux produced by the neutron source, sub-critical multiplication, and by the assembly in the final slightly delayed supercritical configuration. Any one of these monitors would initiate separation of the assembly, a SCRAM, by de-energizing the assembly machine's hydraulic system which drops the lower assembly if the measured neutron flux exceeds a preset limit. The instrumentation and control system of the assembly machine is designed to be fail safe.

A photograph of the first $\mathrm{Nb}-1 \mathrm{Zr}$ critical experiments is shown in Figure 1 to illustrate the various components of the assembly [2]. The bottom reflector and lower core region can be seen resting on the spindle plate. A portion of the upper core region and top reflector can be seen resting on the upper support platform. The upper support plate and collar plate are also clearly visible. 


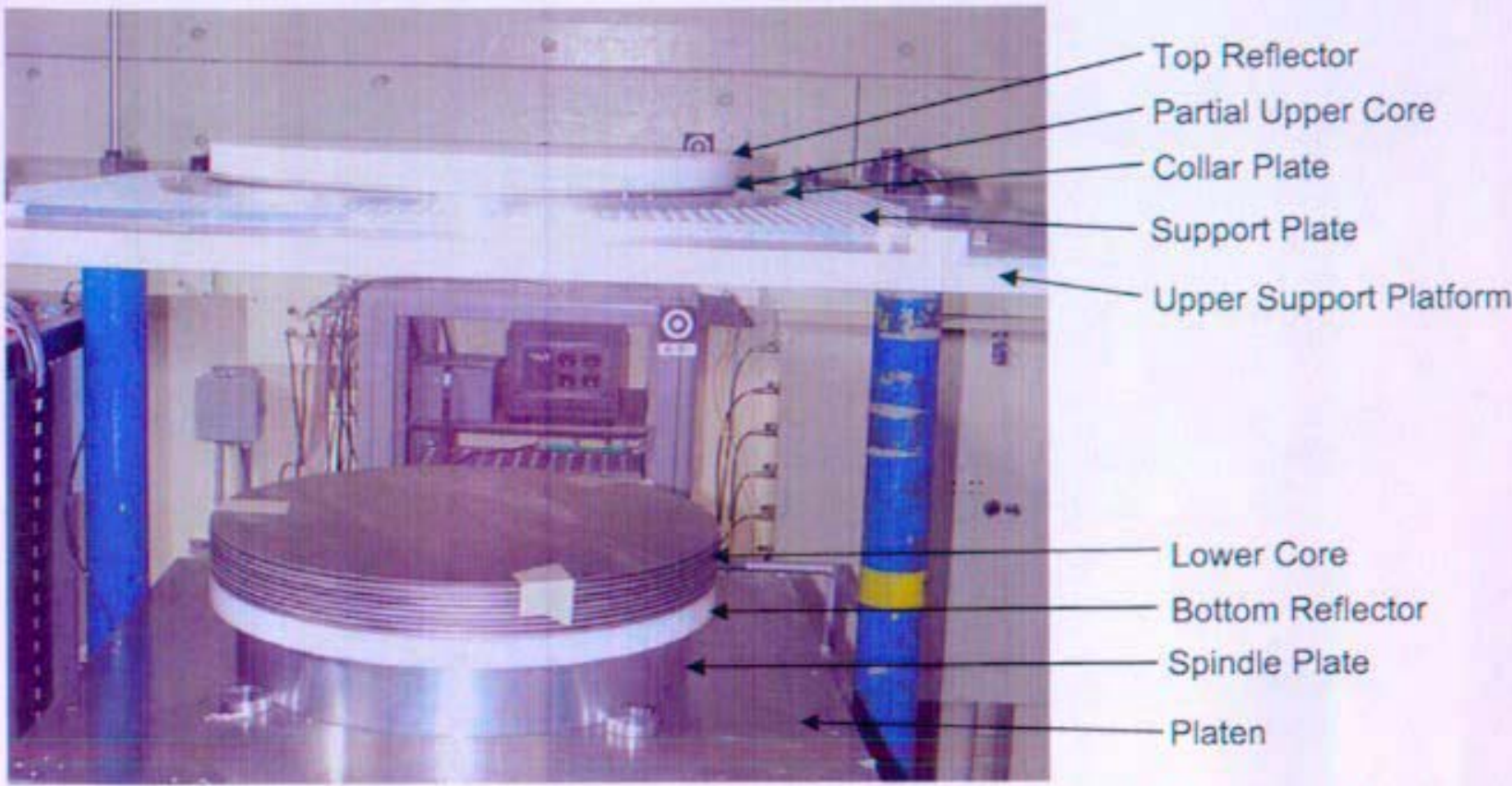

Figure 1. Components of the first $\mathrm{Nb}-1 \mathrm{Zr}$ critical experiment, partially assembled split stack during approach to critical.

\subsection{Assembly Components}

\subsubsection{Assembly Structure}

As illustrated in Figure 1, the experiment assemblies are split into two parts. The bottom part rests on a $1.25^{\prime \prime}$ thick aluminum 6061-T6 support plate called the platen. Figure 2 presents a schematic of the platen. A $3^{\prime \prime}$ thick aluminum 6016-T6 plate known as the spindle plate rests on top of the platen. The spindle plate has an inner diameter (ID) of $2.5^{\prime \prime}$ and an outer diameter (OD) of $19^{\prime \prime}$ and has a hollow center. Figure 3 presents a schematic of the spindle plate. The main function of the hollow spindle plate is to secure the aluminum alignment tube and to decouple the rest of the system from the platen. A threaded aluminum alignment tube screws into the spindle plate. The hollow alignment tube is made of aluminum 6061-T6 and has a $2.48^{\prime \prime} \mathrm{OD}$ and a $2.0^{\prime \prime}$ ID. The length of the specific alignment tubes used in the critical experiments will be determined at the time of the experiment. Approximately half of the HEU, metal, and graphite or polyethylene plates rest on the spindle plate to form the lower core stack. Figure 4 provides an expanded view of the lower stack.

The top part of the experiment rests on a stationary platform. A large flat $45^{\prime \prime} \times 45^{\prime \prime} \times 1 "$ thick aluminum 6061-T6 plate, called the upper support platform, serves as the base upon which the upper stack is placed. The upper support platform has a $29^{\prime \prime} \times 29^{\prime \prime}$ hole in the center of the plate. Figure 5 provides a schematic of the upper support platform. A $34^{\prime \prime} \times 34^{\prime \prime} \times 0.375^{\prime \prime}$ thick aluminum $6061-$ T6 support plate rests on top of the upper support platform. The upper support plate has a 22.125" ID central hole and a $0.075^{\prime \prime}$ deep (modeled as $0.040^{\prime \prime}$ deep in the baseline, Mo, Re, and Ta-2.5W critical experiments since LANL had not determined this depth at the time of the analysis, see Appendix E), 25.000" OD recess is machined into the top of the plate to accommodate the stainless steel diaphragm. Figure 6 provides a schematic of the upper support plate. A $24.80^{\prime \prime}$ diameter and $0.075^{\prime \prime}$ thick (modeled as 0.040 " thick in the baseline, Mo, Re, and Ta-2.5W critical experiments since LANL had not determined this thickness at the time of the analysis) stainless steel diaphragm is placed in the center of the 
recess in the upper support plate. The purpose of the diaphragm is to support the weight of the upper core assembly plates. Figure 7 provides a schematic of the stainless steel diaphragm. A 24.993" OD and 0.375 " thick aluminum 6061-T6 collar rest on top of the stainless steel diaphragm. The collar plate fastens the diaphragm to the upper support plate. Figure 8 provides a schematic of the collar plate. The upper core stack is completed by placing the HEU, cladding metal, and graphite or polyethylene plates on the center of the stainless steel diaphragm. Figure 9 provides an expanded view of the upper core stack.

As mentioned above, the bottom half of the assembly rests on a $3^{\prime \prime}$ thick hollow aluminum spindle plate that is attached to the aluminum platen. The platen rides on a hydraulic lift system and a mechanical vertical positioning system. Criticality is achieved by decreasing the gap between the top and bottom portions of the assembly until the bottom section of the assembly barely lifts the upper section of the assembly. To disassemble the configuration, the bottom stack is dropped to its initial position. There are no control or safety rods inside the assembly. The safety features include three radiation monitors located at different distances from the assembly. If the radiation level exceeds a predetermined level, the radiation monitors will cause the hydraulic lift system to be de-energized which will return the bottom core assembly to its initial position.

Construction of the core assembly begins by placing the graphite or polyethylene reflector plate on top of the spindle plate. Next, a bottom metal reflector plate (with the exception of the baseline and $\mathrm{Re}$ experiments which do not include a bottom metal reflector plate) and one graphite or polyethylene plate are placed on top of the graphite or polyethylene reflector plate to approximate the reactor vessel. Then, approximately half of the stacking units required for criticality are placed on top of the bottom reflector plate. For the baseline experiments a stacking unit is defined as a set of 2 plates consisting of a HEU plate and a graphite or polyethylene plate. For the $\mathrm{Mo}, \mathrm{Nb}-1 \mathrm{Zr}, \mathrm{Re}$, and $\mathrm{Ta}-2.5 \mathrm{~W}$ critical experiments a stacking unit is defined as a set of 4 plates consisting of a lower metal plate, a HEU plate, an upper metal plate, and a graphite or polyethylene plate. Approximately half of the stacking units required for criticality are placed on the stainless steel diaphragm to form the upper core stack. Finally, the upper metal reflector plate (with the exception of the baseline and $\operatorname{Re}$ experiments which do not include a top metal reflector plate) and the graphite or polyethylene reflector plate is placed on top of the upper core stack. The upper reflector may consist of a single reflector plate or a series of thinner reflector plates to permit the fine adjustment of the upper reflector thickness to limit the excess reactivity of the critical assembly upon full closure. 


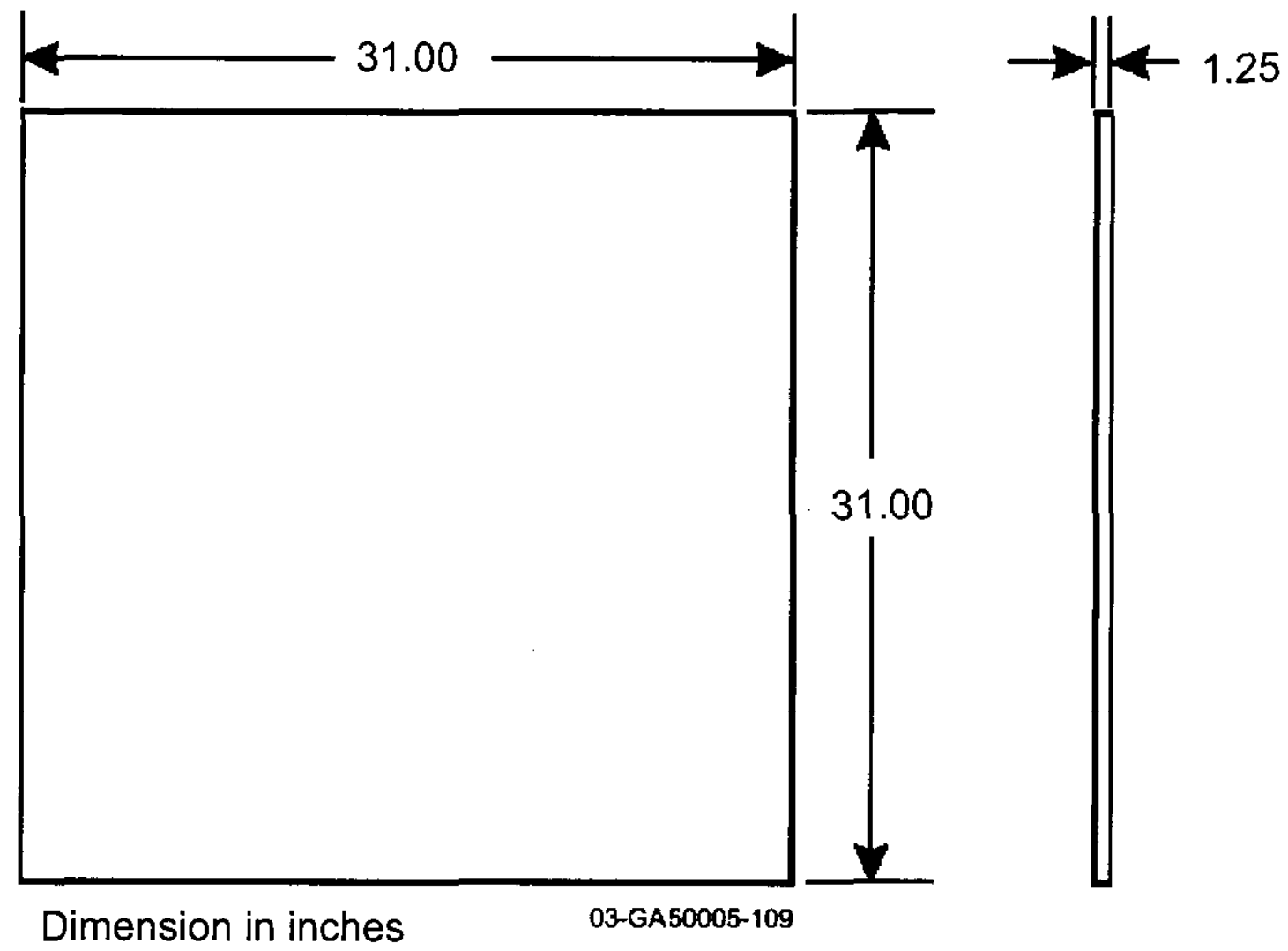

Figure 2. Schematic of the Platen.
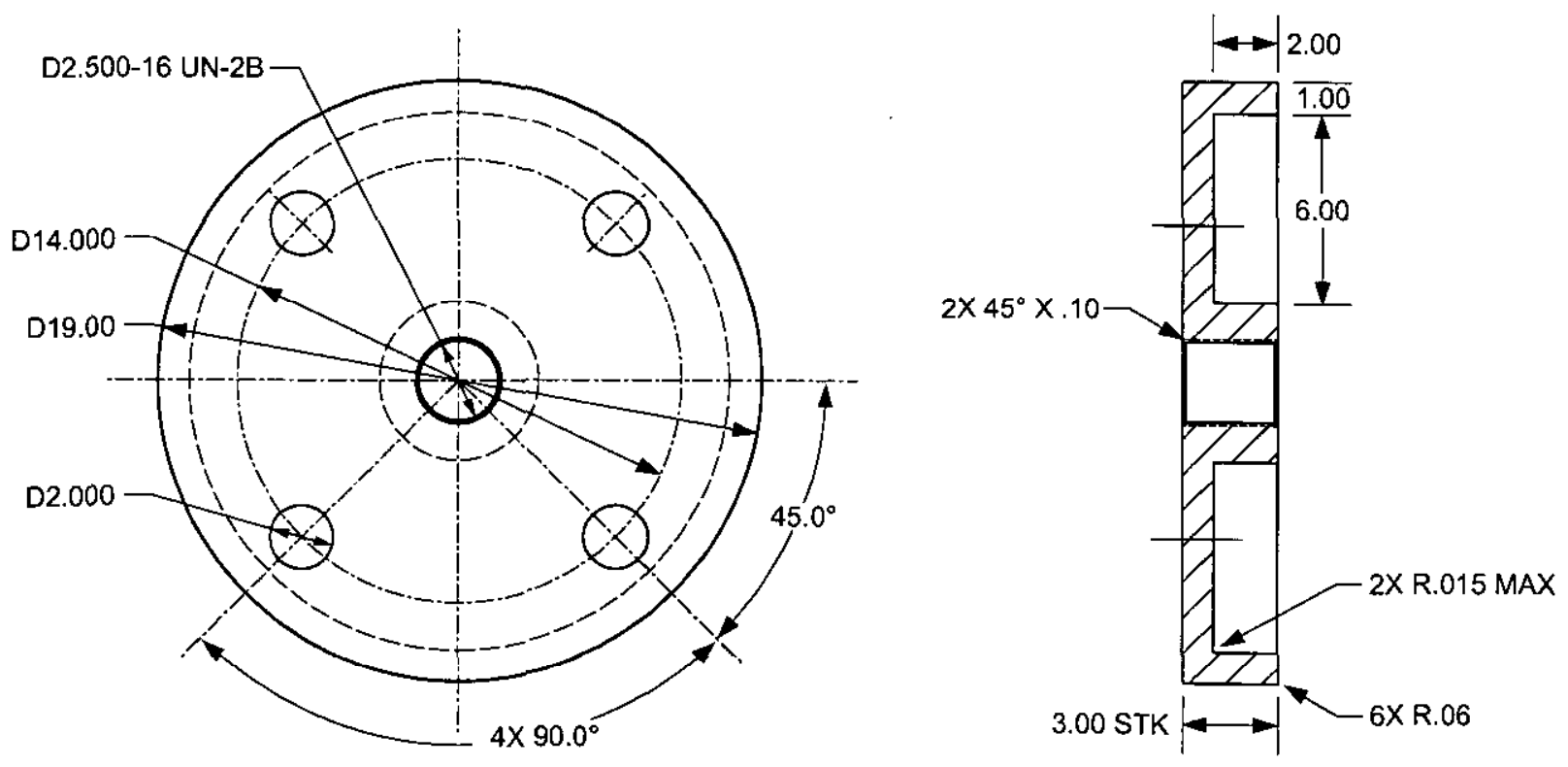

Dimensions in inches

04-GA50001-256

Figure 3. Schematic of the Spindle Plate. 
B-TM-1639

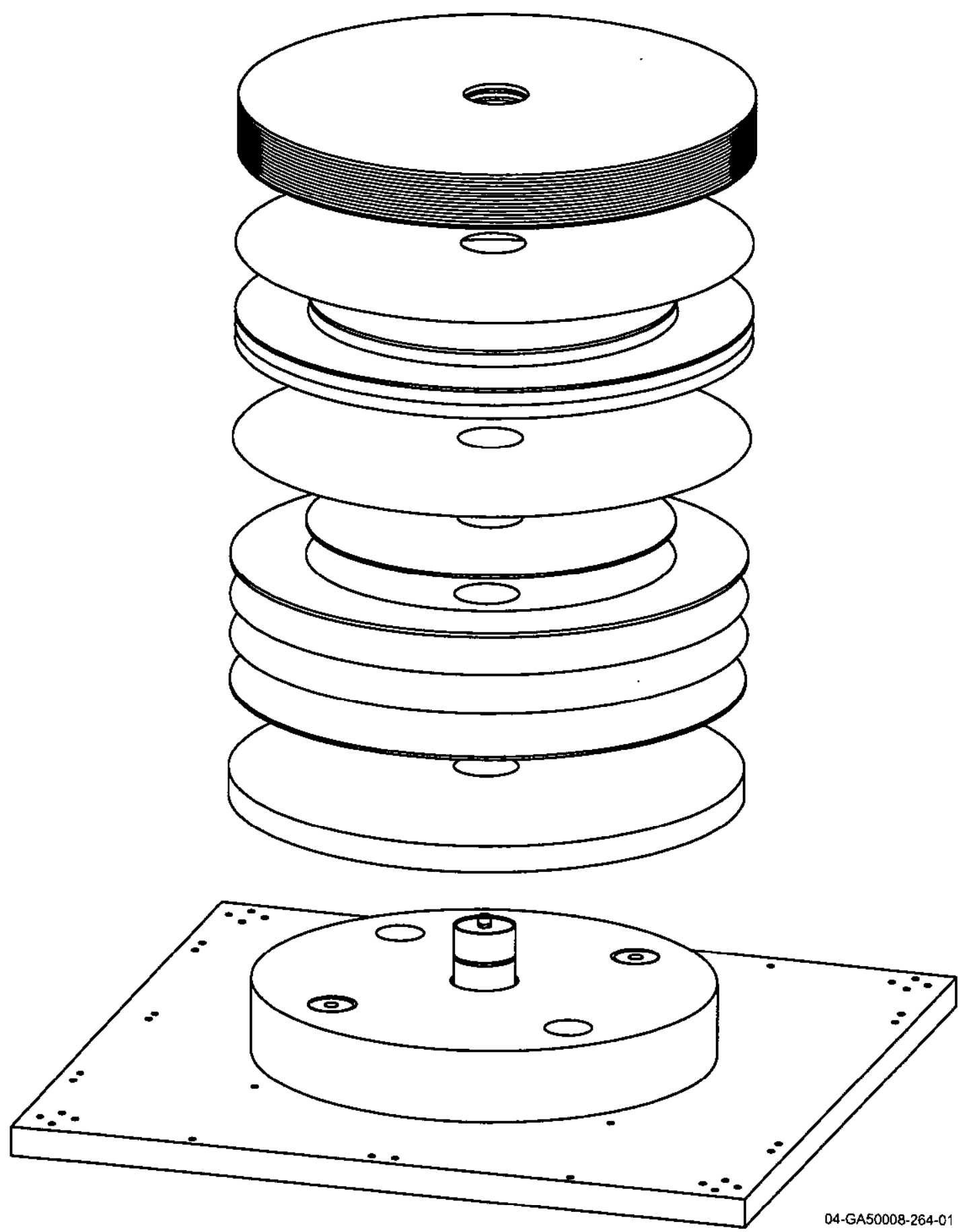

Figure 4. Expanded View of the Lower Stack. 


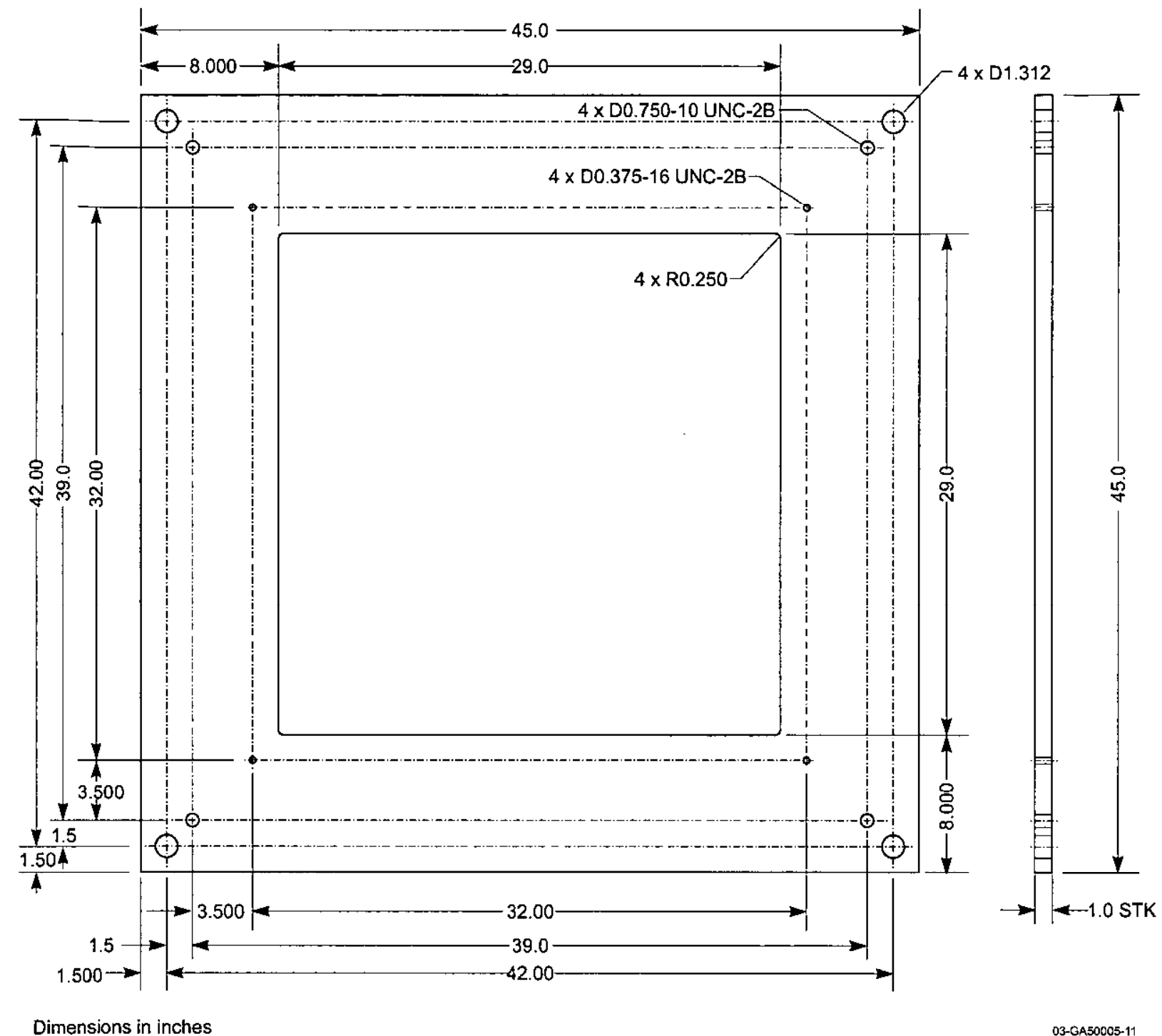

Figure 5. Schematic of the Upper Support Platform. 
B-TM-1639

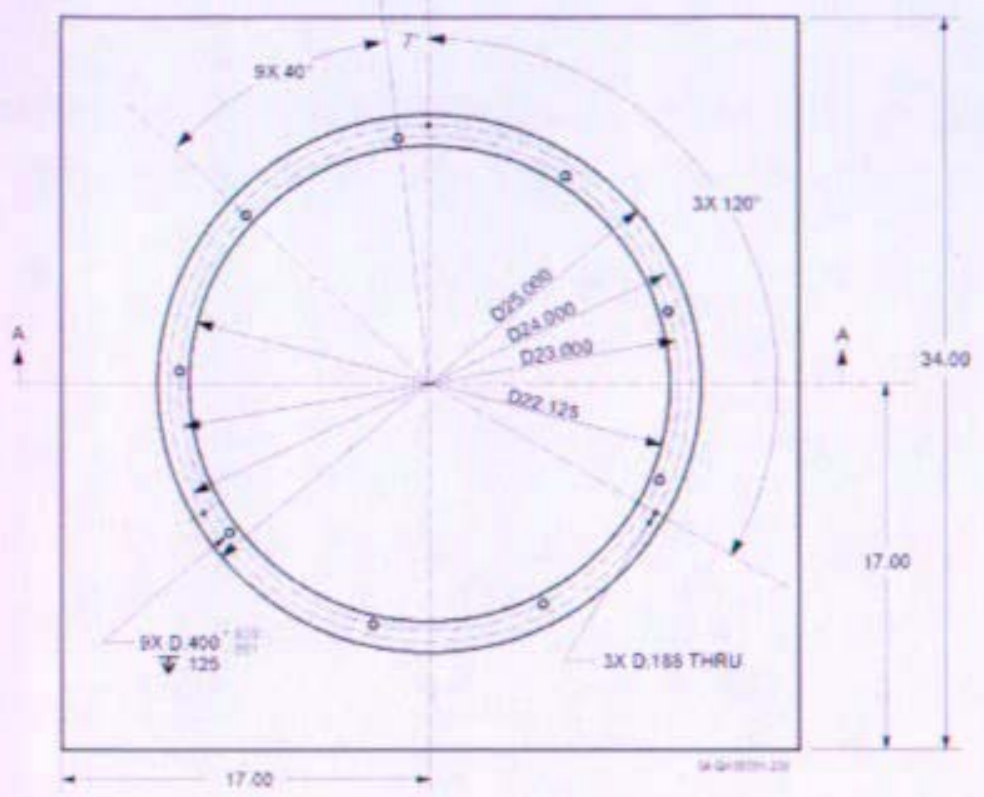

Dinensions is indins
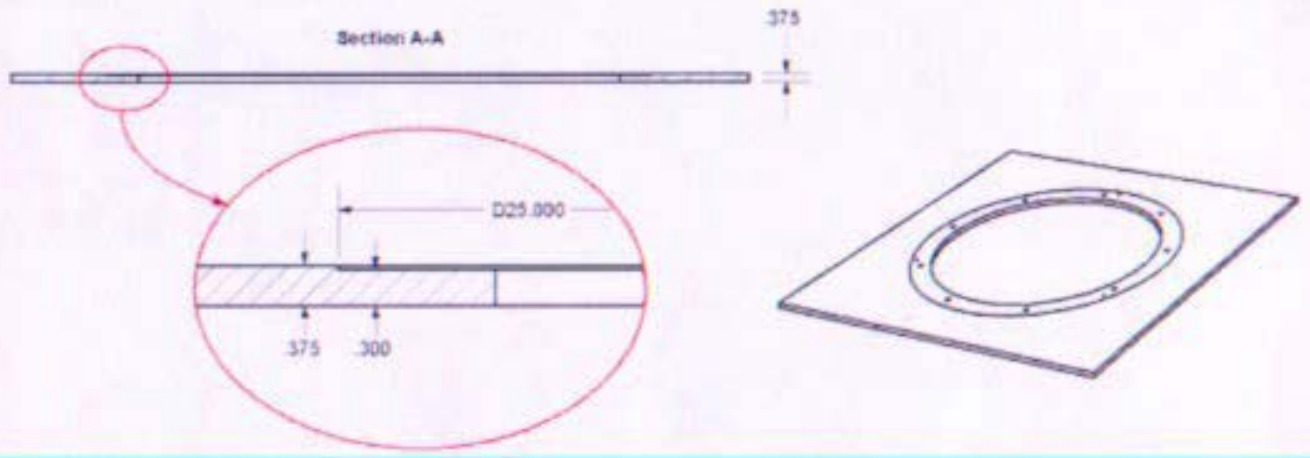

Figure 6. Schematic of the Upper Support Plate. 
B-TM-1639
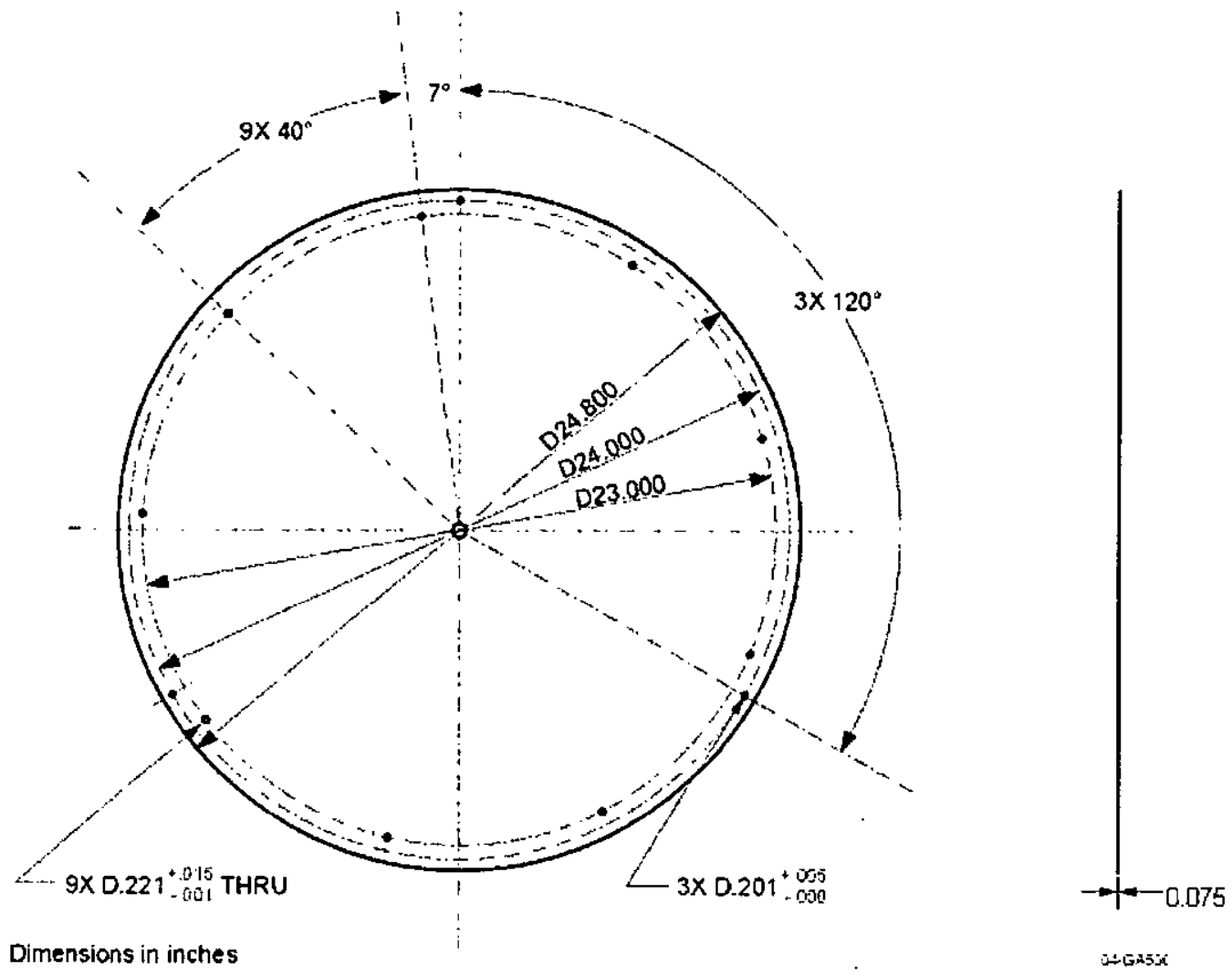

Figure 7. Schematic of the Stainless Steel Diaphragm. 


\section{B-TM-1639}

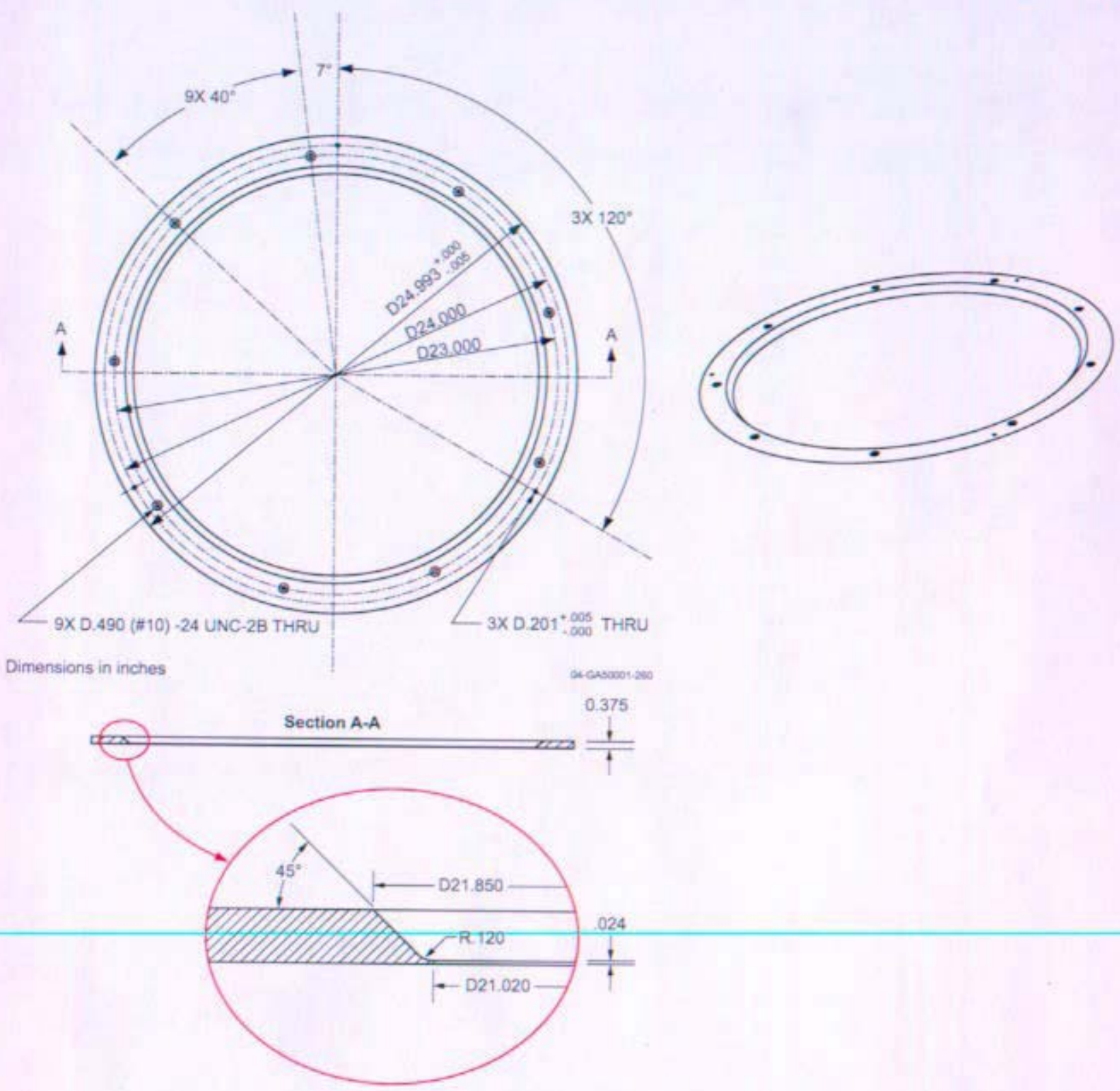

Figure 8. Schematic of the Cylindrical Collar Plate. 
B-TM-1639

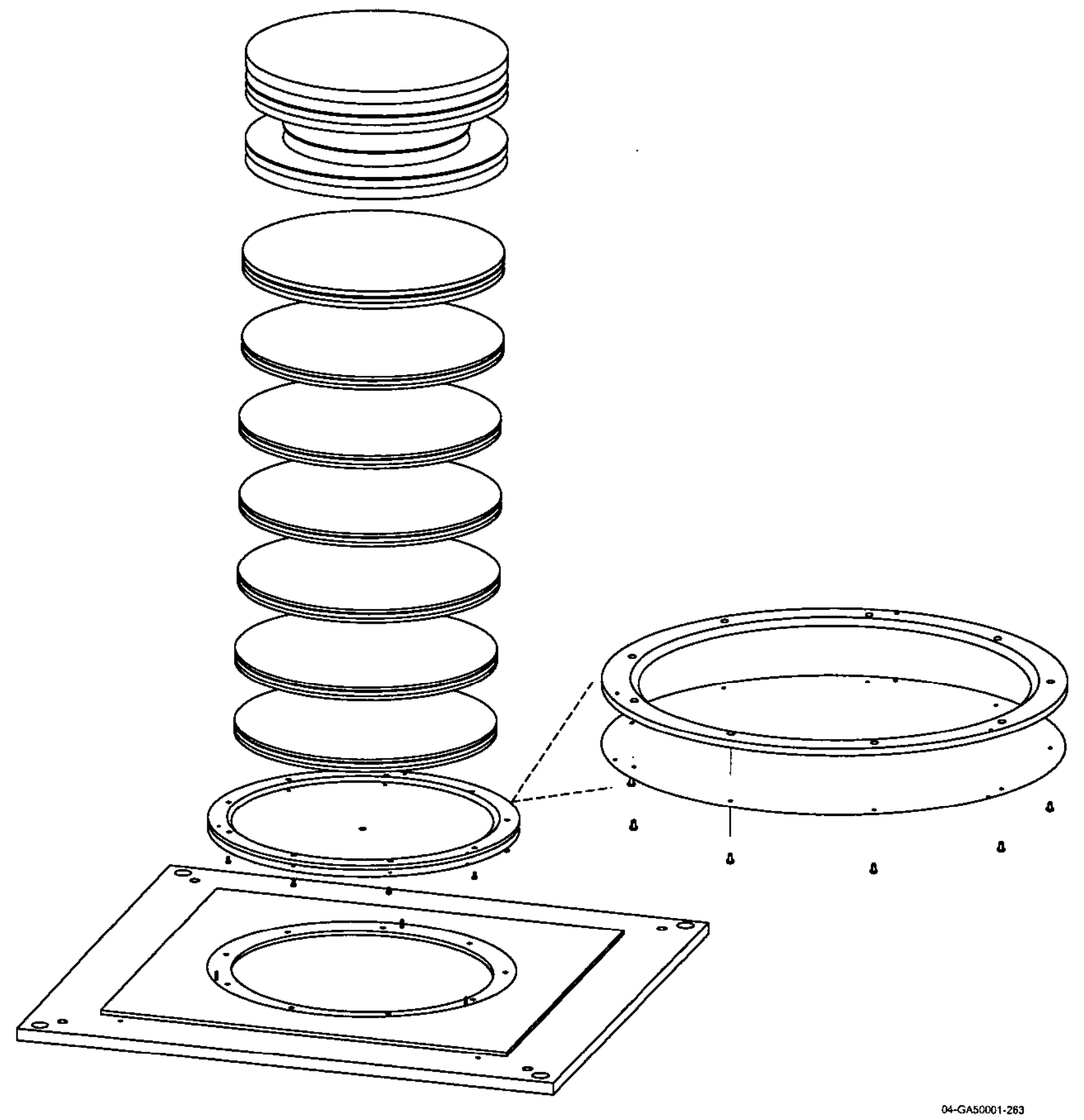

Figure 9. Expanded View of the Upper Stack. 


\section{Description of Materials}

\subsection{HEU Plates}

The HEU metal fuel plates (Jemima plates) to be used in this experiment consist of a tightly nested pair (a disk inside an annular ring, Figure 10) with a HEU1, HEU2, HEU4, or HEU5 disk on the inside and a HEU 3 disk on the outside. All of the HEU fuel plates are nominally $0.118^{\prime \prime}$ thick. The quantity and dimensions of the HEU fuel disks and rings currently in the LANL inventory are provided in Table 3. These HEU fuel disks are assumed to be available to be assembled into a total of $28 \mathrm{HEU}$ fuel plates, with the quantity and dimensions for the assembled HEU fuel plates as listed in Table 4. An average HEU fuel plate uranium density of $18.7434 \mathrm{~g} / \mathrm{cm}^{3}$ and an average ${ }^{235} \mathrm{U}$ enrichment of 93.219 weight percent were assumed, since these were the HEU fuel plate specifications used in the first Nb$1 \mathrm{Zr}$ critical experiment [2]. The average isotopic composition of the HEU fuel plates used in the preexperimental predictions is provided in Table 5.

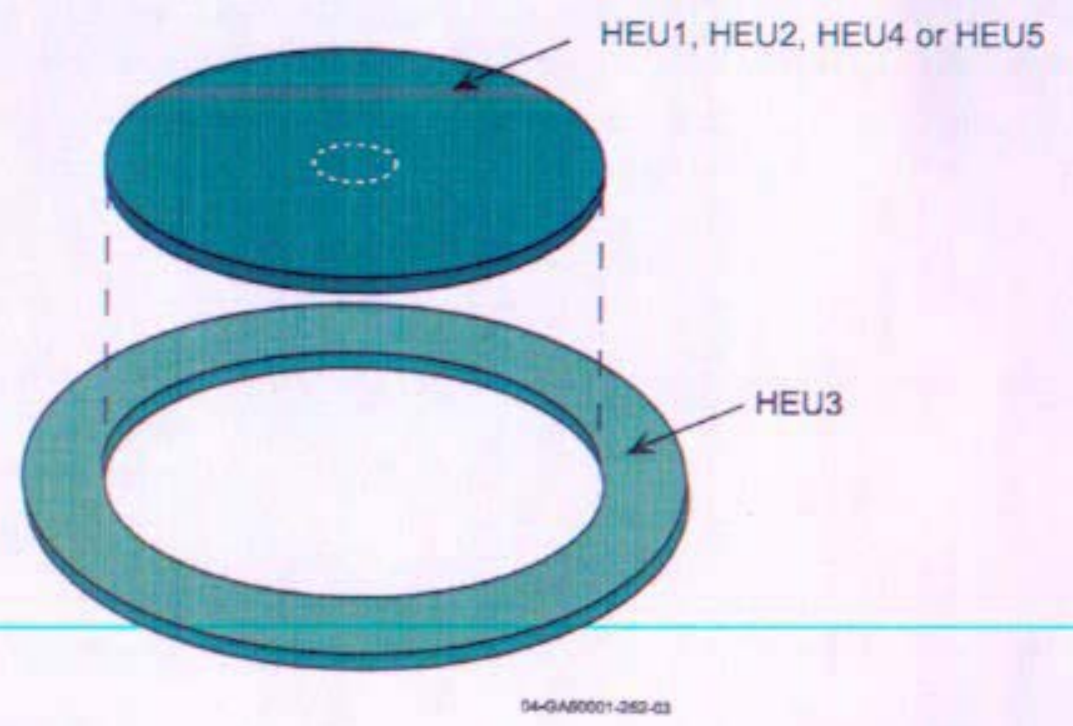

Figure 10. A Nested Pair of an Inner HEU Disk and an Outer HEU Ring.

Table 3. Jemima Plate Inventory

\begin{tabular}{|c|c|c|c|c|}
\hline Plate Type & Quantity & Thickness (in) & $\begin{array}{c}\text { Inner } \\
\text { Diameter } \\
\text { (in) }\end{array}$ & $\begin{array}{c}\text { Outer } \\
\text { Diameter } \\
\text { (in) }\end{array}$ \\
\hline HEU1 & 6 & 0.118 & 0 & 15 \\
\hline HEU2 & 7 & 0.118 & 2.51 & 15 \\
\hline HEU3 & 25 & 0.118 & 15 & 21 \\
\hline HEU4 & 7 & 0.118 & 6.005 & 15 \\
\hline HEU5 & 8 & 0.118 & 10.005 & 15 \\
\hline
\end{tabular}


Table 4. Assembled HEU Fuel Plates

\begin{tabular}{|c|c|c|c|}
\hline Quantity & Thickness (in) & $\begin{array}{c}\text { Inner } \\
\text { Diameter } \\
\text { (in) }\end{array}$ & $\begin{array}{c}\text { Outer } \\
\text { Diameter } \\
\text { (in) }\end{array}$ \\
\hline 6 & 0.118 & 0.0 & 21 \\
\hline 7 & 0.118 & 2.51 & 21 \\
\hline 7 & 0.118 & 6.005 & 21 \\
\hline 5 & 0.118 & 10.005 & 21 \\
\hline 3 & 0.118 & 10.005 & 15 \\
\hline
\end{tabular}

Table 5. Average Isotopic Composition of HEU Fuel Plates

\begin{tabular}{|c|c|}
\hline Isotope & $\begin{array}{c}\text { Number Density } \\
\text { (atoms/barn-cm) }\end{array}$ \\
\hline${ }^{234} \mathrm{U}$ & $4.93652 \times 10^{-4}$ \\
\hline${ }^{235} \mathrm{U}$ & $4.47667 \times 10^{-2}$ \\
\hline${ }^{236} \mathrm{U}$ & $1.59181 \times 10^{-4}$ \\
\hline${ }^{238} \mathrm{U}$ & $2.57214 \times 10^{-3}$ \\
\hline
\end{tabular}

\subsection{Graphite Plates}

Graphite plates of various thicknesses are used in the core region and reflectors for critical experiments 1, 2, and 3 of each material. The quantity and dimensions of the various graphite plates to be used in the core region of the experiments are provided in Table 6. The NRPCT has furnished to LANL 25 solid and 25 annular 0.1 " thick graphite plates fabricated by UCAR Carbon Company for use in the critical experiments. The $0.1^{\prime \prime}$ thick graphite plates were fabricated using PGX-grade graphite with an average density of $1.732 \mathrm{~g} / \mathrm{cm}^{3}$ and a maximum ash content of 0.07 weight percent. The vendor inspection reports for the 0.1 " thick graphite plates are provided in Appendix I. LANL reports to have sufficient $0.197^{\prime \prime}$ and 0.394 " thick graphite plates in their inventory to perform the critical experiments. Similar plates of $0.25 ", 0.5^{\prime \prime}$, and 1.0 " thickness are reported to be available in the LANL inventory for use in the top and bottom reflectors. All of the graphite plates are reported to be fabricated by the same manufacturer with the same grade of graphite. The as-built thickness and mass measurements for the 0.1 " thick graphite plates, as measured by LANL, are provided in Table 7 . LANL had not completed a detailed inventory and as-built characterization of the other graphite plates prior to the termination of NRPCT Project Prometheus work in September. Consequently, as-built graphite plate mass and dimension information was not available for the pre-experimental predictions. The graphite plates were assumed to have an average density of $1.732 \mathrm{~g} / \mathrm{cm}^{3}$ and negligible impurities. Table 8 provides the average isotopic composition used to model the graphite plates. 
Table 6. Graphite Plate Dimensions

\begin{tabular}{|c|c|c|c|}
\hline Quantity & Thickness (in) & $\begin{array}{c}\text { Inner } \\
\text { Diameter } \\
\text { (in) }\end{array}$ & $\begin{array}{c}\text { Outer } \\
\text { Diameter } \\
\text { (in) }\end{array}$ \\
\hline 25 & 0.1 & 0.00 & 21.0 \\
\hline 25 & 0.1 & 2.51 & 21.0 \\
\hline \multirow{2}{*}{15 (total) } & 0.197 & 0.00 & 21.0 \\
\hline \multirow{2}{*}{30 (total) } & $(0.5 \mathrm{~cm})$ & 2.51 & 21.0 \\
\hline \multirow{2}{*}{ Not Available } & 0.394 & 0.00 & 21.0 \\
\hline \multirow{2}{*}{ Not Available } & 0.25 & 2.51 & 21.0 \\
\hline \multirow{2}{*}{ Not Available } & \multirow{2}{*}{0.5} & 0.00 & 21.0 \\
\cline { 3 - 4 } & \multirow{2}{*}{1.0} & 2.51 & 21.0 \\
\cline { 3 - 4 } & & 0.00 & 21.0 \\
\cline { 3 - 4 } & & 2.51 & 21.0 \\
\hline
\end{tabular}

Table 7. As-Built Thickness and Mass Measurements for the 0.1" Thick Graphite Plates

\begin{tabular}{|c|c|c|c|c|c|c|c|c|}
\hline \multirow{2}{*}{$\begin{array}{c}\text { Plate } \\
\text { Identification } \\
\text { Number }\end{array}$} & \multirow{2}{*}{ Type } & \multirow{2}{*}{$\begin{array}{l}\text { Outer } \\
\text { Diameter } \\
\text { (in) }\end{array}$} & \multirow{2}{*}{$\begin{array}{l}\text { Inner } \\
\text { Diameter } \\
\text { (in) }\end{array}$} & \multicolumn{4}{|c|}{ Thickness (in) } & \multirow{2}{*}{$\begin{array}{c}\text { Mass } \\
(\mathrm{g})\end{array}$} \\
\hline & & & & T1 & T2 & T3 & Average & \\
\hline G001 & Solid & 21 & 0 & 0.10155 & 0.10220 & 0.10200 & 0.1019 & 988.6 \\
\hline $\mathrm{G} 002$ & Solid & 21 & 0 & 0.10195 & 0.10190 & 0.10125 & 0.1017 & 980.3 \\
\hline $\mathrm{G} 003$ & Solid & 21 & 0 & 0.10275 & 0.10140 & 0.10085 & 0.1017 & 989.5 \\
\hline G004 & Solid & 21 & 0 & 0.10310 & 0.10515 & 0.10075 & 0.1030 & 986.8 \\
\hline G005 & Solid & 21 & 0 & 0.10425 & 0.10150 & 0.10135 & 0.1024 & 981.9 \\
\hline G006 & Solid & 21 & 0 & 0.10075 & 0.10180 & 0.10235 & 0.1016 & 976.9 \\
\hline G007 & Solid & 21 & 0 & 0.10010 & 0.10110 & 0.10200 & 0.1011 & 981.2 \\
\hline G008 & Solid & 21 & 0 & 0.10375 & 0.10320 & 0.10185 & 0.1029 & 981.0 \\
\hline G009 & Solid & 21 & 0 & 0.10235 & 0.10535 & 0.10080 & 0.1028 & 994.8 \\
\hline G010 & Solid & 21 & 0 & 0.10090 & 0.10600 & 0.10115 & 0.1027 & 981.5 \\
\hline G011 & Solid & 21 & 0 & 0.10510 & 0.10155 & 0.10135 & 0.1027 & 995.0 \\
\hline $\mathrm{G} 012$ & Solid & 21 & 0 & 0.09980 & 0.10250 & 0.10215 & 0.1015 & 993.2 \\
\hline G013 & Solid & 21 & 0 & 0.09955 & 0.10220 & 0.10815 & 0.1033 & 981.6 \\
\hline G014 & Solid & 21 & 0 & 0.10300 & 0.10295 & 0.09960 & 0.1019 & 978.3 \\
\hline G015 & Solid & 21 & 0 & 0.10070 & 0.10265 & 0.10040 & 0.1013 & 977.4 \\
\hline G016 & Solid & 21 & 0 & 0.10230 & 0.10055 & 0.10290 & 0.1019 & 990.4 \\
\hline G017 & Solid & 21 & 0 & 0.10020 & 0.10105 & 0.10265 & 0.1013 & 980.3 \\
\hline G018 & Solid & 21 & 0 & 0.10045 & 0.10140 & 0.10040 & 0.1008 & 980.5 \\
\hline G019 & Solid & 21 & 0 & 0.09960 & 0.10110 & 0.10265 & 0.1011 & 977.5 \\
\hline $\mathrm{G} 020$ & Solid & 21 & 0 & 0.10155 & 0.10050 & 0.10505 & 0.1024 & $9 \overline{86.1}$ \\
\hline G021 & Solid & 21 & 0 & 0.09995 & 0.10095 & 0.10255 & 0.1012 & 978.6 \\
\hline $\mathrm{G} 022$ & Solid & 21 & 0 & 0.10010 & 0.10185 & 0.10240 & 0.1015 & 985.5 \\
\hline G023 & Solid & 21 & 0 & 0.10050 & 0.10380 & 0.10155 & 0.1020 & 982.6 \\
\hline $\mathrm{G} 024$ & Solid & 21 & 0 & 0.10025 & 0.10500 & 0.10450 & 0.1033 & $991 . \overline{3}$ \\
\hline G025 & Solid & 21 & 0 & 0.10050 & 0.09985 & 0.10305 & 0.1011 & 980.4 \\
\hline G100 & Hole & 21 & 2.51 & 0.09895 & 0.10160 & 0.10655 & 0.1024 & 970.7 \\
\hline
\end{tabular}




\begin{tabular}{|c|c|c|c|c|c|c|c|c|}
\hline \multirow{2}{*}{$\begin{array}{c}\text { Plate } \\
\text { Identification } \\
\text { Number }\end{array}$} & \multirow[b]{2}{*}{ Type } & \multirow{2}{*}{$\begin{array}{l}\text { Outer } \\
\text { Diameter } \\
\text { (in) }\end{array}$} & \multirow{2}{*}{$\begin{array}{c}\text { Inner } \\
\text { Diameter } \\
\text { (in) }\end{array}$} & \multicolumn{4}{|c|}{ Thickness (in) } & \multirow{2}{*}{$\begin{array}{c}\text { Mass } \\
(\mathrm{g})\end{array}$} \\
\hline & & & & T1 & T2 & T3 & Average & \\
\hline G101 & Hole & 21 & 2.51 & 0.10160 & 0.10090 & 0.10365 & 0.1021 & 962.0 \\
\hline G102 & Hole & 21 & 2.51 & 0.10095 & 0.09960 & 0.10170 & 0.1008 & 962.1 \\
\hline G103 & Hole & 21 & 2.51 & 0.09975 & 0.10055 & 0.10210 & 0.1008 & 959.9 \\
\hline$\overline{G 104}$ & Hole & 21 & 2.51 & 0.10010 & 0.09960 & 0.10235 & 0.1007 & 966.4 \\
\hline G105 & Hole & 21 & 2.51 & 0.09935 & 0.10215 & 0.10180 & 0.1011 & 960.7 \\
\hline G106 & Hole & 21 & 2.51 & 0.10145 & 0.10055 & 0.10260 & 0.1015 & 963.5 \\
\hline G107 & Hole & 21 & 2.51 & 0.09995 & 0.10045 & $0.10 \overline{440}$ & 0.1016 & 963.6 \\
\hline G108 & Hole & 21 & 2.51 & 0.10055 & 0.10520 & $0 . \overline{10205}$ & 0.1026 & 976.4 \\
\hline G109 & Hole & 21 & 2.51 & 0.10025 & 0.10120 & 0.10220 & 0.1012 & 963.4 \\
\hline G110 & Hole & 21 & 2.51 & 0.10180 & 0.10000 & 0.10080 & 0.1009 & 963.8 \\
\hline G111 & Hole & 21 & 2.51 & 0.09995 & 0.10090 & 0.10145 & 0.1008 & 969.8 \\
\hline G112 & Hole & 21 & 2.51 & 0.09950 & 0.10220 & 0.10100 & 0.1009 & 967.6 \\
\hline $\mathrm{G} 113$ & Hole & 21 & 2.51 & 0.10140 & 0.10125 & 0.10170 & 0.1015 & 963.1 \\
\hline G114 & Hole & 21 & 2.51 & 0.10150 & 0.09970 & 0.10125 & 0.1008 & 961.8 \\
\hline G115 & Hole & 21 & 2.51 & 0.10000 & 0.10160 & 0.10215 & 0.1013 & 962.8 \\
\hline G116 & Hole & 21 & 2.51 & 0.10040 & 0.10120 & 0.10225 & 0.1013 & 961.4 \\
\hline G117 & Hole & 21 & 2.51 & 0.10045 & 0.10025 & 0.10265 & 0.1011 & 969.6 \\
\hline G118 & Hole & 21 & 2.51 & 0.10205 & 0.10000 & 0.10235 & 0.1015 & 971.6 \\
\hline G119 & Hole & 21 & 2.51 & 0.10165 & 0.10590 & 0.10720 & 0.1049 & 971.5 \\
\hline $\mathrm{G} 120$ & Hole & 21 & 2.51 & 0.10120 & 0.09500 & 0.10330 & 0.0998 & 963.5 \\
\hline G121 & Hole & 21 & 2.51 & 0.10595 & 0.10015 & 0.10055 & 0.1022 & 973.1 \\
\hline $\mathrm{G} 122$ & Hole & 21 & 2.51 & 0.10050 & 0.09970 & 0.10120 & 0.1005 & 962.5 \\
\hline G123 & Hole & 21 & 2.51 & 0.10555 & 0.10050 & 0.10230 & 0.1028 & 971.0 \\
\hline G124 & Hole & 21 & 2.51 & 0.10080 & 0.10295 & 0.09965 & 0.1011 & 961.7 \\
\hline
\end{tabular}

Table 8. Average Isotopic Composition of the Graphite Plates

\begin{tabular}{|c|c|}
\hline Nuclide & $\begin{array}{c}\text { Number Density } \\
\text { (atoms/b-cm) }\end{array}$ \\
\hline $\mathrm{C}$ & $8.68421 \times 10^{-2}$ \\
\hline
\end{tabular}

\subsection{Polyethylene Plates}

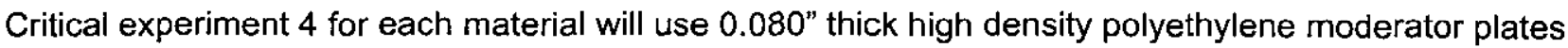
and a nominal $1.0^{\prime \prime}$ thick polyethylene reflector. There are two types of polyethylene plates, a solid plate with a 21" OD and an annular plate with a 21 " OD and a $2.51^{\prime \prime}$ ID. The NRPCT has furnished to LANL a set of $0.080^{\prime \prime}, 0.5^{\prime \prime}$, and $1.0^{\prime \prime}$ thick polyethylene plates to be used in the Prometheus critical experiments. These high density polyethylene plates were manufactured by Standard Machine Company. The inspection reports for the NRPCT furnished polyethylene plates are provided in Appendix J. The quantity and dimensions of the NRPCT furnished polyethylene plates as well as the known LANL polyethylene plate inventory are provided in Table 9 . The high density polyethylene plates have an average density of $0.9573 \mathrm{~g} / \mathrm{cm}^{3}$ and are reported to have negligible impurities [2]. The average polyethylene isotopic composition used for the pre-experimental predictions is provided in Table 10. 
Table 9. Polyethylene Plate Inventory

\begin{tabular}{|c|c|c|c|}
\hline $\begin{array}{c}\text { Nominal } \\
\text { Thickness (in) }\end{array}$ & Quantity & $\begin{array}{c}\text { Inner } \\
\text { Diameter (in) }\end{array}$ & $\begin{array}{c}\text { Outer } \\
\text { Diameter (in) }\end{array}$ \\
\hline \multirow{2}{*}{0.02} & 1 & 0.00 & 21.0 \\
\cline { 2 - 4 } & 1 & 2.51 & 21.0 \\
\hline \multirow{2}{*}{0.04} & 5 & 0.00 & 21.0 \\
\cline { 2 - 4 } & 20 & 2.51 & 21.0 \\
\hline \multirow{2}{*}{0.08} & 20 & 0.00 & 21.0 \\
\hline \multirow{2}{*}{0.5} & 15 & 2.51 & 21.0 \\
\hline \multirow{2}{*}{1.0} & 2 & 0.00 & 21.0 \\
\cline { 2 - 4 } & 2 & 2.51 & 21.0 \\
\hline \multirow{2}{*}{1.125} & 2 & 0.00 & 21.0 \\
\cline { 2 - 4 } & 2 & 2.51 & 21.0 \\
\cline { 2 - 4 } & 1 & 0.00 & 21.0 \\
\hline
\end{tabular}

Table 10. Average Isotopic Composition of the Polyethylene Plates

\begin{tabular}{|c|c|}
\hline Isotope & $\begin{array}{c}\text { Number } \\
\text { Density } \\
\text { (atoms/b-cm) }\end{array}$ \\
\hline $\mathrm{C}$ & $4.11027 \mathrm{E}-02$ \\
\hline $\mathrm{H}$ & $8.22053 \mathrm{E}-02$ \\
\hline
\end{tabular}

\subsection{Aluminum 6061-T6}

The alignment tube, spindle plate, upper support plate, upper support platform, collar, and platen are constructed using aluminum alloy 6061-T6. The density of aluminum $6061-T 6$ is $2.70 \mathrm{~g} / \mathrm{cm}^{3}$ [17]. Table 11 provides the specifications for the chemical composition of Al 6061-T6 [17] as well as the average chemical composition. The average chemical composition was used to calculate the isotopic composition of the aluminum 6061-T6 used in the model. The average isotopic composition for aluminum 6061-T6 is provided in Table 12. Note that Table 12 contains both elemental and isotopic number densities for selected elements.

LANL provided detailed dimensions for each of the aluminum pieces except for the alignment tube [2]. The alignment tube ensures proper alignment of the plates in the lower core region. The alignment tube has a $2.0^{\prime \prime} I D, 2.48$ " OD, and is assumed to extend from the bottom of the spindle plate to the top of the unit below the last stacking unit with a 2.51" ID HEU plate in the lower core region. 
Table 11. Chemical Composition of Aluminum 6061-T6

\begin{tabular}{|c|c|c|}
\hline Element & $\begin{array}{c}\text { Specification } \\
\text { (wt. \%) }\end{array}$ & $\begin{array}{c}\text { Average } \\
\text { (wt. \%) }\end{array}$ \\
\hline $\mathrm{Al}$ & balance & 97.305 \\
\hline $\mathrm{Mg}$ & $0.8-1.2$ & 1.000 \\
\hline $\mathrm{Si}$ & $0.4-0.8$ & 0.600 \\
\hline $\mathrm{Fe}$ & 0.7 max & 0.350 \\
\hline $\mathrm{Cu}$ & $0.15-0.40$ & 0.275 \\
\hline $\mathrm{Cr}$ & $0.04-0.35$ & 0.195 \\
\hline $\mathrm{Zn}$ & 0.25 max & 0.125 \\
\hline $\mathrm{Mn}$ & 0.15 max & 0.075 \\
\hline $\mathrm{Ti}$ & 0.15 max & 0.075 \\
\hline
\end{tabular}

Table 12. Average Isotopic Composition of Aluminum 6061-T6

\begin{tabular}{|c|c|}
\hline Element/Nuclide & $\begin{array}{c}\text { Number } \\
\text { Density } \\
\text { (atoms/b-cm) }\end{array}$ \\
\hline $\mathrm{Al}$ & $5.86385 \mathrm{E}-02$ \\
\hline $\mathrm{Mg}$ & $6.68989 \mathrm{E}-04$ \\
\hline $\mathrm{Si}$ & $3.47363 \mathrm{E}-04$ \\
\hline $\mathrm{Fe}$ & $1.01906 \mathrm{E}-04$ \\
\hline${ }^{54} \mathrm{Fe}$ & $5.95639 \mathrm{E}-06$ \\
\hline${ }^{56} \mathrm{Fe}$ & $9.35026 \mathrm{E}-05$ \\
\hline${ }^{57} \mathrm{Fe}$ & $2.15938 \mathrm{E}-06$ \\
\hline${ }^{56} \mathrm{Fe}$ & $2.87374 \mathrm{E}-07$ \\
\hline $\mathrm{Cu}$ & $7.03654 \mathrm{E}-05$ \\
\hline${ }^{63} \mathrm{Cu}$ & $4.86718 \mathrm{E}-05$ \\
\hline${ }^{65} \mathrm{Cu}$ & $2.16937 \mathrm{E}-05$ \\
\hline $\mathrm{Cr}$ & $6.09788 \mathrm{E}-05$ \\
\hline${ }^{50} \mathrm{Cr}$ & $2.64953 \mathrm{E}-06$ \\
\hline${ }^{52} \mathrm{Cr}$ & $5.10935 \mathrm{E}-05$ \\
\hline${ }^{53} \mathrm{Cr}$ & $5.79359 \mathrm{E}-06$ \\
\hline${ }^{54} \mathrm{Cr}$ & $1.44215 \mathrm{E}-06$ \\
\hline $\mathrm{Zn}$ & $3.10733 \mathrm{E}-05$ \\
\hline $\mathrm{Mn}$ & $2.21974 \mathrm{E}-05$ \\
\hline $\mathrm{Ti}$ & $2.54765 \mathrm{E}-05$ \\
\hline &
\end{tabular}




\subsection{Stainless Steel Diaphragm}

The stainless steel diaphragm is constructed using stainless steel 301 . The density of stainless steel 301 is $8.00 \mathrm{~g} / \mathrm{cm}^{3}$ [18]. Table 13 provides the specifications for the range of acceptable chemical compositions of stainless steel 301 [18] and the average chemical composition. The average weight percents were used to calculate the isotopic composition of the stainless steel 301 used in the model. The average elemental and isotopic compositions of stainless steel 301 are provided in Table 14 .

The stainless steel diaphragm is designed to support the weight of the upper core region. It has a $24.8^{\prime \prime} \mathrm{OD}$ and a $0.075^{\prime \prime}$ thickness (modeled as 0.040" thick in the baseline, Mo, Re, and Ta-2.5W critical experiments since LANL had not determined this thickness at the time of the analysis, see Appendix E). The existing 0.040" diaphragm at LANL was insufficient for safety analyses, and a thicker one $\left(0.075^{\prime \prime}\right)$ had to be procured.

Table 13. Chemical Composition of Stainless Steel 301

\begin{tabular}{|c|c|c|}
\hline Element & $\begin{array}{c}\text { Specification } \\
\text { (wt. \%) }\end{array}$ & $\begin{array}{c}\text { Average } \\
\text { (wt. \%) }\end{array}$ \\
\hline $\mathrm{Fe}$ & Balance & 74.4625 \\
\hline $\mathrm{Cr}$ & $16-18$ & 17.0000 \\
\hline $\mathrm{Ni}$ & $6-8$ & 7.0000 \\
\hline $\mathrm{C}$ & Max 0.15 & 0.0750 \\
\hline $\mathrm{Mn}$ & Max 2 & 1.0000 \\
\hline $\mathrm{N}$ & Max 0.1 & 0.0500 \\
\hline $\mathrm{P}$ & Max 0.045 & 0.0225 \\
\hline $\mathrm{S}$ & Max 0.03 & 0.0150 \\
\hline $\mathrm{Si}$ & Max 0.75 & 0.3750 \\
\hline
\end{tabular}


Table 14. Average Elemental and Isotopic Composition of Stainless Steel 301

\begin{tabular}{|c|c|}
\hline Isotope & $\begin{array}{c}\text { Number } \\
\text { Density } \\
\text { (atoms/b-cm) }\end{array}$ \\
\hline $\mathrm{Fe}$ & $6.42383 \mathrm{E}-02$ \\
\hline${ }^{54} \mathrm{Fe}$ & $3.75473 \mathrm{E}-03$ \\
\hline${ }^{56} \mathrm{Fe}$ & $5.89412 \mathrm{E}-02$ \\
\hline${ }^{57} \mathrm{Fe}$ & $1.36121 \mathrm{E}-03$ \\
\hline${ }^{58} \mathrm{Fe}$ & $1.81152 \mathrm{E}-04$ \\
\hline $\mathrm{Cr}$ & $1.57514 \mathrm{E}-02$ \\
\hline${ }^{50} \mathrm{Cr}$ & $6.84398 \mathrm{E}-04$ \\
\hline${ }^{52} \mathrm{Cr}$ & $1.31979 \mathrm{E}-02$ \\
\hline${ }^{53} \mathrm{Cr}$ & $1.49654 \mathrm{E}-03$ \\
\hline${ }^{54} \mathrm{Cr}$ & $3.72521 \mathrm{E}-04$ \\
\hline $\mathrm{Ni}$ & $5.74579 \mathrm{E}-03$ \\
\hline${ }^{58} \mathrm{Ni}$ & $3.91156 \mathrm{E}-03$ \\
\hline${ }^{60} \mathrm{Ni}$ & $1.50672 \mathrm{E}-03$ \\
\hline${ }^{67} \mathrm{Ni}$ & $6.54963 \mathrm{E}-05$ \\
\hline${ }^{62} \mathrm{Ni}$ & $2.08831 \mathrm{E}-04$ \\
\hline${ }^{64} \mathrm{Ni}$ & $5.31830 \mathrm{E}-05$ \\
\hline $\mathrm{C}$ & $3.00839 \mathrm{E}-04$ \\
\hline $\mathrm{Mn}$ & $8.76936 \mathrm{E}-04$ \\
\hline $\mathrm{N}$ & $1.71979 \mathrm{E}-04$ \\
\hline${ }^{14} \mathrm{~N}$ & $1.71346 \mathrm{E}-04$ \\
\hline${ }^{15} \mathrm{~N}$ & $6.32882 \mathrm{E}-07$ \\
\hline $\mathrm{P}$ & $3.49969 \mathrm{E}-05$ \\
\hline $\mathrm{S}$ & $2.25373 \mathrm{E}-05$ \\
\hline $\mathrm{Si}$ & $6.43265 \mathrm{E}-04$ \\
\hline
\end{tabular}




\subsection{Mo Plates}

The NRPCT has furnished to LANL solid and annular Mo critical experiment plates. The Mo critical experiment plates were fabricated by Schwarzkopf Technologies. The quantity and dimensional specifications for the Mo plates are provided in Table 15. Photographs of a solid and annular Mo plate are provided in Figure 11 and Figure 12. Table 16 provides the as-built dimensions of the Mo plates based on dimensional characterization measurements performed by Schwarzkopf. The outer and inner diameters reported for each plate are based on the average of two diameter measurements taken approximately 90 degrees from each other. The average outer diameter of the Mo plates is 21.000 " with a standard deviation of 0.003 ". The average inner diameter of the annular Mo plates is 2.506 " with a standard deviation of 0.004 ". The differences between the nominal and measured diameters are judged to be negligible. The thickness measurement for each plate is based on the average of 3 thickness measurements. The average measured thickness of the $0.060^{\prime \prime}$ nominal thickness Mo plates is $0.0595^{\prime \prime}$ with a standard deviation of $0.0007^{\prime \prime}$. The average measured thickness of the 0.030 " nominal thickness Mo plates is 0.0301 " with a standard deviation of 0.0003 ".

KAPL performed high-accuracy density measurements on remnant samples from the Mo plates and found the average Mo density to be $10.218 \mathrm{~g} / \mathrm{cm}^{3}$. The results of the density measurements are provided in Table 17. Table 18 provides the guaranteed chemical analysis for the Mo plates and Table 19 provides the results of three chemical analyses using different sized samples and the average of the analyses. The nitrogen content of $0.0006 \%(6 \mathrm{ppm})$ from the chemical analysis of the Mo plates, as shown in Table 19, is $20 \%$ higher than the nitrogen content specification of $5 \mathrm{ppm}$, as set in Table 18. The effect of the nitrogen content being $20 \%$ over specification was negligible. The chemical impurities in the Mo plates are considered to be insignificant; therefore, the Mo plate material was approximated as pure Mo. The average Mo plate elemental composition used in the pre-experimental predictions is provided in Table 20 and is based on an assumed density of $10.22 \mathrm{~g} / \mathrm{cm}^{3}$ (theoretical density) due to the lack of measured density values at that time. Refer to Appendix $F$ for the full Mo dimension and chemistry reports, as provided by the vendors.

Table 15. Specifications for Mo Plates

\begin{tabular}{|c|c|c|c|c|}
\hline Type & Quantity & $\begin{array}{c}\text { Outer Diameter } \\
\text { (in) }\end{array}$ & $\begin{array}{c}\text { Inner Diameter } \\
\text { (in) }\end{array}$ & $\begin{array}{c}\text { Thickness } \\
\text { (in) }\end{array}$ \\
\hline Solid & 32 & $21.000 \pm 0.010$ & - & $0.0300 \pm 0.0030$ \\
\hline Annular & 32 & $21.000 \pm 0.010$ & $2.510 \pm 0.010$ & $0.0300 \pm 0.0030$ \\
\hline Solid & 4 & $21.000 \pm 0.010$ & - & $0.0600 \pm 0.0060$ \\
\hline Annular & 4 & $21.000 \pm 0.010$ & $2.510 \pm 0.010$ & $0.0600 \pm 0.0060$ \\
\hline
\end{tabular}




\section{B-TM-1639}

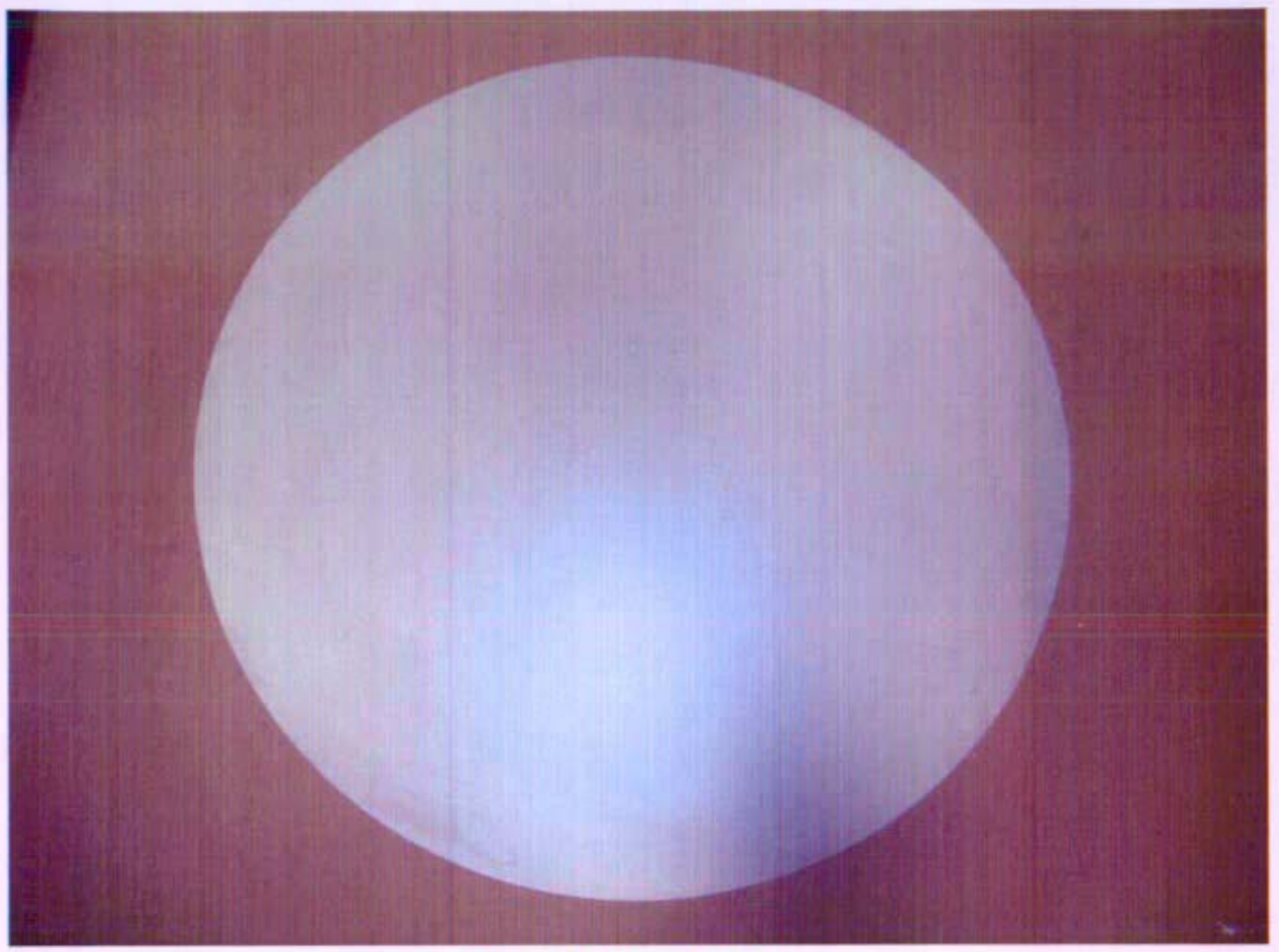

Figure 11. Solid Mo Plate 


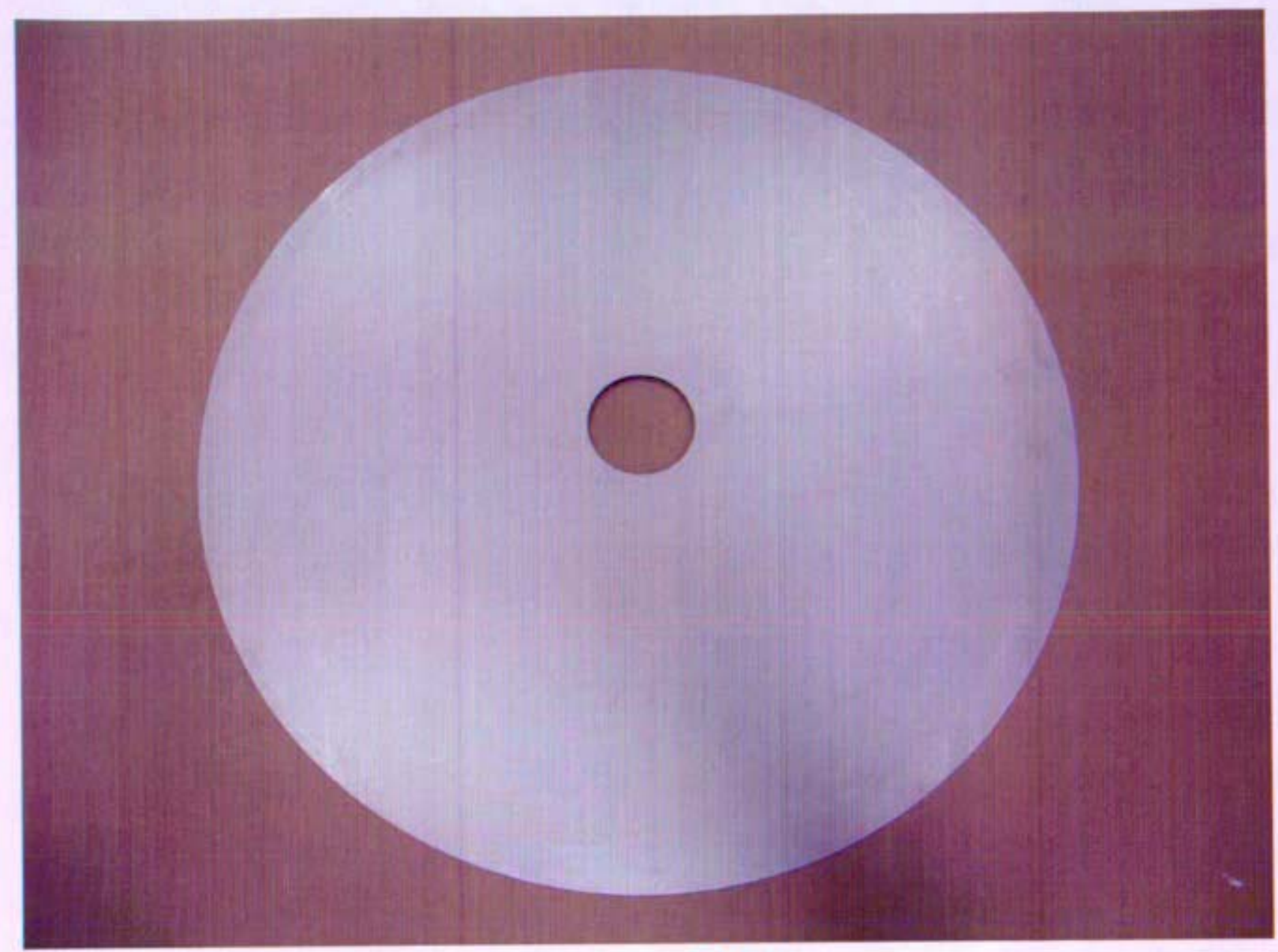

Figure 12. Annular Mo Plate

Table 16. As-Built Dimensions of Mo Plates

\begin{tabular}{|c|c|c|c|c|}
\hline Serial \# & $\begin{array}{c}\text { Average Outer } \\
\text { Diameter (in) }\end{array}$ & $\begin{array}{c}\text { Average Inner } \\
\text { Diameter (in) }\end{array}$ & $\begin{array}{c}\text { Average } \\
\text { Thickness (in) }\end{array}$ & Mass (g) \\
\hline MO-0001 & 21.002 & 2.505 & 0.031 & 1748.0 \\
\hline MO-0002 & 21.002 & 2.503 & 0.031 & 1745.0 \\
\hline MO-0003 & 21.003 & 2.507 & 0.030 & 1726.0 \\
\hline MO-0004 & 20.997 & 2.504 & 0.031 & 1741.0 \\
\hline MO-0005 & 21.002 & 2.506 & 0.030 & 1699.0 \\
\hline MO-0006 & 21.002 & 2.509 & 0.030 & 1718.0 \\
\hline MO-0007 & 21.004 & 2.509 & 0.030 & 1706.0 \\
\hline MO-0008 & 21.000 & 2.499 & 0.030 & 1694.2 \\
\hline MO-0009 & 21.003 & 2.503 & 0.030 & 1694.2 \\
\hline MO-0010 & 21.003 & 2.505 & 0.030 & 1704.4 \\
\hline MO-0011 & 21.000 & 2.509 & 0.030 & 1712.0 \\
\hline MO-0012 & 21.001 & 2.501 & 0.030 & 1704.0 \\
\hline MO-0013 & 21.002 & 2.506 & 0.030 & 1696.0 \\
\hline MO-0014 & 21.003 & 2.503 & 0.030 & 1701.0 \\
\hline
\end{tabular}




\begin{tabular}{|c|c|c|c|c|}
\hline Serial \# & $\begin{array}{l}\text { Average Outer } \\
\text { Diameter (in) }\end{array}$ & $\begin{array}{l}\text { Average Inner } \\
\text { Diameter (in) }\end{array}$ & $\begin{array}{c}\text { Average } \\
\text { Thickness (in) }\end{array}$ & $\operatorname{Mass}(\mathrm{g})$ \\
\hline MO-0015 & 20.998 & 2.504 & 0.030 & 1731.0 \\
\hline MO-0016 & 21.001 & 2.502 & 0.030 & 1718.0 \\
\hline $\mathrm{MO}-0017$ & 21.003 & 2.508 & 0.031 & 1744.0 \\
\hline MO-0018 & 21.002 & 2.504 & 0.030 & 1735.0 \\
\hline MO-0019 & 21.003 & 2.501 & 0.030 & 1712.0 \\
\hline MO-0020 & 21.003 & 2.503 & 0.030 & 1715.0 \\
\hline $\mathrm{MO}-0021$ & 21.003 & 2.503 & 0.030 & 1608.0 \\
\hline $\mathrm{MO}-0022$ & 21.001 & 2.501 & 0.030 & 1720.0 \\
\hline MO-0023 & 21.001 & 0.000 & 0.030 & 1742.8 \\
\hline MO-0024 & 21.002 & 0.000 & 0.030 & 1759.0 \\
\hline MO-0025 & 21.001 & 0.000 & 0.030 & 1718.8 \\
\hline $\mathrm{MO}-0026$ & 21.001 & 0.000 & 0.030 & 1738.0 \\
\hline $\mathrm{MO}-\overline{0027}$ & 21.002 & 0.000 & 0.030 & 1724.4 \\
\hline MO-0028 & 21.001 & 0.000 & 0.030 & 1715.0 \\
\hline MO-0029 & 21.001 & 0.000 & $0 . \overline{030}$ & $17 \overline{27} .4$ \\
\hline $\mathrm{MO}-0030$ & 21.004 & 0.000 & 0.030 & $17 \overline{16.6}$ \\
\hline $\mathrm{MO}-0031$ & 21.002 & 0.000 & 0.030 & 1723.4 \\
\hline MO-0032 & 21.003 & 0.000 & 0.030 & 1746.2 \\
\hline MO-0033 & 21.002 & 0.000 & 0.030 & 1752.2 \\
\hline MO-0034 & 21.000 & 0.000 & 0.030 & 1724.0 \\
\hline MO-0035 & 21.004 & 0.000 & 0.030 & 1740.2 \\
\hline $\mathrm{MO}-0036$ & 21.002 & 0.000 & 0.030 & 1740.0 \\
\hline MO-0037 & 21.002 & 0.000 & 0.030 & 1756.2 \\
\hline MO-0038 & 21.001 & 0.000 & 0.031 & 1746.0 \\
\hline MO-0039 & 21.001 & 0.000 & 0.030 & 1762.8 \\
\hline $\mathrm{MO}-0040$ & 21.000 & 0.000 & 0.030 & 1745.2 \\
\hline MO-0041 & 21.003 & 0.000 & 0.030 & 1747.0 \\
\hline MO-0042 & 21.002 & 0.000 & 0.031 & 1746.2 \\
\hline MO-0051 & 20.996 & 2.511 & 0.029 & 1685.8 \\
\hline MO-0052 & 20.988 & 2.512 & 0.030 & 1729.0 \\
\hline $\mathrm{MO}-0053$ & 20.995 & 2.509 & 0.030 & 1729.4 \\
\hline MO-0054 & 20.999 & 2.511 & 0.030 & 1678.2 \\
\hline$\overline{\mathrm{MO}-0055}$ & 21.000 & 2.510 & 0.030 & 1690.2 \\
\hline MO-0056 & 20.996 & 2.514 & 0.030 & 1700.4 \\
\hline MO-0057 & 20.992 & 2.512 & 0.030 & 1715.4 \\
\hline $\mathrm{MO}-0058$ & 20.998 & 2.513 & 0.030 & 1708.4 \\
\hline $\mathrm{MO}-0059$ & 20.996 & 2.512 & 0.030 & 1703.0 \\
\hline MO-0060 & 20.997 & 2.513 & 0.030 & 1702.4 \\
\hline MO-0061 & 20.994 & 0.000 & 0.030 & 1749.0 \\
\hline MO-0062 & 20.986 & 0.000 & 0.030 & 1721.8 \\
\hline $\mathrm{MO}-0063$ & 20.999 & 0.000 & 0.030 & 1709.2 \\
\hline $\mathrm{MO}-0064$ & 20.997 & 0.000 & 0.030 & 1732.0 \\
\hline MO-0065 & 20.997 & 0.000 & 0.030 & 1736.0 \\
\hline MO-0066 & 20.998 & 0.000 & 0.029 & 1679.2 \\
\hline MO-0067 & 20.999 & 0.000 & 0.031 & 1752.8 \\
\hline MO-0068 & 20.998 & 0.000 & 0.029 & 1695.0 \\
\hline MO-0069 & 20.996 & 0.000 & 0.030 & 1718.2 \\
\hline
\end{tabular}


B-TM-1639

\begin{tabular}{|c|c|c|c|c|}
\hline Serial \# & $\begin{array}{c}\text { Average Outer } \\
\text { Diameter (in) }\end{array}$ & $\begin{array}{c}\text { Average Inner } \\
\text { Diameter (in) }\end{array}$ & $\begin{array}{c}\text { Average } \\
\text { Thickness (in) }\end{array}$ & Mass (g) \\
\hline MO-0070 & 20.998 & 0.000 & 0.030 & 1744.2 \\
\hline MO-0071 & 20.998 & 0.000 & 0.030 & 1715.4 \\
\hline MO-0072 & 21.000 & 0.000 & 0.029 & 1706.8 \\
\hline MO-101 & 21.002 & 0.000 & 0.060 & 3485.0 \\
\hline MO-102 & 21.001 & 0.000 & 0.060 & 3445.2 \\
\hline MO-103 & 20.999 & 0.000 & 0.058 & 3365.4 \\
\hline MO-104 & 21.000 & 0.000 & 0.059 & 3423.4 \\
\hline MO-105 & 21.000 & 2.503 & 0.060 & 3406.2 \\
\hline MO-106 & 20.999 & 2.510 & 0.060 & 3414.8 \\
\hline$M O-107$ & 20.998 & 2.500 & 0.060 & 3417.4 \\
\hline$M O-108$ & 21.000 & 2.501 & 0.060 & 3409.2 \\
\hline
\end{tabular}


B-TM-1639

Table 17. Mo Remnant Sample Density Measurements

\begin{tabular}{|c|c|}
\hline Specimen & $\begin{array}{c}\text { Specimen } \\
\text { Density }\left(\mathbf{g} / \mathbf{c m}^{3}\right)\end{array}$ \\
\hline Mo-105 & 10.218 \\
\hline Mo-108 & 10.215 \\
\hline Mo-107 & 10.217 \\
\hline Mo-0019 & 10.216 \\
\hline Mo-0015 & 10.218 \\
\hline Mo-0008 & 10.216 \\
\hline Mo-0007 & 10.219 \\
\hline Mo-0002 & 10.219 \\
\hline Mo-0017 & 10.223 \\
\hline Mo-0011 & 10.215 \\
\hline Mo-0012 & 10.213 \\
\hline Mo-0013 & 10.220 \\
\hline Mo-0016 & 10.220 \\
\hline Mo-0001 & 10.222 \\
\hline Mo-0021 & 10.220 \\
\hline Mo-0003 & 10.218 \\
\hline Mo-0006 & 10.219 \\
\hline Mo-0014 & 10.222 \\
\hline Mo-0009 & 10.217 \\
\hline Mo-0020 & 10.219 \\
\hline Mo-0022 & 10.221 \\
\hline Mo 2-1 & 10.224 \\
\hline Mo 2-2 & 10.220 \\
\hline Mo 2-3 & 10.218 \\
\hline Mo 2-4 & 10.218 \\
\hline Mo 2-5 & 10.219 \\
\hline Mo 2-6 & 10.221 \\
\hline Mo 2-7 & 10.218 \\
\hline Mo 2-8 & 10.216 \\
\hline Mo 2-9 & 10.218 \\
\hline Mo-051 & 10.220 \\
\hline Mo-052 & 10.216 \\
\hline Mo-053 & 10.215 \\
\hline Mo-054 & 10.218 \\
\hline Mo-055 & 10.214 \\
\hline Mo-056 & 10.218 \\
\hline & \\
\hline
\end{tabular}


Table 18. Chemical Composition Certificate for Mo Plates

\begin{tabular}{|c|c|c|c|c|c|}
\hline Element & $\begin{array}{c}\text { Content by } \\
\text { Weight }\end{array}$ & Element & $\begin{array}{c}\text { Content by } \\
\text { Weight }\end{array}$ & Element & $\begin{array}{c}\text { Content by } \\
\text { Weight }\end{array}$ \\
\hline $\mathrm{Mo}$ & $\min .99 .97 \%$ & $\mathrm{~S}$ & $\max .10 \mathrm{ppm}$ & $\overline{\mathrm{Zn}}$ & $\max .10 \mathrm{ppm}$ \\
\hline $\mathrm{H}$ & $\max 10 \mathrm{ppm}$ & $\mathrm{K}$ & $\max .10 \mathrm{ppm}$ & $\mathrm{As}$ & $\max .5 \mathrm{ppm}$ \\
\hline $\mathrm{C}$ & $\max .30 \mathrm{ppm}$ & $\mathrm{Ca}$ & $\max .20 \mathrm{ppm}$ & $\overline{\mathrm{Zr}}$ & $\max .10 \mathrm{ppm}$ \\
\hline $\mathrm{N}$ & $\max .5 \mathrm{ppm}$ & $\mathrm{Ti}$ & $\max .10 \mathrm{ppm}$ & $\mathrm{Nb}$ & $\max .10 \mathrm{ppm}$ \\
\hline $\mathrm{O}$ & $\max .40 \mathrm{ppm}$ & $\mathrm{Cr}$ & $\max .20 \mathrm{ppm}$ & $\mathrm{Ag}$ & $\max .10 \mathrm{ppm}$ \\
\hline $\mathrm{Na}$ & $\max .10 \mathrm{ppm}$ & $\mathrm{Mn}$ & $\max .2 \mathrm{ppm}$ & $\mathrm{Cd}$ & $\max .5 \mathrm{ppm}$ \\
\hline $\mathrm{Mg}$ & $\max .10 \mathrm{ppm}$ & $\mathrm{Fe}$ & $\max .60 \mathrm{ppm}$ & $\mathrm{Ba}$ & $\max .5 \mathrm{ppm}$ \\
\hline $\mathrm{Al}$ & $\max 10 \mathrm{ppm}$ & $\mathrm{Co}$ & $\max .10 \mathrm{ppm}$ & $\mathrm{Ta}$ & $\max .20 \mathrm{ppm}$ \\
\hline $\mathrm{Si}$ & $\max .30 \mathrm{ppm}$ & $\mathrm{Ni}$ & $\max .10 \mathrm{ppm}$ & $\mathrm{W}$ & $\max .250 \mathrm{ppm}$ \\
\hline $\mathrm{P}$ & $\max .20 \mathrm{ppm}$ & $\mathrm{Cu}$ & $\max .20 \mathrm{ppm}$ & $\mathrm{Pb}$ & $\max .10 \mathrm{ppm}$ \\
\hline
\end{tabular}

Table 19. Chemical Analyses for the Mo Plates

\begin{tabular}{|c|c|c|c|c|}
\hline \multirow{2}{*}{ Element } & \multicolumn{4}{|c|}{ Mo (wt. \%) } \\
\cline { 2 - 5 } & $\mathbf{0 . 0 3 0 " , ~ 2 " x 2 " ~}$ & $\begin{array}{c}\mathbf{0 . 0 3 0 "} \\
\mathbf{2 3 " \times 7 2}\end{array}$ & $\mathbf{0 . 0 5 9 "}$ & Average \\
\hline Mo & $99.98305 \%$ & $99.98045 \%$ & $99.98270 \%$ & $99.98207 \%$ \\
\hline $\mathbf{C}$ & $0.00025 \%$ & $0.00025 \%$ & $0.00025 \%$ & $0.00025 \%$ \\
\hline $\mathbf{F e}$ & $0.00100 \%$ & $0.00110 \%$ & $0.00100 \%$ & $0.00103 \%$ \\
\hline $\mathbf{H}$ & $0.00005 \%$ & $0.00010 \%$ & $0.00005 \%$ & $0.00007 \%$ \\
\hline $\mathbf{N}$ & $0.00060 \%$ & $0.00050 \%$ & $0.00050 \%$ & $0.00053 \%$ \\
\hline $\mathbf{N b}$ & $0.00050 \%$ & $0.00050 \%$ & $0.00050 \%$ & $0.00050 \%$ \\
\hline $\mathbf{N i}$ & $0.00025 \%$ & $0.00025 \%$ & $0.00025 \%$ & $0.00025 \%$ \\
\hline $\mathbf{O}$ & $0.00150 \%$ & $0.00150 \%$ & $0.00070 \%$ & $0.00123 \%$ \\
\hline $\mathbf{S i}$ & $0.00070 \%$ & $0.00025 \%$ & $0.00025 \%$ & $0.00040 \%$ \\
\hline $\mathrm{Ta}$ & $0.00050 \%$ & $0.00050 \%$ & $0.00050 \%$ & $0.00050 \%$ \\
\hline $\mathbf{T i}$ & $0.00010 \%$ & $0.00010 \%$ & $0.00010 \%$ & $0.00010 \%$ \\
\hline $\mathbf{W}$ & $0.01150 \%$ & $0.01450 \%$ & $0.01320 \%$ & $0.01307 \%$ \\
\hline
\end{tabular}

Table 20. Average Elemental Composition of the Mo Plates

\begin{tabular}{|c|c|}
\hline Element & $\begin{array}{c}\text { Number } \\
\text { Density } \\
\text { (atoms/b-cm) }\end{array}$ \\
\hline $\mathrm{Mo}$ & $6.41495 \mathrm{E}-02$ \\
\hline
\end{tabular}




\subsection{Nb-1Zr Plates}

ORNL furnished to LANL solid and annular $\mathrm{Nb}-1 \mathrm{Zr}$ critical experiment plates. The $\mathrm{Nb}-1 \mathrm{Zr}$ critical experiment plates were fabricated from a single heat (heat number 531048 ) of commercial grade $\mathrm{Nb}$ $1 \mathrm{Zr}$ produced by Wah Chang in 1988. Table 21 provides the quantities, dimensions, and manufacturing tolerances of the $\mathrm{Nb}-1 \mathrm{Zr}$ plates furnished to LANL. Table 22 provides the nominal dimensions and as-built masses of the $\mathrm{Nb}-1 \mathrm{Zr}$ plates based on mass measurements performed by LANL. Nb-1Zr plate detailed as-built dimensional characterization measurements were not performed by ORNL; consequently nominal dimensions were used in this analysis. An inferred density, used to determine an inferred thickness for each plate, is calculated by dividing the mass of each plate by its nominal volume. An average density for the $\mathrm{Nb}-1 \mathrm{Zr}$ plates was calculated based on the weighted average of the as-built masses and nominal volume for each plate; this yielded a plate density of $8.6862 \mathrm{~g} / \mathrm{cm}^{3}$. The as-built mass for plate 12 contained a typographical error, producing a lower than actual average plate density. With the typographical error corrected, the total density of the $\mathrm{Nb}-1 \mathrm{Zr}$ plates was $8.6944 \mathrm{~g} / \mathrm{cm}^{3}$. The pre-experimental predictions use the $\mathrm{Nb}-1 \mathrm{Zr}$ plate density of 8.6862 $\mathrm{g} / \mathrm{cm}^{3}$ because they were produced before the typographical error was corrected.

Table 23 provides the results of a chemical analysis performed by Wah Chang both at the top and at the bottom of the ingot used to fabricate the $\mathrm{Nb}-1 \mathrm{Zr}$ plates. The plate elemental composition derived from the chemical analysis at the top of the ingot and the average plate density of $8.6862 \mathrm{~g} / \mathrm{cm}^{3}$ is used in the pre-experimental predictions and is provided in Table 24. The composition from the top of the ingot was selected for consistency with the analysis performed in HEU-MET-FAST-047 [2].

Table 21. Nb-1Zr Plate Inventory

\begin{tabular}{|c|c|c|c|c|}
\hline Type & Quantity & Outer Diameter (in) & Inner Diameter (in) & Thickness (in) \\
\hline Solid & 7 & $21.000+0.000 /-0.030$ & - & 0.010 \\
\hline Annular & 22 & $21.000+0.000 /-0.030$ & $2.500+0.015 /-0.000$ & 0.010 \\
\hline $\begin{array}{c}\text { Solid Half- } \\
\text { round disk }\end{array}$ & 29 & $\begin{array}{c}10.500+0.000 /-0.015 \\
\text { (Radius) }\end{array}$ & - & 0.010 \\
\hline Solid & 38 & $21.000+0.000 /-0.030$ & - & 0.030 \\
\hline Annular & 38 & $21.000+0.000 /-0.030$ & $2.500+0.015 /-0.000$ & 0.030 \\
\hline Solid & 8 & $21.000+0.000 /-0.030$ & - & 0.060 \\
\hline Annular & 8 & $21.000+0.000 /-0.030$ & $2.500+0.015 /-0.000$ & 0.060 \\
\hline
\end{tabular}

Table 22. As-Built and Nominal Dimensions of Nb-1Zr Plates

\begin{tabular}{|c|c|c|c|c|c|c|c|}
\hline \multirow{2}{*}{$\begin{array}{c}\text { Plate } \\
\text { Identification } \\
\text { Number }\end{array}$} & \multirow[b]{2}{*}{ Type } & \multicolumn{3}{|c|}{ Nominal } & \multirow[b]{2}{*}{$\operatorname{Mass}(g)$} & \multirow{2}{*}{$\begin{array}{l}\text { Inferred } \\
\text { Density } \\
\left(\mathrm{g} / \mathrm{cm}^{3}\right) \\
\end{array}$} & \multirow{2}{*}{$\begin{array}{c}\text { Inferred } \\
\text { Thickness } \\
\text { (in) }\end{array}$} \\
\hline & & $O D$ (in) & ID (in) & $\begin{array}{l}\text { Thickness } \\
\text { (in) }\end{array}$ & & & \\
\hline 1 & Solid & 21.00 & 0.00 & 0.010 & 519.5 & 9.153 & 0.0106 \\
\hline 2 & Solid & 21.00 & 0.00 & 0.010 & 505.2 & 8.901 & 0.0103 \\
\hline 3 & Solid & 21.00 & 0.00 & 0.010 & 505.6 & 8.908 & 0.0103 \\
\hline 4 & Solid & 21.00 & 0.00 & 0.010 & 501.3 & 8.832 & 0.0102 \\
\hline 5 & Solid & 21.00 & 0.00 & 0.010 & 502.2 & 8.848 & 0.0102 \\
\hline 6 & Solid & 21.00 & 0.00 & 0.010 & 501.7 & 8.839 & 0.0102 \\
\hline 7 & Solid & 21.00 & 0.00 & 0.010 & 474.1 & 8.353 & 0.0097 \\
\hline 8 & Hole & 21.00 & 2.51 & 0.010 & 480.7 & 8.592 & 0.0099 \\
\hline 9 & Hole & 21.00 & 2.51 & 0.010 & 472.3 & 8.442 & 0.0098 \\
\hline
\end{tabular}


B-TM-1639

\begin{tabular}{|c|c|c|c|c|c|c|c|}
\hline \multirow{2}{*}{$\begin{array}{c}\text { Plate } \\
\text { tdentification } \\
\text { Number }\end{array}$} & \multirow[b]{2}{*}{ Type } & \multicolumn{3}{|c|}{ Nominal } & \multirow[b]{2}{*}{ Mass $(g)$} & \multirow{2}{*}{$\begin{array}{l}\text { Inferred } \\
\text { Density } \\
\left(\mathrm{g} / \mathrm{cm}^{3}\right) \\
\end{array}$} & \multirow{2}{*}{\begin{tabular}{|c|} 
Inferred \\
Thickness \\
(in)
\end{tabular}} \\
\hline & & OD (in) & ID (in) & $\begin{array}{l}\text { Thickness } \\
\text { (in) }\end{array}$ & & & \\
\hline 10 & Hole & 21.00 & 2.51 & 0.010 & 467.0 & 8.347 & 0.0097 \\
\hline 11 & Hole & 21.00 & 2.51 & 0.010 & 494.7 & 8.842 & 0.0102 \\
\hline 12 & Hole & 21.00 & 2.51 & 0.010 & 493.3 & 8.817 & 0.0102 \\
\hline 13 & Hole & 21.00 & 2.51 & 0.010 & 480.7 & 8.592 & 0.0099 \\
\hline 14 & Hole & 21.00 & 2.51 & 0.010 & 477.3 & 8.531 & 0.0099 \\
\hline 15 & Hole & 21.00 & 2.51 & 0.010 & 490.1 & 8.760 & 0.0101 \\
\hline 17 & Hole & 21.00 & 2.51 & 0.010 & 494.7 & 8.842 & 0.0102 \\
\hline 18 & Hole & 21.00 & 2.51 & 0.010 & 489.6 & 8.751 & 0.0101 \\
\hline 19 & Hole & 21.00 & 2.51 & 0.010 & 491.6 & 8.787 & 0.0102 \\
\hline 20 & Hole & 21.00 & 2.51 & 0.010 & 483.3 & 8.638 & 0.0100 \\
\hline 21 & Hole & 21.00 & 2.51 & 0.010 & 511.8 & 9.148 & 0.0106 \\
\hline 22 & Hole & 21.00 & 2.51 & 0.010 & 485.7 & 8.681 & 0.0100 \\
\hline 23 & Hole & 21.00 & 2.51 & 0.010 & 482.3 & 8.621 & 0.0100 \\
\hline 24 & Hole & 21.00 & 2.51 & 0.010 & 479.7 & 8.574 & 0.0099 \\
\hline 25 & Hole & 21.00 & 2.51 & 0.010 & 482.3 & 8.621 & 0.0100 \\
\hline 26 & Hole & 21.00 & 2.51 & 0.010 & 482.2 & 8.619 & 0.0100 \\
\hline 27 & Hole & 21.00 & 2.51 & 0.010 & 483.4 & 8.640 & 0.0100 \\
\hline 28 & Hole & 21.00 & 2.51 & 0.010 & 486.1 & 8.689 & 0.0101 \\
\hline 29 & Hole & 21.00 & 2.51 & 0.010 & 477.0 & 8.526 & 0.0099 \\
\hline 59 & Solid & 21.00 & 0.00 & 0.030 & 1493.6 & 8.772 & 0.0305 \\
\hline 60 & Solid & 21.00 & 0.00 & 0.030 & 1484.9 & 8.721 & 0.0303 \\
\hline 61 & Solid & 21.00 & 0.00 & 0.030 & 1473.9 & 8.656 & 0.0301 \\
\hline 62 & Solid & 21.00 & 0.00 & 0.030 & 1469.5 & 8.630 & 0.0300 \\
\hline 63 & Solid & 21.00 & 0.00 & 0.030 & 1460.7 & 8.578 & 0.0298 \\
\hline 64 & Solid & 21.00 & 0.00 & 0.030 & 1468.6 & 8.625 & 0.0299 \\
\hline 65 & Solid & 21.00 & 0.00 & 0.030 & 1503.8 & 8.832 & 0.0307 \\
\hline 66 & Solid & 21.00 & 0.00 & 0.030 & 1486.0 & 8.727 & 0.0303 \\
\hline 67 & Solid & 21.00 & 0.00 & 0.030 & 1434.5 & 8.425 & 0.0293 \\
\hline 68 & Solid & 21.00 & 0.00 & 0.030 & 1479.5 & 8.689 & 0.0302 \\
\hline 69 & Solid & 21.00 & 0.00 & 0.030 & 1482.5 & 8.707 & 0.0302 \\
\hline 97 & Hole & 21.00 & 2.51 & 0.030 & 1472.2 & 8.771 & 0.0305 \\
\hline 98 & Hole & 21.00 & 2.51 & 0.030 & 1491.6 & 8.887 & 0.0309 \\
\hline 99 & Hole & 21.00 & 2.51 & 0.030 & 1461.4 & 8.707 & 0.0302 \\
\hline 100 & Hole & 21.00 & 2.51 & 0.030 & 1417.3 & 8.444 & 0.0293 \\
\hline 101 & Hole & 21.00 & 2.51 & 0.030 & 1440.1 & 8.580 & 0.0298 \\
\hline 102 & Hole & 21.00 & 2.51 & 0.030 & 1443.4 & 8.600 & 0.0299 \\
\hline 103 & Hole & 21.00 & 2.51 & 0.030 & 1510.3 & 8.998 & 0.0312 \\
\hline 105 & Hole & 21.00 & 2.51 & 0.030 & 1460.5 & 8.702 & 0.0302 \\
\hline 106 & Hole & 21.00 & 2.51 & 0.030 & 1450.4 & 8.641 & 0.0300 \\
\hline 107 & Hole & 21.00 & 2.51 & 0.030 & 1441.4 & 8.588 & 0.0298 \\
\hline 108 & Hole & 21.00 & 2.51 & 0.030 & 1462.3 & 8.712 & 0.0303 \\
\hline 109 & Hole & 21.00 & 2.51 & 0.030 & 1499.5 & 8.934 & 0.0310 \\
\hline 110 & Hole & 21.00 & 2.51 & 0.030 & 1447.9 & 8.627 & 0.0300 \\
\hline 111 & Hole & 21.00 & 2.51 & 0.030 & 1436.5 & 8.559 & 0.0297 \\
\hline 112 & Hole & 21.00 & 2.51 & 0.030 & 1424.2 & 8.485 & 0.0295 \\
\hline 141 & Solid & 21.00 & 0.00 & 0.060 & 3023.4 & 8.878 & 0.0617 \\
\hline 149 & Hole & 21.00 & 2.51 & 0.060 & 2907.6 & 8.662 & 0.0602 \\
\hline
\end{tabular}


Table 23. Chemical Analysis for the Nb-1Zr Plates

\begin{tabular}{|c|c|c|c|}
\hline \multirow{2}{*}{ Element } & \multicolumn{3}{|c|}{ Nb-1Zr (wt. \%) } \\
\cline { 2 - 4 } & Top of Ingot & Bottom of Ingot & Ingot Average \\
\hline $\mathbf{N b}$ & 98.8565 & 98.8615 & 98.859 \\
\hline $\mathbf{Z r}$ & 0.9 & 0.9 & 0.9 \\
\hline $\mathbf{H}$ & 0.0005 & 0.0005 & 0.0005 \\
\hline $\mathbf{C}$ & 0.003 & 0.003 & 0.003 \\
\hline $\mathbf{N}$ & 0.002 & 0.002 & 0.002 \\
\hline $\mathbf{O}$ & 0.011 & 0.005 & 0.008 \\
\hline $\mathrm{Si}$ & 0.005 & 0.005 & 0.005 \\
\hline $\mathrm{Fe}$ & 0.005 & 0.005 & 0.005 \\
\hline $\mathrm{Ni}$ & 0.002 & 0.002 & 0.002 \\
\hline $\mathrm{Mo}$ & 0.005 & 0.005 & 0.005 \\
\hline $\mathrm{Hf}$ & 0.005 & 0.005 & 0.005 \\
\hline $\mathrm{Ta}$ & 0.2 & 0.2 & 0.2 \\
\hline $\mathbf{W}$ & 0.005 & 0.006 & 0.0055 \\
\hline
\end{tabular}

Table 24. Elemental Composition from the Top of the Ingot of the Nb-1Zr Plates

\begin{tabular}{|c|c|}
\hline Element & $\begin{array}{c}\text { Number } \\
\text { Density } \\
\text { (atoms/b-cm) }\end{array}$ \\
\hline $\mathbf{N b}$ & $5.56600 \mathrm{E}-02$ \\
\hline $\mathbf{Z r}$ & $5.16080 \mathrm{E}-04$ \\
\hline $\mathbf{H}$ & $2.59489 \mathrm{E}-05$ \\
\hline $\mathbf{C}$ & $1.30658 \mathrm{E}-05$ \\
\hline $\mathbf{N}$ & $7.46926 \mathrm{E}-06$ \\
\hline $\mathbf{O}$ & $3.59644 \mathrm{E}-05$ \\
\hline $\mathbf{S i}$ & $9.31260 \mathrm{E}-06$ \\
\hline $\mathbf{F e}$ & $4.68348 \mathrm{E}-06$ \\
\hline $\mathbf{N i}$ & $1.78248 \mathrm{E}-06$ \\
\hline $\mathbf{M o}$ & $2.72617 \mathrm{E}-06$ \\
\hline $\mathbf{H f}$ & $1.46534 \mathrm{E}-06$ \\
\hline $\mathrm{Ta}$ & $5.78176 \mathrm{E}-05$ \\
\hline $\mathbf{W}$ & $1.42270 \mathrm{E}-06$ \\
\hline
\end{tabular}


B-TM-1639

\subsection{Re Plates}

The NRPCT furnished to LANL solid and annular Re critical experiment plates. The Re critical experiment plates were fabricated by Rhenium Alloys by stitch welding together three approximately $8 " \times 22 " \times 0.015 "$ Re plates using a laser welder. These stitched-together plates were then Electric Discharged Machined (EDMd) to their final dimensions. The quantity and dimensional specifications for the Re plates are provided in Table 25. Photographs of a solid and annular Re plate are provided in Figure 13 and Figure 14. Table 26 provides the as-built dimensions of the Re plates based on dimensional characterization measurements performed by Rhenium Alloys. The Re plates have been fabricated from two lots of high-purity Re powder material: R-1478 and R-1481. The outer and inner diameters reported for each plate are based on the average of two diameter measurements taken approximately 90 degrees from each other. The average outer diameter of the Re plates is 20.997 " with a standard deviation of $0.002 "$ " The average inner diameter of the annular Re plates is 2.508 " with a standard deviation of $0.002 "$. The differences between the nominal and measured diameters are judged to be negligible.

The thickness measurement for each plate is based on the average of either 4 or 7 thickness measurements. The average measured thickness of the Re plates is $0.0166^{\prime \prime}$ with a standard deviation of $0.0003^{\prime \prime}$. However, the thickness measurements are believed to overestimate the average thickness of the Re plates due to the following factors: normal variation in thickness along the width of the plate due to the rolling process, stitch weld buildup, and a vendor thickness measurement procedure that emphasized characterization of the maximum thickness of the plates. Therefore, to more accurately characterize the average thickness of each $R e$ plate an inferred thickness was determined from the outer diameter, inner diameter, mass of each plate, and the nominal Re density of $21.02 \mathrm{~g} / \mathrm{cm}^{3}$. The average inferred thickness of the Re plates is 0.0161 " with a standard deviation of 0.0004 ". Figure 15 provides a comparison of the measured and inferred thickness for each Re plate. The average inferred thickness is believed to more accurately reproduce the average material loading in the Re plates and is the Re plate thickness used in the pre-experimental predictions.

KAPL has performed high-accuracy density measurements using remnant samples from the Re plates and found the average Re density to be $21.001 \mathrm{~g} / \mathrm{cm}^{3}$. The results of these density measurements are provided in Table 27. The Re plates were expected to be near theoretical density due to the amount of cold working used to fabricate the plates; therefore the average density of Re plates used to calculate the average $R e$ isotopic composition was assumed to be $21.02 \mathrm{~g} / \mathrm{cm}^{3}$ (theoretical density) due to the lack of as-built density measurements at the time the pre-experimental predictions were prepared. Table 28 provides the results of a full spectrum chemical analysis performed by IMR Test Labs for each lot of rhenium material used to fabricate the plates. The chemical impurities in the Re plates are considered to be insignificant, thus, the Re plate material was approximated as pure $\mathrm{Re}$. The average Re plate isotopic composition used in the pre-experimental predictions is provided in Table 29. Refer to Appendix $G$ for the full Re dimension and chemistry reports as provided by the vendors.

Table 25. Specifications for Re Plates

\begin{tabular}{|c|c|c|c|c|}
\hline Type & Quantity & OD (in) & ID (in) & Thickness (in) \\
\hline Solid & 22 & $21.000 \pm 0.010$ & - & $0.0150 \pm 0.0015$ \\
\hline Annular & 22 & $21.000 \pm 0.010$ & $2.510 \pm 0.010$ & $0.0150 \pm 0.0015$ \\
\hline
\end{tabular}




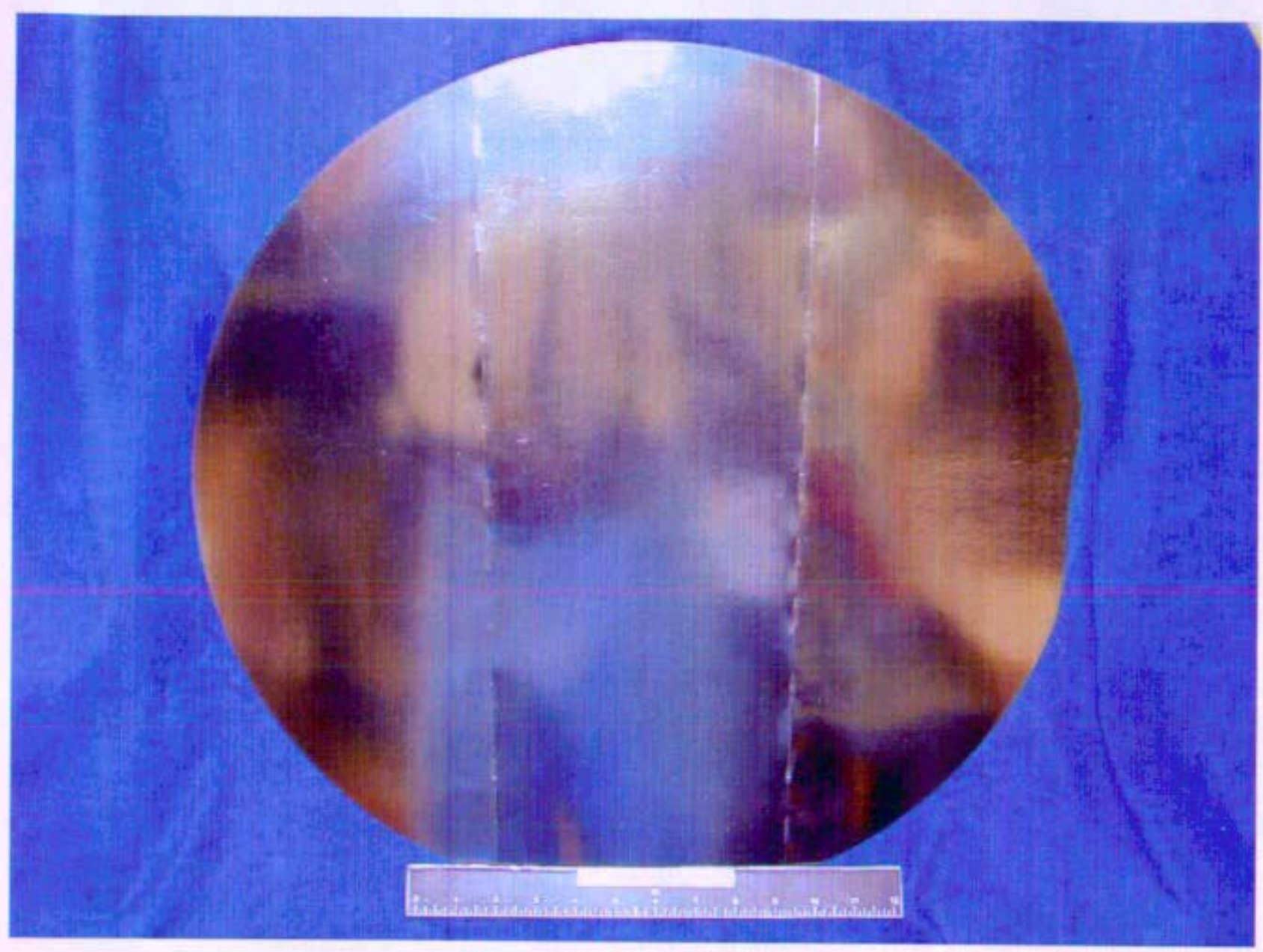

Figure 13. Solid Re Plate 


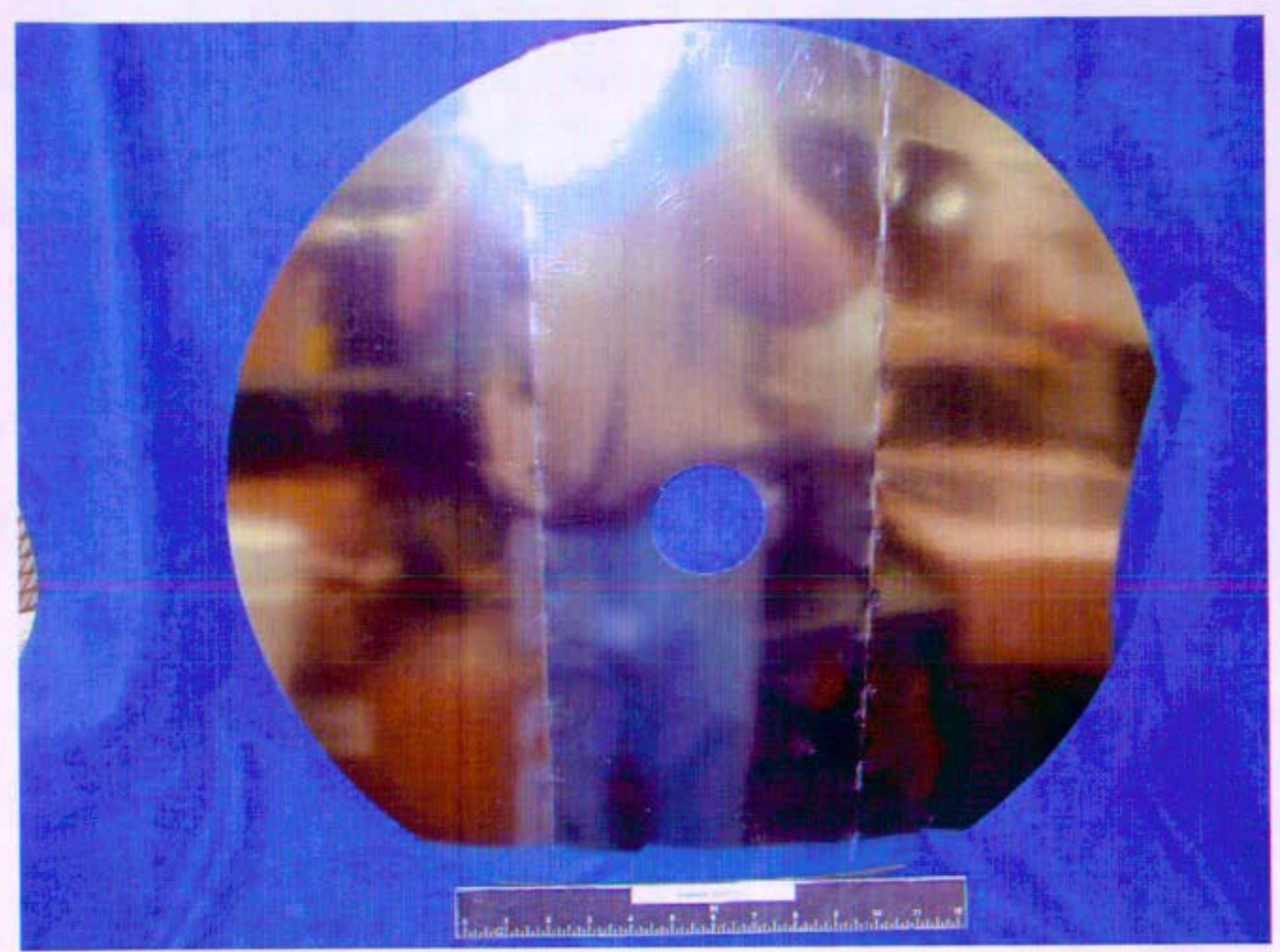

Figure 14. Annular Re Plate 
Table 26. As-Built Dimensions of Re Plates

\begin{tabular}{|c|c|c|c|c|c|c|}
\hline $\begin{array}{c}\text { Plate } \\
\text { Identification } \\
\text { Number }\end{array}$ & $\begin{array}{c}\text { Lot } \\
\text { Number }\end{array}$ & $O D$ (in) & ID (in) & Thickness (in) & $\begin{array}{c}\text { Inferred } \\
\text { Thickness (in) }\end{array}$ & Mass (g) \\
\hline $\operatorname{Re}-01$ & $\begin{array}{l}\text { R-1478/ } \\
\text { R-1481 }\end{array}$ & 21.000 & 0.000 & 0.0164 & 0.0162 & 1929.1 \\
\hline $\operatorname{Re}-02$ & R-1478 & 20.999 & 0.000 & 0.0167 & 0.0165 & 1969.3 \\
\hline $\operatorname{Re}-03$ & $R-1478$ & 20.999 & 0.000 & 0.0170 & 0.0165 & 1970.9 \\
\hline Re-04 & $\mathrm{R}-1478$ & 20.999 & 0.000 & 0.0165 & 0.0166 & 1981.6 \\
\hline Re-05 & $\mathrm{R}-1478$ & 20.995 & 0.000 & 0.0166 & 0.0166 & 1976.3 \\
\hline Re-06 & R-1478 & 20.998 & 0.000 & 0.0165 & 0.0165 & 1966.9 \\
\hline Re-07 & R-1478 & 20.999 & 0.000 & 0.0167 & 0.0165 & 1965.7 \\
\hline $\operatorname{Re}-08$ & $\mathrm{R}-1481$ & 20.997 & 0.000 & 0.0171 & 0.0165 & 1969.9 \\
\hline $\operatorname{Re}-09$ & $\mathrm{R}-1481$ & 20.998 & 0.000 & 0.0170 & 0.0164 & 1953.8 \\
\hline $\operatorname{Re}-10$ & $\mathrm{R}-1481$ & 20.997 & 0.000 & 0.0169 & 0.0163 & 1944.3 \\
\hline $\operatorname{Re}-11$ & R-1481 & 20.998 & 0.000 & 0.0167 & 0.0166 & 1981.6 \\
\hline $\mathrm{Re}-12$ & R-1481 & 20.999 & 0.000 & 0.0165 & 0.0167 & 1992.8 \\
\hline $\operatorname{Re}-13$ & R-1481 & 20.997 & 0.000 & 0.0161 & 0.0155 & 1851.2 \\
\hline Re-14 & R-1481 & 20.999 & 0.000 & 0.0161 & 0.0156 & 1858.0 \\
\hline $\operatorname{Re}-15$ & R-1481 & $20 . \overline{997}$ & 0.000 & 0.0167 & 0.0160 & 1914.1 \\
\hline $\operatorname{Re}-16$ & R-1481 & 20.996 & 0.000 & 0.0163 & 0.0154 & 1835.2 \\
\hline $\operatorname{Re}-17$ & R-1481 & 20.996 & 0.000 & 0.0167 & 0.0160 & $\$ 911.6$ \\
\hline $\operatorname{Re}-18$ & $R-1481$ & 20.999 & 0.000 & 0.0162 & 0.0158 & 1881.1 \\
\hline $\operatorname{Re}-19$ & R-1481 & 20.994 & 0.000 & 0.0166 & 0.0158 & 1886.9 \\
\hline $\operatorname{Re}-20$ & R-1481 & 20.999 & 0.000 & 0.0162 & 0.0154 & 1837.2 \\
\hline $\operatorname{Re}-21$ & $R-1481$ & 20.998 & 0.000 & 0.0172 & 0.0162 & 1929.2 \\
\hline $\operatorname{Re}-22$ & R-1481 & 20.998 & 0.000 & 0.0163 & 0.0159 & 1895.5 \\
\hline $\operatorname{Re}-23$ & R-1481 & 20.997 & 2.508 & 0.0163 & 0.0165 & 1936.7 \\
\hline $\operatorname{Re}-24$ & R-1481 & 20.999 & 2.511 & 0.0167 & 0.0166 & 1957.2 \\
\hline $\mathrm{Re}-25$ & R-1481 & 20.998 & 2.505 & 0.0165 & 0.0163 & 1917.4 \\
\hline Re-26 & R.1481 & 20.998 & 2.509 & 0.0164 & 0.0164 & 1927.8 \\
\hline $\operatorname{Re}-27$ & R-1481 & 20.997 & 2.505 & 0.0166 & 0.0163 & 1920.2 \\
\hline $\operatorname{Re}-28$ & $R-1481$ & 20.997 & 2.510 & 0.0165 & 0.0162 & 1902.8 \\
\hline $\operatorname{Re}-29$ & R-1481 & 20.997 & 2.511 & 0.0163 & 0.0164 & 1926.3 \\
\hline $\operatorname{Re}-30$ & $R=1481$ & 20.997 & 2.510 & 0.0161 & 0.0163 & 1920.1 \\
\hline $\operatorname{Re}-31$ & R-1481 & 20.996 & 2.510 & 0.0167 & 0.0166 & 1950.5 \\
\hline $\operatorname{Re}-32$ & R-1481 & 20.995 & 2.510 & 0.0167 & 0.0163 & 1910.6 \\
\hline $\operatorname{Re}-33$ & $R-1481$ & 20.995 & 2.510 & 0.0168 & 0.0166 & 1945.8 \\
\hline $\mathrm{Re}-34$ & R-1481 & 20.998 & 2.510 & 0.0165 & 0.0164 & 1924.6 \\
\hline $\operatorname{Re}-35$ & R-1481 & 21.004 & 2.508 & 0.0157 & 0.0148 & 1746.3 \\
\hline $\operatorname{Re}-36$ & R-1481 & 20.997 & 2.503 & 0.0167 & 0.0161 & 1898.7 \\
\hline $\mathrm{Re}-37$ & R-1481 & 20.999 & 2.504 & 0.0163 & 0.0156 & 1832.3 \\
\hline $\operatorname{Re}-38$ & R-1481 & 20.995 & 2.540 & 0.0170 & 0.0165 & 1933.9 \\
\hline $\operatorname{Re}-39$ & R-1481 & 20.996 & 2.509 & 0.0164 & 0.0159 & 1874.5 \\
\hline $\operatorname{Re}-40$ & R-1481 & 21.000 & 2.509 & 0.0166 & 0.0158 & 1860.0 \\
\hline $\operatorname{Re}-41$ & R-1481 & 20.996 & 2.507 & 0.0168 & 0.0155 & 1827.7 \\
\hline $\operatorname{Re}-42$ & R-1481 & 20.998 & 2.510 & 0.0164 & 0.0154 & 1813.5 \\
\hline $\operatorname{Re}-43$ & R-1481 & 20.994 & 2.508 & 0.0170 & 0.0160 & 1877.3 \\
\hline $\operatorname{Re}-44$ & R-1481 & 21.001 & 2.508 & 0.0172 & 0.0162 & 1904.9 \\
\hline
\end{tabular}




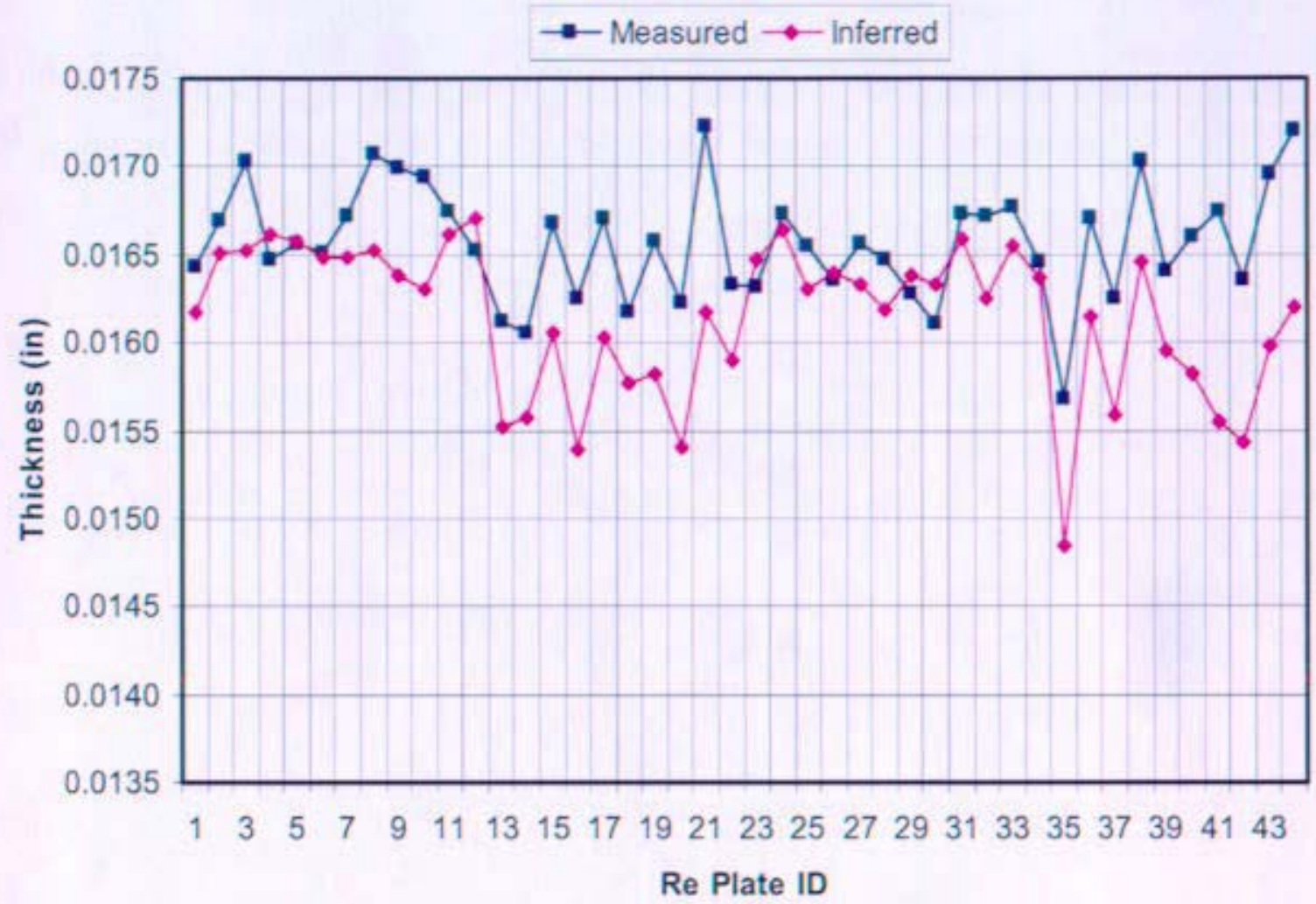

Figure 15. Comparison of Measured and Inferred Re Plate Thicknesses

Table 27. Re Remnant Sample Density Measurements

\begin{tabular}{|c|c|}
\hline Specimen & $\begin{array}{c}\text { Specimen } \\
\text { Density }\left(\mathbf{g} / \mathbf{c m}^{3}\right)\end{array}$ \\
\hline $\operatorname{Re}-1$ & 20.999 \\
\hline $\operatorname{Re}-2$ & 20.999 \\
\hline $\operatorname{Re}-3$ & 20.979 \\
\hline $\operatorname{Re}-4$ & 21.002 \\
\hline $\operatorname{Re}-5$ & 21.010 \\
\hline $\operatorname{Re}-6$ & 21.015 \\
\hline $\operatorname{Re}-7$ & 20.999 \\
\hline $\operatorname{Re}-8$ & 21.008 \\
\hline $\operatorname{Re}-9$ & 21.000 \\
\hline $\operatorname{Re}-10$ & 21.020 \\
\hline $\operatorname{Re}-11$ & 21.014 \\
\hline $\operatorname{Re}-12$ & 20.977 \\
\hline $\operatorname{Re}-13$ & 20.990 \\
\hline $\operatorname{Re}-14$ & 21.006 \\
\hline
\end{tabular}


Table 28. Full Spectrum Chemical Analysis for Re Plates

\begin{tabular}{|c|c|c|}
\hline \multirow{2}{*}{ Element } & \multicolumn{2}{|c|}{ Rhenium Lot (ppm by weight) } \\
\hline & R-1478 & $R-1481$ \\
\hline $\mathrm{H}$ & 6.6 & 8.3 \\
\hline $\mathrm{Li}$ & $<0.005$ & $<0.005$ \\
\hline $\mathrm{Be}$ & $<0.005$ & $<0.005$ \\
\hline $\mathrm{B}$ & $<0.005$ & $<0.005$ \\
\hline $\mathrm{C}$ & 19 & 6 \\
\hline $\mathbf{N}$ & 1 & 2 \\
\hline 0 & 28 & 41 \\
\hline$F$ & $<0.05$ & $<0.05$ \\
\hline $\mathrm{Na}$ & 0.36 & 0.24 \\
\hline $\mathrm{Mg}$ & 0.03 & $<0.01$ \\
\hline Al & 1.2 & 1.1 \\
\hline $\mathrm{Si}$ & 1.7 & 27 \\
\hline$P$ & 0.12 & 0.21 \\
\hline$S$ & 82 & $0 . \overline{14}$ \\
\hline $\mathrm{Cl}$ & 0.13 & 0.22 \\
\hline $\mathrm{K}$ & 0.09 & 0.09 \\
\hline $\mathrm{Ca}$ & 0.44 & 0.09 \\
\hline Sc & $<0.005$ & $<0.005$ \\
\hline $\mathrm{Ti}$ & 0.11 & 0.08 \\
\hline $\mathrm{V}$ & 0.008 & 0.01 \\
\hline $\mathrm{Cr}$ & 2.3 & 4.4 \\
\hline $\mathrm{Mn}$ & 0.14 & 0.34 \\
\hline $\mathrm{Fe}$ & 5.1 & 11 \\
\hline Co & 0.01 & 0.04 \\
\hline $\mathrm{Ni}$ & 2.2 & 3.5 \\
\hline $\mathrm{Cu}$ & 0.07 & 0.12 \\
\hline $\mathrm{Zn}$ & 0.09 & $<0.05$ \\
\hline $\mathrm{Ga}$ & $<0.05$ & $<0.05$ \\
\hline $\mathrm{Ge}$ & $<0.05$ & $<0.05$ \\
\hline As & $<0.05$ & $<0.05$ \\
\hline $\mathrm{Se}$ & $<0.05$ & $<0.05$ \\
\hline $\mathrm{Br}$ & $<0.05$ & $<0.05$ \\
\hline $\mathrm{Rb}$ & $<0.01$ & $<0.01$ \\
\hline$Y$ & $<0.005$ & $<0.005$ \\
\hline $\mathrm{Zr}$ & 0.11 & 0.05 \\
\hline $\mathrm{Nb}$ & 0.01 & 0.01 \\
\hline Mo & 0.58 & 0.65 \\
\hline $\mathrm{Ru}$ & $<0.01$ & $<0.01$ \\
\hline Rh & $<0.01$ & $<0.01$ \\
\hline $\mathrm{Pd}$ & $<0.01$ & $<0.01$ \\
\hline $\mathrm{Ag}$ & $<0.01$ & $<0.01$ \\
\hline $\mathrm{Cd}$ & $<0.1$ & $<0.1$ \\
\hline $\ln$ & $<0.1$ & $<0.1$ \\
\hline Sn & 0.07 & $<0.01$ \\
\hline
\end{tabular}




\begin{tabular}{|c|c|c|}
\hline \multirow{2}{*}{ Element } & \multicolumn{2}{|c|}{ Rhenium Lot (ppm by weight) } \\
\hline & R-1478 & R-1481 \\
\hline $\mathrm{Sb}$ & $<0.01$ & $<0.01$ \\
\hline$\overline{T e}$ & $<0.01$ & $<0.01$ \\
\hline 1 & $<0.01$ & $<0.01$ \\
\hline $\mathrm{Cs}$ & $<0.5$ & $<0.5$ \\
\hline $\mathrm{Ba}$ & $<0.01$ & $0 . \overline{02}$ \\
\hline La & $<0.01$ & $<0.01$ \\
\hline $\mathrm{Ce}$ & $<0.01$ & $<0.01$ \\
\hline $\mathrm{Pr}$ & $<0.01$ & $<0.01$ \\
\hline $\mathrm{Nd}$ & $<0.01$ & $<0.01$ \\
\hline $\mathrm{Sm}$ & $<0.01$ & $<0.01$ \\
\hline Eu & $<0.01$ & $<0.01$ \\
\hline Gd & $<0.01$ & $<0.01$ \\
\hline$\overline{T b}$ & $<0.01$ & $<0.01$ \\
\hline Dy & $<0.01$ & $<0.01$ \\
\hline Ho & $<0.01$ & $<0.01$ \\
\hline $\mathrm{Er}$ & $<0.01$ & $<0.01$ \\
\hline $\mathrm{Tm}$ & $<0.01$ & $<0.01$ \\
\hline $\mathrm{Yb}$ & $<0.01$ & $<0.01$ \\
\hline Lu & $<0.01$ & $<0.01$ \\
\hline $\mathrm{Hf}$ & $<0.01$ & $<0 . \overline{01}$ \\
\hline $\mathrm{Ta}$ & $<5$ & $<5$ \\
\hline$W$ & $<0.2$ & $<0.2$ \\
\hline $\mathrm{Re}$ & Balance & Balance \\
\hline Os & $<0.01$ & $<0.01$ \\
\hline Ir & $<0.01$ & $<0.01$ \\
\hline $\mathrm{Pt}$ & $<0.05$ & $<0.05$ \\
\hline $\mathrm{Au}$ & $<0.5$ & $<0.5$ \\
\hline $\mathrm{Hg}$ & $<0.05$ & $<0.05$ \\
\hline $\mathrm{TI}$ & $<0.01$ & $<0.01$ \\
\hline $\mathrm{Pb}$ & $<0.01$ & 0.01 \\
\hline $\mathrm{Bi}$ & $<0.01$ & $<0.01$ \\
\hline Th & $<0.001$ & $<0.001$ \\
\hline $\mathrm{U}$ & $<0.001$ & $<0.001$ \\
\hline
\end{tabular}

Table 29. Average Isotopic Composition of the Re Plates

\begin{tabular}{|c|c|}
\hline Nuclide & $\begin{array}{c}\text { Number } \\
\text { Density } \\
\text { (atoms/b-cm) }\end{array}$ \\
\hline Re-185 & $2.54249 \times 10^{-2}$ \\
\hline Re-187 & $4.25561 \times 10^{-2}$ \\
\hline
\end{tabular}




\subsection{Ta-2.5W Plates}

The NRPCT furnished to LANL solid and annular Ta-2.5W critical experiment plates. Ta-2.5W was selected as the tantalum alloy to be used in this series of experiments mainly for schedule reasons. A vendor was identified that had a sufficient quantity of Ta-2.5W sheet in inventory and could complete the fabrication of the critical experiment plates before the end of December 2004. This fabrication schedule would support the original January 2005 schedule for performing the Ta critical experiments. The 2.5 weight percent tungsten content in Ta-2.5W was judged to be acceptable for the experiments. Pure Ta was also considered for the experiment but it was found to be more expensive than Ta-2.5W and the vendor was not able to support the desired fabrication schedule. ASTAR-811C and T-111 alloys were also considered. However, it was determined that these alloys were not currently in production, the existing inventory of previously produced material was insufficient to support the critical experiments, and it would not be practical to produce a sufficient quantity of these alloys in time to support the desired critical experiment schedule.

The quantify and dimensional specifications for the Ta-2.5W plates fabricated by Allegheny Teledyne Incorporated - Wah Chang are provided in Table 30. Photographs of a solid and an annular Ta-2.5W plate are provided in Figure 16 and Figure 17. Table 31 and Table 32 provide the as-built dimensions of the solid and annular Ta-2.5W plates based on dimensional characterization measurements performed by Wah Chang. The as-built thickness and mass measurements as performed by LANL for the Ta-2.5W plates are provided in Table 33. The Ta-2.5W plates have been fabricated from two heats of Ta-2.5W material: 11-19-2 and 10-20-2. Some of the plates were selected to be reserved as spares due to fabrication irregularities. The average outer diameter, inner diameter, and thickness for the plates were calculated. The average outer diameter of the Ta- $2.5 \mathrm{~W}$ plates is $21.000^{\prime \prime}$ with a standard deviation of 0.002 ". The average inner diameter of the annular Ta-2.5W plates is $2.512^{\prime \prime}$ with a standard deviation of 0.001". The differences between the nominal and measured diameters are judged to be negligible. The thickness measurement for each plate is based on the average of 3 thickness measurements. The average measured thickness of the Ta- $2.5 \mathrm{~W}$ plates is 0.0246 " with a standard deviation of $0.0007 "$.

KAPL performed high accuracy density measurements using remnant samples from the Ta-2.5W plates and found the average Ta-2.5W density to be $16.726 \mathrm{~g} / \mathrm{cm}^{3}$. The results of these density measurements are provided in Table 34. For the calculation of the average Ta-2.5W plate isotopic composition, the average density of the Ta-2.5W plates was assumed to be $16.7 \mathrm{~g} / \mathrm{cm}^{3}$ due to the lack of density measurements at that time.

Table 35 provides specifications for the range of acceptable chemical compositions of Ta-2.5W [19] and the results of the chemical analyses performed by Wah Chang for each heat of Ta-2.5W material used to fabricate the plates. The tungsten percent abundance is the average of four measurements taken from each lot. While the as-built tungsten content for both heats is below the 2 weight percent lower limit in the Ta-2.5W specification, this is considered acceptable since it will result in a slight increase in the tantalum content of the material used in the critical experiments. The average Ta-2.5W plate elemental composition used in the pre-experimental predictions is provided in Table 36. Refer to Appendix $\mathrm{H}$ for the full Ta-2.5W dimension and chemistry reports, as provided by the vendors.

Table 30. Specifications for Ta-2.5W Plates

\begin{tabular}{|c|c|c|c|c|}
\hline Type & Quantity & OD (in) & ID (in) & Thickness (in) \\
\hline Solid & 42 & $21.000 \pm 0.005$ & - & $0.0250 \pm 0.0025$ \\
\hline Annular & 42 & $21.000 \pm 0.005$ & $2.510+0.005 /-0.000$ & $0.0250 \pm 0.0025$ \\
\hline
\end{tabular}




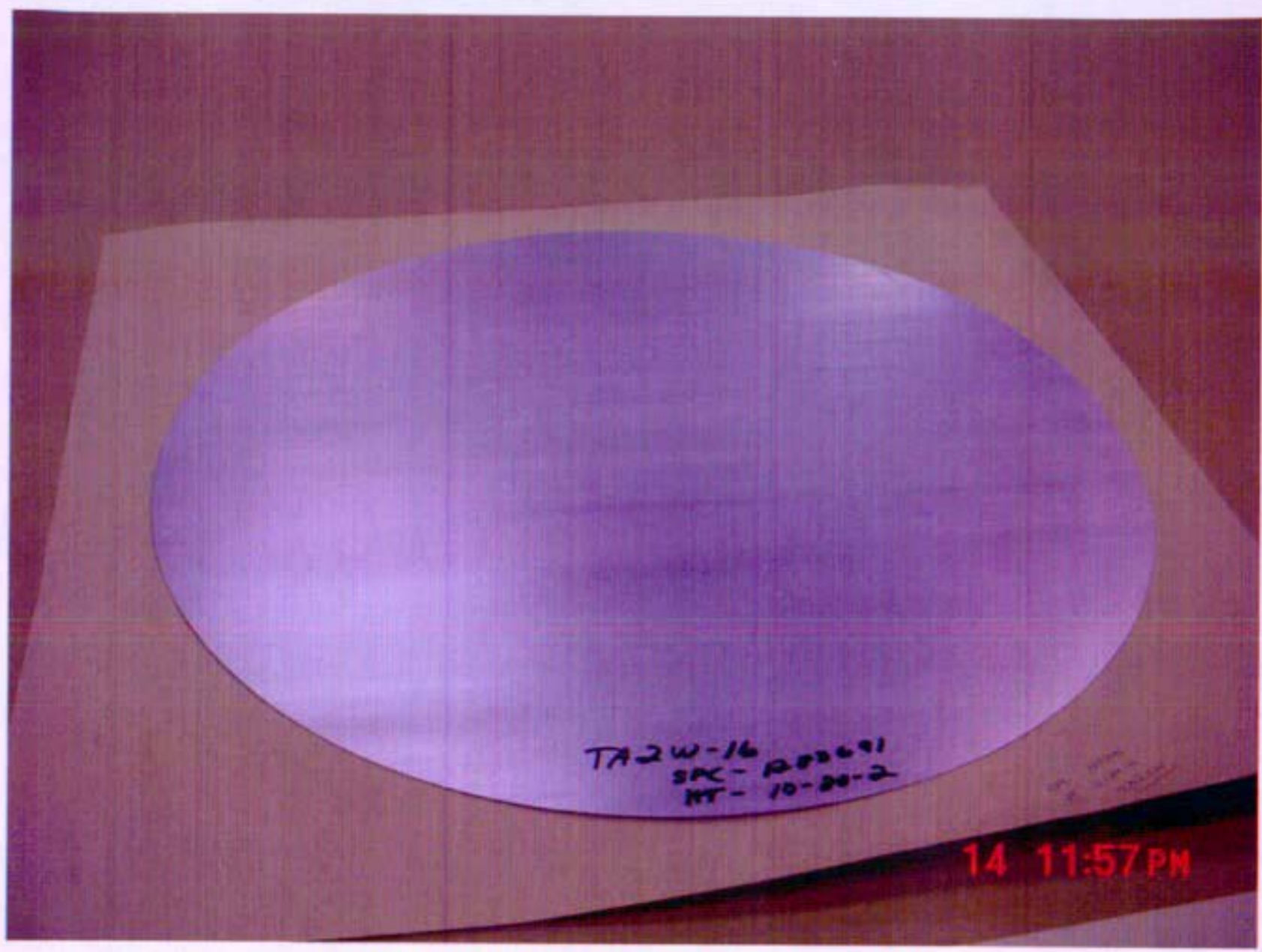

Figure 16. Solid Ta-2.5W Critical Experiment Plate 
B-TM-1639

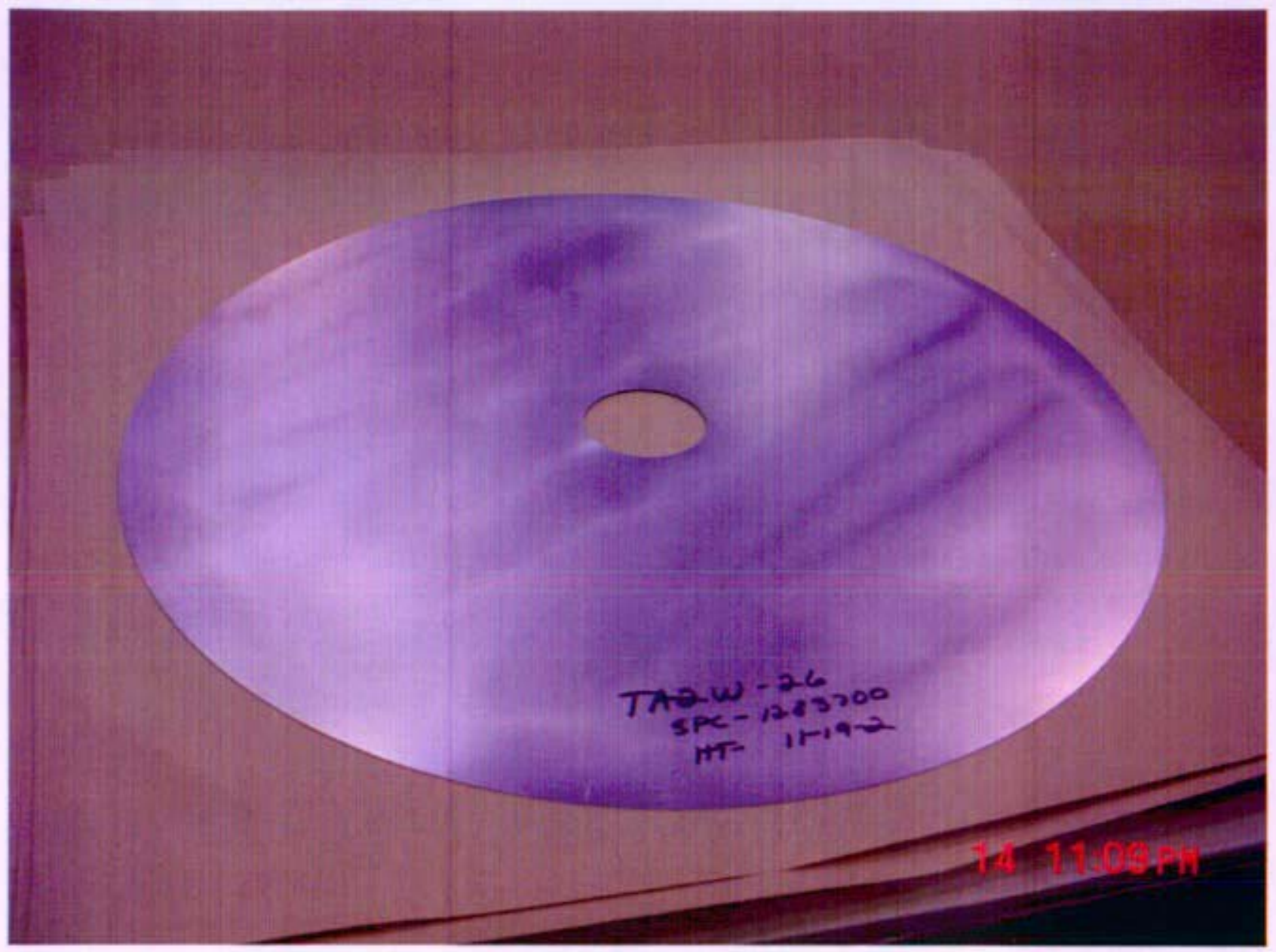

Figure 17. Annular Ta-2.5W Critical Experiment Plate 
Table 31. As-Built Dimensions of the Solid Ta-2.5W Plates

\begin{tabular}{|c|c|c|c|c|c|c|c|}
\hline $\begin{array}{c}\text { Disc } \\
\text { Number }\end{array}$ & $\begin{array}{c}\text { Heat } \\
\text { Number }\end{array}$ & $\begin{array}{c}\text { Outer } \\
\text { Diameter } \\
\text { (in) }\end{array}$ & $\begin{array}{c}\text { Inner } \\
\text { Diameter } \\
\text { (in) }\end{array}$ & $\begin{array}{c}\text { Average } \\
\text { Thickness } \\
\text { (in) }\end{array}$ & $\begin{array}{l}\text { Minimum } \\
\text { Thickness } \\
\text { (in) }\end{array}$ & $\begin{array}{c}\text { Maximum } \\
\text { Thickness } \\
\text { (in) }\end{array}$ & $\begin{array}{c}\text { Reserve } \\
\text { as } \\
\text { Spare } \\
\end{array}$ \\
\hline Ta2W-1 & $11-19-2$ & 21.0035 & 0.0000 & 0.02460 & 0.02455 & 0.02550 & No \\
\hline Ta2W-2 & 11-19-2 & 21.0005 & 0.0000 & 0.02433 & 0.02430 & 0.02460 & No \\
\hline Ta2W-3 & $11-19-2$ & 20.9995 & 0.0000 & 0.02343 & 0.02365 & 0.02505 & No \\
\hline Ta2W-4 & $11-19-2$ & 21.0005 & 0.0000 & 0.02458 & 0.02470 & 0.02555 & No \\
\hline Ta2W-5 & $11-19-2$ & 21.0035 & 0.0000 & 0.02372 & 0.02385 & 0.02440 & No \\
\hline Ta2W-6 & $11-19-2$ & 21.0025 & 0.0000 & 0.02390 & 0.02425 & 0.02475 & No \\
\hline Ta2W-7 & $11-19-2$ & 21.0035 & 0.0000 & 0.02350 & 0.02370 & 0.02400 & No \\
\hline Ta2W-8 & $11-19-2$ & 20.9970 & 0.0000 & 0.02382 & 0.02360 & 0.02575 & No \\
\hline Ta2W-9 & $11-19-2$ & 21.0029 & 0.0000 & 0.02468 & 0.02455 & 0.02500 & No \\
\hline Ta2W-10 & $10-20-2$ & 20.9995 & 0.0000 & 0.02570 & 0.02560 & 0.02605 & No \\
\hline Ta2W-11 & $10-20-2$ & 21.0025 & 0.0000 & 0.02610 & 0.02610 & 0.02615 & No \\
\hline Ta2W-12 & $10-20-2$ & 21.0035 & 0.0000 & 0.02590 & 0.02595 & 0.02610 & No \\
\hline Ta2W-13 & $10-20-2$ & 21.0000 & 0.0000 & 0.02583 & 0.02620 & 0.02675 & No \\
\hline Ta2W-14 & $10-20-2$ & 20.9995 & 0.0000 & 0.02637 & 0.02630 & 0.02700 & No \\
\hline Ta2W-15 & $10-20-2$ & 20.9985 & 0.0000 & 0.02573 & 0.02575 & 0.02610 & No \\
\hline Ta2W-16 & $10-20-2$ & 21.0010 & 0.0000 & 0.02570 & 0.02610 & 0.02730 & No \\
\hline Ta2W-17 & 11-19-2 & 21.0045 & 0.0000 & 0.02482 & 0.02450 & 0.02595 & No \\
\hline Ta2W-18 & $11-19-2$ & 21.0025 & 0.0000 & 0.02467 & 0.02400 & 0.02510 & No \\
\hline Ta2W-19 & $11-19-2$ & 20.9970 & 0.0000 & 0.02423 & 0.02390 & 0.02590 & No \\
\hline Ta2W-20 & $11-19-2$ & 21.0020 & 0.0000 & 0.02418 & 0.02400 & 0.02510 & No \\
\hline Ta2W-21 & $11-19-2$ & 21.0010 & 0.0000 & 0.02457 & 0.02440 & 0.02490 & No \\
\hline Ta2W-22 & $11-19-2$ & 21.0025 & 0.0000 & 0.02487 & 0.02450 & 0.02510 & No \\
\hline Ta2W-23 & $11-19-2$ & 21.0025 & 0.0000 & 0.02485 & 0.02460 & 0.02590 & No \\
\hline Ta2W-24 & $11-19-2$ & 21.0010 & 0.0000 & 0.02457 & 0.02410 & 0.02510 & No \\
\hline Ta2W-25 & $11-19-2$ & 20.9980 & 0.0000 & 0.02398 & 0.02365 & 0.02400 & No \\
\hline Ta2W-26 & $11-19-2$ & 21.0000 & 0.0000 & 0.02515 & 0.02510 & 0.02590 & No \\
\hline Ta2W-27 & $11-19-2$ & 20.9990 & 0.0000 & 0.02505 & 0.02470 & 0.02510 & No \\
\hline Ta2W-28 & $11-19-2$ & 21.0030 & 0.0000 & 0.02472 & 0.02430 & 0.02585 & No \\
\hline Ta2W-29 & $11-19-2$ & 21.0005 & 0.0000 & 0.02458 & 0.02410 & 0.02505 & No \\
\hline Ta2W-30 & 11-19-2 & 21.0020 & 0.0000 & 0.02462 & 0.02415 & 0.02495 & No \\
\hline Ta2W-31 & $11-19-2$ & 20.9990 & 0.0000 & 0.02462 & 0.02440 & 0.02490 & No \\
\hline Ta2W-32 & $11-19-2$ & 21.0020 & 0.0000 & 0.02442 & 0.02430 & 0.02510 & No \\
\hline Ta2W-33 & $11-19-2$ & 20.9995 & 0.0000 & 0.02483 & 0.02440 & 0.02495 & No \\
\hline Ta2W-34 & $11-19-2$ & 20.9975 & 0.0000 & 0.02413 & 0.02380 & 0.02485 & No \\
\hline Ta2W-35 & $11-19-2$ & 20.9980 & 0.0000 & 0.02457 & 0.02405 & 0.02550 & No \\
\hline Ta2W-36 & $11-19-2$ & 21.0010 & 0.0000 & 0.02510 & 0.02440 & 0.02540 & No \\
\hline Ta2W-37 & $11-19-2$ & 20.9980 & 0.0000 & 0.02457 & 0.02419 & 0.02500 & No \\
\hline Ta2W-38 & $11-19-2$ & 21.0010 & 0.0000 & 0.02360 & 0.02330 & 0.02390 & No \\
\hline Ta2W-39 & $11-19-2$ & 20.9980 & 0.0000 & 0.02347 & 0.02320 & 0.02410 & No \\
\hline Ta2W-40 & $11-19-2$ & 21.0005 & 0.0000 & 0.02473 & 0.02410 & 0.02495 & No \\
\hline Ta2W-41 & $10-20-2$ & 20.9990 & 0.0000 & 0.02477 & $0 . \overline{02410}$ & 0.02480 & Yes \\
\hline Ta2W-42 & $10-20-2$ & 21.0005 & 0.0000 & 0.02450 & 0.02400 & 0.02480 & Yes \\
\hline
\end{tabular}


Table 32. As-Built Dimensions of the Annular Ta-2.5W Plates

\begin{tabular}{|c|c|c|c|c|c|c|c|}
\hline $\begin{array}{l}\text { Disc } \\
\text { Number }\end{array}$ & $\begin{array}{c}\text { Heat } \\
\text { Number }\end{array}$ & $\begin{array}{c}\text { Outer } \\
\text { Diameter } \\
\text { (in) }\end{array}$ & $\begin{array}{c}\text { Inner } \\
\text { Diameter } \\
\text { (in) }\end{array}$ & $\begin{array}{l}\text { Average } \\
\text { Thickness } \\
\text { (in) }\end{array}$ & $\begin{array}{l}\text { Minimum } \\
\text { Thickness } \\
\text { (in) }\end{array}$ & $\begin{array}{l}\text { Maximum } \\
\text { Thickness } \\
\text { (in) }\end{array}$ & $\begin{array}{c}\text { Reserve } \\
\text { as } \\
\text { Spare }\end{array}$ \\
\hline Ta2W-1 & $10-20-2$ & 20.9995 & 2.5125 & 0.02360 & 0.02340 & 0.02425 & No \\
\hline Ta2W-2 & $10-20-2$ & 21.0000 & 2.5120 & 0.02510 & 0.02480 & 0.02520 & No \\
\hline Ta2W-3 & $10-20-2$ & 20.9970 & 2.5125 & 0.02330 & 0.02390 & 0.02445 & No \\
\hline Ta2W-4 & $10-20-2$ & 20.9995 & 2.5110 & 0.02343 & 0.02335 & 0.02390 & No \\
\hline Ta2W-5 & $10-20-2$ & 21.0000 & 2.5115 & 0.02473 & 0.02475 & 0.02490 & No \\
\hline Ta2W-6 & $10-20-2$ & 21.0020 & 2.5120 & 0.02513 & 0.02485 & 0.02650 & No \\
\hline Ta2W-7 & $10-20-2$ & 20.9980 & 2.5115 & 0.02475 & 0.02450 & 0.02500 & No \\
\hline Ta2W-8 & $10-20-2$ & 20.9975 & 2.5120 & 0.02503 & 0.02485 & 0.02550 & No \\
\hline Ta2W-9 & $10-20-2$ & 20.9980 & 2.5120 & 0.02513 & 0.02510 & 0.02525 & No \\
\hline Ta2W-10 & $10-20-2$ & 20.9985 & 2.5115 & 0.02497 & 0.02485 & 0.02525 & No \\
\hline Ta2W-11 & $11-19-2$ & 20.9975 & 2.5120 & 0.02493 & $0.0 \overline{2450}$ & 0.02510 & No \\
\hline Ta2W-12 & $11-19-2$ & 20.9995 & 2.5105 & 0.02535 & 0.02470 & 0.02590 & No \\
\hline Ta2W-13 & $11-19-2$ & 21.0015 & 2.5110 & 0.02530 & 0.02475 & 0.02560 & No \\
\hline Ta2W-14 & $11-19-2$ & 21.0010 & 2.5120 & 0.02497 & 0.02474 & 0.02510 & No \\
\hline Ta2W-15 & $11-19-2$ & 21.0000 & 2.5115 & 0.02405 & 0.02305 & 0.02420 & No \\
\hline Ta2W-16 & $11-19-2$ & 21.0020 & 2.5120 & 0.02467 & 0.02440 & 0.02460 & No \\
\hline Ta2W-17 & $11-19-2$ & 20.9980 & 2.5110 & 0.02385 & 0.02330 & 0.02430 & No \\
\hline Ta2W-18 & $11-19-2$ & 20.9995 & 2.5120 & 0.02557 & 0.02495 & 0.02560 & No \\
\hline Ta2W-19 & $11-19-2$ & 21.0005 & 2.5125 & 0.02502 & 0.02480 & 0.02510 & No \\
\hline Ta2W-20 & $11-19-2$ & 20.9980 & 2.5120 & 0.02383 & 0.02260 & 0.02395 & No \\
\hline $\mathrm{Ta} 2 \mathrm{~W}-21$ & $11-19-2$ & 20.9985 & 2.5120 & 0.02388 & 0.02380 & 0.02460 & No \\
\hline Ta2W-22 & $11-19-2$ & 20.9980 & 2.5115 & 0.02397 & 0.02375 & 0.02410 & No \\
\hline Ta2W-23 & $11-19-2$ & 20.9985 & 2.5130 & 0.02462 & 0.02410 & 0.02460 & No \\
\hline Ta2W-24 & $11-19-2$ & 21.0000 & 2.5110 & 0.02538 & 0.02415 & 0.02610 & No \\
\hline Ta2W-25 & $11-19-2$ & 20.9990 & 2.5105 & 0.02462 & 0.02429 & 0.02500 & No \\
\hline Ta2W-26 & $11-19-2$ & 21.0005 & 2.5115 & 0.02465 & 0.02465 & 0.02470 & No \\
\hline Ta2W-27 & $11-19-2$ & 21.0005 & 2.5110 & 0.02298 & 0.02335 & 0.02340 & Yes \\
\hline Ta2W-28 & $11-19-2$ & 21.0000 & 2.5110 & 0.02425 & 0.02350 & 0.02460 & Yes \\
\hline Ta2W-29 & $11-19-2$ & 20.9995 & 2.5105 & 0.02472 & 0.02410 & 0.02465 & No \\
\hline Ta2W-30 & $11-19-2$ & 20.9970 & 2.5120 & 0.02312 & 0.02290 & 0.02390 & Yes \\
\hline Ta2W-31 & $11-19-2$ & 21.0000 & 2.5105 & 0.02407 & 0.02410 & 0.02440 & No \\
\hline Ta2W-32 & $11-19-2$ & 21.0005 & 2.5115 & 0.02383 & 0.02385 & 0.02410 & Yes \\
\hline Ta2W-33 & $11-19-2$ & 20.9995 & 2.5120 & 0.02367 & 0.02355 & 0.02400 & Yes \\
\hline Ta2W-34 & $11-19-2$ & 20.9985 & 2.5115 & 0.02375 & 0.02345 & 0.02405 & No \\
\hline Ta2W-35 & $11-19-2$ & 21.0000 & 2.5120 & 0.02402 & 0.02385 & 0.02415 & Yes \\
\hline Ta2W-36 & $11-19-2$ & 20.9925 & 2.5110 & 0.02292 & 0.02285 & 0.02380 & Yes \\
\hline Ta2W-37 & $11-19-2$ & 21.0005 & 2.5115 & 0.02400 & 0.02380 & 0.02460 & Yes \\
\hline Ta2W-38 & $11-19-2$ & 20.9995 & 2.5110 & 0.02402 & 0.02395 & 0.02465 & Yes \\
\hline Ta2W-39 & $11-19-2$ & 21.0000 & 2.5115 & 0.02323 & 0.02240 & 0.02425 & Yes \\
\hline Ta2W-40 & $11-19-2$ & 20.9995 & 2.5120 & 0.02415 & 0.02400 & 0.02440 & No \\
\hline Ta2W-41 & $11-19-2$ & 21.0005 & 2.5105 & 0.02490 & 0.02450 & 0.02500 & Yes \\
\hline Ta2W-42 & $11-19-2$ & 20.9990 & 2.5145 & 0.02307 & 0.02295 & 0.02350 & No \\
\hline
\end{tabular}


Table 33. As-built Thickness and Mass Measurements of the Ta-2.5W Plates, Performed by LANL

\begin{tabular}{|c|c|c|c|c|c|c|c|c|}
\hline \multirow{2}{*}{$\begin{array}{l}\text { Plate } \\
\text { Identification } \\
\text { Number }\end{array}$} & \multirow{2}{*}{ Type } & \multirow{2}{*}{$\begin{array}{l}\text { Outer } \\
\text { Diameter } \\
\text { (in) }\end{array}$} & \multirow{2}{*}{$\begin{array}{c}\text { Inner } \\
\text { Diameter } \\
\text { (in) }\end{array}$} & \multicolumn{4}{|c|}{ Thickness (in) } & \multirow{2}{*}{$\begin{array}{c}\text { Mass } \\
(g)\end{array}$} \\
\hline & & & & T1 & T2 & T3 & Average & \\
\hline TA2W-01 & Hole & 21.00 & 2.51 & 0.02410 & 0.02390 & 0.02370 & 0.0239 & 2216.9 \\
\hline TA2W-02 & Hole & 21.00 & 2.51 & 0.02555 & 0.02575 & 0.02525 & 0.0255 & 2366.6 \\
\hline TA2W-03 & Hole & 21.00 & 2.51 & 0.02370 & 0.02330 & 0.02345 & 0.0235 & 2181.1 \\
\hline TA2W-04 & Hole & 21.00 & 2.51 & 0.02510 & 0.02405 & 0.02380 & 0.0243 & 2229.1 \\
\hline TA2W-05 & Hole & 21.00 & 2.51 & 0.02530 & 0.02525 & 0.02465 & 0.0251 & 2326.4 \\
\hline TA2W-06 & Hole & 21.00 & 2.51 & 0.02610 & 0.02575 & 0.02490 & 0.0256 & 2357.4 \\
\hline TA2W-07 & Hole & 21.00 & 2.51 & 0.02490 & 0.02500 & 0.02505 & 0.0250 & 2321.1 \\
\hline TA2W-08 & Hole & 21.00 & 2.51 & 0.02475 & 0.02495 & 0.02560 & 0.0251 & 2340.6 \\
\hline TA2W-09 & Hole & 21.00 & 2.51 & 0.02535 & 0.02540 & 0.02570 & 0.0255 & 2369.4 \\
\hline TA2W-10 & Hole & 21.00 & 2.51 & 0.02535 & 0.02560 & 0.02500 & 0.0253 & 2362.7 \\
\hline TA2W-11 & Hole & 21.00 & 2.51 & 0.02550 & 0.02540 & 0.02515 & 0.0254 & 2340.5 \\
\hline TA2W-12 & Hole & 21.00 & 2.51 & 0.02590 & 0.02505 & 0.02550 & 0.0255 & 2372.1 \\
\hline TA2W-13 & Hole & 21.00 & 2.51 & 0.02580 & 0.02550 & 0.02540 & 0.0256 & 2366.3 \\
\hline TA2W-14 & Hole & 21.00 & 2.51 & 0.02560 & 0.02505 & 0.02525 & 0.0253 & 2348.2 \\
\hline TA2W-15 & Hole & 21.00 & 2.51 & 0.02375 & 0.02430 & 0.02480 & 0.0243 & 2252.8 \\
\hline TA2W-16 & Hole & 21.00 & 2.51 & 0.02500 & 0.02525 & 0.02495 & 0.0251 & 2331.2 \\
\hline TA2W-17 & Hole & 21.00 & 2.51 & 0.02505 & 0.02380 & 0.02505 & 0.0246 & 2287.3 \\
\hline TA2W-18 & Hole & 21.00 & 2.51 & 0.02540 & 0.02545 & 0.02565 & 0.0255 & 2383.0 \\
\hline TA2W-19 & Hole & 21.00 & 2.51 & 0.02545 & 0.02520 & 0.02550 & 0.0254 & 2361.8 \\
\hline TA2W-20 & Hole & 21.00 & 2.51 & 0.02410 & 0.02395 & 0.02380 & 0.0240 & 2213.9 \\
\hline TA2W-21 & Hole & 21.00 & 2.51 & 0.02510 & 0.02480 & 0.02410 & 0.0247 & 2269.5 \\
\hline TA2W-22 & Hole & 21.00 & 2.51 & 0.02475 & 0.02450 & 0.02390 & 0.0244 & 2257.6 \\
\hline TA2W-23 & Hole & 21.00 & 2.51 & 0.02455 & 0.02470 & 0.02530 & 0.0249 & 2295.8 \\
\hline TA2W-24 & Hole & 21.00 & 2.51 & 0.02560 & 0.02475 & 0.02615 & 0.0255 & 2338.7 \\
\hline TA2W-25 & Hole & 21.00 & 2.51 & 0.02475 & 0.02480 & 0.02490 & 0.0248 & 2305.2 \\
\hline TA2W-26 & Hole & 21.00 & 2.51 & 0.02470 & 0.02505 & 0.02490 & 0.0249 & 2328.2 \\
\hline TA2W-27 & Hole & 21.00 & 2.51 & 0.02295 & 0.02330 & 0.02325 & 0.0232 & 2161.3 \\
\hline TA2W-28 & Hole & 21.00 & 2.51 & 0.02390 & 0.02480 & 0.02450 & 0.0244 & 2261.0 \\
\hline TA2W-29 & Hole & 21.00 & 2.51 & 0.02490 & 0.02495 & 0.02475 & 0.0249 & 2308.9 \\
\hline TA2W-30 & Hole & 21.00 & 2.51 & 0.02490 & 0.02380 & 0.02280 & 0.0238 & 2172.9 \\
\hline TA2W-31 & Hole & 21.00 & 2.51 & 0.02465 & 0.02420 & 0.02470 & 0.0245 & 2252.5 \\
\hline TA2W-32 & Hole & 21.00 & 2.51 & 0.02430 & 0.02415 & 0.02445 & 0.0243 & 2275.1 \\
\hline TA2W-33 & Hole & 21.00 & 2.51 & 0.02590 & 0.02400 & 0.02480 & 0.0249 & 2245.4 \\
\hline TA2W-34 & Hole & 21.00 & 2.51 & 0.02505 & 0.02460 & 0.02405 & 0.0246 & 2241.7 \\
\hline TA2W-35 & Hole & 21.00 & 2.51 & 0.02500 & 0.02465 & 0.02480 & 0.0248 & 2277.5 \\
\hline TA2W-36 & Hole & 21.00 & 2.51 & 0.02365 & 0.02335 & 0.02375 & 0.0236 & 2177.6 \\
\hline TA2W-37 & Hole & 21.00 & 2.51 & 0.02485 & 0.02510 & 0.02605 & 0.0253 & 2301.0 \\
\hline TA2W-38 & Hole & 21.00 & 2.51 & 0.02490 & 0.02495 & 0.02485 & 0.0249 & 2270.5 \\
\hline TA2W-39 & Hole & 21.00 & 2.51 & 0.02420 & 0.02280 & 0.02415 & 0.0237 & 2209.5 \\
\hline TA2W-40 & Hole & 21.00 & 2.51 & 0.02435 & 0.02450 & 0.02435 & 0.0244 & 2286.9 \\
\hline TA2W-41 & Hole & 21.00 & 2.51 & 0.02510 & 0.02500 & 0.02510 & 0.0251 & 2343.6 \\
\hline TA2W-42 & Hole & 21.00 & 2.51 & 0.02340 & 0.02330 & 0.02355 & 0.0234 & 2173.4 \\
\hline TA2W-01 & Solid & 21.00 & 0.00 & 0.02460 & 0.02540 & 0.02545 & 0.0252 & 2367.5 \\
\hline TA2W-02 & Solid & 21.00 & 0.00 & 0.02460 & 0.02495 & 0.02470 & 0.0248 & 2325.1 \\
\hline TA2W-03 & Solid & 21.00 & 0.00 & 0.02385 & 0.02455 & 0.02405 & 0.0242 & 2266.6 \\
\hline
\end{tabular}




\begin{tabular}{|c|c|c|c|c|c|c|c|c|}
\hline \multirow{2}{*}{$\begin{array}{l}\text { Plate } \\
\text { Identification } \\
\text { Number }\end{array}$} & \multirow{2}{*}{ Type } & \multirow{2}{*}{$\begin{array}{l}\text { Outer } \\
\text { Diameter } \\
\text { (in) }\end{array}$} & \multirow{2}{*}{$\begin{array}{l}\text { Inner } \\
\text { Diameter } \\
\text { (in) }\end{array}$} & \multicolumn{4}{|c|}{ Thickness (in) } & \multirow{2}{*}{$\begin{array}{l}\text { Mass } \\
\text { (g) }\end{array}$} \\
\hline & & & & T1 & T2 & T3 & Average & \\
\hline TA2W-04 & Solid & 21.00 & 0.00 & 0.02505 & 0.02485 & 0.02475 & 0.0249 & 2341.3 \\
\hline TA2W-05 & Solid & 21.00 & 0.00 & 0.02420 & 0.02465 & 0.02430 & 0.0244 & 2291.9 \\
\hline TA2W-06 & Solid & 21.00 & 0.00 & 0.02485 & 0.02430 & 0.02500 & 0.0247 & 2318.0 \\
\hline TA2W-07 & Solid & 21.00 & 0.00 & 0.02415 & 0.02375 & 0.02395 & 0.0240 & 2258.0 \\
\hline TA2W-08 & Solid & 21.00 & 0.00 & 0.02480 & 0.02395 & 0.02375 & 0.0242 & 2289.6 \\
\hline TA2W-09 & Solid & 21.00 & 0.00 & 0.02545 & 0.02445 & 0.02415 & 0.0247 & 2359.4 \\
\hline TA2W-10 & Solid & 21.00 & 0.00 & 0.02650 & 0.02610 & 0.02630 & 0.0263 & 2457.0 \\
\hline TA2W-11 & Solid & 21.00 & 0.00 & 0.02700 & 0.02705 & 0.02675 & 0.0269 & 2554.9 \\
\hline TA2W-12 & Solid & 21.00 & 0.00 & 0.02785 & 0.02710 & 0.02695 & 0.0273 & 2507.5 \\
\hline TA2W-13 & Solid & 21.00 & 0.00 & 0.02675 & 0.02635 & 0.02715 & 0.0268 & 2500.9 \\
\hline TA2W-14 & Solid & 21.00 & 0.00 & 0.02670 & 0.02745 & 0.02700 & 0.0271 & 2540.5 \\
\hline TA2W-15 & Solid & 21.00 & 0.00 & 0.02685 & 0.02635 & 0.02715 & 0.0268 & 2482.8 \\
\hline TA2W-16 & Solid & 21.00 & 0.00 & 0.02655 & 0.02670 & 0.02625 & 0.0265 & 2509.0 \\
\hline TA2W-17 & Solid & 21.00 & 0.00 & 0.02495 & 0.02480 & 0.02595 & 0.0252 & 2385.0 \\
\hline TA2W-18 & Solid & 21.00 & 0.00 & 0.02445 & 0.02475 & 0.02460 & 0.0246 & 2337.2 \\
\hline TA2W-19 & Solid & 21.00 & 0.00 & 0.02595 & 0.02615 & 0.02595 & 0.0260 & 2397.4 \\
\hline TA2W-20 & Solid & 21.00 & 0.00 & 0.02495 & 0.02500 & 0.02465 & 0.0249 & 2346.4 \\
\hline TA2W-21 & Solid & 21.00 & 0.00 & 0.02525 & 0.02475 & 0.02455 & 0.0249 & 2329.1 \\
\hline TA2W-22 & Solid & 21.00 & 0.00 & 0.02540 & 0.02445 & 0.02470 & 0.0249 & 2351.2 \\
\hline TA2W-23 & Solid & 21.00 & 0.00 & 0.02495 & 0.02590 & 0.02575 & 0.0255 & 5.6 \\
\hline TA2W-24 & Solid & 21.00 & 0.00 & 0.02575 & 0.02560 & 0.02505 & 0.0255 & 2409.5 \\
\hline TA2W-25 & Solid & 21.00 & 0.00 & 0.02490 & 0.02390 & 0.02410 & 0.0243 & 2274.8 \\
\hline TA2W-26 & Solid & 21.00 & 0.00 & 0.02575 & 0.02535 & 0.02625 & 0.0258 & 2432.1 \\
\hline TA2W-27 & Solid & 21.00 & 0.00 & 0.02485 & 0.02415 & 0.02485 & 0.0246 & 2357.3 \\
\hline TA2W-28 & Solid & 21.00 & 0.00 & 0.02560 & 0.02555 & 0.02445 & 0.0252 & 2371.1 \\
\hline TA2W-29 & Solid & 21.00 & 0.00 & 0.02505 & 0.02520 & 0.02415 & 0.0248 & 2317.6 \\
\hline TA2W-30 & Solid & 21.00 & 0.00 & 0.02515 & 0.02490 & 0.02560 & 0.0252 & 2388.5 \\
\hline TA2W-31 & Solid & 21.00 & 0.00 & 0.02460 & 0.02505 & 0.02525 & 0.0250 & 2341.0 \\
\hline TA2W-32 & Solid & 21.00 & 0.00 & 0.02555 & 0.02555 & 0.02485 & 0.0253 & 2393.2 \\
\hline TA2W-33 & Solid & 21.00 & 0.00 & 0.02565 & 0.02530 & 0.02485 & 0.0253 & 2362.2 \\
\hline TA2W-34 & Solid & 21.00 & 0.00 & 0.02425 & 0.02455 & 0.02420 & 0.0243 & 2297.5 \\
\hline TA2W-35 & Solid & 21.00 & 0.00 & 0.02500 & 0.02590 & 0.02465 & 0.0252 & 2325.0 \\
\hline TA2W-36 & Solid & 21.00 & 0.00 & 0.02495 & 0.02485 & 0.02515 & 0.0250 & 2380.9 \\
\hline TA2W-37 & Solid & 21.00 & 0.00 & 0.02505 & 0.02510 & 0.02500 & 0.0251 & 2348.1 \\
\hline TA2W-38 & Solid & 21.00 & 0.00 & 0.02415 & 0.02375 & 0.02435 & 0.0241 & 2256.8 \\
\hline TA2W-39 & Solid & 21.00 & 0.00 & 0.02355 & 0.02405 & 0.02355 & 0.0237 & 2236.4 \\
\hline TA2W-40 & Solid & 21.00 & 0.00 & 0.02565 & 0.02570 & 0.02470 & 0.0254 & 2353.6 \\
\hline TA2W-41 & Solid & 21.00 & 0.00 & 0.02520 & 0.02490 & 0.02495 & $0 . \overline{0250}$ & 2360.1 \\
\hline TA2W-42 & Solid & 21.00 & 0.00 & 0.02480 & 0.02515 & 0.02500 & 0.0250 & 2388.7 \\
\hline
\end{tabular}


Table 34. Ta-2.5W Remnant Sample Density Measurements

\begin{tabular}{|c|c|}
\hline Specimen & $\begin{array}{c}\text { Specimen } \\
\text { Density } \\
\text { (g/cm }\end{array}$ \\
\hline Ta 11-19-2 \#1 & 16.715 \\
\hline Ta 11-19-2 \#2 & 16.722 \\
\hline Ta 11-19-2 \#3 & 16.724 \\
\hline Ta 11-19-2 \#4 & 16.718 \\
\hline Ta 10-20-2 \#1 & 16.726 \\
\hline Ta 10-20-2 \#2 & 16.727 \\
\hline Ta 10-20-2 \#3 & 16.740 \\
\hline Ta 10-20-2 \#4 & 16.724 \\
\hline Ta 10-20-2 \#5 & 16.731 \\
\hline Ta 10-20-2 \#6 & 16.728 \\
\hline Ta 10-20-2 \#7 & 16.734 \\
\hline Ta-11-19-2 \#7 & 16.736 \\
\hline Ta-11-19-2 \#5 & 16.718 \\
\hline Ta-11-19-2 \#6 & 16.724 \\
\hline
\end{tabular}

Table 35. Chemical Analyses for the Ta-2.5W Plates

\begin{tabular}{|c|c|c|c|c|}
\hline \multirow{2}{*}{ Element } & \multicolumn{5}{|c|}{ Ta-2.5W (wt. \%) } \\
\cline { 2 - 5 } & Specification & Heat 11-19-2002 & Heat 10-10-2002 & Average \\
\hline $\mathrm{Ta}$ & balance & balance & balance & 98.061 \\
\hline $\mathrm{W}$ & $2.0-3.5$ & 1.825 & 1.975 & 1.900 \\
\hline $\mathrm{C}$ & $\max 0.010$ & 0.003 & 0.003 & 0.003 \\
\hline $\mathrm{Fe}$ & $\max 0.010$ & $<0.0050$ & $<0.0050$ & 0.0025 \\
\hline $\mathrm{H}$ & $\max 0.0015$ & $<0.0003$ & $<0.0003$ & 0.00015 \\
\hline $\mathrm{Mo}$ & $\max 0.020$ & $<0.0050$ & $<0.0050$ & 0.0025 \\
\hline $\mathrm{N}$ & $\max 0.010$ & $<0.0020$ & $<0.0020$ & 0.0010 \\
\hline $\mathrm{Nb}$ & $\max 0.50$ & 0.02 & 0.02 & 0.02 \\
\hline $\mathrm{Ni}$ & $\max 0.010$ & $<0.0050$ & $<0.0050$ & 0.0025 \\
\hline $\mathrm{O}$ & $\max 0.015$ & $<0.0050$ & $<0.0050$ & 0.0025 \\
\hline $\mathrm{Si}$ & $\max 0.005$ & $<0.0050$ & $<0.0050$ & 0.0025 \\
\hline $\mathrm{Ti}$ & $\max 0.010$ & $<0.0050$ & $<0.0050$ & 0.0025 \\
\hline
\end{tabular}


B-TM-1639

Table 36. Average Elemental Composition of the Ta-2.5W Plates

\begin{tabular}{|c|c|}
\hline Element & $\begin{array}{c}\text { Number } \\
\text { Density } \\
\text { (atoms/b-cm) }\end{array}$ \\
\hline $\mathrm{Ta}$ & $5.45016 \mathrm{E}-02$ \\
\hline $\mathrm{W}$ & $1.03940 \mathrm{E}-03$ \\
\hline $\mathrm{C}$ & $2.51200 \mathrm{E}-05$ \\
\hline $\mathrm{Fe}$ & $4.50218 \mathrm{E}-06$ \\
\hline $\mathrm{H}$ & $1.49666 \mathrm{E}-05$ \\
\hline $\mathrm{Mo}$ & $2.62064 \mathrm{E}-06$ \\
\hline $\mathrm{N}$ & $7.18012 \mathrm{E}-06$ \\
\hline $\mathrm{Nb}$ & $2.16497 \mathrm{E}-05$ \\
\hline $\mathrm{Ni}$ & $4.28369 \mathrm{E}-06$ \\
\hline $\mathrm{O}$ & $1.57146 \mathrm{E}-05$ \\
\hline $\mathrm{Si}$ & $8.95211 \mathrm{E}-06$ \\
\hline $\mathrm{Ti}$ & $5.25256 \mathrm{E}-06$ \\
\hline
\end{tabular}




\section{NRPCT Pre-Experimental Predictions}

This section provides the pre-experimental predictions and supporting analysis for the Prometheus critical experiments. Three experiments have been designed to bracket the neutron energy spectra expected in Prometheus reactor designs under normal operating conditions and one experiment has been designed to simulate an accident condition in which the core is flooded with water. Experiment 1 is designed to approximate the neutron energy spectrum in the center of the core. Experiments 2 and 3 are designed to bracket the core average neutron energy spectrum. Experiment 4 is designed to simulate the average neutron energy spectrum when the core is flooded with water.

Three computer-generated 3-D images of the critical experiment, consisting of one overview and two close-up views, are presented in Figure 18, Figure 19, and Figure 20. These figures show representative pictures of what the critical experiments analyzed in this report would look like. The aluminum support structure is shown in yellow-green, the graphite/polyethylene moderator is shown in blue, the HEU is shown in red, the refractory metal test plates are shown in green, and the stainless steel diaphragm is shown in purple. The upper aluminum support structure has been removed from Figure 20 in order to illustrate the presence of the stainless steel diaphragm. The model in the images is the Ta-2.5W-4 experiment, and was modeled in RACER with 16 stacking units and a polyethylene top reflector thickness of $1.04 "$. The images were generated by a utility that enables 3-D visualizations.

Several simplifying assumptions were made in the pre-experimental predictions. Based on the analysis of similar critical experiments, these simplifying assumptions are expected to have a worth similar to the experimental uncertainty. These assumptions include:

- The use of average plate thicknesses, masses, and number densities since the detailed asbuilt configuration of each experiment cannot be known until the experiment is conducted.

- The use of nominal graphite dimensions and isotopic compositions since detailed as-built information was not available at the time of the analysis.

- The use of nominal dimensions and average polyethylene number densities from similar experiments since detailed as-built information was not available at the time of the analysis.

- The collar plate (Figure 8) was approximated as an annular ring with an inner diameter of 21.4684 " to preserve the collar plate volume and mass.

- A $0.040^{\prime \prime}$ thick stainless steel diaphragm was assumed in the baseline, Mo, Re, and Ta-2.5W experiments (the same diaphragm used in the $\mathrm{Nb}-1 \mathrm{Zr}$ with Polyethylene experiment [2]) since LANL had not determined the diaphragm thickness to be used in the baseline, Mo, Re, and Ta-2.5W experiments at the time of analysis (see Appendix E).

- A $0.075^{\prime \prime}$ thick stainless steel diaphragm was assumed in the $\mathrm{Nb}-1 \mathrm{Zr}$ experiments since the asbuilt dimensions of the diaphragm to be used in the critical experiments had not been provided by LANL at the time of the analysis, but a $0.075^{\prime \prime}$ thick stainless steel diaphragm had been in the qualification process.

- The $\mathrm{Nb}-1 \mathrm{Zr}$ assembly was split around the diaphragm to allow the mass of the top core to fall within the diaphragm mass limit of $150 \mathrm{~kg}$ as set by LANL.

- The baseline, Mo, Re, and Ta-2.5W assemblies were split approximately half above and half below the diaphragm since LANL had not determined the diaphragm weight limit at the time of the analysis.

- The alignment tube was assumed to extend from the bottom of the spindle plate to the bottom of the last stacking unit with a $2.51^{\prime \prime}$ ID since LANL had not specified the actual length of the alignment tubes to be used in the experiments.

- The presence of the neutron source was neglected. 
- A target delayed critical $k_{\text {eff }}$ between 1.0000 and 1.0020 was assumed in the RCP01 and MCNP5 analyses to determine the top reflector thickness.

RCP01 [9], MCNP5 [10], MCNP5 with space cross sections (Appendix C), and RACER [11] analyses were performed to provide additional confidence in these pre-experimental predictions through the use of multiple independent computer codes. No attempt is made within this document to provide a complete and detailed understanding of the reasons for the differences in predictions between the different computer codes, as this would have been addressed in future work. These differences may be attributed to three broad categories: modeling differences, cross section data differences, and methods differences. A general summary of the known differences between the independent analyses and the expected impact of these differences is provided below. It should also be noted that an accurate set of critical experiment measurements would have been useful in resolving these differences in predicted eigenvalues.

- The RCP01, MCNP5, MCNP5 with space cross sections, and RACER analyses were performed using equivalent geometry and material models. The only differences are related to the representation of air inside and surrounding the assemblies. The RCP01 models include an enclosing cylinder of dilute Helium with a number density of $1 \times 10^{-20}$ atoms/barn-cm and the RACER models included an enclosing sphere of Helium with a number density of $1 \times 10^{-14}$ atoms/barn-cm, to represent air inside and surrounding the assemblies. The MCNP5 models represent air as void. Studies done to investigate the impact of this approximation on eigenvalue calculations found the influence to be negligible.

- There are differences in the cross section data used in the RCP01, MCNP5, MCNP5 with space cross sections, and RACER analyses. The origin of the cross section data used in each independent series of analyses is summarized in Table 37. The MCNP5 analyses used ENDF/B-VI.8 cross sections. The RCP01 analyses used a preliminary version of the SPACE05A cross section set. The RCP01 and MCNP5 analyses were performed by Bettis before the final SPACE05A cross section library was available. The MCNP5 with space cross sections and RACER analyses were performed by KAPL several months after the Bettis analyses and used the SPACE05A cross section set. The SPACE05A cross section set (Appendix C) was specified by the Bettis/KAPL nuclear data communities for use in space reactor nuclear analyses and used the best neutron cross section evaluations that were available at the time. The use of different cross section data is expected to have a first order effect on the predicted eigenvalues.

- The RCP01 and MCNP5 analyses used some elemental cross section evaluations while the MCNP5 with space cross sections and RACER analyses used isotopic evaluations. In the MCNP5 analyses elemental evaluations were used when a complete set of isotopic cross section evaluations were not available. In the RCP01 analyses the elemental evaluations were used for minor alloy constituents or impurities that were not expected to have a significant neutronic impact or when a complete set of isotopic evaluations were not available. The use of selected elemental cross section instead of isotopic cross section evaluations is expected to have a second order effect on the predicted eigenvalues.

- Different unresolved resonance treatments were use by the codes systems. In the RCP01 analyses the capture, fission and elastic scattering cross sections in the unresolved resonance energy range are constructed by sampling from the Porter-Thomas distributions used to represent the unresolved resonance data sets in the cross section evaluations. The MCNP5 and RACER analyses use a probability table treatment for the unresolved resonance data. A summary of the unresolved resonance treatment ranges for the SPACE05A and the ENDF/BVI. 8 cross sections used in the MCNP5 analyses are provided in Table 38 and Table 39. These same values apply to the unresolved resonance treatment ranges used in RACER. Differences in the methods and data used to represent unresolved resonances are expected to have a first order' effect on the predicted eigenvalues. 
- RCP01 and RACER used a fixed energy mesh for all nuclides to represent the continuous energy cross section while MCNP5 uses a different energy mesh for each nuclide. This methods difference is expected to have a second order effect on the predicted eigenvalues.

- Both RCP01 and RACER approximate inelastic scattering using a multigroup averaged inelastic scattering cross section and energy transfer matrix truncated at $5.53 \mathrm{keV} .(n, 2 \mathrm{n})$ and other high energy neutron producing reactions are added to the multigroup inelastic scattering cross section and the energy transfer matrix is adjusted to account for neutron multiplicity. MCNP5 makes not additional approximations in the treatment of inelastic scattering and other high energy neutron producing reactions. This methods difference is expected to have a second order effect on predicted eigenvalues.

- RCP01, RACER, and MCNP5 all model bound-atom thermal neutron scattering effects for graphite and polyethylene. RCP01 uses a multigroup $P_{3}$ thermal scattering kernel generated from the $S(\alpha, \beta, T)$ thermal scattering law data, while MCNP5 and RACER use a direct $S(\alpha, \beta, T)$ treatment for thermal neutron scattering. This methods difference is expected to have a second order effect on the predicted eigenvalues.

- Finally, the independent analyses each used different running strategies; however these differences are expected to have a negligible effect on predicted eigenvalues. RCP01 calculations were performed using 100 inactive iterations with 500 neutron histories per iteration followed by a 1.25 ramp-up rate, 600 active iterations with 10,000 neutron histories per iteration for a total of six million active histories. Survey calculations were performed using a single random number skip and calculations for the approach to critical were performed by statistically combining the results from 20 independent RCP01 calculations (equivalent to $120,000,000$ active histories). MCNP5 calculations were performed using 100 inactive iterations with 5000 neutron histories per iteration and 1150 active iterations with 5000 neutron histories per iteration for a total of $5,750,000$ active histories. MCNP5 with space cross sections calculations were performed using 175 inactive iterations with 20,000 neutron histories per iteration and 1425 active iterations with 20,000 neutron histories per iteration for a total of $28,500,000$ active histories. RACER calculations were performed using 80 inactive iterations with 100,000 neutron histories per iteration and 520 active iterations with 100,000 neutron histories per iteration for a total of $52,000,000$ active histories. 


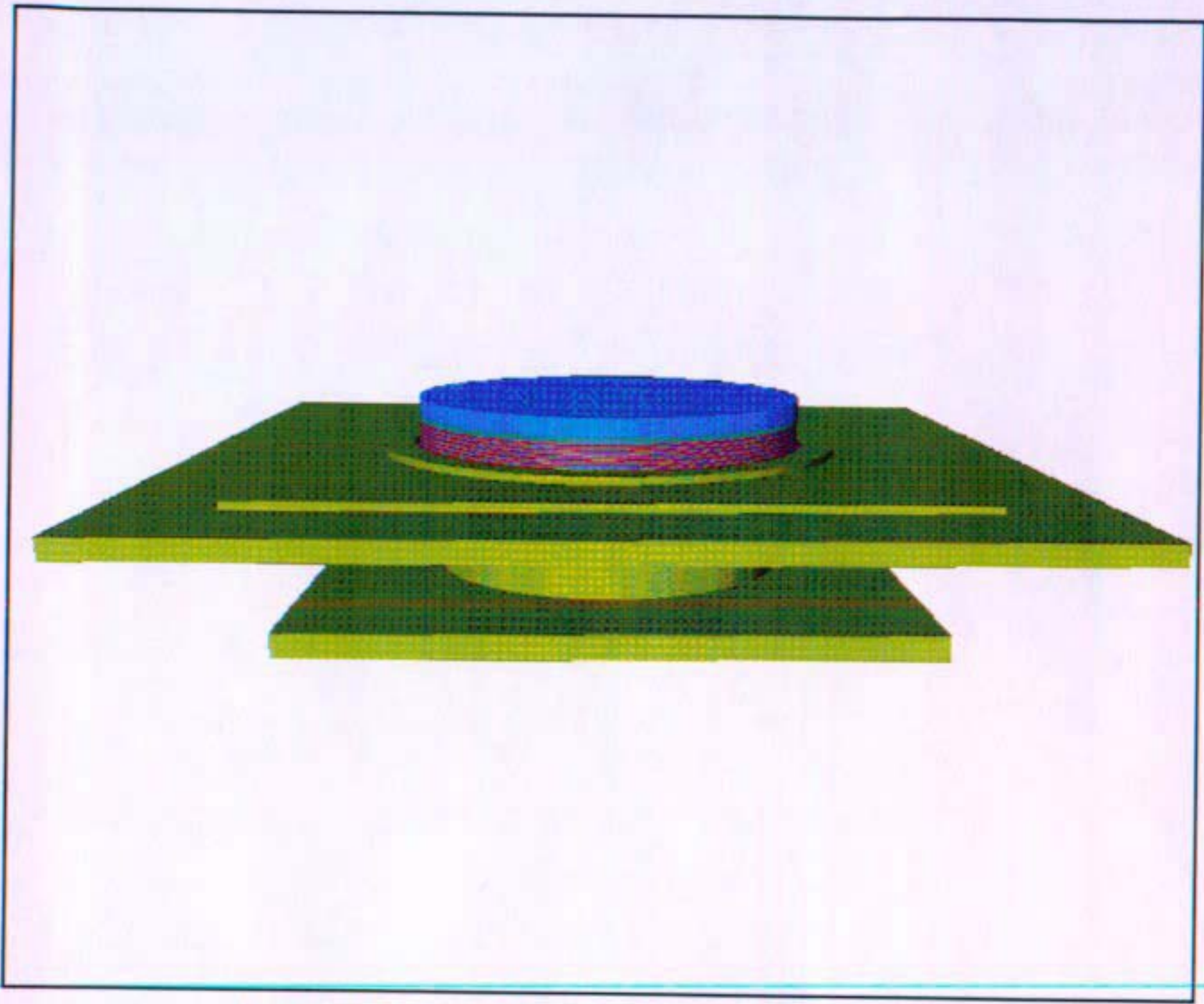

Figure 18. Overview of the Critical Experiment Configuration 
B-TM-1639

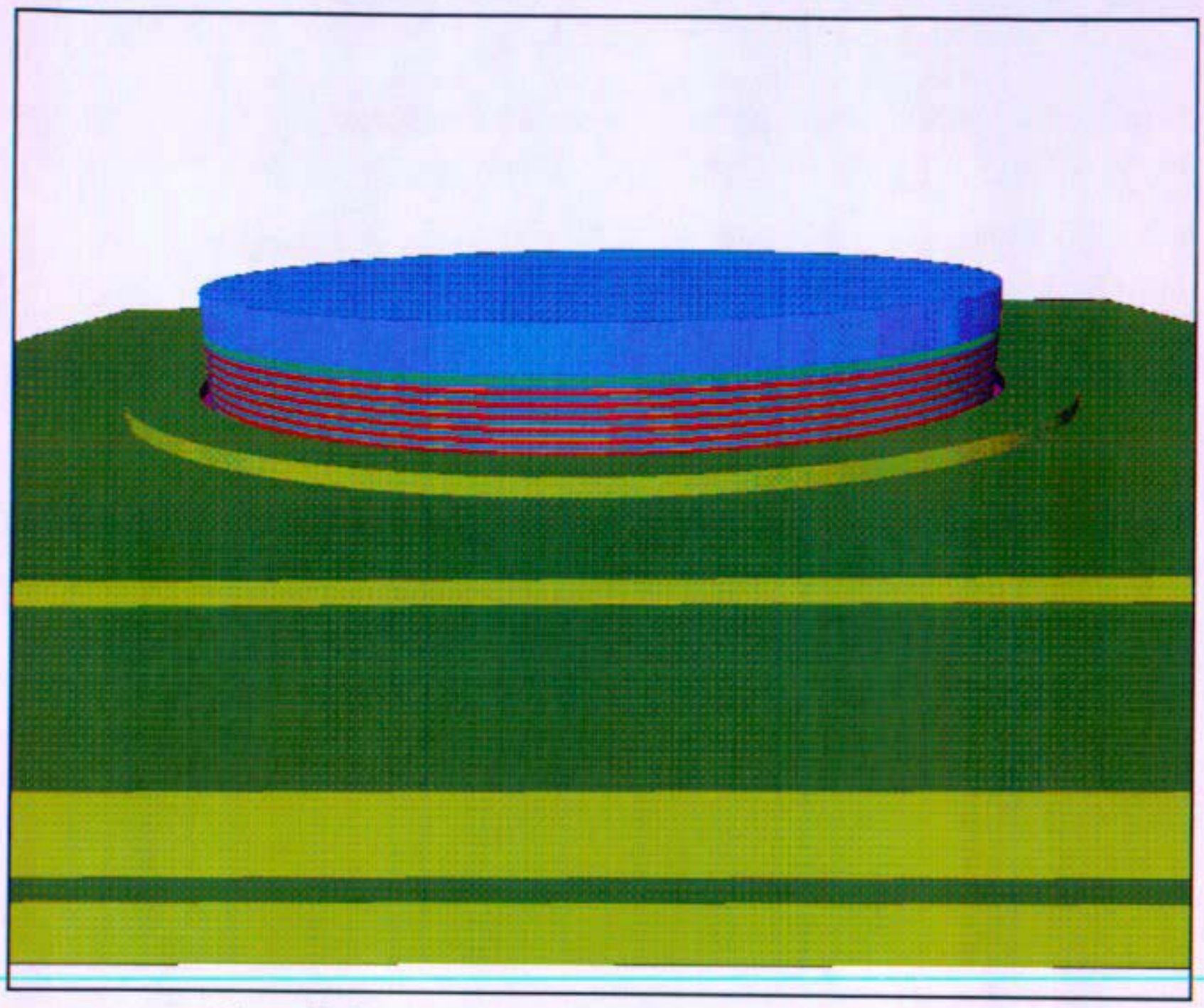

Figure 19. Close-up View of the Critical Experiment Configuration 


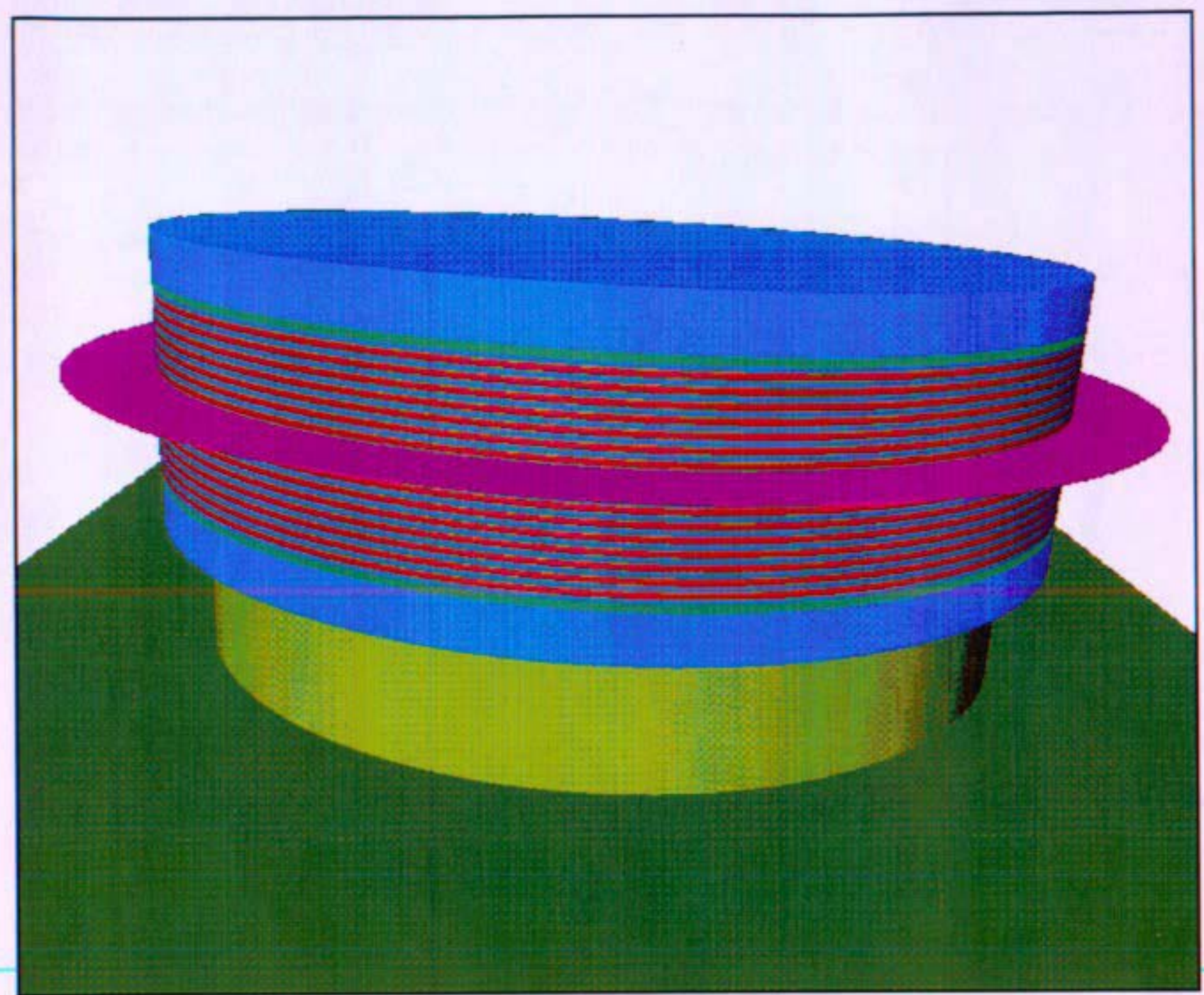

Figure 20. Close-up View of the Critical Experiment Configuration, without the Upper Aluminum Support Structure 
Table 37. Cross Section Data Sources

\begin{tabular}{|c|c|c|c|c|}
\hline \multirow[t]{2}{*}{ Nuclides/Elements } & \multicolumn{4}{|c|}{ Cross Section Evaluation Used } \\
\hline & RCP01 & MCNP5 & MCNP5 (SPACE05A) & RACER \\
\hline Al-27 & ENDF/B-VI.4 & ENDF/B-VI.8 & ENDF/B-VI.8 & ENDF/B-VI.8 \\
\hline C-nat & ENDF/B-VI.1 & ENDF/B-VI.6 & ENDF/B-VI.6 & ENDF/B-VI.6 \\
\hline Cr-nat & ENDF/B-VI.5 & - & - & - \\
\hline $\mathrm{Cr}-50$ & - & ENDF/B-VI.8 & ENDF/B-VI.8 & ENDF/B-V/.8 \\
\hline Cr-52 & - & ENDF/B-VI.8 & ENDF/B-VI.8 & ENDF/B-VI.8 \\
\hline Cr-53 & - & ENDF/B-VI.8 & ENDF/B-VI.8 & ENDF/B-VI.8 \\
\hline $\mathrm{Cr}-54$ & - & ENDF/B-VI.8 & ENDF/B-VI.8 & ENDF/B-VI.8 \\
\hline Cu-nat & ENDF/B-VI.2 & - & - & - \\
\hline Cu-63 & - & ENDF/B-VI.8 & ENDF/B-VI.8 & ENDF/B-VI.8 \\
\hline Cu-65 & - & ENDF/B-VI.8 & ENDF/B-VI.8 & ENDF/B-VI.8 \\
\hline Fe-nat & ENDF/B-VI.5 & - & - & - \\
\hline $\mathrm{Fe}-54$ & ENDF/B-VI.5 & ENDF/B-VI.8 & ENDF/B-VI.8 & ENDF/B-VI.8 \\
\hline $\mathrm{Fe}-56$ & ENDF/B-VI.1 & ENDF/B-V/.8 & ENDF/B-VI.8 & ENDF/B-VI.8 \\
\hline $\mathrm{Fe}-57$ & ENDF/B-VI.1 & ENDF/B-VI.8 & ENDF/B-VI.8 & ENDF/B-VI.8 \\
\hline Fe-58 & ENDF/B-VI.5 & ENDF/B-VI.8 & ENDF/B-VI.8 & ENDF/B-VI.8 \\
\hline $\mathrm{H}-1$ & ENDF/B-VI.5 & ENDF/B-VI.8 & ENDF/B-VI.8 & ENDF/B-VI.8 \\
\hline Hf-nat & ENDF/B-VI.2 & - & - & - \\
\hline $\mathrm{Hf}-174$ & - & ENDF/B-VI.2 & ENDF/B-VI.2 & ENDF/B-V!.2 \\
\hline Hf-176 & - & ENDF/B-V!.2 & ENDF/B-VI.2 & ENDF/B-Vl.2 \\
\hline $\mathrm{Hf}-177$ & - & ENDF/B-VI.2 & ENDF/B-VI.2 & ENDF/B-VI.2 \\
\hline Hf-178 & - & ENDF/B-VI.2 & ENDF/B-VI.2 & ENDF/B-VI.2 \\
\hline $\mathrm{Hf}-179$ & - & ENDF/B-VI.2 & ENDF/B-VI.2 & ENDF/B-VI.2 \\
\hline $\mathrm{Hf}-180$ & - & ENDF/B-VI.2 & ENDF/B-VI.2 & ENDF/B-VI.2 \\
\hline Mg-nat & ENDF/B-VI.0 & ENDF/B-VI.8 & - & - \\
\hline $\mathrm{Mg}-24$ & - & - & JENDL-3.2 & JENDL-3.2 \\
\hline $\mathrm{Mg}-25$ & - & - & JENDL-3.2 & JENDL-3.2 \\
\hline $\mathrm{Mg}-26$ & - & - & JENDL-3.2 & JENDL-3.2 \\
\hline Mn-55 & ENDF/B-VI.5 & ENDF/B-VI.8 & ENDF/B-VI.8 & ENDF/B-VI.8 \\
\hline Mo-nat & ENDF/B-VI. $0^{\dagger}$ & ENDF/B-VI.0 & - & - \\
\hline Mo-92 & JENDL-3.1 & - & JENDL-3.2 & JENDL-3.2 \\
\hline Mo-94 & JENDL-3.1 & - & JENDL-3.2 & JENDL-3.2 \\
\hline Mo-95 & JENDL-3.1 & - & JENDL-3.2 & JENDL-3.2 \\
\hline Mo-96 & JENDL-3.1 & - & JENDL-3.2 & JENDL-3.2 \\
\hline Mo-97 & JENDL-3.1 & - & JENDL-3.2 & JENDL-3.2 \\
\hline Mo-98 & JENDL-3.1 & - & JENDL-3.2 & JENDL-3.2 \\
\hline Mo-100 & JENDL-3.1 & - & JENDL-3.2 & JENDL-3.2 \\
\hline $\mathrm{N}$-nat & ENDF/B-VI.3 & - & - & - \\
\hline $\mathrm{N}-14$ & - & ENDF/B-VI. 8 & ENDF/B-VI.8 & ENDF/B-VI.8 \\
\hline $\mathrm{N}-15$ & - & ENDF/B-VI.0 & ENDF/B-VI.0 & ENDF/B-VI.0 \\
\hline $\mathrm{Nb}-93$ & ENDF/B-VI.1 & ENDF/B-VI.6 & ENDF/B-VI.6 & ENDF/B-VI.6 \\
\hline Ni-nat & ENDF/B-VI.5 & - & - & - \\
\hline $\mathrm{Ni}-58$ & - & ENDF/B-VI. $\overline{8}$ & ENDF/B-VI.8 & ENDF/B-VI.8 \\
\hline
\end{tabular}

\footnotetext{
" $\mathrm{Fe}$-nat used for $\mathrm{Fe}$ impurity in $\mathrm{Nb}-1 \mathrm{Zr}$ and Fe alloy constituent in Al-6061 and SS-301 compositions.

${ }^{\dagger}$ Mo-nat used for Mo impurity in Ta-2.5W compositions, isotopic cross section used for all other materials.
} 


\begin{tabular}{|c|c|c|c|c|}
\hline \multirow[t]{2}{*}{ Nuclides/Elements } & \multicolumn{4}{|c|}{ Cross Section Evaluation Used } \\
\hline & RCP01 & MCNP5 & MCNP5 (SPACE05A) & RACER \\
\hline $\mathrm{Ni}-60$ & - & ENDF/B-VI.8 & ENDF/B-VI.8 & ENDF/B-VI.8 \\
\hline $\mathrm{Ni}-61$ & - & ENDF/B-VI.8 & ENDF/B-VI.8 & ENDF/B-V/.8 \\
\hline $\mathrm{Ni}-62$ & - & ENDF/B-VI.8 & ENDF/B-VI.8 & ENDF/B-VI.8 \\
\hline $\mathrm{Ni}-64$ & - & ENDF/B-VI.8 & ENDF/B-VI.8 & ENDF/B-VI.8 \\
\hline O-nat & ENDF/B-VI.8 & - & - & - \\
\hline $0-16$ & - & ENDF/B-VI.8 & ENDF/B-VI.8 & ENDF/B-V/.8 \\
\hline $0-17$ & - & ENDF/B-VI.0 & ENDF/B-VI.O & ENDF/B-VI.0 \\
\hline P-31 & ENDF/B-VI.0 & ENDF/B-VI.6 & ENDF/B-VI.6 & ENDF/B-VI.6 \\
\hline $\mathrm{Re}-185$ & ENDF/B-VI.0 & ENDF/B-VI.0 & ENDF/B-VI.0 & ENDF/B-VI.0 \\
\hline $\operatorname{Re}-187$ & ENDF/B-VI.0 & ENDF/B-VI.0 & ENDF/B-VI.0 & ENDF/B-V/.0 \\
\hline S-nat & ENDF/B-VI.0 & ENDF/B-VI.8 & - & - \\
\hline S-32 & - & - & JENDL-3.2 & JENDL-3.2 \\
\hline S-33 & - & - & JENDL-3.2 & JENDL-3.2 \\
\hline S-34 & - & - & JENDL-3.2 & JENDL-3.2 \\
\hline S-36 & - & - & JENDL-3.2 & JENDL-3.2 \\
\hline Si-nat & ENDF/B-VI.5 & ENDF/B-VI.0 & - & - \\
\hline Si-28 & - & - & ENDF/B-VI.5 & ENDF/B-VI.5 \\
\hline Si-29 & - & - & ENDF/B-VI.5 & ENDF/B-VI.5 \\
\hline Si-30 & - & - & ENDF/B-VI.5 & ENDF/B-VI.5 \\
\hline Ta-181 & ENDF/B-VI.0 & ENDF/B-VI.0 & ENDF/B-VI.0 & ENDF/B-VI.0 \\
\hline Ti-nat & ENDF/B-VI.0 & ENDF/B-VI.8 & - & - \\
\hline $\mathrm{Ti}-46$ & - & - & JENDL-3.2 & JENDL-3.2 \\
\hline $\mathrm{Ti}-47$ & - & - & JENDL-3.2 & JENDL-3.2 \\
\hline $\mathrm{Ti}-48$ & - & - & JENDL-3.2 & JENDL-3.2 \\
\hline Ti-49 & - & - & JENDL-3.2 & JENDL-3.2 \\
\hline Ti-50 & - & - & JENDL-3.2 & JENDL-3.2 \\
\hline U-234 & ENDF/B-VI.0 & ENDF/B-VI.0 & ENDF/B-VI.0 & ENDF/B-VI.0 \\
\hline $\mathrm{U}-235$ & ENDF/B-VI.5 & ENDF/B-VI.5 & ENDF/B-VI.5 & ENDF/B-VI.5 \\
\hline $\mathrm{U}-236$ & ENDF/B-VI.0 & ENDF/B-VI.0 & ENDF/B-VI.0 & ENDF/B-VI.0 \\
\hline $\mathrm{U}-238$ & ENDF/B-VI.5 & ENDF/B-VI.5 & ENDF/B-VI.5 & ENDF/B-VI.5 \\
\hline W-nat & ENDF/B-VI. $1^{\ddagger}$ & $=$ & - & - \\
\hline$W-182$ & ENDF/B-VI.0 & ENDF/B-VI.8 & ENDF/B-VI.8 & ENDF/B-VI.8 \\
\hline W-183 & ENDF/B-VI.0 & ENDF/B-VI.8 & ENDF/B-VI.8 & ENDF/B-VI.8 \\
\hline W-184 & ENDF/B-VI.0 & ENDF/B-VI.8 & ENDF/B-VI.8 & ENDF/B-VI.8 \\
\hline$W-186$ & ENDF/B-VI.0 & ENDF/B-VI.8 & ENDF/B-VI.8 & ENDF/B-VI.8 \\
\hline Zr-nat & ENDF/B-VI.1 & ENDF/B-VI.1 & ENDF/B-VI.1 & ENDF/B-VI. 1 \\
\hline
\end{tabular}

${ }^{\ddagger} \mathrm{W}$-nat used for $\mathrm{W}$ impurity in $\mathrm{Nb}-1 \mathrm{Zr}$ composition, isotopic cross sections used for all other materials. 
Table 38. MCNP5 with Space Cross Sections Unresolved Resonance Region Treatment

\begin{tabular}{|c|c|c|}
\hline \multicolumn{3}{|c|}{ SPACE05A MCNP5 XS } \\
\hline Isotope & $\begin{array}{c}\text { URR start } \\
\text { (eV) }\end{array}$ & $\begin{array}{c}\text { URR end } \\
\text { (eV) }\end{array}$ \\
\hline Mo-92 & $5.00 E+04$ & $1.00 \mathrm{E}+05$ \\
\hline Mo-94 & $2.00 E+04$ & $1.00 \mathrm{E}+05$ \\
\hline Mo-95 & $2.00 \mathrm{E}+03$ & $1.00 \mathrm{E}+05$ \\
\hline Mo-96 & $1.90 E+04$ & $1.00 \mathrm{E}+05$ \\
\hline Mo-97 & $1.80 \mathrm{E}+03$ & $1.00 \mathrm{E}+05$ \\
\hline Mo-98 & $3.20 \mathrm{E}+04$ & $1.00 \mathrm{E}+05$ \\
\hline Mo-100 & $2.60 \mathrm{E}+04$ & $1.00 \mathrm{E}+05$ \\
\hline Ta-181 & $3.30 \mathrm{E}+02$ & $5.00 \mathrm{E}+03$ \\
\hline W-182 & $4.50 \mathrm{E}+03$ & $1.00 \mathrm{E}+05$ \\
\hline $\mathrm{W}-183$ & $7.65 \mathrm{E}+02$ & $4.50 \mathrm{E}+04$ \\
\hline $\mathrm{W}-184$ & $2.65 \mathrm{E}+03$ & $1.00 \mathrm{E}+05$ \\
\hline $\mathrm{W}-186$ & $3.20 \mathrm{E}+03$ & $1.00 \mathrm{E}+05$ \\
\hline $\mathrm{U}-234$ & $1.50 \mathrm{E}+03$ & $1.00 \mathrm{E}+05$ \\
\hline $\mathrm{U}-235$ & $2.25 \mathrm{E}+03$ & $2.50 \mathrm{E}+04$ \\
\hline $\mathrm{U}-236$ & $1.50 \mathrm{E}+03$ & $1.00 \mathrm{E}+05$ \\
\hline $\mathrm{U}-238$ & $1.00 \mathrm{E}+04$ & $1.49 \mathrm{E}+05$ \\
\hline Re-185 & $2.00 \mathrm{E}+03$ & $3.50 \mathrm{E}+04$ \\
\hline Re-187 & $2.00 \mathrm{E}+03$ & $3.50 \mathrm{E}+04$ \\
\hline $\mathrm{Hf}-174$ & $2.30 \mathrm{E}+02$ & $9.00 \mathrm{E}+04$ \\
\hline $\mathrm{Hf}-176$ & $1.08 \mathrm{E}+03$ & $9.00 \mathrm{E}+04$ \\
\hline $\mathrm{Hf}-177$ & $7.00 \mathrm{E}+02$ & $9.00 \mathrm{E}+04$ \\
\hline $\mathrm{Hf}-178$ & $2.10 \mathrm{E}+03$ & $9.00 \mathrm{E}+04$ \\
\hline $\mathrm{Hf}-179$ & $4.50 \mathrm{E}+02$ & $9.00 \mathrm{E}+04$ \\
\hline $\mathrm{Hf}-180$ & $1.00 \mathrm{E}+04$ & $9.00 \mathrm{E}+04$ \\
\hline
\end{tabular}

Table 39. MCNP5 ENDF/B-VI.8 Cross Sections Unresolved Resonance Region Treatment

\begin{tabular}{|c|c|c|}
\hline \multicolumn{3}{|c|}{ ENDF/B-VI.8 MCNP5 XS } \\
\hline Isotope & $\begin{array}{c}\text { URR start } \\
(\mathrm{eV})\end{array}$ & $\begin{array}{c}\text { URR end } \\
(\mathrm{eV})\end{array}$ \\
\hline $\mathrm{W}-182$ & $4.50 \mathrm{E}+03$ & $1.00 \mathrm{E}+05$ \\
\hline $\mathrm{W}-183$ & $7.65 \mathrm{E}+02$ & $4.50 \mathrm{E}+04$ \\
\hline $\mathrm{W}-184$ & $2.65 \mathrm{E}+03$ & $1.00 \mathrm{E}+05$ \\
\hline $\mathrm{W}-186$ & $3.20 \mathrm{E}+03$ & $1.00 \mathrm{E}+05$ \\
\hline $\mathrm{U}-234$ & $1.50 \mathrm{E}+03$ & $1.00 \mathrm{E}+05$ \\
\hline $\mathrm{U}-235$ & $2.25 \mathrm{E}+03$ & $2.50 \mathrm{E}+04$ \\
\hline $\mathrm{U}-236$ & $1.50 \mathrm{E}+03$ & $1.00 \mathrm{E}+05$ \\
\hline $\mathrm{U}-238$ & $1.00 \mathrm{E}+04$ & $1.49 \mathrm{E}+05$ \\
\hline Re-185 & $2.00 \mathrm{E}+03$ & $3.50 \mathrm{E}+04$ \\
\hline Re-187 & $2.00 \mathrm{E}+03$ & $3.50 \mathrm{E}+04$ \\
\hline $\mathrm{Hf}-174$ & $2.30 \mathrm{E}+02$ & $9.00 \mathrm{E}+04$ \\
\hline $\mathrm{Hf}-176$ & $1.08 \mathrm{E}+03$ & $9.00 \mathrm{E}+04$ \\
\hline $\mathrm{Hf}-177$ & $7.00 \mathrm{E}+02$ & $9.00 \mathrm{E}+04$ \\
\hline $\mathrm{Hf}-178$ & $2.10 \mathrm{E}+03$ & $9.00 \mathrm{E}+04$ \\
\hline $\mathrm{Hf}-179$ & $4.50 \mathrm{E}+02$ & $9.00 \mathrm{E}+04$ \\
\hline $\mathrm{Hf}-180$ & $1.00 \mathrm{E}+04$ & $9.00 \mathrm{E}+04$ \\
\hline
\end{tabular}




\subsection{Baseline Critical Experiments}

\subsubsection{Base-1 Experiment}

The Base- 1 experiment is designed to simulate the hardest neutron spectrum, which is in the center of the Prometheus reactor core during normal operating conditions. A cross-sectional view and closeup view of the experimental configuration are provided in Figure 21 and Figure 22 where aluminum is yellow, graphite is blue, HEU is red, and stainless steel is purple (all dimensions in figures are in centimeters). The Base- 1 assembly configuration, including plate layout and dimensions, is shown in Table 40. RCP01, MCNP5, MCNP5 with space cross sections, and RACER all predict an assembly height of 5.946". The assembly rests on a 3.0" thick hollow Al 6061-T6 spindie plate that has a 19" OD and $2.50^{\prime \prime}$ inner diameter. The active core region of the assembly is $3.646^{\prime \prime}$ high and contains 16 stacking units consisting of a single $0.118^{\prime \prime}$ thick HEU plate and a 0.100 " thick graphite plate and 1 stacking unit consisting of a 0.118 " thick HEU plate, for a total of 17 stacking units. The assembly is reflected by a 1.0 " thick graphite bottom reflector and a 1.30" thick graphite top reflector. A hollow Al 6061-T6 alignment tube is assumed to extend from the bottom of the spindle plate to the top of the $6^{\text {th }}$ stacking unit. All other regions are modeled as void, except as noted in Section 4.0 for the RACER models. The Base- 1 assembly has a total mass of $246.2 \mathrm{~kg}$ including $208.0 \mathrm{~kg}$ of HEU and $38.1 \mathrm{~kg}$ of graphite. The distribution of material in the top and bottom half of the assembly is given in Table 41.

A series of analyses have been performed to predict the $k_{\text {eff }}$ of the Base- 1 assembly during the approach to critical as a function of both the number of stacking units and the graphite top reflector thickness. Figure 23 presents the RCP01 and MCNP5 predicted $k_{\text {eff }}$ as a function of the number of stacking units in the Base- 1 assembly. The error bars indicate the size of the $95 \%$ confidence interval in the Monte Carlo calculations. As illustrated in Figure 23, both the MCNP5 and RCP01 predictions are very close. The average difference between the MCNP5 and RCP01 predicted $k_{\text {eff }}$ is $0.0007 \pm$ $0.0004 \Delta k$ over the range from 8 to 28 stacking units. Figure 24 and Table 42 provide a comparison of the predicted $k_{\text {eff }}$ of the Base-1 assembly with 17 and 18 stacking units as a function of the graphite top reflector thickness. The experimental configurations that were predicted to achieve delayed criticality within Technical Safety Requirements (TSR) limits $(\rho<0.5 \$)$ are highlighted in green in Table 42. The Base-1 assembly is classified as a fast spectrum assembly with the following representative fission fractions, as predicted by MCNP5: $87.0 \%$ fast ( $E>100 \mathrm{keV}$ ), $13.0 \%$ intermediate $(0.625 \mathrm{eV}<E<100 \mathrm{keV})$, and $0.0 \%$ thermal $(E<0.625 \mathrm{eV})$. It should be noted for all TA-18 pre-experimental predictions that there are slight differences in fission fractions between the different computer codes, but the differences are minimal and can be neglected for the purposes of classifying the experiment. 
B-TM-1639

용

ㅇํ

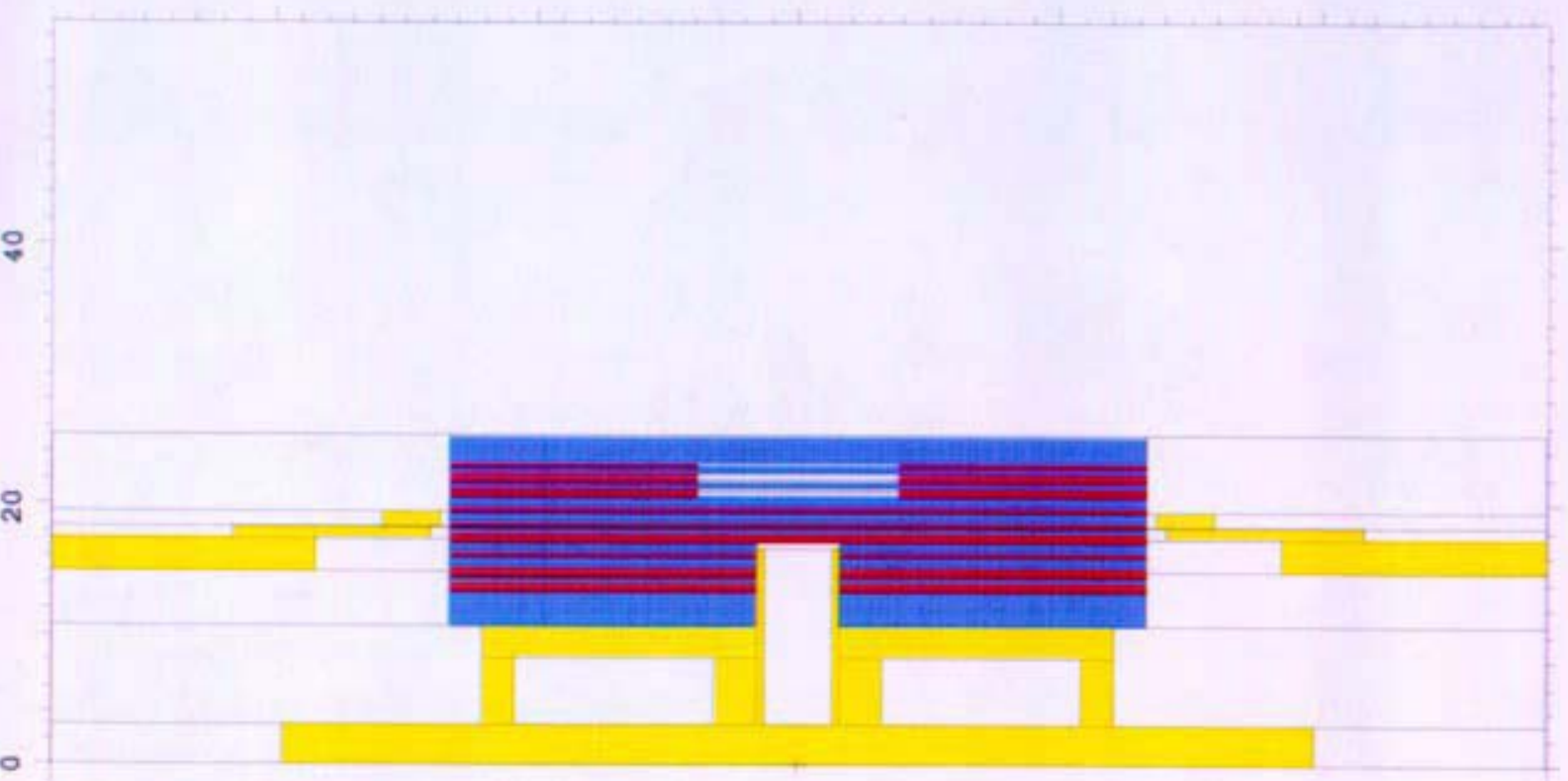

สิ

운

$-40 \quad-20$

20

40

Figure 21. Cross-sectional View of the Base-1 Assembly 
$\hat{i}$

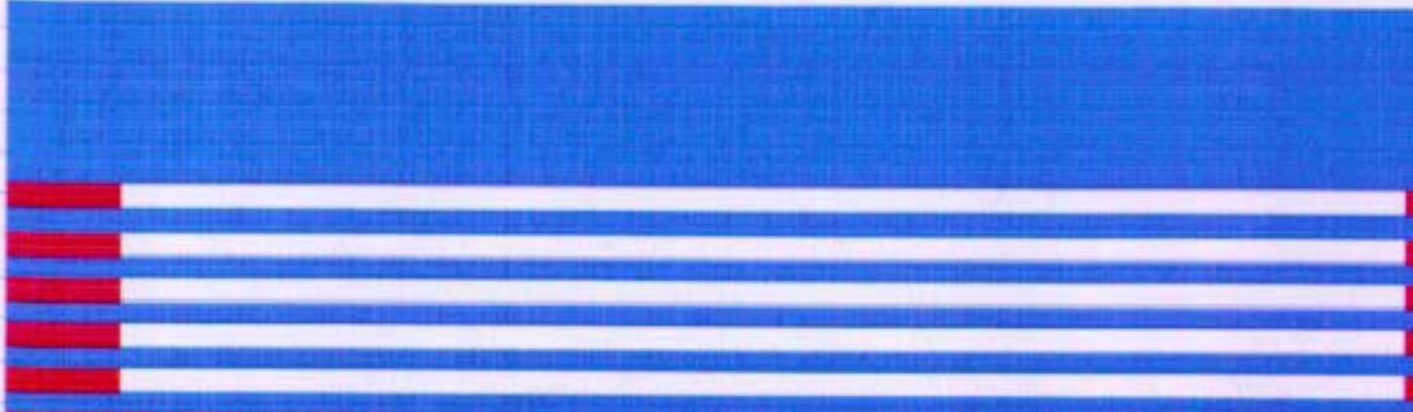

Cin

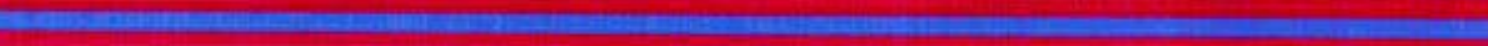

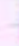
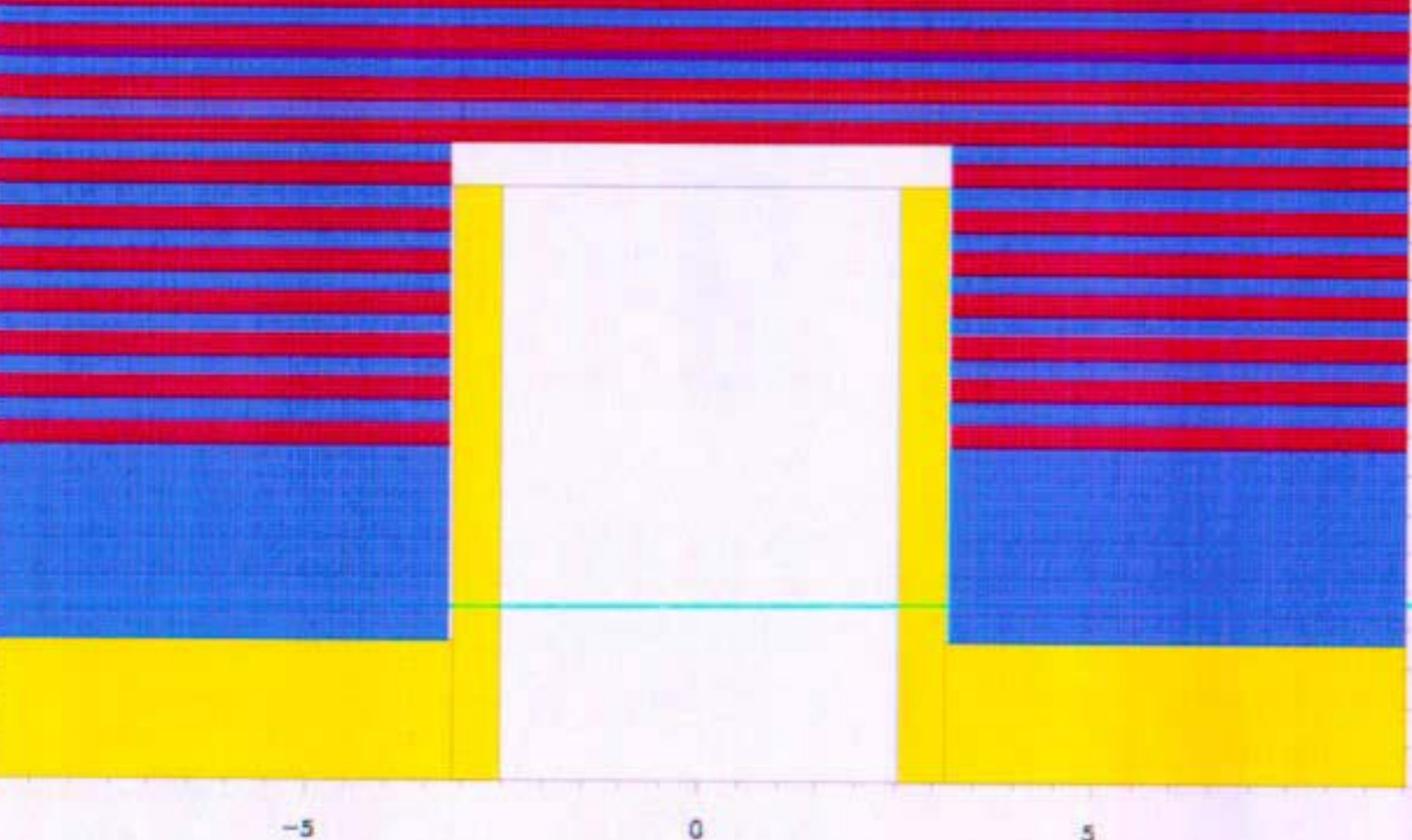

Figure 22. Cross-sectional Close-up View of the Base-1 Assembly 
Table 40. Predicted Critical Configuration for the Base-1 Assembly

\begin{tabular}{|c|c|c|c|c|c|}
\hline Unit & Material & $\begin{array}{l}\text { Thickness } \\
\text { (in) }\end{array}$ & $\begin{array}{c}\text { Inner } \\
\text { Diameter (in) }\end{array}$ & $\begin{array}{c}\text { Outer } \\
\text { Diameter (in) }\end{array}$ & $\begin{array}{l}\text { Assembly } \\
\text { Height (in) }\end{array}$ \\
\hline $\begin{array}{l}\text { Bottom } \\
\text { Reflector }\end{array}$ & Graphlte & 1.00 & 2.51 & 21.0 & 1.000 \\
\hline \multirow{2}{*}{1} & HEU & 0.118 & 2.51 & 21.0 & 1.118 \\
\hline & Graphite & 0.100 & 2.51 & 21.0 & 1.218 \\
\hline \multirow{2}{*}{2} & HEU & 0.118 & 2.51 & 21.0 & 1.336 \\
\hline & Graphite & 0.100 & 2.51 & 21.0 & 1.436 \\
\hline \multirow{2}{*}{3} & HEU & 0.118 & 2.51 & 21.0 & 1.554 \\
\hline & Graphite & 0.100 & 2.51 & 21.0 & 1.654 \\
\hline \multirow{2}{*}{4} & $\mathrm{HEU}$ & 0.118 & 2.51 & 21.0 & 1.772 \\
\hline & Graphite & 0.100 & 2.51 & 21.0 & 1.872 \\
\hline \multirow{2}{*}{5} & HEU & 0.118 & 2.51 & 21.0 & 1.990 \\
\hline & Graphite & 0.100 & 2.51 & 21.0 & 2.090 \\
\hline \multirow{2}{*}{6} & HEU & 0.118 & 2.51 & 21.0 & 2.208 \\
\hline & Graphite & 0.100 & 2.51 & 21.0 & 2.308 \\
\hline \multirow{2}{*}{7} & HEU & 0.118 & 2.51 & 21.0 & 2.426 \\
\hline & Graphite & 0.100 & 2.51 & 21.0 & 2.526 \\
\hline \multirow{2}{*}{8} & HEU & 0.118 & 0 & 21.0 & 2.644 \\
\hline & Graphite & 0.100 & 0 & 21.0 & 2.744 \\
\hline \multirow{2}{*}{9} & HEU & 0.118 & 0 & 21.0 & 2.862 \\
\hline & Graphite & 0.100 & 0 & 21.0 & 2.962 \\
\hline Diaphragm & Stainless Steel & 0.040 & 0 & 24.8 & 3.002 \\
\hline \multirow{2}{*}{10} & HEU & 0.118 & 0 & 21.0 & 3.120 \\
\hline & Graphite & 0.100 & 0 & 21.0 & 3.220 \\
\hline \multirow{2}{*}{11} & HEU & 0.118 & 0 & 21.0 & 3.338 \\
\hline & Graphite & 0.100 & 0 & 21.0 & 3.438 \\
\hline \multirow{2}{*}{12} & $\mathrm{HEU}$ & 0.118 & 0 & 21.0 & 3.556 \\
\hline & Graphite & 0.100 & 0 & 21.0 & 3.656 \\
\hline \multirow{2}{*}{13} & HEU & 0.118 & 0 & 21.0 & 3.774 \\
\hline & Graphite & 0.100 & 0 & 21.0 & 3.874 \\
\hline \multirow{2}{*}{14} & HEU & 0.118 & 6.005 & 21.0 & 3.992 \\
\hline & Graphite & 0.100 & 0 & 21.0 & 4.092 \\
\hline \multirow{2}{*}{15} & HEU & 0.118 & 6.005 & 21.0 & 4.210 \\
\hline & Graphite & 0.100 & 0 & 21.0 & 4.310 \\
\hline \multirow{2}{*}{16} & HEU & 0.118 & 6.005 & 21.0 & 4.428 \\
\hline & Graphite & 0.100 & 0 & 21.0 & 4.528 \\
\hline 17 & HEU & 0.118 & 6.005 & 21.0 & 4.646 \\
\hline $\begin{array}{c}\text { Top } \\
\text { Reflector }\end{array}$ & Graphite & 1.30 & 0 & 21.0 & 5.946 \\
\hline
\end{tabular}

Table 41. Base-1 Assembly Material Mass Distribution

\begin{tabular}{|c|c|c|c|}
\hline \multirow{2}{*}{ Material } & \multicolumn{3}{|c|}{ Mass $(\mathrm{kg})$} \\
\cline { 2 - 4 } & $\begin{array}{c}\text { Lower } \\
\text { Assembly }\end{array}$ & $\begin{array}{c}\text { Upper } \\
\text { Assembly }\end{array}$ & Total \\
\hline HEU & 111.7 & 96.3 & 208.0 \\
\hline Graphite & 18.4 & 19.7 & 38.1 \\
\hline Total & 130.2 & 116.0 & $\mathbf{2 4 6 . 2}$ \\
\hline
\end{tabular}


B-TM-1639

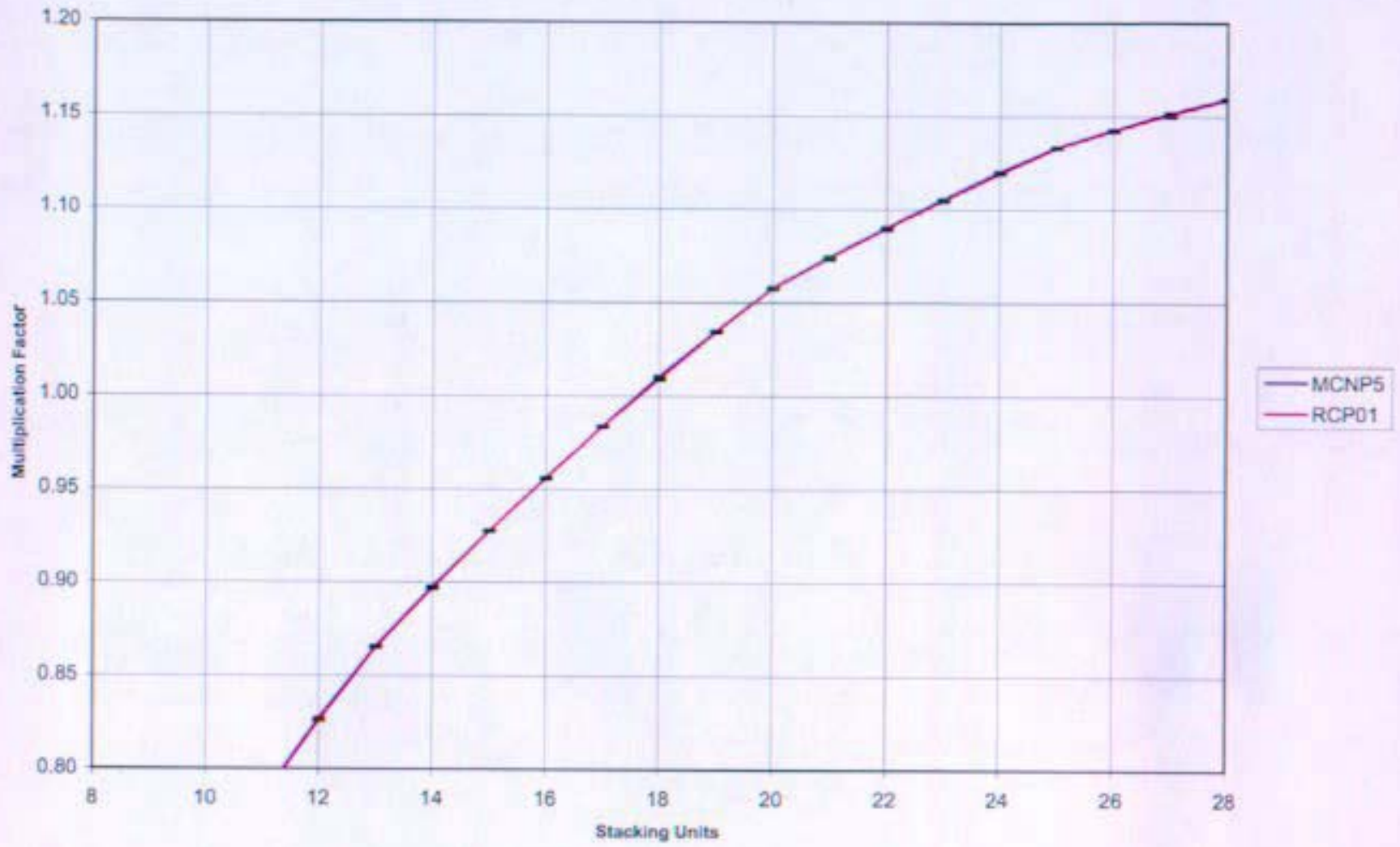

Figure 23. Base-1 Assembly $k_{\text {eff }}$ as a Function of the Number of Stacking Units

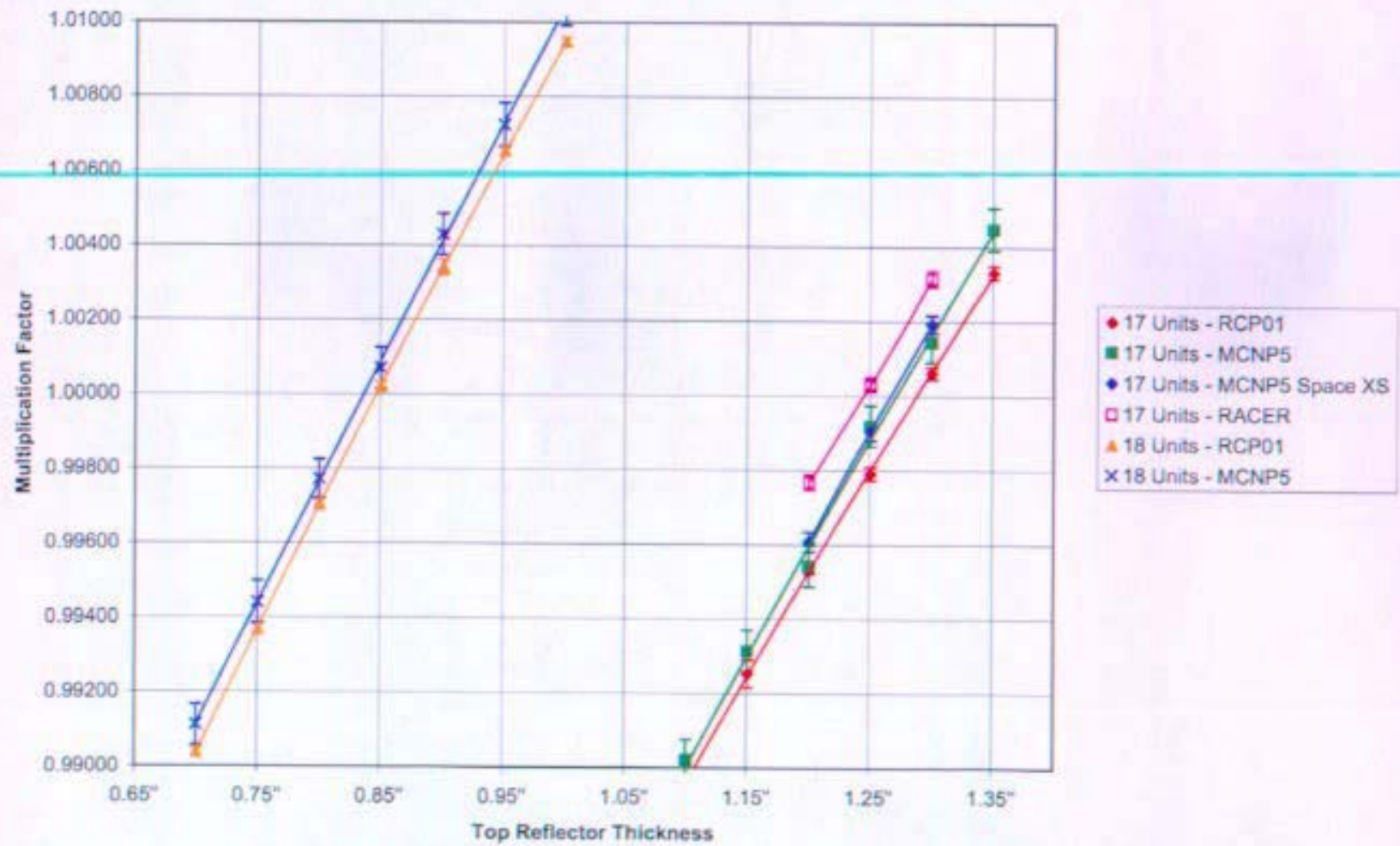

Figure 24. Base-1 Assembly $k_{\text {eff }}$ as a Function of the Top Reflector Thickness 
Table 42. Base-1 Assembly $k_{\text {eff }}$ as a Function of the Top Reflector Thickness

\begin{tabular}{|c|c|c|c|c|c|c|c|c|}
\hline \multicolumn{9}{|c|}{ Predicted Top Reflector Thickness } \\
\hline \multicolumn{9}{|c|}{17 Stacking Units } \\
\hline \multirow{2}{*}{$\begin{array}{c}\text { Top } \\
\text { Reflector } \\
\text { Thickness } \\
\text { (in) } \\
\end{array}$} & \multicolumn{2}{|c|}{ MCNP5 } & \multicolumn{2}{|c|}{ MCNP5 (Space XS) } & \multicolumn{2}{|c|}{ RCP01 } & \multicolumn{2}{|c|}{ RACER } \\
\hline & $k_{\text {off }}$ & $95 \% \mathrm{Cl}$ & $k_{\text {eff }}$ & $95 \% \mathrm{Cl}$ & $k_{\text {eff }}$ & $95 \% \mathrm{Cl}$ & $k_{\text {eff }}$ & $95 \% \mathrm{Cl}$ \\
\hline 1.00 & 0.98370 & 0.00055 & - & - & 0.98355 & 0.00015 & - & - \\
\hline 1.10 & 0.99019 & 0.00055 & - & - & 0.98961 & 0.00013 & - & - \\
\hline 1.15 & 0.99313 & 0.00055 & - & - & 0.99251 & 0.00038 & - & - \\
\hline 1.20 & 0.99540 & 0.00055 & 0.99606 & 0.00026 & 0.99532 & 0.00012 & 0.99767 & 0.00021 \\
\hline 1.25 & 0.99917 & 0.00055 & 0.99904 & 0.00026 & 0.99790 & 0.00018 & 1.00030 & 0.00019 \\
\hline 1.30 & 1.00142 & 0.00053 & 1.00191 & 0.00024 & 1.00061 & 0.60015 & 1.00314 & 0.00021 \\
\hline 1.35 & 1.00446 & 0.00057 & - & - & 1.00331 & 0.00018 & - & - \\
\hline \multicolumn{9}{|c|}{18 Stacking Units } \\
\hline \multirow{2}{*}{$\begin{array}{c}\text { Top } \\
\text { Reflector } \\
\text { Thickness } \\
\text { (in) }\end{array}$} & \multicolumn{2}{|c|}{ MCNP5 } & \multicolumn{2}{|c|}{ MCNP5 (Space XS) } & \multicolumn{2}{|c|}{ RCP01 } & \multicolumn{2}{|c|}{ RACER } \\
\hline & $k_{\text {eff }}$ & $95 \% \mathrm{Cl}$ & $k_{\text {eff }}$ & $95 \% \mathrm{Cl}$ & $k_{\text {eff }}$ & $95 \% \mathrm{Cl}$ & $k_{\text {eff }}$ & $95 \% \mathrm{Cl}$ \\
\hline 0.70 & 0.99110 & 0.00055 & \multirow{7}{*}{\multicolumn{2}{|c|}{$\begin{array}{l}\text { Not investigated due } \\
\text { to termination of } \\
\text { project. }\end{array}$}} & 0.99036 & 0.00013 & \multirow{7}{*}{\multicolumn{2}{|c|}{$\begin{array}{l}\text { Not investigated } \\
\text { due to termination } \\
\text { of project. }\end{array}$}} \\
\hline 0.75 & 0.99440 & 0.00057 & & & 0.99367 & 0.00012 & & \\
\hline 0.80 & 0.99771 & 0.00053 & & & 0.99704 & 0.00016 & & \\
\hline 0.85 & 1.00069 & 0.00055 & & & 1.00019 & 0.00013 & & \\
\hline 0.90 & 1.00428 & 0.00055 & & & 1.00340 & 0.00020 & & \\
\hline 0.95 & 1.00722 & 0.00059 & & & 1.00652 & 0.00014 & & \\
\hline 1.00 & 1.01046 & 0.00057 & & & 1.00947 & 0.00012 & & \\
\hline
\end{tabular}




\subsubsection{Base-2 Experiment}

The Base-2 experiment is designed to bracket the average neutron spectrum of the Prometheus reactor core. It is designed to be harder than the expected average neutron energy spectrum of the core but softer than the Base-1 experiment. Additional graphite has been added to the assembly to simulate the effect of neutron moderation near the reflector. A cross-sectional view and close-up view of the experimental configuration are provided in Figure 25 and Figure 26 where aluminum is yellow, graphite is blue, HEU is red, and stainless steel is purple (all dimensions in figures are in centimeters). The assembly configuration, including plate layout and dimensions, is shown in Table 43. The RCP01 analysis predicts an assembly height of $8.968^{\prime \prime}$ and the MCNP5, MCNP5 with space cross sections, and RACER analyses predict an assembly height of $8.868^{\prime \prime}$. The assembly rests on a $3.0^{\prime \prime}$ thick hollow Al 6061-T6 spindle plate that has a $19^{\prime \prime}$ OD and 2.50" inner diameter. The active core region of the assembly is $4.568^{\prime \prime}$ high and contains 14 stacking units consisting of a $0.118^{\prime \prime}$ thick HEU plate and a $0.197^{\prime \prime}$ thick graphite plate and 1 stacking unit consisting of a single $0.118^{\prime \prime}$ thick HEU plate, for a total of 15 stacking units. The bottom reflector consists of a $2.0^{\prime \prime}$ thick graphite reflector. The RCP01 predicted top reflector consists of a 2.40" thick graphite reflector and the MCNP5, MCNP5 with space cross sections, and RACER predicted top reflector consists of a 2.30" thick graphite reflector. A hollow Al 6061-T6 alignment tube is assumed to extend from the bottom of the spindle plate to the top of the $6^{\text {th }}$ stacking unit. All other regions are modeled as void, except as noted in Section 4.0 for the RACER models. The Base-2 assembly contains $185.0 \mathrm{~kg}$ of HEU. The distribution of materials in the top and bottom half of the assembly is given in Table 44 for the RCP01, MCNP5, MCNP5 with space cross sections, and RACER predicted critical configurations.

A series of analyses have been performed to predict the $k_{\text {eff }}$ of the Base- 2 assembly during the approach to critical as a function of both the number of stacking units and the graphite top reflector thickness. Figure 27 presents the RCP01 and MCNP5 predicted $k_{\text {eff }}$ as a function of the number of stacking units in the Base-2 assembly. The error bars indicate the size of the $95 \%$ confidence interval in the Monte Carlo calculations. As illustrated in Figure 27, both the MCNP5 and RCP01 predictions are close. The average difference between the MCNP5 and RCP01 predicted $k_{\text {eff }}$ is $0.0025 \pm 0.0005$ $\Delta k$ over the range from 8 to 28 stacking units. Figure 28 and Table 45 provide a comparison of the predicted $k_{\text {eft }}$ of the Base- 2 assembly with 15 and 16 stacking units as a function of the graphite top reflector thickness. The experimental configurations that were predicted to achieve delayed criticality within TSR limits $(\rho<0.5 \$)$ are highlighted in green in Table 45 . The Base-2 assembly is classified as a fast spectrum assembly with the following representative fission fractions, as predicted by MCNP5: $79.3 \%$ fast $(E>100 \mathrm{keV}), 20.7 \%$ intermediate $(0.625 \mathrm{eV}<E<100 \mathrm{keV})$, and $0.0 \%$ thermal $(E<$ $0.625 \mathrm{eV})$. 
B-TM-1639

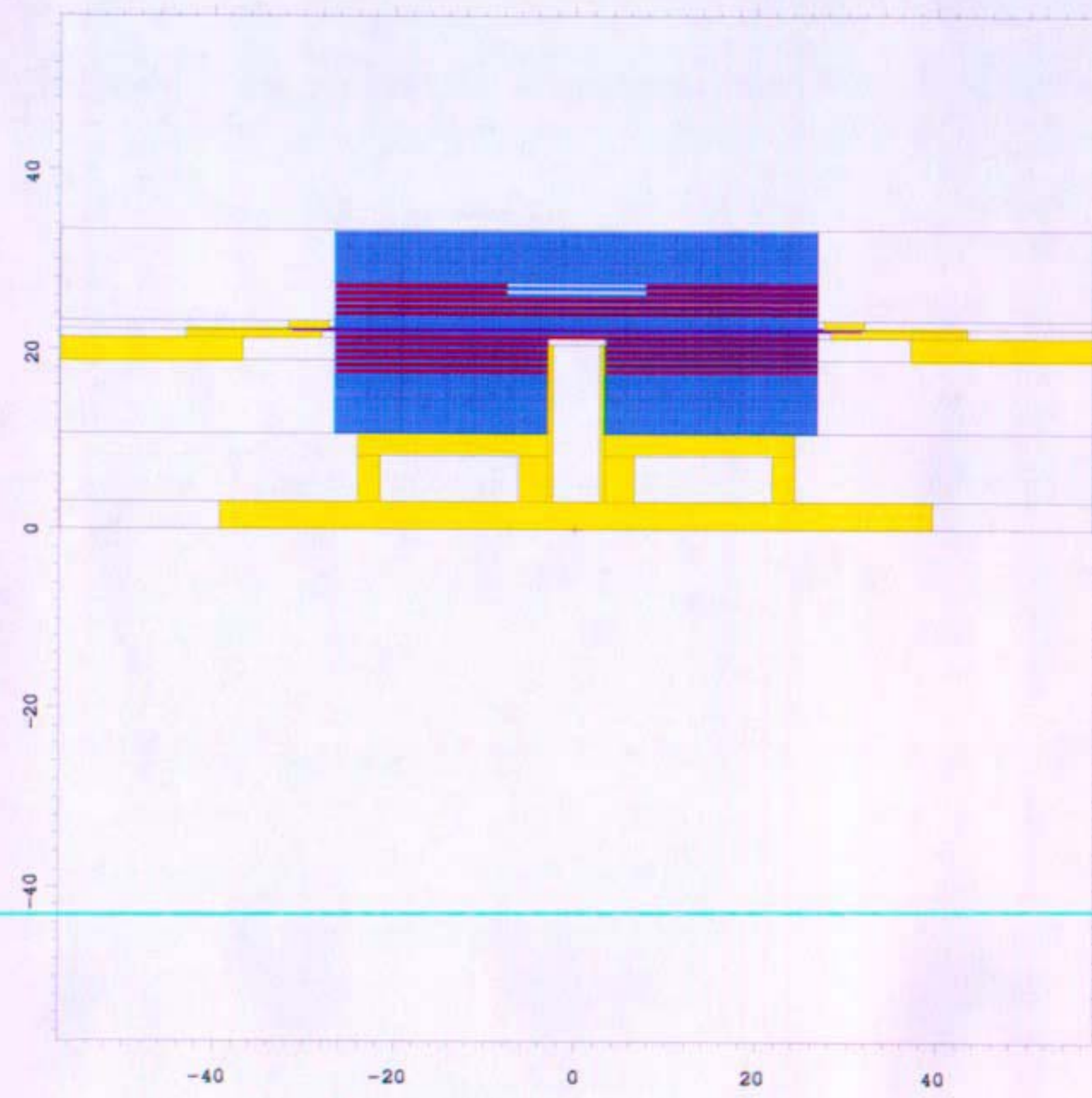

Figure 25. Cross-sectional View of the Base-2 Assembly 
B-TM-1639

$\stackrel{-1}{1}$
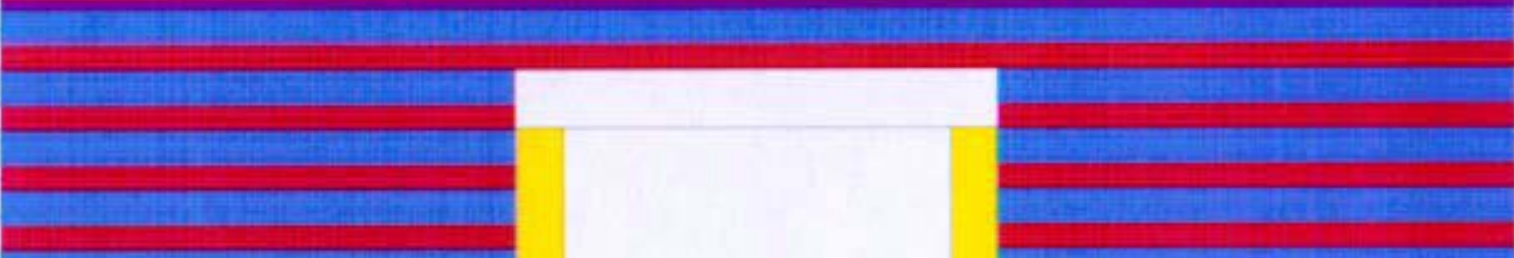

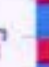
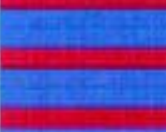

\section{gas}

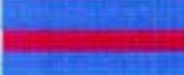

$\circ$

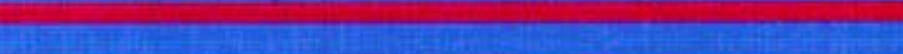


Table 43. Predicted Critical Configuration for the Base-2 Assembly

\begin{tabular}{|c|c|c|c|c|c|}
\hline Unit & Material & Thickness (in) & $\begin{array}{c}\text { Inner } \\
\text { Diameter (in) }\end{array}$ & $\begin{array}{c}\text { Outer } \\
\text { Diameter (in) }\end{array}$ & $\begin{array}{l}\text { Assembly } \\
\text { Height (in) }\end{array}$ \\
\hline $\begin{array}{l}\text { Bottom } \\
\text { Reflector }\end{array}$ & Graphite & 2.00 & 2.51 & $21: 0$ & 2.000 \\
\hline \multirow{2}{*}{1} & HEU & 0.118 & 2.51 & 21.0 & 2.118 \\
\hline & Graphite & 0.197 & 2.51 & 21.0 & 2.315 \\
\hline \multirow{2}{*}{2} & HEU & 0.118 & 2.51 & 21.0 & 2.433 \\
\hline & Graphite & 0.197 & 2.51 & 21.0 & 2.630 \\
\hline \multirow{2}{*}{3} & HEU & 0.118 & 2.51 & 21.0 & 2.748 \\
\hline & Graphite & 0.197 & 2.51 & 21.0 & 2.945 \\
\hline \multirow{2}{*}{4} & HEU & 0.118 & 2.51 & 21.0 & 3.063 \\
\hline & Graphite & 0.197 & 2.51 & 21.0 & 3.260 \\
\hline \multirow{2}{*}{5} & HEU & 0.118 & 2.51 & 21.0 & 3.378 \\
\hline & Graphite & 0.197 & 2.51 & 21.0 & 3.575 \\
\hline \multirow{2}{*}{6} & HEU & 0.118 & 2.51 & 21.0 & 3.693 \\
\hline & Graphite & 0.197 & 2.51 & 21.0 & 3.890 \\
\hline \multirow{2}{*}{7} & HEU & 0.118 & 2.51 & 21.0 & 4.008 \\
\hline & Graphite & 0.197 & 2.51 & 21.0 & 4.205 \\
\hline \multirow{2}{*}{8} & HEU & 0.118 & 0 & 21.0 & 4.323 \\
\hline & Graphite & 0.197 & 0 & 21.0 & 4.520 \\
\hline Diaphragm & Stainless Steel & 0.040 & 0 & 24.8 & 4.560 \\
\hline \multirow{2}{*}{9} & HEU & 0.118 & 0 & 21.0 & 4.678 \\
\hline & Graphite & 0.197 & 0 & 21.0 & 4.875 \\
\hline \multirow{2}{*}{10} & HEU & 0.118 & 0 & 21.0 & 4.993 \\
\hline & Graphite & 0.197 & 0 & 21.0 & 5.190 \\
\hline \multirow{2}{*}{11} & $\mathrm{HEU}$ & 0.118 & 0 & 21.0 & 5.308 \\
\hline & Graphite & 0.197 & 0 & 21.0 & 5.505 \\
\hline \multirow{2}{*}{12} & HEU & 0.118 & 0 & 21.0 & 5.623 \\
\hline & Graphite & 0.197 & 0 & 21.0 & 5.820 \\
\hline \multirow{2}{*}{13} & HEU & 0.118 & 0 & 21.0 & 5.938 \\
\hline & Graphite & 0.197 & 0 & 21.0 & 6.135 \\
\hline \multirow{2}{*}{14} & HEU & 0.118 & 6.005 & 21.0 & 6.253 \\
\hline & Graphite & 0.197 & 0 & 21.0 & 6.450 \\
\hline 15 & $\mathrm{HEU}$ & 0.118 & 6.005 & 21.0 & 6.568 \\
\hline $\begin{array}{c}\text { Top } \\
\text { Reflector }\end{array}$ & Graphite & $\begin{array}{l}2.40 \text { (RCP01) } \\
2.30 \text { (MCNP5 } \\
\text { MCNP5 Space } \\
\text { XS.RACER) }\end{array}$ & 0 & 21.0 & $\begin{array}{l}8.968 \text { (RCP01) } \\
8.868 \text { (MCNP5, } \\
\text { MCNP5 Space } \\
\text { XS RACER) }\end{array}$ \\
\hline
\end{tabular}

Table 44. Base-2 Assembly Material Mass Distribution

\begin{tabular}{|c|c|c|c|c|c|c|}
\hline \multirow{3}{*}{ Material } & \multicolumn{5}{|c|}{ Mass (kg) } \\
\cline { 2 - 7 } & \multicolumn{2}{|c|}{ MCNP5/MCNP5 (Space XS)/RACER } & \multicolumn{1}{c|}{ RCP01 } \\
\cline { 2 - 7 } & $\begin{array}{c}\text { Lower } \\
\text { Assembly }\end{array}$ & $\begin{array}{c}\text { Upper } \\
\text { Assembly }\end{array}$ & Total & $\begin{array}{c}\text { Lower } \\
\text { Assembly }\end{array}$ & $\begin{array}{c}\text { Upper } \\
\text { Assembly }\end{array}$ & Total \\
\hline HEU & 99.2 & 85.8 & 185.0 & 99.2 & 85.8 & 185.0 \\
\hline Graphite & 34.7 & 34.2 & 68.9 & 34.7 & 35.2 & 69.9 \\
\hline Total & 133.9 & 120.1 & 253.9 & 133.9 & 121.0 & 254.9 \\
\hline
\end{tabular}




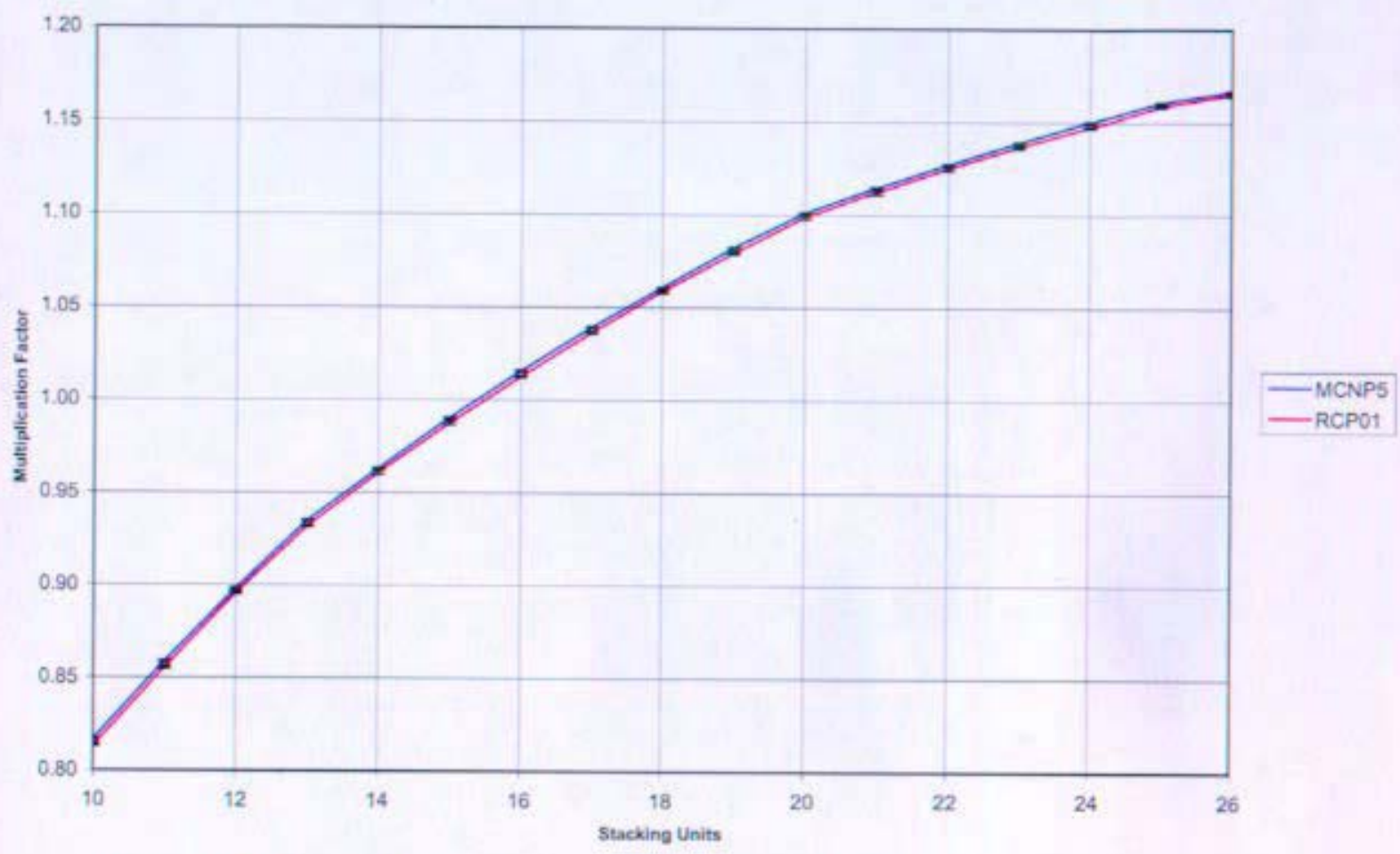

Figure 27. Base-2 Assembly $k_{\text {eff }}$ as a Function of the Number of Stacking Units

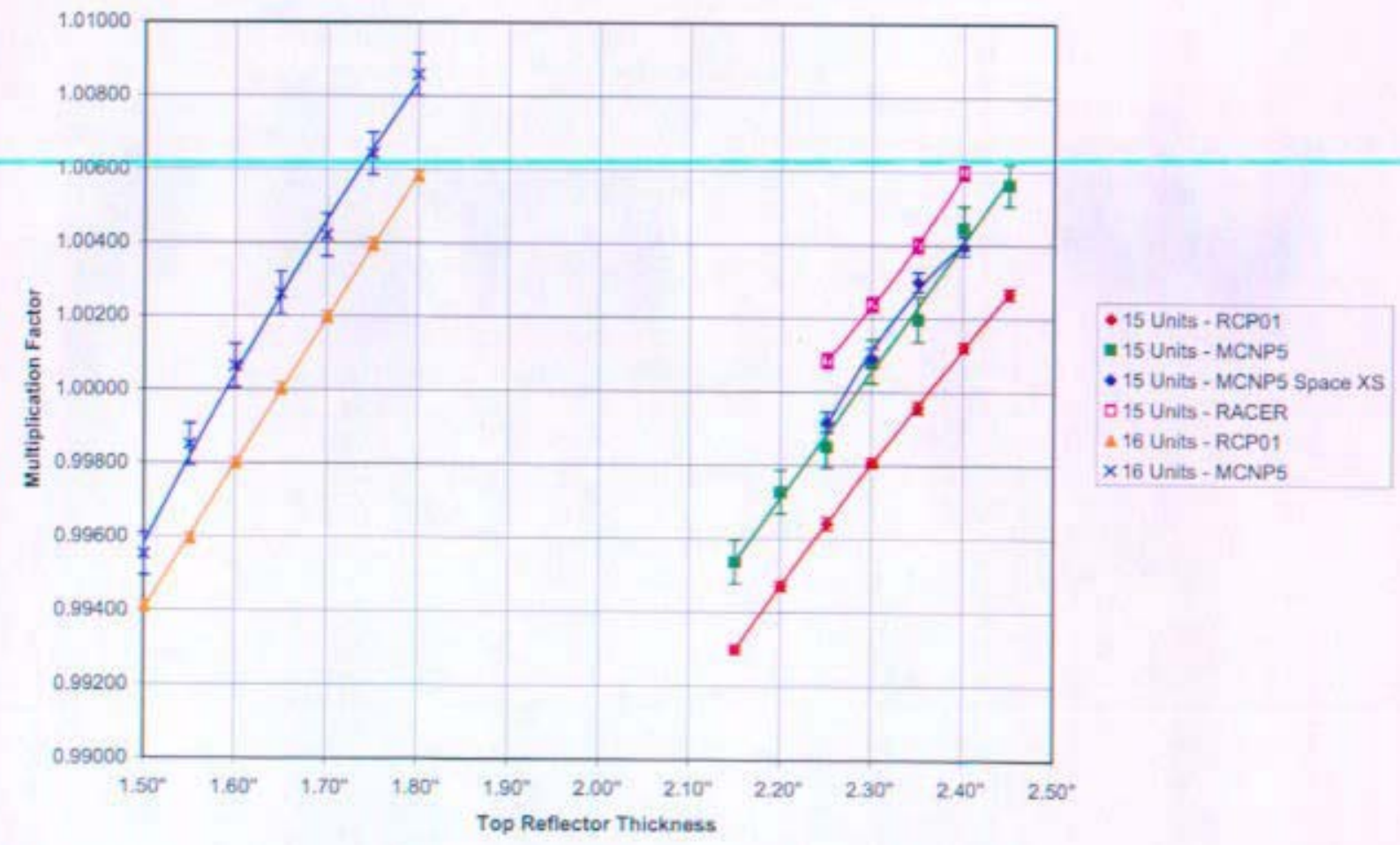

Figure 28. Base-2 Assembly $k_{\text {eff }}$ as a Function of the Top Reflector Thickness 
Table 45. Base-2 Assembly $k_{\text {eff }}$ as a Function of the Top Reflector Thickness

\begin{tabular}{|c|c|c|c|c|c|c|c|c|}
\hline \multicolumn{9}{|c|}{ Predicted Top Reflector Thickness } \\
\hline \multicolumn{9}{|c|}{15 Stacking Units } \\
\hline \multirow{2}{*}{$\begin{array}{c}\text { Top } \\
\text { Reflector } \\
\text { Thickness } \\
\text { (in) }\end{array}$} & \multicolumn{2}{|c|}{ MCNP5 } & \multicolumn{2}{|c|}{ MCNP5 (Space XS) } & \multicolumn{2}{|c|}{ RCP01 } & \multicolumn{2}{|c|}{ RACER } \\
\hline & $k_{\text {eff }}$ & $95 \% \mathrm{Cl}$ & $k_{\text {etf }}$ & $95 \% \mathrm{Cl}$ & $\mathbf{k}_{\text {eff }}$ & $95 \% \mathrm{Cl}$ & $k_{\text {eff }}$ & $95 \% \mathrm{Cl}$ \\
\hline 2.15 & 0.99536 & 0.00059 & - & - & 0.99299 & 0.00012 & - & - \\
\hline 2.20 & 0.99726 & 0.00059 & - & - & 0.99472 & 0.00013 & - & - \\
\hline 2.25 & 0.99849 & 0.00057 & 0.99916 & 0.00028 & 0.99641 & 0.00018 & 1.00084 & 0.00020 \\
\hline 2.30 & 1.00082 & 0.00059 & 1.00091 & 0.00026 & 0.99807 & 0.00012 & 1.00238 & 0.00020 \\
\hline 2.35 & 1.00197 & 0.00061 & 1.00299 & 0.00026 & 0.99957 & 0.00015 & 1.00399 & 0.00021 \\
\hline 2.40 & 1.00445 & 0.00059 & 1.00396 & 0.00026 & 1.00121 & 0.00013 & 1.00597 & 0.00019 \\
\hline 2.45 & 1.00562 & 0.00057 & - & - & 1.00266 & 0.00015 & - & - \\
\hline \multicolumn{9}{|c|}{16 Stacking Units } \\
\hline $\begin{array}{c}\text { Top } \\
\text { Reflector }\end{array}$ & \multicolumn{2}{|c|}{ MCNP5 } & \multicolumn{2}{|c|}{ MCNP5 (Space XS) } & \multicolumn{2}{|c|}{ RCP01 } & \multicolumn{2}{|c|}{ RACER } \\
\hline $\begin{array}{l}\text { Thickness } \\
\text { (in) }\end{array}$ & $k_{\text {eff }}$ & $95 \% \mathrm{Cl}$ & $k_{\text {eff }}$ & $95 \% \mathrm{Cl}$ & $k_{\text {eff }}$ & $95 \% \mathrm{Cl}$ & $k_{\text {eff }}$ & $95 \% \mathrm{Cl}$ \\
\hline 1.50 & 0.99551 & 0.00057 & \multirow{7}{*}{\multicolumn{2}{|c|}{$\begin{array}{l}\text { Not investigated due } \\
\text { to termination of } \\
\text { project. }\end{array}$}} & 0.99411 & 0.00015 & \multirow{7}{*}{\multicolumn{2}{|c|}{$\begin{array}{l}\text { Not investigated } \\
\text { due to termination } \\
\text { of project. }\end{array}$}} \\
\hline 1.55 & 0.99850 & 0.00057 & & & 0.99595 & 0.00013 & & \\
\hline 1.60 & 1.00064 & 0.00059 & & & 0.99799 & 0.00014 & & \\
\hline 1.65 & 1.00261 & 0.00059 & & & 1.00002 & 0.00017 & & \\
\hline 1.70 & 1.00420 & 0.00059 & & & 1.00197 & 0.00015 & & \\
\hline 1.75 & 1.00642 & 0.00057 & & & 1.00395 & 0.00017 & & \\
\hline 1.80 & 1.00857 & 0.00057 & & & 1.00582 & 0.00014 & & \\
\hline
\end{tabular}




\subsubsection{Base-3 Experiment}

The Base- 3 experiment is designed to bracket the average neutron spectrum of the Prometheus reactor core. It is designed to be softer than the expected average neutron energy spectrum of the core. Additional graphite has been added to the assembly to simulate the effect of neutron moderation near the reflector. A cross-sectional view and close-up view of the experimental configuration are provided in Figure 29 and Figure 30 where aluminum is yellow, graphite is blue, HEU is red, and stainless steel is purple (all dimensions in figures are in centimeters). The assembly configuration, including plate layout and dimensions, is shown in Table 46. The RCP01 analysis predicts an assembly height of $16.702^{\prime \prime}$ and the MCNP5, MCNP5 with space cross sections, and RACER analyses predict an assembly height of $16.152^{\prime \prime}$. The assembly rests on a 3.0" thick hollow Al 6061-T6 spindle plate that has a $19^{\prime \prime} \mathrm{OD}$ and $2.50^{\prime \prime}$ inner diameter. The active core region of the assembly is $6.302^{\prime \prime}$ high and contains 12 stacking units consisting of a $0.118^{\prime \prime}$ thick HEU plate and a $0.394^{\prime \prime}$ thick graphite plate and 1 stacking unit consisting of a single $0.118^{\prime \prime}$ thick HEU plate, for a total of 13 stacking units. The bottom reflector consists of a $5.0^{\mathrm{n}}$ thick graphite reflector. The RCP01 predicted top reflector consists of a 5.40" thick graphite reflector and the MCNP5, MCNP5 with space cross sections, and RACER predicted top reflector consists of a $4.85^{\prime \prime}$ thick graphite reflector. A hollow Al $6061-T 6$ alignment tube is assumed to extend from the bottom of the spindle plate to the top of the $6^{\text {th }}$ stacking unit. All other regions are modeled as void, except as noted in Section 4.0 for the RACER models. The Base- 3 assembly contains $161.9 \mathrm{~kg}$ of HEU. The distribution of materials in the top and bottom half of the assembly is given in Table 47 for the RCP01, MCNP5, MCNP5 with space cross sections, and RACER predicted critical configurations.

A series of analyses have been performed to predict the $k_{\text {eff }}$ of the Base- 3 assembly during the approach to critical as a function of both the number of stacking units and the graphite top reflector thickness. Figure 31 presents the RCP01 and MCNP5 predicted $k_{\text {eff }}$ as a function of the number of stacking units in the Base- 3 assembly. The error bars indicate the size of the $95 \%$ confidence interval in the Monte Carlo calculations. The average difference between the MCNP5 and RCP01 predicted $k_{\text {eff }}$ is $0.0049 \pm 0.0004 \Delta k$ over the range from 8 to 28 stacking units. Figure 32 and Table 48 provide a comparison of the predicted $k_{\mathrm{eff}}$ of the Base- 3 assembly with 13 stacking units as a function of the graphite top reflector thickness. The experimental configurations that were predicted to achieve delayed criticality within TSR limits $(\rho<0.5 \$)$ are highlighted in green in Table 48 . The Base-3 assembly is classified as a fast spectrum assembly with the following representative fission fractions, as predicted by MCNP5: $66.4 \%$ fast ( $E>100 \mathrm{keV}), 33.6 \%$ intermediate $(0.625 \mathrm{eV}<\mathrm{E}<100 \mathrm{keV})$, and $0.1 \%$ thermal $(E<0.625 \mathrm{eV})$. 


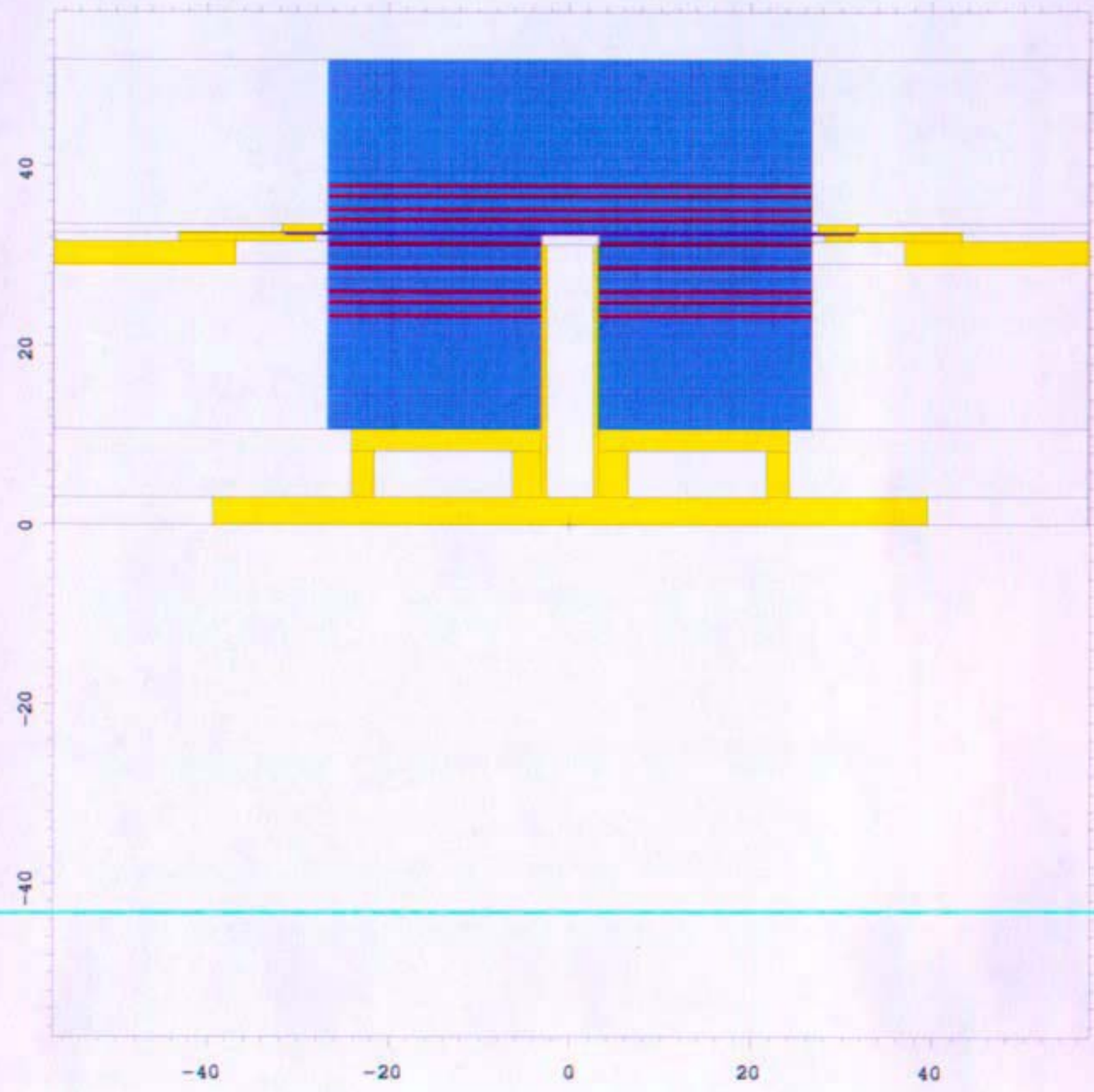

Figure 29. Cross-sectional View of the Base-3 Assembly 
$\stackrel{-1}{2}$

$\circ$

$\hat{\imath}$

구

$-10$

$-5$

0

Figure 30. Cross-sectional Close-up View of the Base-3 Assembly 
Table 46. Predicted Critical Configuration for the Base-3 Assembly.

\begin{tabular}{|c|c|c|c|c|c|}
\hline Unit & Material & Thickness (in) & $\begin{array}{c}\text { Inner } \\
\text { Diameter } \\
\text { (in) }\end{array}$ & $\begin{array}{l}\text { Outer } \\
\text { Diameter } \\
\text { (in) }\end{array}$ & $\begin{array}{l}\text { Assembly Height } \\
\text { (in) }\end{array}$ \\
\hline $\begin{array}{l}\text { Bottom } \\
\text { Reflector }\end{array}$ & Graptite & 5.00 & 2.51 & 21,0 & 5,000 \\
\hline \multirow{2}{*}{1} & HEU & 0.118 & 2.51 & 21.0 & 5.118 \\
\hline & Graphite & 0.394 & 2.51 & 21.0 & 5.512 \\
\hline \multirow{2}{*}{2} & HEU & 0.118 & 2.51 & 21.0 & 5.630 \\
\hline & Graphite & 0.394 & 2.51 & 21.0 & 6.024 \\
\hline \multirow{2}{*}{3} & HEU & 0.118 & 2.51 & 21.0 & 6.142 \\
\hline & Graphite & 0.394 & 2.51 & 21.0 & 6.536 \\
\hline \multirow{2}{*}{4} & HEU & 0.118 & 2.51 & 21.0 & 6.654 \\
\hline & Graphite & 0.394 & 2.51 & 21.0 & 7.048 \\
\hline \multirow{2}{*}{5} & $\mathrm{HEU}$ & 0.118 & 2.51 & 21.0 & 7.166 \\
\hline & Graphite & 0.394 & 2.51 & 21.0 & 7.560 \\
\hline \multirow{2}{*}{6} & HEU & 0.118 & 2.51 & 21.0 & 7.678 \\
\hline & Graphite & 0.394 & 2.51 & 21.0 & 8.072 \\
\hline \multirow{2}{*}{7} & HEU & 0.118 & 2.51 & 21.0 & 8.190 \\
\hline & Graphite & 0.394 & 2.51 & 21.0 & 8.584 \\
\hline Diaphragm & Stainless Steel & 0.040 & 0. & 24.8 & 8.624 \\
\hline \multirow{2}{*}{8} & HEU & 0.118 & 0 & 21.0 & 8.742 \\
\hline & Graphite & 0.394 & 0 & 21.0 & 9.136 \\
\hline \multirow{2}{*}{9} & HEU & 0.118 & 0 & 21.0 & 9.254 \\
\hline & Graphite & 0.394 & 0 & 21.0 & 9.648 \\
\hline \multirow{2}{*}{10} & HEU & 0.118 & 0 & 21.0 & 9.766 \\
\hline & Graphite & 0.394 & 0 & 21.0 & 10.160 \\
\hline \multirow{2}{*}{11} & HEU & 0.118 & 0 & 21.0 & 10.278 \\
\hline & Graphite & 0.394 & 0 & 21.0 & 10.672 \\
\hline \multirow{2}{*}{12} & HEU & 0.118 & 0 & 21.0 & 10.790 \\
\hline & Graphite & 0.394 & 0 & 21.0 & 11.184 \\
\hline 13 & $\mathrm{HEU}$ & 0.118 & 0 & 21.0 & 11.302 \\
\hline $\begin{array}{l}\text { Top } \\
\text { Reflector }\end{array}$ & Graphite & $\begin{array}{l}5.40 \text { (RCP01) } \\
4.85 \text { (MCNP5, } \\
\text { MCNP5 Space } \\
\text { XS. RACER) }\end{array}$ & 0 & 21.0 & $\begin{array}{l}16.702 \text { (RCP01) } \\
\text { 16.152 (MCNP5, } \\
\text { MCNP5 Space } \\
\text { XS, RACER) }\end{array}$ \\
\hline
\end{tabular}

Table 47. Base-3 Assembly Material Mass Distribution

\begin{tabular}{|c|c|c|c|c|c|c|}
\hline \multirow{3}{*}{ Material } & \multicolumn{6}{|c|}{ Mass (kg) } \\
\hline & \multicolumn{3}{|c|}{ MCNP5/MCNP5 (Space XS)/RACER } & \multicolumn{3}{|c|}{ RCP01 } \\
\hline & $\begin{array}{l}\text { Lower } \\
\text { Assembly }\end{array}$ & $\begin{array}{c}\text { Upper } \\
\text { Assembly }\end{array}$ & Total & $\begin{array}{l}\text { Lower } \\
\text { Assembly }\end{array}$ & $\begin{array}{c}\text { Upper } \\
\text { Assembly }\end{array}$ & Total \\
\hline HEU & 86.6 & 75.3 & 161.9 & 86.6 & 75.3 & 161.9 \\
\hline Graphite & 75.2 & 67.0 & 142.2 & 75.2 & 72.5 & 147.6 \\
\hline Total & 161.8 & 142.4 & 304.2 & 161.8 & 147.8 & 309.6 \\
\hline
\end{tabular}


B-TM-1639

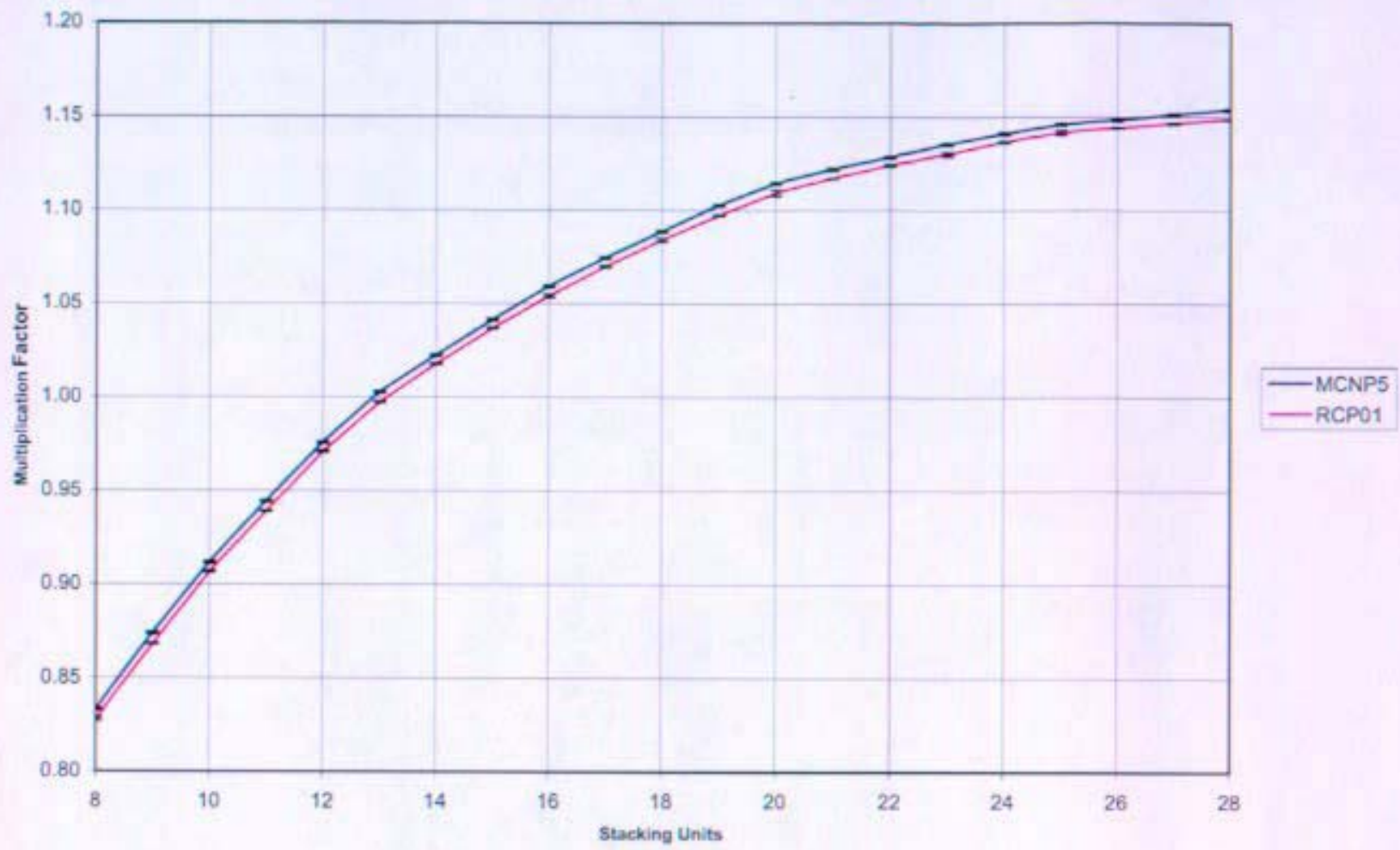

Figure 31. Base-3 Assembly $k_{\text {eff }}$ as a Function of the Number of Stacking Units

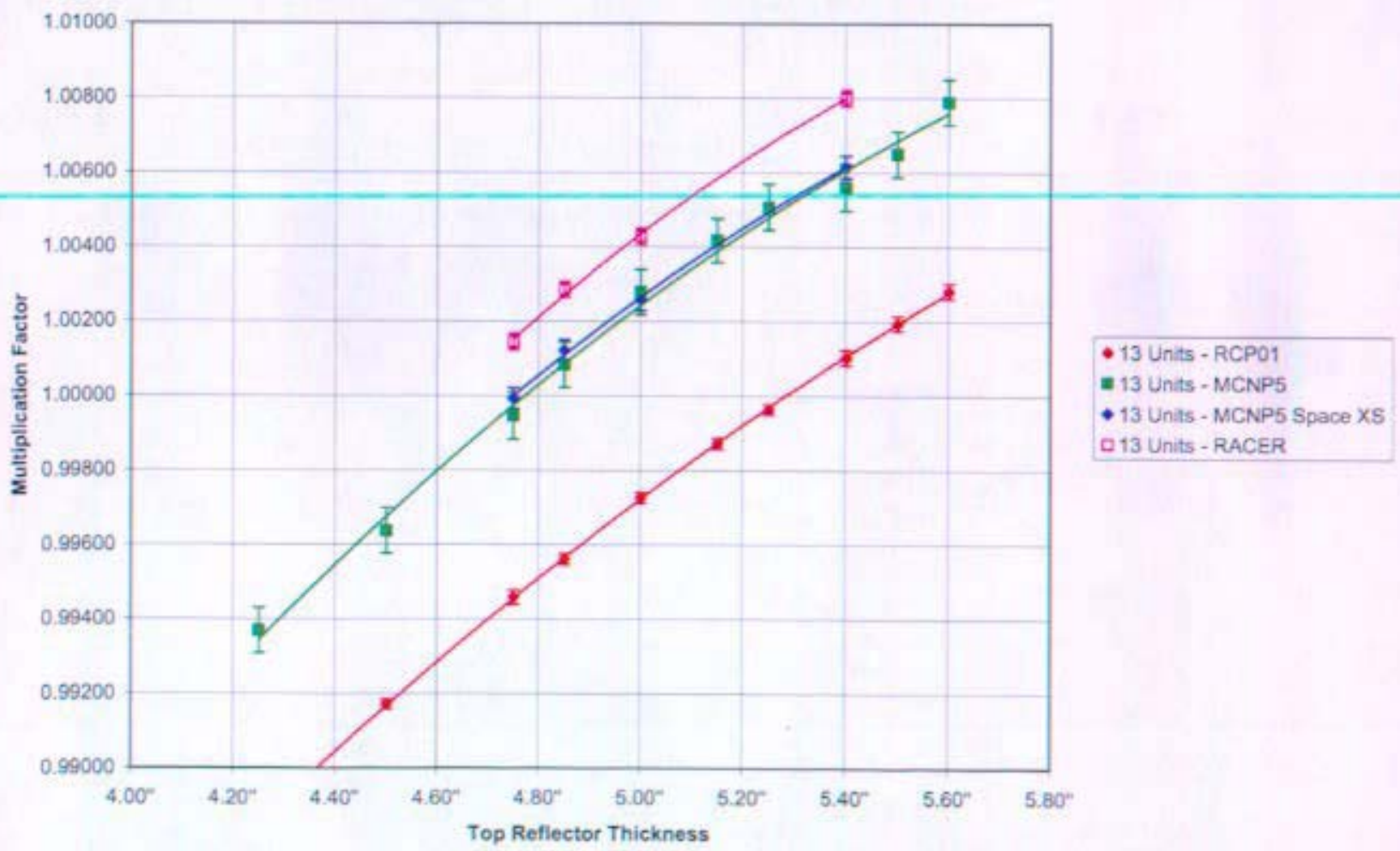

Figure 32. Base-3 Assembly $k_{\text {eff }}$ as a Function of the Top Reflector Thickness 
Table 48. Base-3 Assembly $k_{\text {eff }}$ as a Function of the Top Reflector Thickness

\begin{tabular}{|c|c|c|c|c|c|c|c|c|}
\hline \multicolumn{9}{|c|}{ Predicted Top Reflector Thickness } \\
\hline \multicolumn{9}{|c|}{13 Stacking Units } \\
\hline $\begin{array}{c}\text { Top } \\
\text { Reflector }\end{array}$ & \multicolumn{2}{|c|}{ MCNP5 } & \multicolumn{2}{|c|}{ MCNP5 (Space XS) } & \multicolumn{2}{|c|}{ RCP01 } & \multicolumn{2}{|c|}{ RACER } \\
\hline (in) & $k_{\text {eff }}$ & $95 \% \mathrm{Cl}$ & $k_{\text {eff }}$ & $95 \% \mathrm{Cl}$ & $k_{\text {elf }}$ & $95 \% \mathrm{Cl}$ & $k_{\text {eft }}$ & $95 \% \mathrm{Cl}$ \\
\hline 4.25 & 0.99368 & 0.00061 & - & - & 0.98852 & 0.00013 & - & - \\
\hline 4.50 & 0.99636 & 0.00061 & - & - & 0.99170 & 0.00013 & - & - \\
\hline 4.75 & 0.99944 & 0.00063 & 0.99991 & 0.00028 & 0.99458 & 0.00020 & 1.00144 & 0.00022 \\
\hline 4.85 & 1.00081 & 0.00061 & 1.00120 & 0.00028 & 0.99561 & 0.00014 & 1.00284 & 0,0002 \\
\hline 5.00 & 1.00276 & 0.00061 & 1.00255 & 0.00028 & 0.99724 & 0.00015 & 1.00427 & 0.00022 \\
\hline 5.15 & 1.00415 & 0.00059 & - & - & 0.99871 & 0.00015 & - & - \\
\hline 5.25 & 1.00505 & 0.00061 & - & - & 0.99963 & 0.00013 & - & - \\
\hline 5.40 & 1.00558 & 0.00063 & 1.00613 & 0.0003 & 1.00101 & 0.00020 & 1.00799 & 0.00022 \\
\hline 5.50 & 1.00647 & 0.00061 & - & - & 1.00194 & 0.00020 & - & - \\
\hline 5.60 & 1.00787 & 0.00061 & - & - & 1.00280 & 0.00020 & - & - \\
\hline
\end{tabular}




\subsubsection{Base-4 Experiment}

The Base- 4 experiment is designed to simulate the average neutron spectrum of the Prometheus reactor core when flooded with water. Polyethylene is used to simulate flooding with water. A crosssectional view and close-up view of the experimental configuration are provided in Figure 33 and Figure 34 where aluminum is yellow, polyethylene is blue, HEU is red, and stainless steel is purple (all dimensions in figures are in centimeters). The assembly configuration, including plate layout and dimensions, is shown in Table 49. The RCP01 analysis predicts an assembly height of $4.078^{\circ}$ and the MCNP5, MCNP5 with space cross sections, and RACER analyses predict an assembly height of $4.058^{\prime \prime}$. The assembly rests on a 3.0" thick hollow Al 6061-T6 spindle plate that has a $19^{\prime \prime}$ OD and $2.50^{\prime \prime}$ inner diameter. The active core region of the assembly is $2.138^{\prime \prime}$ high and contains 10 stacking units consisting of a $0.118^{\prime \prime}$ thick HEU plate and a $0.080^{\prime \prime}$ thick polyethylene plate and 1 stacking unit consisting of a single $0.118^{\prime \prime}$ thick HEU plate, for a total of 11 stacking units. The bottom reflector consists of a 1.0" thick polyethylene reflector. The RCP01 predicted top reflector consists of a $0.94^{\prime \prime}$ thick polyethylene reflector and the MCNP5, MCNP5 with space cross sections, and RACER predicted top reflector consists of a 0.92 " thick polyethylene reflector. A hollow Al 6061-T6 alignment tube is assumed to extend from the bottom of the spindle plate to the top of the $5^{\text {th }}$ stacking unit. All other regions are modeled as void, except as noted in Section 4.0 for the RACER models. The Base4 assembly contains $137.0 \mathrm{~kg}$ of HEU. The distribution of materials in the top and bottom half of the assembly is given in Table 50 for the RCP01, MCNP5, MCNP5 with space cross sections, and RACER predicted critical configurations.

A series of analyses have been performed to predict the $k_{\text {eff }}$ of the Base- 4 assembly during the approach to critical as a function of both the number of stacking units and the polyethylene top reflector thickness. Figure 35 presents the RCP01 and MCNP5 predicted $k_{\text {eff }}$ as a function of the number of stacking units in the Base-4 assembly. The error bars indicate the size of the $95 \%$ confidence interval in the Monte Carlo calculations. As illustrated in Figure 35, both the MCNP5 and RCP01 predictions are close. The average difference between the MCNP5 and RCP01 predicted $k_{\text {eff }}$ is $0.0027 \pm 0.0005 \Delta k$ over the range from 8 to 28 stacking units. Figure 36 and Table 51 provide a comparison of the predicted $\mathrm{K}_{\mathrm{eff}}$ of the Base-4 assembly with 11 stacking units as a function of the polyethylene top reflector thickness. The experimental configurations that were predicted to achieve delayed criticality within TSR $(\rho>0.5 S)$ limits are highlighted in green in Table 51 . The Base-4 assembly is classified as a mixed spectrum assembly with the following representative fission fractions, as predicted by MCNP5: $44.1 \%$ fast ( $E>100 \mathrm{keV}), 45.2 \%$ intermediate $(0.625 \mathrm{eV}<\mathrm{E}<100$ $\mathrm{keV})$, and $10.7 \%$ thermal $(\mathrm{E}<0.625 \mathrm{eV})$. 
B-TM-1639

ำ

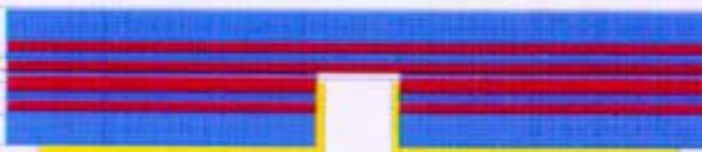

ণั่

$\stackrel{ }{7}$

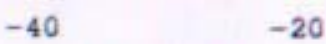

0

20

40

Figure 33. Cross-sectional View of the Base-4 Assembly 
$\varphi$

N

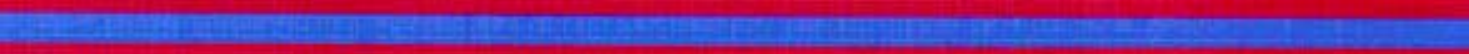

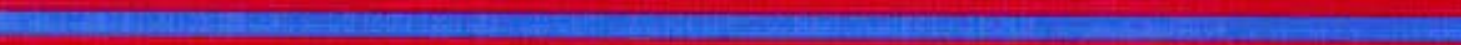

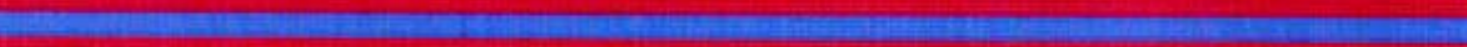
-

$\circ$
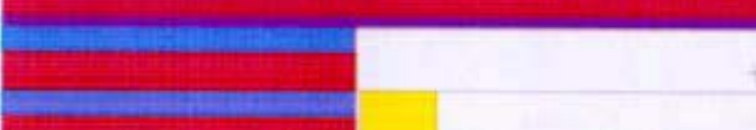

\%

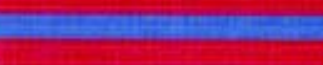

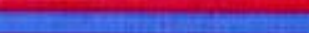

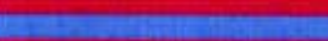

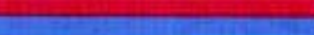
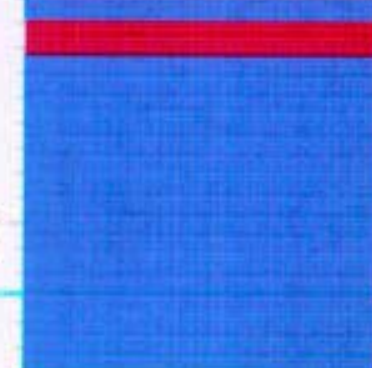

$i$

$-6$

$-4$

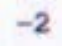

0

2

6

Figure 34. Cross-sectional Close-up View of the Base-4 Assembly 
Table 49. Predicted Critical Configuration of the Base-4 Assembly

\begin{tabular}{|c|c|c|c|c|c|}
\hline Unit & Material & Thickness (in) & $\begin{array}{c}\text { Inner } \\
\text { Diameter } \\
\text { (in) }\end{array}$ & $\begin{array}{l}\text { Outer } \\
\text { Diameter } \\
\text { (in) }\end{array}$ & $\begin{array}{l}\text { Assembly Height } \\
\text { (in) }\end{array}$ \\
\hline $\begin{array}{l}\text { Bottom } \\
\text { Reflector }\end{array}$ & Poly & 1,00 & $2.5 ;$ & 21.0 & 1,000 \\
\hline \multirow{2}{*}{1} & HEU & 0.118 & 2.51 & 21.0 & 1.118 \\
\hline & Poly & 0.080 & 2.51 & 21.0 & 1.198 \\
\hline \multirow{2}{*}{2} & HEU & 0.118 & 2.51 & 21.0 & 1.316 \\
\hline & Poly & 0.080 & 2.51 & 21.0 & 1.396 \\
\hline \multirow{2}{*}{3} & HEU & 0.118 & 2.51 & 21.0 & 1.514 \\
\hline & Poly & 0.080 & 2.51 & 21.0 & 1.594 \\
\hline \multirow{2}{*}{4} & HEU & 0.118 & 2.51 & 21.0 & 1.712 \\
\hline & Poly & 0.080 & 2.51 & 21.0 & 1.792 \\
\hline \multirow{2}{*}{5} & HEU & 0.118 & 2.51 & 21.0 & 1.910 \\
\hline & Poly & 0.080 & 2.51 & 21.0 & 1.990 \\
\hline \multirow{2}{*}{6} & HEU & 0.118 & 2.51 & 21.0 & 2.108 \\
\hline & Poly & 0.080 & 2.51 & 21.0 & 2.188 \\
\hline Diaphragm & Stainiess Stee! & 0.040 & 0 & 24.8 & 2.228 \\
\hline \multirow{2}{*}{7} & HEU & 0.118 & 0 & 21.0 & 2.346 \\
\hline & Poly & 0.080 & 0 & 21.0 & 2.426 \\
\hline \multirow{2}{*}{8} & HEU & 0.118 & 0 & 21.0 & 2.544 \\
\hline & Poly & 0.080 & 0 & 21.0 & 2.624 \\
\hline \multirow{2}{*}{9} & HEU & 0.118 & 0 & 21.0 & 2.742 \\
\hline & Poly & 0.080 & 0 & 21.0 & 2.822 \\
\hline \multirow{2}{*}{10} & HEU & 0.118 & 0 & 21.0 & 2.940 \\
\hline & Poly & 0.080 & 0 & 21.0 & 3.020 \\
\hline 11 & HEU & 0.118 & 0 & 21.0 & 3.138 \\
\hline $\begin{array}{l}\text { Top } \\
\text { Reflector }\end{array}$ & Poly & $\begin{array}{l}0.94 \text { (RCP01) } \\
0.92 \text { (MCNP5, } \\
\text { MCNP5 Space } \\
\text { XS. RACER) }\end{array}$ & 0 & 21.0 & $\begin{array}{l}4.078 \text { (RCP01) } \\
4.058 \text { (MCNP5, } \\
\text { MCNP5 Space } \\
\text { XS, RACER) }\end{array}$ \\
\hline
\end{tabular}

Table 50. Base-4 Assembly Material Mass Distribution

\begin{tabular}{|c|c|c|c|c|c|c|}
\hline \multirow{3}{*}{ Material } & \multicolumn{6}{|c|}{ Mass (kg) } \\
\hline & \multicolumn{3}{|c|}{ MCNP5/MCNP5 (Space XS)/RACER } & \multicolumn{3}{|c|}{ RCP01 } \\
\hline & $\begin{array}{c}\text { Lower } \\
\text { Assembly }\end{array}$ & $\begin{array}{c}\text { Upper } \\
\text { Assembly }\end{array}$ & Total & $\begin{array}{l}\text { Lower } \\
\text { Assembly }\end{array}$ & $\begin{array}{c}\text { Upper } \\
\text { Assembly }\end{array}$ & Total \\
\hline HEU & 74.2 & 62.8 & 137.0 & 74.2 & 62.8 & 137.0 \\
\hline Polyethylene & 7.9 & 6.7 & 14.7 & 7.9 & 6.8 & 14.8 \\
\hline Total & 82.2 & 69.5 & 151.7 & 82.2 & 69.6 & 151.8 \\
\hline
\end{tabular}


B-TM-1639

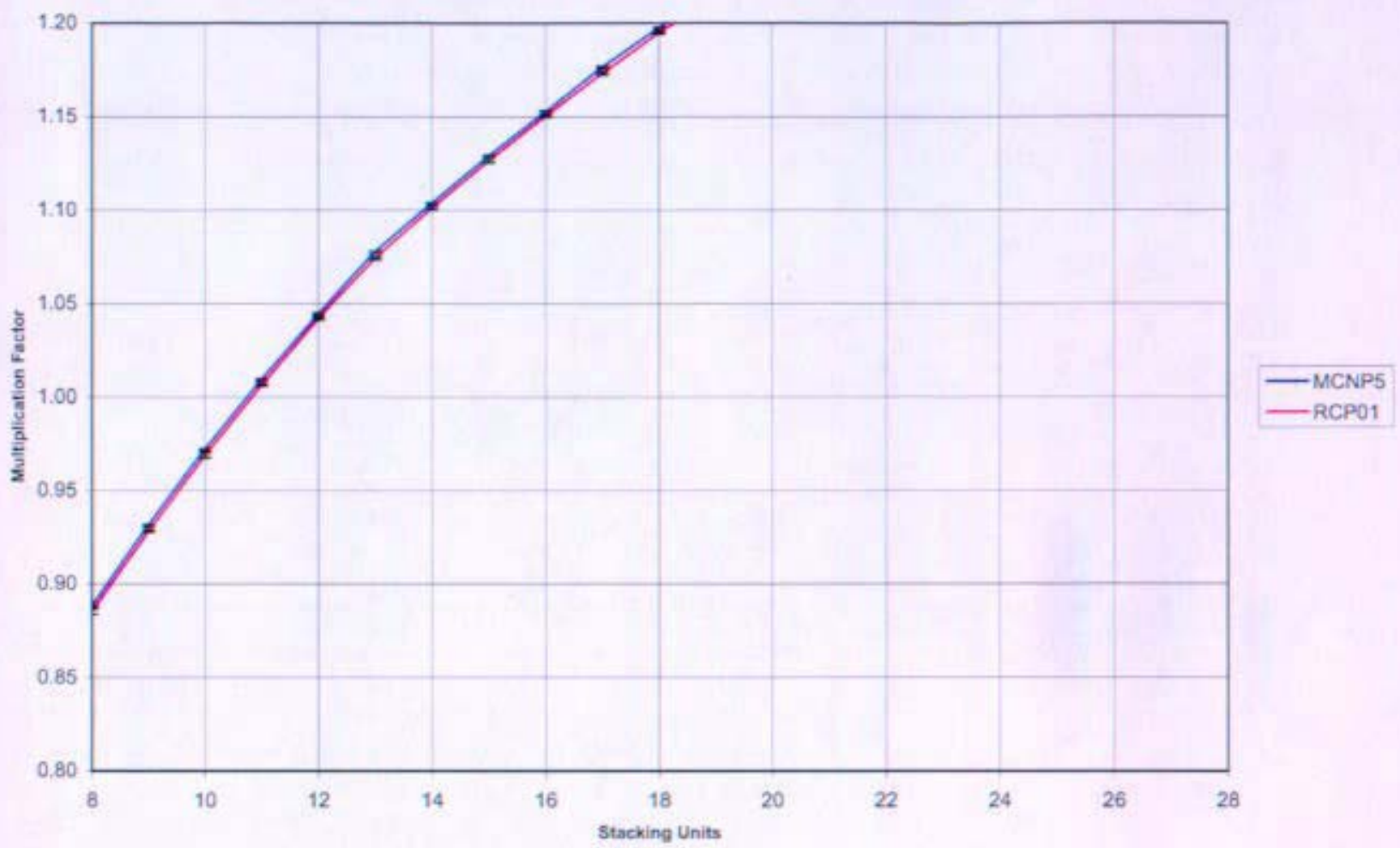

Figure 35. Base-4 Assembly $k_{\text {eff }}$ as a Function of the Number of Stacking Units

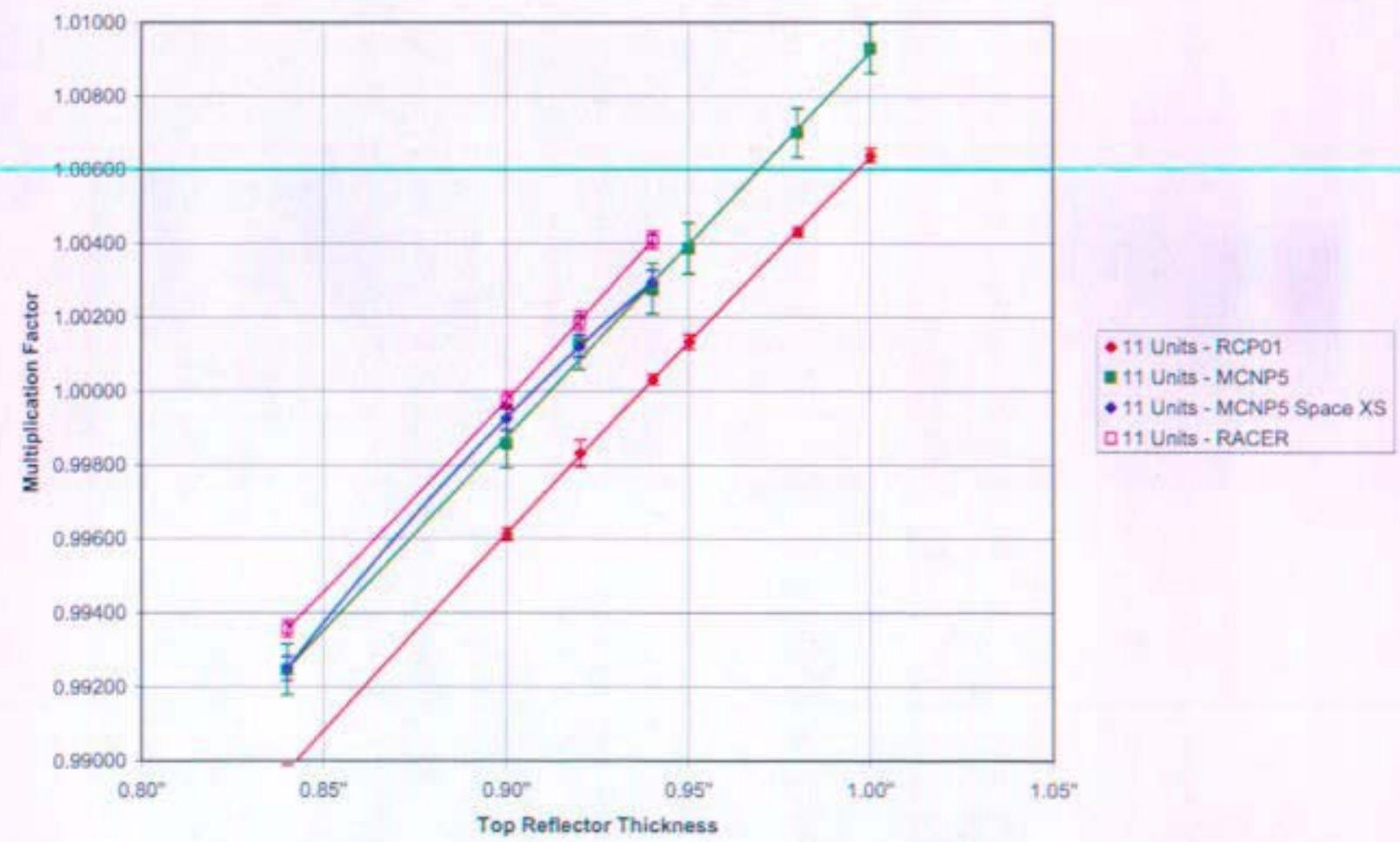

Figure 36. Base-4 Assembly $k_{\text {eff }}$ as a Function of the Top Reflector Thickness 
Table 51. Base-4 Assembly $k_{\text {eff }}$ as a Function of the Top Reflector Thickness

\begin{tabular}{|c|c|c|c|c|c|c|c|c|}
\hline \multicolumn{9}{|c|}{ Predicted Top Reflector Thickness } \\
\hline \multicolumn{9}{|c|}{11 Stacking Units } \\
\hline \multirow{2}{*}{$\begin{array}{c}\text { Top } \\
\text { Reflector } \\
\text { Thickness } \\
\text { (in) }\end{array}$} & \multicolumn{2}{|c|}{ MCNP5 } & \multicolumn{2}{|c|}{ MCNP5 (Space XS) } & \multicolumn{2}{|c|}{ RCP01 } & \multicolumn{2}{|c|}{ RACER } \\
\hline & $k_{\text {eff }}$ & $95 \% \mathrm{Cl}$ & $k_{\text {off }}$ & $95 \% \mathrm{Cl}$ & $k_{\text {eff }}$ & $95 \% \mathrm{Cl}$ & $k_{\text {off }}$ & $95 \% \mathrm{Cl}$ \\
\hline 0.84 & 0.99246 & 0.00069 & 0.99249 & 0.00032 & 0.98974 & 0.00015 & 0.99357 & 0.00023 \\
\hline 0.90 & 0.99856 & 0.00067 & 0.99925 & 0.00032 & 0.99612 & 0.00017 & 0.99975 & 0.00024 \\
\hline 0.92 & 1.00126 & 0,00069 & 1.00120 & $0,0.0030$ & 0,99830 & 0.00036 & 1.00191 & 0.00025 \\
\hline 0.94 & 1.00276 & 0.00069 & 1.00293 & 0.00032 & 1.00030 & 0.00014 & 1.00409 & 0.00024 \\
\hline 0.95 & 1.00385 & 0.00069 & - & - & 1.00132 & 0.00020 & - & - \\
\hline 0.98 & 1.00699 & 0.00067 & - & - & 1.00431 & 0.00013 & - & - \\
\hline 1.00 & 1.00928 & 0.00067 & - & - & 1.00639 & 0.00018 & - & - \\
\hline
\end{tabular}




\subsubsection{Baseline Critical Experiments Summary and Conclusions}

This document provides the pre-experimental predictions for the baseline critical experiments including the effect of the Planet assembly machine structure. These critical experiments are being performed to:

1. serve as the baseline against which any biases observed in the Mo, $\mathrm{Nb}, \mathrm{Re}$, and $\mathrm{Ta}$ critical experiment series may be compared,

2. assess the adequacy of existing neutron cross section evaluations in neutron energy spectra expected for the Prometheus reactor under normal and accident conditions, and

3. reduce the uncertainty in $k_{\text {eff }}$ for the Prometheus reactor by performing benchmark quality critical experiments that bracket the neutron energy spectra expected under normal and accident conditions.

The first 3 experiments are designed to bracket the neutron energy spectrum expected in the Prometheus space nuclear reactor under normal operating conditions. The Base-4 experiment is designed to approximate the neutron energy spectrum expected in accident conditions in which the core is flooded by water. A summary of the fission fraction in the thermal, intermediate, and fast energy ranges for each of the baseline critical experiments is provided in Table 52. The Base-1, Base2 , and Base-3 experiments are classified as fast spectrum experiments while the Base- 4 experiment is classified as a mixed spectrum experiment. A summary of the pre-experimental predictions for each of the baseline critical experiments is provided in Table 53. Predictions from RCP01, MCNP5, MCNP5 with space cross sections, and RACER analyses are reported.

A comparison of the RCP01 and MCNP5 predicted fission reaction rate spectra is provided in Figure 37. The fission reaction rate spectra predicted by both codes are quite close in the fast energy range, but differences begin to appear below about $30 \mathrm{keV}$. Note that the RCP01 fission reaction rates are plotted as a single multigroup between $5 \times 10^{-4} \mathrm{eV}$ and $0.625 \mathrm{eV}$ for convenience while the MCNP5 fission reaction rates are plotted using the normal RCP01 25 thermal multigroup structure. The RCP01 predicted fission reaction rate spectra cumulative distribution functions (CDFs) for the baseline experiments are provided in Figure 38. The first three baseline experiments clearly have fast spectra while the Base-4 experiment has a mixed spectrum.

Table 52. A Summary of the Energy Spectrum Covered in the Baseline Critical Experiments

\begin{tabular}{|c|c|c|c|}
\hline \multirow{2}{*}{ Experiment } & \multicolumn{3}{|c|}{ Percent Fissions by Energy (MCNP5 Predictions) } \\
\cline { 2 - 4 } & $<0.625 \mathrm{eV}$ & $0.625 \mathrm{eV}-100 \mathrm{keV}$ & $>100 \mathrm{keV}$ \\
\hline Base-1 & $0.0 \%$ & $13.0 \%$ & $87.0 \%$ \\
\hline Base-2 & $0.0 \%$ & $20.7 \%$ & $79.3 \%$ \\
\hline Base-3 & $0.1 \%$ & $33.6 \%$ & $66.4 \%$ \\
\hline Base-4 & $10.7 \%$ & $45.2 \%$ & $44.1 \%$ \\
\hline
\end{tabular}


Table 53. A Summary of the Pre-Experimental Predictions for the Baseline Critical Experiments

\begin{tabular}{|c|c|c|c|c|c|c|c|}
\hline Experiment & $\begin{array}{c}\text { Monte } \\
\text { Carlo Code }\end{array}$ & $\begin{array}{l}\text { Stacking } \\
\text { Units }\end{array}$ & $\begin{array}{c}\text { Top } \\
\text { Reflector } \\
\text { Thickness } \\
\text { (in) }\end{array}$ & $\mathbf{k}_{\text {etf }}$ & $\begin{array}{c}95 \% \\
\text { Confidence } \\
\text { Interval }\end{array}$ & $\begin{array}{l}\text { Mass } \\
\text { of HEU } \\
(\mathrm{kg})\end{array}$ & $\begin{array}{c}\text { Mass of } \\
\text { Moderator } \\
\text { (graphite/ } \\
\text { polyethylene) } \\
(\mathrm{kg})\end{array}$ \\
\hline \multirow{4}{*}{ Base-1 } & RCP01 & 17 & 1.30 & 1.00061 & 0.00015 & 208.0 & 38.1 \\
\hline & MCNP5 & 17 & 1.30 & 1.00142 & 0.00053 & 208.0 & 38.1 \\
\hline & $\begin{array}{c}\text { MCNP5 } \\
\text { (Space XS) }\end{array}$ & 17 & 1.30 & 1.00191 & 0.00024 & 208.0 & 38.1 \\
\hline & RACER & 17 & 1.30 & 1.00314 & 0.00021 & 208.0 & 38.1 \\
\hline \multirow{4}{*}{ Base-2 } & RCP01 & 15 & 2.40 & 1.00121 & 0.00013 & 185.0 & 69.9 \\
\hline & MCNP5 & 15 & 2.30 & 1.00082 & 0.00059 & 185.0 & 68.9 \\
\hline & $\begin{array}{c}\text { MCNP5 } \\
\text { (Space XS) }\end{array}$ & 15 & 2.30 & 1.00091 & 0.00026 & 185.0 & 68.9 \\
\hline & RACER & 15 & 2.30 & 1.00238 & 0.00020 & 185.0 & 68.9 \\
\hline \multirow{4}{*}{ Base-3 } & RCP01 & 13 & 5.40 & 1.00101 & 0.00020 & 161.9 & 147.6 \\
\hline & MCNP5 & 13 & 4.85 & 1.00081 & 0.00061 & 161.9 & 142.2 \\
\hline & $\begin{array}{c}\text { MCNP5 } \\
\text { (Space XS) }\end{array}$ & 13 & 4.85 & 1.00120 & 0.00028 & 161.9 & 142.2 \\
\hline & RACER & 13 & 4.85 & 1.00284 & 0.00021 & 161.9 & 142.2 \\
\hline \multirow{4}{*}{ Base-4 } & RCP01 & 11 & 0.94 & 1.00030 & 0.00014 & 137.0 & 14.8 \\
\hline & MCNP5 & 11 & 0.92 & 1.00126 & 0.00069 & 137.0 & 14.7 \\
\hline & $\begin{array}{c}\text { MCNP5 } \\
\text { (Space XS) }\end{array}$ & 11 & 0.92 & 1.00120 & 0.00030 & 137.0 & 14.7 \\
\hline & RACER & 11 & 0.92 & 1.00191 & 0.00025 & 137.0 & 14.7 \\
\hline
\end{tabular}


B-TM-1639

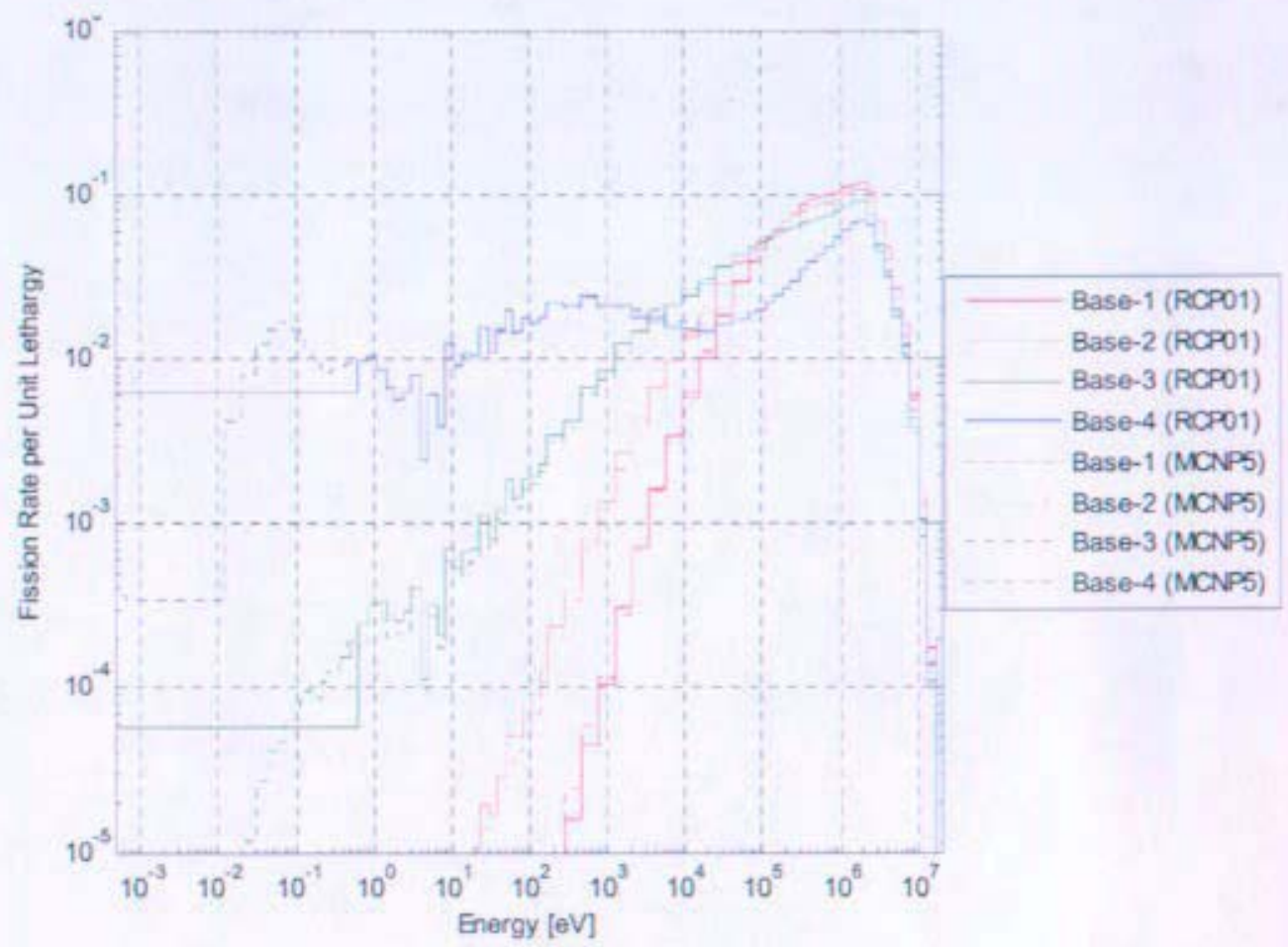

Figure 37. Comparison of the RCP01 and MCNP5 Fission Rate Spectra for the Baseline Critical Experiments

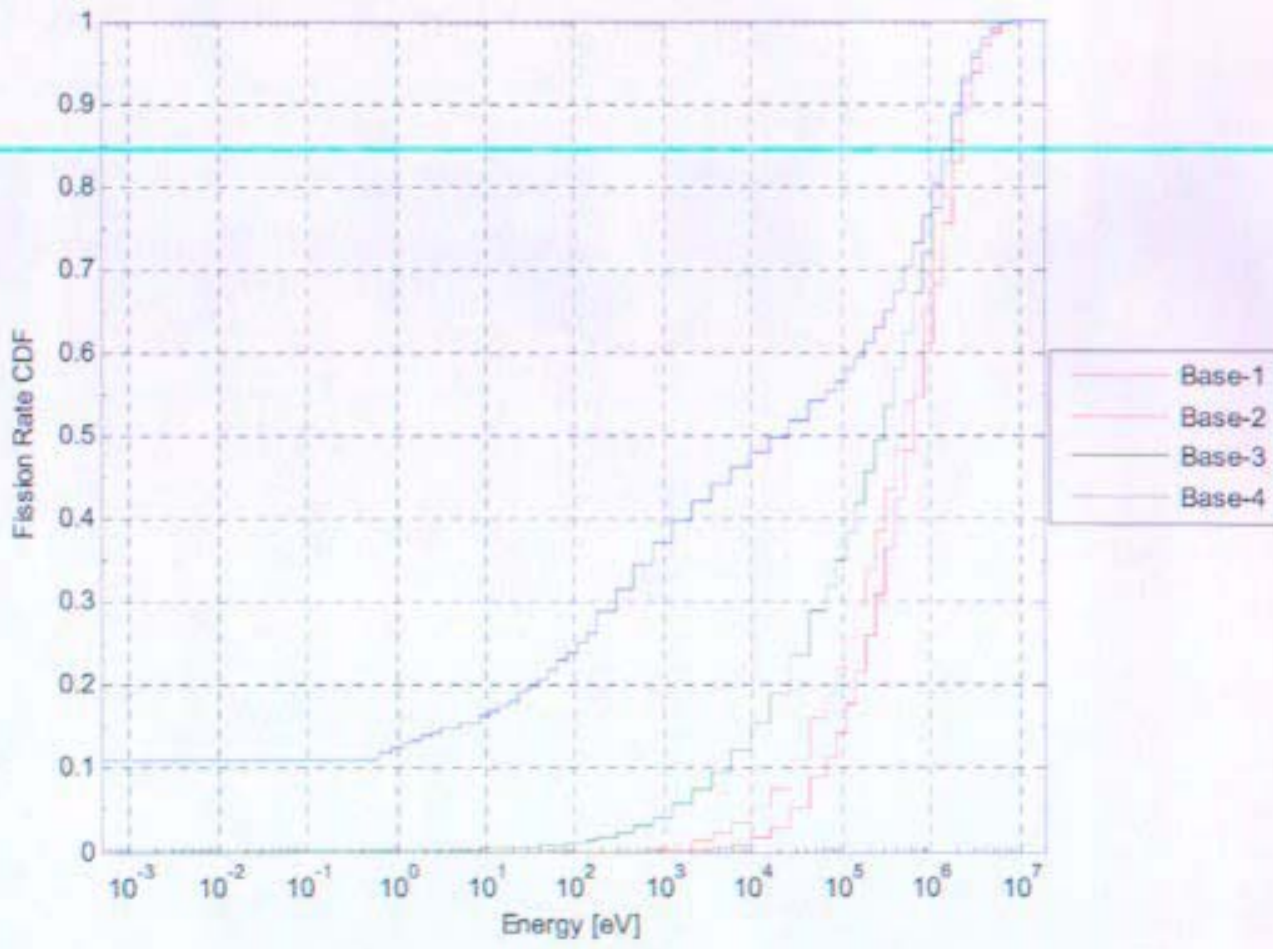

Figure 38. RCP01 Fission CDFs for the Baseline Critical Experiments 


\subsection{Molybdenum Critical Experiments}

\subsubsection{Mo-1 Experiment}

The Mo-1 experiment is designed to simulate the hardest neutron spectrum, which is in the center of the Prometheus reactor core during normal operating conditions. A cross-sectional view and close-up view of the experimental configuration are provided in Figure 39 and Figure 40 where aluminum is yellow, graphite is blue, Mo is green, HEU is red, and stainless steel is purple (all dimensions in figures are in centimeters). The Mo-1 assembly configuration, including plate layout and dimensions, is shown in Table 54. The RCP01 analysis predicts an assembly height of 7.498", the MCNP5 analysis predicts an assembly height of 7.298", and the MCNP5 with space cross sections and RACER analyses predict an assembly height of $7.348^{\prime \prime}$. The assembly rests on a $3.0^{\prime \prime}$ thick hollow Al 6061-T6 spindle plate that has a $19^{\prime \prime} \mathrm{OD}$ and $2.50^{\prime \prime}$ inner diameter. The active core region of the assembly is $4.591^{\prime \prime}$ high and contains one 0.100 " thick graphite plate and 16 stacking units consisting of a $0.0301^{\prime \prime}$ thick Mo plate, a $0.118^{\prime \prime}$ thick HEU plate, a $0.0301^{\prime \prime}$ thick Mo plate, and a $0.100^{\prime \prime}$ thick graphite plate. The bottom reflector for the assembly consists of a $1.0^{\prime \prime}$ thick graphite reflector and a $0.1785^{\prime \prime}$ thick Mo reflector. The RCP01 predicted top reflector consists of a $0.1785^{\prime \prime}$ thick Mo reflector and a $1.55^{\prime \prime}$ thick graphite reflector, while the MCNP5 predicted top reflector consists of a $0.1785^{\prime \prime}$ thick Mo reflector and a $1.35^{\prime \prime}$ thick graphite reflector. The MCNP5 with space cross sections and RACER predicted top reflector consists of a $0.1785^{\prime \prime}$ thick Mo reflector and a $1.40^{\prime \prime}$ thick graphite reflector. A hollow Al 6061-T6 alignment tube is assumed to extend from the bottom of the spindle plate to the top of the $6^{\text {th }}$ stacking unit. All other regions are modeled as void, except as noted in Section 4.0 for the RACER models. The Mo-1 assembly contains $196.5 \mathrm{~kg}$ of HEU and $76.1 \mathrm{~kg}$ of Mo. The distribution of material in the top and bottom half of the assembly is given in Table 55 for the RCP01, MCNP5, MCNP5 with space cross sections, and RACER predicted critical configurations.

A series of analyses have been performed to predict the $k_{\text {eff }}$ of the Mo-1 assembly during the approach to critical as a function of both the number of stacking units and the graphite top reflector thickness. Figure 41 presents the RCP01 and MCNP5 predicted $k_{\text {eff }}$ as a function of the number of stacking units in the Mo-1 assembly. The error bars indicate the size of the $95 \%$ confidence interval in the Monte Carlo calculations. The average difference between the MCNP5 and RCP01 predicted $k_{\text {off }}$ is $0.0068+0.0011 \Delta \mathrm{k}$ over the range from 8 to 28 stacking units. For an explanation of the bias, please refer to Section 4.2 .5 . Figure 42 and Table 56 provide a comparison of the predicted $k_{\text {eff }}$ of the Mo-1 assembly with 16 and 17 stacking units as a function of the graphite top reflector thickness. The experimental configurations that were predicted to achieve delayed criticality within TSR limits $(\rho<$ $0.5 \$)$ are highlighted in green in Table 56. The Mo-1 assembly is classified as a fast spectrum assembly with the following representative fission fractions, as predicted by MCNP5: $85.1 \%$ fast ( $E>$ $100 \mathrm{keV}), 14.9 \%$ intermediate $(0.625 \mathrm{eV}<E<100 \mathrm{keV})$, and $0.0 \%$ thermal $(E<0.625 \mathrm{eV})$. 


\section{B-TM-1639}

우

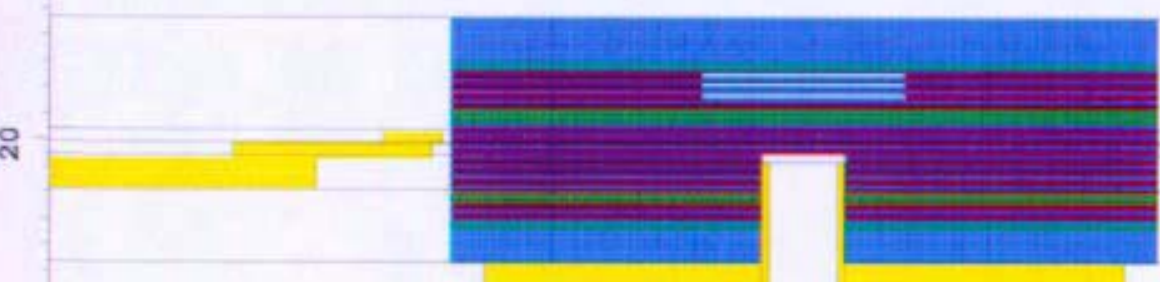

$\circ$

$\stackrel{\text { ฺ }}{1}$

$\%$

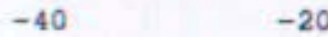

0

20

40

Figure 39. Cross-sectional View of the Mo-1 Assembly 
$\infty$

$\varphi$

$\mathrm{N}$

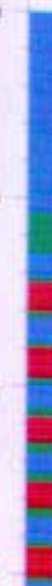

E

o

พ

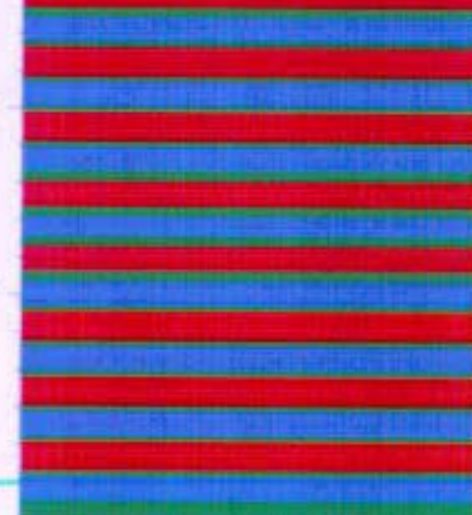

†

i

$-8$
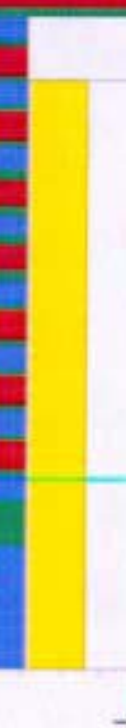

Figure 40. Cross-sectional Close-up View of the Mo-1 Assembly 
Table 54. Predicted Critical Configuration for the Mo-1 Assembly

\begin{tabular}{|c|c|c|c|c|c|}
\hline Unit & Material & Thickness (in) & $\begin{array}{c}\text { Inner } \\
\text { Diameter } \\
\text { (in) }\end{array}$ & $\begin{array}{l}\text { Outer } \\
\text { Diameter } \\
\text { (in) }\end{array}$ & $\begin{array}{l}\text { Assembly Height } \\
\text { (in) }\end{array}$ \\
\hline \multirow{3}{*}{$\begin{array}{l}\text { Bottom } \\
\text { Reflector }\end{array}$} & Graphite & 1.00 & 251 & 21.0 & 10000 \\
\hline & Mo & 0.1785 & 2.51 & 21.0 & 1.1765 \\
\hline & Graphite & 0.100 & 2.51 & 21.0 & 1.2785 \\
\hline \multirow{4}{*}{1} & Mo & 0.0301 & 2.51 & 21.0 & 1.3086 \\
\hline & HEU & 0.118 & 2.51 & 21.0 & 1.4266 \\
\hline & Mo & 0.0301 & 2.51 & 21.0 & 1.4567 \\
\hline & Graphite & 0.100 & 2.51 & 21.0 & 1.5567 \\
\hline \multirow{4}{*}{2} & Mo & 0.0301 & 2.51 & 21.0 & 1.5868 \\
\hline & HEU & 0.118 & 2.51 & 21.0 & 1.7048 \\
\hline & Mo & 0.0301 & 2.51 & 21.0 & 1.7349 \\
\hline & Graphite & 0.100 & 2.51 & 21.0 & 1.8349 \\
\hline \multirow{4}{*}{3} & Mo & 0.0301 & 2.51 & 21.0 & 1.8650 \\
\hline & HEU & 0.118 & 2.51 & 21.0 & 1.9830 \\
\hline & Mo & 0.0301 & 2.51 & 21.0 & 2.0131 \\
\hline & Graphite & 0.100 & 2.51 & 21.0 & 2.1131 \\
\hline \multirow{4}{*}{4} & Mo & 0.0301 & 2.51 & 21.0 & 2.1432 \\
\hline & HEU & 0.118 & 2.51 & 21.0 & 2.2612 \\
\hline & Mo & 0.0301 & 2.51 & 21.0 & 2.2913 \\
\hline & Graphite & 0.100 & 2.51 & 21.0 & 2.3913 \\
\hline \multirow{4}{*}{5} & Mo & 0.0301 & 2.51 & 21.0 & 2.4214 \\
\hline & HEU & 0.118 & 2.51 & 21.0 & 2.5394 \\
\hline & Mo & 0.0301 & 2.51 & 21.0 & 2.5695 \\
\hline & Graphite & 0.100 & 2.51 & 21.0 & 2.6695 \\
\hline \multirow{4}{*}{6} & Mo & 0.0301 & 2.51 & 21.0 & 2.6996 \\
\hline & HEU & 0.118 & 2.51 & 21.0 & 2.8176 \\
\hline & Mo & 0.0301 & 2.51 & 21.0 & 2.8477 \\
\hline & Graphite & 0.100 & 2.51 & 21.0 & 2.9477 \\
\hline \multirow{4}{*}{7} & Mo & 0.0301 & 2.51 & 21.0 & 2.9778 \\
\hline & HEU & 0.118 & 2.51 & 21.0 & 3.0958 \\
\hline & Mo & 0.0301 & 2.51 & 21.0 & 3.1259 \\
\hline & Graphite & 0.100 & 2.51 & 21.0 & 3.2259 \\
\hline \multirow{4}{*}{8} & Mo & 0.0301 & 0 & 21.0 & 3.2560 \\
\hline & HEU & 0.118 & 0 & 21.0 & 3.3740 \\
\hline & Mo & 0.0301 & 0 & 21.0 & 3.4041 \\
\hline & Graphite & 0.100 & 0 & 21.0 & 3.5041 \\
\hline Diaphragm & Stainless Steel & 0.040 & 0 & 24.8 & 3.5441 \\
\hline \multirow{4}{*}{9} & Mo & 0.0301 & 0 & 21.0 & 3.5742 \\
\hline & HEU & 0.118 & 0 & 21.0 & 3.6922 \\
\hline & Mo & 0.0301 & 0 & 21.0 & 3.7223 \\
\hline & Graphite & 0.100 & 0 & 21.0 & 3.8223 \\
\hline \multirow{4}{*}{10} & Mo & 0.0301 & 0 & 21.0 & 3.8524 \\
\hline & HEU & 0.118 & 0 & 21.0 & 3.9704 \\
\hline & Mo & 0.0301 & 0 & 21.0 & 4.0005 \\
\hline & Graphite & 0.100 & 0 & 21.0 & 4.1005 \\
\hline
\end{tabular}




\begin{tabular}{|c|c|c|c|c|c|}
\hline Unit & Material & Thickness (in) & $\begin{array}{c}\text { Inner } \\
\text { Diameter } \\
\text { (in) }\end{array}$ & $\begin{array}{l}\text { Outer } \\
\text { Diameter } \\
\text { (in) }\end{array}$ & $\begin{array}{l}\text { Assembly Height } \\
\text { (in) }\end{array}$ \\
\hline \multirow{4}{*}{11} & Mo & 0.0301 & 0 & 21.0 & 4.1306 \\
\hline & HEU & 0.118 & 0 & 21.0 & 4.2486 \\
\hline & Mo & 0.0301 & 0 & 21.0 & 4.2787 \\
\hline & Graphite & 0.100 & 0 & 21.0 & 4.3787 \\
\hline \multirow{4}{*}{12} & Mo & 0.0301 & 0 & 21.0 & 4.4088 \\
\hline & HEU & 0.118 & 0 & 21.0 & 4.5268 \\
\hline & Mo & 0.0301 & 0 & 21.0 & 4.5569 \\
\hline & Graphite & 0.100 & 0 & 21.0 & 4.6569 \\
\hline \multirow{4}{*}{13} & Mo & 0.0301 & 0 & 21.0 & 4.6870 \\
\hline & HEU & 0.118 & 0 & 21.0 & 4.8050 \\
\hline & Mo & 0.0301 & 0 & 21.0 & 4.8351 \\
\hline & Graphite & 0.100 & 0 & 21.0 & 4.9351 \\
\hline \multirow{4}{*}{14} & Mo & 0.0301 & 0 & 21.0 & 4.9652 \\
\hline & HEU & 0.118 & 6.005 & 21.0 & 5.0832 \\
\hline & Mo & 0.0301 & 0 & 21.0 & 5.1133 \\
\hline & Graphite & 0.100 & 0 & 21.0 & 5.2133 \\
\hline \multirow{4}{*}{15} & Mo & 0.0301 & 0 & 21.0 & 5.2434 \\
\hline & HEU & 0.118 & 6.005 & 21.0 & 5.3614 \\
\hline & Mo & 0.0301 & 0 & 21.0 & 5.3915 \\
\hline & Graphite & 0.100 & 0 & 21.0 & 5.4915 \\
\hline \multirow{4}{*}{16} & Mo & 0.0301 & 0 & 21.0 & 5.5216 \\
\hline & HEU & 0.118 & 6.005 & 21.0 & 5.6396 \\
\hline & Mo & 0.0301 & 0 & 21.0 & 5.6697 \\
\hline & Graphite & 0.100 & 0 & 21.0 & 5.7697 \\
\hline \multirow[b]{2}{*}{$\begin{array}{c}\text { Top } \\
\text { Reflector }\end{array}$} & Mo & 0.1785 & 0 & 21.0 & 5.9482 \\
\hline & Graphite & $\begin{array}{l}1.55 \text { (RCP01) } \\
1.35 \text { (MCNP5) } \\
1.40 \text { (RACER. } \\
\text { 1CNP5 Space XS) }\end{array}$ & $0^{\prime}$ & 21,0 & $\begin{array}{l}7.4982 \text { (RCPQ1) } \\
7.2982 \text { (MCNP5) } \\
7.3482 \text { (RACER. } \\
\text { MCNP5 SpaCe XS) }\end{array}$ \\
\hline
\end{tabular}

Table 55. Mo-1 Assembly Material Mass Distribution

\begin{tabular}{|c|c|c|c|c|c|c|c|c|c|}
\hline \multirow{3}{*}{ Material } & \multicolumn{9}{|c|}{ Mass (kg) } \\
\hline & \multicolumn{3}{|c|}{ MCNP5 } & \multicolumn{3}{|c|}{ RCP01 } & \multicolumn{3}{|c|}{ MCNP5 (Space XS)/RACER } \\
\hline & $\begin{array}{l}\text { Lower } \\
\text { Assembly }\end{array}$ & $\begin{array}{c}\text { Upper } \\
\text { Assembly }\end{array}$ & Total & $\begin{array}{c}\text { Lower } \\
\text { Assembly }\end{array}$ & $\begin{array}{c}\text { Upper } \\
\text { Assembly }\end{array}$ & Total & $\begin{array}{c}\text { Lower } \\
\text { Assembly }\end{array}$ & $\begin{array}{c}\text { Upper } \\
\text { Assembly }\end{array}$ & Total \\
\hline HEU & 99.2 & 97.3 & 196.5 & 99.2 & 97.3 & 196.5 & 99.2 & 97.3 & 196.5 \\
\hline Mo & 37.8 & 38.3 & 76.1 & 37.8 & 38.3 & 76.1 & 37.8 & 38.3 & 76.1 \\
\hline Graphite & 18.4 & 21.1 & 39.6 & 18.4 & 23.1 & 41.5 & 18.4 & 21.6 & 40.1 \\
\hline Total & 155.4 & 156.8 & 312.2 & 155.4 & 158.7 & 314.1 & 155.4 & 157.3 & 312.7 \\
\hline
\end{tabular}


B-TM-1639

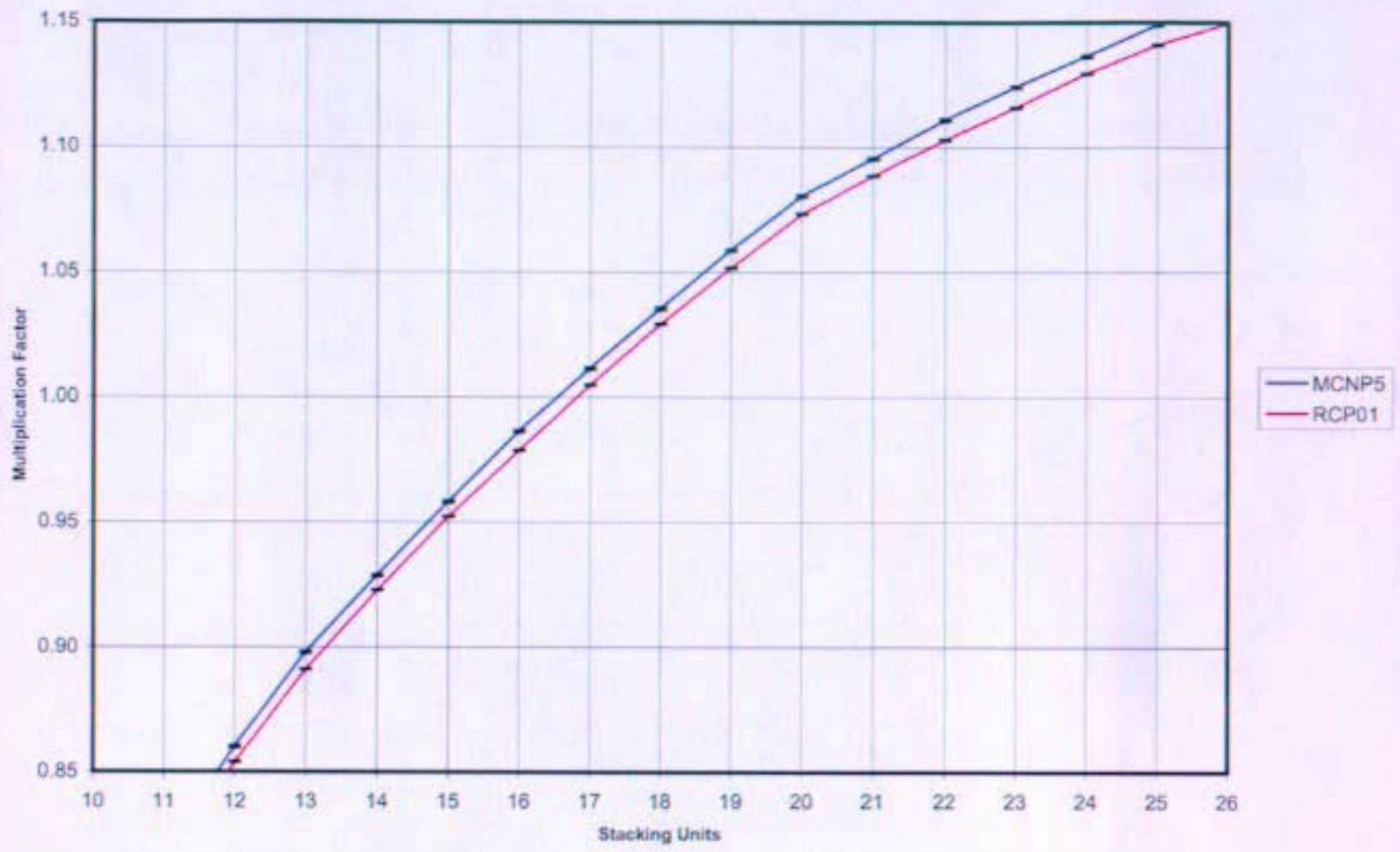

Figure 41. Mo-1 Assembly $k_{\text {eff }}$ as a Function of the Number of Stacking Units

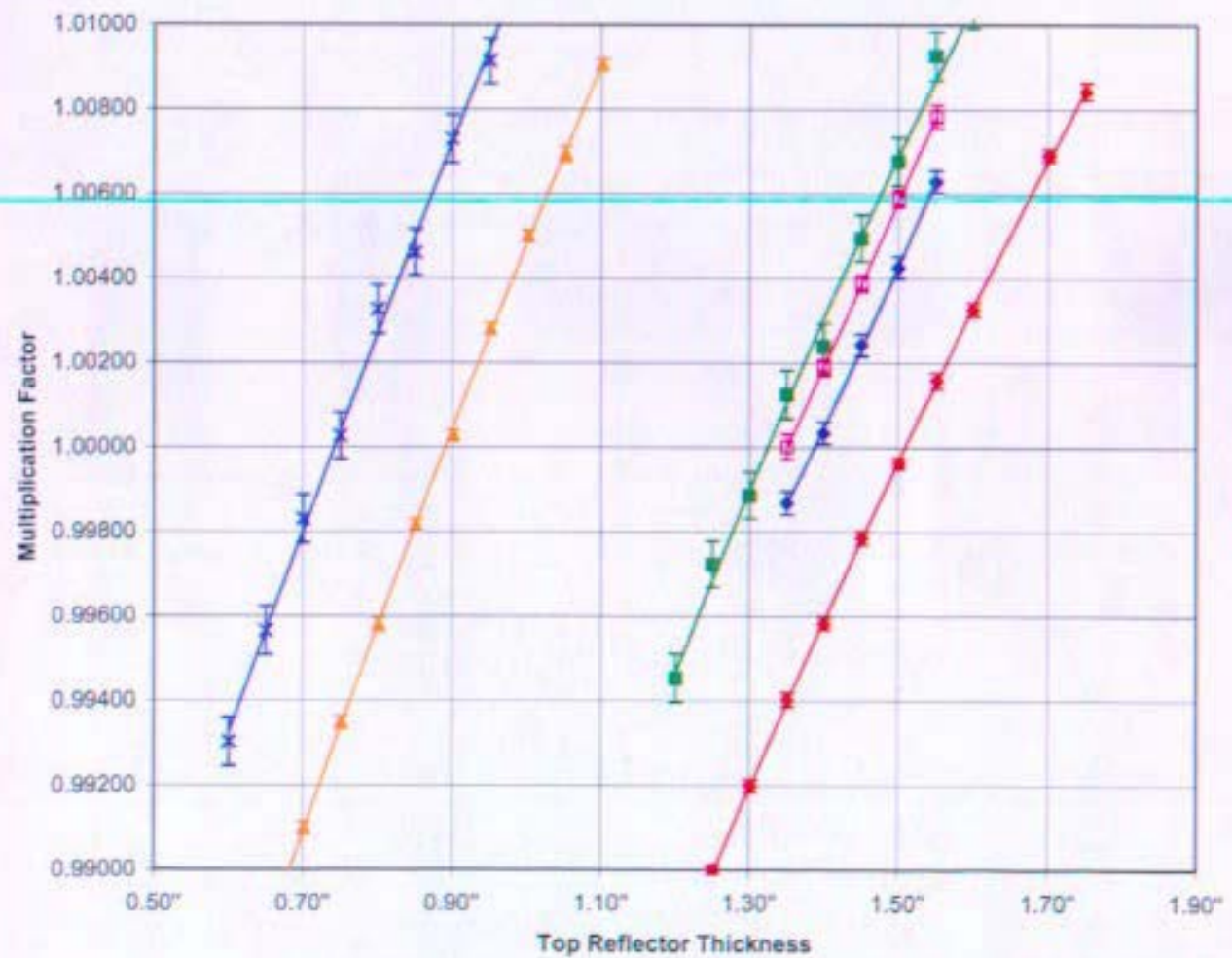

- 16 Units - RCP01

= 16 Units - MCNP5

- 16 Units - MCNP5 Space XS

Q 16 Units - RACER

$\triangle 17$ Units - RCP01

$\times 17$ Units - MCNP5

Figure 42. Mo-1 Assembly $k_{\text {eff }}$ as a Function of the Top Reflector Thickness 
Table 56. Mo-1 Assembly $k_{\text {eff }}$ as a Function of the Top Reflector Thickness

\begin{tabular}{|c|c|c|c|c|c|c|c|c|}
\hline \multicolumn{9}{|c|}{ Predicted Top Reflector Thickness } \\
\hline \multicolumn{9}{|c|}{16 Stacking Units } \\
\hline \multirow{2}{*}{$\begin{array}{c}\text { Top } \\
\text { Reflector } \\
\text { Thickness } \\
\text { (in) }\end{array}$} & \multicolumn{2}{|c|}{ MCNP5 } & \multicolumn{2}{|c|}{ MCNP5 (Space XS) } & \multicolumn{2}{|c|}{ RCP01 } & \multicolumn{2}{|c|}{ RACER } \\
\hline & $k_{\text {eff }}$ & $95 \% \mathrm{Cl}$ & $k_{\text {off }}$ & $95 \% \mathrm{Cl}$ & $k_{\text {eff }}$ & $95 \% \mathrm{Cl}$ & $k_{\text {eff }}$ & $95 \% \mathrm{Cl}$ \\
\hline 1.20 & 0.99452 & 0.00057 & - & - & 0.98780 & 0.00014 & $\cdot$ & $\cdot$ \\
\hline 1.25 & 0.99722 & 0.00055 & - & - & 0.99000 & 0.00011 & - & - \\
\hline 1.30 & 0.99885 & 0.00055 & - & - & 0.99198 & 0.00015 & - & - \\
\hline 1.35 & 1.00123 & 0.00057 & 0.99867 & 0.00028 & 0.99401 & 0.00017 & 1.00001 & 0.00030 \\
\hline 1.40 & 1.00237 & 0.00055 & 1.00033 & 0.00026 & 0.99582 & 0.00015 & 1.00188 & 0.00019 \\
\hline 1.45 & 1.00493 & 0.00055 & 1.00241 & 0.00026 & 0.99784 & 0.00016 & 1.00387 & 0.00019 \\
\hline 1.50 & 1.00675 & 0.00057 & 1.00424 & 0.00026 & 0.99960 & 0.00012 & 1.00588 & 0.00021 \\
\hline 1.55 & 1.00925 & 0.00057 & 1.00628 & 0.00026 & 1.00157 & 0.00018 & 1.00782 & 0.00028 \\
\hline 1.60 & 1.01047 & 0.00057 & - & - & 1.00326 & 0.00015 & - & - \\
\hline 1.70 & 1.01371 & 0.00057 & - & - & 1.00691 & 0.00015 & - & - \\
\hline 1.75 & 1.01521 & 0.00059 & - & - & 1.00842 & 0.00020 & - & - \\
\hline \multicolumn{9}{|c|}{17 Stacking Units } \\
\hline \multirow{2}{*}{$\begin{array}{c}\text { Top } \\
\text { Reflector } \\
\text { Thickness } \\
\text { (in) }\end{array}$} & \multicolumn{2}{|c|}{ MCNP5 } & \multicolumn{2}{|c|}{ MCNP5 (Space XS) } & \multicolumn{2}{|c|}{ RCP01 } & \multicolumn{2}{|c|}{ RACER } \\
\hline & $k_{\text {eff }}$ & $95 \% \mathrm{Cl}$ & $\mathrm{K}_{\mathrm{e} \text { eff }}$ & $95 \% \mathrm{Cl}$ & $k_{\text {eff }}$ & $95 \% \mathrm{Cl}$ & $k_{\text {eff }}$ & $95 \% \mathrm{Cl}$ \\
\hline 0.60 & 0.99302 & 0.00057 & \multirow{8}{*}{\multicolumn{2}{|c|}{$\begin{array}{c}\text { Not investigated due } \\
\text { to termination of } \\
\text { project. }\end{array}$}} & 0.98584 & 0.00018 & \multirow{8}{*}{\multicolumn{2}{|c|}{$\begin{array}{l}\text { Not investigated } \\
\text { due to termination } \\
\text { of project. }\end{array}$}} \\
\hline 0.65 & 0.99564 & 0.00057 & & & 0.98838 & 0.00012 & & \\
\hline 0.70 & 0.99829 & 0.00057 & & & 0.99099 & 0.00013 & & \\
\hline 0.75 & 1.00026 & 0.00055 & & & 0.99347 & 0.00016 & & \\
\hline 0.80 & 1.00324 & 0.00057 & & & 0.99579 & 0.00016 & & \\
\hline 0.85 & 1.00459 & 0.00055 & & & 0.99815 & 0.00014 & & \\
\hline 0.90 & 1.00728 & 0.00057 & & & 1.00028 & 0.00012 & & \\
\hline 0.95 & 1.00913 & 0.00053 & & & 1.00279 & 0.00014 & & \\
\hline 1.00 & 1.01157 & 0.00055 & & & 1.00500 & 0.00013 & & \\
\hline 1.05 & 1.01381 & 0.00057 & & & 1.00694 & 0.00018 & & \\
\hline 1.10 & 1.01611 & 0.00055 & & & 1.00905 & 0.00014 & & \\
\hline
\end{tabular}




\subsubsection{Mo-2 Experiment}

The Mo-2 experiment is designed to bracket the average neutron spectrum of the Prometheus reactor core. It is designed to be harder than the expected average neutron energy spectrum of the core but softer than the Mo-1 experiment. Additional graphite has been added to the assembly to simulate the effect of neutron moderation near the reflector. A cross-sectional view and close-up view of the experimental configuration are provided in Figure 43 and Figure 44 where aluminum is yellow, graphite is blue, Mo is green, HEU is red, and stainless steel is purple (all dimensions in figures are in centimeters). The assembly configuration, including plate layout and dimensions, is shown in Table 57. The RCP01 analysis predicts an assembly height of 10.372 ", the MCNP5 analysis predicts an assembly height of $10.072^{\prime \prime}$, and the MCNP5 with space cross sections and RACER analyses predict an assembly height of 10.122 ". The assembly rests on a $3.0^{\prime \prime}$ thick hollow Al 6061-T6 spindle plate that has a $19^{\prime \prime} \mathrm{OD}$ and $2.50^{\prime \prime}$ inner diameter. The active core region of the assembly is $5.865^{\circ}$ high and contains one $0.197^{\prime \prime}$ thick graphite plate and 15 stacking units consisting of a $0.0301^{\prime \prime}$ thick Mo plate, a $0.118^{\prime \prime}$ thick HEU plate, a $0.0301^{\prime \prime}$ thick Mo plate, and a $0.197^{\prime \prime}$ thick graphite plate. The bottom reflector consists of a $2.0^{\prime \prime}$ thick graphite reflector and a $0.1785^{\prime \prime}$ thick Mo reflector. The RCP01 predicted top reflector consists of a $0.1785^{\prime \prime}$ thick Mo reflector and a $2.15^{\prime \prime}$ thick graphite reflector, while the MCNP5 predicted top reflector consists of a $0.1785^{\prime \prime}$ thick Mo reflector and a $1.85^{\prime \prime}$ thick graphite reflector. The MCNP5 with space cross sections and RACER predicted top reflector consists of a $0.1785^{\prime \prime}$ thick Mo reflector and a 1.90" thick graphite reflector. A hollow Al 6061-T6 alignment tube is assumed to extend from the bottom of the spindle plate to the top of the $6^{\text {th }}$ stacking unit. All other regions are modeled as void, except as noted in Section 4.0 for the RACER models. The Mo-2 assembly contains $185.0 \mathrm{~kg}$ of HEU and $72.6 \mathrm{~kg}$ of Mo. The distribution of materials in the top and bottom half of the assembly is given in Table 58 for the RCP01, MCNP5, MCNP5 with space cross sections, and RACER predicted critical configurations.

A series of analyses have been performed to predict the $k_{\text {eff }}$ of the Mo-2 assembly during the approach to critical as a function of both the number of stacking units and the graphite top reflector thickness. Figure 45 presents the RCP01 and MCNP5 predicted $k_{\text {eff }}$ as a function of the number of stacking units in the Mo-2 assembly. The error bars indicate the size of the $95 \%$ confidence interval in the Monte Carlo calculations. The average difference between the MCNP5 and RCP01 predicted $k_{\text {eff }}$ is $0.0071 \pm 0.0006 \Delta \mathrm{k}$ over the range from 8 to 28 stacking units. For an explanation of the bias, please refer to Section 4.2.5. Figure 46 and Table 59 provide a comparison of the predicted $k_{\text {eff }}$ of the Mo-2 assembly with 14 and 15 stacking units as a function of the graphite top reflector thickness. The experimental configurations that were predicted to achieve delayed criticality within TSR limits $(\rho<$ $0.5 \$)$ are highlighted in green in Table 59. The Mo-2 assembly is classified as a fast spectrum assembly with the following representative fission fractions, as predicted by MCNP5: $78.1 \%$ fast ( $E>$ $100 \mathrm{keV}), 21.9 \%$ intermediate $(0.625 \mathrm{eV}<\mathrm{E}<100 \mathrm{keV})$, and $0.0 \%$ thermal $(\mathrm{E}<0.625 \mathrm{eV})$. 
B-TM-1639

?

สำ
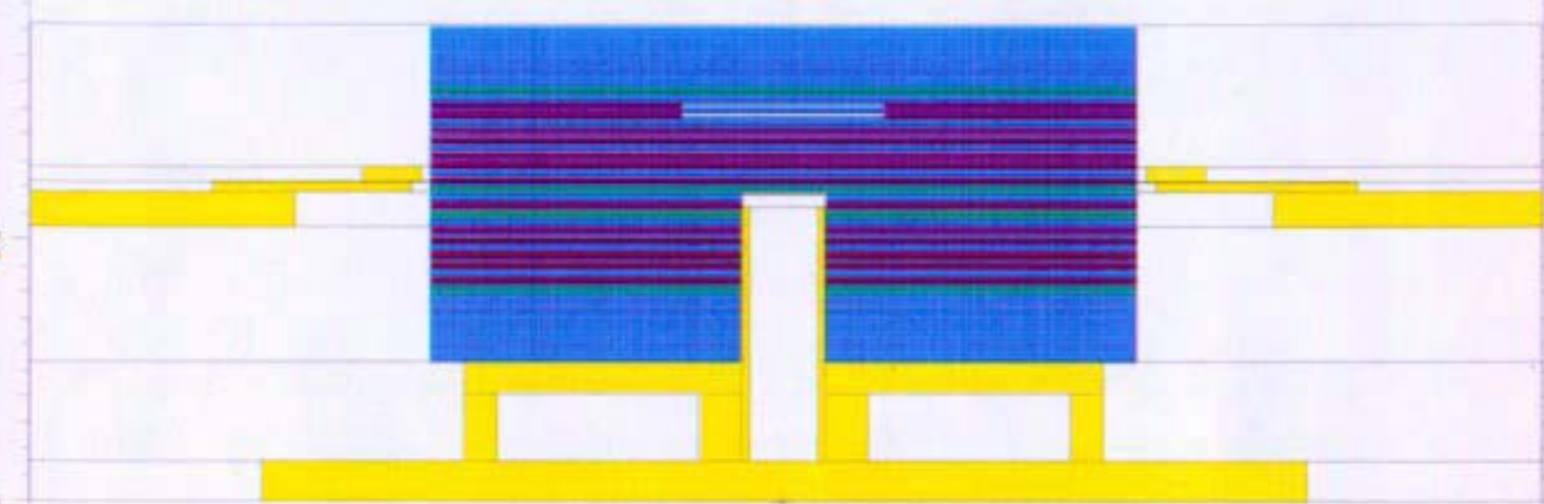

$\circ$

ণ

?

$\begin{array}{llll}-40 & -20 & 0 & 20\end{array}$

Figure 43. Cross-sectional View of the Mo-2 Assembly 
$\infty$

6

$\uparrow$

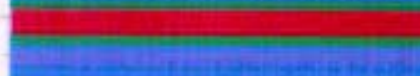

$+\frac{1}{2}$

$\sim$

v
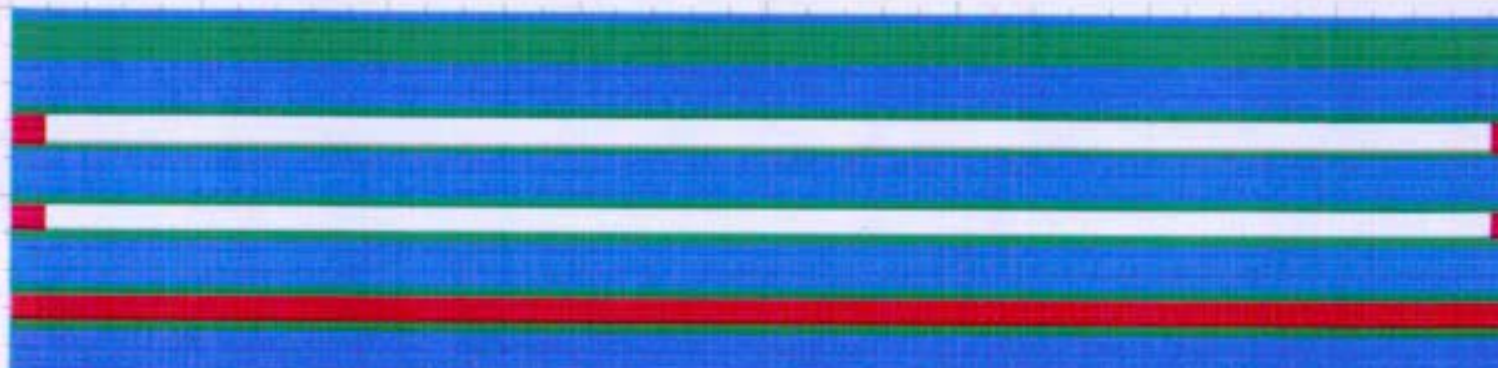

$=$
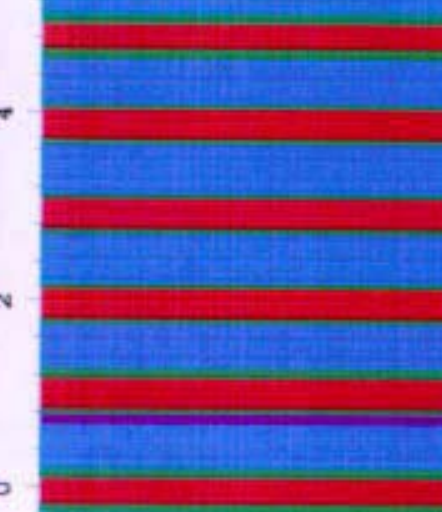

i

$\varphi$
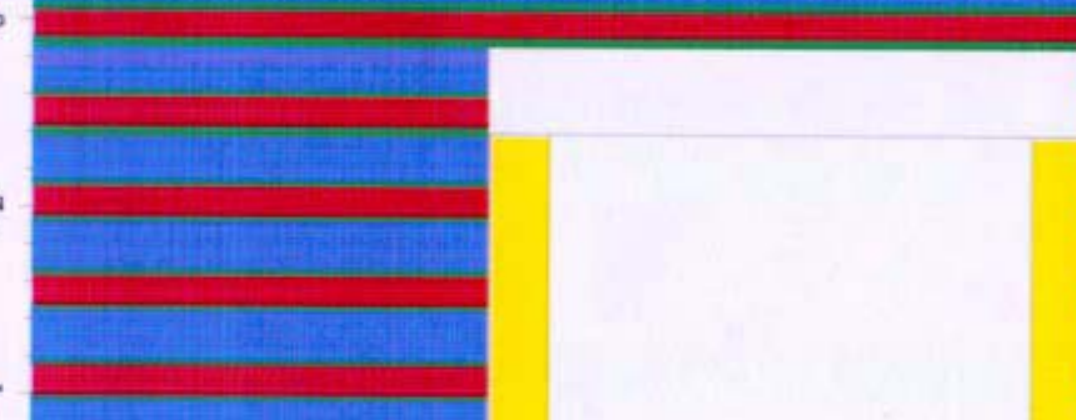

$-8$

$-6$

$-4$

$-2$

0

2

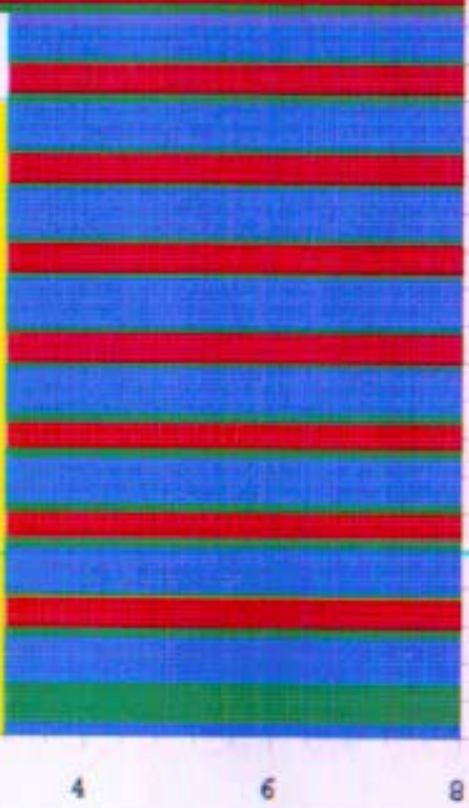

Figure 44. Cross-sectional Close-up View of the Mo-2 Assembly 
Table 57. Predicted Critical Configuration for the Mo-2 Assembly

\begin{tabular}{|c|c|c|c|c|c|}
\hline Unit & Material & Thickness (in) & $\begin{array}{c}\text { Inner } \\
\text { Diameter } \\
\text { (in) }\end{array}$ & $\begin{array}{l}\text { Outer } \\
\text { Diameter } \\
\text { (in) }\end{array}$ & $\begin{array}{l}\text { Assembly Height } \\
\text { (in) }\end{array}$ \\
\hline \multirow{3}{*}{$\begin{array}{l}\text { Bottom } \\
\text { Reflector }\end{array}$} & Graphite & 200 & 2.51 & 21.6 & 20000 \\
\hline & Mo & 0.1785 & 2.51 & 210 & 2.1785 \\
\hline & Graphits & 0.197 & 251 & 21.0 & 2.3755 \\
\hline \multirow{4}{*}{1} & Mo & 0.0301 & 2.51 & 21.0 & 2.4056 \\
\hline & HEU & 0.118 & 2.51 & 21.0 & 2.5236 \\
\hline & Mo & 0.0301 & 2.51 & 21.0 & 2.5537 \\
\hline & Graphite & 0.197 & 2.51 & 21.0 & 2.7507 \\
\hline \multirow{4}{*}{2} & Mo & 0.0301 & 2.51 & 21.0 & 2.7808 \\
\hline & HEU & 0.118 & 2.51 & 21.0 & 2.8988 \\
\hline & Mo & 0.0301 & 2.51 & 21.0 & 2.9289 \\
\hline & Graphite & 0.197 & 2.51 & 21.0 & 3.1259 \\
\hline \multirow{4}{*}{3} & Mo & 0.0301 & 2.51 & 21.0 & 3.1560 \\
\hline & HEU & 0.118 & 2.51 & 21.0 & 3.2740 \\
\hline & Mo & 0.0301 & 2.51 & 21.0 & 3.3041 \\
\hline & Graphite & 0.197 & 2.51 & 21.0 & 3.5011 \\
\hline \multirow{4}{*}{4} & Mo & 0.0301 & 2.51 & 21.0 & 3.5312 \\
\hline & HEU & 0.118 & 2.51 & 21.0 & 3.6492 \\
\hline & Mo & 0.0301 & 2.51 & 21.0 & 3.6793 \\
\hline & Graphite & 0.197 & 2.51 & 21.0 & 3.8763 \\
\hline \multirow{4}{*}{5} & Mo & 0.0301 & 2.51 & 21.0 & 3.9064 \\
\hline & HEU & 0.118 & 2.51 & 21.0 & 4.0244 \\
\hline & Mo & 0.0301 & 2.51 & 21.0 & 4.0545 \\
\hline & Graphite & 0.197 & 2.51 & 21.0 & 4.2515 \\
\hline \multirow{4}{*}{6} & Mo & 0.0301 & 2.51 & 21.0 & 4.2816 \\
\hline & HEU & 0.118 & 2.51 & 21.0 & 4.3996 \\
\hline & Mo & 0.0301 & 2.51 & 21.0 & 4.4297 \\
\hline & Graphite & 0.197 & 2.51 & 21.0 & 4.6267 \\
\hline \multirow{4}{*}{7} & Mo & 0.0301 & 2.51 & 21.0 & 4.6568 \\
\hline & HEU & 0.118 & 2.51 & 21.0 & 4.7748 \\
\hline & Mo & 0.0301 & 2.51 & 21.0 & 4.8049 \\
\hline & Graphite & 0.197 & 2.51 & 21.0 & 5.0019 \\
\hline \multirow{4}{*}{8} & Mo & 0.0301 & 0 & 21.0 & 5.0320 \\
\hline & HEU & 0.118 & 0 & 21,0 & 5.1500 \\
\hline & Mo & 0.0301 & 0 & 21.0 & 5.1801 \\
\hline & Graphite & 0.197 & 0 & 21.0 & 5.3771 \\
\hline Diaphragm & Stainless Steel & 0.040 & 0 & 24.8 & 5.4171 \\
\hline \multirow{4}{*}{9} & Mo & 0.0301 & 0 & 21.0 & 5.4472 \\
\hline & HEU & 0.118 & 0 & 21.0 & 5.5652 \\
\hline & Mo & 0.0301 & 0 & 21.0 & 5.5953 \\
\hline & Graphite & 0.197 & 0 & 21.0 & 5.7923 \\
\hline \multirow{4}{*}{10} & Mo & 0.0301 & 0 & 21.0 & 5.8224 \\
\hline & HEU & 0.118 & 0 & 21.0 & 5.9404 \\
\hline & Mo & 0.0301 & 0 & 21.0 & 5.9705 \\
\hline & Graphite & 0.197 & 0 & 21.0 & 6.1675 \\
\hline
\end{tabular}




\begin{tabular}{|c|c|c|c|c|c|}
\hline Unit & Material & Thickness (in) & $\begin{array}{c}\text { Inner } \\
\text { Diameter } \\
\text { (in) }\end{array}$ & $\begin{array}{l}\text { Outer } \\
\text { Diameter } \\
\text { (in) }\end{array}$ & $\begin{array}{l}\text { Assembly Height } \\
\text { (in) }\end{array}$ \\
\hline \multirow{4}{*}{11} & Mo & 0.0301 & 0 & 21.0 & 6.1976 \\
\hline & HEU & 0.118 & 0 & 21.0 & 6.3156 \\
\hline & Mo & 0.0301 & 0 & 21.0 & 6.3457 \\
\hline & Graphite & 0.197 & 0 & 21.0 & 6.5427 \\
\hline \multirow{4}{*}{12} & Mo & 0.0301 & 0 & 21.0 & 6.5728 \\
\hline & HEU & 0.118 & 0 & 21.0 & 6.6908 \\
\hline & Mo & 0.0301 & 0 & 21.0 & 6.7209 \\
\hline & Graphite & 0.197 & 0 & 21.0 & 6.9179 \\
\hline \multirow{4}{*}{13} & Mo & 0.0301 & 0 & 21.0 & 6.9480 \\
\hline & HEU & 0.118 & 0 & 21.0 & 7.0660 \\
\hline & Mo & 0.0301 & 0 & 21.0 & 7.0961 \\
\hline & Graphite & 0.197 & 0 & 21.0 & 7.2931 \\
\hline \multirow{4}{*}{14} & Mo & 0.0301 & 0 & 21.0 & 7.3232 \\
\hline & HEU & 0.118 & 6.005 & 21.0 & 7.4412 \\
\hline & Mo & 0.0301 & 0 & 21.0 & 7.4713 \\
\hline & Graphite & 0.197 & 0 & 21.0 & 7.6683 \\
\hline \multirow{4}{*}{15} & Mo & 0.0301 & 0 & 21.0 & 7.6984 \\
\hline & HEU & 0.118 & 6.005 & 21.0 & 7.8164 \\
\hline & Mo & 0.0301 & 0 & 21.0 & 7.8465 \\
\hline & Graphite & 0.197 & 0 & 21.0 & 8.0435 \\
\hline \multirow[b]{2}{*}{$\begin{array}{l}\text { Top } \\
\text { Reflector }\end{array}$} & Mo & 0.1785 & 0 & $21: 0$ & 8.2220 \\
\hline & Graphite & $\begin{array}{l}2.15 \text { (RCPO1) } \\
1.85 \text { (MCNP5) } \\
1.90 \text { (RACER, } \\
\text { MCNP5 } \\
\text { Space XS) }\end{array}$ & 0 & 21.0 & $\begin{array}{r}10.3720 \text { (RCP01) } \\
10.0720 \text { (MCNP5) } \\
10.1220 \text { (RACER } \\
\text { MCNP5 } \\
\text { Space XS) }\end{array}$ \\
\hline
\end{tabular}

Table 58. Mo-2 Assembly Material Mass Distribution

\begin{tabular}{|c|c|c|c|c|c|c|c|c|c|}
\hline \multirow{3}{*}{ Material } & \multicolumn{9}{|c|}{ Mass (kg) } \\
\cline { 2 - 11 } & \multicolumn{3}{|c|}{ MCNP5 } & \multicolumn{3}{c|}{ RCP01 } & \multicolumn{2}{c|}{ MCNP5 (Space XS)/RACER } \\
\cline { 2 - 10 } & $\begin{array}{c}\text { Lower } \\
\text { Assembly }\end{array}$ & $\begin{array}{c}\text { Upper } \\
\text { Assembly }\end{array}$ & Total & $\begin{array}{c}\text { Lower } \\
\text { Assembly }\end{array}$ & $\begin{array}{c}\text { Upper } \\
\text { Assembly }\end{array}$ & Total & $\begin{array}{c}\text { Lower } \\
\text { Assembly }\end{array}$ & $\begin{array}{c}\text { Upper } \\
\text { Assembly }\end{array}$ & Total \\
\hline HEU & 99.2 & 85.8 & 185.0 & 99.2 & 85.8 & 185.0 & 99.2 & 85.8 & 185.0 \\
\hline Mo & 37.8 & 34.8 & 72.6 & 37.8 & 34.8 & 72.6 & 37.8 & 34.8 & 72.6 \\
\hline Graphite & 36.6 & 31.7 & 68.3 & 36.6 & 34.7 & 71.3 & 36.6 & 32.2 & 68.8 \\
\hline Total & 173.6 & 152.4 & 325.9 & 173.6 & 155.3 & 328.9 & 173.6 & 152.9 & 326.4 \\
\hline
\end{tabular}




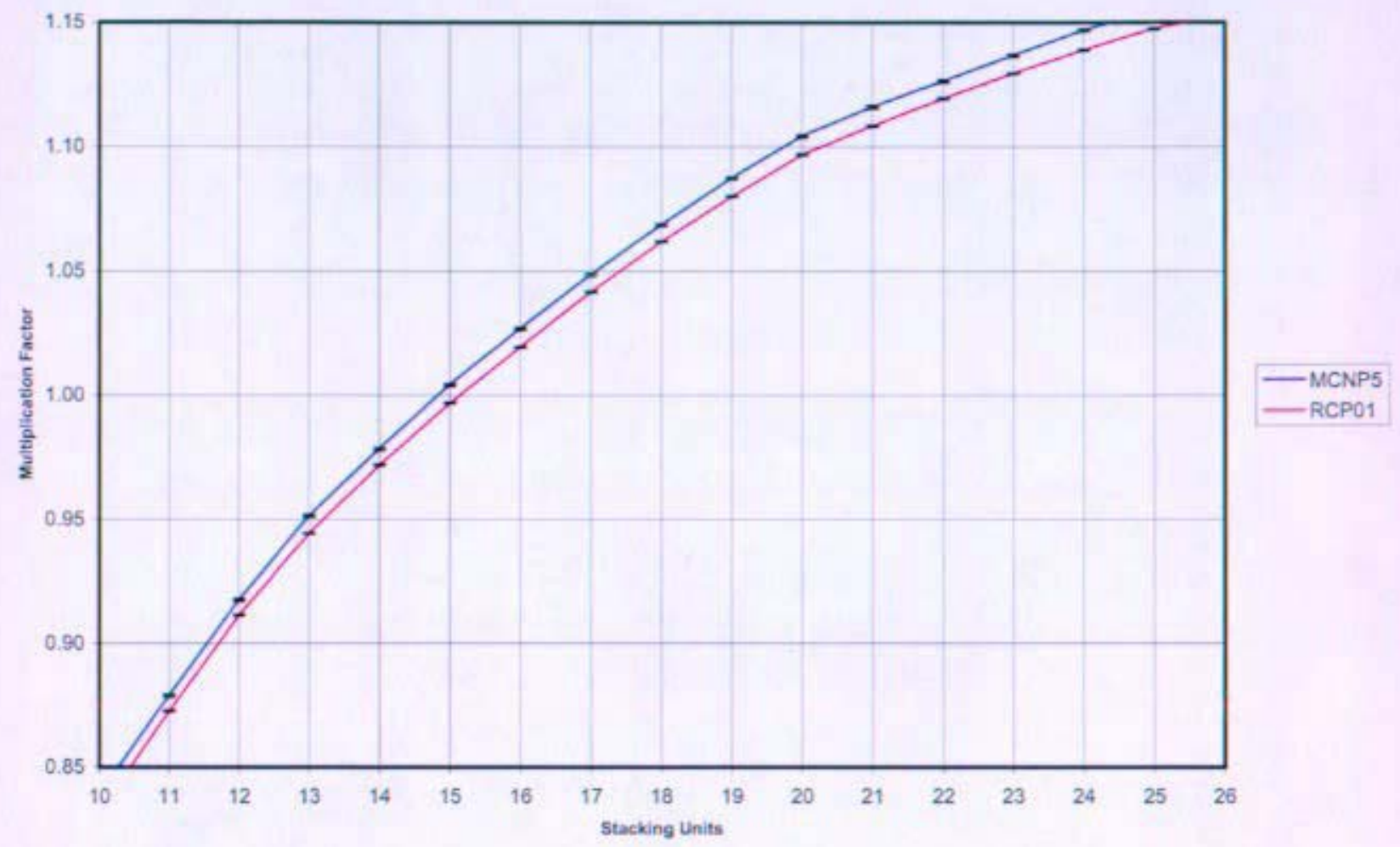

Figure 45. Mo-2 Assembly $\mathrm{k}_{\text {eff }}$ as a Function of the Number of Stacking Units

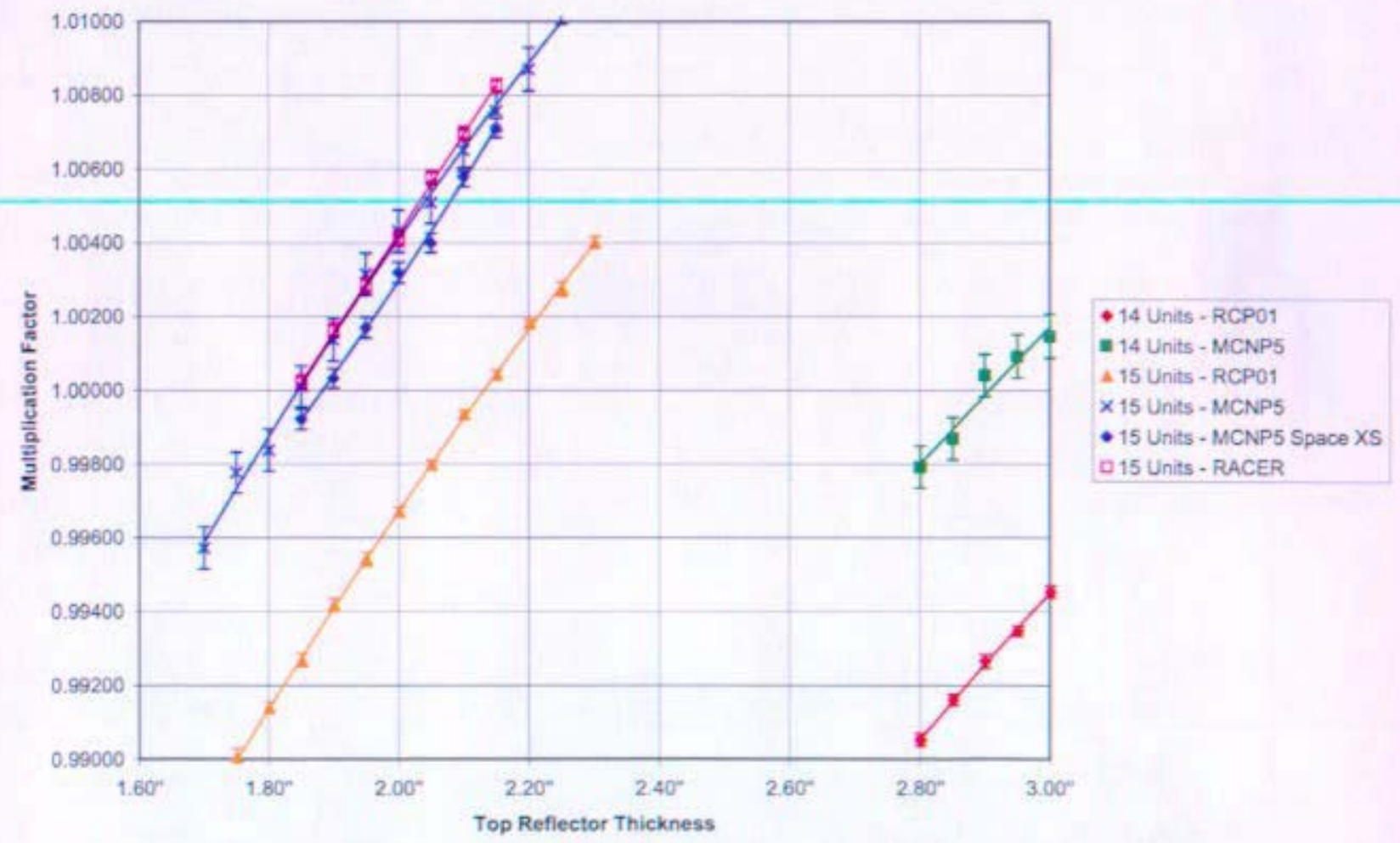

Figure 46. Mo-2 Assembly $k_{\text {eff }}$ as a Function of the Top Reflector Thickness 
Table 59. Mo-2 Assembly $k_{\text {eff }}$ as a Function of the Top Reflector Thickness

\begin{tabular}{|c|c|c|c|c|c|c|c|c|}
\hline \multicolumn{9}{|c|}{ Predicted Top Reflector Thickness } \\
\hline \multicolumn{9}{|c|}{14 Stacking Units } \\
\hline \multirow{2}{*}{$\begin{array}{c}\text { Top } \\
\text { Reflector } \\
\text { Thickness } \\
\text { (in) }\end{array}$} & \multicolumn{2}{|c|}{ MCNP5 } & \multicolumn{2}{|c|}{ MCNP5 (Space XS) } & \multicolumn{2}{|c|}{ RCP01 } & \multicolumn{2}{|c|}{ RACER } \\
\hline & $k_{\text {ett }}$ & $95 \% \mathrm{Cl}$ & $k_{\text {eff }}$ & $95 \% \mathrm{Cl}$ & $k_{\text {eff }}$ & $95 \% \mathrm{Cl}$ & $k_{\text {eff }}$ & $95 \% \mathrm{Cl}$ \\
\hline 2.80 & 0.99790 & 0.00057 & \multirow{13}{*}{\multicolumn{2}{|c|}{$\begin{array}{l}\text { Not investigated } \\
\text { due to termination } \\
\text { of project. }\end{array}$}} & 0.99051 & 0.00017 & \multirow{13}{*}{\multicolumn{2}{|c|}{$\begin{array}{l}\text { Not investigated } \\
\text { due to termination } \\
\text { of project. }\end{array}$}} \\
\hline 2.85 & 0.99868 & 0.00057 & & & 0.99159 & 0.00015 & & \\
\hline 2.90 & 1.00039 & 0.00057 & & & 0.99264 & 0.00018 & & \\
\hline 2.95 & 1.00090 & 0.00059 & & & 0.99346 & 0.00013 & & \\
\hline 3.00 & 1.00145 & 0.00059 & & & 0.99453 & 0.00016 & & \\
\hline 3.05 & 1.00240 & 0.00059 & & & 0.99546 & 0.00014 & & \\
\hline 3.10 & 1.00341 & 0.00059 & & & 0.99641 & 0.00014 & & \\
\hline 3.20 & 1.00552 & 0.00059 & & & 0.99822 & 0.00018 & & \\
\hline 3.30 & 1.00719 & 0.00057 & & & 0.99982 & 0.00018 & & \\
\hline 3.35 & 1.00783 & 0.00057 & & & 1.00075 & 0.00017 & & \\
\hline 3.40 & 1.00901 & 0.00057 & & & 1.00160 & 0.00022 & & \\
\hline 3.50 & 1.01001 & 0.00059 & & & 1.00319 & 0.00022 & & \\
\hline 3.60 & 1.01242 & 0.00057 & & & 1.00464 & 0.00016 & & \\
\hline \multicolumn{9}{|c|}{15 Stacking Units } \\
\hline Top & \multicolumn{2}{|c|}{ MCNP5 } & \multicolumn{2}{|c|}{ MCNP5 (Space XS) } & \multicolumn{2}{|c|}{ RCP01 } & \multicolumn{2}{|c|}{ RACER } \\
\hline $\begin{array}{l}\text { Thickness } \\
\text { (in) }\end{array}$ & $k_{\text {eff }}$ & $95 \% \mathrm{Cl}$ & $k_{\text {eff }}$ & $95 \% \mathrm{Cl}$ & $k_{\text {eff }}$ & $95 \% \mathrm{Cl}$ & $k_{\text {eff }}$ & $95 \% \mathrm{Cl}$ \\
\hline 1.70 & 0.99570 & 0.00057 & - & - & 0.98851 & 0.00015 & - & - \\
\hline 1.75 & 0.99775 & 0.00055 & - & - & 0.99005 & 0.00023 & - & - \\
\hline 1.80 & 0.99836 & 0.00057 & - & - & 0.99139 & 0.00016 & - & - \\
\hline 1.85 & 1.00009 & 0.00055 & 0.99920 & 0.00028 & 0.99268 & 0.00018 & 1.00021 & 0.00020 \\
\hline 1.90 & 1.00135 & 0.00057 & 1.00031 & 0.00026 & 0.99417 & 0.00017 & 1.00162 & 0.00020 \\
\hline 1.95 & 1.00313 & 0.00057 & 1.00168 & 0.00028 & 0.99540 & 0.00018 & 1.00284 & 0.00021 \\
\hline 2.00 & 1.00430 & 0.00057 & 1.00317 & 0.00028 & 0.99668 & 0.00014 & 1.00411 & 0.00021 \\
\hline 2.05 & 1.00507 & 0.00057 & 1.00398 & 0.00026 & 0.99796 & 0.00013 & 1.00576 & 0.00019 \\
\hline 2.10 & 1.00649 & 0.00057 & 1.00577 & 0.00026 & 0.99933 & 0.00011 & 1.00696 & 0.00020 \\
\hline 2.15 & 1.00756 & 0.00055 & 1.00710 & 0.00026 & 1.00041 & 0.00013 & 1.00825 & 0.00019 \\
\hline 2.20 & 1.00869 & 0.00059 & - & - & 1.00181 & 0.00010 & - & - \\
\hline 2.25 & 1.01046 & 0.00055 & - & - & 1.00274 & 0.00019 & - & - \\
\hline 2.30 & 1.01085 & 0.00057 & - & - & 1.00401 & 0.00016 & - & - \\
\hline
\end{tabular}




\subsubsection{Mo-3 Experiment}

The Mo-3 experiment is designed to bracket the average neutron spectrum of the Prometheus reactor core. It is designed to be softer than the expected average neutron energy spectrum of the core. Additional graphite has been added to the assembly to simulate the effect of neutron moderation near the reflector. A cross-sectional view and close-up view of the experimental configuration are provided in Figure 47 and Figure 48 where aluminum is yellow, graphite is blue, Mo is green, HEU is red, and stainless steel is purple (all dimensions in figures are in centimeters). The assembly configuration, including plate layout and dimensions, is shown in Table 60. The RCP01 and MCNP5 analyses predict an assembly height of $18.552 "$ ", while the MCNP5 with space cross sections and RACER analyses predict an assembly height of 17.552". The assembly rests on a $3.0^{\prime \prime}$ thick hollow Al 6061-T6 spindle plate that has a $19^{\prime \prime} \mathrm{OD}$ and $2.50^{\prime \prime}$ inner diameter. The active core region of the assembly is $8.445^{\prime \prime}$ high and contains one $0.394^{\prime \prime}$ thick graphite plate and 14 stacking units consisting of a $0.0301 "$ thick Mo plate, a $0.118^{\prime \prime}$ thick HEU plate, a $0.0301^{\prime \prime}$ thick Mo plate, and a $0.394^{\prime \prime}$ thick graphite plate. MCNP5 predicts a top HEU plate ID of $10.005^{\prime \prime}$ instead of the $6.005^{\prime \prime}$ ID of the top HEU plate found in the RCP01, MCNP5 with space cross sections, and RACER predictions. The bottom reflector consists of a $5.0^{\prime \prime}$ thick graphite reflector and a $0.1785^{\prime \prime}$ thick Mo reflector. The RCP01 and MCNP5 predicted top reflector consists of a $0.1785^{\prime \prime}$ thick Mo reflector and a $4.75^{\prime \prime}$ thick graphite reflector, while the MCNP5 with space cross sections and RACER predicted top reflector consists of a $0.1785^{\prime \prime}$ thick Mo reflector and a 3.75" thick graphite reflector. A hollow AI 6061-T6 alignment tube is assumed to extend from the bottom of the spindle plate to the top of the $6^{\text {th }}$ stacking unit. All other regions are modeled as void, except as noted in Section 4.0 for the RACER models. The Mo-3 assembly contains $69.1 \mathrm{~kg}$ of Mo. The distribution of materials in the top and bottom half of the assembly is given in Table 61 for the RCP01, MCNP5, MCNP5 with space cross sections, and RACER predicted critical configurations. It is important to note that the HEU mass in the upper assembly varies between the predicted critical configurations since MCNP5 predicted a critical configuration with a different top HEU fuel plate ID.

A series of analyses have been performed to predict the $k_{\text {eff }}$ of the Mo-3 assembly during the approach to critical as a function of both the number of stacking units and the graphite top reflector thickness. Figure 49 presents the RCP01 and MCNP5 predicted $k_{\text {eff }}$ as a function of the number of stacking units in the Mo-3 assembly. The error bars indicate the size of the $95 \%$ confidence interval in the Monte Carlo calculations. The average difference between the MCNP5 and RCP01 predicted $k_{\text {eft }}$ is $0.0072 \pm 0.0005 \Delta \mathrm{k}$ over the range from 8 to 28 stacking units. For an explanation of the bias, please refer to Section 4.2.5. Figure 50 and Table 62 provide a comparison of the predicted $k_{\text {eff }}$ of the Mo-3 assembly with 14 stacking units with a 6.005" ID top HEU fuel plate and 14 stacking units with a $10.005^{\prime \prime}$ ID top HEU fuel plate as a function of the graphite top reflector thickness. The experimental configurations that were predicted to achieve delayed criticality within TSR limits $(\rho<0.5 \$)$ are highlighted in green in Table 62 . The Mo-3 assembly is classified as a fast spectrum assembly with the following representative fission fractions, as predicted by MCNP5: $65.9 \%$ fast ( $\mathrm{E}>100 \mathrm{keV}$ ), $34.1 \%$ intermediate $(0.625 \mathrm{eV}<E<100 \mathrm{keV})$, and $0.1 \%$ thermal $(E<0.625 \mathrm{eV})$. 
B-TM-1639

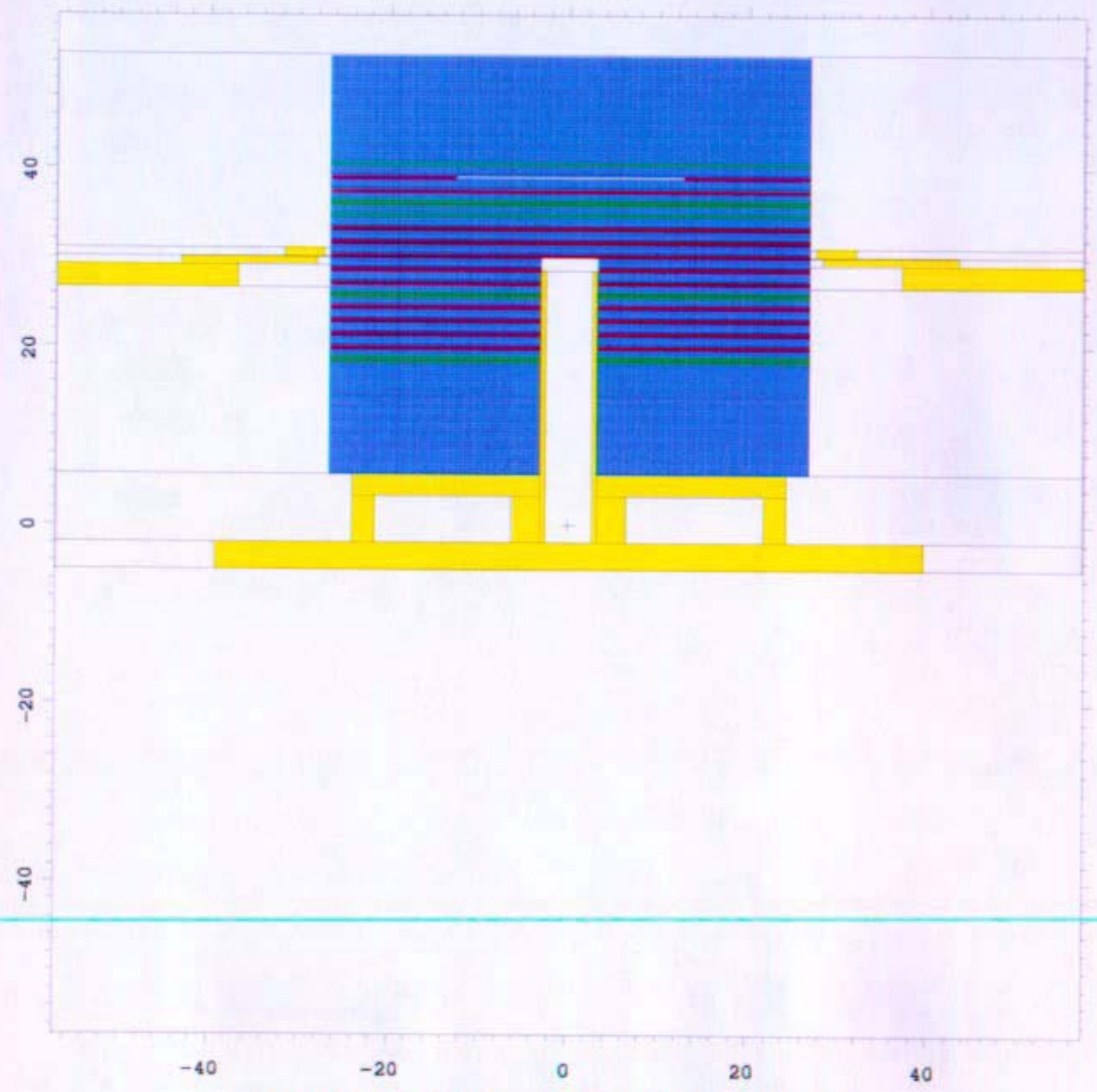

Figure 47. Cross-sectional View of the Mo-3 Assembly 
일

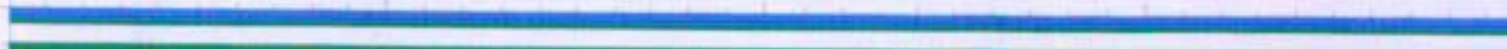

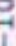

Figure 48. Cross-sectional Close-up View of the Mo-3 Assembly 
Table 60. Predicted Critical Configuration for the Mo-3 Assembly.

\begin{tabular}{|c|c|c|c|c|c|}
\hline Unit & Material & Thickness (in) & Inner Diameter (in) & $\begin{array}{c}\text { Outer } \\
\text { Diameter (in) }\end{array}$ & $\begin{array}{l}\text { Assembly Height } \\
\text { (in) }\end{array}$ \\
\hline \multirow{3}{*}{$\begin{array}{l}\text { Bottom } \\
\text { Reflector }\end{array}$} & Graphite & 5.00 & 2.51 & 21.0 & 5.0000 \\
\hline & Mo & 0.1785 & 2.51 & 21.0 & 6.1785 \\
\hline & Graphite & 0.394 & 2.51 & 21.0 & 5.5725 \\
\hline \multirow{4}{*}{1} & Mo & 0.0301 & 2.51 & 21.0 & 5.6026 \\
\hline & HEU & 0.118 & 2.51 & 21.0 & 5.7206 \\
\hline & Mo & 0.0301 & 2.51 & 21.0 & 5.7507 \\
\hline & Graphite & 0.394 & 2.51 & 21.0 & 6.1447 \\
\hline \multirow{4}{*}{2} & Mo & 0.0301 & 2.51 & 21.0 & 6.1748 \\
\hline & HEU & 0.118 & 2.51 & 21.0 & 6.2928 \\
\hline & Mo & 0.0301 & 2.51 & 21.0 & 6.3229 \\
\hline & Graphite & 0.394 & 2.51 & 21.0 & 6.7169 \\
\hline \multirow{4}{*}{3} & Mo & 0.0301 & 2.51 & 21.0 & 6.7470 \\
\hline & HEU & 0.118 & 2.51 & 21.0 & 6.8650 \\
\hline & Mo & 0.0301 & 2.51 & 21.0 & 6.8951 \\
\hline & Graphite & 0.394 & 2.51 & 21.0 & 7.2891 \\
\hline \multirow{4}{*}{4} & Mo & 0.0301 & 2.51 & 21.0 & 7.3192 \\
\hline & HEU & 0.118 & 2.51 & 21.0 & 7.4372 \\
\hline & Mo & 0.0301 & 2.51 & 21.0 & 7.4673 \\
\hline & Graphite & 0.394 & 2.51 & 21.0 & 7.8613 \\
\hline \multirow{4}{*}{5} & Mo & 0.0301 & 2.51 & 21.0 & 7.8914 \\
\hline & HEU & 0.118 & 2.51 & 21.0 & 8.0094 \\
\hline & Mo & 0.0301 & 2.51 & 21.0 & 8.0395 \\
\hline & Graphite & 0.394 & 2.51 & 21.0 & 8.4335 \\
\hline \multirow{4}{*}{6} & Mo & 0.0301 & 2.51 & 21.0 & 8.4636 \\
\hline & HEU & 0.118 & 2.51 & 21.0 & 8.5816 \\
\hline & Mo & 0.0301 & 2.51 & 21.0 & 8.6117 \\
\hline & Graphite & 0.394 & 2.51 & 21.0 & 9.0057 \\
\hline \multirow{4}{*}{7} & $\mathrm{Mo}$ & 0.0301 & 2.51 & 21.0 & 9.0358 \\
\hline & HEU & 0.118 & 2.51 & 21.0 & 9.1538 \\
\hline & Mo & 0.0301 & 2.51 & 21.0 & 9.1839 \\
\hline & Graphite & 0.394 & 2.51 & 21.0 & 9.5779 \\
\hline Diaphragm & Stainless Steel & 0.040 & 0 & 24.8 & 9.6179 \\
\hline \multirow{4}{*}{$x^{-1}+2$} & Mo & 0.0301 & 0 & 21.0 & 9.6480 \\
\hline & HEU & 0.118 & 0 & 21.0 & 9.7660 \\
\hline & Mo & 0.0301 & 0 & 21.0 & 9.7961 \\
\hline & Graphite & 0.394 & 0 & 21.0 & 10.1901 \\
\hline \multirow{4}{*}{9} & Mo & 0.0301 & 0 & 21.0 & 10.2202 \\
\hline & HEU & 0.118 & 0 & 21.0 & 10.3382 \\
\hline & Mo & 0.0301 & 0 & 21.0 & 10.3683 \\
\hline & Graphite & 0.394 & 0 & 21.0 & 10.7623 \\
\hline \multirow{4}{*}{10} & Mo & 0.0301 & 0 & 21.0 & 10.7924 \\
\hline & HEU & 0.118 & 0 & 21.0 & 10.9104 \\
\hline & Mo & 0.0301 & 0 & 21.0 & 10.9405 \\
\hline & Graphite & 0.394 & 0 & 21.0 & 11.3345 \\
\hline
\end{tabular}




\begin{tabular}{|c|c|c|c|c|c|}
\hline Unit & Material & Thickness (in) & Inner Diameter (in) & $\begin{array}{c}\text { Outer } \\
\text { Diameter (in) }\end{array}$ & $\begin{array}{l}\text { Assembly Height } \\
\text { (in) }\end{array}$ \\
\hline \multirow{4}{*}{11} & Mo & 0.0301 & 0 & 21.0 & 11.3646 \\
\hline & HEU & 0.118 & 0 & 21.0 & 11.4826 \\
\hline & Mo & 0.0301 & 0 & 21.0 & 11.5127 \\
\hline & Graphite & 0.394 & 0 & 21.0 & 11.9067 \\
\hline \multirow{4}{*}{12} & Mo & 0.0301 & 0 & 21.0 & 11.9368 \\
\hline & HEU & 0.118 & 0 & 21.0 & 12.0548 \\
\hline & Mo & 0.0301 & 0 & 21.0 & 12.0849 \\
\hline & Graphite & 0.394 & 0 & 21.0 & 12.4789 \\
\hline \multirow{4}{*}{13} & Mo & 0.0301 & 0 & 21.0 & 12.5090 \\
\hline & HEU & 0.118 & 0 & 21.0 & 12.6270 \\
\hline & Mo & 0.0301 & 0 & 21.0 & 12.6571 \\
\hline & Graphite & 0.394 & 0 & 21.0 & 13.0511 \\
\hline \multirow{4}{*}{14} & Mo & 0.0301 & 0 & 21.0 & 13.0812 \\
\hline & HEU & 0.118 & $\begin{array}{c}6.005 \text { (RCP01, } \\
\text { MCNP5 Space XS, } \\
\text { RACER) } \\
10.005 \text { (MCNP5) }\end{array}$ & 21.0 & 13.1992 \\
\hline & Mo & 0.0301 & 0 & 21.0 & 13.2293 \\
\hline & Graphite & 0.394 & 0 & 21.0 & 13.6233 \\
\hline & Mo & 0.1785 & 0 & 21.0 & 13.8018 \\
\hline $\begin{array}{c}\text { Top } \\
\text { Reflector }\end{array}$ & Graphite & $\begin{array}{r}4.75 \text { (RCP01, } \\
\text { MONP5) } \\
3.75 \text { (RACER, } \\
\text { MCNP5 } \\
\text { Space XS) }\end{array}$ & 0 & 21.0 & $\begin{array}{r}18.5518 \text { (RCP01, } \\
\text { MCNP5) } \\
17.5518 \text { (RACER, } \\
\text { MCNPS } \\
\text { Space XS }\end{array}$ \\
\hline
\end{tabular}

Table 61. Mo-3 Assembly Material Mass Distribution

\begin{tabular}{|c|c|c|c|c|c|c|c|c|c|}
\hline \multirow{3}{*}{ Material } & \multicolumn{9}{|c|}{ Mass (kg) } \\
\hline & \multicolumn{3}{|c|}{ MCNP5 } & \multicolumn{3}{|c|}{ RCP01 } & \multicolumn{3}{|c|}{ MCNP5 (Space XS)/RACER } \\
\hline & $\begin{array}{c}\text { Lower } \\
\text { Assembly }\end{array}$ & $\begin{array}{c}\text { Upper } \\
\text { Assembly }\end{array}$ & Total & $\begin{array}{c}\text { Lower } \\
\text { Assembly }\end{array}$ & $\begin{array}{c}\text { Upper } \\
\text { Assembly }\end{array}$ & Total & $\begin{array}{c}\text { Lower } \\
\text { Assembly }\end{array}$ & $\begin{array}{c}\text { Upper } \\
\text { Assembly }\end{array}$ & Total \\
\hline HEU & 86.6 & 85.0 & 171.6 & 86.6 & 86.8 & 173.5 & 86.6 & 86.8 & 173.5 \\
\hline Mo & 34.3 & 34.8 & 69.1 & 34.3 & 34.8 & 69.1 & 34.3 & 34.8 & 69.1 \\
\hline Graphite & 79.0 & 73.8 & 152.8 & 79.0 & 73.8 & 152.8 & 79.0 & 64.0 & 143.0 \\
\hline Total & 199.9 & 193.6 & 393.5 & 199.9 & 195.5 & 395.4 & 199.9 & 185.6 & 385.5 \\
\hline
\end{tabular}


B-TM-1639

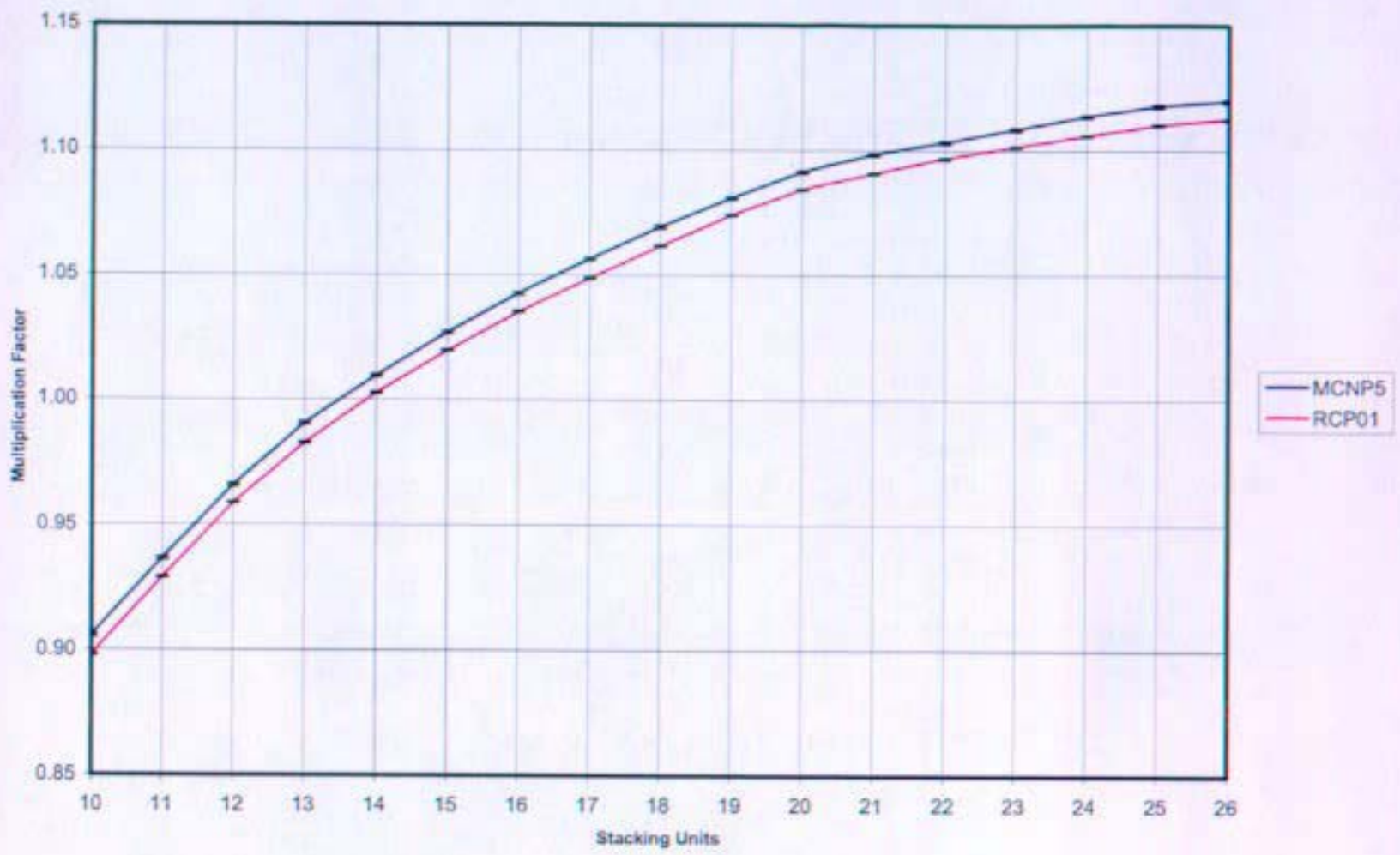

Figure 49. Mo-3 Assembly $k_{\text {eff }}$ as a Function of the Number of Stacking Units

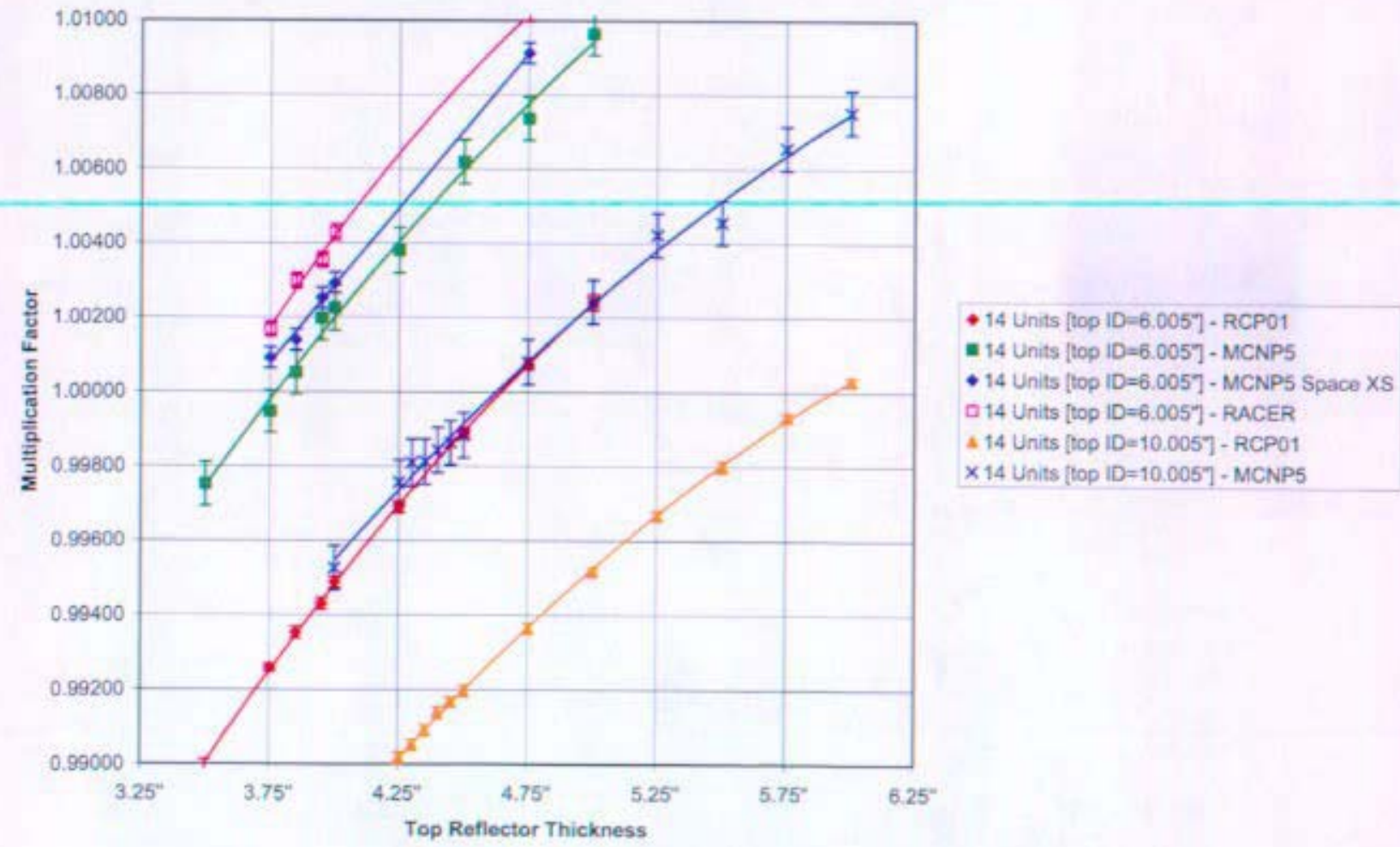

Figure 50. Mo-3 Assembly $k_{\text {eft }}$ as a Function of the Top Reflector Thickness 
Table 62. Mo-3 Assembly $k_{\text {eff }}$ as a Function of the Top Reflector Thickness

\begin{tabular}{|c|c|c|c|c|c|c|c|c|}
\hline \multicolumn{9}{|c|}{ Predicted Top Reflector Thickness } \\
\hline \multicolumn{9}{|c|}{14 Stacking Units } \\
\hline \multirow{2}{*}{$\begin{array}{l}\text { Top } \\
\text { Reflector } \\
\text { Thickness } \\
\text { (in) }\end{array}$} & \multicolumn{2}{|c|}{ MCNP5 } & \multicolumn{2}{|c|}{ MCNP5 (Space XS) } & \multicolumn{2}{|c|}{ RCP01 } & \multicolumn{2}{|c|}{ RACER } \\
\hline & $k_{\text {ett }}$ & $95 \% \mathrm{Cl}$ & $k_{\text {eff }}$ & $95 \% \mathrm{Cl}$ & $k_{\text {eff }}$ & $95 \% \mathrm{Cl}$ & $k_{\text {etf }}$ & $95 \% \mathrm{Cl}$ \\
\hline 3.50 & 0.99751 & 0.00059 & $=$ & - & 0.98994 & 0.00018 & - & - \\
\hline 3.75 & 0.99945 & 0.00057 & 1.00090 & 0.00028 & 0.99259 & 0.00010 & 1.00168 & 0,00020 \\
\hline 3.85 & 1.00050 & 0.00059 & 1.00138 & 0.00028 & 0.99353 & 0.00016 & 1.00298 & 0.00021 \\
\hline 3.95 & 1.00196 & 0.00059 & 1.00251 & 0.00028 & 0.99430 & 0.00016 & 1.00354 & 0.00021 \\
\hline 4.00 & 1.00224 & 0.00061 & 1.00292 & 0.00028 & 0.99488 & 0.00015 & 1.00429 & 0.00022 \\
\hline 4.25 & 1.00379 & 0.00061 & - & - & 0.99690 & 0.00015 & - & - \\
\hline 4.50 & 1.00618 & 0.00059 & - & - & 0.99887 & 0.00013 & - & - \\
\hline 4.75 & 1.00735 & 0.00059 & 1.00912 & 0.00028 & 1.00075 & 0.00015 & 1.01019 & 0.00022 \\
\hline 5.00 & 1.00963 & 0.00057 & - & - & 1.00241 & 0.00021 & - & - \\
\hline \multicolumn{9}{|c|}{14 Stacking Units with a $10.005^{\prime \prime}$ ID top HEU fuel plate } \\
\hline \multirow{2}{*}{$\begin{array}{l}\text { Top } \\
\text { Reflector } \\
\text { Thickness } \\
\text { (in) }\end{array}$} & \multicolumn{2}{|c|}{ MCNP5 } & \multicolumn{2}{|c|}{ MCNP5 (Space XS) } & \multicolumn{2}{|c|}{ RCP01 } & \multicolumn{2}{|c|}{ RACER } \\
\hline & $k_{\text {eft }}$ & $95 \% \mathrm{Cl}$ & $k_{\text {eff }}$ & $95 \% \mathrm{Cl}$ & $\mathbf{k}_{\text {eff }}$ & $95 \% \mathrm{Cl}$ & $\mathbf{k}_{\text {eff }}$ & $95 \% \mathrm{Cl}$ \\
\hline 4.00 & 0.99526 & 0.00059 & \multirow{7}{*}{\multicolumn{2}{|c|}{$\begin{array}{l}\text { Not investigated } \\
\text { due to termination }\end{array}$}} & 0.98807 & 0.00017 & \multirow{7}{*}{\multicolumn{2}{|c|}{$\begin{array}{l}\text { Not investigated } \\
\text { due to termination }\end{array}$}} \\
\hline 4.25 & 0.99756 & 0.00059 & & & 0.99015 & 0.00015 & & \\
\hline 4.30 & 0.99808 & 0.00063 & & & 0.99050 & 0.00015 & & \\
\hline 4.35 & 0.99811 & 0.00061 & & & 0.99089 & 0.00015 & & \\
\hline 4.40 & 0.99842 & 0.00061 & & & 0.99137 & 0.00016 & & \\
\hline 4.45 & 0.99862 & 0.00059 & & & 0.99165 & 0.00013 & & \\
\hline 4.50 & 0.99882 & 0.00061 & & & 0.99196 & 0.00015 & & \\
\hline 4.75 & 1.00079 & 0.00061 & \multirow{6}{*}{\multicolumn{2}{|c|}{ of project. }} & 0.99363 & 0.00014 & \multirow{6}{*}{\multicolumn{2}{|c|}{ of project. }} \\
\hline 5.00 & 1.00241 & 0.00059 & & & 0.99516 & 0.00010 & & \\
\hline 5.25 & 1.00421 & 0.00059 & & & 0.99666 & 0.00013 & & \\
\hline 5.50 & 1.00455 & 0.00059 & & & 0.99798 & 0.00015 & & \\
\hline 5.75 & 1.00655 & 0.00059 & & & 0.99931 & 0.00010 & & \\
\hline 6.00 & 1.00751 & 0.00059 & & & 1.00028 & 0.00010 & & \\
\hline
\end{tabular}




\subsubsection{Mo-4 Experiment}

The Mo-4 experiment is designed to simulate the average neutron spectrum of the Prometheus reactor core when flooded with water. Polyethylene is used to simulate flooding with water. A crosssectional view and close-up view of the experimental configuration are provided in Figure 51 and Figure 52 where aluminum is yellow, polyethylene is light blue, Mo is green, HEU is red, and stainless steel is purple (all dimensions in figures are in centimeters). The assembly configuration, including plate layout and dimensions, is shown in Table 63. The RCP01 analysis predicts an assembly height of 5.317", the MCNP5 analysis predicts an assembly height of $5.257^{\prime \prime}$, and the MCNP5 with space cross sections and RACER analyses predict an assembly height of $5.197^{\prime \prime}$. The assembly rests on a $3.0^{\prime \prime}$ thick hollow Al 6061-T6 spindle plate that has a $19^{\prime \prime} \mathrm{OD}$ and $2.50^{\prime \prime}$ inner diameter. The active core region of the assembly is $2.960^{\prime \prime}$ high and contains one $0.080^{\prime \prime}$ thick polyethylene plate and 11 stacking units consisting of a $0.0301^{\prime \prime}$ thick Mo plate, a $0.118^{\prime \prime}$ thick HEU plate, a $0.0301^{\prime \prime}$ thick Mo

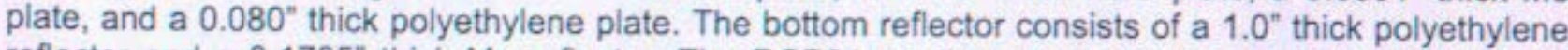
reflector and a $0.1785^{\prime \prime}$ thick Mo reflector. The RCP01 predicted top reflector consists of a $0.1785^{\prime \prime}$ thick Mo reflector and a 1.00" thick polyethylene reflector, the MCNP5 predicted top reflector consists of a $0.1785^{\prime \prime}$ thick Mo reflector and a $0.94^{\prime \prime}$ thick polyethylene reflector, and the MCNP5 with space cross sections and RACER predicted top reflector consists of a $0.1785^{\prime \prime}$ thick Mo reflector and a $0.88^{\prime \prime}$ thick polyethylene reflector. A hollow Al 6061-T6 alignment tube is assumed to extend from the bottom of the spindle plate to the top of the $5^{\text {th }}$ stacking unit. All other regions are modeled as void, except as noted in Section 4.0 for the RACER models. The Mo-4 assembly contains $137.0 \mathrm{~kg}$ of HEU and $58.7 \mathrm{~kg}$ of Mo. The distribution of materials in the top and bottom half of the assembly is given in Table 64 for the RCP01, MCNP5, MCNP5 with space cross sections, and RACER predicted critical configurations.

A series of analyses have been performed to predict the $k_{\text {eff }}$ of the Mo-4 assembly during the approach to critical as a function of both the number of stacking units and the polyethylene top reflector thickness. Figure 53 presents the RCP01 and MCNP5 predicted $k_{\text {eff }}$ as a function of the number of stacking units in the Mo-4 assembly. The error bars indicate the size of the $95 \%$ confidence interval in the Monte Carlo calculations. The average difference between the MCNP5 and RCP01 predicted $k_{\text {eff }}$ is $0.0037 \pm 0.0006 \Delta \mathrm{k}$ over the range from 8 to 28 stacking units. For an explanation of the bias, please refer to Section 4.2.5. Figure 54 and Table 65 provide a comparison of the predicted $k_{\text {eft }}$ of the Mo-4 assembly with 10 and 11 stacking units as a function of the polyethylene top reflector thickness. The experimental configurations that were predicted to achieve delayed criticality within TSR limits $(\rho<0.5 \$)$ are highlighted in green in Table 65. The Mo-4 assembly is classified as a mixed spectrum assembly with the following representative fission fractions, as predicted by MCNP5: $45.2 \%$ fast $(E>100 \mathrm{keV}), 45.3 \%$ intermediate $(0.625 \mathrm{eV}<E<100 \mathrm{keV})$, and $9.5 \%$ thermal $(E<0.625 \mathrm{eV})$. 
B-TM-1639

?

ำ

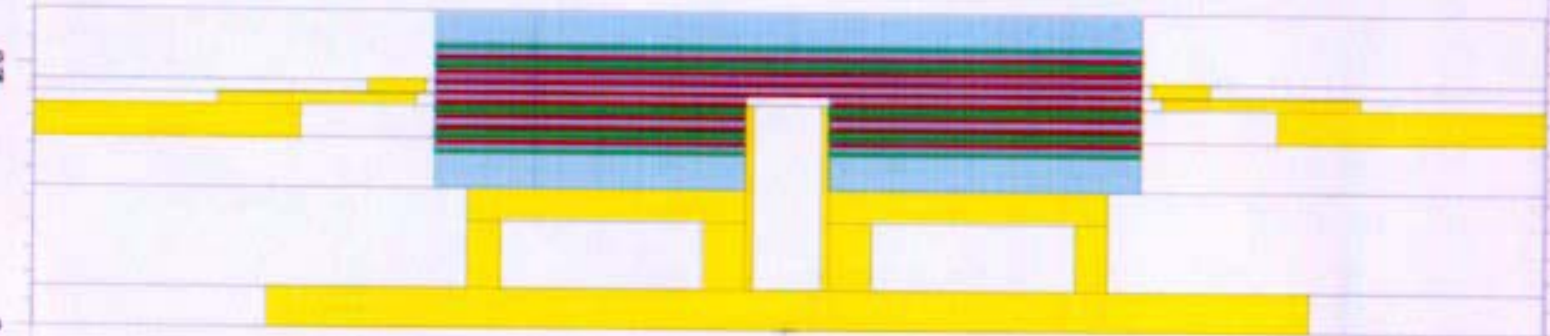

ชุ

$ㅇ ㅜ$

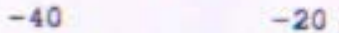

0

20

40

Figure 51. Cross-sectional View of the Mo-4 Assembly 


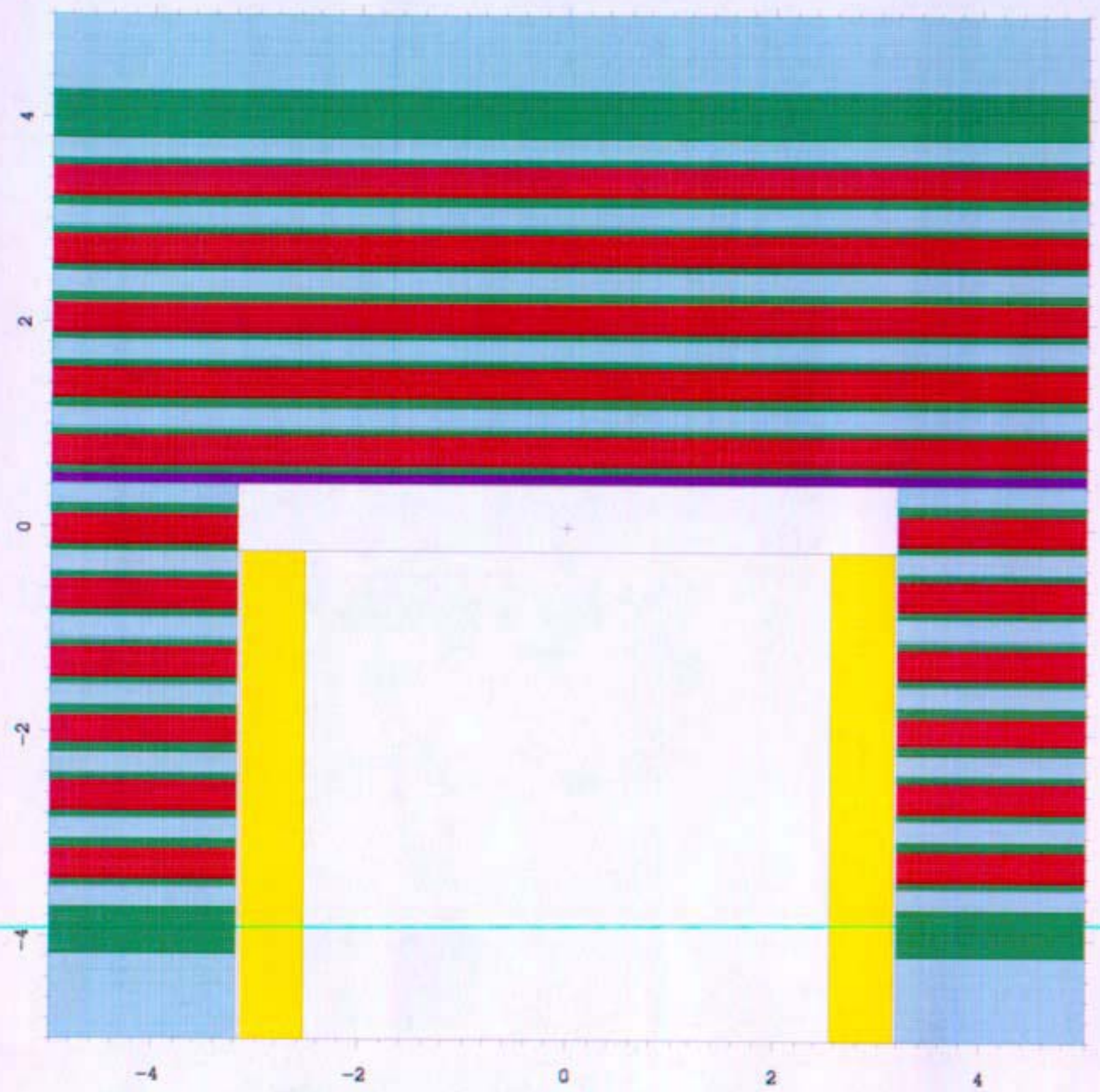

Figure 52. Cross-sectional Close-up View of the Mo-4 Assembly 
Table 63. Predicted Critical Configuration of the Mo-4 Assembly

\begin{tabular}{|c|c|c|c|c|c|}
\hline Unit & Material & Thickness (in) & $\begin{array}{c}\text { Inner } \\
\text { Diameter (in) }\end{array}$ & $\begin{array}{c}\text { Outer } \\
\text { Diameter (in) }\end{array}$ & $\begin{array}{l}\text { Assembly Height } \\
\text { (in) }\end{array}$ \\
\hline \multirow{3}{*}{$\begin{array}{l}\text { Boltom } \\
\text { Reflector }\end{array}$} & Poly & 1.00 & 2.51 & 21.0 & 1.0000 \\
\hline & Mo & 0.1785 & 2.51 & 21.0 & 1.1785 \\
\hline & Poly & 0.080 & 2.51 & 21.0 & 1.2585 \\
\hline \multirow{4}{*}{1} & Mo & 0.0301 & 2.51 & 21.0 & 1.2886 \\
\hline & HEU & 0.118 & 2.51 & 21.0 & 1.4066 \\
\hline & Mo & 0.0301 & 2.51 & 21.0 & 1.4367 \\
\hline & Poly & 0.080 & 2.51 & 21.0 & 1.5167 \\
\hline \multirow{4}{*}{2} & Mo & 0.0301 & 2.51 & 21.0 & 1.5468 \\
\hline & HEU & 0.118 & 2.51 & 21.0 & 1.6648 \\
\hline & Mo & 0.0301 & 2.51 & 21.0 & 1.6949 \\
\hline & Poly & 0.080 & 2.51 & 21.0 & 1.7749 \\
\hline \multirow{4}{*}{3} & Mo & 0.0301 & 2.51 & 21.0 & 1.8050 \\
\hline & HEU & 0.118 & 2.51 & 21.0 & 1.9230 \\
\hline & Mo & 0.0301 & 2.51 & 21.0 & 1.9531 \\
\hline & Poly & 0.080 & 2.51 & 21.0 & 2.0331 \\
\hline \multirow{4}{*}{4} & Mo & 0.0301 & 2.51 & 21.0 & 2.0632 \\
\hline & HEU & 0.118 & 2.51 & 21.0 & 2.1812 \\
\hline & Mo & 0.0301 & 2.51 & 21.0 & 2.2113 \\
\hline & Poly & 0.080 & 2.51 & 21.0 & 2.2913 \\
\hline \multirow{4}{*}{5} & Mo & 0.0301 & 2.51 & 21.0 & 2.3214 \\
\hline & HEU & 0.118 & 2.51 & 21.0 & 2.4394 \\
\hline & Mo & 0.0301 & 2.51 & 21.0 & 2.4695 \\
\hline & Poly & 0.080 & 2.51 & 21.0 & 2.5495 \\
\hline \multirow{4}{*}{6} & Mo & 0.0301 & 2.51 & 21.0 & 2.5796 \\
\hline & HEU & 0.118 & 2.51 & 21.0 & 2.6976 \\
\hline & Mo & 0.0301 & 2.51 & 21.0 & 2.7277 \\
\hline & Poly & 0.080 & 2.51 & 21.0 & 2.8077 \\
\hline Diaphragm & Stainless Steel & 0.040 & 0 & 24.8 & 2.8477 \\
\hline \multirow{4}{*}{7} & Mo & 0.0301 & 0 & 21.0 & 2.8778 \\
\hline & HEU & 0.118 & 0 & 21.0 & 2.9958 \\
\hline & Mo & 0.0301 & 0 & 21.0 & 3.0259 \\
\hline & Poly & 0.080 & 0 & 21.0 & 3.1059 \\
\hline \multirow{4}{*}{8} & Mo & 0.0301 & 0 & 21.0 & 3.1360 \\
\hline & HEU & 0.118 & 0 & 21.0 & 3.2540 \\
\hline & Mo & 0.0301 & 0 & 21.0 & 3.2841 \\
\hline & Poly & 0.080 & 0 & 21.0 & 3.3641 \\
\hline \multirow{4}{*}{9} & Mo & 0.0301 & 0 & 21.0 & 3.3942 \\
\hline & HEU & 0.118 & 0 & 21.0 & 3.5122 \\
\hline & Mo & 0.0301 & 0 & 21.0 & 3.5423 \\
\hline & Poly & 0.080 & 0 & 21.0 & 3.6223 \\
\hline \multirow{4}{*}{10} & Mo & 0.0301 & 0 & 21.0 & 3.6524 \\
\hline & HEU & 0.118 & 0 & 21.0 & 3.7704 \\
\hline & Mo & 0.0301 & 0 & 21.0 & 3.8005 \\
\hline & Poly & 0.080 & 0 & 21.0 & 3.8805 \\
\hline
\end{tabular}


B-TM-1639

\begin{tabular}{|c|c|c|c|c|c|}
\hline Unit & Material & Thickness (in) & $\begin{array}{c}\text { Inner } \\
\text { Diameter (in) }\end{array}$ & $\begin{array}{c}\text { Outer } \\
\text { Diameter (in) }\end{array}$ & $\begin{array}{l}\text { Assembly Height } \\
\text { (in) }\end{array}$ \\
\hline \multirow{4}{*}{11} & Mo & 0.0301 & 0 & 21.0 & 3.9106 \\
\hline & HEU & 0.118 & 0 & 21.0 & 4.0286 \\
\hline & Mo & 0.0301 & 0 & 21.0 & 4.0587 \\
\hline & Poly & 0.080 & 0 & 21.0 & 4.1387 \\
\hline \multirow[b]{2}{*}{$\begin{array}{l}\text { Top } \\
\text { Reflector }\end{array}$} & Mo & 0.1785 & 0 & 21.0 & 4.3172 \\
\hline & Poly & $\begin{array}{c}1.00 \text { (RCPD1) } \\
0.94 \text { (MCNP5) } \\
0.88 \text { (RACER } \\
\text { MCNP5 Space Xs) }\end{array}$ & 0 & 210 & $\begin{array}{l}5.3172 \text { (RCPO1) } \\
5.2572 \text { (MCNP5) } \\
5.1972 \text { (RACER, } \\
\text { MCNP5 Space XS) }\end{array}$ \\
\hline
\end{tabular}

Table 64. Mo-4 Assembly Material Mass Distribution

\begin{tabular}{|c|c|c|c|c|c|c|c|c|c|}
\hline \multirow{3}{*}{ Material } & \multicolumn{9}{|c|}{ Mass (kg) } \\
\cline { 2 - 12 } & \multicolumn{3}{|c|}{ MCNP5 } & \multicolumn{3}{c|}{ RCP01 } \\
\cline { 2 - 11 } & $\begin{array}{c}\text { Lower } \\
\text { Assembly }\end{array}$ & $\begin{array}{c}\text { Upper } \\
\text { Assembly }\end{array}$ & Total & $\begin{array}{c}\text { Lower } \\
\text { Assembly }\end{array}$ & $\begin{array}{c}\text { Upper } \\
\text { Assembly }\end{array}$ & Total & $\begin{array}{c}\text { Lower } \\
\text { Assembly }\end{array}$ & $\begin{array}{c}\text { Upper } \\
\text { Assembly }\end{array}$ & Total \\
\hline HEU & 74.2 & 62.8 & 137.0 & 74.2 & 62.8 & 137.0 & 74.2 & 62.8 & 137.0 \\
\hline Mo & 30.9 & 27.8 & 58.7 & 30.9 & 27.8 & 58.7 & 30.9 & 27.8 & 58.7 \\
\hline Polyethylene & 8.4 & 7.3 & 15.6 & 8.4 & 7.6 & 16.0 & 8.4 & 7.0 & 15.3 \\
\hline Total & 113.5 & $\mathbf{9 7 . 9}$ & $\mathbf{2 1 1 . 3}$ & $\mathbf{1 1 3 . 5}$ & $\mathbf{9 8 . 2}$ & $\mathbf{2 1 1 . 6}$ & $\mathbf{1 1 3 . 5}$ & $\mathbf{9 7 . 5}$ & $\mathbf{2 1 1 . 0}$ \\
\hline
\end{tabular}




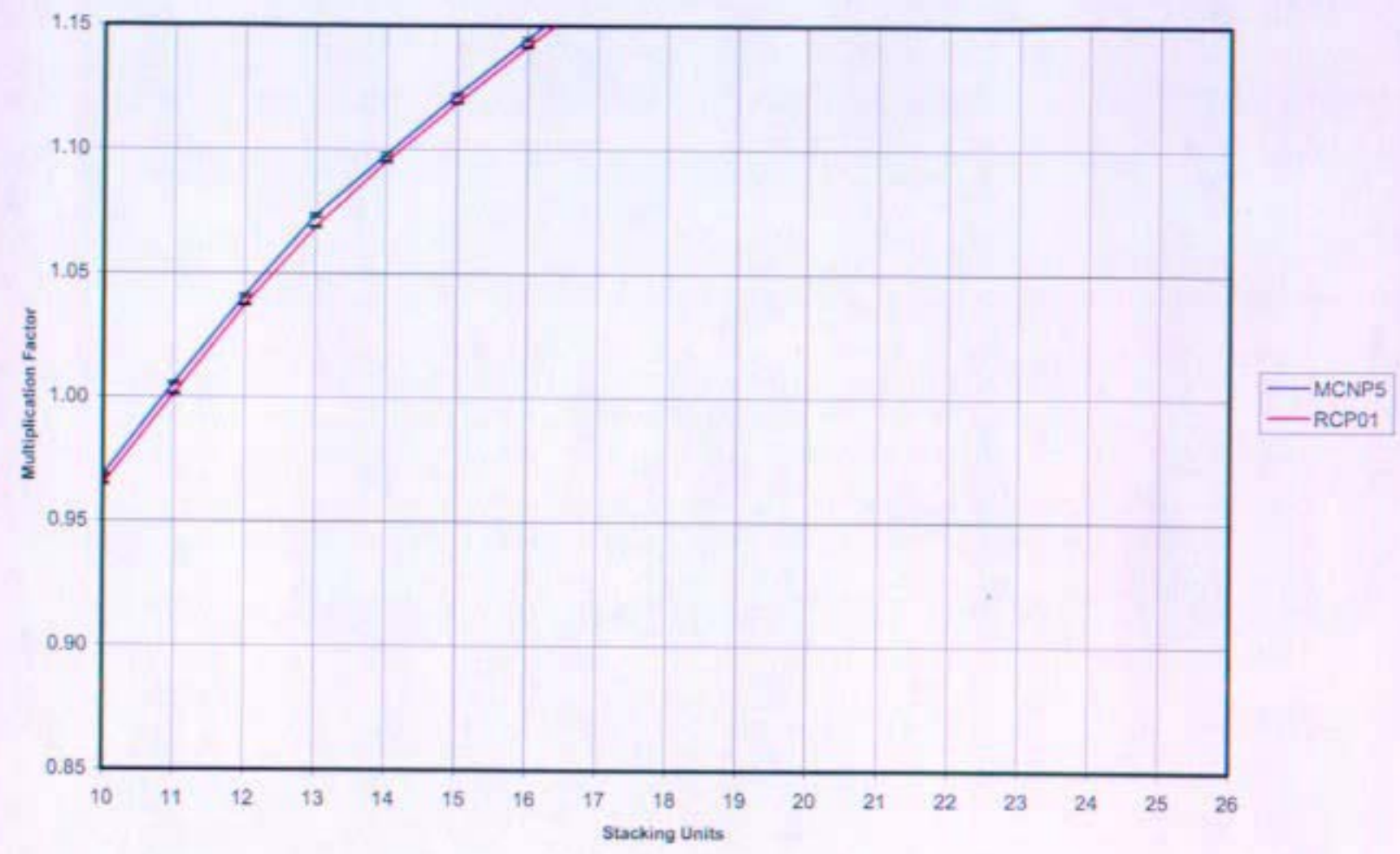

Figure 53. Mo-4 Assembly $k_{\text {ett }}$ as a Function of the Number of Stacking Units

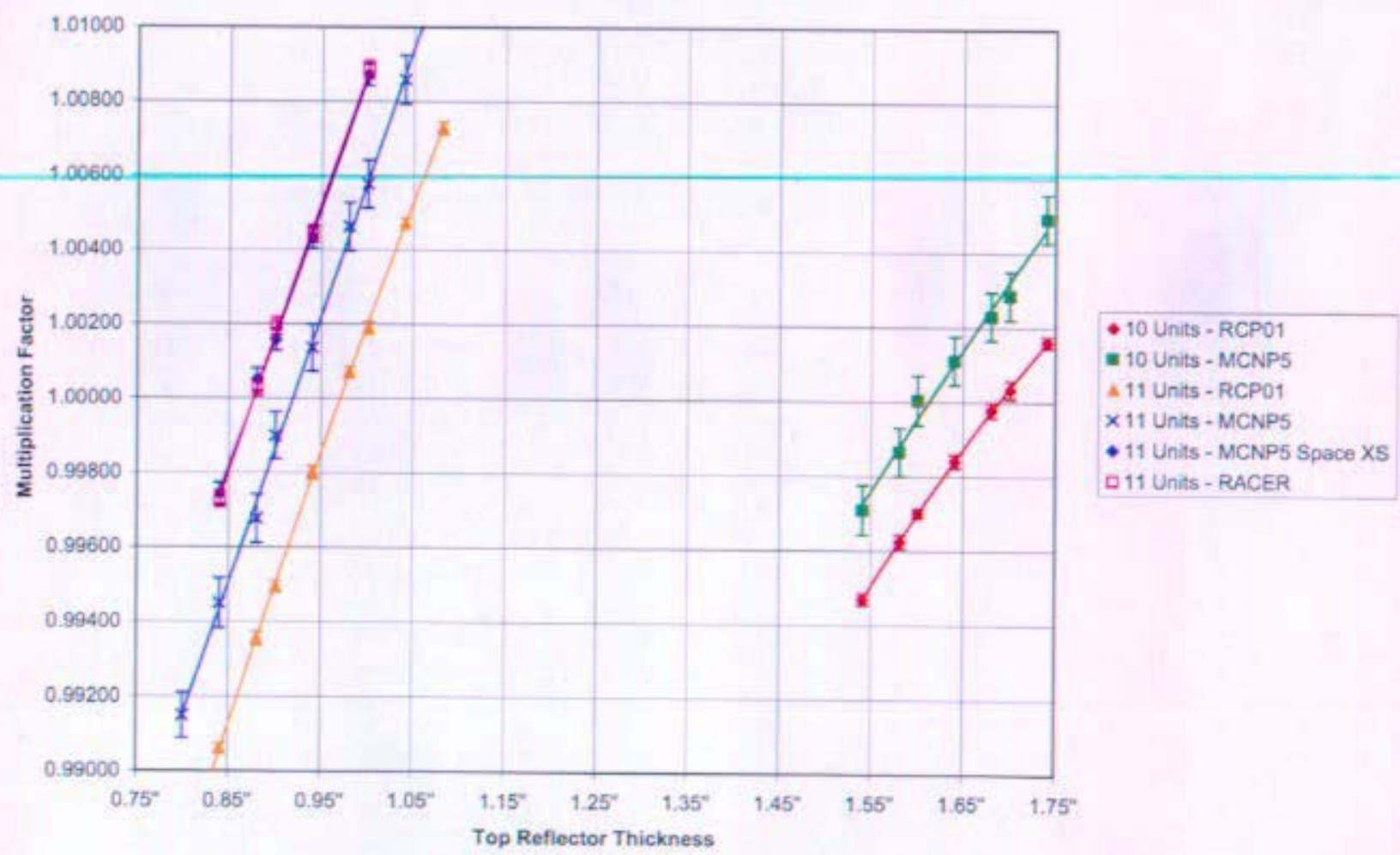

Figure 54. Mo-4 Assembly $k_{\text {eft }}$ as a Function of the Top Reflector Thickness 
Table 65. Mo-4 Assembly $k_{\text {eff }}$ as a Function of the Top Reflector Thickness

\begin{tabular}{|c|c|c|c|c|c|c|c|c|}
\hline \multicolumn{9}{|c|}{ Predicted Top Reflector Thickness } \\
\hline \multicolumn{9}{|c|}{10 Stacking Units } \\
\hline \multirow{2}{*}{$\begin{array}{c}\text { Top } \\
\text { Reflector } \\
\text { Thickness } \\
\text { (in) } \\
\end{array}$} & \multicolumn{2}{|c|}{ MCNP5 } & \multicolumn{2}{|c|}{ MCNP5 (Space XS) } & \multicolumn{2}{|c|}{ RCP01 } & \multicolumn{2}{|c|}{ RACER } \\
\hline & $k_{\text {eff }}$ & $95 \% \mathrm{Cl}$ & $k_{\text {eff }}$ & $95 \% \mathrm{Cl}$ & $k_{\text {eff }}$ & $95 \% \mathrm{Cl}$ & $k_{\text {eff }}$ & $95 \% \mathrm{Cl}$ \\
\hline 1.54 & 0.99708 & 0.00067 & \multirow{7}{*}{\multicolumn{2}{|c|}{$\begin{array}{l}\text { Not investigated due } \\
\text { to termination of } \\
\text { project. }\end{array}$}} & 0.99469 & 0.00015 & \multirow{7}{*}{\multicolumn{2}{|c|}{$\begin{array}{l}\text { Not investigated } \\
\text { due to termination } \\
\text { of project. }\end{array}$}} \\
\hline 1.58 & 0.99864 & 0.00065 & & & 0.99624 & 0.00019 & & \\
\hline 1.60 & 1.00003 & 0.00067 & & & 0.99700 & 0.00012 & & \\
\hline 1.64 & 1.00110 & 0.00065 & & & 0.99841 & 0.00018 & & \\
\hline 1.68 & 1.00229 & 0.00065 & & & 0.99978 & 0.00020 & & \\
\hline 1.70 & 1.00284 & 0.00065 & & & 1.00033 & 0.00024 & & \\
\hline 1.74 & 1.00491 & 0.00065 & & & 1.00160 & 0.00015 & & \\
\hline \multicolumn{9}{|c|}{11 Stacking Units } \\
\hline \multirow{2}{*}{$\begin{array}{l}\text { Top } \\
\text { Reflector } \\
\text { Thickness } \\
\text { (in) }\end{array}$} & \multicolumn{2}{|c|}{ MCNP5 } & \multicolumn{2}{|c|}{ MCNP5 (Space XS) } & \multicolumn{2}{|c|}{ RCP01 } & \multicolumn{2}{|c|}{ RACER } \\
\hline & $k_{\text {eff }}$ & $95 \% \mathrm{Cl}$ & $k_{\text {eff }}$ & $95 \% \mathrm{Cl}$ & $k_{\text {eff }}$ & $95 \% \mathrm{Cl}$ & $k_{\text {eff }}$ & $95 \% \mathrm{Cl}$ \\
\hline 0.80 & 0.99148 & 0.00061 & - & - & 0.98734 & 0.00018 & - & - \\
\hline 0.84 & 0.99449 & 0.00067 & 0.99742 & 0.00030 & 0.99061 & 0.00013 & 0.99729 & 0.00023 \\
\hline 0.88 & 0.99676 & 0.00065 & 1.00050 & 0.00030 & 0.99356 & 0.00018 & 1.00030 & 0.00023 \\
\hline 0.90 & 0.99899 & 0.00063 & 1.00157 & 0.00030 & 0.99494 & 0.00016 & 1.00195 & 0.00024 \\
\hline 0.94 & 1.00135 & 0.00063 & 1.00433 & 0.00030 & 0.99800 & 0.00018 & 1.00443 & 0.00023 \\
\hline 0.98 & 1.00462 & 0.00065 & - & - & 1.00070 & 0.00015 & - & - \\
\hline 1.00 & 1.00577 & 0.00065 & 1.00872 & 0.00030 & 1.00189 & 0.00017 & 1.00886 & 0.00024 \\
\hline 1.04 & 1.00858 & 0.00065 & - & - & 1.00472 & 0.00013 & - & - \\
\hline 1.08 & 1.01166 & 0.00067 & - & - & 1.00728 & 0.00016 & - & - \\
\hline
\end{tabular}




\subsubsection{Molybdenum Critical Experiments Summary and Conclusions}

This document provides the pre-experimental predictions for the Mo critical experiments including the effect of the Planet assembly machine structure. These critical experiments are being performed to:

1. determine the adequacy of the existing Mo neutron cross section evaluations in neutron energy spectra characteristic of Prometheus reactor designs under normal and accident conditions,

2. reduce the uncertainty in $\mathrm{k}_{\mathrm{eff}}$ for Prometheus reactor designs containing substantial amounts of Mo by performing benchmark quality critical experiments that bracket the neutron energy spectra expected under normal and accident conditions, and

3. provide benchmark critical experiments needed to develop improved Mo neutron cross section evaluations if new evaluations are determined to be required.

The first 3 experiments are designed to bracket the neutron energy spectrum expected in the Prometheus space nuclear reactor under normal operating conditions. The Mo-4 experiment is designed to approximate the neutron energy spectrum expected in accident conditions in which the core is flooded with water. A summary of the fission fraction in the thermal, intermediate, and fast energy ranges for each of the Mo critical experiments is provided in Table 66. The Mo-1, Mo-2, and Mo-3 experiments are classified as fast spectrum experiments while the Mo-4 experiment is classified as a mixed spectrum experiment. A summary of the pre-experimental predictions for each of the Mo critical experiments is provided in Table 67. Predictions from RCP01, MCNP5, MCNP5 with space cross sections, and RACER analyses are reported.

Comparisons of the RCP01 and MCNP5 predicted fission reaction rate spectra and RCP01 predicted fission reaction rate spectra CDFs are provided in Figure 55 and Figure 56. Comparisons of RCP01 and MCNP5 predicted Mo absorption rate spectra are provided in Figure 57 and Figure 59 . The lack of an unresolved resonance treatment in the MCNP5 nat-Mo neutron cross section data clearly results in greater absorption relative to RCP01 between $1.423 \mathrm{keV}$ and $100.09 \mathrm{keV}$ in all four experiments.

The four experiments also appear to be sensitive to the differences in available cross-section data. RCP01, MCNP5 with space cross sections, and RACER predictions have used the more complete JENDL 3.2 evaluation, which contains data for additional non-neutron-producing capture reactions $(n, a),(n, y),(n, p),(n, d)$, and $(n, t)$. The MCNP5 predictions necessitate use of the ENDF/B-VI.0 dataset, which only contains data for $(n, y)$ neutron absorption reactions. These differences in crosssection data, as well as the afore-mentioned unresolved resonance data difference, are highlighted in Figure 58. It is important to note that the lack of unresolved resonance treatment and the incomplete neutron reaction data used in the MCNP5 analysis are competing effects. Both impact the reactivity incorrectly, but do so in an opposing manner. The ENDF/B-VI.O dataset's lack of unresolved resonance treatment overestimates $\mathrm{Mo}$ absorption in the $1 \mathrm{keV}-100 \mathrm{keV}$ range and incomplete nuclear reaction data underestimates Mo absorption in the $>100 \mathrm{keV}$ range. This bias in the nuclear data set highlights the need to conduct these experiments in order to reduce the reactivity error associated with incomplete nuclear data for Prometheus reactor designs that contain significant amounts of Mo.

The RCP01 analyses of all four experiments predict increased parasitic molybdenum neutron absorption in the fast neutron energy range (>100 keV, but especially $>1 \mathrm{MeV}$ ), shown in Figure 59 . The increased non-neutron-producing absorption in the fast energy range has the net effect of lowering the overall multiplication factor, resulting in the increased RCP01-predicted reflector 
thicknesses for Mo-1, Mo-2, and Mo-4 and increased critical mass for Mo-3 as presented in Table 67. MCNP5 with space cross sections and RACER predictions follow this same relative trend for Mo-1 and $\mathrm{Mo}-2$, yielding predicted reflector thicknesses that are larger than MCNP5 predictions. Their smaller predicted reflectors in Mo-3 and Mo-4, however, appear to predict that the drop in absorptions in the unresolved resonance region when using JENDL 3.2 evaluations will outweigh the lower fast spectrum parasitic losses of ENDF/B-VI.O as the experiments shift to a more intermediate neutron flux.

Table 66. A Summary of the Energy Spectrum Covered in the Mo Critical Experiments

\begin{tabular}{|c|c|c|c|}
\hline \multirow{2}{*}{ Experiment } & \multicolumn{3}{|c|}{ Percent Fissions by Energy (MCNP5 Predictions) } \\
\cline { 2 - 4 } & $<0.625 \mathrm{eV}$ & $\mathbf{0 . 6 2 5 e V - 1 0 0 k e V}$ & $>100 \mathrm{keV}$ \\
\hline Mo-1 & $0.0 \%$ & $14.9 \%$ & $85.1 \%$ \\
\hline Mo-2 & $0.0 \%$ & $21.9 \%$ & $78.1 \%$ \\
\hline Mo-3 & $0.1 \%$ & $34.1 \%$ & $65.9 \%$ \\
\hline Mo-4 & $9.5 \%$ & $45.3 \%$ & $45.2 \%$ \\
\hline
\end{tabular}

Table 67. A Summary of the Pre-Experimental Predictions for the Mo Critical Experiments

\begin{tabular}{|c|c|c|c|c|c|c|c|c|c|}
\hline Experiment & $\begin{array}{c}\text { Monte } \\
\text { Carlo Code }\end{array}$ & $\begin{array}{l}\text { Stacking } \\
\text { Units }\end{array}$ & $\begin{array}{c}\text { Inner } \\
\text { Diameter } \\
\text { of Top } \\
\text { HEU } \\
\text { Plate (in) } \\
\end{array}$ & $\begin{array}{c}\text { Top } \\
\text { Reflector } \\
\text { Thickness } \\
\text { (in) }\end{array}$ & $k_{\text {eff }}$ & $\begin{array}{c}95 \% \\
\begin{array}{c}\text { Confidence } \\
\text { Level }\end{array}\end{array}$ & $\begin{array}{c}\text { Mass } \\
\text { of } \\
\text { HEU } \\
(\mathrm{kg})\end{array}$ & $\begin{array}{c}\text { Mass } \\
\text { of } \\
\text { Mo } \\
(\mathrm{kg})\end{array}$ & $\begin{array}{c}\text { Mass of } \\
\text { Moderator } \\
\text { (graphite/ } \\
\text { polyethylene) } \\
\text { (kg) }\end{array}$ \\
\hline \multirow{5}{*}{ Mo-1 } & RCP01 & 16 & 6.005 & 1.55 & 1.00157 & 0.00018 & 196.5 & 76.1 & 41.5 \\
\hline & MCNP5 & 16 & 6.005 & 1.35 & 1.00123 & 0.00057 & 196.5 & 76.1 & 39.6 \\
\hline & $\begin{array}{c}\text { MCNP5 } \\
\text { (Space XS) }\end{array}$ & 16 & 6.005 & 1.40 & 1.00033 & 0.00026 & 196.5 & 76.1 & 40.1 \\
\hline & RACER & 16 & 6.005 & 1.40 & 1.00188 & 0.00019 & 196.5 & 76.1 & 40.1 \\
\hline & RCP01 & 15 & 6.005 & 2.15 & 1.00041 & 0.00013 & 185.0 & 72.6 & 71.3 \\
\hline \multirow{3}{*}{ Mo-2 } & MCNP5 & 15 & 6.005 & 1.85 & 1.00009 & 0.00055 & 185.0 & 72.6 & 68.3 \\
\hline & $\begin{array}{c}\text { MCNP5 } \\
\text { (Space XS) }\end{array}$ & 15 & 6.005 & 1.90 & 1.00031 & 0.00026 & 185.0 & 72.6 & 68.8 \\
\hline & RACER & 15 & 6.005 & 1.90 & 1.00162 & 0.00020 & 185.0 & 72.6 & 68.8 \\
\hline \multirow{5}{*}{ Mo-3 } & RCP01 & 14 & 6.005 & 4.75 & 1.00075 & 0.00015 & 173.5 & 69.1 & 152.8 \\
\hline & MCNP5 & 14 & 10.005 & 4.75 & 1.00079 & 0.00061 & 171.6 & 69.1 & 152.8 \\
\hline & MCNP5* & 14 & 6.005 & 3.85 & 1.00050 & 0.00059 & 173.5 & 69.1 & 144.7 \\
\hline & $\begin{array}{c}\text { MCNP5 } \\
\text { (Space XS) }\end{array}$ & 14 & 6.005 & 3.75 & 1.00090 & 0.00028 & 173.5 & 69.1 & 143.0 \\
\hline & RACER & 14 & 6.005 & 3.75 & 1.00168 & 0.00020 & 173.5 & 69.1 & 143.0 \\
\hline \multirow{4}{*}{ Mo-4 } & RCP01 & 11 & 0 & 1.00 & 1.00189 & 0.00017 & 137.0 & 58.7 & 16.0 \\
\hline & MCNP5 & 11 & 0 & 0.94 & 1.00135 & 0.00063 & 137.0 & 58.7 & 15.6 \\
\hline & $\begin{array}{c}\text { MCNP5 } \\
\text { (Space XS) }\end{array}$ & 11 & 0 & 0.88 & 1.00050 & 0.00030 & 137.0 & 58.7 & 15.3 \\
\hline & RACER & 11 & 0 & 0.88 & 1.00030 & 0.00023 & 137.0 & 58.7 & 15.3 \\
\hline
\end{tabular}

- NOTE: The Mo-3 configuration listed for MCNP5 with 14 stacking units, a top HEU plate inner diameter of $6.005^{\prime \prime}$, and top reflector thickness of $3.85^{\prime \prime}$ is not analyzed as a critical configuration elsewhere in this document, but is presented for comparison purposes since the other predicted critical configurations for the Mo-3 experiment all have an inner diameter of $6.005^{\prime \prime}$ for the top HEU plate. 
B-TM-1639

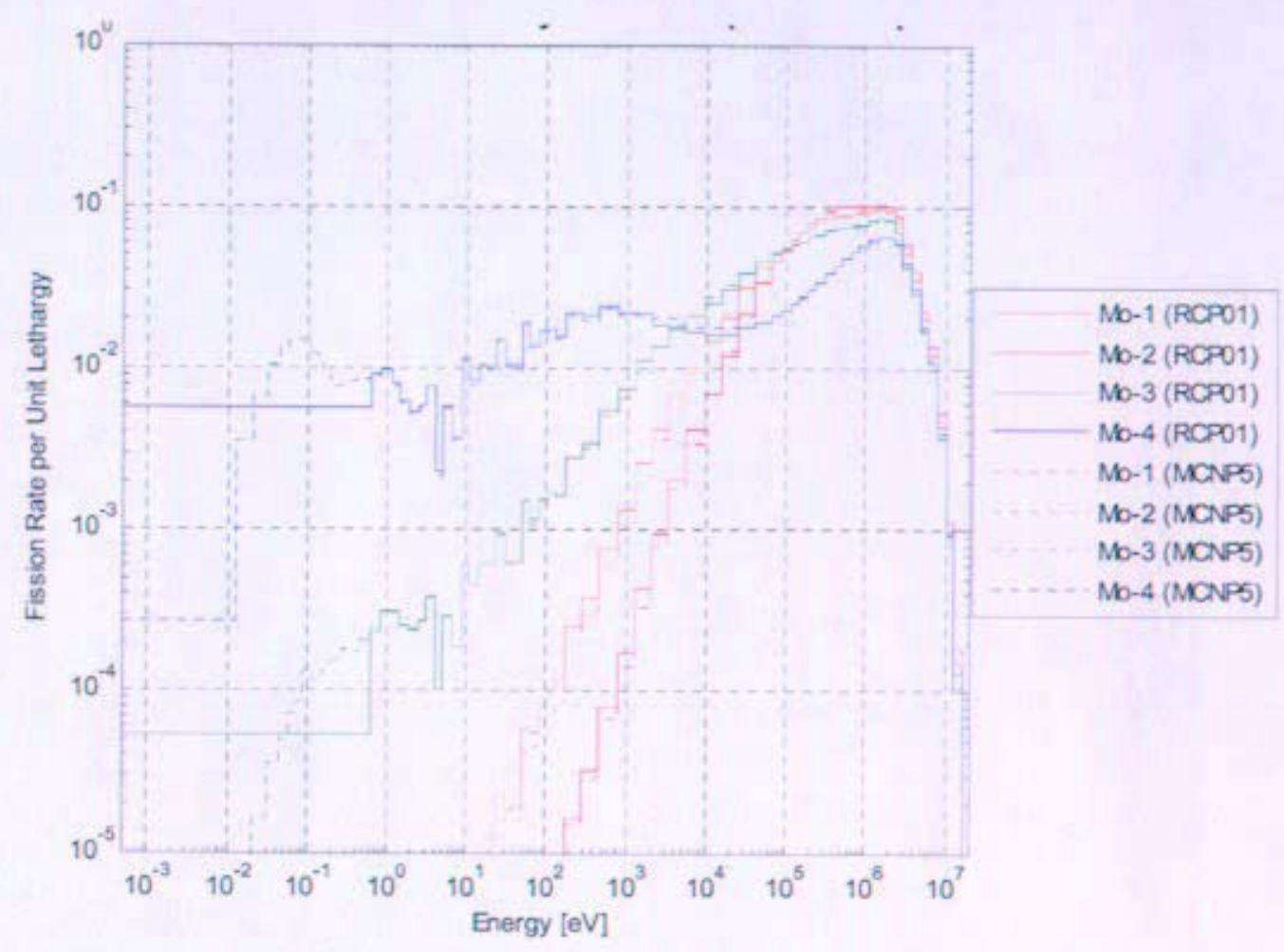

Figure 55: Comparison of the RCP01 and MCNP5 Fission Rate Spectra for the Mo Critical Experiments

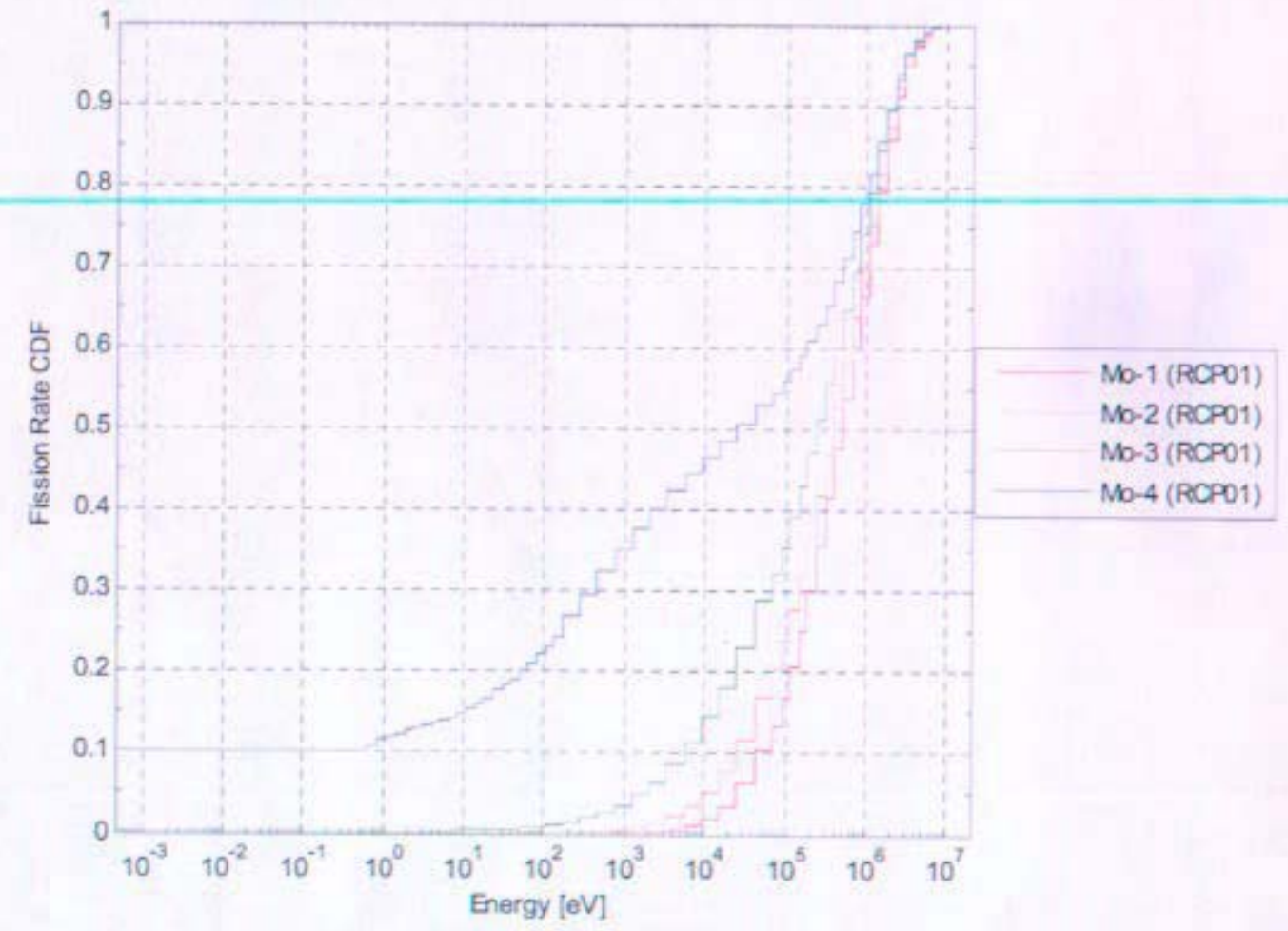

Figure 56: RCP01 Fission CDFs for the Mo Critical Experiments 


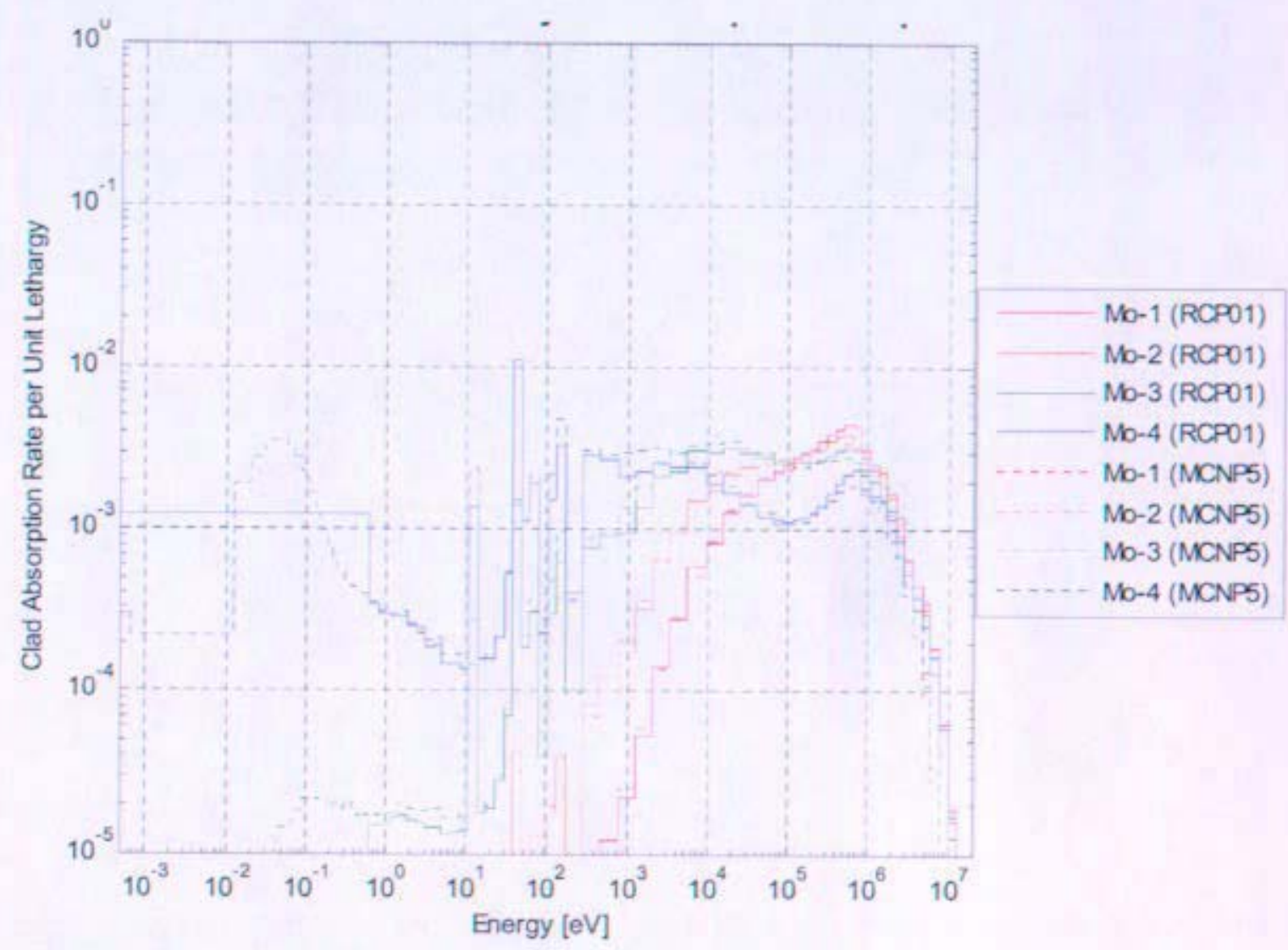

Figure 57: Comparison of the RCP01 and MCNP5 Mo Absorption Rate Spectra for the Mo Critical Experiments 


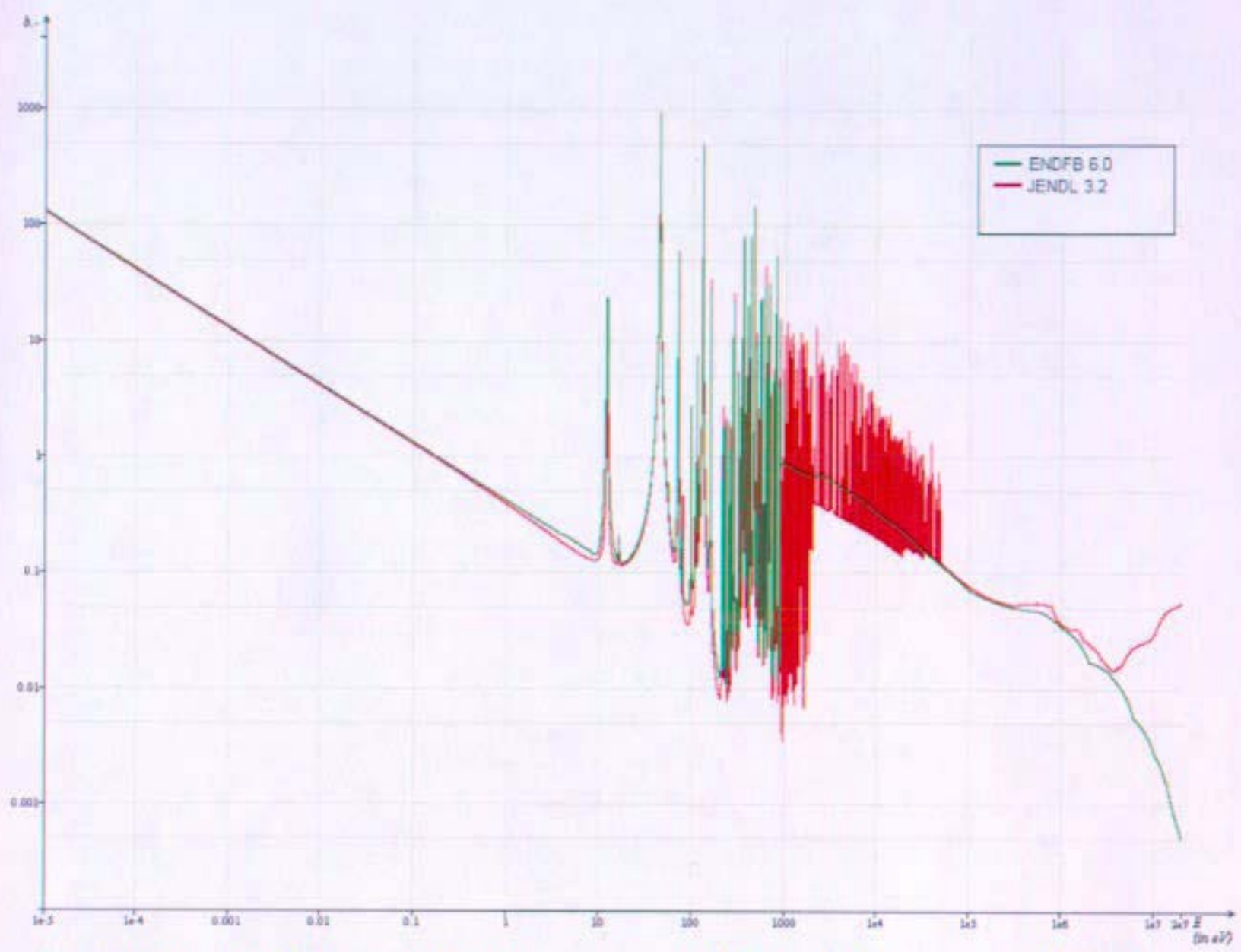

Figure 58: Neutron Absorption Cross-Section vs. Energy for Natural Molybdenum (ENDF/BVI.0) and Isotopically-Combined Equivalent (JENDL 3.2) [20] 
B-TM-1639
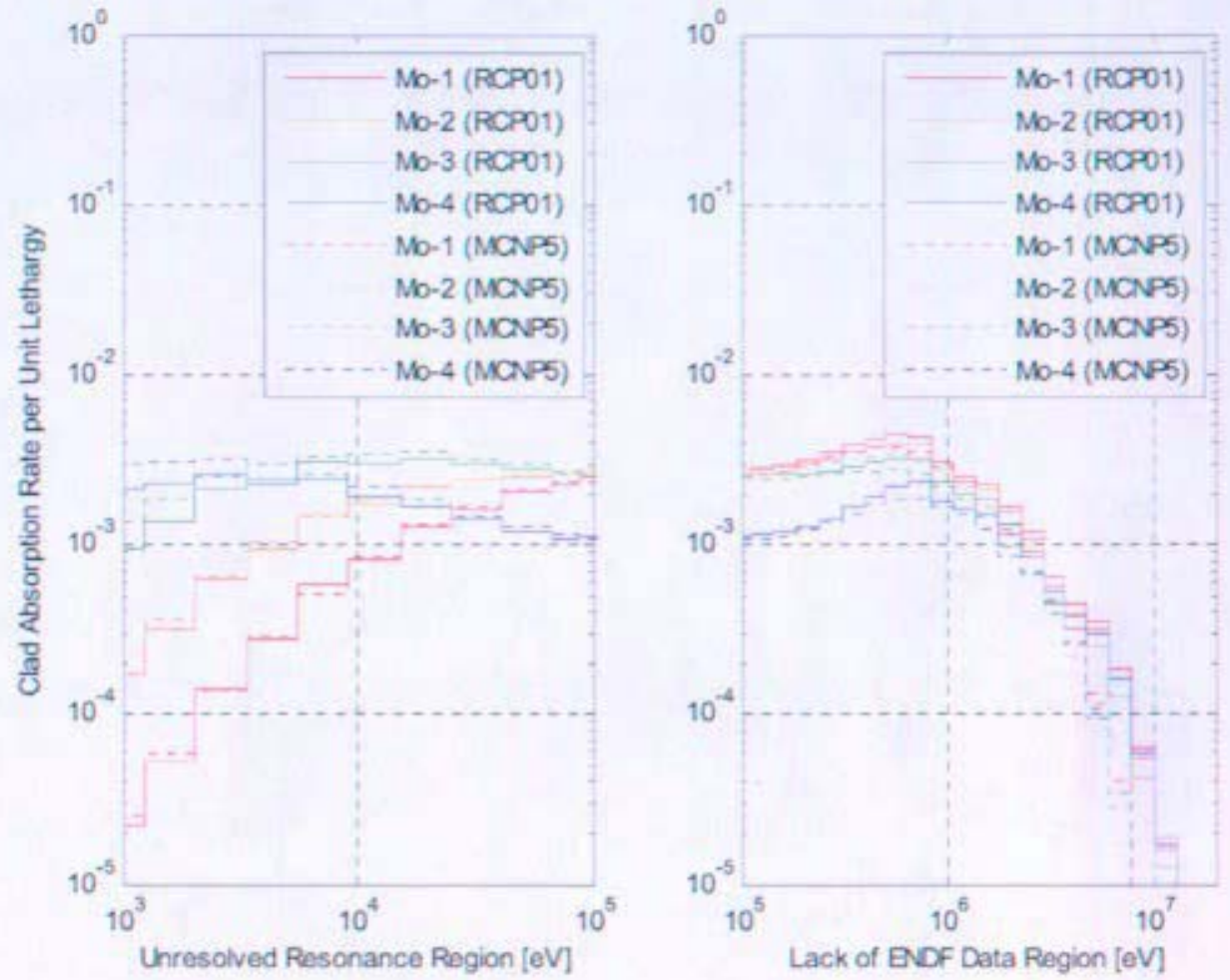

Figure 59: Comparison of RCP01 and MCNP5 Mo Absorption Rate Spectra over Ranges of Varying Cross-Section Data 


\subsection{Niobium Critical Experiments}

\subsubsection{Nb-1Zr-2 Experiment}

The $\mathrm{Nb}-1 \mathrm{Zr}-2$ experiment is designed to bracket the average neutron spectrum of the Prometheus reactor core. It is designed to be harder than the expected average neutron energy spectrum of the core. Graphite has been added to the assembly to simulate the effect of neutron moderation near the reflector. A cross-sectional view and close-up view of the experimental configuration are provided in Figure 60 and Figure 61 where aluminum is yellow, graphite is blue, Nb-1Zr is green, HEU is red, and stainless steel is purple (all dimensions in figures are in centimeters). The assembly configuration, including plate layout and dimensions, is shown in Table 68. The RCP01 analysis predicts an assembly height of 10.852" and the MCNP5, MCNP5 with space cross sections, and RACER analyses predict an assembly height of $10.702^{\prime \prime}$. The assembly rests on a 3.0" thick hollow Al 6061-T6 spindle plate that has a $19^{\prime \prime} \mathrm{OD}$ and $2.50^{\prime \prime}$ inner diameter. The active core region of the assembly is $6.592^{\prime \prime}$ high and contains one $0.197^{\prime \prime}$ thick graphite plate and 16 stacking units consisting of $0.040^{\prime \prime}$ of $\mathrm{Nb}-1 \mathrm{Zr}$, a $0.118^{\prime \prime}$ thick HEU plate, $0.040^{\prime \prime}$ of $\mathrm{Nb}-1 \mathrm{Zr}$, and a $0.197^{\prime \prime}$ thick graphite plate. The bottom reflector consists of a $2.0^{\prime \prime}$ thick graphite reflector and a $0.180^{\prime \prime}$ thick $\mathrm{Nb}-1 \mathrm{Zr}$ reflector. The RCP01 predicted top reflector consists of a $0.180^{\prime \prime}$ thick $\mathrm{Nb}-1 \mathrm{Zr}$ reflector and a $1.90^{\prime \prime}$ thick graphite reflector. The MCNP5, MCNP5 with space cross sections, and RACER predicted top reflector consists of a $0.180^{\prime \prime}$ thick $\mathrm{Nb}-1 \mathrm{Zr}$ reflector and a $1.75^{\prime \prime}$ thick graphite reflector. A hollow Al 6061-T6 alignment tube is assumed to extend from the bottom of the spindle plate to the top of the $6^{\text {th }}$ stacking unit. All other regions are modeled as void, except as noted in Section 4.0 for the RACER models. The Nb-1 $\mathrm{Zr}-2$ assembly contains $196.5 \mathrm{~kg}$ of HEU and $80.3 \mathrm{~kg}$ of Nb-1Zr. The distribution of materials in the top and bottom half of the assembly is given in Table 69 for the RCP01, MCNP5, MCNP5 with space cross sections, and RACER predicted critical configurations.

A series of analyses have been performed to predict the $k_{\text {eff }}$ of the $\mathrm{Nb}-1 \mathrm{Zr}-2$ assembly during the approach to critical as a function of both the number of stacking units and the graphite top reflector thickness. Figure 62 presents the RCP01 and MCNP5 predicted $k_{\text {eff }}$ as a function of the number of stacking units in the $\mathrm{Nb}-1 \mathrm{Zr}-2$ assembly. The error bars indicate the size of the $95 \%$ confidence interval in the Monte Carlo calculations. As illustrated in Figure 62, both the MCNP5 and RCP01 predictions are close. The average difference between the MCNP5 and RCP01 predicted $k_{\text {off }}$ is $0.0031 \pm 0.0004 \Delta \mathrm{k}$ over the range from 8 to 28 stacking units. Figure 63 and Table 70 provide a comparison of the predicted $\mathrm{k}_{\text {eff }}$ of the $\mathrm{Nb}-1 \mathrm{Zr}-2$ assembly with 16 stacking units as a function of the graphite top reflector thickness. The experimental configurations that were predicted to achieve delayed criticality within TSR limits $(\rho<0.5$ S) are highlighted in green in Table 70 . The Nb-1Zr-2 assembly is classified as a fast spectrum assembly with the following representative fission fractions as predicted by MCNP5: $77.9 \%$ fast ( $\mathrm{E}>100 \mathrm{keV}), 22.1 \%$ intermediate $(0.625 \mathrm{eV}<\mathrm{E}<100 \mathrm{keV})$, and $0.0 \%$ thermal $(E<0.625 \mathrm{eV})$. 
$\stackrel{?}{*}$

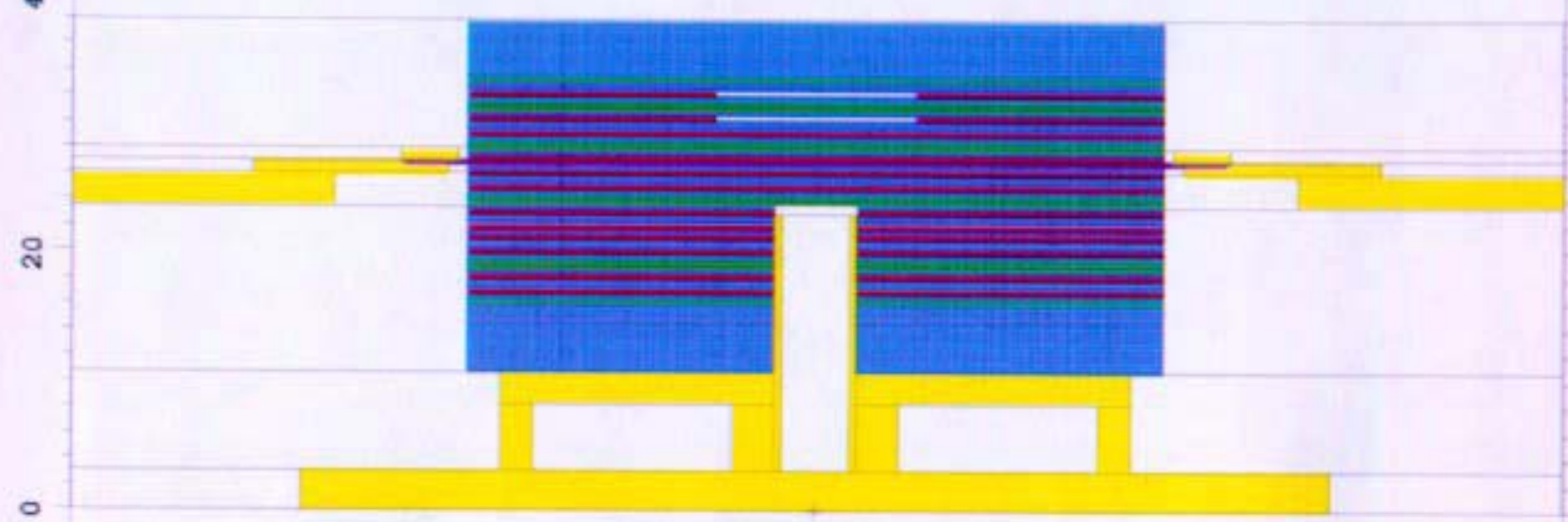

$\circ$

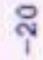

$\stackrel{9}{7}$

$\begin{array}{llll}-40 & -20 & 0 & 20\end{array}$

Figure 60. Cross-sectional View of the Nb-1Zr-2 Assembly 


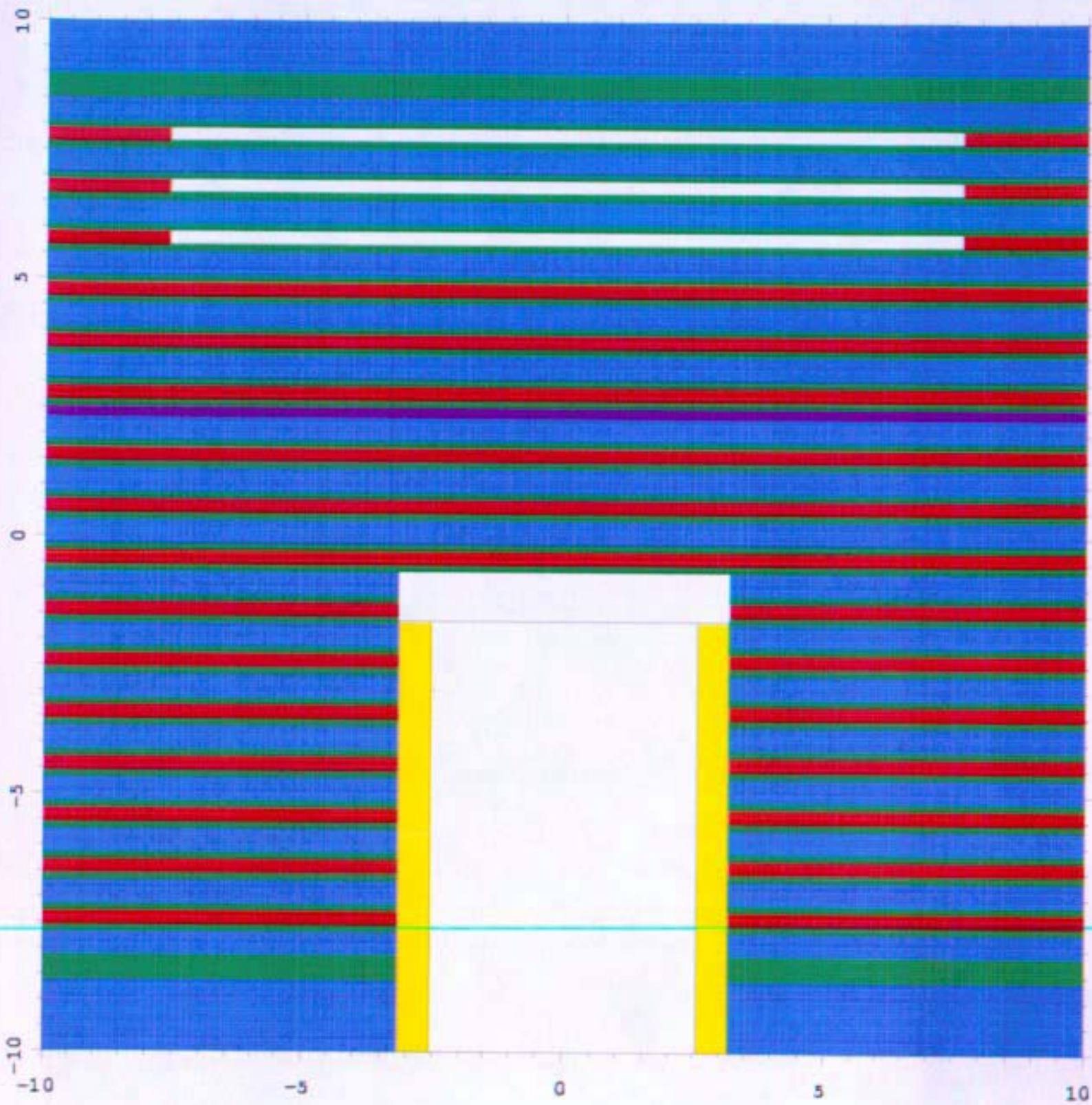

Figure 61. Cross-sectional Close-up View of the $\mathrm{Nb}-1 \mathrm{Zr}-2$ Assembly 
Table 68. Predicted Critical Configuration for the $\mathrm{Nb}-1 \mathrm{Zr}-2$ Assembly

\begin{tabular}{|c|c|c|c|c|c|}
\hline Unit & Material & Thickness (in) & $\begin{array}{c}\text { Inner } \\
\text { Diameter (in) }\end{array}$ & $\begin{array}{c}\text { Outer } \\
\text { Diameter (in) }\end{array}$ & $\begin{array}{l}\text { Assembly Height } \\
\text { (in) }\end{array}$ \\
\hline \multirow{3}{*}{$\begin{array}{l}\text { Bottom } \\
\text { Reflector }\end{array}$} & Graphite & 2.00 & 251 & 21.0 & 2.0000 \\
\hline & $\mathrm{Nb}-1 \mathrm{Zr}$ & 0.180 & 2.51 & 21.0 & 2.1800 \\
\hline & Graphite & 0.197 & 2.51 & 21.0 & 23770 \\
\hline \multirow{4}{*}{1} & $\mathrm{Nb}-1 \mathrm{Zr}$ & 0.040 & 2.51 & 21.0 & 2.4170 \\
\hline & HEU & 0.118 & 2.51 & 21.0 & 2.5350 \\
\hline & $\mathrm{Nb}-1 \mathrm{Zr}$ & 0.040 & 2.51 & 21.0 & 2.5750 \\
\hline & Graphite & 0.197 & 2.51 & 21.0 & 2.7720 \\
\hline \multirow{4}{*}{2} & $\mathrm{Nb}-1 \mathrm{Zr}$ & 0.040 & 2.51 & 21.0 & 2.8120 \\
\hline & HEU & 0.118 & 2.51 & 21.0 & 2.9300 \\
\hline & $\mathrm{Nb}-1 \mathrm{Zr}$ & 0.040 & 2.51 & 21.0 & 2.9700 \\
\hline & Graphite & 0.197 & 2.51 & 21.0 & 3.1670 \\
\hline \multirow{4}{*}{3} & $\mathrm{Nb}-1 \mathrm{Zr}$ & 0.040 & 2.51 & 21.0 & 3.2070 \\
\hline & $\mathrm{HEU}$ & 0.118 & 2.51 & 21.0 & 3.3250 \\
\hline & $\mathrm{Nb}-1 \mathrm{Zr}$ & 0.040 & 2.51 & 21.0 & 3.3650 \\
\hline & Graphite & 0.197 & 2.51 & 21.0 & 3.5620 \\
\hline \multirow{4}{*}{4} & $\mathrm{Nb}-1 \mathrm{Zr}$ & 0.040 & 2.51 & 21.0 & 3.6020 \\
\hline & $\mathrm{HEU}$ & 0.118 & 2.51 & 21.0 & 3.7200 \\
\hline & $\mathrm{Nb}-1 \mathrm{Zr}$ & 0.040 & 2.51 & 21.0 & 3.7600 \\
\hline & Graphite & 0.197 & 2.51 & 21.0 & 3.9570 \\
\hline \multirow{4}{*}{5} & $\mathrm{Nb}-1 \mathrm{Zr}$ & 0.040 & 2.51 & 21.0 & 3.9970 \\
\hline & HEU & 0.118 & 2.51 & 21.0 & 4.1150 \\
\hline & $\mathrm{Nb}-1 \mathrm{Zr}$ & 0.040 & 2.51 & 21.0 & 4.1550 \\
\hline & Graphite & 0.197 & 2.51 & 21.0 & 4.3520 \\
\hline \multirow{4}{*}{6} & $\mathrm{Nb}-1 \mathrm{Zr}$ & 0.040 & 2.51 & 21.0 & 4.3920 \\
\hline & HEU & 0.118 & 2.51 & 21.0 & 4.5100 \\
\hline & $\mathrm{Nb}-1 \mathrm{Zr}$ & 0.040 & 2.51 & 21.0 & 4.5500 \\
\hline & Graphite & 0.197 & 2.51 & 21.0 & 4.7470 \\
\hline \multirow{4}{*}{7} & $\mathrm{Nb}-1 \mathrm{Zr}$ & 0.040 & 2.51 & 21.0 & 4.7870 \\
\hline & HEU & 0.118 & 2.51 & 21.0 & 4.9050 \\
\hline & $\mathrm{Nb}-1 \mathrm{Zr}$ & 0.040 & 2.51 & 21.0 & 4.9450 \\
\hline & Graphite & 0.197 & 2.51 & 21.0 & 5.1420 \\
\hline \multirow{4}{*}{8} & $\mathrm{Nb}-1 \mathrm{Zr}$ & 0.040 & 0 & 21.0 & 5.1820 \\
\hline & HEU & 0.118 & 0 & 21.0 & 5.3000 \\
\hline & $\mathrm{Nb}-1 \mathrm{Zr}$ & 0.040 & 0 & 21.0 & 5.3400 \\
\hline & Graphite & 0.197 & 0 & 21.0 & 5.5370 \\
\hline \multirow{4}{*}{9} & $\mathrm{Nb}-1 \mathrm{Zr}$ & 0.040 & 0 & 21.0 & 5.5770 \\
\hline & HEU & 0.118 & 0 & 21.0 & 5.6950 \\
\hline & $\mathrm{Nb}-1 \mathrm{Zr}$ & 0.040 & 0 & 21.0 & 5.7350 \\
\hline & Graphite & 0.197 & 0 & 21.0 & 5.9320 \\
\hline \multirow{4}{*}{10} & $\mathrm{Nb}-1 \mathrm{Zr}$ & 0.040 & 0 & 21.0 & 5.9720 \\
\hline & $\mathrm{HEU}$ & 0.118 & 0 & 21.0 & 6.0900 \\
\hline & $\mathrm{Nb}-1 \mathrm{Zr}$ & 0.040 & 0 & 21.0 & 6.1300 \\
\hline & Graphite & 0.197 & 0 & 21.0 & 6.3270 \\
\hline Diaphragm & Stainiess Steel & 0.075 & 0 & 24.8 & 6.4020 \\
\hline
\end{tabular}




\begin{tabular}{|c|c|c|c|c|c|}
\hline Unit & Material & Thickness (in) & $\begin{array}{c}\text { Inner } \\
\text { Diameter (in) }\end{array}$ & $\begin{array}{c}\text { Outer } \\
\text { Diameter (in) }\end{array}$ & $\begin{array}{l}\text { Assembly Height } \\
\text { (in) }\end{array}$ \\
\hline \multirow{4}{*}{11} & $\mathrm{Nb}-1 \mathrm{Zr}$ & 0.040 & 0 & 21.0 & 6.4420 \\
\hline & HEU & 0.118 & 0 & 21.0 & 6.5600 \\
\hline & $\mathrm{Nb}-1 \mathrm{Zr}$ & 0.040 & 0 & 21.0 & 6.6000 \\
\hline & Graphite & 0.197 & 0 & 21.0 & 6.7970 \\
\hline \multirow{4}{*}{12} & $\mathrm{Nb}-1 \mathrm{Zr}$ & 0.040 & 0 & 21.0 & 6.8370 \\
\hline & HEU & 0.118 & 0 & 21.0 & 6.9550 \\
\hline & $\mathrm{Nb}-1 \mathrm{Zr}$ & 0.040 & 0 & 21.0 & 6.9950 \\
\hline & Graphite & 0.197 & 0 & 21.0 & 7.1920 \\
\hline \multirow{4}{*}{13} & $\mathrm{Nb}-1 \mathrm{Zr}$ & 0.040 & 0 & 21.0 & 7.2320 \\
\hline & HEU & 0.118 & 0 & 21.0 & 7.3500 \\
\hline & $\mathrm{Nb}-1 \mathrm{Zr}$ & 0.040 & 0 & 21.0 & 7.3900 \\
\hline & Graphite & 0.197 & 0 & 21.0 & 7.5870 \\
\hline \multirow{4}{*}{14} & $\mathrm{Nb}-1 \mathrm{Zr}$ & 0.040 & 0 & 21.0 & 7.6270 \\
\hline & HEU & 0.118 & 6.005 & 21.0 & 7.7450 \\
\hline & $\mathrm{Nb}-1 \mathrm{Zr}$ & 0.040 & 0 & 21.0 & 7.7850 \\
\hline & Graphite & 0.197 & 0 & 21.0 & 7.9820 \\
\hline \multirow{4}{*}{15} & $\mathrm{Nb}-1 \mathrm{Zr}$ & 0.040 & 0 & 21.0 & 8.0220 \\
\hline & HEU & 0.118 & 6.005 & 21.0 & 8.1400 \\
\hline & $\mathrm{Nb}-1 \mathrm{Zr}$ & 0.040 & 0 & 21.0 & 8.1800 \\
\hline & Graphite & 0.197 & 0 & 21.0 & 8.3770 \\
\hline \multirow{4}{*}{16} & $\mathrm{Nb}-1 \mathrm{Zr}$ & 0.040 & 0 & 21.0 & 8.4170 \\
\hline & HEU & 0.118 & 6.005 & 21.0 & 8.5350 \\
\hline & $\mathrm{Nb}-1 \mathrm{Zr}$ & 0.040 & 0 & 21.0 & 8.5750 \\
\hline & Graphite & 0.197 & 0 & 21.0 & 8.7720 \\
\hline \multirow[b]{2}{*}{$\begin{array}{c}\text { Top } \\
\text { Reflector }\end{array}$} & $\mathrm{Nb}-1 \mathrm{Zr}$ & 0.180 & 0 & 210 & 8.9520 \\
\hline & Graphite & $\begin{array}{l}1.90 \text { (RCPO1) } \\
1.75 \text { (MCNP5) } \\
\text { MCNPS Space } \\
\text { XS RACER) }\end{array}$ & 0 & 21.0 & $\begin{array}{c}10.8520 \text { (RCP01) } \\
10.7020 \text { (MCNP5 } \\
\text { MCNP5 Space XS } \\
\text { RACER) }\end{array}$ \\
\hline
\end{tabular}

Table 69. Nb-1Zr-2 Assembly Material Mass Distribution

\begin{tabular}{|c|c|c|c|c|c|c|}
\hline \multirow{3}{*}{ Material } & \multicolumn{6}{|c|}{ Mass (kg) } \\
\cline { 2 - 7 } & \multicolumn{2}{|c|}{ MCNP5/MCNP5 (Space XS)/RACER } & \multicolumn{3}{c|}{ RCP01 } \\
\cline { 2 - 7 } & $\begin{array}{c}\text { Lower } \\
\text { Assembly }\end{array}$ & $\begin{array}{c}\text { Upper } \\
\text { Assembly }\end{array}$ & Total & $\begin{array}{c}\text { Lower } \\
\text { Assembly }\end{array}$ & $\begin{array}{c}\text { Upper } \\
\text { Assembly }\end{array}$ & Total \\
\hline HEU & 124.3 & 72.2 & 196.5 & 124.3 & 72.2 & 196.5 \\
\hline Nb-1Zr & 47.8 & 32.5 & 80.3 & 47.8 & 32.5 & 80.3 \\
\hline Graphite & 40.5 & 28.8 & 69.3 & 40.5 & 30.3 & 70.8 \\
\hline Total & $\mathbf{2 1 2 . 5}$ & 133.6 & $\mathbf{3 4 6 . 1}$ & $\mathbf{2 1 2 . 5}$ & $\mathbf{1 3 5 . 1}$ & $\mathbf{3 4 7 . 6}$ \\
\hline
\end{tabular}


B-TM-1639

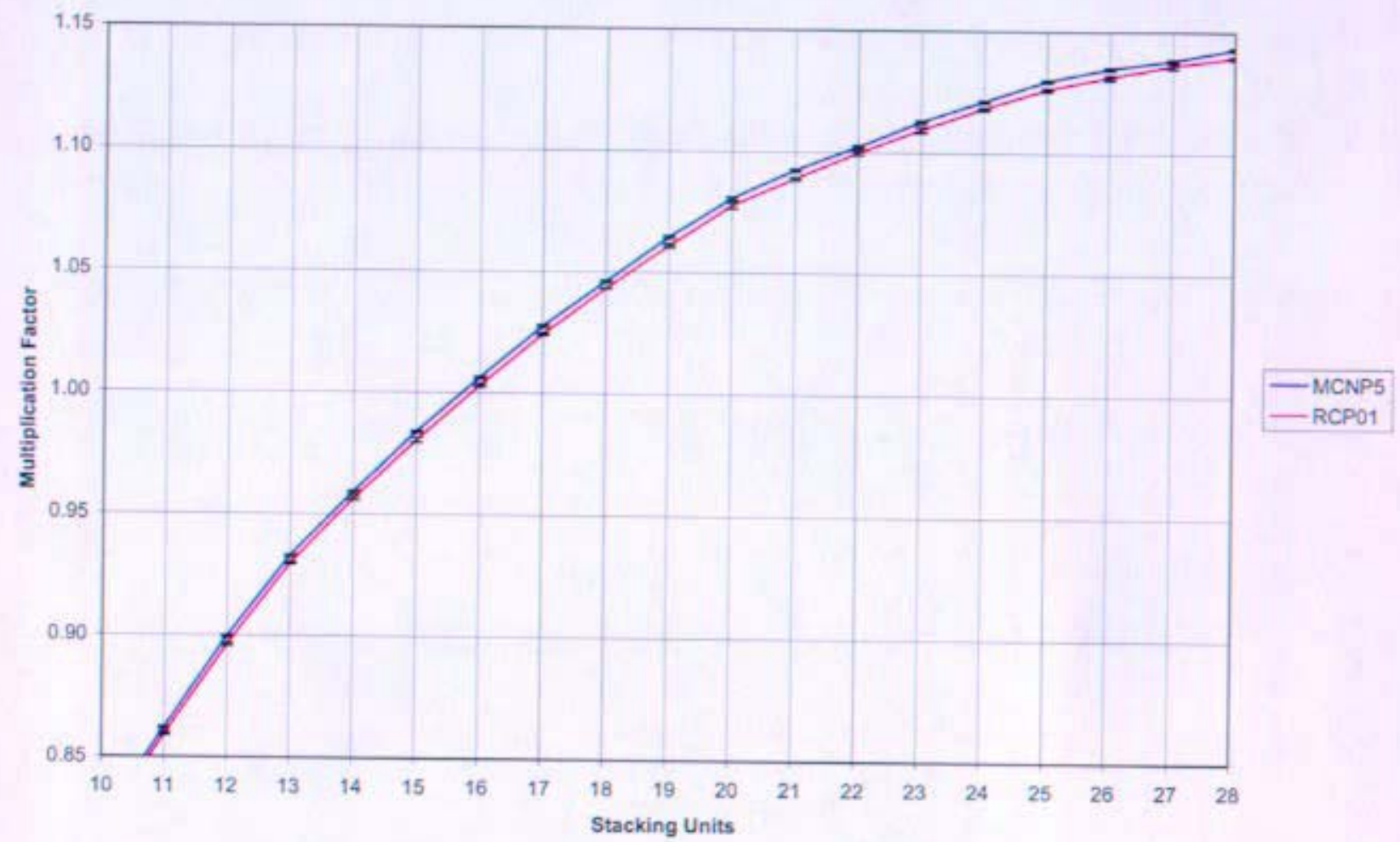

Figure 62. Nb-1Zr-2 Assembly $k_{\text {eft }}$ as a Function of the Number of Stacking Units

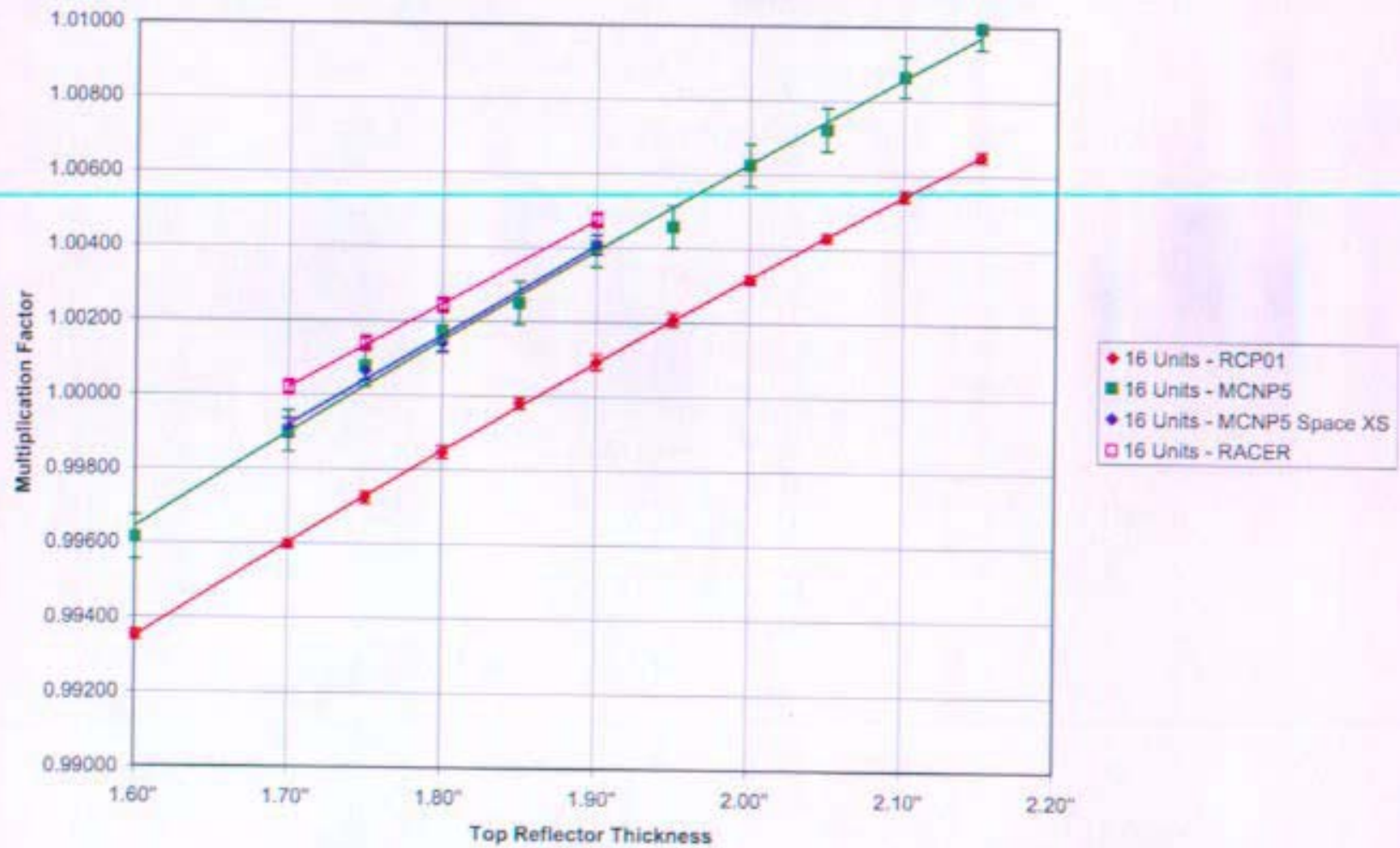

Figure 63. Nb-1Zr-2 Assembly $\mathrm{k}_{\text {eff }}$ as a Function of the Top Reflector Thickness 
Table 70. Nb-1 Zr-2 Assembly $k_{\text {eff }}$ as a Function of the Top Reflector Thickness

\begin{tabular}{|c|c|c|c|c|c|c|c|c|}
\hline \multicolumn{9}{|c|}{ Predicted Top Reflector Thickness } \\
\hline \multicolumn{9}{|c|}{16 Stacking Units } \\
\hline \multirow{2}{*}{$\begin{array}{c}\text { Top } \\
\text { Reflector } \\
\text { Thickness } \\
\text { (in) }\end{array}$} & \multicolumn{2}{|c|}{ MCNP5 } & \multicolumn{2}{|c|}{ MCNP5 (Space XS) } & \multicolumn{2}{|c|}{ RCP01 } & \multicolumn{2}{|c|}{ RACER } \\
\hline & $k_{\text {eff }}$ & $95 \% \mathrm{Cl}$ & $k_{\text {eff }}$ & $95 \% \mathrm{Cl}$ & $k_{\text {eff }}$ & $95 \% \mathrm{Cl}$ & $k_{\text {eff }}$ & $95 \% \mathrm{Cl}$ \\
\hline 1.60 & 0.99613 & 0.00059 & - & $\cdot$ & 0.99352 & 0.00013 & - & - \\
\hline 1.70 & 0.99900 & 0.00055 & 0.99909 & 0.00026 & 0.99598 & 0.00010 & 1.00019 & 0.00020 \\
\hline 1.75 & 1.00075 & 0.00055 & 1.00064 & 0.00026 & 0.99724 & 0.00015 & 1.09138 & 0.00020 \\
\hline 1.80 & 1.00172 & 0.00055 & 1.00140 & 0.00026 & 0.99847 & 0.00017 & 1.00243 & 0.00020 \\
\hline 1.85 & 1.00247 & 0.00057 & - & - & 0.99979 & 0.00014 & - & - \\
\hline 1.90 & 1.00403 & 0.00057 & 1.00406 & 0.00026 & 1.00092 & 0.00021 & 1.00474 & 0.00020 \\
\hline 1.95 & 1.00456 & 0.00057 & - & - & 1.00208 & 0.00017 & - & - \\
\hline 2.00 & 1.00623 & 0.00057 & - & - & 1.00316 & 0.00011 & - & - \\
\hline 2.05 & 1.00720 & 0.00059 & - & - & 1.00429 & 0.00012 & - & - \\
\hline 2.10 & 1.00864 & 0.00055 & - & - & 1.00544 & 0.00015 & - & - \\
\hline 2.15 & 1.00995 & 0.00057 & - & - & 1.00650 & 0.00014 & - & - \\
\hline
\end{tabular}




\subsubsection{Nb-1Zr-3 Experiment}

The $\mathrm{Nb}-1 \mathrm{Zr}-3$ experiment is designed to bracket the average neutron spectrum of the Prometheus reactor core. It is designed to be softer than the expected average neutron energy spectrum of the core. Additional graphite has been added to the assembly to simulate the effect of neutron moderation near the reflector. A cross-sectional view and close-up view of the experimental configuration are provided in Figure 64 and Figure 65 where aluminum is yellow, graphite is blue, Nb-1Zr is green, HEU is red, and stainless steel is purple (all dimensions in figures are in centimeters). The assembly configuration, including plate layout and dimensions, is shown in Table 71. The RCP01 analysis predicts an assembly height of 19.709" and the MCNP5, MCNP5 with space cross sections, and RACER analyses predict an assembly height of 18.959". The assembly rests on a $3.0^{\prime \prime}$ thick hollow Al $6061-T 6$ spindle plate that has a $19^{\prime \prime} \mathrm{OD}$ and $2.50^{\prime \prime}$ inner diameter. The active core region of the assembly is 9.349" high and contains one $0.394^{\prime \prime}$ thick graphite plate and 15 stacking units consisting of $0.040^{\prime \prime}$ of $\mathrm{Nb}-1 \mathrm{Zr}$, a $0.118^{\prime \prime}$ thick HEU plate, $0.040^{\prime \prime}$ of $\mathrm{Nb}-1 \mathrm{Zr}$, and a $0.394^{\prime \prime}$ thick graphite plate. The bottom reflector consists of a $5.0^{\prime \prime}$ thick graphite reflector and a $0.180^{\prime \prime}$ thick $\mathrm{Nb}-1 \mathrm{Zr}$ reflector. The RCP01 predicted top reflector consists of a $0.180^{\prime \prime}$ thick $\mathrm{Nb}-1 \mathrm{Zr}$ reflector and a $5.00^{\prime \prime}$ thick graphite reflector. The MCNP5, MCNP5 with space cross sections, and RACER predicted top reflector consists of a $0.180^{\prime \prime}$ thick $\mathrm{Nb}-1 \mathrm{Zr}$ reflector and a $4.25^{\prime \prime}$ thick graphite reflector. A hollow Al 6061-T6 alignment tube is assumed to extend from the bottom of the spindle plate to the top of the $6^{\text {th }}$ stacking unit. All other regions are modeled as void, except as noted in Section 4.0 for the RACER models. The $\mathrm{Nb}-1 \mathrm{Zr}-3$ assembly contains $185.0 \mathrm{~kg}$ of HEU and $76.4 \mathrm{~kg}$ of $\mathrm{Nb}-1 \mathrm{Zr}$. The distribution of materials in the top and bottom half of the assembly is given in Table 72 for the RCP01, MCNP5, MCNP5 with space cross sections, and RACER predicted critical configurations.

A series of analyses have been performed to predict the $\mathrm{K}_{\text {eff }}$ of the $\mathrm{Nb}-1 \mathrm{Zr}-3$ assembly during the approach to critical as a function of both the number of stacking units and the graphite top reflector thickness. Figure 66 presents the RCP01 and MCNP5 predicted $\mathrm{k}_{\text {off }}$ as a function of the number of stacking units in the $\mathrm{Nb}-1 \mathrm{Zr}-3$ assembly. The error bars indicate the size of the $95 \%$ confidence interval in the Monte Carlo calculations. As illustrated in Figure 66, the MCNP5 and RCP01 predictions are close. The average difference between the MCNP5 and RCP01 predicted $k_{\mathrm{eff}}$ is $0.0054 \pm 0.0007 \Delta \mathrm{k}$ over the range from 8 to 28 stacking units. Figure 67 and Table 73 provide a comparison of the predicted $\mathrm{k}_{\text {eff }}$ of the $\mathrm{Nb}-1 \mathrm{Zr}-3$ assembly with 15 stacking units as a function of the graphite top reflector thickness. The experimental configurations that were predicted to achieve delayed criticality within TSR limits $(\rho<0.5 \$)$ are highlighted in green in Table 73 . The Nb-1Zr-3 assembly is classified as a fast spectrum assembly with the following representative fission fractions, as predicted by MCNP5: $66.1 \%$ fast $(E>100 \mathrm{keV}), 33.9 \%$ intermediate $(0.625 \mathrm{eV}<\mathrm{E}<100 \mathrm{keV})$, and $0.1 \%$ thermal $(E<0.625 \mathrm{eV})$. 


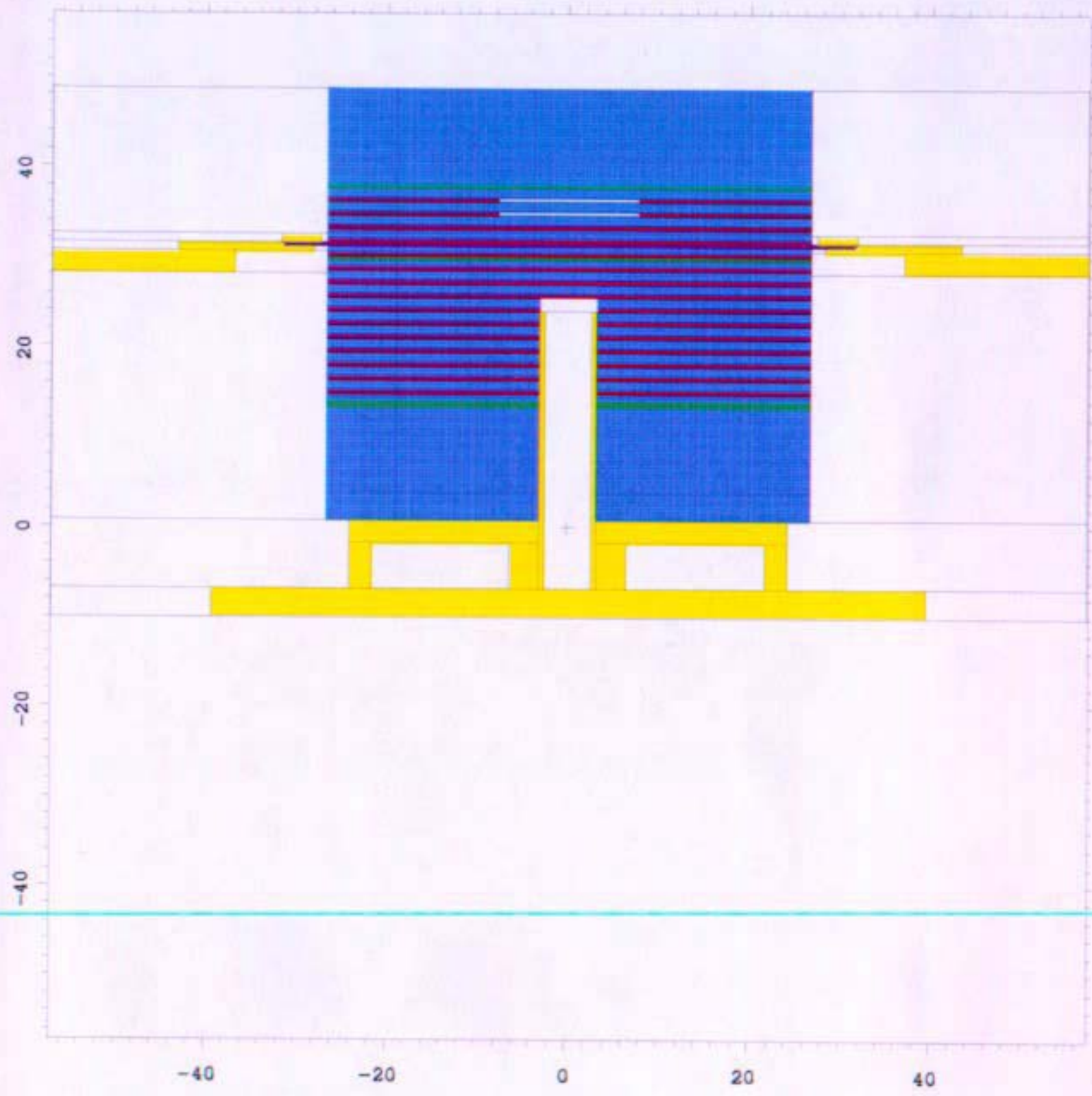

Figure 64 . Cross-sectional View of the Nb-1Zr-3 Assembly 
요

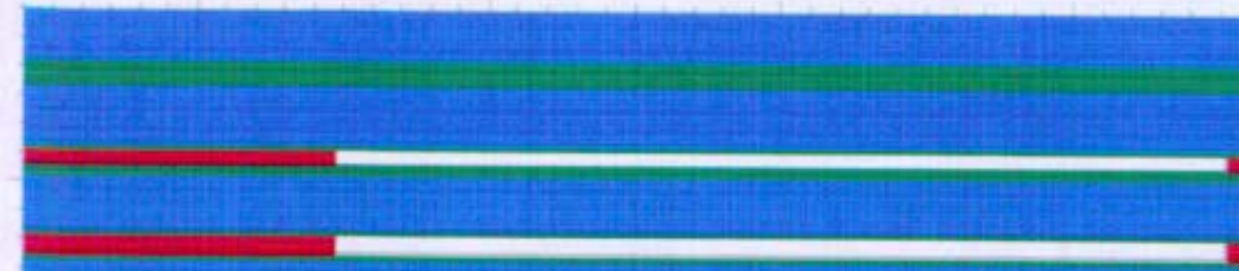

n

$\circ$

n

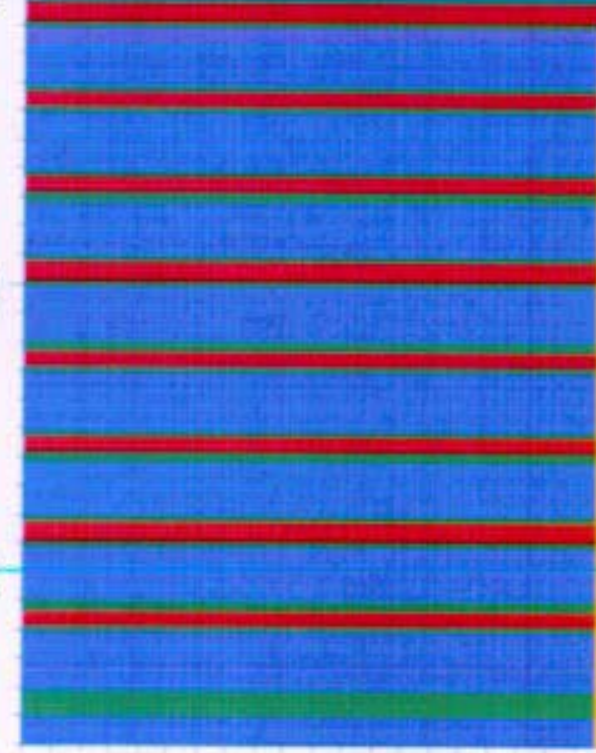

$-10$

$-5$

0

5

10

Figure 65. Cross-sectional Close-up View of the $\mathrm{Nb}-1 \mathrm{Zr}-3$ Assembly 
Table 71. Predicted Critical Configuration for the Nb-1Zr-3 Assembly.

\begin{tabular}{|c|c|c|c|c|c|}
\hline Unit & Material & Thickness (in) & $\begin{array}{c}\text { Inner } \\
\text { Diameter (in) }\end{array}$ & $\begin{array}{c}\text { Outer } \\
\text { Diameter (in) }\end{array}$ & $\begin{array}{l}\text { Assembly Height } \\
\text { (in) }\end{array}$ \\
\hline \multirow{3}{*}{$\begin{array}{l}\text { Bottom } \\
\text { Reflector }\end{array}$} & Graphite & 5.00 & 2.51 & 21,0 & 5.0000 \\
\hline & $\mathrm{Nb}-1 \mathrm{Zr}$ & 0.180 & 2.51 & 21.0 & 5.1800 \\
\hline & Graprite & 0.394 & 2.51 & 21.0 & 5.5740 \\
\hline \multirow{4}{*}{1} & $\mathrm{Nb}-1 \mathrm{Zr}$ & 0.040 & 2.51 & 21.0 & 5.6140 \\
\hline & HEU & 0.118 & 2.51 & 21.0 & 5.7320 \\
\hline & $\mathrm{Nb}-1 \mathrm{Zr}$ & 0.040 & 2.51 & 21.0 & 5.7720 \\
\hline & Graphite & 0.394 & 2.51 & 21.0 & 6.1660 \\
\hline \multirow{4}{*}{2} & $\mathrm{Nb}-1 \mathrm{Zr}$ & 0.040 & 2.51 & 21.0 & 6.2060 \\
\hline & HEU & 0.118 & 2.51 & 21.0 & 6.3240 \\
\hline & $\mathrm{Nb}-1 \mathrm{Zr}$ & 0.040 & 2.51 & 21.0 & 6.3640 \\
\hline & Graphite & 0.394 & 2.51 & 21.0 & 6.7580 \\
\hline \multirow{4}{*}{3} & $\mathrm{Nb}-1 \mathrm{Zr}$ & 0.040 & 2.51 & 21.0 & 6.7980 \\
\hline & $\mathrm{HEU}$ & 0.118 & 2.51 & 21.0 & 6.9160 \\
\hline & $\mathrm{Nb}-1 \mathrm{Zr}$ & 0.040 & 2.51 & 21.0 & 6.9560 \\
\hline & Graphite & 0.394 & 2.51 & 21.0 & 7.3500 \\
\hline \multirow{4}{*}{4} & $\mathrm{Nb}-1 \mathrm{Zr}$ & 0.040 & 2.51 & 21.0 & 7.3900 \\
\hline & HEU & 0.118 & 2.51 & 21.0 & 7.5080 \\
\hline & $\mathrm{Nb}-1 \mathrm{Zr}$ & 0.040 & 2.51 & 21.0 & 7.5480 \\
\hline & Graphite & 0.394 & 2.51 & 21.0 & 7.9420 \\
\hline \multirow{4}{*}{5} & $\mathrm{Nb}-1 \mathrm{Zr}$ & 0.040 & 2.51 & 21.0 & 7.9820 \\
\hline & HEU & 0.118 & 2.51 & 21.0 & 8.1000 \\
\hline & $\mathrm{Nb}-1 \mathrm{Zr}$ & 0.040 & 2.51 & 21.0 & 8.1400 \\
\hline & Graphite & 0.394 & 2.51 & 21.0 & 8.5340 \\
\hline \multirow{4}{*}{6} & $\mathrm{Nb}-1 \mathrm{Zr}$ & 0.040 & 2.51 & 21.0 & 8.5740 \\
\hline & HEU & 0.118 & 2.51 & 21.0 & 8.6920 \\
\hline & $\mathrm{Nb}-1 \mathrm{Zr}$ & 0.040 & 2.51 & 21.0 & 8.7320 \\
\hline & Graphite & 0.394 & 2.51 & 21.0 & 9.1260 \\
\hline \multirow{4}{*}{7} & $\mathrm{Nb}-1 \mathrm{Zr}$ & 0.040 & 2.51 & 21.0 & $9.1660^{\circ}$ \\
\hline & $\mathrm{HEU}$ & 0.118 & 2.51 & 21.0 & 9.2840 \\
\hline & $\mathrm{Nb}-1 \mathrm{Zr}$ & 0.040 & 2.51 & 21.0 & 9.3240 \\
\hline & Graphite & 0.394 & 2.51 & 21.0 & 9.7180 \\
\hline \multirow{4}{*}{8} & $\mathrm{Nb}-1 \mathrm{Zr}$ & 0.040 & 0 & 21.0 & 9.7580 \\
\hline & HEU & 0.118 & 0 & 21.0 & 9.8760 \\
\hline & $\mathrm{Nb}-1 \mathrm{Zr}$ & 0.040 & 0 & 21.0 & 9.9160 \\
\hline & Graphite & 0.394 & 0 & 21.0 & 10.3100 \\
\hline \multirow{4}{*}{9} & $\mathrm{Nb}-1 \mathrm{Zr}$ & 0.040 & 0 & 21.0 & 10.3500 \\
\hline & HEU & 0.118 & 0 & 21.0 & 10.4680 \\
\hline & $\mathrm{Nb}-1 \mathrm{Zr}$ & 0.040 & 0 & 21.0 & 10.5080 \\
\hline & Graphite & 0.394 & 0 & 21.0 & 10.9020 \\
\hline \multirow{4}{*}{10} & $\mathrm{Nb}-1 \mathrm{Zr}$ & 0.040 & 0 & 21.0 & 10.9420 \\
\hline & HEU & 0.118 & 0 & 21.0 & 11.0600 \\
\hline & $\mathrm{Nb}-1 \mathrm{Zr}$ & 0.040 & 0 & 21.0 & 11.1000 \\
\hline & Graphite & 0.394 & 0 & 21.0 & 11.4940 \\
\hline \multirow{4}{*}{11} & $\mathrm{Nb}-1 \mathrm{Zr}$ & 0.040 & 0 & 21.0 & 11.5340 \\
\hline & HEU & 0.118 & 0 & 21.0 & 11.6520 \\
\hline & $\mathrm{Nb}-1 \mathrm{Zr}$ & 0.040 & 0 & 21.0 & 11.6920 \\
\hline & Graphite & 0.394 & 0 & 21.0 & 12.0860 \\
\hline
\end{tabular}




\begin{tabular}{|c|c|c|c|c|c|}
\hline Unit & Material & Thickness (in) & $\begin{array}{c}\text { Inner } \\
\text { Diameter (in) }\end{array}$ & $\begin{array}{c}\text { Outer } \\
\text { Diameter (in) }\end{array}$ & $\begin{array}{l}\text { Assembly Height } \\
\text { (in) }\end{array}$ \\
\hline Diaphragm & Stainless Steel & 0.075 & 0 & 24.8 & 12.1610 \\
\hline \multirow{4}{*}{12} & $\mathrm{Nb}-1 \mathrm{Zr}$ & 0.040 & 0 & 21.0 & 12.2010 \\
\hline & HEU & 0.118 & 0 & 21.0 & 12.3190 \\
\hline & $\mathrm{Nb}-1 \mathrm{Zr}$ & 0.040 & 0 & 21.0 & 12.3590 \\
\hline & Graphite & 0.394 & 0 & 21.0 & 12.7530 \\
\hline \multirow{4}{*}{13} & $\mathrm{Nb}-1 \mathrm{Zr}$ & 0.040 & 0 & 21.0 & 12.7930 \\
\hline & HEU & 0.118 & 0 & 21.0 & 12.9110 \\
\hline & $\mathrm{Nb}-1 \mathrm{Zr}$ & 0.040 & 0 & 21.0 & 12.9510 \\
\hline & Graphite & 0.394 & 0 & 21.0 & 13.3450 \\
\hline \multirow{4}{*}{14} & $\mathrm{Nb}-1 \mathrm{Zr}$ & 0.040 & 0 & 21.0 & 13.3850 \\
\hline & HEU & 0.118 & 6.005 & 21.0 & 13.5030 \\
\hline & $\mathrm{Nb}-1 \mathrm{Zr}$ & 0.040 & 0 & 21.0 & 13.5430 \\
\hline & Graphite & 0.394 & 0 & 21.0 & 13.9370 \\
\hline \multirow{4}{*}{15} & $\mathrm{Nb}-1 \mathrm{Zr}$ & 0.040 & 0 & 21.0 & 13.9770 \\
\hline & HEU & 0.118 & 6.005 & 21.0 & 14.0950 \\
\hline & $\mathrm{Nb}-1 \mathrm{Zr}$ & 0.040 & 0 & 21.0 & 14.1350 \\
\hline & Graphite & 0.394 & 0 & 21.0 & 14.5290 \\
\hline \multirow[b]{2}{*}{$\begin{array}{l}\text { Top } \\
\text { Reflector }\end{array}$} & $\mathrm{Nb}-1 \mathrm{Zr}$ & 0.180 & 0 & 21.0 & 14.7090 \\
\hline & Graphite & $\begin{array}{c}5.00 \text { (RCP01) } \\
4.25 \text { (MCNP5 } \\
\text { MCNP5 Space X8 } \\
\text { RACER) }\end{array}$ & 0 & 21,0 & $\begin{array}{c}19.7090 \text { (RCP01) } \\
18.9590 \text { (MCNP5 } \\
\text { MCNP5 Space XS } \\
\text { RACER) }\end{array}$ \\
\hline
\end{tabular}

Table 72. Nb-1Zr-3 Assembly Material Mass Distribution

\begin{tabular}{|c|c|c|c|c|c|c|}
\hline \multirow{3}{*}{ Material } & \multicolumn{6}{|c|}{ Mass $(\mathrm{kg})$} \\
\hline & \multicolumn{3}{|c|}{ MCNP5/MCNP5 (Space XS)/RACER } & \multicolumn{3}{|c|}{ RCP01 } \\
\hline & $\begin{array}{c}\text { Lower } \\
\text { Assembly }\end{array}$ & $\begin{array}{c}\text { Upper } \\
\text { Assembly }\end{array}$ & Total & $\begin{array}{c}\text { Lower } \\
\text { Assembly }\end{array}$ & $\begin{array}{c}\text { Upper } \\
\text { Assembly }\end{array}$ & Total \\
\hline HEU & 136.8 & 48.2 & 185.0 & 136.8 & 48.2 & 185.0 \\
\hline $\mathrm{Nb}-1 \mathrm{Zr}$ & 51.7 & 24.7 & 76.4 & 51.7 & 24.7 & 76.4 \\
\hline Graphite & 94.5 & 57.3 & 151.8 & 94.5 & 64.6 & 159.1 \\
\hline Total & 283.1 & 130.1 & 413.2 & 283.1 & 137.5 & 420.5 \\
\hline
\end{tabular}




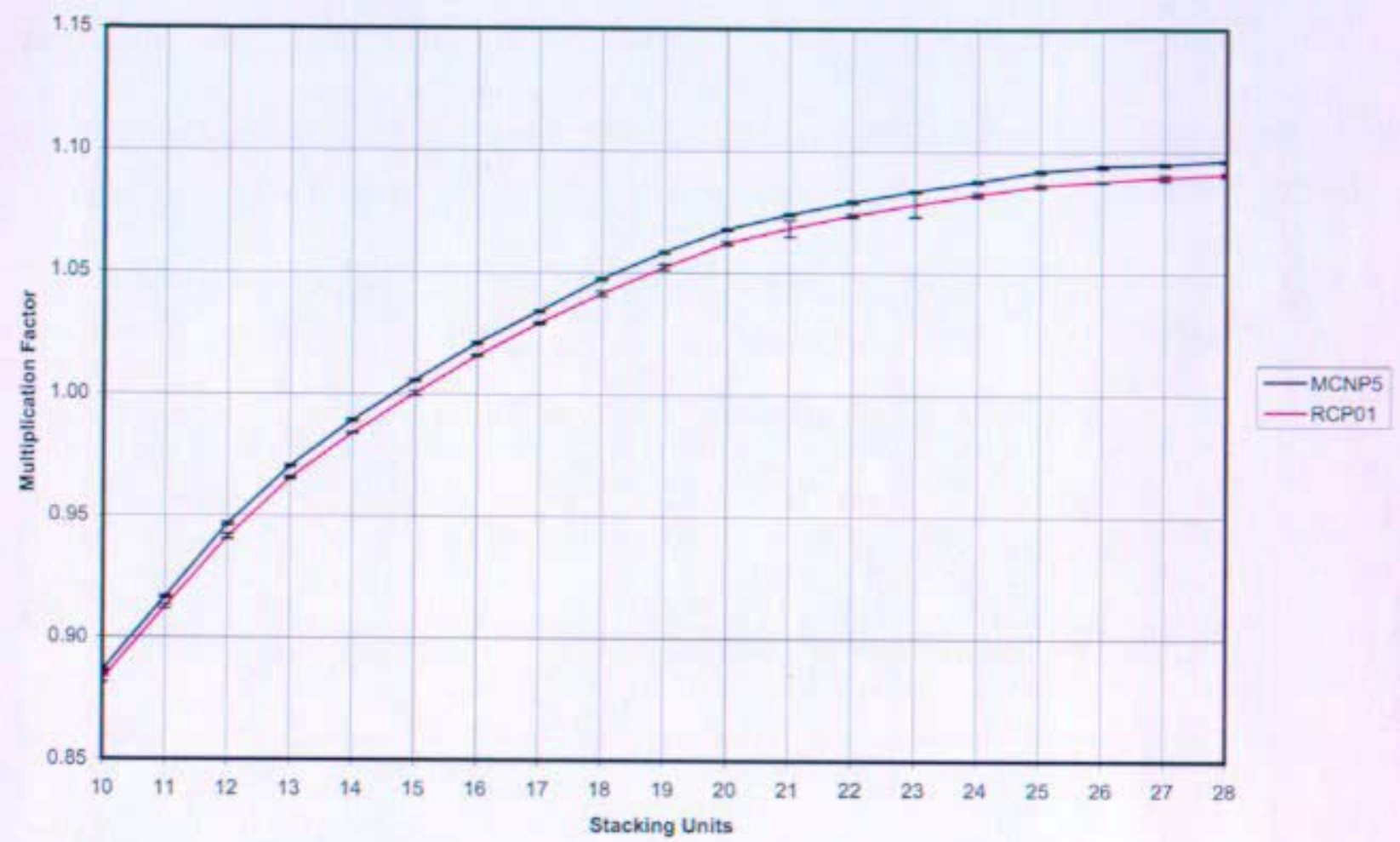

Figure 66. Nb-1Zr-3 Assembly $k_{\text {eff }}$ as a Function of the Number of Stacking Units

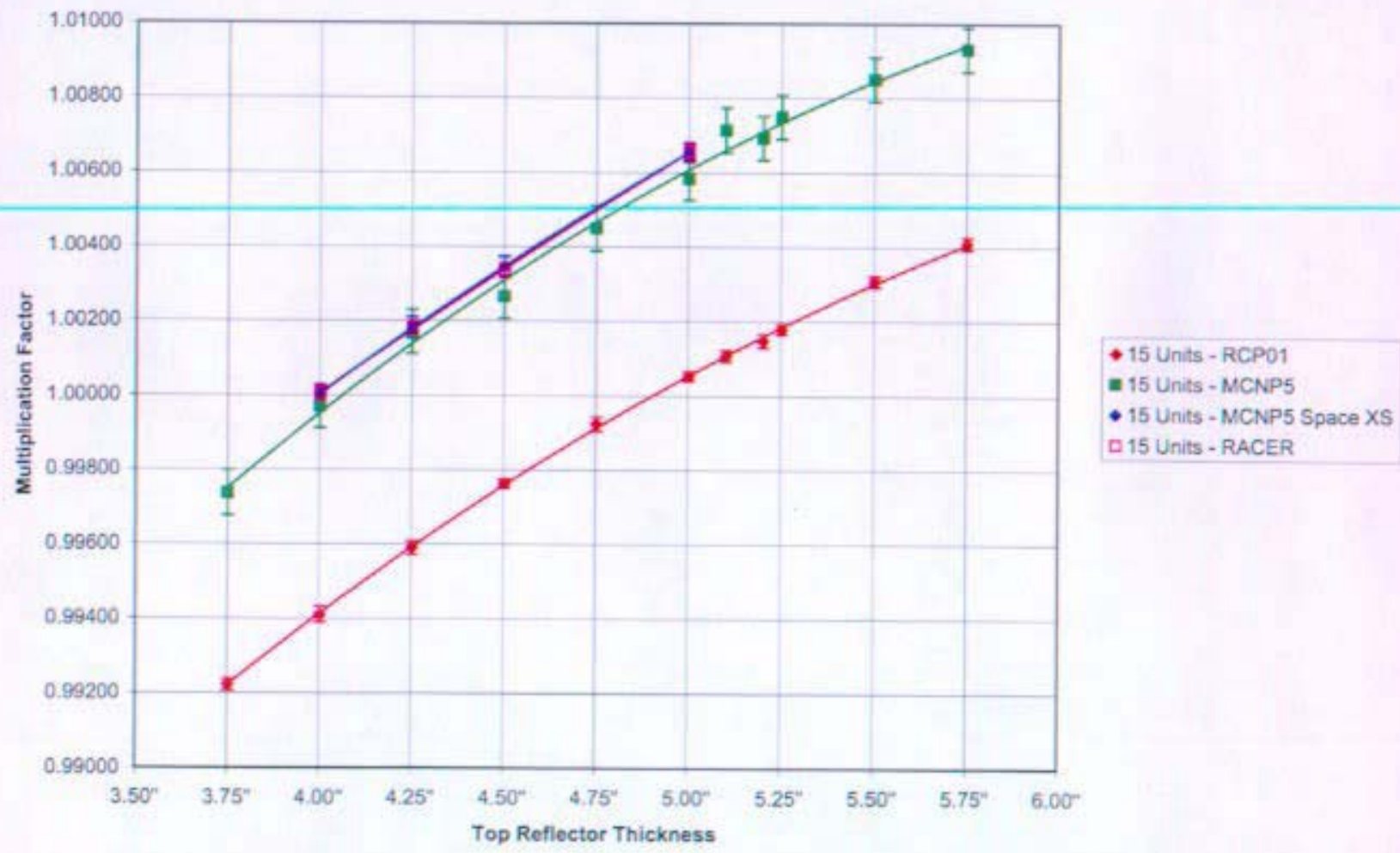

Figure 67. Nb-1Zr-3 Assembly $k_{\text {ent }}$ as a Function of the Top Reflector Thickness 
Table 73. Nb-1 Zr-3 Assembly $k_{\text {eff }}$ as a Function of the Top Reflector Thickness

\begin{tabular}{|c|c|c|c|c|c|c|c|c|}
\hline \multicolumn{9}{|c|}{ Predicted Top Reflector Thickness } \\
\hline \multicolumn{9}{|c|}{15 Stacking Units } \\
\hline \multirow{2}{*}{$\begin{array}{c}\text { Top } \\
\text { Reflector } \\
\text { Thickness } \\
\text { (in) }\end{array}$} & \multicolumn{2}{|c|}{ MCNP5 } & \multicolumn{2}{|c|}{ MCNP5 (Space XS) } & \multicolumn{2}{|c|}{ RCP01 } & \multicolumn{2}{|c|}{ RACER } \\
\hline & $k_{\text {eff }}$ & $95 \% \mathrm{Cl}$ & $\mathbf{k}_{\text {eff }}$ & $95 \% \mathrm{Cl}$ & $\mathbf{k}_{\text {eff }}$ & $95 \% \mathrm{Cl}$ & $k_{\text {eft }}$ & $95 \% \mathrm{Cl}$ \\
\hline 3.75 & 0.99736 & 0.00061 & - & - & 0.99222 & 0.00015 & - & - \\
\hline 4.00 & 0.99968 & 0.00057 & 1.00001 & 0.00026 & 0.99411 & 0.00021 & 1.00004 & 0.00020 \\
\hline 4.25 & 1.00169 & 0.00059 & 1.00180 & 0,00028 & 0.99589 & 0.00018 & 1.00179 & 0.00020 \\
\hline 4.50 & 1.00264 & 0.00059 & 1.00344 & 0.00028 & 0.99763 & 0.00011 & 1.00336 & 0.00020 \\
\hline 4.75 & 1.00448 & 0.00061 & - & - & 0.99923 & 0.00018 & - & - \\
\hline 5.00 & 1.00581 & 0.00057 & 1.00653 & 0.00026 & 1.00062 & 0.00012 & 1.00654 & 0.00021 \\
\hline 5.10 & 1.00712 & 0.00061 & - & - & 1.00107 & 0.00015 & - & - \\
\hline 5.20 & 1.00691 & 0.00059 & - & - & 1.00147 & 0.00018 & - & - \\
\hline 5.25 & 1.00748 & 0.00059 & - & - & 1.00178 & 0.00013 & - & - \\
\hline 5.50 & 1.00848 & 0.00059 & - & - & 1.00307 & 0.00015 & - & - \\
\hline 5.75 & 1.00929 & 0.00059 & - & - & 1.00410 & 0.00016 & - & - \\
\hline
\end{tabular}




\subsubsection{Niobium Critical Experiments Summary and Conclusions}

This document provides the pre-experimental predictions for the $\mathrm{Nb}-1 \mathrm{Zr}$ critical experiments including the effect of the Planet assembly machine structure. These critical experiments are being performed to:

1. determine the adequacy of the existing $\mathrm{Nb}$ neutron cross section evaluations in neutron energy spectra characteristic of Prometheus reactor designs under normal and accident conditions,

2. reduce the uncertainty in $\mathrm{K}_{\mathrm{eff}}$ for Prometheus reactor designs containing substantial amounts of $\mathrm{Nb}$ by performing benchmark quality critical experiments that bracket the neutron energy spectra expected under normal and accident conditions, and

3. provide benchmark critical experiments needed to develop improved $\mathrm{Nb}$ neutron cross section evaluations if new evaluations are determined to be required.

Experiments 2 and 3 are designed to bracket the neutron energy spectrum expected in the Prometheus space nuclear reactor under normal operating conditions. A summary of the fission fraction in the thermal, intermediate, and fast energy ranges for each of the $\mathrm{Nb}-1 \mathrm{Zr}$ critical experiments is provided in Table $74 . \mathrm{Nb}-1 \mathrm{Zr}-2$ and $\mathrm{Nb}-1 \mathrm{Zr}-3$ are classified as fast spectrum experiments. A summary of the pre-experimental predictions for each of the $\mathrm{Nb}-1 \mathrm{Zr}$ critical experiments is provided in Table 75. Predictions from RCP01, MCNP5, MCNP5 with space cross sections, and RACER analyses are reported.

Comparisons of the RCP01 and MCNP5 predicted fission reaction rate spectra and RCP01 predicted fission reaction rate spectrum CDFs are provided in Figure 68 and Figure 69 . Nb-1Zr experiments 2 and 3 clearly have a fast spectrum. Comparisons of the RCP01 and MCNP5 predicted $\mathrm{Nb}-1 \mathrm{Zr}$ absorption rate spectra are provided in Figure 70. The differences in the RCP01 and MCNP5 predicted absorption rates are believed to be primarily due to the different versions of the ${ }^{93} \mathrm{Nb}$ cross section evaluation used in the analyses. The RCP01 analyses used the ENDF/B-VI.1 ${ }^{93} \mathrm{Nb}$ evaluation while the MCNP5 analyses used the ENDF/B-VI.6. Neither ${ }^{93} \mathrm{Nb}$ cross section evaluations contained unresolved resonance data. SPACE05A used the same ENDF/B-VI.6 evaluations used in MCNP5's default cross cross sections, as evidenced by the very close agreement between the RACER and MCNP5 with space cross sections analyses and the MCNP5 with default cross sections analysis

Table 74. A Summary of the Energy Spectrum Covered in the $\mathrm{Nb}-1 \mathrm{Zr}$ Critical Experiments

\begin{tabular}{|c|c|c|c|}
\hline \multirow{2}{*}{ Experiment } & \multicolumn{3}{|c|}{ Percent Fissions by Energy (MCNP5 Predictions) } \\
\cline { 2 - 4 } & $<0.625 \mathrm{eV}$ & $\mathbf{0 . 6 2 5 e V}-100 \mathrm{keV}$ & $>100 \mathrm{keV}$ \\
\hline $\mathrm{Nb}-1 \mathrm{Zr}-2$ & $0.0 \%$ & $22.1 \%$ & $77.9 \%$ \\
\hline $\mathrm{Nb}-1 \mathrm{Zr}-3$ & $0.1 \%$ & $33.9 \%$ & $66.1 \%$ \\
\hline
\end{tabular}


B-TM-1639

Table 75. A Summary of the Pre-Experimental Predictions for the $\mathrm{Nb}-1 \mathrm{Zr}$ Critical Experiments

\begin{tabular}{|c|c|c|c|c|c|c|c|c|}
\hline Experiment & $\begin{array}{c}\text { Monte } \\
\text { Carlo Code }\end{array}$ & $\begin{array}{l}\text { Stacking } \\
\text { Units }\end{array}$ & $\begin{array}{c}\text { Top } \\
\text { Reflector } \\
\text { Thickness } \\
\text { (in) }\end{array}$ & $k_{\text {eff }}$ & $\begin{array}{c}95 \% \\
\text { Confidence } \\
\text { Level }\end{array}$ & $\begin{array}{c}\text { Mass } \\
\text { of HEU } \\
(\mathrm{kg})\end{array}$ & $\begin{array}{c}\text { Mass } \\
\text { of } \mathrm{Nb}- \\
1 \mathrm{Zr}(\mathrm{kg})\end{array}$ & $\begin{array}{l}\text { Mass of } \\
\text { Graphite } \\
(\mathrm{kg})\end{array}$ \\
\hline \multirow{4}{*}{$\mathrm{Nb}-1 \mathrm{Zr}-2$} & RCP01 & 16 & 1.90 & 1.00092 & 0.00021 & 196.5 & 80.3 & 70.8 \\
\hline & MCNP5 & 16 & 1.75 & 1.00075 & 0.00055 & 196.5 & 80.3 & 69.3 \\
\hline & $\begin{array}{c}\text { MCNP5 } \\
\text { (Space XS) }\end{array}$ & 16 & 1.75 & 1.00064 & 0.00026 & 196.5 & 80.3 & 69.3 \\
\hline & RACER & 16 & 1.75 & 1.00138 & 0.00020 & 196.5 & 80.3 & 69.3 \\
\hline \multirow{4}{*}{$\mathrm{Nb}-1 \mathrm{Zr}-3$} & RCP01 & 15 & 5.00 & 1.00052 & 0.00012 & 185.0 & 76.4 & 159.1 \\
\hline & MCNP5 & 15 & 4.25 & 1.00169 & 0.00059 & 185.0 & 76.4 & 151.8 \\
\hline & $\begin{array}{c}\text { MCNP5 } \\
\text { (Space XS) }\end{array}$ & 15 & 4.25 & 1.00180 & 0.00028 & 185.0 & 76.4 & 151.8 \\
\hline & RACER & 15 & 4.25 & 1.00179 & 0.00020 & 185.0 & 76.4 & 151.8 \\
\hline
\end{tabular}

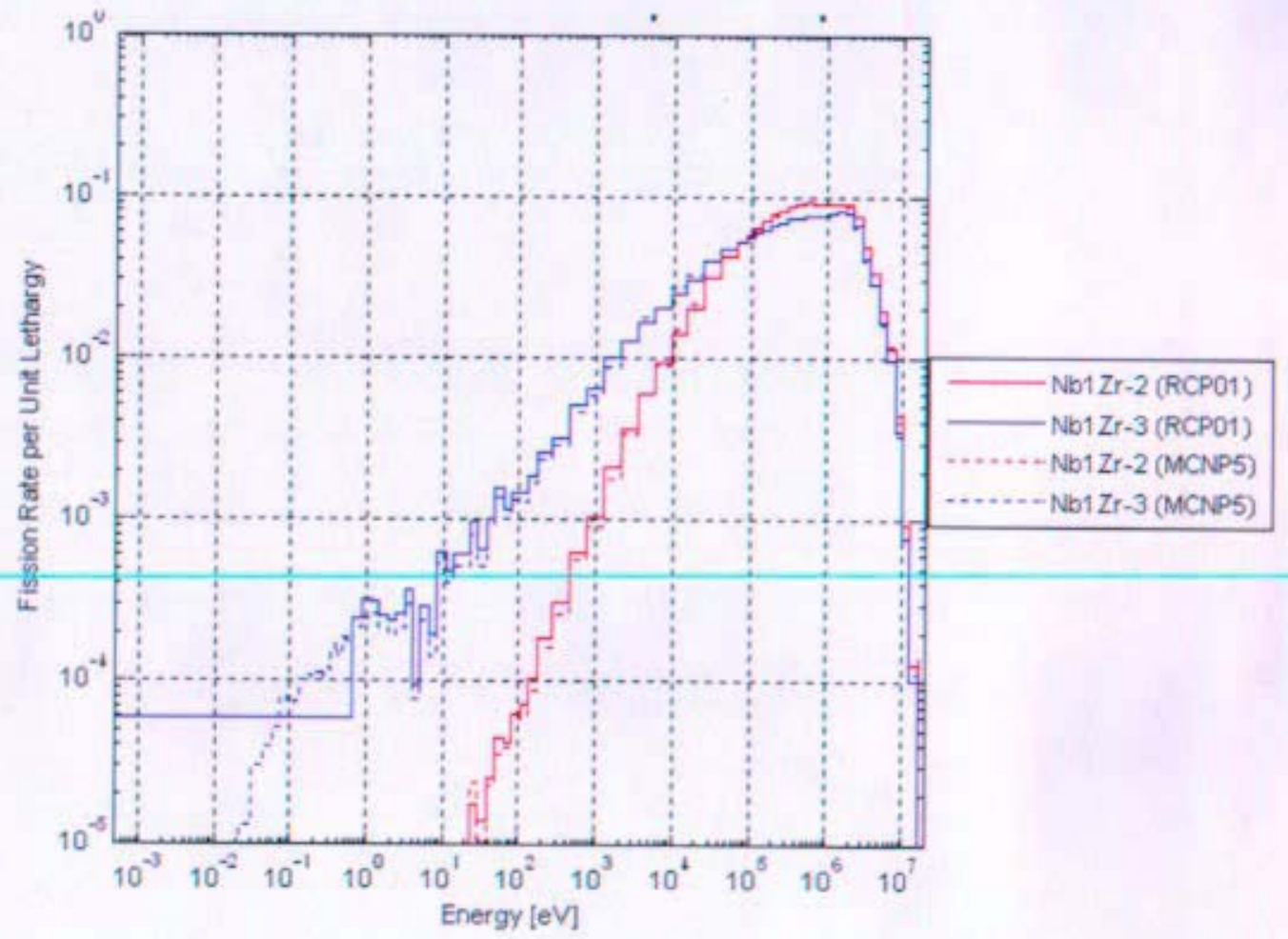

Figure 68: Comparison of RCP01 and MCNP5 Fission Rate Spectra for Nb-1Zr Critical Experiments 


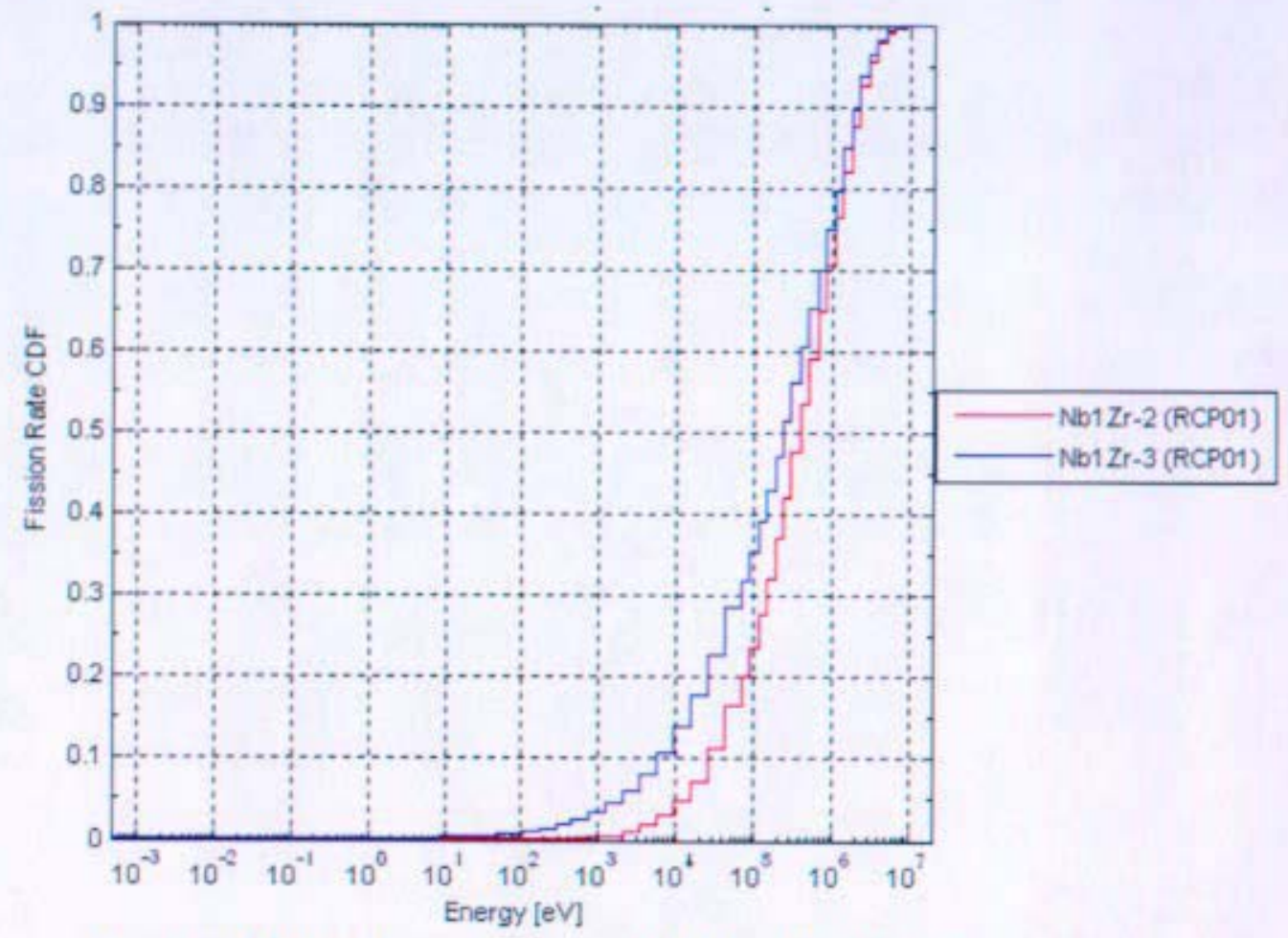

Figure 69: RCP01 Fission CDFs for the Nb-1Zr Critical Experiments

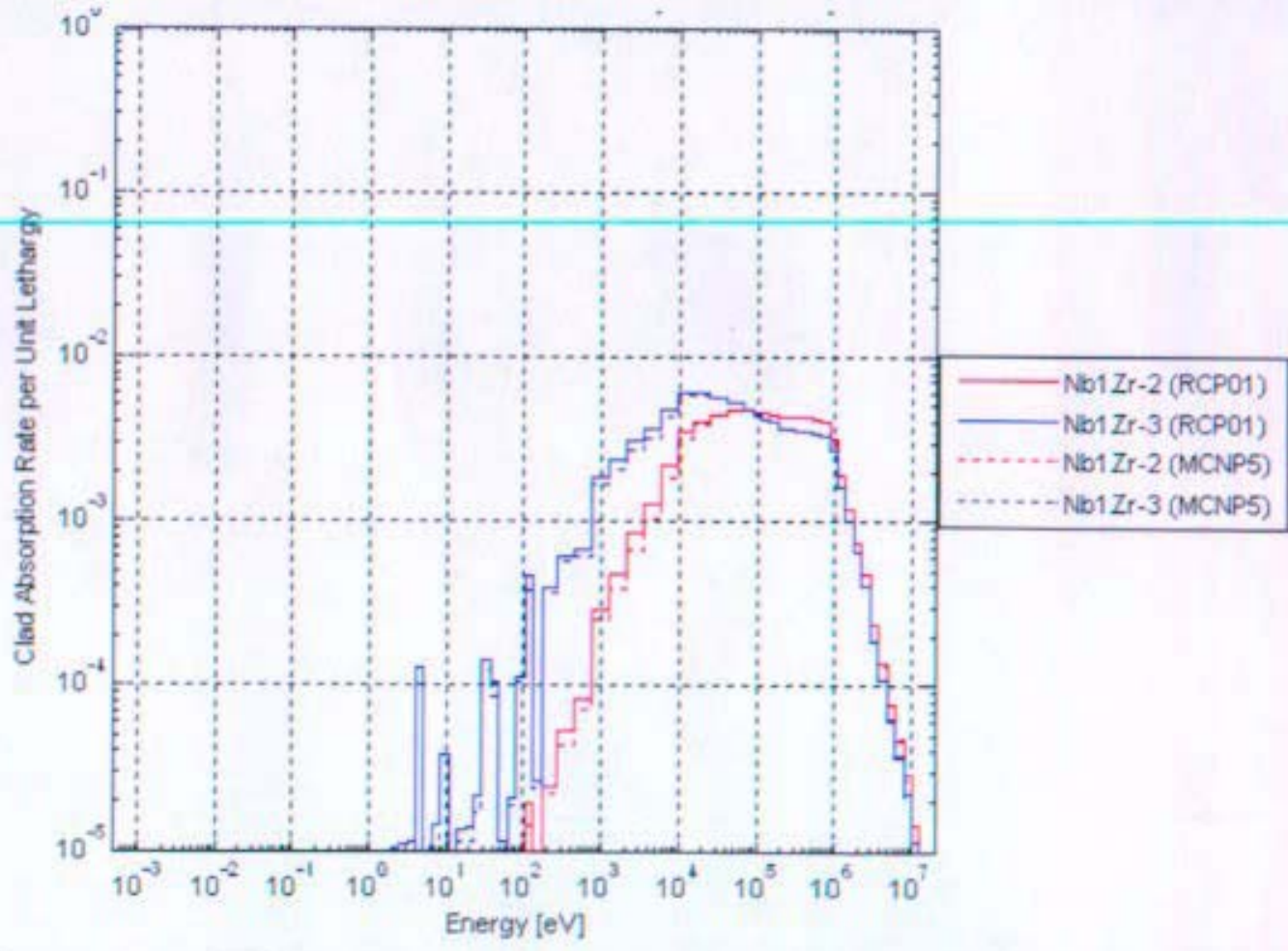

Figure 70: Comparison of RCP01 and MCNP5 Nb-1Zr Absorption Rate Spectra for Nb-1Zr Critical Experiments 


\subsection{Rhenium Critical Experiments}

\subsubsection{Re-1 Experiment}

The Re-1 experiment is designed to simulate the hardest neutron spectrum, which is in the center of the Prometheus reactor core during normal operating conditions. A cross-sectional view and close-up view of the experimental configuration are provided in Figure 71 and Figure 72 where aluminum is yellow, graphite is blue, Re is green, HEU is red, and stainless steel is purple (all dimensions in figures are in centimeters). The Re-1 assembly configuration, including plate layout and dimensions, is shown in Table 76. RCP01 and MCNP5 predict an assembly height of 6.694", while MCNP5 with space cross sections and RACER predict an assembly height of $6.644^{\prime \prime}$. The assembly rests on a $3.0^{\prime \prime}$ thick hollow Al 6061-T6 spindle plate that has a $19^{\prime \prime} \mathrm{OD}$ and $2.50^{\prime \prime}$ inner diameter. The active core region of the assembly is $4.444^{\prime \prime}$ high and contains 17 stacking units consisting of a $0.0161^{\prime \prime}$ thick Re plate, a $0.118^{\prime \prime}$ thick HEU plate, a $0.0161^{\prime \prime}$ thick Re plate, and a $0.100^{\prime \prime}$ thick graphite plate and 1 stacking unit consisting of a $0.0161^{\prime \prime}$ thick Re plate, a $0.118^{\prime \prime}$ thick HEU plate, and a $0.0161^{\prime \prime}$ thick Re plate, for a total of 18 stacking units. The RCP01 and MCNP5 analyses predict a 1.0" thick graphite bottom reflector and a $1.25^{\prime \prime}$ thick graphite top reflector. The MCNP5 with space cross sections and RACER analyses predict a 1.0" thick graphite bottom reflector and a 1.20" thick graphite top reflector. A hollow Al 6061-T6 alignment tube is assumed to extend from the bottom of the spindle plate to the top of the $6^{\text {th }}$ stacking unit. All other regions are modeled as void, except as noted in Section 4.0 for the RACER models. The Re-1 assembly contains $219.6 \mathrm{~kg}$ of $\mathrm{HEU}$ and $68.8 \mathrm{~kg}$ of Re. The distribution of material in the top and bottom half of the assembly is given in Table 77 for RCP01, MCNP5, MCNP5 with space cross sections, and RACER predicted critical configurations.

A series of analyses have been performed to predict the $\mathrm{k}_{\mathrm{eff}}$ of the $\mathrm{Re}-1$ assembly during the approach to critical as a function of both the number of stacking units and the graphite top reflector thickness. Figure 73 presents the RCP01 and MCNP5 predicted $k_{\text {eff }}$ as a function of the number of stacking units in the Re-1 assembly. The error bars indicate the size of the $95 \%$ confidence interval in the Monte Carlo calculations. As illustrated in Figure 73, both the MCNP5 and RCP01 predictions are close. The average difference between the MCNP5 and RCP01 predicted $k_{\text {eff }}$ is $0.0013 \pm 0.0006 \Delta k$ over the range from 8 to 28 stacking units. Figure 74 and Table 78 provide a comparison of the predicted $k_{\text {eff }}$ of the Re-1 assembly with 18 and 19 stacking units as a function of the graphite top reflector thickness. The experimental configurations that were predicted to achieve delayed criticality within TSR limits $(\rho<0.5 \$)$ are highlighted in green in Table 78 . The $R e-1$ assembly is classified as a fast spectrum assembly with the following representative fission fractions, as predicted by MCNP5: $83.1 \%$ fast $(E>100 \mathrm{keV}), 16.9 \%$ intermediate $(0.625 \mathrm{eV}<\mathrm{E}<100 \mathrm{keV})$, and $0.0 \%$ thermal $(E<$ $0.625 \mathrm{eV})$. 


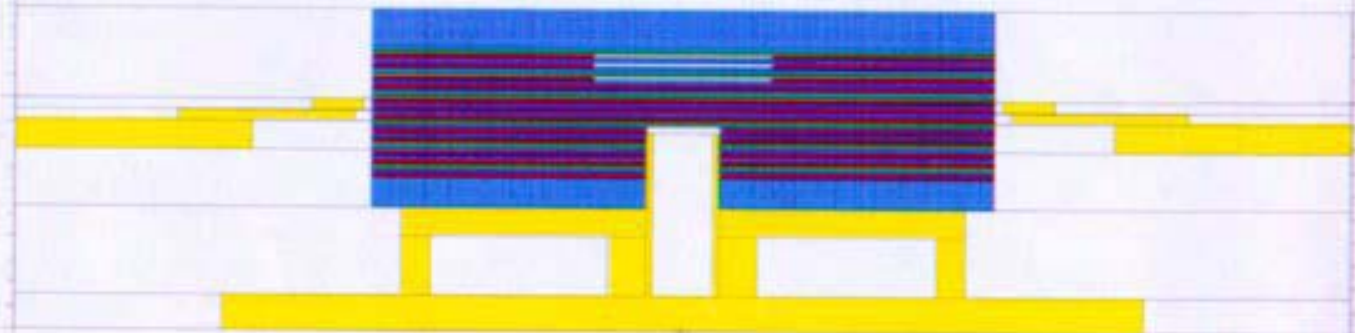

ส

우

Figure 71. Cross-sectional View of the Re-1 Assembly 


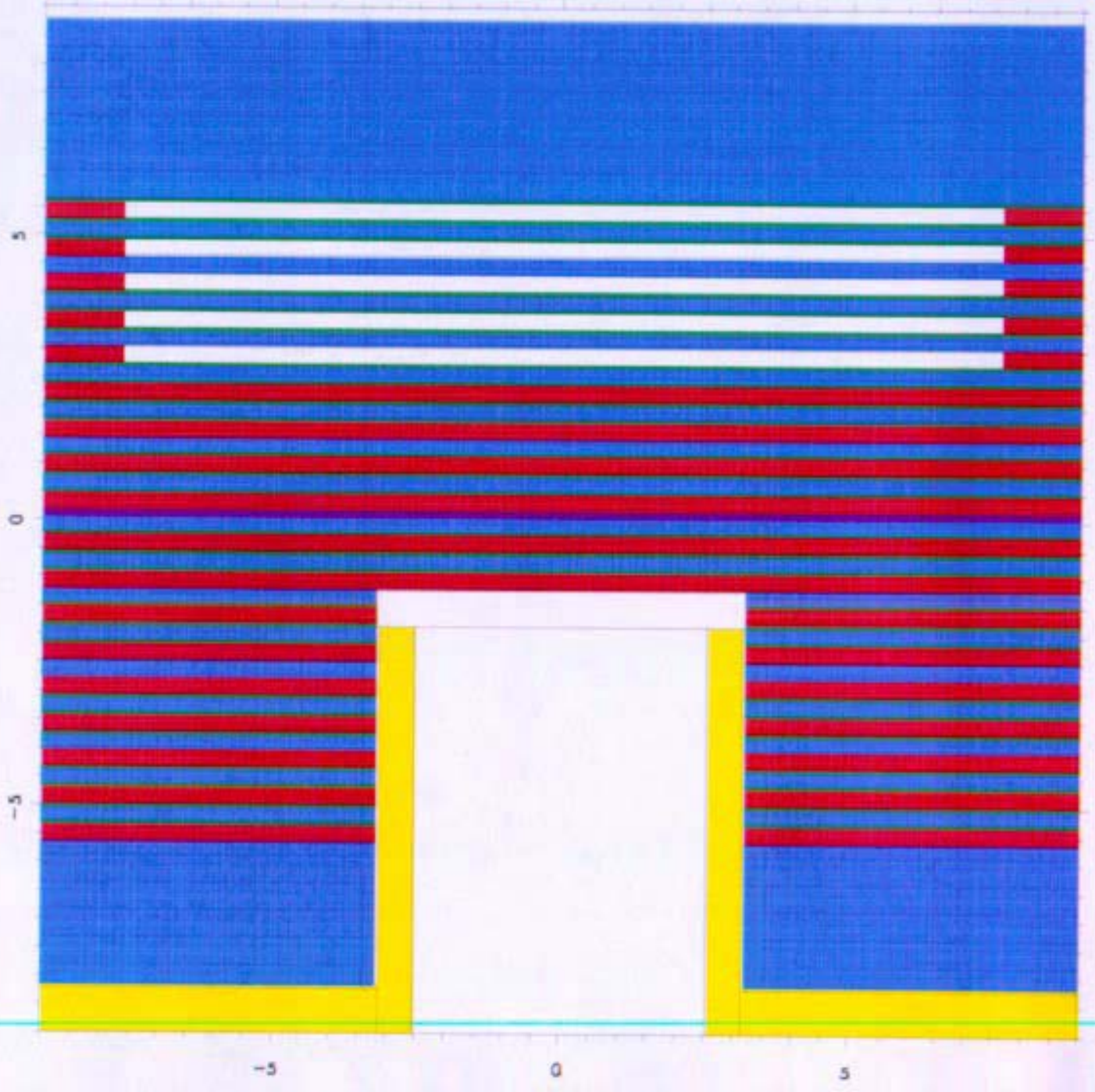

Figure 72. Cross-sectional Close-up View of the Re-1 Assembly 
Table 76. Predicted Critical Configuration for the Re-1 Assembly

\begin{tabular}{|c|c|c|c|c|c|}
\hline Unit & Material & Thickness (in) & \begin{tabular}{c|} 
Inner \\
Diameter (in)
\end{tabular} & \begin{tabular}{|c|} 
Outer \\
Diameter (in)
\end{tabular} & $\begin{array}{l}\text { Assembly Height } \\
\text { (in) }\end{array}$ \\
\hline $\begin{array}{l}\text { Bottom } \\
\text { Reflector }\end{array}$ & Graphite & 1.00 & 2.51 & 210 & 1.0000 \\
\hline \multirow{4}{*}{1} & $\mathrm{Re}$ & 0.0161 & 2.51 & 21.0 & 1.0161 \\
\hline & HEU & 0.118 & 2.51 & 21.0 & 1.1341 \\
\hline & $\mathrm{Re}$ & 0.0161 & 2.51 & 21.0 & 1.1502 \\
\hline & Graphite & 0.100 & 2.51 & 21.0 & 1.2502 \\
\hline \multirow{4}{*}{2} & $\mathrm{Re}$ & 0.0161 & 2.51 & 21.0 & 1.2663 \\
\hline & HEU & 0.118 & 2.51 & 21.0 & 1.3843 \\
\hline & $\mathrm{Re}$ & 0.0161 & 2.51 & 21.0 & 1.4004 \\
\hline & Graphite & 0.100 & 2.51 & 21.0 & 1.5004 \\
\hline \multirow{4}{*}{3} & $\mathrm{Re}$ & 0.0161 & 2.51 & 21.0 & 1.5165 \\
\hline & HEU & 0.118 & 2.51 & 21.0 & 1.6345 \\
\hline & $\mathrm{Re}$ & 0.0161 & 2.51 & 21.0 & 1.6506 \\
\hline & Graphite & 0.100 & 2.51 & 21.0 & 1.7506 \\
\hline \multirow{4}{*}{4} & $\mathrm{Re}$ & 0.0161 & 2.51 & 21.0 & 1.7667 \\
\hline & HEU & 0.118 & 2.51 & 21.0 & 1.8847 \\
\hline & $\mathrm{Re}$ & 0.0161 & 2.51 & 21.0 & 1.9008 \\
\hline & Graphite & 0.100 & 2.51 & 21.0 & 2.0008 \\
\hline \multirow{4}{*}{5} & $\mathrm{Re}$ & 0.0161 & 2.51 & 21.0 & 2.0169 \\
\hline & HEU & 0.118 & 2.51 & 21.0 & 2.1349 \\
\hline & $\mathrm{Re}$ & 0.0161 & 2.51 & 21.0 & 2.1510 \\
\hline & Graphite & 0.100 & 2.51 & 21.0 & 2.2510 \\
\hline \multirow{4}{*}{6} & $\mathrm{Re}$ & 0.0161 & 2.51 & 21.0 & 2.2671 \\
\hline & HEU & 0.118 & 2.51 & 21.0 & 2.3851 \\
\hline & $\mathrm{Re}$ & 0.0161 & 2.51 & 21.0 & 2.4012 \\
\hline & Graphite & 0.100 & 2.51 & 21.0 & 2.5012 \\
\hline \multirow{4}{*}{7} & $\mathrm{Re}$ & 0.0161 & 2.51 & 21.0 & 2.5173 \\
\hline & $\mathrm{HEU}$ & 0.118 & 2.51 & 21.0 & 2.6353 \\
\hline & $\mathrm{Re}$ & 0.0161 & 2.51 & 21.0 & 2.6514 \\
\hline & Graphite & 0.100 & 2.51 & 21.0 & 2.7514 \\
\hline \multirow{4}{*}{8} & $\mathrm{Re}$ & 0.0161 & 0 & 21.0 & 2.7675 \\
\hline & HEU & 0.118 & 0 & 21.0 & 2.8855 \\
\hline & $\mathrm{Re}$ & 0.0161 & 0 & 21.0 & 2.9016 \\
\hline & Graphite & 0.100 & 0 & 21.0 & 3.0016 \\
\hline \multirow{4}{*}{9} & $\mathrm{Re}$ & 0.0161 & 0 & 21.0 & 3.0177 \\
\hline & HEU & 0.118 & 0 & 21.0 & 3.1357 \\
\hline & $\mathrm{Re}$ & 0.0161 & 0 & 21.0 & 3.1518 \\
\hline & Graphite & 0.100 & 0 & 21.0 & 3.2518 \\
\hline Diaphragm & Stainless Steel & 0.040 & 0 & 24.8 & 3.2918 \\
\hline \multirow{4}{*}{10} & $\mathrm{Re}$ & 0.0161 & 0 & 21.0 & 3.3079 \\
\hline & HEU & 0.118 & 0 & 21.0 & 3.4259 \\
\hline & $\mathrm{Re}$ & 0.0161 & 0 & 21.0 & 3.4420 \\
\hline & Graphite & 0.100 & 0 & 21.0 & 3.5420 \\
\hline
\end{tabular}




\begin{tabular}{|c|c|c|c|c|c|}
\hline Unit & Material & Thickness (in) & \begin{tabular}{|c|} 
Inner \\
Diameter (in)
\end{tabular} & $\begin{array}{c}\text { Outer } \\
\text { Diameter (in) }\end{array}$ & $\begin{array}{l}\text { Assembly Height } \\
\text { (in) }\end{array}$ \\
\hline \multirow{4}{*}{11} & $\mathrm{Re}$ & 0.0161 & 0 & 21.0 & 3.5581 \\
\hline & HEU & 0.118 & 0 & 21.0 & 3.6761 \\
\hline & $\mathrm{Re}$ & 0.0161 & 0 & 21.0 & 3.6922 \\
\hline & Graphite & 0.100 & 0 & 21.0 & 3.7922 \\
\hline \multirow{4}{*}{12} & $\mathrm{Re}$ & 0.0161 & 0 & 21.0 & 3.8083 \\
\hline & HEU & 0.118 & 0 & 21.0 & 3.9263 \\
\hline & $\mathrm{Re}$ & 0.0161 & 0 & 21.0 & 3.9424 \\
\hline & Graphite & 0.100 & 0 & 21.0 & 4.0424 \\
\hline \multirow{4}{*}{13} & $\mathrm{Re}$ & 0.0161 & 0 & 21.0 & 4.0585 \\
\hline & HEU & 0.118 & 0 & 21.0 & 4.1765 \\
\hline & $\mathrm{Re}$ & 0.0161 & 0 & 21.0 & 4.1926 \\
\hline & Graphite & 0.100 & 0 & 21.0 & 4.2926 \\
\hline \multirow{4}{*}{14} & $\mathrm{Re}$ & 0.0161 & 0 & 21.0 & 4.3087 \\
\hline & HEU & 0.118 & 6.005 & 21.0 & 4.4267 \\
\hline & $\mathrm{Re}$ & 0.0161 & 0 & 21.0 & 4.4428 \\
\hline & Graphite & 0.100 & 0 & 21.0 & 4.5428 \\
\hline \multirow{4}{*}{15} & $\mathrm{Re}$ & 0.0161 & 0 & 21.0 & 4.5589 \\
\hline & HEU & 0.118 & 6.005 & 21.0 & 4.6769 \\
\hline & $\mathrm{Re}$ & 0.0161 & 0 & 21.0 & 4.6930 \\
\hline & Graphite & 0.100 & 0 & 21.0 & 4.7930 \\
\hline \multirow{4}{*}{16} & $\mathrm{Re}$ & 0.0161 & 0 & 21.0 & 4.8091 \\
\hline & HEU & 0.118 & 6.005 & 21.0 & 4.9271 \\
\hline & $\mathrm{Re}$ & 0.0161 & 0 & 21.0 & 4.9432 \\
\hline & Graphite & 0.100 & 0 & 21.0 & 5.0432 \\
\hline \multirow{4}{*}{17} & $\mathrm{Re}$ & 0.0161 & 0 & 21.0 & 5.0593 \\
\hline & HEU & 0.118 & 6.005 & 21.0 & 5.1773 \\
\hline & $\mathrm{Re}$ & 0.0161 & 0 & 21.0 & 5.1934 \\
\hline & Graphite & 0.100 & 0 & 21.0 & 5.2934 \\
\hline \multirow{3}{*}{18} & $\mathrm{Re}$ & 0.0161 & 0 & 21.0 & 5.3095 \\
\hline & HEU & 0.118 & 6.005 & 21.0 & 5.4275 \\
\hline & $\mathrm{Re}$ & 0.0161 & 0 & 21.0 & 5.4436 \\
\hline $\begin{array}{l}\text { Top } \\
\text { eflector }\end{array}$ & Graphite & $\begin{array}{l}1.25 \text { (RCP01, } \\
\text { MCNP5) } \\
1.20 \text { (RACER. } \\
\text { MCNP5 Space } \\
\text { XS) }\end{array}$ & 0. & 21.0 & $\begin{array}{c}\text { 6.6936 (RCP01, } \\
\text { MCNP5) } \\
\text { 6.6436 (RACER } \\
\text { MCNP5 Space XS) }\end{array}$ \\
\hline
\end{tabular}

Table 77. Re-1 Assembly Material Mass Distribution

\begin{tabular}{|c|c|c|c|c|c|c|}
\hline \multirow{3}{*}{ Material } & \multicolumn{6}{|c|}{ Mass (kg) } \\
\cline { 2 - 7 } & \multicolumn{3}{|c|}{ MCNP5/RCP01 } & \multicolumn{2}{c|}{ MCNP5 (Space XS)/RACER } \\
\cline { 2 - 7 } & $\begin{array}{c}\text { Lower } \\
\text { Assembly }\end{array}$ & $\begin{array}{c}\text { Upper } \\
\text { Assembly }\end{array}$ & Total & $\begin{array}{c}\text { Lower } \\
\text { Assembly }\end{array}$ & $\begin{array}{c}\text { Upper } \\
\text { Assembly }\end{array}$ & Total \\
\hline HEU & 111.7 & 107.8 & 219.6 & 111.7 & 107.8 & 219.6 \\
\hline Re & 34.2 & 34.6 & 68.8 & 34.2 & 34.6 & 68.8 \\
\hline Graphite & 18.4 & 20.2 & 38.6 & 18.4 & 19.7 & 38.1 \\
\hline Total & 164.4 & 162.6 & 326.9 & 164.4 & 162.1 & 326.4 \\
\hline
\end{tabular}




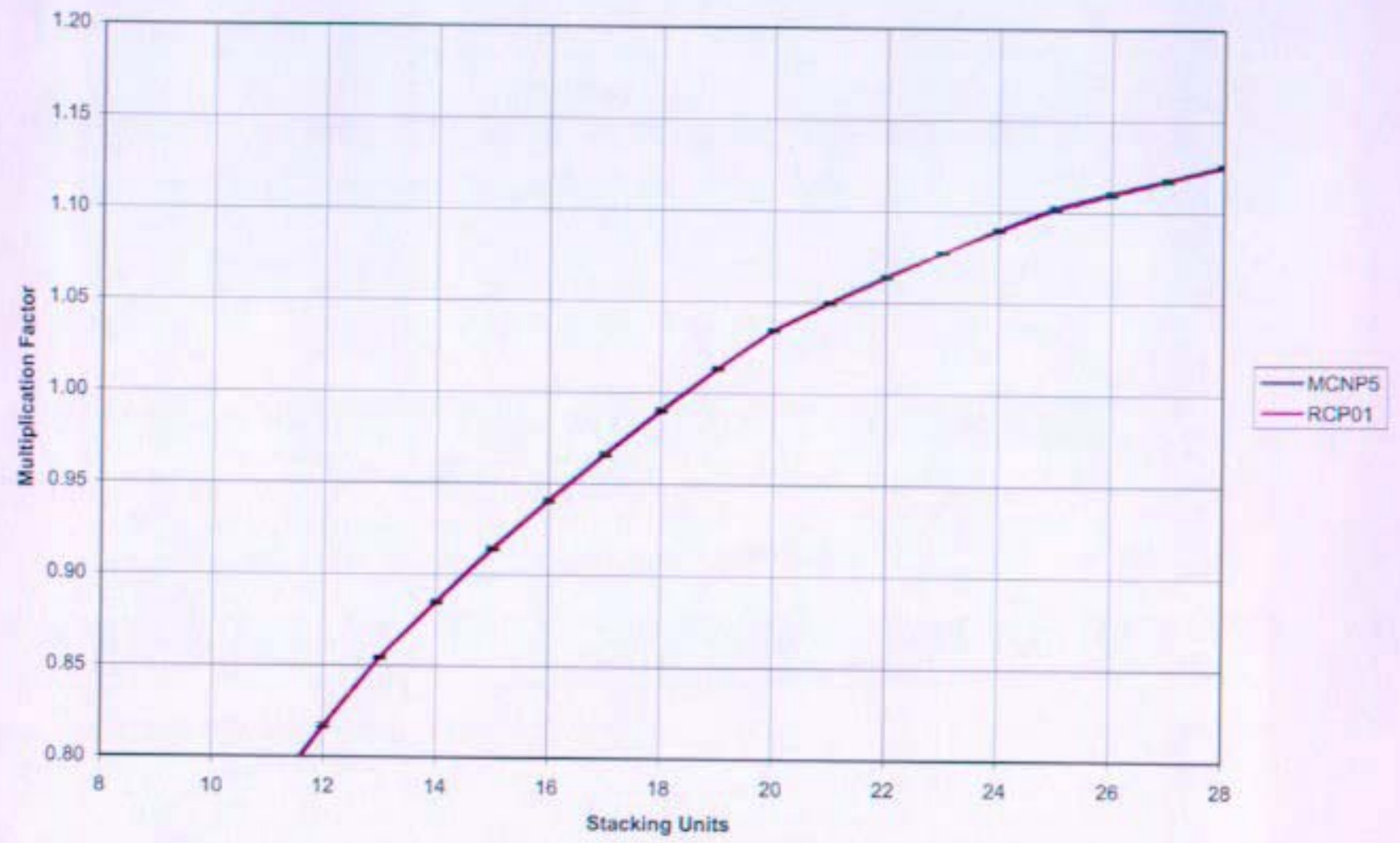

Figure 73. Re-1 Assembly $k_{\text {eff }}$ as a Function of the Number of Stacking Units

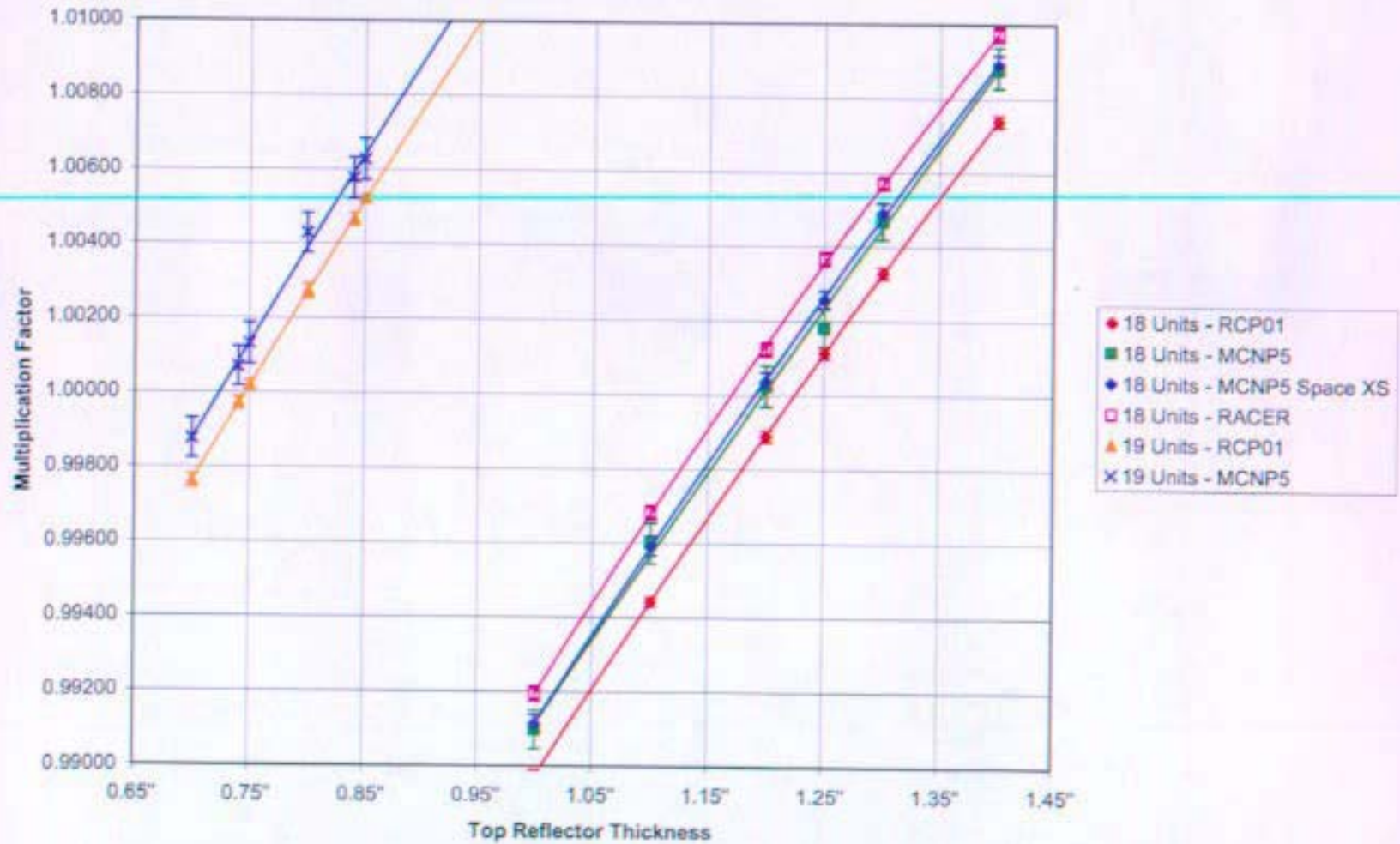

Figure 74. Re-1 Assembly $k_{\text {eff }}$ as a Function of the Top Reflector Thickness 
Table 78. Re-1 Assembly $k_{e f f}$ as a Function of the Top Reflector Thickness

\begin{tabular}{|c|c|c|c|c|c|c|c|c|}
\hline \multicolumn{9}{|c|}{ Predicted Top Reflector Thickness } \\
\hline \multicolumn{9}{|c|}{18 Stacking Units } \\
\hline \multirow{2}{*}{$\begin{array}{c}\text { Top } \\
\text { Reflector } \\
\text { Thickness } \\
\text { (in) }\end{array}$} & \multicolumn{2}{|c|}{ MCNP5 } & \multicolumn{2}{|c|}{ MCNP5 (Space XS) } & \multicolumn{2}{|c|}{ RCP01 } & \multicolumn{2}{|c|}{ RACER } \\
\hline & $k_{\text {eff }}$ & $95 \% \mathrm{Cl}$ & $k_{\text {eff }}$ & $95 \% \mathrm{Cl}$ & $k_{\text {etf }}$ & $95 \% \mathrm{Cl}$ & $k_{\text {eff }}$ & $95 \% \mathrm{Cl}$ \\
\hline 1.00 & 0.99096 & 0.00051 & 0.99112 & 0.00024 & 0.98972 & 0.00017 & 0.99194 & 0.00020 \\
\hline 1.10 & 0.99598 & 0.00055 & 0.99591 & 0.00026 & 0.99441 & 0.00012 & 0.99682 & 0.00018 \\
\hline 1,20 & 1.00022 & 0.00055 & 1.00035 & 0.00024 & 0.99888 & 0.00016 & 1.00122 & 0.00019 \\
\hline 1.25 & 1.00179 & 0.00053 & 1.00255 & 0.00024 & 1.00113 & 0.00016 & 1.00366 & 0.00019 \\
\hline 1.30 & 1.00467 & 0.00051 & 1.00489 & 0.00026 & 1.00328 & 0.00015 & 1.00570 & 0.00018 \\
\hline 1.40 & 1.00882 & 0.00055 & 1.00890 & 0.00026 & 1.00739 & 0.00015 & 1.00972 & 0.00019 \\
\hline \multicolumn{9}{|c|}{19 Stacking Units } \\
\hline \multirow{2}{*}{\begin{tabular}{|c|} 
Top \\
Reflector \\
Thickness \\
(in) \\
\end{tabular}} & \multicolumn{2}{|c|}{ MCNP5 } & \multicolumn{2}{|c|}{ MCNP5 (Space XS) } & \multicolumn{2}{|c|}{ RCP01 } & \multicolumn{2}{|c|}{ RACER } \\
\hline & $k_{\text {eff }}$ & $95 \% \mathrm{Cl}$ & $k_{\text {etf }}$ & $95 \% \mathrm{Cl}$ & $\mathbf{k}_{\text {eff }}$ & $95 \% \mathrm{Cl}$ & $k_{\text {eff }}$ & $95 \% \mathrm{Cl}$ \\
\hline 0.70 & 0.99875 & 0.00053 & \multirow{7}{*}{\multicolumn{2}{|c|}{$\begin{array}{l}\text { Not investigated due } \\
\text { to termination of } \\
\text { project. }\end{array}$}} & 0.99761 & 0.00017 & \multirow{7}{*}{\multicolumn{2}{|c|}{$\begin{array}{c}\text { Not investigated } \\
\text { due to termination } \\
\text { of project. }\end{array}$}} \\
\hline 0.74 & 1.00068 & 0.00053 & & & 0.99971 & 0.00017 & & \\
\hline 0.75 & 1.00130 & 0.00055 & & & 1.00019 & 0.00013 & & \\
\hline 0.80 & 1.00427 & 0.00053 & & & 1.00272 & 0.00020 & & \\
\hline 0.84 & 1.00575 & 0.00055 & & & 1.00465 & 0.00018 & & \\
\hline 0.85 & 1.00626 & 0.00055 & & & 1.00521 & 0.00009 & & \\
\hline 1.00 & 1.01378 & 0.00053 & & & 1.01238 & 0.00015 & & \\
\hline
\end{tabular}


B-TM-1639

\subsubsection{Re-2 Experiment}

The Re-2 experiment is designed to bracket the average neutron spectrum of the Prometheus reactor core. It is designed to be harder than the expected average neutron energy spectrum of the core but softer than the Re-1 experiment. Additional graphite has been added to the assembly to simulate the effect of neutron moderation near the reflector. A cross-sectional view and close-up view of the experimental configuration are provided in Figure 75 and Figure 76 where aluminum is yellow, graphite is blue, Re is green, HEU is red, and stainless steel is purple (all dimensions in figures are in centimeters). The assembly configuration, including plate layout and dimensions, is shown in Table 79. The RCP01 analysis predicts an assembly height of $9.595^{\prime \prime}$ and the MCNP5, MCNP5 with space cross sections, and RACER analyses predict an assembly height of $9.495^{\circ}$. The assembly rests on a $3.0^{\prime \prime}$ thick hollow Al 6061-T6 spindle plate that has a $19^{\prime \prime} \mathrm{OD}$ and $2.50^{\prime \prime}$ inner diameter. The active core region of the assembly is $5.745^{\prime \prime}$ high and contains 16 stacking units consisting of a $0.0161^{\prime \prime}$ thick Re plate, a $0.118^{\prime \prime}$ thick HEU plate, a $0.0161^{\prime \prime}$ thick Re plate, and a $0.197^{\prime \prime}$ thick graphite plate and 1 stacking unit consisting of a $0.0161^{\prime \prime}$ thick Re plate, a $0.118^{\prime \prime}$ thick HEU plate, and a $0.0161^{\prime \prime}$ thick Re plate, for a total of 17 stacking units. The bottom reflector consists of a $2.0^{\prime \prime}$ thick graphite reflector. The RCP01 predicted top reflector consists of a 1.85" thick graphite reflector and the MCNP5, MCNP5 with space cross sections, and RACER predicted top reflector consists of a $1.75^{\prime \prime}$ thick graphite reflector. A hollow Al 6061-T6 alignment tube is assumed to extend from the bottom of the spindle plate to the top of the $6^{\text {th }}$ stacking unit. All other regions are modeled as void, except as noted in Section 4.0 for the RACER models. The Re-2 assembly contains $208.0 \mathrm{~kg}$ of HEU and $64.9 \mathrm{~kg}$ of Re. The distribution of materials in the top and bottom half of the assembly is given in Table 80 for the RCP01, MCNP5, MCNP5 with space cross sections, and RACER predicted critical configurations.

A series of analyses have been performed to predict the $k_{\text {eff }}$ of the $R e-2$ assembly during the approach to critical as a function of both the number of stacking units and the graphite top reflector thickness. Figure 77 presents the RCP01 and MCNP5 predicted $k_{\text {eff }}$ as a function of the number of stacking units in the Re-2 assembly. The error bars indicate the size of the $95 \%$ confidence interval in the Monte Carlo calculations. As illustrated in Figure 77, both the MCNP5 and RCP01 predictions are close. The average difference between the MCNP5 and RCP01 predicted $k_{\text {eff }}$ is $0.0030 \pm 0.0006 \Delta k$ over the range from 8 to 28 stacking units. Figure 78 and Table 81 provide a comparison of the predicted $k_{\text {eff }}$ of the Re-2 assembly with 16 and 17 stacking units as a function of the graphite top reflector thickness. The experimental configurations that were predicted to achieve delayed criticality within TSR limits $(\rho<0.5 \$)$ are highlighted in green in Table 81 . The Re-2 assembly is classified as a fast spectrum assembly with the following representative fission fractions, as predicted by MCNP5: $76.8 \%$ fast $(E>100 \mathrm{keV}), 23.2 \%$ intermediate $(0.625 \mathrm{eV}<E<100 \mathrm{keV})$, and $0.0 \%$ thermal $(E<$ $0.625 \mathrm{eV})$. 


\section{B-TM-1639}

?

오

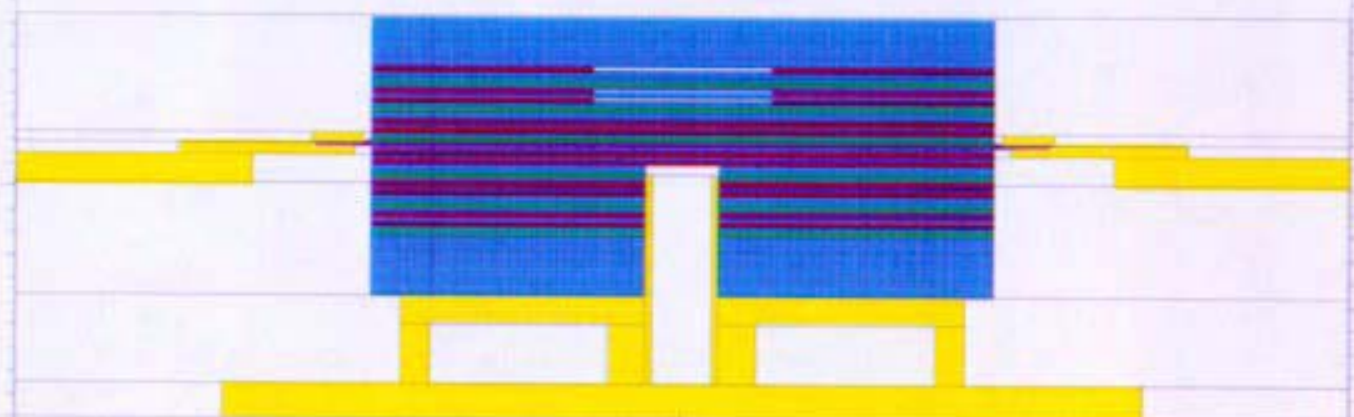

พ

우

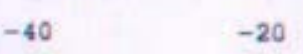

0

20

40

Figure 75. Cross-sectional View of the Re-2 Assembly 


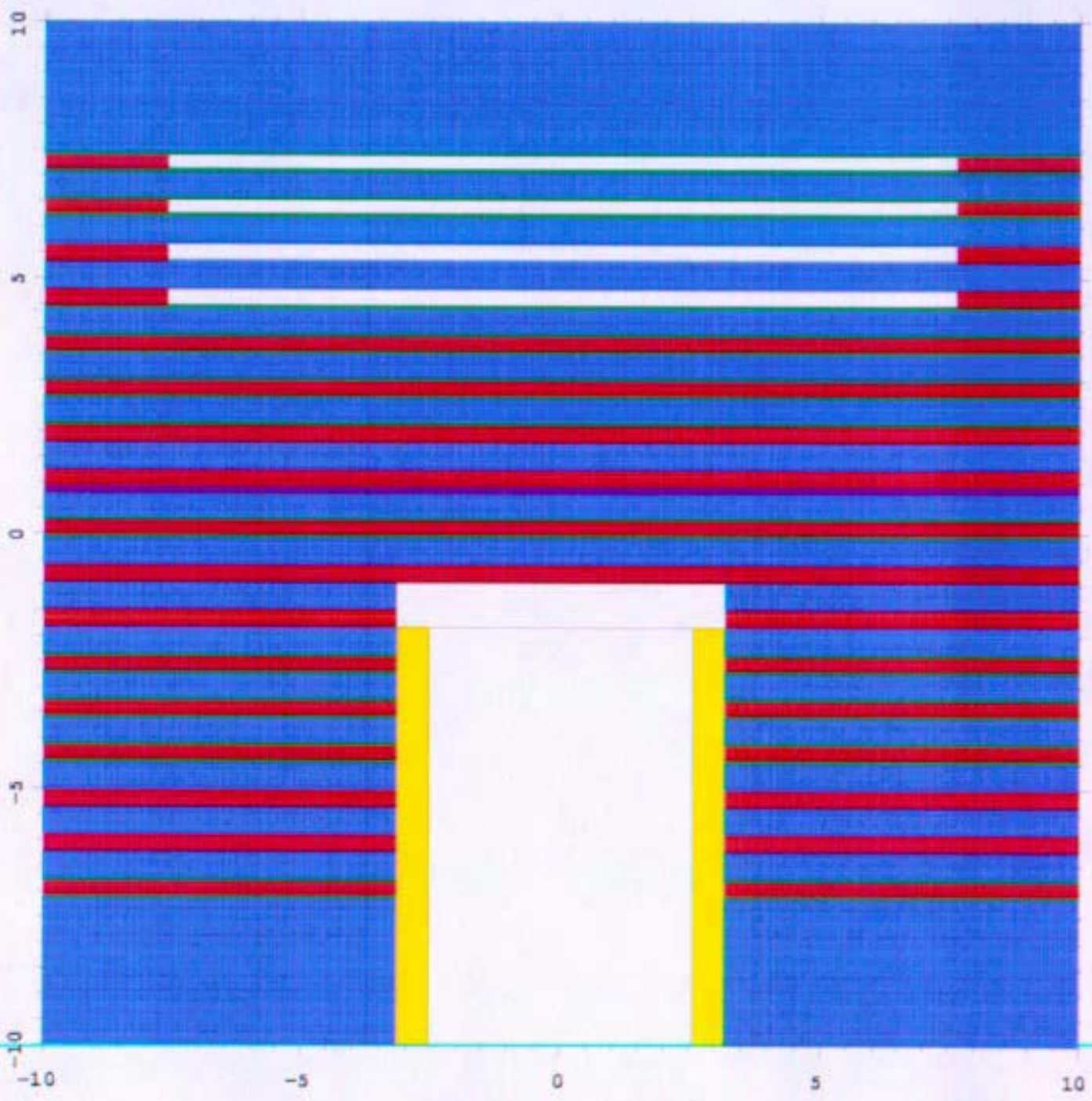

Figure 76. Cross-sectional Close-up View of the Re-2 Assembly 
Table 79. Predicted Critical Configuration for the Re-2 Assembly

\begin{tabular}{|c|c|c|c|c|c|}
\hline Unit & Material & Thickness (in) & $\begin{array}{c}\text { Inner } \\
\text { Diameter (in) }\end{array}$ & $\begin{array}{c}\text { Outer } \\
\text { Diameter (in) }\end{array}$ & $\begin{array}{l}\text { Assembly } \\
\text { Height (in) }\end{array}$ \\
\hline $\begin{array}{l}\text { Bottom } \\
\text { Reflector }\end{array}$ & Graphite & 2.00 & 2.51 & 21.0 & 2.0000 \\
\hline \multirow{4}{*}{1} & $\mathrm{Re}$ & 0.0161 & 2.51 & 21.0 & 2.0161 \\
\hline & HEU & 0.118 & 2.51 & 21.0 & 2.1341 \\
\hline & $\mathrm{Re}$ & 0.0161 & 2.51 & 21.0 & 2.1502 \\
\hline & Graphite & 0.197 & 2.51 & 21.0 & 2.3472 \\
\hline \multirow{4}{*}{2} & $\mathrm{Re}$ & 0.0161 & 2.51 & 21.0 & 2.3633 \\
\hline & HEU & 0.118 & 2.51 & 21.0 & 2.4813 \\
\hline & $\mathrm{Re}$ & 0.0161 & 2.51 & 21.0 & 2.4974 \\
\hline & Graphite & 0.197 & 2.51 & 21.0 & 2.6944 \\
\hline \multirow{4}{*}{3} & $\mathrm{Re}$ & 0.0161 & 2.51 & 21.0 & 2.7105 \\
\hline & HEU & 0.118 & 2.51 & 21.0 & 2.8285 \\
\hline & $\mathrm{Re}$ & 0.0161 & 2.51 & 21.0 & 2.8446 \\
\hline & Graphite & 0.197 & 2.51 & 21.0 & 3.0416 \\
\hline \multirow{4}{*}{4} & $\mathrm{Re}$ & 0.0161 & 2.51 & 21.0 & 3.0577 \\
\hline & HEU & 0.118 & 2.51 & 21.0 & 3.1757 \\
\hline & $\mathrm{Re}$ & 0.0161 & 2.51 & 21.0 & 3.1918 \\
\hline & Graphite & 0.197 & 2.51 & 21.0 & 3.3888 \\
\hline \multirow{4}{*}{5} & $\operatorname{Re}$ & 0.0161 & 2.51 & 21.0 & 3.4049 \\
\hline & HEU & 0.118 & 2.51 & 21.0 & 3.5229 \\
\hline & $\operatorname{Re}$ & 0.0161 & 2.51 & 21.0 & 3.5390 \\
\hline & Graphite & 0.197 & 2.51 & 21.0 & 3.7360 \\
\hline \multirow{5}{*}{6} & $\mathrm{Re}$ & 0.0161 & 2.51 & 21.0 & 3.7521 \\
\hline & HEU & 0.118 & 2.51 & 21.0 & 3.8701 \\
\hline & $\mathrm{Re}$ & 0.0161 & 2.51 & 21.0 & 3.8862 \\
\hline & Graphite & 0.197 & 2.51 & 21.0 & 4.0832 \\
\hline & $\mathrm{Re}$ & 0.0161 & 2.51 & 21.0 & 4.0993 \\
\hline \multirow{3}{*}{7} & HEU & 0.118 & 2.51 & 21.0 & 4.2173 \\
\hline & $\mathrm{Re}$ & 0.0161 & 2.51 & 21.0 & 4.2334 \\
\hline & Graphite & 0.197 & 2.51 & 21.0 & 4.4304 \\
\hline \multirow{4}{*}{8} & $\mathrm{Re}$ & 0.0161 & 0 & 21.0 & 4.4465 \\
\hline & HEU & 0.118 & 0 & 21.0 & 4.5645 \\
\hline & $\mathrm{Re}$ & 0.0161 & 0 & 21.0 & 4.5806 \\
\hline & Graphite & 0.197 & 0 & 21.0 & 4.7776 \\
\hline \multirow{4}{*}{9} & $\mathrm{Re}$ & 0.0161 & 0 & 21.0 & 4.7937 \\
\hline & HEU & 0.118 & 0 & 21.0 & 4.9117 \\
\hline & $\mathrm{Re}$ & 0.0161 & 0 & 21.0 & 4.9278 \\
\hline & Graphite & 0.197 & 0 & 21.0 & 5.1248 \\
\hline Diaphragm & Stainiess Steel & 0.040 & 0 & 24.8 & 5.1648 \\
\hline \multirow{4}{*}{10} & $\mathrm{Re}$ & 0.0161 & 0 & 21.0 & 5.1809 \\
\hline & HEU & 0.118 & 0 & 21.0 & 5.2989 \\
\hline & $\mathrm{Re}$ & 0.0161 & 0 & 21.0 & 5.3150 \\
\hline & Graphite & 0.197 & 0 & 21.0 & 5.5120 \\
\hline
\end{tabular}




\begin{tabular}{|c|c|c|c|c|c|}
\hline Unit & Material & Thickness (in) & $\begin{array}{c}\text { Inner } \\
\text { Diameter (in) }\end{array}$ & $\begin{array}{c}\text { Outer } \\
\text { Diameter (in) }\end{array}$ & $\begin{array}{l}\text { Assembly } \\
\text { Height (in) }\end{array}$ \\
\hline \multirow{4}{*}{11} & $\mathrm{Re}$ & 0.0161 & 0 & 21.0 & 5.5281 \\
\hline & HEU & 0.118 & 0 & 21.0 & 5.6461 \\
\hline & $\mathrm{Re}$ & 0.0161 & 0 & 21.0 & 5.6622 \\
\hline & Graphite & 0.197 & 0 & 21.0 & 5.8592 \\
\hline \multirow{4}{*}{12} & $\mathrm{Re}$ & 0.0161 & 0 & 21.0 & 5.8753 \\
\hline & HEU & 0.118 & 0 & 21.0 & 5.9933 \\
\hline & $\mathrm{Re}$ & 0.0161 & 0 & 21.0 & 6.0094 \\
\hline & Graphite & 0.197 & 0 & 21.0 & 6.2064 \\
\hline \multirow{4}{*}{13} & $\mathrm{Re}$ & 0.0161 & 0 & 21.0 & 6.2225 \\
\hline & HEU & 0.118 & 0 & 21.0 & 6.3405 \\
\hline & $\mathrm{Re}$ & 0.0161 & 0 & 21.0 & 6.3566 \\
\hline & Graphite & 0.197 & 0 & 21.0 & 6.5536 \\
\hline \multirow{4}{*}{14} & $\mathrm{Re}$ & 0.0161 & 0 & 21.0 & 6.5697 \\
\hline & HEU & 0.118 & 6.005 & 21.0 & 6.6877 \\
\hline & $\operatorname{Re}$ & 0.0161 & 0 & 21.0 & 6.7038 \\
\hline & Graphite & 0.197 & 0 & 21.0 & 6.9008 \\
\hline \multirow{4}{*}{15} & $\mathrm{Re}$ & 0.0161 & 0 & 21.0 & 6.9169 \\
\hline & HEU & 0.118 & 6.005 & 21.0 & 7.0349 \\
\hline & $\mathrm{Re}$ & 0.0161 & 0 & 21.0 & 7.0510 \\
\hline & Graphite & 0.197 & 0 & 21.0 & 7.2480 \\
\hline \multirow{4}{*}{16} & $\mathrm{Re}$ & 0.0161 & 0 & 21.0 & 7.2641 \\
\hline & HEU & 0.118 & 6.005 & 21.0 & 7.3821 \\
\hline & $\mathrm{Re}$ & 0.0161 & 0 & 21.0 & 7.3982 \\
\hline & Graphite & 0.197 & 0 & 21.0 & 7.5952 \\
\hline \multirow{3}{*}{17} & $\mathrm{Re}$ & 0.0161 & 0 & 21.0 & 7.6113 \\
\hline & HEU & 0.118 & 6.005 & 21.0 & 7.7293 \\
\hline & $\mathrm{Re}$ & 0.0161 & 0 & 21.0 & 7.7454 \\
\hline $\begin{array}{l}\text { Top } \\
\text { Reflector }\end{array}$ & Graphite & $\begin{array}{l}1.85 \text { (RCP01) } \\
1.75 \text { (MCNP5, } \\
\text { MCNP5 Space } \\
\text { XS RACER) }\end{array}$ & 0 & 21.0 & $\begin{array}{c}9.5954 \text { (RCP01) } \\
9.4954 \text { (MCNP5, } \\
\text { MCNP5 Space } \\
\text { XS, RACER) }\end{array}$ \\
\hline
\end{tabular}

Table 80. Re-2 Assembly Material Mass Distribution

\begin{tabular}{|c|c|c|c|c|c|c|}
\hline \multirow{3}{*}{ Material } & \multicolumn{6}{|c|}{ Mass $(\mathrm{kg})$} \\
\hline & \multicolumn{3}{|c|}{ MCNP5/MCNP5 (Space XS)/RACER } & \multicolumn{3}{|c|}{ RCP01 } \\
\hline & $\begin{array}{c}\text { Lower } \\
\text { Assembly }\end{array}$ & $\begin{array}{c}\text { Upper } \\
\text { Assembly }\end{array}$ & Total & $\begin{array}{l}\text { Lower } \\
\text { Assembly }\end{array}$ & $\begin{array}{c}\text { Upper } \\
\text { Assembly }\end{array}$ & Total \\
\hline HEU & 111.7 & 96.3 & 208.0 & 111.7 & 96.3 & 208.0 \\
\hline $\mathrm{Re}$ & 34.2 & 30.7 & 64.9 & 34.2 & 30.7 & 64.9 \\
\hline Graphite & 36.6 & 30.8 & 67.4 & 36.6 & 31.7 & 68.4 \\
\hline Total & 182.5 & 157.8 & 340.4 & 182.5 & 158.8 & 341.3 \\
\hline
\end{tabular}


B-TM-1639

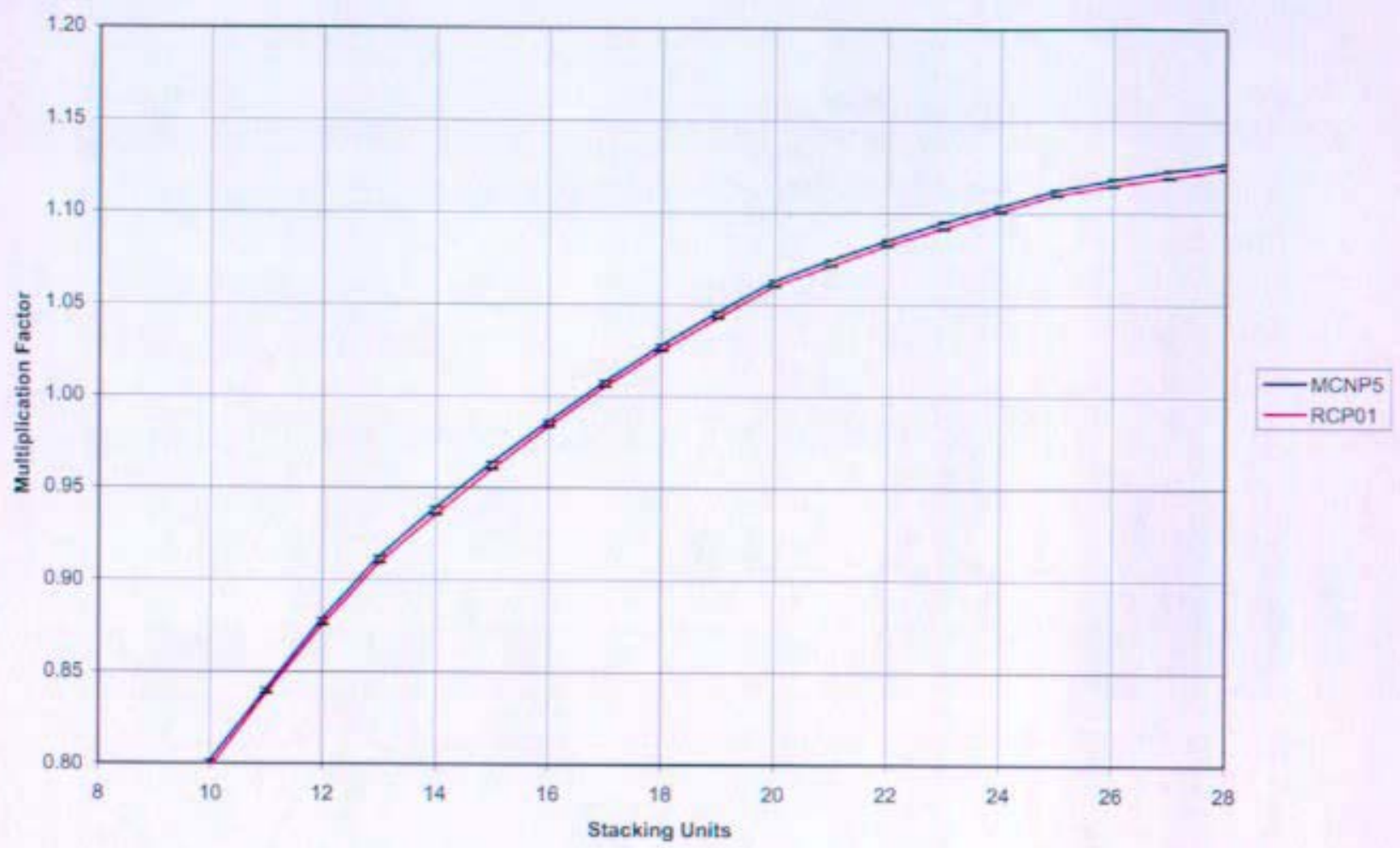

Figure 77. Re-2 Assembly $k_{\text {eff }}$ as a Function of the Number of Stacking Units

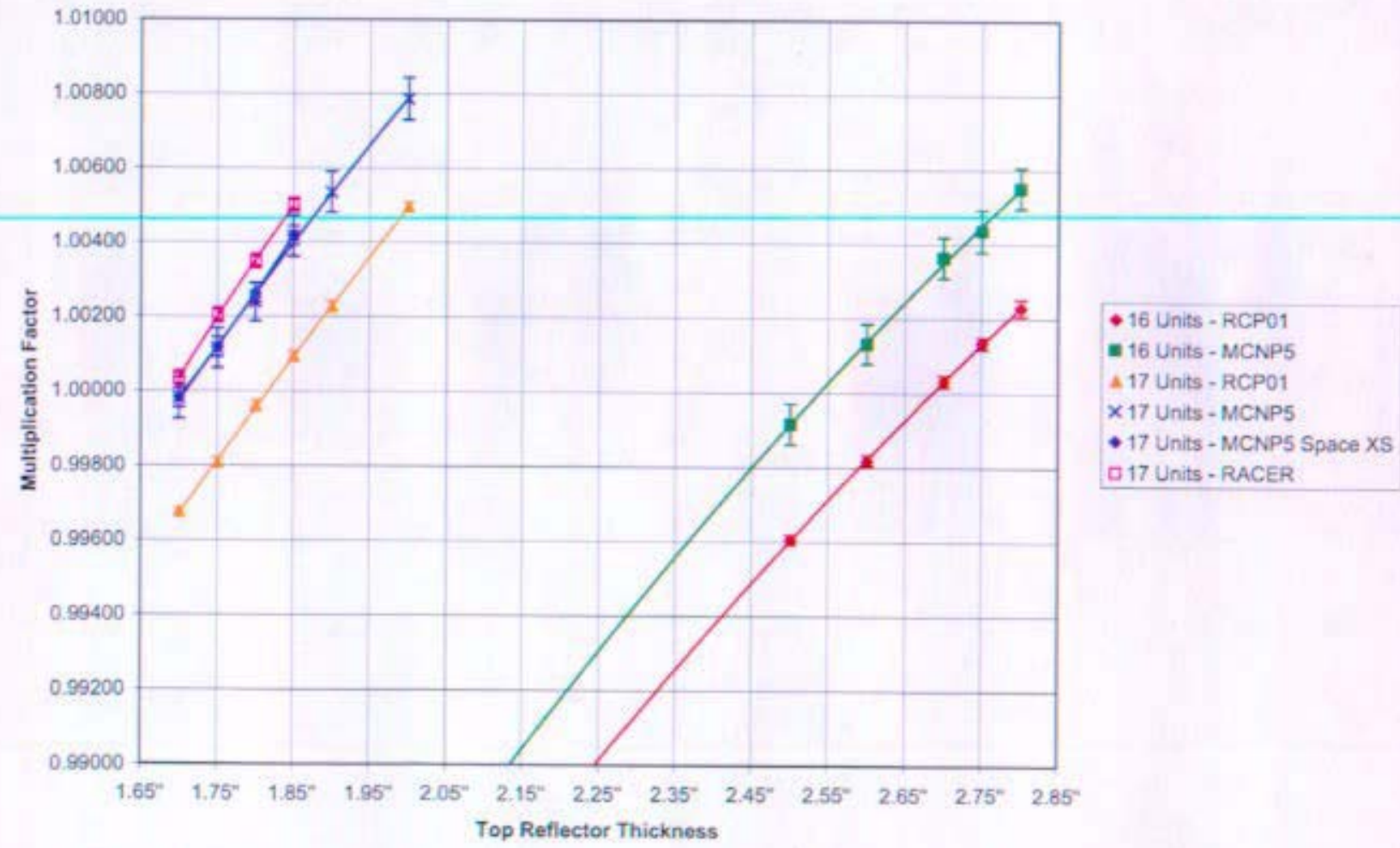

Figure 78. Re-2 Assembly $k_{\text {eff }}$ as a Function of the Top Reflector Thickness 
Table 81. Re-2 Assembly $k_{\text {eff }}$ as a Function of the Top Reflector Thickness

\begin{tabular}{|c|c|c|c|c|c|c|c|c|}
\hline \multicolumn{9}{|c|}{ Predicted Top Reflector Thickness } \\
\hline \multicolumn{9}{|c|}{16 Stacking Units } \\
\hline \multirow{2}{*}{$\begin{array}{c}\text { Top } \\
\text { Reflector } \\
\text { Thickness } \\
\text { (in) }\end{array}$} & \multicolumn{2}{|c|}{ MCNP5 } & \multicolumn{2}{|c|}{ MCNP5 (Space XS) } & \multicolumn{2}{|c|}{ RCP01 } & \multicolumn{2}{|c|}{ RACER } \\
\hline & $k_{\text {eff }}$ & $95 \% \mathrm{Cl}$ & $\mathrm{k}_{\text {eff }}$ & $95 \% \mathrm{Cl}$ & $k_{\text {eff }}$ & $95 \% \mathrm{Cl}$ & $k_{\text {eff }}$ & $95 \% \mathrm{Cl}$ \\
\hline 2.00 & 0.98622 & 0.00055 & \multirow{6}{*}{\multicolumn{2}{|c|}{$\begin{array}{l}\text { Not investigated due } \\
\text { to termination of } \\
\text { project. }\end{array}$}} & 0.98361 & 0.00014 & \multirow{6}{*}{\multicolumn{2}{|c|}{$\begin{array}{l}\text { Not investigated } \\
\text { due to termination } \\
\text { of project. }\end{array}$}} \\
\hline 2.50 & 0.99913 & 0.00055 & & & 0.99604 & 0.00013 & & \\
\hline 2.60 & 1.00130 & 0.00053 & & & 0.99819 & 0.00014 & & \\
\hline 2.70 & 1.00362 & 0.00055 & & & 1.00031 & 0.00015 & & \\
\hline 2.75 & 1.00434 & 0.00057 & & & 1.00133 & 0.00015 & & \\
\hline 2.80 & 1.00549 & 0.00055 & & & 1.00228 & 0.00022 & & \\
\hline \\
\hline \multirow{2}{*}{$\begin{array}{l}\text { Top } \\
\text { Reflector } \\
\text { Thickness } \\
\text { (in) } \\
\end{array}$} & \multicolumn{2}{|c|}{ MCNP5 } & \multicolumn{2}{|c|}{ MCNP5 (Space XS) } & \multicolumn{2}{|c|}{ RCP01 } & \multicolumn{2}{|c|}{ RACER } \\
\hline & $k_{\text {eff }}$ & $95 \% \mathrm{Cl}$ & $k_{\text {eff }}$ & $95 \% \mathrm{Cl}$ & $k_{\text {eff }}$ & $95 \% \mathrm{Cl}$ & $k_{\text {eff }}$ & $95 \% \mathrm{Cl}$ \\
\hline 1.70 & 0.99979 & 0.00055 & 0.99980 & 0.00026 & 0.99675 & 0.00012 & 1.00034 & 0.00019 \\
\hline 1.75 & 1.00113 & 0.00053 & 1.00116 & 0.00026 & 0.99807 & 0.00013 & 1.00204 & 0.00019 \\
\hline 1.80 & 1.00237 & 0,00051 & 1.00262 & 0.00026 & 0.99960 & 0.00014 & 1.00348 & 0.00019 \\
\hline 1.85 & 1.00415 & 0.00055 & 1.00416 & 0.00026 & 1.00093 & 0.00014 & 1.00500 & 0.00018 \\
\hline 1.90 & 1.00533 & 0.00055 & - & - & 1.00227 & 0.00014 & - & - \\
\hline 2.00 & 1.00785 & 0.00057 & - & - & 1.00495 & 0.00012 & - & - \\
\hline
\end{tabular}




\subsubsection{Re-3 Experiment}

The Re-3 experiment is designed to bracket the average neutron spectrum of the Prometheus reactor core. It is designed to be softer than the expected average neutron energy spectrum of the core. Additional graphite has been added to the assembly to simulate the effect of neutron moderation near the reflector. A cross-sectional view and close-up view of the experimental configuration are provided in Figure 79 and Figure 80 where aluminum is yellow, graphite is blue, Re is green, HEU is red, and stainless steel is purple (all dimensions in figures are in centimeters). The assembly configuration, including plate layout and dimensions, is shown in Table 82. The RCP01 analysis predicts an assembly height of $18.803^{\prime \prime}$ and the MCNP5, MCNP5 with space cross sections, and RACER analyses predict an assembly height of $17.853^{\prime \prime}$. The assembly rests on a $3.0^{\prime \prime}$ thick hollow Al 6061-T6 spindle plate that has a $19^{\prime \prime} \mathrm{OD}$ and $2.50^{\prime \prime}$ inner diameter. The active core region of the assembly is $8.353^{\prime \prime}$ high and contains 15 stacking units consisting of a $0.0161^{\prime \prime}$ thick Re plate, a $0.118^{\prime \prime}$ thick HEU plate, a $0.0161^{\prime \prime}$ thick Re plate, and a $0.394^{\prime \prime}$ thick graphite plate and 1 stacking unit consisting of a $0.0161^{\prime \prime}$ thick Re plate, a $0.118^{\prime \prime}$ thick HEU plate, and a $0.0161^{\prime \prime}$ thick Re plate, for a total of 16 stacking units. The bottom reflector consists of a 5.0" thick graphite reflector. The RCP01 predicted top reflector consists of a 5.45" thick graphite reflector and the MCNP5, MCNP5 with space cross sections, and RACER predicted top reflector consists of a $4.50^{\prime \prime}$ thick graphite reflector. A hollow Al 6061-T6 alignment tube is assumed to extend from the bottom of the spindle plate to the top of the $6^{\text {th }}$ stacking unit. All other regions are modeled as void, except as noted in Section 4.0 for the RACER models. The Re-3 assembly contains $196.5 \mathrm{~kg}$ of HEU and $61.1 \mathrm{~kg}$ of Re. The distribution of materials in the top and bottom half of the assembly is given in Table 83 for the RCP01, MCNP5, MCNP5 with space cross sections, and RACER predicted critical configurations.

A series of analyses have been performed to predict the $k_{\text {eff }}$ of the $R e-3$ assembly during the approach to critical as a function of both the number of stacking units and the graphite top reflector thickness. Figure 81 presents the RCP01 and MCNP5 predicted $k_{\text {eff }}$ as a function of the number of stacking units in the Re-3 assembly. The error bars indicate the size of the $95 \%$ confidence interval in the Monte Carlo calculations. The average difference between the MCNP5 and RCP01 predicted $k_{\text {eff }}$ is $0.0052 \pm 0.0006 \Delta \mathrm{k}$ over the range from 8 to 28 stacking units. Figure 82 and Table 84 provide a comparison of the predicted $k_{\text {off }}$ of the $R e-3$ assembly with 16 stacking units as a function of the graphite top reflector thickness. The experimental configurations that were predicted to achieve delayed criticality within TSR limits $(\rho<0.5 \$)$ are highlighted in green in Table 84 . The Re- 3 assembly is classified as a fast spectrum assembly with the following representative fission fractions as predicted by MCNP5: $65.8 \%$ fast ( $E>100 \mathrm{keV}), 34.1 \%$ intermediate $(0.625 \mathrm{eV}<\mathrm{E}<100 \mathrm{keV})$, and $0.04 \%$ thermal $(E<0.625 \mathrm{eV})$. 
B-TM-1639

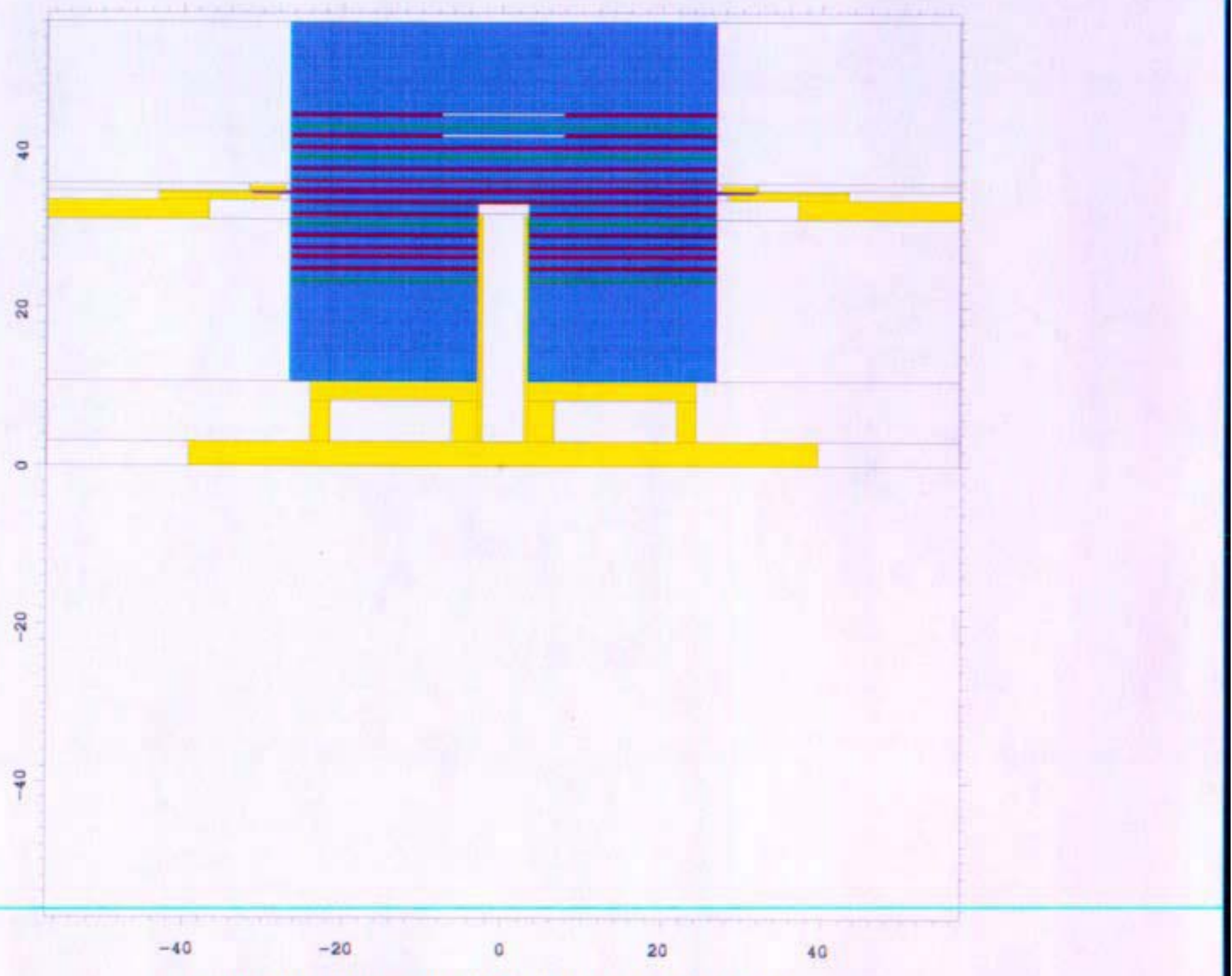

Figure 79. Cross-sectional View of the Re-3 Assembly 
B-TM-1639

$\stackrel{9}{9}$

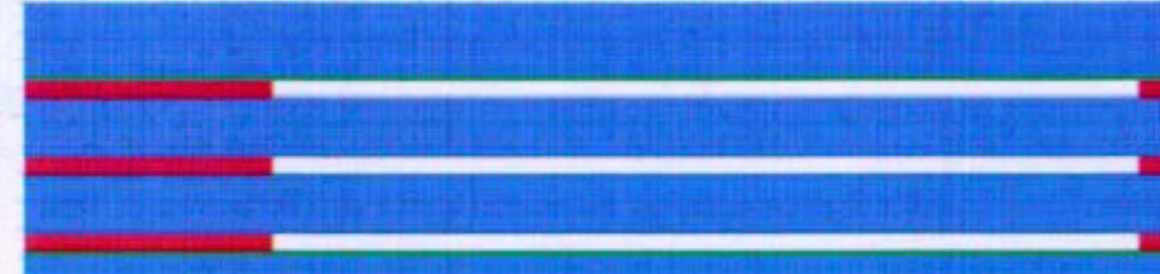

ค

$\circ$

$\stackrel{7}{7}$

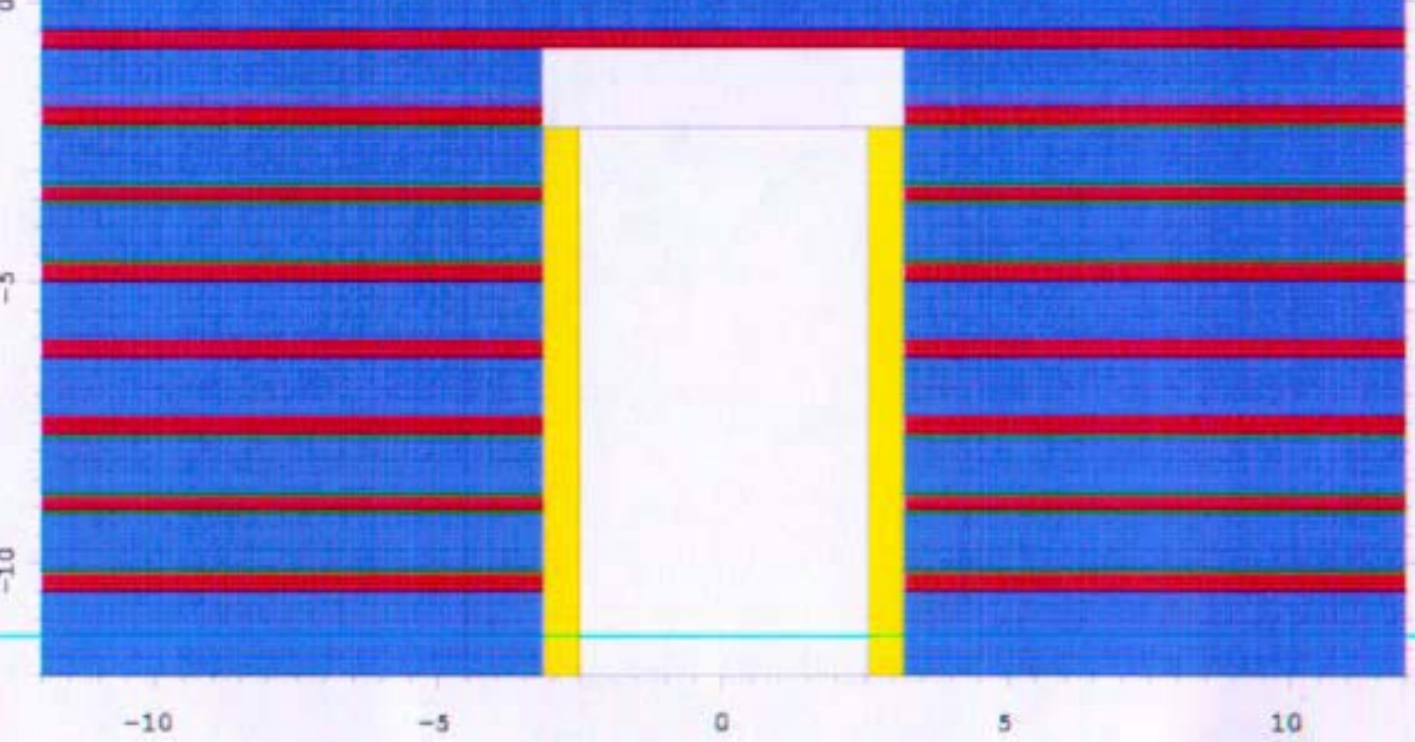

Figure 80. Cross-sectional Close-up View of the Re-3 Assembly 
Table 82. Predicted Critical Configuration for the Re-3 Assembly.

\begin{tabular}{|c|c|c|c|c|c|}
\hline Unit & Material & Thickness (in) & $\begin{array}{c}\text { Inner } \\
\text { Diameter (in) }\end{array}$ & $\begin{array}{c}\text { Outer } \\
\text { Diameter (in) }\end{array}$ & $\begin{array}{l}\text { Assembly Height } \\
\text { (in) }\end{array}$ \\
\hline $\begin{array}{l}\text { Bottom } \\
\text { Reflector }\end{array}$ & Graphite & 5.00 & 2.51 & 21.0 & 5.0000 \\
\hline \multirow{4}{*}{1} & $\mathrm{Re}$ & 0.0161 & 2.51 & 21.0 & 5.0161 \\
\hline & HEU & 0.118 & 2.51 & 21.0 & 5.1341 \\
\hline & $\operatorname{Re}$ & 0.0161 & 2.51 & 21.0 & 5.1502 \\
\hline & Graphite & 0.394 & 2.51 & 21.0 & 5.5442 \\
\hline \multirow{4}{*}{2} & $\mathrm{Re}$ & 0.0161 & 2.51 & 21.0 & 5.5603 \\
\hline & HEU & 0.118 & 2.51 & 21.0 & 5.6783 \\
\hline & $\operatorname{Re}$ & 0.0161 & 2.51 & 21.0 & 5.6944 \\
\hline & Graphite & 0.394 & 2.51 & 21.0 & 6.0884 \\
\hline \multirow{4}{*}{3} & $\operatorname{Re}$ & 0.0161 & 2.51 & 21.0 & 6.1045 \\
\hline & HEU & 0.118 & 2.51 & 21.0 & 6.2225 \\
\hline & $\mathrm{Re}$ & 0.0161 & 2.51 & 21.0 & 6.2386 \\
\hline & Graphite & 0.394 & 2.51 & 21.0 & 6.6326 \\
\hline \multirow{4}{*}{4} & $\mathrm{Re}$ & 0.0161 & 2.51 & 21.0 & 6.6487 \\
\hline & HEU & 0.118 & 2.51 & 21.0 & 6.7667 \\
\hline & $\mathrm{Re}$ & 0.0161 & 2.51 & 21.0 & 6.7828 \\
\hline & Graphite & 0.394 & 2.51 & 21.0 & 7.1768 \\
\hline \multirow{4}{*}{5} & $\mathrm{Re}$ & 0.0161 & 2.51 & 21.0 & 7.1929 \\
\hline & HEU & 0.118 & 2.51 & 21.0 & 7.3109 \\
\hline & $\mathrm{Re}$ & 0.0161 & 2.51 & 21.0 & 7.3270 \\
\hline & Graphite & 0.394 & 2.51 & 21.0 & 7.7210 \\
\hline \multirow{4}{*}{6} & $\mathrm{Re}$ & 0.0161 & 2.51 & 21.0 & 7.7371 \\
\hline & HEU & 0.118 & 2.51 & 21.0 & 7.8551 \\
\hline & $\operatorname{Re}$ & 0.0161 & 2.51 & 21.0 & 7.8712 \\
\hline & Graphite & 0.394 & 2.51 & 21.0 & 8.2652 \\
\hline \multirow{4}{*}{7} & $\mathrm{Re}$ & 0.0161 & 2.51 & 21.0 & 8.2813 \\
\hline & $\mathrm{HEU}$ & 0.118 & 2.51 & 21.0 & 8.3993 \\
\hline & $\mathrm{Re}$ & 0.0161 & 2.51 & 21.0 & 8.4154 \\
\hline & Graphite & 0.394 & 2.51 & 21.0 & 8.8094 \\
\hline \multirow{4}{*}{8} & $\mathrm{Re}$ & 0.0161 & 0 & 21.0 & 8.8255 \\
\hline & HEU & 0.118 & 0 & 21.0 & 8.9435 \\
\hline & $\mathrm{Re}$ & 0.0161 & 0 & 21.0 & 8.9596 \\
\hline & Graphite & 0.394 & 0 & 21.0 & 9.3536 \\
\hline Diaphragm & Stainless Steel & 0.040 & 0 & 24.8 & 9.3936 \\
\hline \multirow{4}{*}{15} & $\mathrm{Re}$ & 0.0161 & 0 & 21.0 & 9.4097 \\
\hline & HEU & 0.118 & 0 & 21.0 & 9.5277 \\
\hline & $\mathrm{Re}$ & 0.0161 & 0 & 21.0 & 9.5438 \\
\hline & Graphite & 0.394 & 0 & 21.0 & 9.9378 \\
\hline \multirow{4}{*}{10} & $\operatorname{Re}$ & 0.0161 & 0 & 21.0 & 9.9539 \\
\hline & $\mathrm{HEU}$ & 0.118 & 0 & 21.0 & 10.0719 \\
\hline & $\mathrm{Re}$ & 0.0161 & 0 & 21.0 & 10.0880 \\
\hline & Graphite & 0.394 & 0 & 21.0 & 10.4820 \\
\hline
\end{tabular}




\begin{tabular}{|c|c|c|c|c|c|}
\hline Unit & Material & Thickness (in) & $\begin{array}{c}\text { Inner } \\
\text { Diameter (in) }\end{array}$ & $\begin{array}{c}\text { Outer } \\
\text { Diameter (in) }\end{array}$ & $\begin{array}{l}\text { Assembly Height } \\
\text { (in) }\end{array}$ \\
\hline \multirow{4}{*}{11} & $\mathrm{Re}$ & 0.0161 & 0 & 21.0 & 10.4981 \\
\hline & HEU & 0.118 & 0 & 21.0 & 10.6161 \\
\hline & $\mathrm{Re}$ & 0.0161 & 0 & 21.0 & 10.6322 \\
\hline & Graphite & 0.394 & 0 & 21.0 & 11.0262 \\
\hline \multirow{4}{*}{12} & $\mathrm{Re}$ & 0.0161 & 0 & 21.0 & 11.0423 \\
\hline & HEU & 0.118 & 0 & 21.0 & 11.1603 \\
\hline & $\mathrm{Re}$ & 0.0161 & 0 & 21.0 & 11.1764 \\
\hline & Graphite & 0.394 & 0 & 21.0 & 11.5704 \\
\hline \multirow{4}{*}{13} & $\mathrm{Re}$ & 0.0161 & 0 & 21.0 & 11.5865 \\
\hline & HEU & 0.118 & 0 & 21.0 & 11.7045 \\
\hline & $\operatorname{Re}$ & 0.0161 & 0 & 21.0 & 11.7206 \\
\hline & Graphite & 0.394 & 0 & 21.0 & 12.1146 \\
\hline \multirow{4}{*}{14} & $\mathrm{Re}$ & 0.0161 & 0 & 21.0 & 12.1307 \\
\hline & HEU & 0.118 & 6.005 & 21.0 & 12.2487 \\
\hline & $\mathrm{Re}$ & 0.0161 & 0 & 21.0 & 12.2648 \\
\hline & Graphite & 0.394 & 0 & 21.0 & 12.6588 \\
\hline \multirow{4}{*}{15} & $\mathrm{Re}$ & 0.0161 & 0 & 21.0 & 12.6749 \\
\hline & HEU & 0.118 & 6.005 & 21.0 & 12.7929 \\
\hline & $\mathrm{Re}$ & 0.0161 & 0 & 21.0 & 12.8090 \\
\hline & Graphite & 0.394 & 0 & 21.0 & 13.2030 \\
\hline \multirow{3}{*}{16} & $\mathrm{Re}$ & 0.0161 & 0 & 21.0 & 13.2191 \\
\hline & HEU & 0.118 & 6.005 & 21.0 & 13.3371 \\
\hline & $\mathrm{Re}$ & 0.0161 & 0 & 21.0 & 13.3532 \\
\hline $\begin{array}{l}\text { Top } \\
\text { Reflector }\end{array}$ & Graphite & $\begin{array}{l}5.45 \text { (RCP01) } \\
4.50 \text { (MCNPS. } \\
\text { MCNP5 Space } \\
\text { XS, RACER) }\end{array}$ & 0 & 210 & $\begin{array}{c}18.8032 \text { (RCPD1) } \\
17.8532 \text { (MCNP5 } \\
\text { MCNP5 Space } \\
\text { XS. RACER) }\end{array}$ \\
\hline
\end{tabular}

Table 83. Re-3 Assembly Material Mass Distribution

\begin{tabular}{|c|c|c|c|c|c|c|}
\hline \multirow{3}{*}{ Material } & \multicolumn{6}{|c|}{ Mass (kg) } \\
\cline { 2 - 7 } & MCNP5/MCNP5 (Space XS)/RACER & \multicolumn{1}{c|}{ RCP01 } \\
\cline { 2 - 7 } & $\begin{array}{c}\text { Lower } \\
\text { Assembly }\end{array}$ & $\begin{array}{c}\text { Upper } \\
\text { Assembly }\end{array}$ & Total & $\begin{array}{c}\text { Lower } \\
\text { Assembly }\end{array}$ & $\begin{array}{c}\text { Upper } \\
\text { Assembly }\end{array}$ & Total \\
\hline HEU & 99.2 & 97.3 & 196.5 & 99.2 & 97.3 & 196.5 \\
\hline Re & 30.3 & 30.7 & 61.1 & 30.3 & 30.7 & 61.1 \\
\hline Graphite & 79.1 & 71.4 & 150.4 & 79.1 & 81.2 & 160.2 \\
\hline Total & $\mathbf{2 0 8 . 6}$ & 199.4 & $\mathbf{4 0 8 . 0}$ & $\mathbf{2 0 8 . 6}$ & $\mathbf{2 0 9 . 2}$ & $\mathbf{4 1 7 . 8}$ \\
\hline
\end{tabular}


B-TM-1639

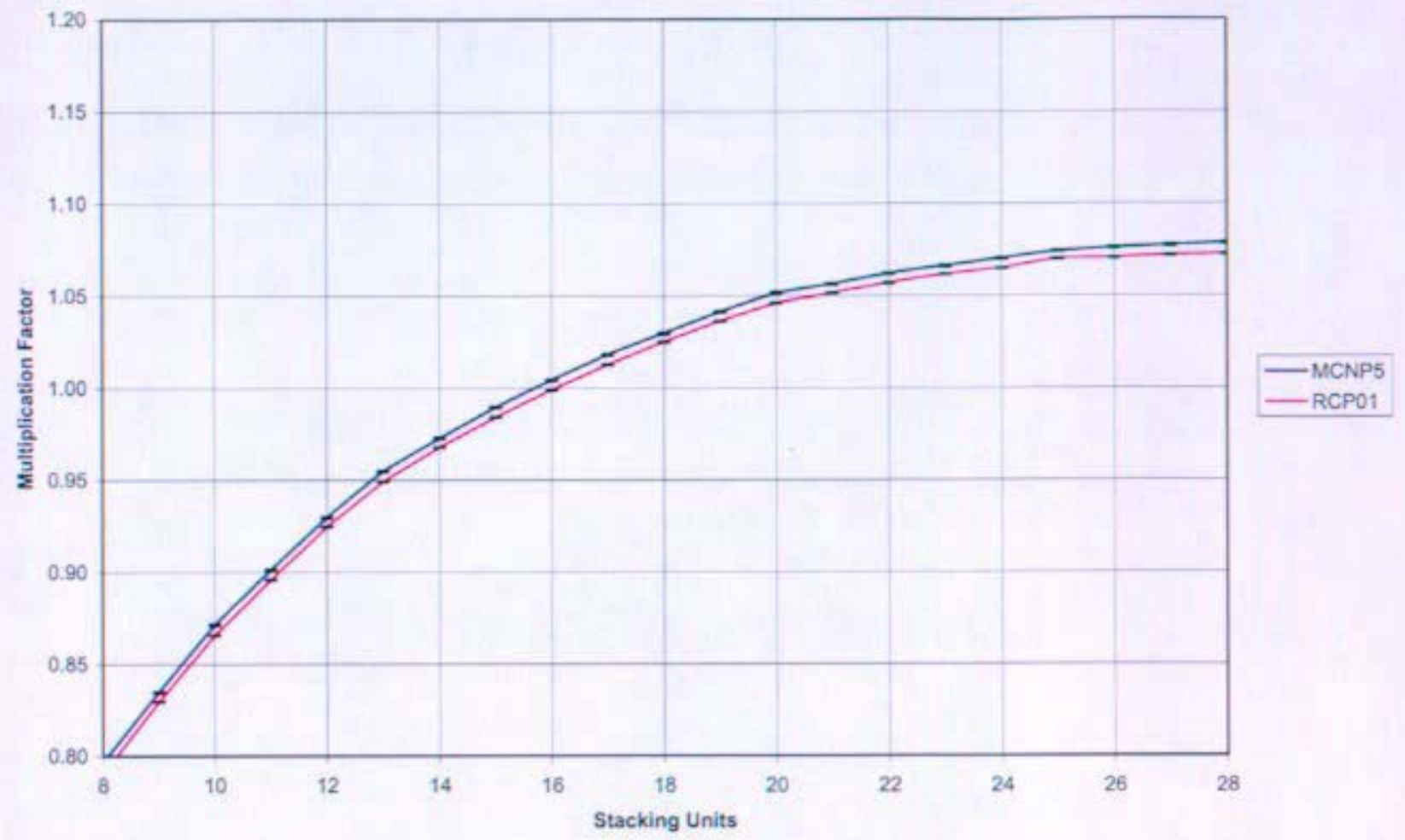

Figure 81. Re-3 Assembly $k_{\text {eff }}$ as a Function of the Number of Stacking Units

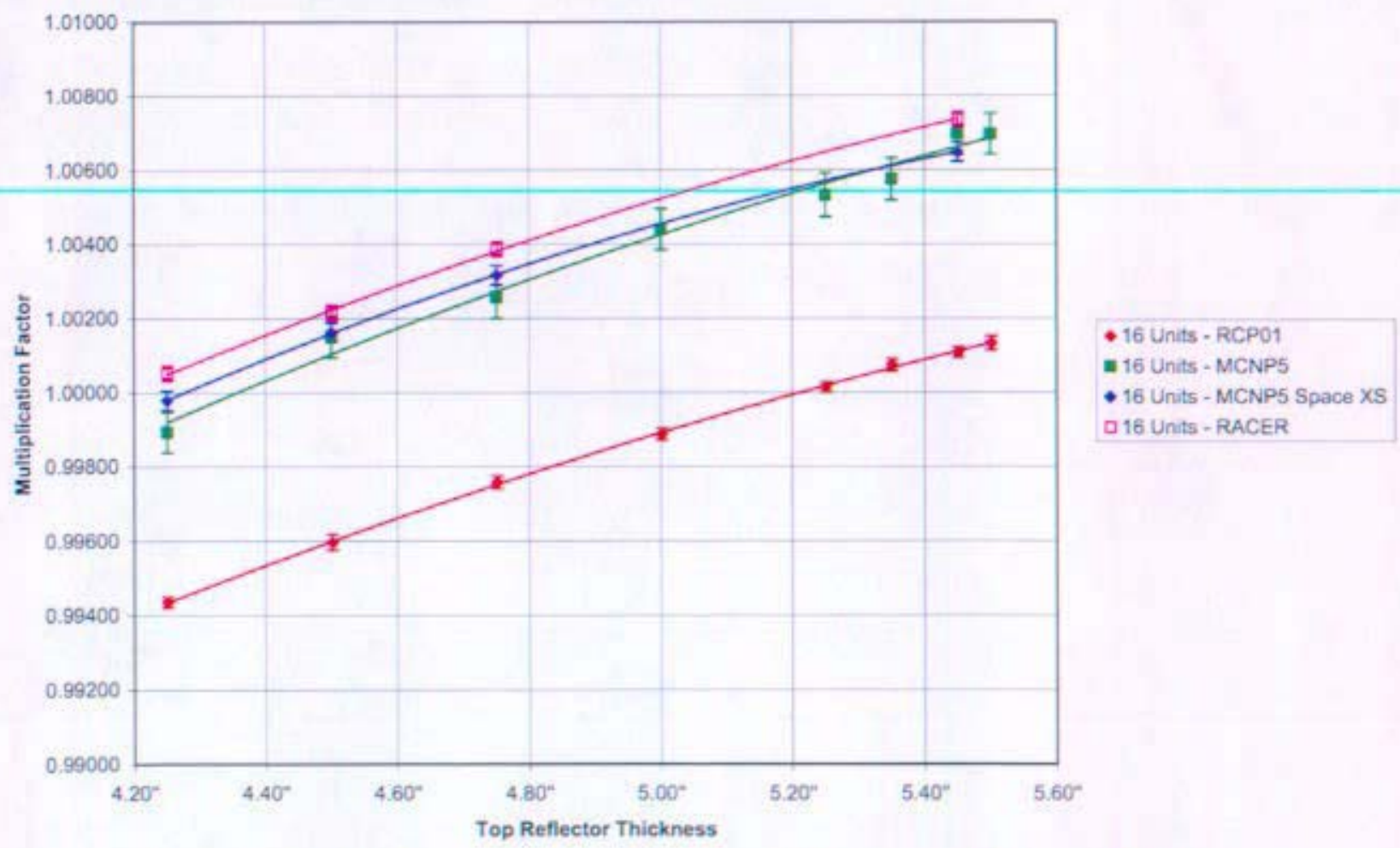

Figure 82. Re-3 Assembly $k_{\text {eft }}$ as a Function of the Top Reflector Thickness 
Table 84. Re-3 Assembly $k_{\text {eff }}$ as a Function of the Top Reflector Thickness

\begin{tabular}{|c|c|c|c|c|c|c|c|c|}
\hline \multicolumn{9}{|c|}{ Predicted Top Reflector Thickness } \\
\hline \multicolumn{9}{|c|}{16 Stacking Units } \\
\hline \multirow{2}{*}{$\begin{array}{c}\text { Top } \\
\text { Reflector } \\
\text { Thickness } \\
\text { (in) }\end{array}$} & \multicolumn{2}{|c|}{ MCNP5 } & \multicolumn{2}{|c|}{ MCNP5 (Space XS) } & \multicolumn{2}{|c|}{ RCP01 } & \multicolumn{2}{|c|}{ RACER } \\
\hline & $k_{\text {eff }}$ & $95 \% \mathrm{Cl}$ & $\mathbf{k}_{\text {eff }}$ & $95 \% \mathrm{Cl}$ & $\mathbf{k}_{\text {eff }}$ & $95 \% \mathrm{Cl}$ & $\mathbf{k}_{\text {eff }}$ & $95 \% \mathrm{Cl}$ \\
\hline 4.25 & 0.99893 & 0.00055 & 0.99978 & 0.00026 & 0.99435 & 0.00014 & 1.00052 & 0.00020 \\
\hline 4,50 & 1.00150 & 0.00057 & 1.00161 & 0.00026 & 0.99596 & 0.00022 & 1.00216 & 0.00020 \\
\hline 4.75 & 1.00257 & 0.00057 & 1.00316 & 0.00026 & 0.99757 & 0.00017 & 1.00386 & 0.00020 \\
\hline 5.00 & 1.00440 & 0.00055 & - & - & 0.99887 & 0.00016 & - & - \\
\hline 5.25 & 1.00532 & 0.00059 & - & - & 1.00015 & 0.00014 & - & - \\
\hline 5.35 & 1.00575 & 0.00057 & - & - & 1.00074 & 0.00016 & - & - \\
\hline 5.45 & 1.00697 & 0.00057 & 1.00648 & 0.00026 & 1.00108 & 0,00014 & 1.00737 & 0.00020 \\
\hline 5.50 & 1.00697 & 0.00055 & - & - & 1.00133 & 0.00019 & - & - \\
\hline
\end{tabular}




\subsubsection{Re-4 Experiment}

The $\mathrm{Re}-4$ experiment is designed to simulate the average neutron spectrum of the Prometheus reactor core when flooded with water. Polyethylene is used to simulate flooding with water. A crosssectional view and close-up view of the experimental configuration are provided in Figure 83 and Figure 84 where aluminum is yellow, polyethylene is light blue, Re is green, HEU is red, and stainless steel is purple (all dimensions in figures are in centimeters). The assembly configuration, including plate layout and dimensions, is shown in Table 85. The RCP01 analysis predicts an assembly height of $5.613^{\prime \prime}$ and the MCNP5, MCNP5 with space cross sections, and RACER analyses predict an assembly height of $5.513^{\prime \prime}$. The assembly rests on a $3.0^{\prime \prime}$ thick hollow Al 6061-T6 spindle plate that has a $19^{\prime \prime} \mathrm{OD}$ and $2.50^{\prime \prime}$ inner diameter. The active core region of the assembly is $3.413^{\prime \prime}$ high and contains 14 stacking units consisting of a $0.0161^{\prime \prime}$ thick Re plate, a $0.118^{\prime \prime}$ thick HEU plate, a $0.0161^{\prime \prime}$ thick Re plate, and a $0.080^{\prime \prime}$ thick polyethylene plate and 1 stacking unit consisting of a $0.0161^{\prime \prime}$ thick Re plate, a $0.118^{\prime \prime}$ thick HEU plate, and a $0.0161^{\prime \prime}$ thick Re plate, for a total of 15 stacking units. The bottom reflector consists of a 1.0" thick graphite reflector. The RCP01 predicted top reflector consists of a 1.20" thick polyethylene reflector and the MCNP5, MCNP5 with space cross sections, and RACER predicted top reflector consists of a 1.10" thick polyethylene reflector. A hollow Al 6061-T6 alignment tube is assumed to extend from the bottom of the spindle plate to the top of the $6^{\text {th }}$ stacking unit. All other regions are modeled as void, except as noted in Section 4.0 for the RACER models. The Re-4 assembly contains $185.0 \mathrm{~kg}$ of HEU and $57.2 \mathrm{~kg}$ of Re. The distribution of materials in the top and bottom half of the assembly is given in Table 86 for the RCP01, MCNP5, MCNP5 with space cross sections, and RACER predicted critical configurations.

A series of analyses have been performed to predict the $k_{\text {eft }}$ of the $R e-4$ assembly during the approach to critical as a function of both the number of stacking units and the polyethylene top reflector thickness. Figure 85 presents the RCP01 and MCNP5 predicted $k_{\text {eff }}$ as a function of the number of stacking units in the Re-4 assembly. The error bars indicate the size of the $95 \%$ confidence interval in the Monte Carlo calculations. As illustrated in Figure 85, both the MCNP5 and RCP01 predictions are close. The average difference between the MCNP5 and RCP01 predicted $k_{\text {eff }}$ is $0.0041 \pm 0.0007 \Delta k$ over the range from 8 to 28 stacking units. Figure 86 and Table 87 provide a comparison of the predicted $\mathrm{K}_{\text {eft }}$ of the $\mathrm{Re}-4$ assembly with 15 and 16 stacking units as a function of the polyethylene top reflector thickness. It should be noted that the RACER predicted eigenvalues are below that of the MCNP5 with space cross sections, contrary to the results of other experiments. The experimental configurations that were predicted to achieve delayed criticality within TSR limits $(\rho<$ $0.5 \$$ ) are highlighted in green in Table 87 . The Re-4 assembly is classified as a mixed spectrum assembly with the following representative fission fractions, as predicted by MCNP5: $48.7 \%$ fast (E > $100 \mathrm{keV}), 44.6 \%$ intermediate $(0.625 \mathrm{eV}<E<100 \mathrm{keV})$, and $6.7 \%$ thermal $(E<0.625 \mathrm{eV})$. 


\section{B-TM-1639}

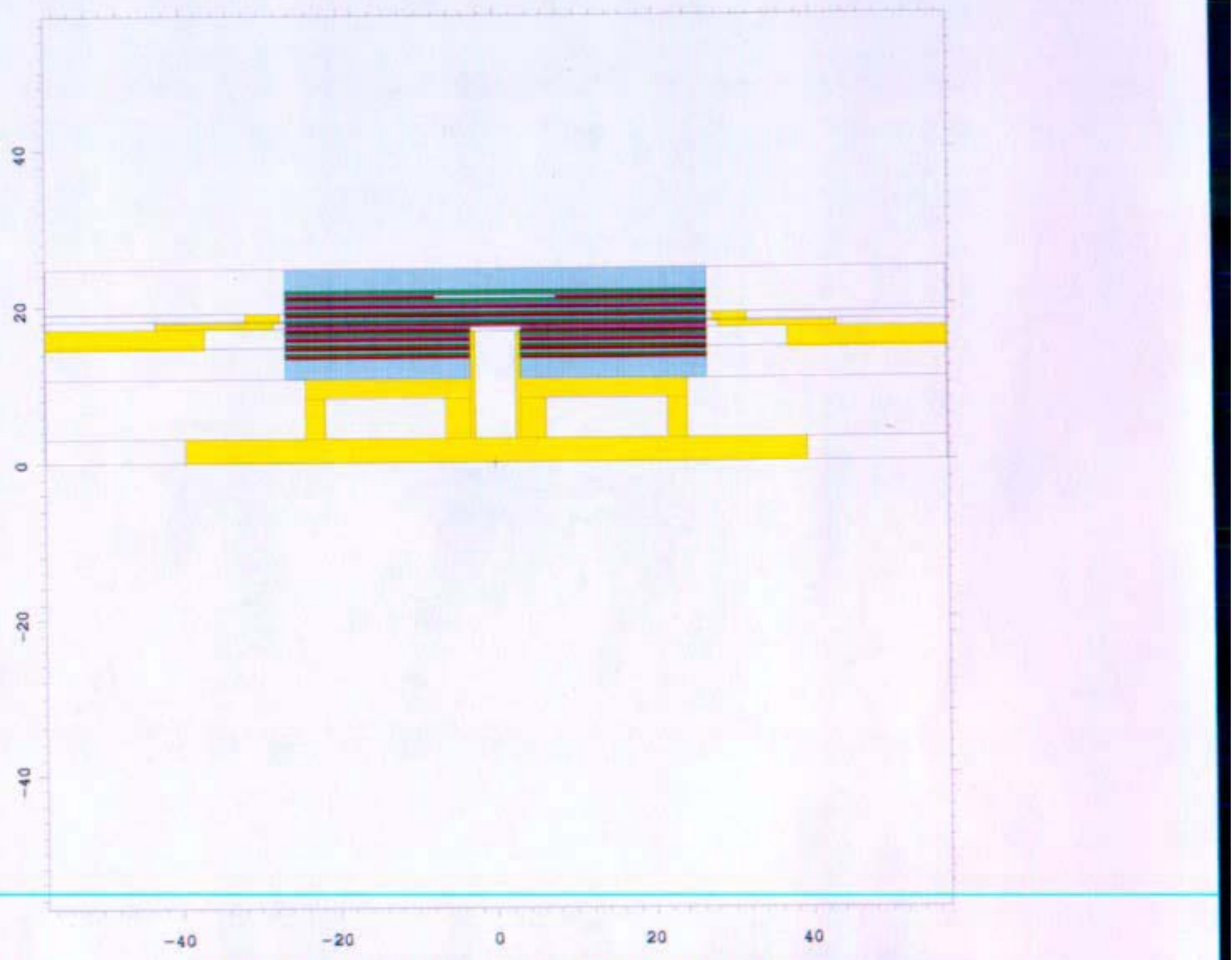

Figure 83. Cross-sectional View of the Re-4 Assembly 


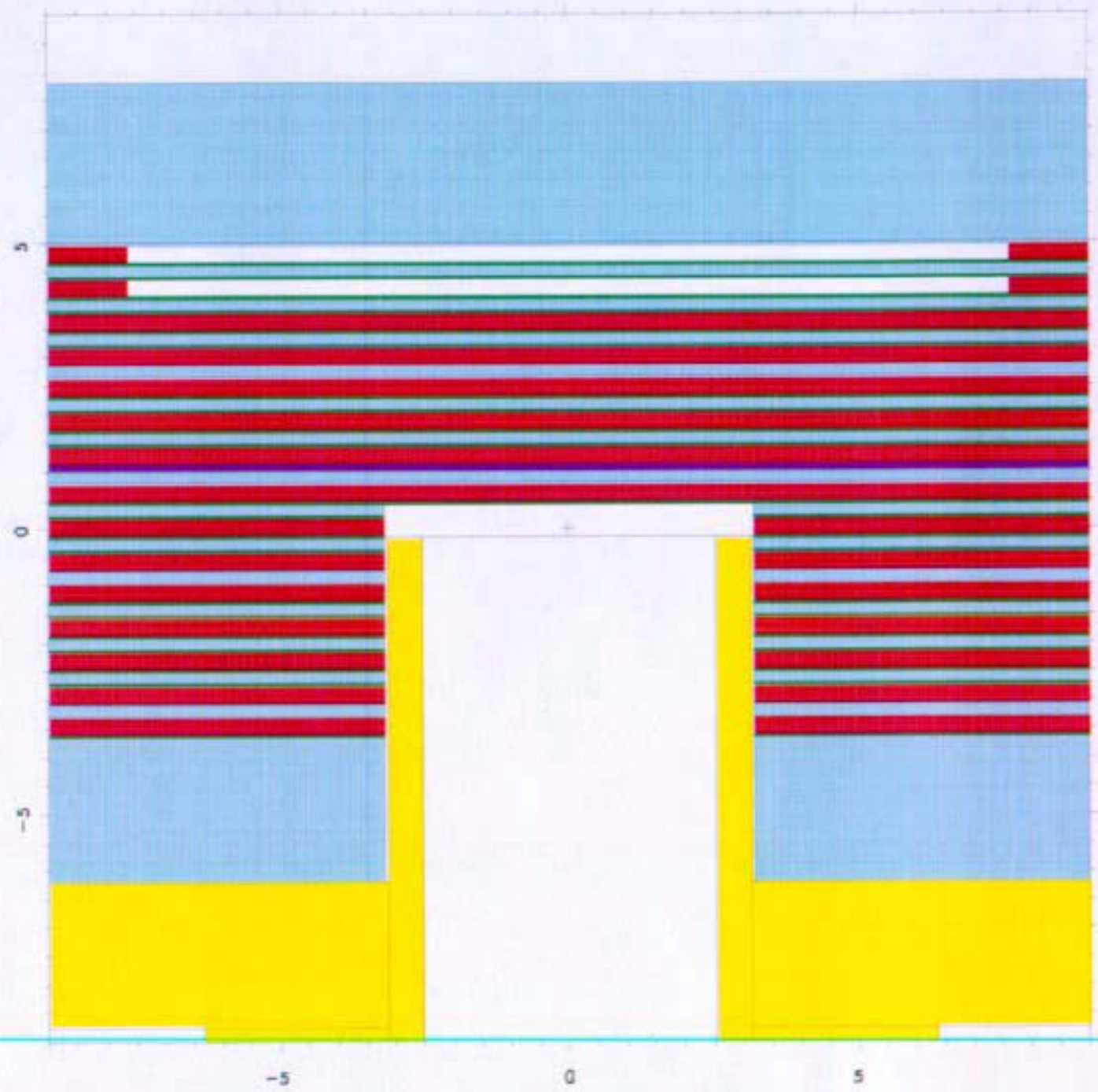

Figure 84. Cross-sectional Close-up View of the Re-4 Assembly 
Table 85. Predicted Critical Configuration of the Re-4 Assembly

\begin{tabular}{|c|c|c|c|c|c|}
\hline Unit & Material & Thickness (in) & $\begin{array}{c}\text { Inner } \\
\text { Diameter (in) }\end{array}$ & $\begin{array}{c}\text { Outer } \\
\text { Diameter (in) }\end{array}$ & $\begin{array}{l}\text { Assembly Height } \\
\text { (in) }\end{array}$ \\
\hline $\begin{array}{l}\text { Bottom } \\
\text { Reflector }\end{array}$ & Poly & 1.00 & 2.51 & 21.0 & 1.0000 \\
\hline \multirow{4}{*}{1} & $\mathrm{Re}$ & 0.0161 & 2.51 & 21.0 & 1.0161 \\
\hline & HEU & 0.118 & 2.51 & 21.0 & 1.1341 \\
\hline & $\mathrm{Re}$ & 0.0161 & 2.51 & 21.0 & 1.1502 \\
\hline & Poly & 0.080 & 2.51 & 21.0 & 1.2302 \\
\hline \multirow{4}{*}{2} & $\mathrm{Re}$ & 0.0161 & 2.51 & 21.0 & 1.2463 \\
\hline & HEU & 0.118 & 2.51 & 21.0 & 1.3643 \\
\hline & $\mathrm{Re}$ & 0.0161 & 2.51 & 21.0 & 1.3804 \\
\hline & Poly & 0.080 & 2.51 & 21.0 & 1.4604 \\
\hline \multirow{4}{*}{3} & $\operatorname{Re}$ & 0.0161 & 2.51 & 21.0 & 1.4765 \\
\hline & HEU & 0.118 & 2.51 & 21.0 & 1.5945 \\
\hline & $\mathrm{Re}$ & 0.0161 & 2.51 & 21.0 & 1.6106 \\
\hline & Poly & 0.080 & 2.51 & 21.0 & 1.6906 \\
\hline \multirow{4}{*}{4} & $R e$ & 0.0161 & 2.51 & 21.0 & 1.7067 \\
\hline & HEU & 0.118 & 2.51 & 21.0 & 1.8247 \\
\hline & $\mathrm{Re}$ & 0.0161 & 2.51 & 21.0 & 1.8408 \\
\hline & Poly & 0.080 & 2.51 & 21.0 & 1.9208 \\
\hline \multirow{4}{*}{5} & $\mathrm{Re}$ & 0.0161 & 2.51 & 21.0 & 1.9369 \\
\hline & HEU & 0.118 & 2.51 & 21.0 & 2.0549 \\
\hline & $\mathrm{Re}$ & 0.0161 & 2.51 & 21.0 & 2.0710 \\
\hline & Poly & 0.080 & 2.51 & 21.0 & 2.1510 \\
\hline \multirow{4}{*}{6} & $\mathrm{Re}$ & 0.0161 & 2.51 & 21.0 & 2.1671 \\
\hline & HEU & 0.118 & 2.51 & 21.0 & 2.2851 \\
\hline & $\mathrm{Re}$ & 0.0161 & 2.51 & 21.0 & 2.3012 \\
\hline & Poly & 0.080 & 2.51 & 21.0 & 2.3812 \\
\hline \multirow{4}{*}{7} & $\mathrm{Re}$ & 0.0161 & 2.51 & 21.0 & 2.3973 \\
\hline & $\mathrm{HEU}$ & 0.118 & 2.51 & 21.0 & 2.5153 \\
\hline & $\mathrm{Re}$ & 0.0161 & 2.51 & 21.0 & 2.5314 \\
\hline & Poly & 0.080 & 2.51 & 21.0 & 2.6114 \\
\hline \multirow{4}{*}{8} & $\mathrm{Re}$ & 0.0161 & 0 & 21.0 & 2.6275 \\
\hline & $\mathrm{HEU}$ & 0.118 & 0 & 21.0 & 2.7455 \\
\hline & $\mathrm{Re}$ & 0.0161 & 0 & 21.0 & 2.7616 \\
\hline & Poly & 0.080 & 0 & 21.0 & 2.8416 \\
\hline Diaphragm & Stainless Steel & 0.040 & 0 & 24.8 & 2.8816 \\
\hline \multirow{4}{*}{9} & $\mathrm{Re}$ & 0.0161 & 0 & 21.0 & 2.8977 \\
\hline & HEU & 0.118 & 0 & 21.0 & 3.0157 \\
\hline & $\mathrm{Re}$ & 0.0161 & 0 & 21.0 & 3.0318 \\
\hline & Poly & 0.080 & 0 & 21.0 & 3.1118 \\
\hline \multirow{4}{*}{10} & $\mathrm{Re}$ & 0.0161 & 0 & 21.0 & 3.1279 \\
\hline & HEU & 0.118 & 0 & 21.0 & 3.2459 \\
\hline & $\mathrm{Re}$ & 0.0161 & 0 & 21.0 & 3.2620 \\
\hline & Poly & 0.080 & 0 & 21.0 & 3.3420 \\
\hline
\end{tabular}




\begin{tabular}{|c|c|c|c|c|c|}
\hline Unit & Material & Thickness (in) & $\begin{array}{c}\text { Inner } \\
\text { Diameter (in) }\end{array}$ & $\begin{array}{c}\text { Outer } \\
\text { Diameter (in) }\end{array}$ & $\begin{array}{l}\text { Assembly Height } \\
\text { (in) }\end{array}$ \\
\hline \multirow{4}{*}{11} & $\mathrm{Re}$ & 0.0161 & 0 & 21.0 & 3.3581 \\
\hline & HEU & 0.118 & 0 & 21.0 & 3.4761 \\
\hline & $\mathrm{Re}$ & 0.0161 & 0 & 21.0 & 3.4922 \\
\hline & Poly & 0.080 & 0 & 21.0 & 3.5722 \\
\hline \multirow{4}{*}{12} & $\mathrm{Re}$ & 0.0161 & 0 & 21.0 & 3.5883 \\
\hline & HEU & 0.118 & 0 & 21.0 & 3.7063 \\
\hline & $\mathrm{Re}$ & 0.0161 & 0 & 21.0 & 3.7224 \\
\hline & Poly & 0.080 & 0 & 21.0 & 3.8024 \\
\hline \multirow{4}{*}{13} & $\mathrm{Re}$ & 0.0161 & 0 & 21.0 & 3.8185 \\
\hline & HEU & 0.118 & 0 & 21.0 & 3.9365 \\
\hline & $\mathrm{Re}$ & 0.0161 & 0 & 21.0 & 3.9526 \\
\hline & Poly & 0.080 & 0 & 21.0 & 4.0326 \\
\hline \multirow{4}{*}{14} & $\mathrm{Re}$ & 0.0161 & 0 & 21.0 & 4.0487 \\
\hline & HEU & 0.118 & 6.005 & 21.0 & 4.1667 \\
\hline & $\mathrm{Re}$ & 0.0161 & 0 & 21.0 & 4.1828 \\
\hline & Poly & 0.080 & 0 & 21.0 & 4.2628 \\
\hline \multirow{3}{*}{15} & $\mathrm{Re}$ & 0.0161 & 0 & 21.0 & 4.2789 \\
\hline & HEU & 0.118 & 6.005 & 21.0 & 4.3969 \\
\hline & $\mathrm{Re}$ & 0.0161 & 0 & 21.0 & 4.4130 \\
\hline $\begin{array}{l}\text { Top } \\
\text { Reflector }\end{array}$ & Poly & $\begin{array}{l}1.20 \text { (RCP01) } \\
1.10 \text { (MCNP5, } \\
\text { MCNP5 Space } \\
\text { XS. RACER) }\end{array}$ & 0 & 21.0 & $\begin{array}{l}5.6130 \text { (RCP01) } \\
5.5130 \text { (MCNP5 } \\
\text { MCNP5 Space } \\
\text { XS, RACER) }\end{array}$ \\
\hline
\end{tabular}

Table 86. Re-4 Assembly Material Mass Distribution

\begin{tabular}{|c|c|c|c|c|c|c|}
\hline \multirow{2}{*}{ Material } & \multicolumn{5}{|c|}{ Mass (kg) } \\
\cline { 2 - 7 } & MCNP5/MCNP5 (Space XS)/RACER & \multicolumn{2}{c|}{ RCP01 } \\
\cline { 2 - 7 } & $\begin{array}{c}\text { Lower } \\
\text { Assembly }\end{array}$ & $\begin{array}{c}\text { Upper } \\
\text { Assembly }\end{array}$ & Total & $\begin{array}{c}\text { Lower } \\
\text { Assembly }\end{array}$ & $\begin{array}{c}\text { Upper } \\
\text { Assembly }\end{array}$ & Total \\
\hline HEU & 99.2 & 85.8 & 185.0 & 99.2 & 85.8 & 185.0 \\
\hline Re & 30.3 & 26.9 & 57.2 & 30.3 & 26.9 & 57.2 \\
\hline Polyethylene & 8.8 & 8.6 & 17.4 & 8.8 & 9.3 & 18.1 \\
\hline Total & 138.3 & 121.3 & 259.6 & 138.3 & 122.0 & 260.4 \\
\hline
\end{tabular}




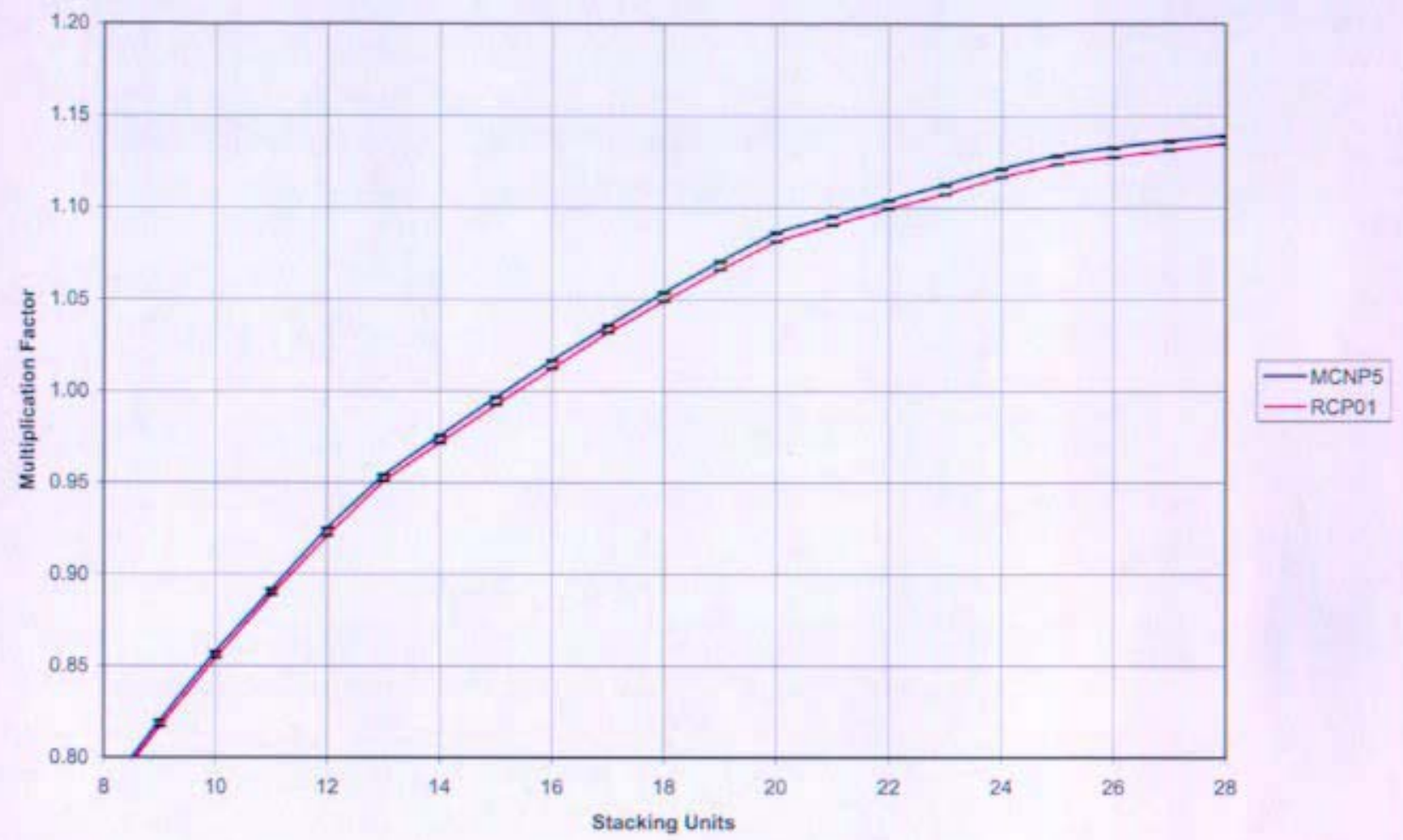

Figure 85. Re-4 Assembly $k_{\text {eff }}$ as a Function of the Number of Stacking Units

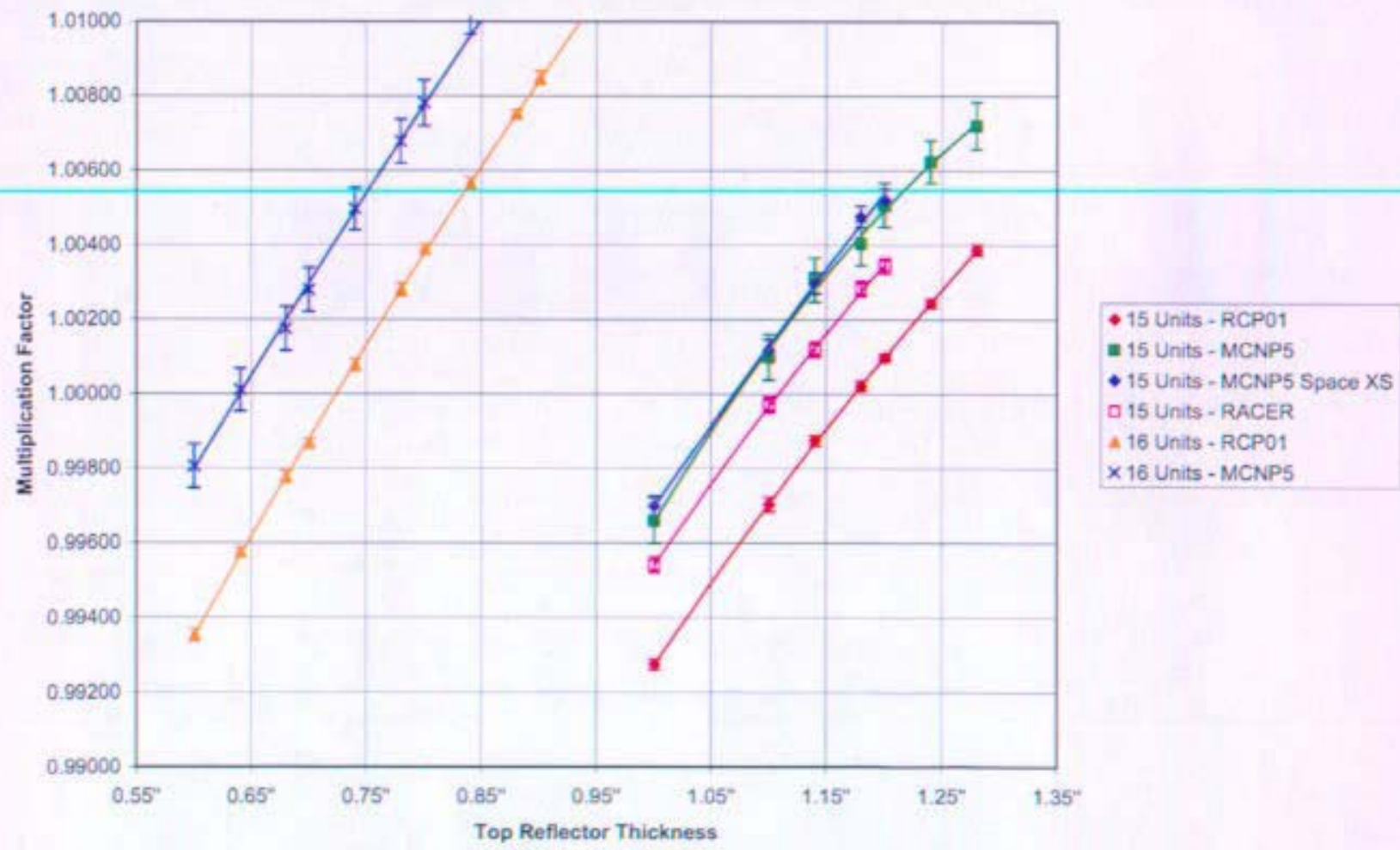

Figure 86. Re-4 Assembly $k_{\text {eff }}$ as a Function of the Top Reflector Thickness 
Table 87. Re-4 Assembly $k_{\text {eff }}$ as a Function of the Top Reflector Thickness

\begin{tabular}{|c|c|c|c|c|c|c|c|c|}
\hline \multicolumn{9}{|c|}{ Predicted Top Reflector Thickness } \\
\hline \multicolumn{9}{|c|}{15 Stacking Units } \\
\hline \multirow{2}{*}{$\begin{array}{c}\text { Top } \\
\text { Reflector } \\
\text { Thickness } \\
\text { (in) }\end{array}$} & \multicolumn{2}{|c|}{ MCNP5 } & \multicolumn{2}{|c|}{ MCNP5 (Space XS) } & \multicolumn{2}{|c|}{ RCP01 } & \multicolumn{2}{|c|}{ RACER } \\
\hline & $k_{\text {eff }}$ & $95 \% \mathrm{Cl}$ & $k_{\text {eff }}$ & $95 \% \mathrm{Cl}$ & $k_{\text {eff }}$ & $95 \% \mathrm{Cl}$ & $k_{\text {eff }}$ & $95 \% \mathrm{Cl}$ \\
\hline 1.00 & 0.99658 & 0.00061 & 0.99697 & 0.00026 & 0.99273 & 0.00014 & 0.99540 & 0.00021 \\
\hline 1.10 & 1.00097 & 0.00061 & 1.00117 & 0.00028 & 0.99702 & 0.00019 & 0.99969 & 0.00021 \\
\hline 1.14 & 1.00305 & 0.00059 & 1.00296 & 0.00028 & 0.99873 & 0,00013 & 1.00118 & 0.00020 \\
\hline 1.18 & 1.00402 & 0.00059 & 1.00475 & 0.00028 & 1.00021 & 0.00013 & 1.00281 & 0.00021 \\
\hline 1.20 & 1.00506 & 0.00059 & 1.00520 & 0.00028 & 1.00097 & 0.00010 & 1.00343 & 0.00021 \\
\hline 1.24 & 1.00622 & 0.00057 & - & - & 1.00242 & 0.00012 & - & - \\
\hline 1.28 & 1.00719 & 0.00063 & - & - & 1.00387 & 0.00014 & - & - \\
\hline \multicolumn{9}{|c|}{16 Stacking Units } \\
\hline \multirow{2}{*}{$\begin{array}{c}\text { Top } \\
\text { Reflector } \\
\text { Thickness } \\
\text { (in) } \\
\end{array}$} & \multicolumn{2}{|c|}{ MCNP5 } & \multicolumn{2}{|c|}{ MCNP5 (Space XS) } & \multicolumn{2}{|c|}{ RCP01 } & \multicolumn{2}{|c|}{ RACER } \\
\hline & $\mathbf{k}_{\text {eff }}$ & $95 \% \mathrm{Cl}$ & $k_{\text {eff }}$ & $95 \% \mathrm{Cl}$ & $k_{\text {eff }}$ & $95 \% \mathrm{Cl}$ & $k_{\text {eff }}$ & $95 \% \mathrm{Cl}$ \\
\hline 0.60 & 0.99804 & 0.00059 & \multirow{11}{*}{\multicolumn{2}{|c|}{$\begin{array}{l}\text { Not investigated due } \\
\text { to termination of } \\
\text { project. }\end{array}$}} & 0.99352 & 0.00017 & \multirow{11}{*}{\multicolumn{2}{|c|}{$\begin{array}{l}\text { Not investigated } \\
\text { due to termination } \\
\text { of project. }\end{array}$}} \\
\hline 0.64 & 1.00009 & 0.00057 & & & 0.99575 & 0.00013 & & \\
\hline 0.68 & 1.00174 & 0.00059 & & & 0.99776 & 0.00017 & & \\
\hline 0.70 & 1.00278 & 0.00059 & & & 0.99867 & 0.00011 & & \\
\hline 0.74 & 1.00496 & 0.00057 & & & 1.00077 & 0.00016 & & \\
\hline 0.78 & 1.00677 & 0.00059 & & & 1.00279 & 0.00018 & & \\
\hline 0.80 & 1.00780 & 0.00061 & & & 1.00388 & 0.00013 & & \\
\hline 0.84 & 1.01024 & 0.00059 & & & 1.00565 & 0.00016 & & \\
\hline 0.88 & 1.01086 & 0.00061 & & & 1.00751 & 0.00011 & & \\
\hline 0.90 & 1.01229 & 0.00061 & & & 1.00848 & 0.00018 & & \\
\hline 1.00 & 1.01671 & 0.00059 & & & 1.01272 & 0.00018 & & \\
\hline
\end{tabular}




\subsubsection{Rhenium Critical Experiments Summary and Conclusions}

This document provides the pre-experimental predictions for the Re critical experiments including the effect of the Planet assembly machine structure. These critical experiments are being performed to:

1. determine the adequacy of the existing ${ }^{185} \mathrm{Re}$ and ${ }^{187} \mathrm{Re}$ neutron cross section evaluations in a neutron energy spectrum characteristic of the Prometheus reactor designs under normal and accident conditions,

2. reduce the uncertainty in $k_{\text {eff }}$ for Prometheus reactor designs containing substantial amounts of rhenium by performing benchmark quality critical experiments that bracket the neutron energy spectra expected under normal and accident conditions, and

3. provide benchmark critical experiments needed to develop improved ${ }^{185} \mathrm{Re}$ and ${ }^{187} \mathrm{Re}$ neutron cross section evaluations if new evaluations are determined to be required.

The first 3 experiments are designed to bracket the neutron energy spectrum expected in the Prometheus space nuclear reactor under normal operating conditions. The Re-4 experiment is designed to approximate the neutron energy spectrum expected in accident conditions in which the core is flooded and surrounded by water or wet sand. A summary of the fission fraction in the thermal, intermediate, and fast energy ranges for each of the Re critical experiments is provided in Table 88 . $\operatorname{Re}-1, \operatorname{Re}-2$, and $R e-3$ experiments are fast spectrum experiments while the $\operatorname{Re}-4$ experiment is a mixed spectrum experiment. A summary of the pre-experimental predictions for each of the Re critical experiments is provided in Table 89. Predictions from RCP01, MCNP5, MCNP5 with space cross sections, and RACER analyses are reported.

Table 88. A Summary of the Energy Spectrum Covered in the Re Critical Experiments

\begin{tabular}{|c|c|c|c|}
\hline \multirow{2}{*}{ Experiment } & \multicolumn{3}{|c|}{ Percent Fissions by Energy (MCNP5 Predictions) } \\
\cline { 2 - 4 } & $<0.625 \mathrm{eV}$ & $0.625 \mathrm{eV}-100 \mathrm{keV}$ & $>100 \mathrm{keV}$ \\
\hline Re-1 & $0.00 \%$ & $16.93 \%$ & $83.07 \%$ \\
\hline $\mathrm{Re}-2$ & $0.00 \%$ & $23.23 \%$ & $76.77 \%$ \\
\hline $\mathrm{Re}-3$ & $0.04 \%$ & $34.13 \%$ & $65.83 \%$ \\
\hline $\mathrm{Re}-4$ & $6.72 \%$ & $44.62 \%$ & $48.65 \%$ \\
\hline
\end{tabular}


B-TM-1639

Table 89. A Summary of the Pre-Experimental Predictions for the Re Critical Experiments

\begin{tabular}{|c|c|c|c|c|c|c|c|c|}
\hline Experiment & $\begin{array}{c}\text { Monte } \\
\text { Carlo Code }\end{array}$ & $\begin{array}{l}\text { Stacking } \\
\text { Units }\end{array}$ & $\begin{array}{l}\text { Top } \\
\text { Reflector } \\
\text { Thickness } \\
\text { (in) }\end{array}$ & $\mathbf{k}_{\text {eff }}$ & $\begin{array}{c}95 \% \\
\text { Confidence } \\
\text { Level }\end{array}$ & $\begin{array}{c}\text { Mass } \\
\text { of HEU } \\
(\mathrm{kg})\end{array}$ & $\begin{array}{l}\text { Mass } \\
\text { of Re } \\
(\mathrm{kg})\end{array}$ & $\begin{array}{c}\text { Mass of } \\
\text { Moderator } \\
\text { (graphitel } \\
\text { polyethylene) } \\
(\mathbf{k g})\end{array}$ \\
\hline \multirow{4}{*}{$\operatorname{Re}-1$} & RCP01 & 18 & 1.25 & 1.00113 & 0.00016 & 219.6 & 68.8 & 38.6 \\
\hline & MCNP5 & 18 & 1.25 & 1.00179 & 0.00053 & 219.6 & 68.8 & 38.6 \\
\hline & $\begin{array}{c}\text { MCNP5 } \\
\text { (Space XS) }\end{array}$ & 18 & 1.20 & 1.00035 & 0.00024 & 219.6 & 68.8 & 38.1 \\
\hline & RACER & 18 & 1.20 & 1.00122 & 0.00019 & 219.6 & 68.8 & 38.1 \\
\hline \multirow{4}{*}{ Re-2 } & RCP01 & 17 & 1.85 & 1.00093 & 0.00014 & 208.0 & 64.9 & 68.4 \\
\hline & MCNP5 & 17 & 1.75 & 1.00113 & 0.00053 & 208.0 & 64.9 & 67.4 \\
\hline & $\begin{array}{c}\text { MCNP5 } \\
\text { (Space XS) }\end{array}$ & 17 & 1.75 & 1.00116 & 0.00026 & 208.0 & 64.9 & 67.4 \\
\hline & RACER & 17 & 1.75 & 1.00204 & 0.00019 & 208.0 & 64.9 & 67.4 \\
\hline \multirow{4}{*}{$\mathrm{Re}-3$} & RCP01 & 16 & 5.45 & 1.00108 & 0.00014 & 196.5 & 61.1 & 160.2 \\
\hline & MCNP5 & 16 & 4.50 & 1.00150 & 0.00057 & 196.5 & 61.1 & 150.4 \\
\hline & $\begin{array}{c}\text { MCNP5 } \\
\text { (Space XS) }\end{array}$ & 16 & 4.50 & 1.00161 & 0.00026 & 196.5 & 61.1 & 150.4 \\
\hline & RACER & 16 & 4.50 & 1.00216 & 0.00020 & 196.5 & 61.1 & 150.4 \\
\hline \multirow{4}{*}{$\operatorname{Re}-4$} & RCP01 & 15 & 1.20 & 1.00097 & 0.00010 & 185.0 & 57.2 & 18.1 \\
\hline & MCNP5 & 15 & 1.10 & 1.00097 & 0.00061 & 185.0 & 57.2 & 17.4 \\
\hline & $\begin{array}{c}\text { MCNP5 } \\
\text { (Space XS) }\end{array}$ & 15 & 1.10 & 1.00117 & 0.00028 & 185.0 & 57.2 & 17.4 \\
\hline & RACER & 15 & 1.10 & 0.99969 & 0.00021 & 185.0 & 57.2 & 17.4 \\
\hline
\end{tabular}




\subsection{Tantalum Critical Experiments}

\subsubsection{Ta-2.5W-1 Experiment}

The Ta-2.5W-1 experiment is designed to simulate the hardest neutron spectrum, which is in the center of the Prometheus reactor core during normal operating conditions. A cross-sectional view and close-up view of the experimental configuration are provided in Figure 87 and Figure 88 where aluminum is yellow, graphite is blue, Ta-2.5W is green, $\mathrm{HEU}$ is red, and stainless steel is purple (all dimensions in figures are in centimeters). The Ta-2.5W-1 assembly configuration, including plate layout and dimensions, is shown in Table 90. The RCP01 analysis predicts an assembly height of 7.350" and the MCNP5, MCNP5 with space cross sections, and RACER analyses predict an assembly height of $7.300^{\prime \prime}$. The assembly rests on a $3.0^{\prime \prime}$ thick hollow Al 6061-T6 spindle plate that has a $19^{\prime \prime} \mathrm{OD}$ and $2.50^{\prime \prime}$ inner diameter. The active core region of the assembly is $4.950^{\prime \prime}$ high and contains one $0.100^{\prime \prime}$ thick graphite plate and 18 stacking units consisting of a $0.0246^{\prime \prime}$ thick Ta-2.5W plate, a $0.118^{\prime \prime}$ thick HEU plate, a $0.0246^{\prime \prime}$ thick Ta-2.5W plate, and a $0.100^{\prime \prime}$ thick graphite plate. The bottom reflector consists of a $1.0^{\prime \prime}$ thick graphite reflector and a $0.15^{\prime \prime}$ thick Ta-2.5W reflector. The RCP01 predicted top reflector consists of a $0.15^{\prime \prime}$ thick Ta-2.5W reflector and a $1.10^{\prime \prime}$ thick graphite reflector, while the MCNP5, MCNP5 with space cross sections, and RACER predicted top reflector consists of a $0.15^{\prime \prime}$ thick Ta-2.5W reflector and a 1.05" thick graphite reflector. A hollow Al 6061-T6 alignment tube is assumed to extend from the bottom of the spindle plate to the top of the $6^{\text {th }}$ stacking unit. All other regions are modeled as void, except as noted in Section 4.0 for the RACER models. The Ta-2.5W-1 assembly contains $219.6 \mathrm{~kg}$ of HEU and $111.7 \mathrm{~kg}$ of Ta-2.5W. The distribution of material in the top and bottom half of the assembly is given in Table 91 for the RCP01, MCNP5, MCNP5 with space cross sections, and RACER predicted critical configurations.

A series of analyses have been performed to predict the $k_{\text {eff }}$ of the Ta- $2.5 \mathrm{~W}-1$ assembly during the approach to critical as a function of both the number of stacking units and the graphite top reflector thickness. Figure 89 presents the RCP01 and MCNP5 predicted $k_{\text {eff }}$ as a function of the number of stacking units in the Ta-2.5W-1 assembly. The error bars indicate the size of the $95 \%$ confidence interval in the Monte Carlo calculations. As illustrated in Figure 89, both the MCNP5 and RCP01 predictions are close. The average difference between the MCNP5 and RCP01 predicted $k_{\text {eff }}$ is $0.0025 \pm 0.0004 \Delta \mathrm{k}$ over the range from 8 to 28 stacking units. Figure 90 and Table 92 provide a comparison of the predicted $k_{\text {eff }}$ of the Ta-2.5W-1 assembly with 18 and 19 stacking units as a function of the graphite top reflector thickness. The experimental configurations that were predicted to achieve delayed criticality within TSR limits $(\rho<0.5 \$)$ are highlighted in green in Table 92. The Ta$2.5 \mathrm{~W}-1$ assembly is classified as a fast spectrum assembly with the following representative fission fractions, as predicted by MCNP5: $86.0 \%$ fast ( $E>100 \mathrm{keV}), 14.0 \%$ intermediate $(0.625 \mathrm{eV}<\mathrm{E}<100$ $\mathrm{keV})$, and $0.0 \%$ thermal $(\mathrm{E}<0.625 \mathrm{eV})$. 
B-TM-1639

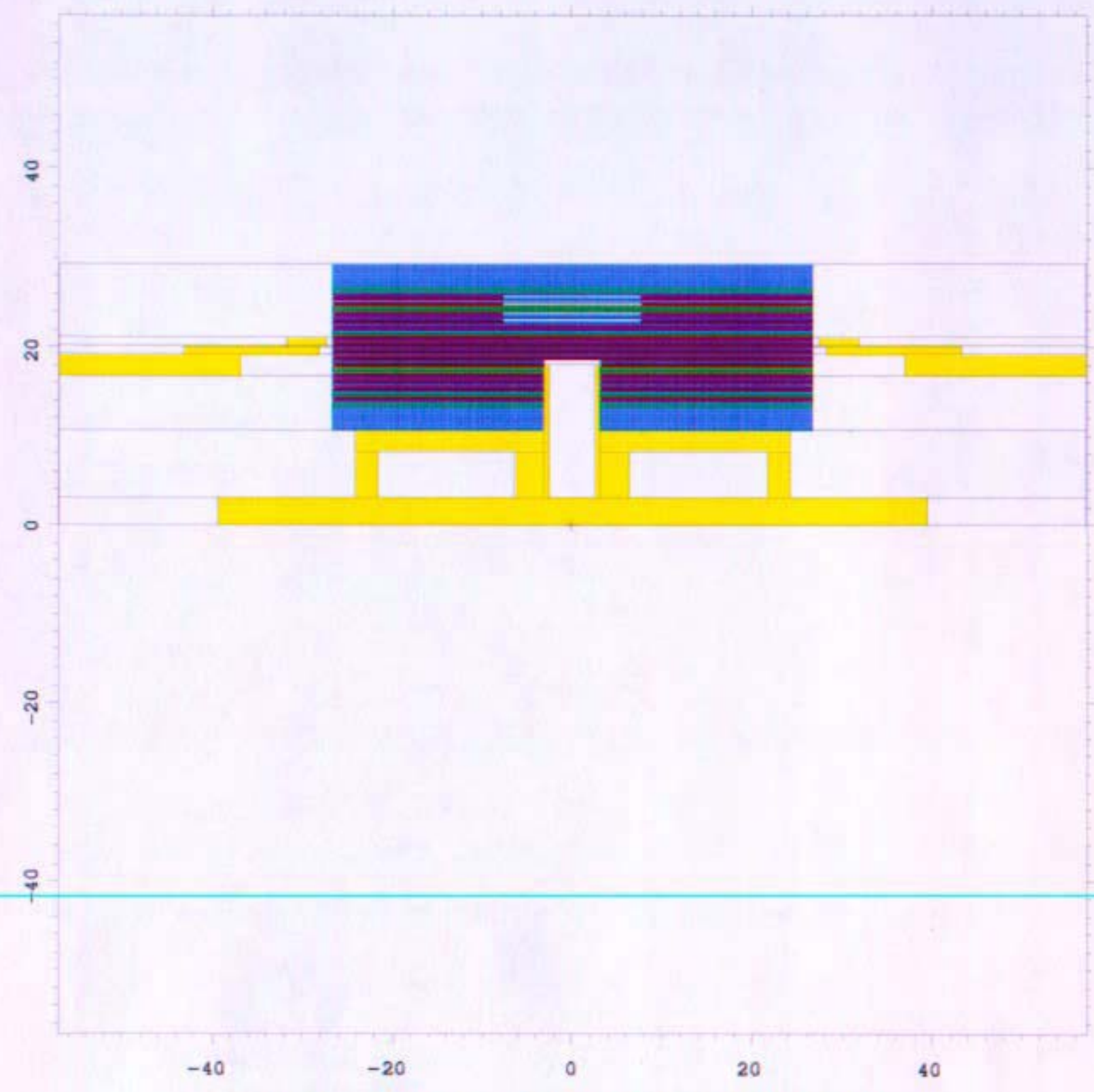

Figure 87. Cross-sectional View of the Ta-2.5W-1 Assembly 


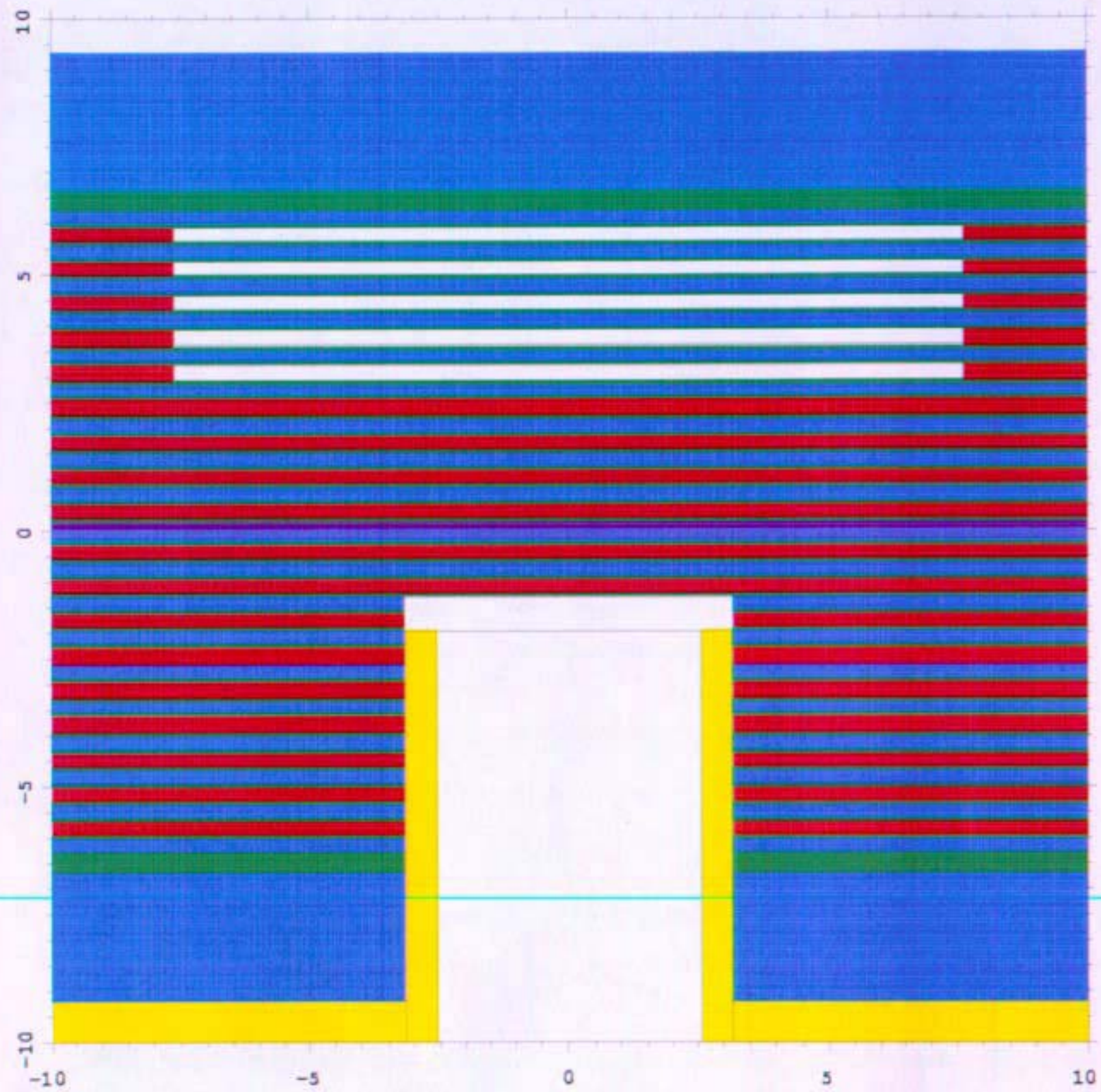

Figure 88. Cross-sectional Close-up View of the Ta-2.5W-1 Assembly 
Table 90. Predicted Critical Configuration for the Ta-2.5W-1 Assembly

\begin{tabular}{|c|c|c|c|c|c|}
\hline Unit & Material & Thickness (in) & $\begin{array}{c}\text { Inner } \\
\text { Diameter (in) }\end{array}$ & $\begin{array}{c}\text { Outer } \\
\text { Diameter (in) }\end{array}$ & $\begin{array}{l}\text { Assembly Height } \\
\text { (in) }\end{array}$ \\
\hline \multirow{3}{*}{$\begin{array}{l}\text { Bottom } \\
\text { Reflector }\end{array}$} & Graphite & 1.00 & 2.51 & 21.0 & 1.0000 \\
\hline & $\mathrm{Ta}-2.5 \mathrm{~W}$ & 0.150 & 2.51 & 210 & 1.1500 \\
\hline & Graphite & 0.100 & 2.51 & 210 & 12500 \\
\hline \multirow{4}{*}{1} & Ta-2.5W & 0.0246 & 2.51 & 21.0 & 1.2746 \\
\hline & HEU & 0.118 & 2.51 & 21.0 & 1.3926 \\
\hline & $\mathrm{Ta}-2.5 \mathrm{~W}$ & 0.0246 & 2.51 & 21.0 & 1.4172 \\
\hline & Graphite & 0.100 & 2.51 & 21.0 & 1.5172 \\
\hline \multirow{4}{*}{2} & $\mathrm{Ta}-2.5 \mathrm{~W}$ & 0.0246 & 2.51 & 21.0 & 1.5418 \\
\hline & HEU & 0.118 & 2.51 & 21.0 & 1.6598 \\
\hline & $\mathrm{Ta}-2.5 \mathrm{~W}$ & 0.0246 & 2.51 & 21.0 & 1.6844 \\
\hline & Graphite & 0.100 & 2.51 & 21.0 & 1.7844 \\
\hline \multirow{4}{*}{3} & $\mathrm{Ta}-2.5 \mathrm{~W}$ & 0.0246 & 2.51 & 21.0 & 1.8090 \\
\hline & HEU & 0.118 & 2.51 & 21.0 & 1.9270 \\
\hline & $\mathrm{Ta}-2.5 \mathrm{~W}$ & 0.0246 & 2.51 & 21.0 & 1.9516 \\
\hline & Graphite & 0.100 & 2.51 & 21.0 & 2.0516 \\
\hline \multirow{4}{*}{4} & Ta-2.5W & 0.0246 & 2.51 & 21.0 & 2.0762 \\
\hline & HEU & 0.118 & 2.51 & 21.0 & 2.1942 \\
\hline & Ta-2.5W & 0.0246 & 2.51 & 21.0 & 2.2188 \\
\hline & Graphite & 0.100 & 2.51 & 21.0 & 2.3188 \\
\hline \multirow{4}{*}{5} & $\mathrm{Ta}-2.5 \mathrm{~W}$ & 0.0246 & 2.51 & 21.0 & 2.3434 \\
\hline & HEU & 0.118 & 2.51 & 21.0 & 2.4614 \\
\hline & $\mathrm{Ta}-2.5 \mathrm{~W}$ & 0.0246 & 2.51 & 21.0 & 2.4860 \\
\hline & Graphite & 0.100 & 2.51 & 21.0 & 2.5860 \\
\hline \multirow{4}{*}{6} & $\mathrm{Ta}-2.5 \mathrm{~W}$ & 0.0246 & 2.51 & 21.0 & 2.6106 \\
\hline & HEU & 0.118 & 2.51 & 21.0 & 2.7286 \\
\hline & Ta-2.5W & 0.0246 & 2.51 & 21.0 & 2.7532 \\
\hline & Graphite & 0.100 & 2.51 & 21.0 & 2.8532 \\
\hline \multirow{4}{*}{7} & $\mathrm{Ta}-2.5 \mathrm{~W}$ & 0.0246 & 2.51 & 21.0 & 2.8778 \\
\hline & HEU & 0.118 & 2.51 & 21.0 & 2.9958 \\
\hline & $\mathrm{Ta}-2.5 \mathrm{~W}$ & 0.0246 & 2.51 & 21.0 & 3.0204 \\
\hline & Graphite & 0.100 & 2.51 & 21.0 & 3.1204 \\
\hline \multirow{4}{*}{8} & $\mathrm{Ta}-2.5 \mathrm{~W}$ & 0.0246 & 0 & 21.0 & 3.1450 \\
\hline & HEU & 0.118 & 0 & 21.0 & 3.2630 \\
\hline & $\mathrm{Ta}-2.5 \mathrm{~W}$ & 0.0246 & 0 & 21.0 & 3.2876 \\
\hline & Graphite & 0.100 & 0 & 21.0 & 3.3876 \\
\hline \multirow{4}{*}{9} & Ta-2.5W & 0.0246 & 0 & 21.0 & 3.4122 \\
\hline & HEU & 0.118 & 0 & 21.0 & 3.5302 \\
\hline & $\mathrm{Ta}-2.5 \mathrm{~W}$ & 0.0246 & 0 & 21.0 & 3.5548 \\
\hline & Graphite & 0.100 & 0 & 21.0 & 3.6548 \\
\hline Diaphragm & Stainiess Steel & 0.040 & 0 & 24.8 & 3.6948 \\
\hline \multirow{4}{*}{10} & $\mathrm{Ta}-2.5 \mathrm{~W}$ & 0.0246 & 0 & 21.0 & 3.7194 \\
\hline & $\mathrm{HEU}$ & 0.118 & 0 & 21.0 & 3.8374 \\
\hline & $\mathrm{Ta}-2.5 \mathrm{~W}$ & 0.0246 & 0 & 21.0 & 3.8620 \\
\hline & Graphite & 0.100 & 0 & 21.0 & 3.9620 \\
\hline
\end{tabular}




\begin{tabular}{|c|c|c|c|c|c|}
\hline Unit & Material & Thickness (in) & $\begin{array}{c}\text { Inner } \\
\text { Diameter (in) }\end{array}$ & $\begin{array}{c}\text { Outer } \\
\text { Diameter (in) }\end{array}$ & $\begin{array}{l}\text { Assembly Height } \\
\text { (in) }\end{array}$ \\
\hline \multirow{4}{*}{11} & $\mathrm{Ta}-2.5 \mathrm{~W}$ & 0.0246 & 0 & 21.0 & 3.9866 \\
\hline & HEU & 0.118 & 0 & 21.0 & 4.1046 \\
\hline & $\mathrm{Ta}-2.5 \mathrm{~W}$ & 0.0246 & 0 & 21.0 & 4.1292 \\
\hline & Graphite & 0.100 & 0 & 21.0 & 4.2292 \\
\hline \multirow{4}{*}{12} & $\mathrm{Ta}-2.5 \mathrm{~W}$ & 0.0246 & 0 & 21.0 & 4.2538 \\
\hline & $\mathrm{HEU}$ & 0.118 & 0 & 21.0 & 4.3718 \\
\hline & $\mathrm{Ta}-2.5 \mathrm{~W}$ & 0.0246 & 0 & 21.0 & 4.3964 \\
\hline & Graphite & 0.100 & 0 & 21.0 & 4.4964 \\
\hline \multirow{4}{*}{13} & $\mathrm{Ta}-2.5 \mathrm{~W}$ & 0.0246 & 0 & 21.0 & 4.5210 \\
\hline & $\mathrm{HEU}$ & 0.118 & 0 & 21.0 & 4.6390 \\
\hline & $\mathrm{Ta}-2.5 \mathrm{~W}$ & 0.0246 & 0 & 21.0 & 4.6636 \\
\hline & Graphite & 0.100 & 0 & 21.0 & 4.7636 \\
\hline \multirow{4}{*}{14} & $\mathrm{Ta}-2.5 \mathrm{~W}$ & 0.0246 & 0 & 21.0 & 4.7882 \\
\hline & HEU & 0.118 & 6.005 & 21.0 & 4.9062 \\
\hline & $\mathrm{Ta}-2.5 \mathrm{~W}$ & 0.0246 & 0 & 21.0 & 4.9308 \\
\hline & Graphite & 0.100 & 0 & 21.0 & 5.0308 \\
\hline \multirow{4}{*}{15} & $\mathrm{Ta}-2.5 \mathrm{~W}$ & 0.0246 & 0 & 21.0 & 5.0554 \\
\hline & HEU & 0.118 & 6.005 & 21.0 & 5.1734 \\
\hline & $\mathrm{Ta}-2.5 \mathrm{~W}$ & 0.0246 & 0 & 21.0 & 5.1980 \\
\hline & Graphite & 0.100 & 0 & 21.0 & 5.2980 \\
\hline \multirow{4}{*}{16} & $\mathrm{Ta}-2.5 \mathrm{~W}$ & 0.0246 & 0 & 21.0 & 5.3226 \\
\hline & HEU & 0.118 & 6.005 & 21.0 & 5.4406 \\
\hline & $\mathrm{Ta}-2.5 \mathrm{~W}$ & 0.0246 & 0 & 21.0 & 5.4652 \\
\hline & Graphite & 0.100 & 0 & 21.0 & 5.5652 \\
\hline \multirow{4}{*}{17} & $\mathrm{Ta}-2.5 \mathrm{~W}$ & 0.0246 & 0 & 21.0 & 5.5898 \\
\hline & HEU & 0.118 & 6.005 & 21.0 & 5.7078 \\
\hline & $\mathrm{Ta}-2.5 \mathrm{~W}$ & 0.0246 & 0 & 21.0 & 5.7324 \\
\hline & Graphite & 0.100 & 0 & 21.0 & 5.8324 \\
\hline \multirow{4}{*}{18} & $\mathrm{Ta}-2.5 \mathrm{~W}$ & 0.0246 & 0 & 21.0 & 5.8570 \\
\hline & HEU & 0.118 & 6.005 & 21.0 & 5.9750 \\
\hline & $\mathrm{Ta}-2.5 \mathrm{~W}$ & 0.0246 & 0 & 21.0 & 5.9996 \\
\hline & Graphite & 0.100 & 0 & 21.0 & 6.0996 \\
\hline \multirow[b]{2}{*}{$\begin{array}{l}\text { Top } \\
\text { Reflector }\end{array}$} & Ta-2.5W & 0.150 & 0 & 21.0 & 6.2496 \\
\hline & Graphite & $\begin{array}{l}\text { 1. } 10 \text { (RCP01) } \\
1.05 \text { (MCNP5) } \\
\text { MONP5 SpaCe } \\
\text { XS, RACER) }\end{array}$ & 0 & 21.0 & $\begin{array}{l}7.3496 \text { (RCP01) } \\
7.2996 \text { (MCNP5 } \\
\text { MONP5 SPaCB } \\
\text { XS, RAOER) }\end{array}$ \\
\hline
\end{tabular}

Table 91. Ta-2.5W-1 Assembly Material Mass Distribution

\begin{tabular}{|c|c|c|c|c|c|c|}
\hline \multirow{3}{*}{ Material } & \multicolumn{5}{|c|}{ Mass (kg) } \\
\cline { 2 - 7 } & \multicolumn{2}{|c|}{ MCNP5/MCNP5 (Space XS)/RACER } & \multicolumn{3}{c|}{ RCP01 } \\
\cline { 2 - 7 } & $\begin{array}{c}\text { Lower } \\
\text { Assembly }\end{array}$ & $\begin{array}{c}\text { Upper } \\
\text { Assembly }\end{array}$ & Total & $\begin{array}{c}\text { Lower } \\
\text { Assembly }\end{array}$ & $\begin{array}{c}\text { Upper } \\
\text { Assembly }\end{array}$ & Total \\
\hline HEU & 111.7 & 107.8 & 219.6 & 111.7 & 107.8 & 219.6 \\
\hline Ta-2.5W & 55.5 & 56.2 & 111.7 & 55.5 & 56.2 & 111.7 \\
\hline Graphite & 19.4 & 19.2 & 38.6 & 19.4 & 19.7 & 39.1 \\
\hline Total & 186.7 & 183.2 & 369.9 & 186.7 & 183.7 & $\mathbf{3 7 0 . 4}$ \\
\hline
\end{tabular}




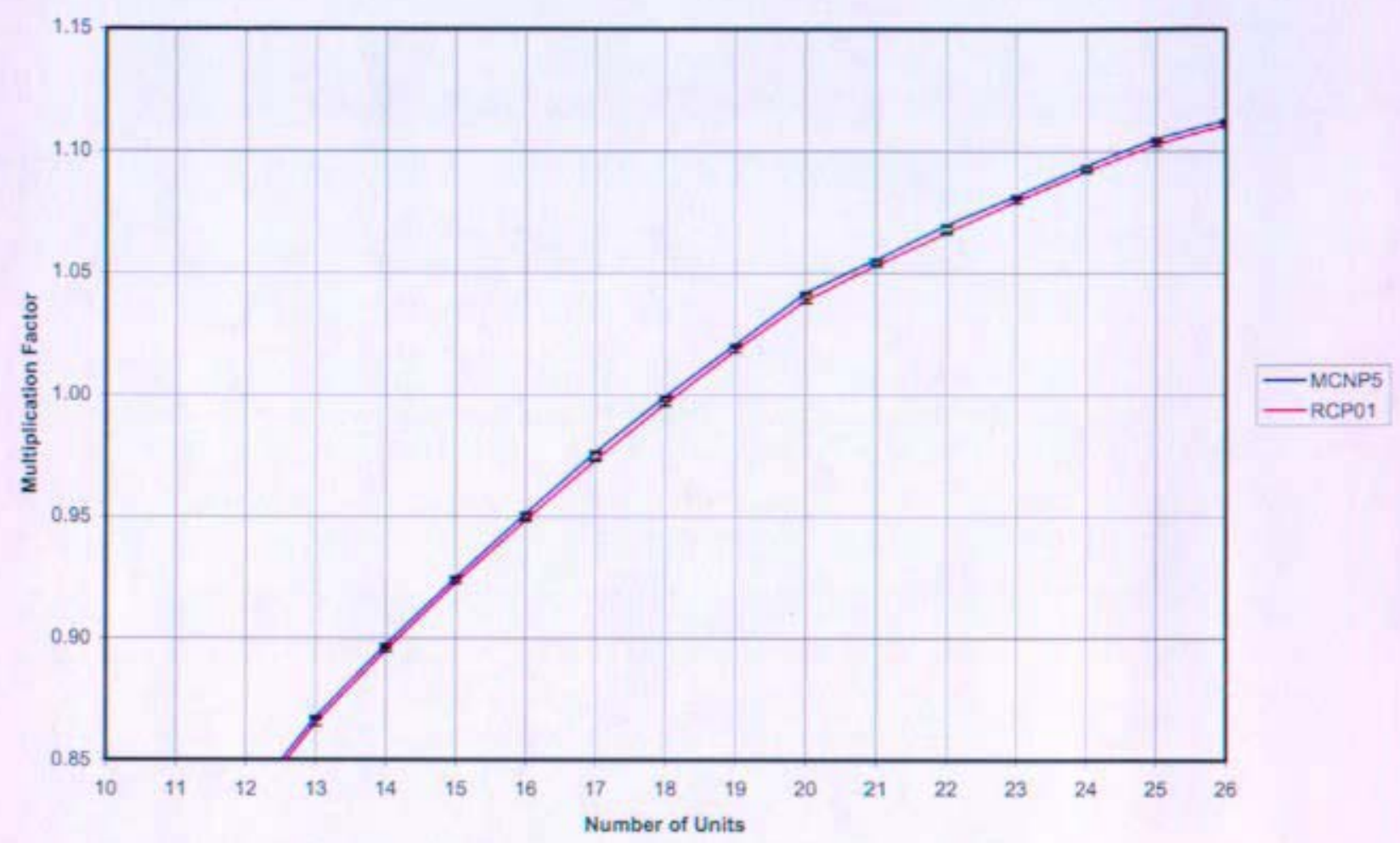

Figure 89. Ta-2.5W-1 Assembly $k_{\text {eff }}$ as a Function of the Number of Stacking Units

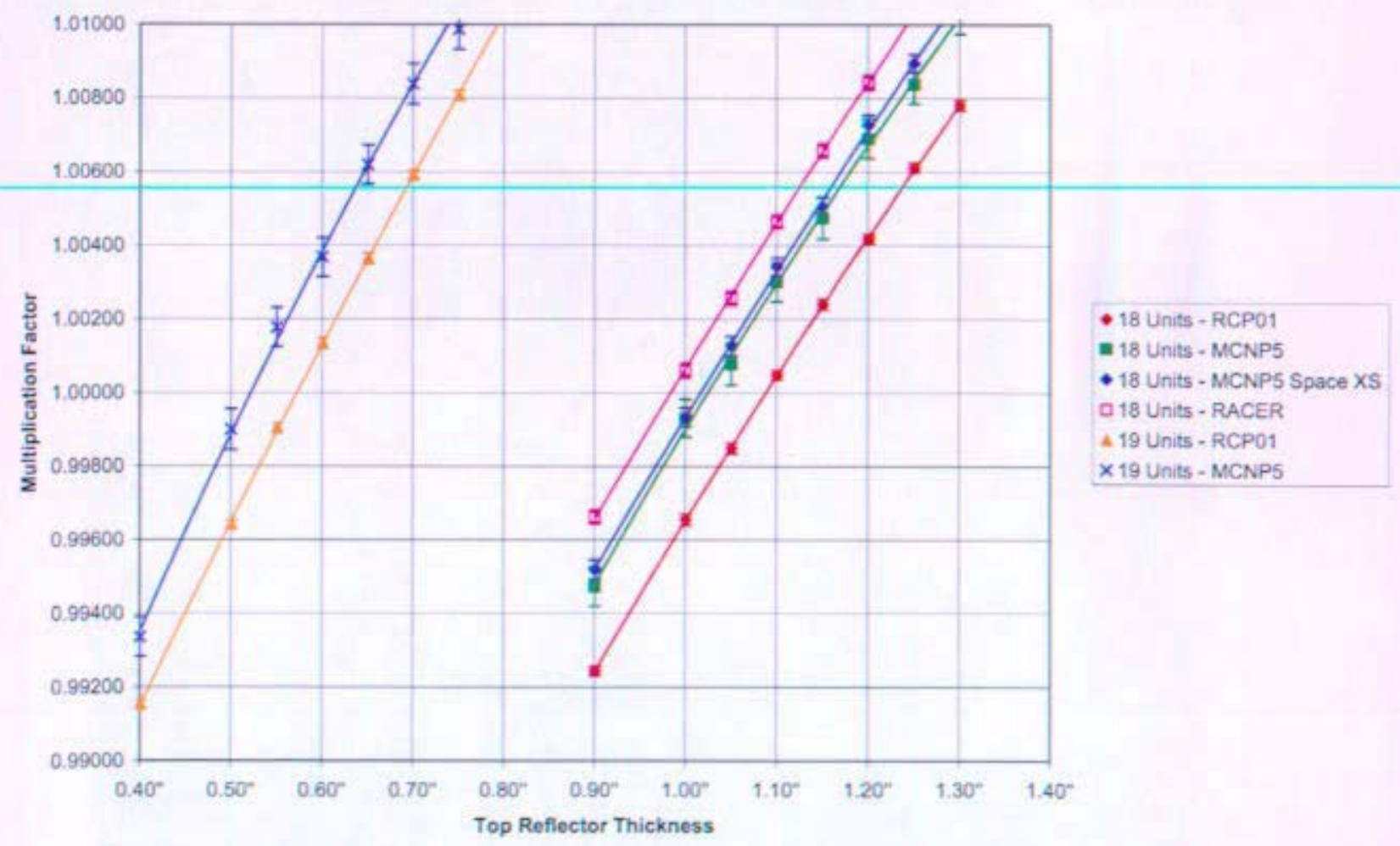

Figure 90. Ta-2.5W-1 Assembly $k_{\text {eff }}$ as a Function of the Top Reflector Thickness 
Table 92. Ta-2.5W-1 Assembly $k_{\text {eff }}$ as a Function of the Top Reflector Thickness

\begin{tabular}{|c|c|c|c|c|c|c|c|c|}
\hline \multicolumn{9}{|c|}{ Predicted Top Reflector Thickness } \\
\hline \multicolumn{9}{|c|}{18 Stacking Units } \\
\hline \multirow{2}{*}{$\begin{array}{c}\text { Top } \\
\text { Reflector } \\
\text { Thickness } \\
\text { (in) }\end{array}$} & \multicolumn{2}{|c|}{ MCNP5 } & \multicolumn{2}{|c|}{ MCNP5 (Space XS) } & \multicolumn{2}{|c|}{ RCP01 } & \multicolumn{2}{|c|}{ RACER } \\
\hline & $\mathbf{k}_{\text {eff }}$ & $95 \% \mathrm{Cl}$ & $\mathbf{k}_{\text {eff }}$ & $95 \% \mathrm{Cl}$ & $k_{\text {eff }}$ & $95 \% \mathrm{Cl}$ & $k_{\text {eff }}$ & $95 \% \mathrm{Cl}$ \\
\hline 0.90 & 0.99471 & 0.00053 & 0.99518 & 0.00026 & 0.99243 & 0.00013 & 0.99661 & 0.00019 \\
\hline 1.00 & 0.99930 & 0.00051 & 0.99932 & 0.00026 & 0.99654 & 0.00015 & 1.00061 & 0.00019 \\
\hline 1.05 & 1.00077 & 0,00057 & 1.00126 & 0.00026 & 0.99849 & 0.00014 & 1.00257 & 0.00019 \\
\hline 1.10 & 1.00299 & 0.00053 & 1.00341 & 0.00024 & 1.00048 & 0.00012 & 1.00465 & 0.00018 \\
\hline 1.15 & 1.00473 & 0.00057 & 1.00504 & 0.00024 & 1.00240 & 0.00014 & 1.00658 & 0.00019 \\
\hline 1.20 & 1.00688 & 0.00053 & 1.00726 & 0.00026 & 1.00418 & 0.00013 & 1.00843 & 0.00020 \\
\hline 1.25 & 1.00836 & 0.00053 & 1.00894 & 0.00024 & 1.00611 & 0.00013 & 1.01043 & 0.00019 \\
\hline 1.30 & 1.01024 & 0.00051 & 1.01076 & 0.00024 & 1.00780 & 0.00014 & 1.01201 & 0.00018 \\
\hline \multicolumn{9}{|c|}{19 Stacking Units } \\
\hline \multirow{2}{*}{$\begin{array}{c}\text { Top } \\
\text { Reflector } \\
\text { Thickness } \\
\text { (in) }\end{array}$} & \multicolumn{2}{|c|}{ MCNP5 } & \multicolumn{2}{|c|}{ MCNP5 (Space XS) } & \multicolumn{2}{|c|}{ RCP01 } & \multicolumn{2}{|c|}{ RACER } \\
\hline & $k_{\text {eff }}$ & $95 \% \mathrm{Cl}$ & $k_{\text {off }}$ & $95 \% \mathrm{Cl}$ & $k_{\text {eff }}$ & $95 \% \mathrm{Cl}$ & $\mathbf{k}_{\text {eff }}$ & $95 \% \mathrm{Cl}$ \\
\hline 0.40 & 0.99335 & 0.00053 & \multirow{8}{*}{\multicolumn{2}{|c|}{$\begin{array}{l}\text { Not investigated due } \\
\text { to termination of } \\
\text { project. }\end{array}$}} & 0.99153 & 0.00011 & \multirow{8}{*}{\multicolumn{2}{|c|}{$\begin{array}{l}\text { Not investigated } \\
\text { due to termination } \\
\text { of project. }\end{array}$}} \\
\hline 0.50 & 0.99899 & 0.00055 & & & 0.99640 & 0.00012 & & \\
\hline 0.55 & 1.00177 & 0.00053 & & & 0.99904 & 0.00013 & & \\
\hline 0.60 & 1.00367 & 0.00053 & & & 1.00134 & 0.00015 & & \\
\hline 0.65 & 1.00618 & 0.00053 & & & 1.00364 & 0.00015 & & \\
\hline 0.70 & 1.00837 & 0.00055 & & & 1.00591 & 0.00012 & & \\
\hline 0.75 & 1.00986 & 0.00055 & & & 1.00806 & 0.00014 & & \\
\hline 0.80 & 1.01296 & 0.00055 & & & 1.01035 & 0.00017 & & \\
\hline
\end{tabular}




\subsubsection{Ta-2.5W-2 Experiment}

The Ta-2.5W-2 experiment is designed to bracket the average neutron spectrum of the Prometheus reactor core. It is designed to be harder than the expected average neutron energy spectrum of the core but softer than the Ta-2.5W-1 experiment. Additional graphite has been added to the assembly to simulate the effect of neutron moderation near the reflector. A cross-sectional view and close-up view of the experimental configuration are provided in Figure 91 and Figure 92 where aluminum is yellow, graphite is blue, Ta-2.5W is green, HEU is red, and stainless steel is purple (all dimensions in figures are in centimeters). The assembly configuration, including plate layout and dimensions, is shown in Table 93. The RCP01 analysis predicts an assembly height of 10.678", the MCNP5 analysis predicts an assembly height of $10.478^{\prime \prime}$, and the MCNP5 with space cross sections and RACER analyses predict an assembly height of $10.428^{\prime \prime}$. The assembly rests on a 3.0" thick hollow Al 6061-T6 spindle plate that has a $19^{\prime \prime} \mathrm{OD}$ and $2.50^{\prime \prime}$ inner diameter. The active core region of the assembly is $6.428^{\prime \prime}$ high and contains one $0.197^{\prime \prime}$ thick graphite plate and 17 stacking units consisting of a $0.0246^{\prime \prime}$ thick Ta-2.5W plate, a $0.118^{\prime \prime}$ thick HEU plate, a $0.0246^{\prime \prime}$ thick Ta-2.5W plate, and a $0.197^{\prime \prime}$ thick graphite plate. The bottom reflector consists of a $2.0^{\prime \prime}$ thick graphite reflector and a $0.15^{\prime \prime}$ thick Ta$2.5 \mathrm{~W}$ reflector. The RCP01 predicted top reflector consists of a $0.15^{\prime \prime}$ thick Ta-2.5W reflector and a $1.95^{\prime \prime}$ thick graphite reflector, the MCNP5 predicted top reflector consists of a $0.15^{\prime \prime}$ thick Ta-2.5W reflector and a 1.75" thick graphite reflector, and the MCNP5 with space cross sections and RACER predicted top reflector consists of a $0.15^{\prime \prime}$ thick Ta-2.5W reflector and a $1.70^{\prime \prime}$ thick graphite reflector. A hollow Al 6061-T6 alignment tube is assumed to extend from the bottom of the spindle plate to the top of the $6^{\text {th }}$ stacking unit. All other regions are modeled as void, except as noted in Section 4.0 for the RACER models. The Ta-2.5W-2 assembly contains $208.0 \mathrm{~kg}$ of HEU and $107.0 \mathrm{~kg}$ of Ta-2.5W. The distribution of materials in the top and bottom half of the assembly is given in Table 94 for the RCP01, MCNP5, MCNP5 with space cross sections, and RACER predicted critical configurations.

A series of analyses have been performed to predict the $k_{\text {eft }}$ of the Ta- $2.5 \mathrm{~W}-2$ assembly during the approach to critical as a function of both the number of stacking units and the graphite top reflector thickness. Figure 93 presents the RCP01 and MCNP5 predicted $k_{\text {eff }}$ as a function of the number of stacking units in the Ta-2.5W-2 assembly. The error bars indicate the size of the $95 \%$ confidence interval in the Monte Carlo calculations. As illustrated in Figure 93, both the MCNP5 and RCP01 predictions are close. The average difference between the MCNP5 and RCP01 predicted $k_{\text {eff }}$ is $0.0034 \pm 0.0004 \Delta \mathrm{k}$ over the range from 8 to 28 stacking units. Figure 94 and Table 95 provide a comparison of the predicted $\mathrm{k}_{\mathrm{eff}}$ of the Ta-2.5W-2 assembly with 17 stacking units as a function of the graphite top reflector thickness. The experimental configurations predicted to achieve delayed criticality within TSR limits $(\rho<0.5 \$)$ are highlighted in green in Table 95 . The Ta- $2.5 \mathrm{~W}-2$ assembly is classified as a fast spectrum assembly with the following representative fission fractions, as predicted by MCNP5: $79.3 \%$ fast $(E>100 \mathrm{keV}), 20.7 \%$ intermediate $(0.625 \mathrm{eV}<E<100 \mathrm{keV})$, and $0.0 \%$ thermal $(E<0.625 \mathrm{eV})$. 


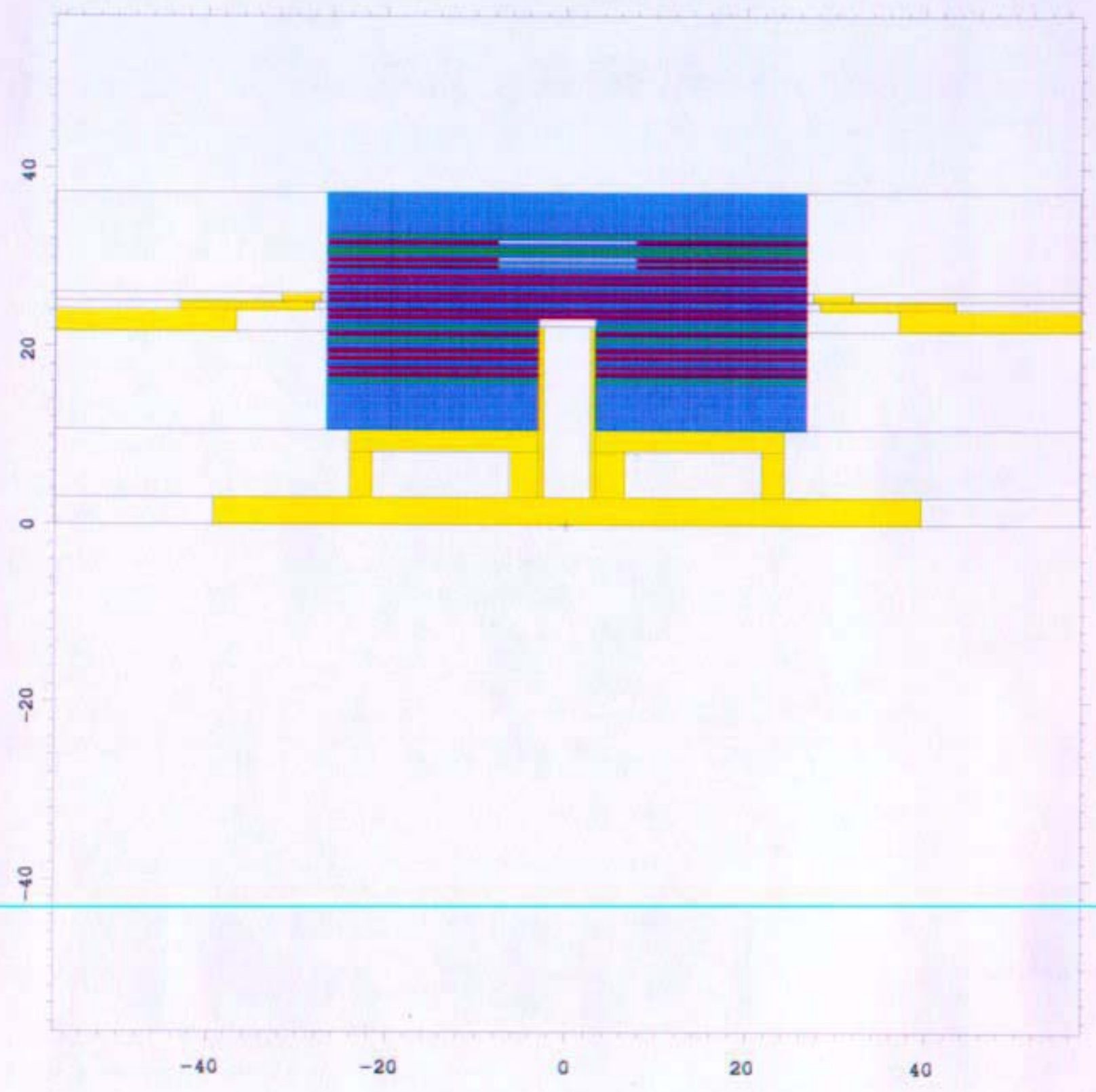

Figure 91. Cross-sectional View of the Ta-2.5W-2 Assembly 
$\circ$

i

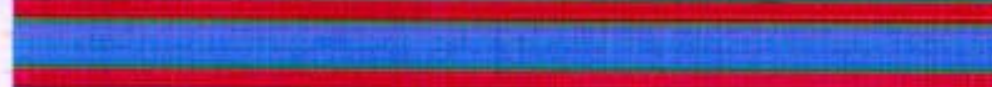

우

$-10$
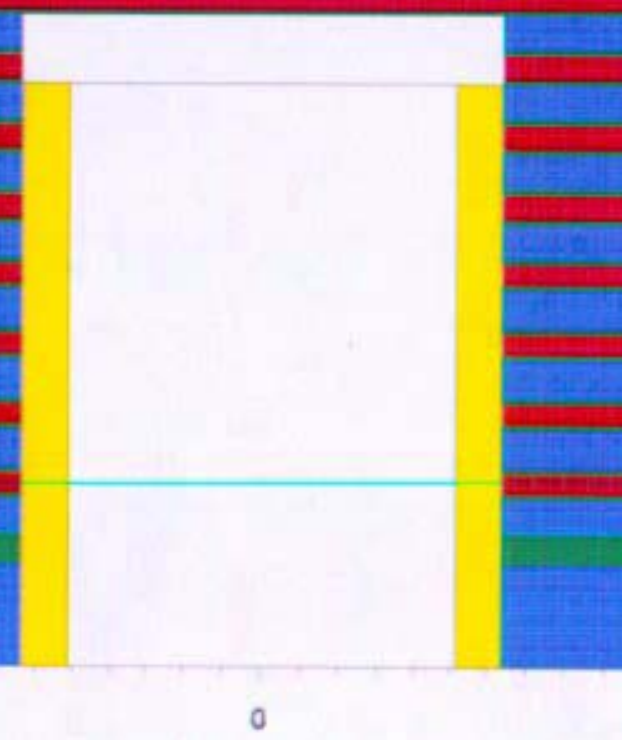

$s$

Figure 92. Cross-sectional Close-up View of the Ta-2.5W-2 Assembly 
Table 93. Predicted Critical Configuration for the Ta-2.5W-2 Assembly

\begin{tabular}{|c|c|c|c|c|c|}
\hline Unit & Material & Thickness (in) & $\begin{array}{c}\text { Inner } \\
\text { Diameter (in) }\end{array}$ & $\begin{array}{c}\text { Outer } \\
\text { Diameter (in) }\end{array}$ & $\begin{array}{l}\text { Assembly Height } \\
\text { (in) }\end{array}$ \\
\hline \multirow{3}{*}{$\begin{array}{l}\text { Bottom } \\
\text { Reflector }\end{array}$} & Graphite & 2.00 & 251 & 210 & 2.0000 \\
\hline & Ta-2.5W & 0.150 & 2.51 & 21.0 & 2.1500 \\
\hline & Graphite & 0.197 & 2.51 & 21.0 & 2.3470 \\
\hline \multirow{4}{*}{1} & Ta-2.5W & 0.0246 & 2.51 & 21.0 & 2.3716 \\
\hline & HEU & 0.118 & 2.51 & 21.0 & 2.4896 \\
\hline & Ta-2.5W & 0.0246 & 2.51 & 21.0 & 2.5142 \\
\hline & Graphite & 0.197 & 2.51 & 21.0 & 2.7112 \\
\hline \multirow{4}{*}{2} & $\mathrm{Ta}-2.5 \mathrm{~W}$ & 0.0246 & 2.51 & 21.0 & 2.7358 \\
\hline & HEU & 0.118 & 2.51 & 21.0 & 2.8538 \\
\hline & Ta-2.5W & 0.0246 & 2.51 & 21.0 & 2.8784 \\
\hline & Graphite & 0.197 & 2.51 & 21.0 & 3.0754 \\
\hline \multirow{4}{*}{3} & $\mathrm{Ta}-2.5 \mathrm{~W}$ & 0.0246 & 2.51 & 21.0 & 3.1000 \\
\hline & HEU & 0.118 & 2.51 & 21.0 & 3.2180 \\
\hline & $\mathrm{Ta}-2.5 \mathrm{~W}$ & 0.0246 & 2.51 & 21.0 & 3.2426 \\
\hline & Graphite & 0.197 & 2.51 & 21.0 & 3.4396 \\
\hline \multirow{4}{*}{4} & $\mathrm{Ta}-2.5 \mathrm{~W}$ & 0.0246 & 2.51 & 21.0 & 3.4642 \\
\hline & HEU & 0.118 & 2.51 & 21.0 & 3.5822 \\
\hline & $\mathrm{Ta}-2.5 \mathrm{~W}$ & 0.0246 & 2.51 & 21.0 & 3.6068 \\
\hline & Graphite & 0.197 & 2.51 & 21.0 & 3.8038 \\
\hline \multirow{4}{*}{5} & Ta-2.5W & 0.0246 & 2.51 & 21.0 & 3.8284 \\
\hline & HEU & 0.118 & 2.51 & 21.0 & 3.9464 \\
\hline & $\mathrm{Ta}-2.5 \mathrm{~W}$ & 0.0246 & 2.51 & 21.0 & 3.9710 \\
\hline & Graphite & 0.197 & 2.51 & 21.0 & 4.1680 \\
\hline \multirow{4}{*}{6} & $\mathrm{Ta}-2.5 \mathrm{~W}$ & 0.0246 & 2.51 & 21.0 & 4.1926 \\
\hline & HEU & 0.118 & 2.51 & 21.0 & 4.3106 \\
\hline & $\mathrm{Ta}-2.5 \mathrm{~W}$ & 0.0246 & 2.51 & 21.0 & 4.3352 \\
\hline & Graphite & 0.197 & 2.51 & 21.0 & 4.5322 \\
\hline \multirow{4}{*}{7} & Ta-2.5W & 0.0246 & 2.51 & 21.0 & 4.5568 \\
\hline & HEU & 0.118 & 2.51 & 21.0 & 4.6748 \\
\hline & Ta-2.5W & 0.0246 & 2.51 & 21.0 & 4.6994 \\
\hline & Graphite & 0.197 & 2.51 & 21.0 & 4.8964 \\
\hline \multirow{4}{*}{8} & $\mathrm{Ta}-2.5 \mathrm{~W}$ & 0.0246 & 0 & 21.0 & 4.9210 \\
\hline & HEU & 0.118 & 0 & 21.0 & 5.0390 \\
\hline & $\mathrm{Ta}-2.5 \mathrm{~W}$ & 0.0246 & 0 & 21.0 & 5.0636 \\
\hline & Graphite & 0.197 & 0 & 21.0 & 5.2606 \\
\hline \multirow{4}{*}{9} & Ta-2.5W & 0.0246 & 0 & 21.0 & 5.2852 \\
\hline & HEU & 0.118 & 0 & 21.0 & 5.4032 \\
\hline & Ta-2.5W & 0.0246 & 0 & 21.0 & 5.4278 \\
\hline & Graphite & 0.197 & 0 & 21.0 & 5.6248 \\
\hline Diaphragm & Stainless Steel & 0.040 & 0 & 24.8 & 5.6648 \\
\hline \multirow{4}{*}{10} & $\mathrm{Ta}-2.5 \mathrm{~W}$ & 0.0246 & 0 & 21.0 & 5.6894 \\
\hline & $\mathrm{HEU}$ & 0.118 & 0 & 21.0 & 5.8074 \\
\hline & $\mathrm{Ta}-2.5 \mathrm{~W}$ & 0.0246 & 0 & 21.0 & 5.8320 \\
\hline & Graphite & 0.197 & 0 & 21.0 & 6.0290 \\
\hline
\end{tabular}




\begin{tabular}{|c|c|c|c|c|c|}
\hline Unit & Material & Thickness (in) & $\begin{array}{c}\text { Inner } \\
\text { Diameter (in) }\end{array}$ & $\begin{array}{c}\text { Outer } \\
\text { Diameter (in) }\end{array}$ & $\begin{array}{l}\text { Assembly Height } \\
\text { (in) }\end{array}$ \\
\hline \multirow{4}{*}{11} & $\mathrm{Ta}-2.5 \mathrm{~W}$ & 0.0246 & 0 & 21.0 & 6.0536 \\
\hline & HEU & 0.118 & 0 & 21.0 & 6.1716 \\
\hline & $\mathrm{Ta}-2.5 \mathrm{~W}$ & 0.0246 & 0 & 21.0 & 6.1962 \\
\hline & Graphite & 0.197 & 0 & 21.0 & 6.3932 \\
\hline \multirow{4}{*}{12} & $\mathrm{Ta}-2.5 \mathrm{~W}$ & 0.0246 & 0 & 21.0 & 6.4178 \\
\hline & HEU & 0.118 & 0 & 21.0 & 6.5358 \\
\hline & $\mathrm{Ta}-2.5 \mathrm{~W}$ & 0.0246 & 0 & 21.0 & 6.5604 \\
\hline & Graphite & 0.197 & 0 & 21.0 & 6.7574 \\
\hline \multirow{4}{*}{13} & $\mathrm{Ta}-2.5 \mathrm{~W}$ & 0.0246 & 0 & 21.0 & 6.7820 \\
\hline & HEU & 0.118 & 0 & 21.0 & 6.9000 \\
\hline & $\mathrm{Ta}-2.5 \mathrm{~W}$ & 0.0246 & 0 & 21.0 & 6.9246 \\
\hline & Graphite & 0.197 & 0 & 21.0 & 7.1216 \\
\hline \multirow{4}{*}{14} & $\mathrm{Ta}-2.5 \mathrm{~W}$ & 0.0246 & 0 & 21.0 & 7.1462 \\
\hline & HEU & 0.118 & 6.005 & 21.0 & 7.2642 \\
\hline & $\mathrm{Ta}-2.5 \mathrm{~W}$ & 0.0246 & 0 & 21.0 & 7.2888 \\
\hline & Graphite & 0.197 & 0 & 21.0 & 7.4858 \\
\hline \multirow{4}{*}{15} & $\mathrm{Ta}-2.5 \mathrm{~W}$ & 0.0246 & 0 & 21.0 & 7.5104 \\
\hline & HEU & 0.118 & 6.005 & 21.0 & 7.6284 \\
\hline & $\mathrm{Ta}-2.5 \mathrm{~W}$ & 0.0246 & 0 & 21.0 & 7.6530 \\
\hline & Graphite & 0.197 & 0 & 21.0 & 7.8500 \\
\hline \multirow{4}{*}{16} & Ta-2.5W & 0.0246 & 0 & 21.0 & 7.8746 \\
\hline & HEU & 0.118 & 6.005 & 21.0 & 7.9926 \\
\hline & $\mathrm{Ta}-2.5 \mathrm{~W}$ & 0.0246 & 0 & 21.0 & 8.0172 \\
\hline & Graphite & 0.197 & 0 & 21.0 & 8.2142 \\
\hline \multirow{4}{*}{17} & $\mathrm{Ta}-2.5 \mathrm{~W}$ & 0.0246 & 0 & 21.0 & 8.2388 \\
\hline & HEU & 0.118 & 6.005 & 21.0 & 8.3568 \\
\hline & $\mathrm{Ta}-2.5 \mathrm{~W}$ & 0.0246 & 0 & 21.0 & 8.3814 \\
\hline & Graphite & 0.197 & 0 & 21.0 & 8.5784 \\
\hline \multirow[b]{2}{*}{$\begin{array}{l}\text { Top } \\
\text { Reflector }\end{array}$} & Ta-2.5W & 0.150 & 0 & 21.0 & 87284 \\
\hline & Graphite & $\begin{array}{c}1.95 \text { (RCP01) } \\
1.75 \text { (MCNPS) } \\
1.70 \text { (RACER, } \\
\text { MCNP5 Space XS) }\end{array}$ & a & 21.0 & $\begin{array}{l}10.6784 \text { (RCPO1) } \\
10.4784 \text { (MCNP5) } \\
10.4284 \text { (RACER } \\
\text { MCNP5 Space XS) }\end{array}$ \\
\hline
\end{tabular}

Table 94. Ta-2.5W-2 Assembly Material Mass Distribution

\begin{tabular}{|c|c|c|c|c|c|c|c|c|c|}
\hline \multirow{3}{*}{ Material } & \multicolumn{9}{|c|}{ Mass (kg) } \\
\hline & \multicolumn{3}{|c|}{ MCNP5 } & \multicolumn{3}{|c|}{ RCP01 } & \multicolumn{3}{|c|}{ MCNP5 (Space XS)/RACER } \\
\hline & $\begin{array}{c}\text { Lower } \\
\text { Assembly }\end{array}$ & $\begin{array}{c}\text { Upper } \\
\text { Assembly }\end{array}$ & Total & $\begin{array}{c}\text { Lower } \\
\text { Assembly }\end{array}$ & $\begin{array}{c}\text { Upper } \\
\text { Assembly }\end{array}$ & Total & $\begin{array}{l}\text { Lower } \\
\text { Assembly }\end{array}$ & $\begin{array}{c}\text { Upper } \\
\text { Assembly }\end{array}$ & Total \\
\hline HEU & 111.7 & 96.3 & 208.0 & 111.7 & 96.3 & 208.0 & 111.7 & 96.3 & 208.0 \\
\hline $\mathrm{Ta}-2.5 \mathrm{~W}$ & 55.5 & 51.5 & 107.0 & 55.5 & 51.5 & 107.0 & 55.5 & 51.5 & 107.0 \\
\hline Graphite & 38.5 & 32.7 & 71.2 & 38.5 & 34.7 & 73.2 & 38.5 & 32.2 & 70.7 \\
\hline Total & 205.8 & 180.5 & 386.3 & 205.8 & 182.5 & 388.3 & 205.8 & 180.1 & 385.8 \\
\hline
\end{tabular}




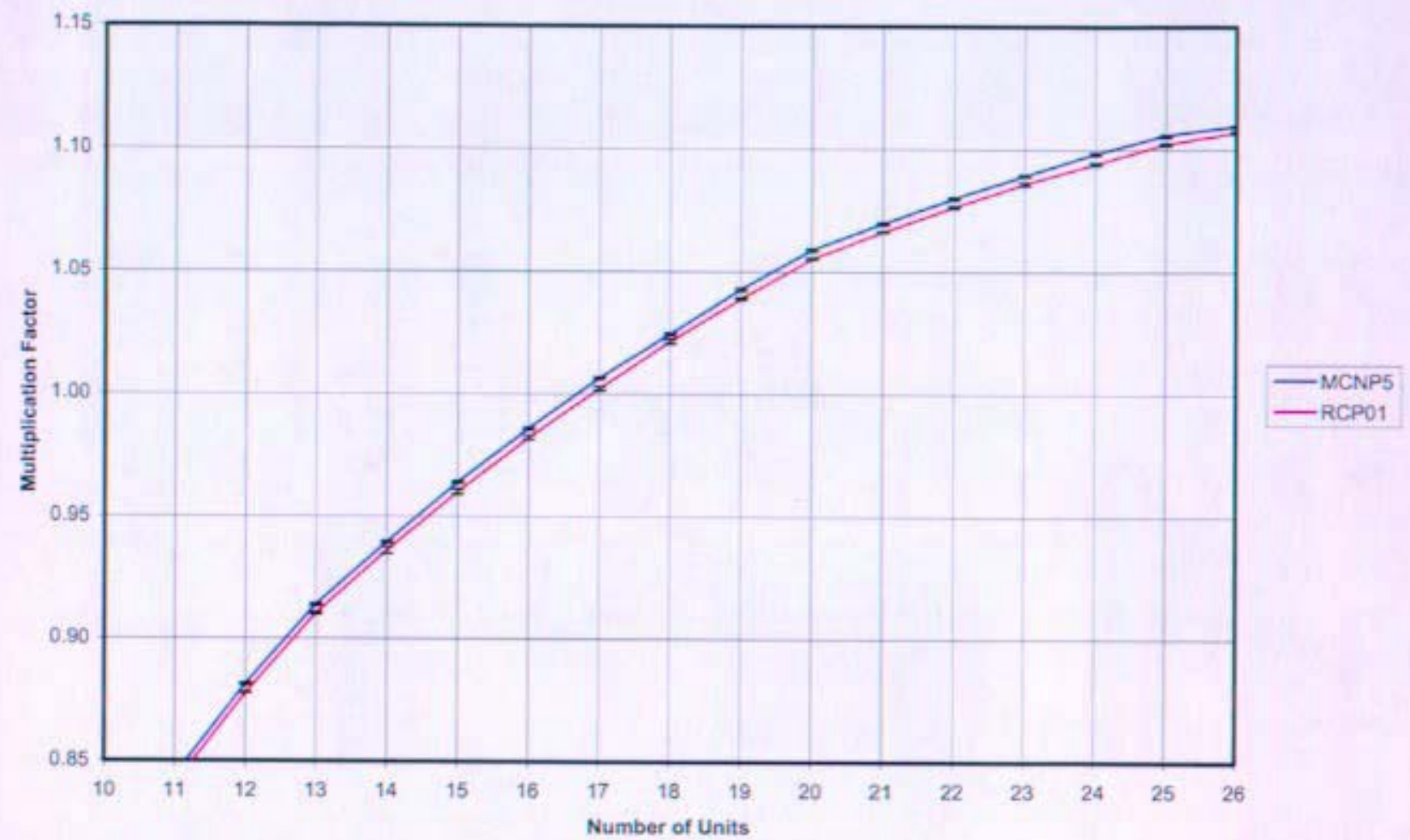

Figure 93. Ta-2.5W-2 Assembly $k_{\text {eff }}$ as a Function of the Number of Stacking Units

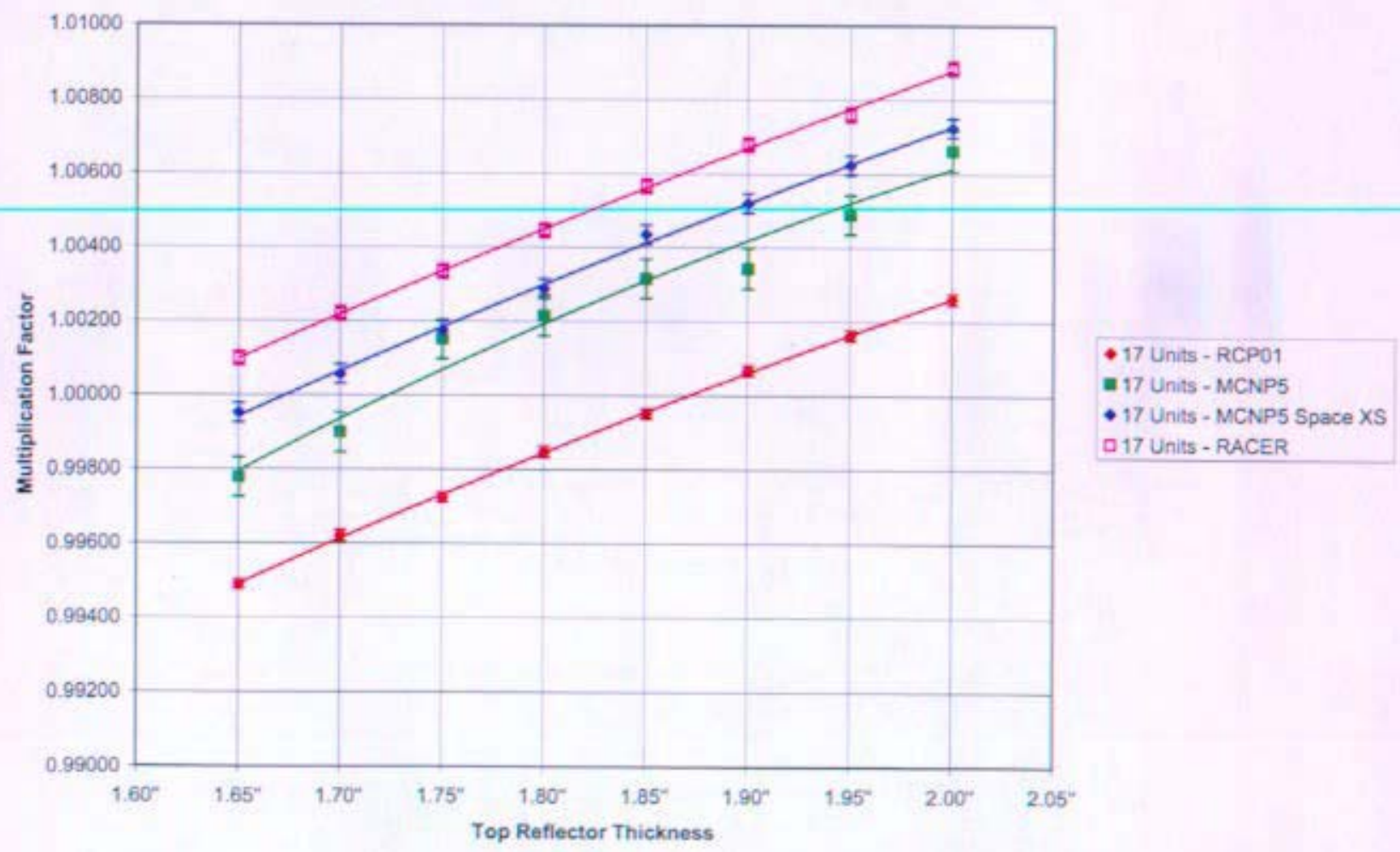

Figure 94. Ta-2.5W-2 Assembly $k_{\text {eff }}$ as a Function of the Top Reflector Thickness 
Table 95. Ta-2.5W-2 Assembly $k_{\text {eff }}$ as a Function of the Top Reflector Thickness

\begin{tabular}{|c|c|c|c|c|c|c|c|c|}
\hline \multicolumn{9}{|c|}{ Predicted Top Reflector Thickness } \\
\hline \multicolumn{9}{|c|}{17 Stacking Units } \\
\hline \multirow{2}{*}{$\begin{array}{c}\text { Top } \\
\text { Reflector } \\
\text { Thickness } \\
\text { (in) }\end{array}$} & \multicolumn{2}{|c|}{ MCNP5 } & \multicolumn{2}{|c|}{ MCNP5 (Space XS) } & \multicolumn{2}{|c|}{ RCP01 } & \multicolumn{2}{|c|}{ RACER } \\
\hline & $k_{\text {eff }}$ & $95 \% \mathrm{Cl}$ & $k_{\text {eff }}$ & $95 \% \mathrm{Cl}$ & $k_{\text {eff }}$ & $95 \% \mathrm{Cl}$ & $k_{\text {eff }}$ & $95 \% \mathrm{Cl}$ \\
\hline 1.65 & 0.99777 & 0.00053 & 0.99951 & 0.00026 & 0.99489 & 0.00012 & 1.00098 & 0.00019 \\
\hline 1.70 & 0.99898 & 0.00053 & 1.00055 & 0.00026 & 0.99619 & 0.00015 & 1.00219 & 000019 \\
\hline 1.75 & 1.00150 & 0.00053 & 1.00175 & 0.00024 & 0.99723 & 0.00013 & 1.00335 & 0.00019 \\
\hline 1.80 & 1.00214 & 0.00055 & 1.00287 & 0.00026 & 0.99847 & 0.00014 & 1.00445 & 0.00019 \\
\hline 1.85 & 1.00314 & 0.00053 & 1.00434 & 0.00026 & 0.99950 & 0.00013 & 1.00566 & 0.00019 \\
\hline 1.90 & 1.00342 & 0.00055 & 1.00519 & 0.00026 & 1.00067 & 0.00014 & 1.00679 & 0.00019 \\
\hline 1.95 & 1.00488 & 0.00053 & 1.00622 & 0.00026 & 1,00162 & 0.00014 & 1.00759 & 0.00020 \\
\hline 2.00 & 1.00661 & 0.00055 & 1.00723 & 0.00026 & 1.00261 & 0.00014 & 1.00885 & 0.00019 \\
\hline
\end{tabular}




\subsubsection{Ta-2.5W-3 Experiment}

The Ta-2.5W-3 experiment is designed to bracket the average neutron spectrum of the Prometheus reactor core. It is designed to be softer than the expected average neutron energy spectrum of the core. Additional graphite has been added to the assembly to simulate the effect of neutron moderation near the reflector. A cross-sectional view and close-up view of the experimental configuration are provided in Figure 95 and Figure 96 where aluminum is yellow, graphite is blue, Ta-2.5W is green, $\mathrm{HEU}$ is red, and stainless steel is purple (all dimensions in figures are in centimeters). The assembly configuration, including plate layout and dimensions, is shown in Table 96. The RCP01 analysis predicts an assembly height of $20.836^{\prime \prime}$, the MCNP5 analysis predicts an assembly height of 20.036 ", and the MCNP5 with space cross sections and RACER analyses predict an assembly height of 19.086". The assembly rests on a 3.0" thick hollow Al 6061-T6 spindle plate that has a $19^{\prime \prime}$ OD and $2.50^{\prime \prime}$ inner diameter. The active core region of the assembly is $10.536^{\prime \prime}$ high and contains one $0.394^{\prime \prime}$ graphite plate and 18 stacking units consisting of a $0.0246^{\prime \prime}$ thick Ta-2.5W plate, a $0.118^{\prime \prime}$ thick HEU plate, a $0.0246^{\prime \prime}$ thick Ta-2.5W plate, and a $0.394^{\prime \prime}$ thick graphite plate. The bottom reflector consists of a $5.0^{\prime \prime}$ thick graphite reflector and a $0.15^{\prime \prime}$ thick Ta-2.5W reflector. The RCP01 predicted top reflector consists of a $0.15^{\prime \prime}$ thick Ta-2.5W reflector and a 5.00" thick graphite reflector, the MCNP5 predicted top reflector consists of a $0.15^{\prime \prime}$ thick Ta-2.5W reflector and a 4.20 " thick graphite reflector, and the MCNP5 with space cross sections and RACER predicted top reflector consists of a $0.15^{\prime \prime}$ thick Ta-2.5W reflector and a $3.25^{\prime \prime}$ thick graphite reflector. A hollow Al $6061-T 6$ alignment tube is assumed to extend from the bottom of the spindle plate to the top of the $6^{\text {th }}$ stacking unit. All other regions are modeled as void, except as noted in Section 4.0 for the RACER models. The Ta-2.5W-3 assembly contains $217.8 \mathrm{~kg}$ of HEU and $111.7 \mathrm{~kg}$ of Ta-2.5W. The distribution of materials in the top and bottom half of the assembly is given in Table 97 for the RCP01, MCNP5, MCNP5 with space cross sections, and RACER predicted critical configurations.

A series of analyses have been performed to predict the $k_{\text {eff }}$ of the Ta-2.5W-3 assembly during the approach to critical as a function of both the number of stacking units and the graphite top reflector thickness. Figure 97 presents the RCP01 and MCNP5 predicted $k_{\text {eff }}$ as a function of the number of stacking units in the Ta-2.5W-3 assembly. The error bars indicate the size of the $95 \%$ confidence interval in the Monte Carlo calculations. As illustrated in Figure 97, both the MCNP5 and RCP01 predictions are very close. The average difference between the MCNP5 and RCP01 predicted $k_{\text {eff }}$ is $0.0018 \pm 0.0010 \Delta \mathrm{k}$ over the range from 8 to 28 stacking units. Figure 98 and Table 98 provide a comparison of the predicted $k_{\text {eff }}$ of the Ta- $2.5 \mathrm{~W}-3$ assembly with 17 stacking units, 18 stacking units, and 18 stacking units with a $10.005^{\prime \prime}$ ID top HEU fuel plate as a function of the graphite top reflector thickness. The experimental configurations that were predicted to achieve delayed criticality within TSR limits $(\rho<0.5 S)$ are highlighted in green in Table 98. The Ta-2.5W-3 assembly is classified as a fast spectrum assembly with the following representative fission fractions, as predicted by MCNP5: $68.9 \%$ fast $(E>100 \mathrm{keV}), 31.0 \%$ intermediate $(0.625 \mathrm{eV}<E<100 \mathrm{keV})$, and $0.03 \%$ thermal $(E<$ $0.625 \mathrm{eV}$ ). 


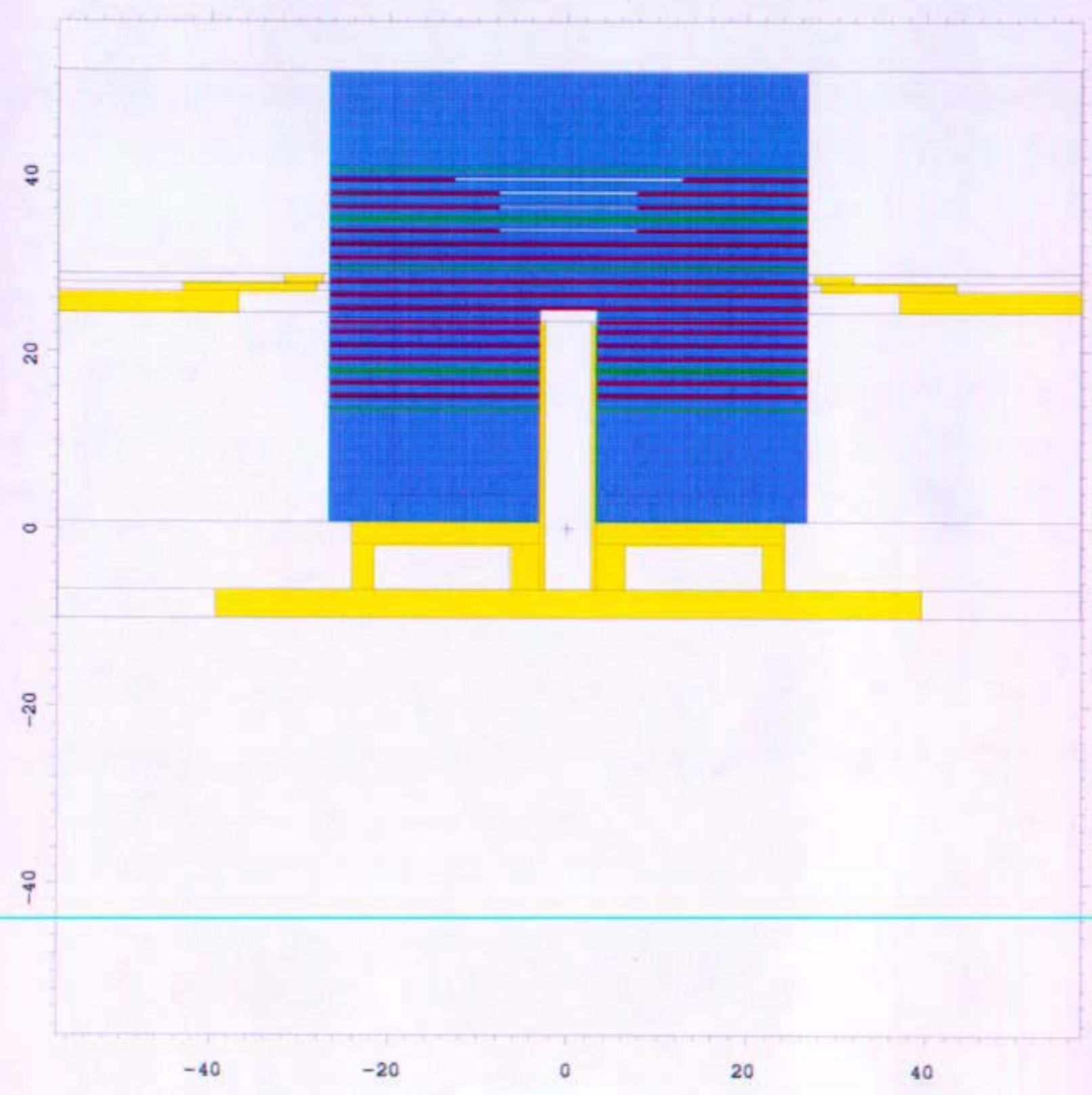

Figure 95. Cross-sectional View of the Ta-2.5W-3 Assembly 


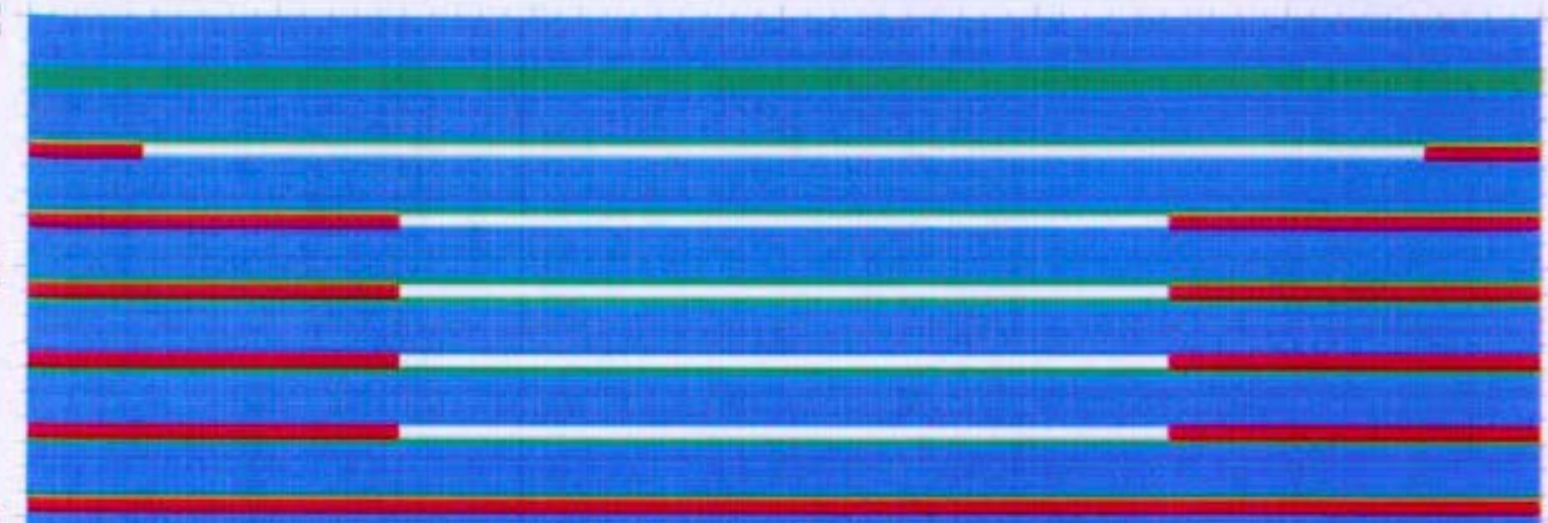

n

$\circ$

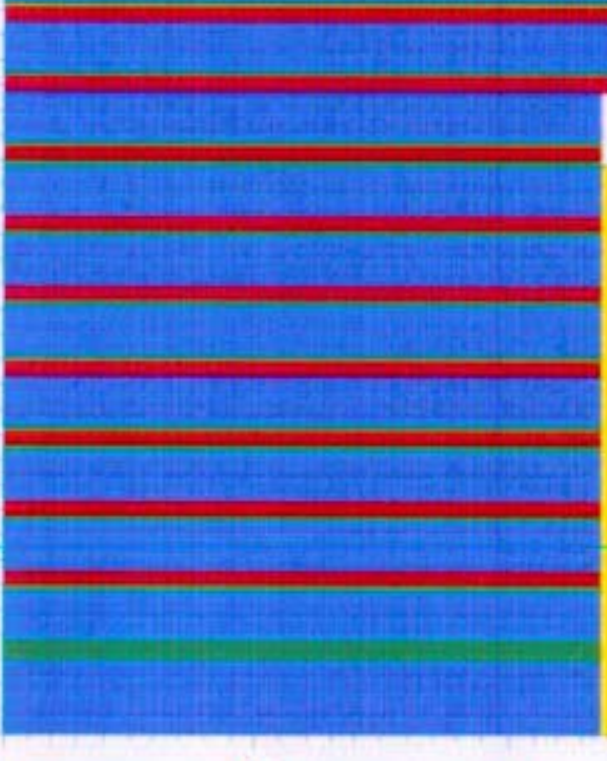

$-10$

$-5$

0

5

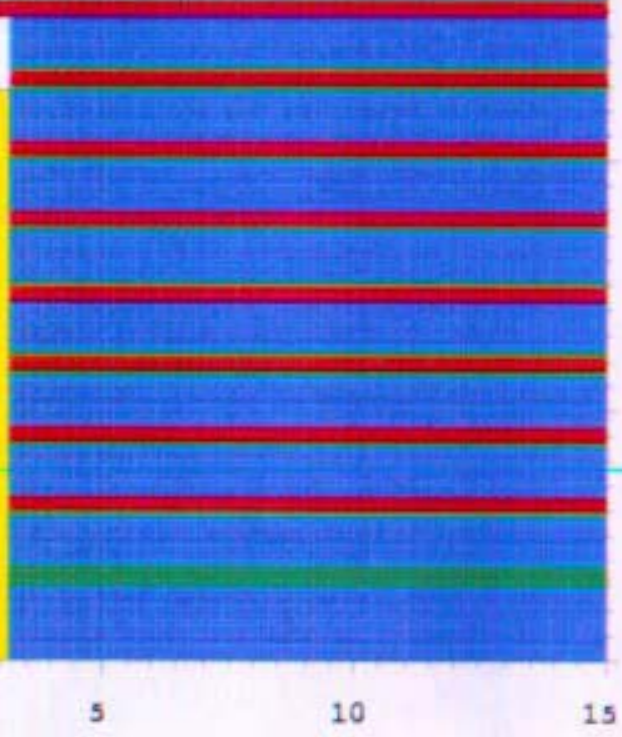

Figure 96. Cross-sectional Close-up View of the Ta-2.5W-3 Assembly 
Table 96. Predicted Critical Configuration for the Ta-2.5W-3 Assembly.

\begin{tabular}{|c|c|c|c|c|c|}
\hline Unit & Material & Thickness (in) & $\begin{array}{c}\text { Inner } \\
\text { Diameter (in) }\end{array}$ & $\begin{array}{c}\text { Outer } \\
\text { Diameter (in) }\end{array}$ & $\begin{array}{l}\text { Assembly Height } \\
\text { (in) }\end{array}$ \\
\hline \multirow{3}{*}{$\begin{array}{l}\text { Bottom } \\
\text { Reflector }\end{array}$} & Graphite & 5.00 & 2.51 & 21.0 & 5.0000 \\
\hline & $\mathrm{Ta}-2.5 \mathrm{~W}$ & 0.150 & 2.51 & 21.0 & 5.1500 \\
\hline & Graphite & 0.394 & 2.51 & 21.0 & 5.5440 \\
\hline \multirow{4}{*}{1} & $\mathrm{Ta}-2.5 \mathrm{~W}$ & 0.0246 & 2.51 & 21.0 & 5.5686 \\
\hline & HEU & 0.118 & 2.51 & 21.0 & 5.6866 \\
\hline & Ta-2.5W & 0.0246 & 2.51 & 21.0 & 5.7112 \\
\hline & Graphite & 0.394 & 2.51 & 21.0 & 6.1052 \\
\hline \multirow{4}{*}{2} & $\mathrm{Ta}-2.5 \mathrm{~W}$ & 0.0246 & 2.51 & 21.0 & 6.1298 \\
\hline & HEU & 0.118 & 2.51 & 21.0 & 6.2478 \\
\hline & Ta-2.5W & 0.0246 & 2.51 & 21.0 & 6.2724 \\
\hline & Graphite & 0.394 & 2.51 & 21.0 & 6.6664 \\
\hline \multirow{4}{*}{3} & $\mathrm{Ta}-2.5 \mathrm{~W}$ & 0.0246 & 2.51 & 21.0 & 6.6910 \\
\hline & HEU & 0.118 & 2.51 & 21.0 & 6.8090 \\
\hline & $\mathrm{Ta}-2.5 \mathrm{~W}$ & 0.0246 & 2.51 & 21.0 & 6.8336 \\
\hline & Graphite & 0.394 & 2.51 & 21.0 & 7.2276 \\
\hline \multirow{4}{*}{4} & $\mathrm{Ta}-2.5 \mathrm{~W}$ & 0.0246 & 2.51 & 21.0 & 7.2522 \\
\hline & HEU & 0.118 & 2.51 & 21.0 & 7.3702 \\
\hline & $\mathrm{Ta}-2.5 \mathrm{~W}$ & 0.0246 & 2.51 & 21.0 & 7.3948 \\
\hline & Graphite & 0.394 & 2.51 & 21.0 & 7.7888 \\
\hline \multirow{4}{*}{5} & $\mathrm{Ta}-2.5 \mathrm{~W}$ & 0.0246 & 2.51 & 21.0 & 7.8134 \\
\hline & HEU & 0.118 & 2.51 & 21.0 & 7.9314 \\
\hline & $\mathrm{Ta}-2.5 \mathrm{~W}$ & 0.0246 & 2.51 & 21.0 & 7.9560 \\
\hline & Graphite & 0.394 & 2.51 & 21.0 & 8.3500 \\
\hline \multirow{4}{*}{6} & $\mathrm{Ta}-2.5 \mathrm{~W}$ & 0.0246 & 2.51 & 21.0 & 8.3746 \\
\hline & HEU & 0.118 & 2.51 & 21.0 & 8.4926 \\
\hline & $\mathrm{Ta}-2.5 \mathrm{~W}$ & 0.0246 & 2.51 & 21.0 & 8.5172 \\
\hline & Graphite & 0.394 & 2.51 & 21.0 & 8.9112 \\
\hline \multirow{4}{*}{7} & Ta-2.5W & 0.0246 & 2.51 & 21.0 & 8.9358 \\
\hline & HEU & 0.118 & 2.51 & 21.0 & 9.0538 \\
\hline & Ta-2.5W & 0.0246 & 2.51 & 21.0 & 9.0784 \\
\hline & Graphite & 0.394 & 2.51 & 21.0 & 9.4724 \\
\hline \multirow{4}{*}{8} & $\mathrm{Ta}-2.5 \mathrm{~W}$ & 0.0246 & 0 & 21.0 & 9.4970 \\
\hline & HEU & 0.118 & 0 & 21.0 & 9.6150 \\
\hline & $\mathrm{Ta}-2.5 \mathrm{~W}$ & 0.0246 & 0 & 21.0 & 9.6396 \\
\hline & Graphite & 0.394 & 0 & 21.0 & 10.0336 \\
\hline \multirow{4}{*}{9} & $\mathrm{Ta}-2.5 \mathrm{~W}$ & 0.0246 & 0 & 21.0 & 10.0582 \\
\hline & HEU & 0.118 & 0 & 21.0 & 10.1762 \\
\hline & Ta-2.5W & 0.0246 & 0 & 21.0 & 10.2008 \\
\hline & Graphite & 0.394 & 0 & 21.0 & 10.5948 \\
\hline Diaphragm & Stainless Steel & 0.040 & 0 & 24.8 & 10.6348 \\
\hline \multirow{4}{*}{10} & $\mathrm{Ta}-2.5 \mathrm{~W}$ & 0.0246 & 0 & 21.0 & 10.6594 \\
\hline & HEU & 0.118 & 0 & 21.0 & 10.7774 \\
\hline & $\mathrm{Ta}-2.5 \mathrm{~W}$ & 0.0246 & 0 & 21.0 & 10.8020 \\
\hline & Graphite & 0.394 & 0 & 21.0 & 11.1960 \\
\hline
\end{tabular}




\begin{tabular}{|c|c|c|c|c|c|}
\hline Unit & Material & Thickness (in) & $\begin{array}{c}\text { Inner } \\
\text { Diameter (in) }\end{array}$ & $\begin{array}{c}\text { Outer } \\
\text { Diameter (in) }\end{array}$ & $\begin{array}{l}\text { Assembly Height } \\
\text { (in) }\end{array}$ \\
\hline \multirow{4}{*}{11} & $\mathrm{Ta}-2.5 \mathrm{~W}$ & 0.0246 & 0 & 21.0 & 11.2206 \\
\hline & $\mathrm{HEU}$ & 0.118 & 0 & 21.0 & 11.3386 \\
\hline & Ta-2.5W & 0.0246 & 0 & 21.0 & 11.3632 \\
\hline & Graphite & 0.394 & 0 & 21.0 & 11.7572 \\
\hline \multirow{4}{*}{12} & Ta-2.5W & 0.0246 & 0 & 21.0 & 11.7818 \\
\hline & HEU & 0.118 & 0 & 21.0 & 11.8998 \\
\hline & Ta-2.5W & 0.0246 & 0 & 21.0 & 11.9244 \\
\hline & Graphite & 0.394 & 0 & 21.0 & 12.3184 \\
\hline \multirow{4}{*}{13} & $\mathrm{Ta}-2.5 \mathrm{~W}$ & 0.0246 & 0 & 21.0 & 12.3430 \\
\hline & HEU & 0.118 & 0 & 21.0 & 12.4610 \\
\hline & Ta-2.5W & 0.0246 & 0 & 21.0 & 12.4856 \\
\hline & Graphite & 0.394 & 0 & 21.0 & 12.8796 \\
\hline \multirow{4}{*}{14} & $\mathrm{Ta}-2.5 \mathrm{~W}$ & 0.0246 & 0 & 21.0 & 12.9042 \\
\hline & HEU & 0.118 & 6.005 & 21.0 & 13.0222 \\
\hline & $\mathrm{Ta}-2.5 \mathrm{~W}$ & 0.0246 & 0 & 21.0 & 13.0468 \\
\hline & Graphite & 0.394 & 0 & 21.0 & 13.4408 \\
\hline \multirow{4}{*}{15} & $\mathrm{Ta}-2.5 \mathrm{~W}$ & 0.0246 & 0 & 21.0 & 13.4654 \\
\hline & HEU & 0.118 & 6.005 & 21.0 & 13.5834 \\
\hline & $\mathrm{Ta}-2.5 \mathrm{~W}$ & 0.0246 & 0 & 21.0 & 13.6080 \\
\hline & Graphite & 0.394 & 0 & 21.0 & 14.0020 \\
\hline \multirow{4}{*}{16} & Ta-2.5W & 0.0246 & 0 & 21.0 & 14.0266 \\
\hline & HEU & 0.118 & 6.005 & 21.0 & 14.1446 \\
\hline & $\mathrm{Ta}-2.5 \mathrm{~W}$ & 0.0246 & 0 & 21.0 & 14.1692 \\
\hline & Graphite & 0.394 & 0 & 21.0 & 14.5632 \\
\hline \multirow{4}{*}{17} & $\mathrm{Ta}-2.5 \mathrm{~W}$ & 0.0246 & 0 & 21.0 & 14.5878 \\
\hline & HEU & 0.118 & 6.005 & 21.0 & 14.7058 \\
\hline & Ta-2.5W & 0.0246 & 0 & 21.0 & 14.7304 \\
\hline & Graphite & 0.394 & 0 & 21.0 & 15.1244 \\
\hline \multirow{4}{*}{18} & Ta-2.5W & 0.0246 & 0 & 21.0 & 15.1490 \\
\hline & HEU & 0.118 & 10.005 & 15.0 & 15.2670 \\
\hline & Ta-2.5W & 0.0246 & 0 & 21.0 & 15.2916 \\
\hline & Graphite & 0.394 & 0 & 21.0 & 15.6856 \\
\hline \multirow[b]{2}{*}{$\begin{array}{c}\text { Top } \\
\text { Refiector }\end{array}$} & Ta-2.5W & 0.150 & 0 & 21.0 & 15.8356 \\
\hline & Graphite & $\begin{array}{l}5.00 \text { (RCP01) } \\
4.20 \text { (MCNP5) } \\
3.25 \text { (RACER. } \\
\text { MCNP5 Space XS) }\end{array}$ & 0 & 27.0 & $\begin{array}{l}20.8356 \text { (RCP01) } \\
20.0356 \text { (MCNP5) } \\
19.0856 \text { (RACER, } \\
\text { MCNP5 Space XS) }\end{array}$ \\
\hline
\end{tabular}

Table 97. Ta-2.5W-3 Assembly Material Mass Distribution

\begin{tabular}{|c|c|c|c|c|c|c|c|c|c|}
\hline \multirow{3}{*}{ Material } & \multicolumn{9}{|c|}{ Mass (kg) } \\
\hline & \multicolumn{3}{|c|}{ MCNP5 } & \multicolumn{3}{|c|}{ RCP01 } & \multicolumn{3}{|c|}{ MCNP5 (Space XS)/RACER } \\
\hline & $\begin{array}{l}\text { Lower } \\
\text { Assembly }\end{array}$ & $\begin{array}{l}\text { Upper } \\
\text { Assembly }\end{array}$ & Total & $\begin{array}{c}\text { Lower } \\
\text { Assembly }\end{array}$ & $\begin{array}{l}\text { Upper } \\
\text { Assembly }\end{array}$ & Total & $\begin{array}{l}\text { Lower } \\
\text { Assembly }\end{array}$ & $\begin{array}{l}\text { Upper } \\
\text { Assembly }\end{array}$ & Total \\
\hline HEU & 111.7 & 106.0 & 217.8 & 111.7 & 106.0 & 217.8 & 111.7 & 106.0 & 217.8 \\
\hline $\mathrm{Ta}-2.5 \mathrm{~W}$ & 55.5 & 56.2 & 111.7 & 55.5 & 56.2 & 111.7 & 55.5 & 56.2 & 111.7 \\
\hline Graphite & 86.7 & 76.2 & 162.9 & 86.7 & 84.0 & 170.8 & 86.7 & 66.8 & 153.6 \\
\hline Total & 254.0 & 238.4 & 492.4 & 254.0 & 246.2 & 500.2 & 254.0 & 229.0 & 483.0 \\
\hline
\end{tabular}




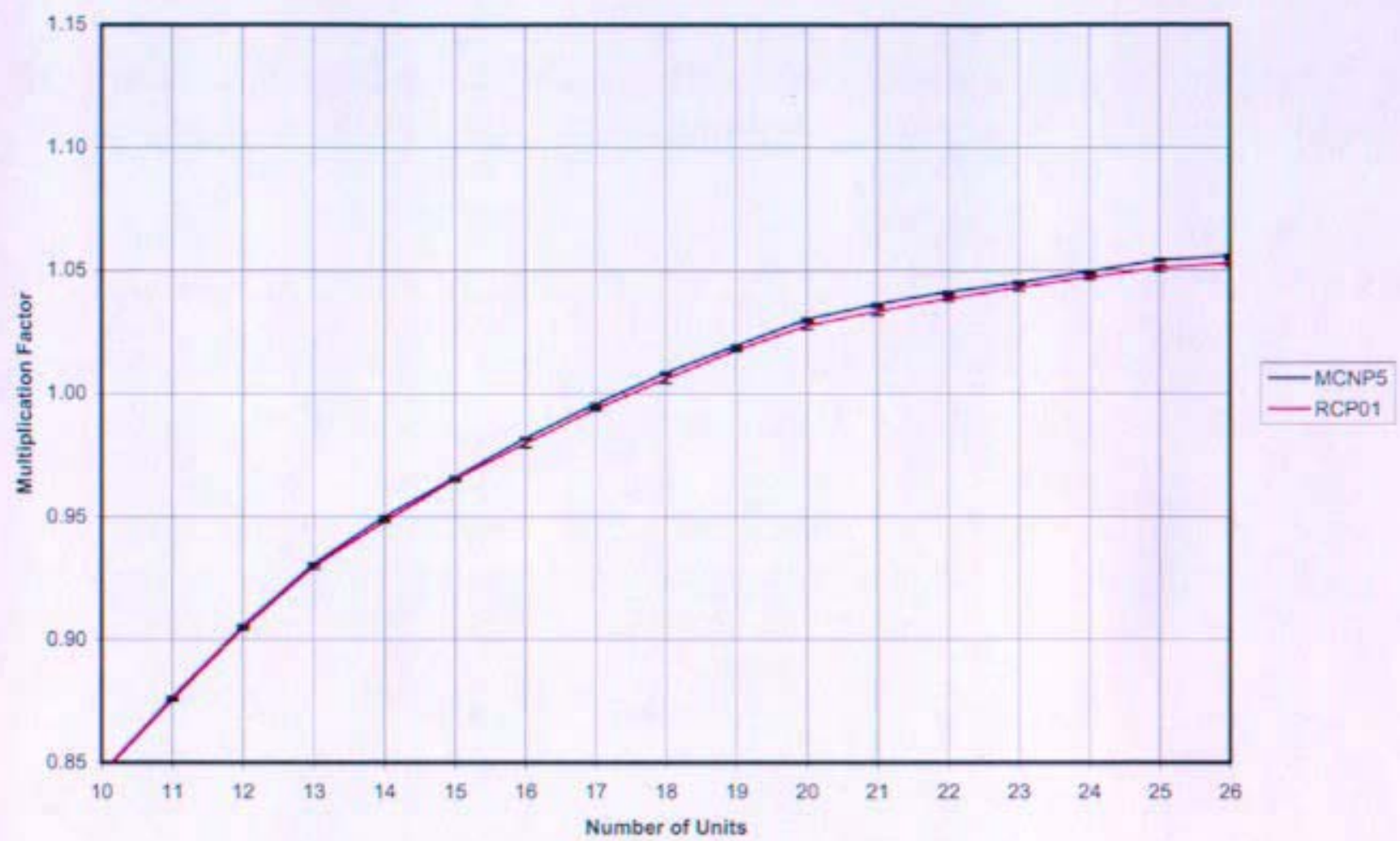

Figure 97. Ta-2.5W-3 Assembly $k_{\text {eff }}$ as a Function of the Number of Stacking Units

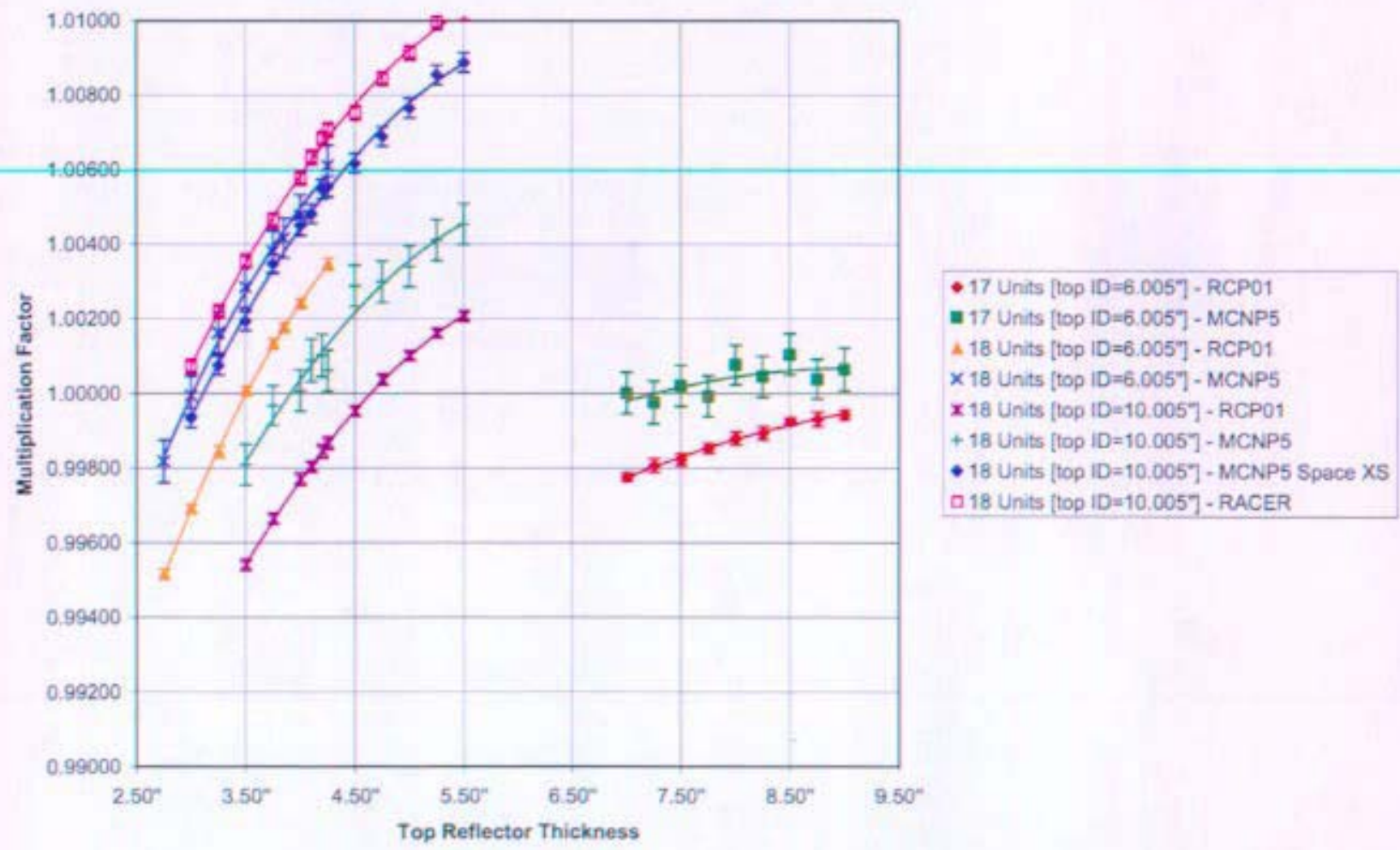

Figure 98. Ta-2.5W-3 Assembly $k_{\text {eff }}$ as a Function of the Top Reflector Thickness 
Table 98. Ta-2.5W-3 Assembly $k_{\text {eff }}$ as a Function of the Top Reflector Thickness

\begin{tabular}{|c|c|c|c|c|c|c|c|c|}
\hline \multicolumn{9}{|c|}{ Predicted Top Reflector Thickness } \\
\hline \multicolumn{9}{|c|}{17 Stacking Units } \\
\hline \multirow{2}{*}{$\begin{array}{c}\text { Top } \\
\text { Reflector } \\
\text { Thickness } \\
\text { (in) }\end{array}$} & \multicolumn{2}{|c|}{ MCNP5 } & \multicolumn{2}{|c|}{ MCNP5 (Space XS) } & \multicolumn{2}{|c|}{ RCP01 } & \multicolumn{2}{|c|}{ RACER } \\
\hline & $k_{\text {eff }}$ & $95 \% \mathrm{Cl}$ & $k_{\text {eft }}$ & $95 \% \mathrm{Cl}$ & $k_{\text {eff }}$ & $95 \% \mathrm{Cl}$ & $k_{\text {eff }}$ & $95 \% \mathrm{Cl}$ \\
\hline 7.00 & 0.99999 & 0.00055 & \multirow{9}{*}{\multicolumn{2}{|c|}{$\begin{array}{l}\text { Not investigated due } \\
\text { to termination of } \\
\text { project. }\end{array}$}} & 0.99775 & 0.00011 & \multirow{9}{*}{\multicolumn{2}{|c|}{$\begin{array}{l}\text { Not investigated } \\
\text { due to termination } \\
\text { of project. }\end{array}$}} \\
\hline 7.25 & 0.99973 & 0.00057 & & & 0.99806 & 0.00019 & & \\
\hline 7.50 & 1.00018 & 0.00055 & & & 0.99822 & 0.00016 & & \\
\hline 7.75 & 0.99990 & 0.00055 & & & 0.99852 & 0.00013 & & \\
\hline 8.00 & 1.00074 & 0.00053 & & & 0.99879 & 0.00017 & & \\
\hline 8.25 & 1.00043 & 0.00055 & & & 0.99893 & 0.00017 & & \\
\hline 8.50 & 1.00102 & 0.00055 & & & 0.99923 & 0.00010 & & \\
\hline 8.75 & 1.00036 & 0.00053 & & & 0.99930 & 0.00019 & & \\
\hline 9.00 & 1.00062 & 0.00057 & & & 0.99942 & 0.00 & & \\
\hline \multicolumn{9}{|c|}{18 Stacking Units } \\
\hline Top & \multicolumn{2}{|c|}{ MCNP5 } & \multicolumn{2}{|c|}{ MCNP5 (Space XS) } & \multicolumn{2}{|c|}{ RCP01 } & \multicolumn{2}{|c|}{ RACER } \\
\hline $\begin{array}{l}\text { Reflector } \\
\text { Thickness } \\
\text { (in) }\end{array}$ & $k_{\text {eff }}$ & $95 \% \mathrm{Cl}$ & $k_{\text {eff }}$ & $95 \%$ & $k_{\text {eff }}$ & $95 \% \mathrm{Cl}$ & $k_{\text {eff }}$ & $95 \% \mathrm{Cl}$ \\
\hline 2.75 & 0.99816 & 0.00057 & \multirow{8}{*}{\multicolumn{2}{|c|}{$\begin{array}{l}\text { Not investigated due } \\
\text { to termination of } \\
\text { project. }\end{array}$}} & 0.99514 & 0.00014 & \multirow{8}{*}{\multicolumn{2}{|c|}{$\begin{array}{l}\text { Not investigated } \\
\text { due to termination } \\
\text { of project. }\end{array}$}} \\
\hline 3.00 & 0.99992 & 0.00053 & & & 0.99690 & 0.00011 & & \\
\hline 3.25 & 1.00161 & 0.00055 & & & 0.99843 & 0.00016 & & \\
\hline 3.50 & 1.00283 & 0.00055 & & & 1.00007 & 0.00009 & & \\
\hline 3.75 & 1.00379 & 0.00055 & & & 1.00133 & 0.00013 & & \\
\hline 3.85 & 1.00415 & 0.00053 & & & 1.00177 & 0.00011 & & \\
\hline 4.00 & 1.00476 & 0.00055 & & & 1.00240 & 0.00013 & & \\
\hline 4.25 & 1.00609 & 0.00055 & & & 1.00345 & 0.00016 & & \\
\hline \multicolumn{9}{|c|}{18 Stacking Units (top HEU plate ID $=10.005^{\prime \prime}$ ) } \\
\hline Top & \multicolumn{2}{|c|}{ MCNP5 } & \multicolumn{2}{|c|}{ MCNP5 (Space XS) } & \multicolumn{2}{|c|}{ RCP01 } & \multicolumn{2}{|c|}{ RACER } \\
\hline $\begin{array}{l}\text { Thickness } \\
\text { (in) }\end{array}$ & $k_{\text {ett }}$ & $95 \% \mathrm{Cl}$ & $k_{\text {eff }}$ & $95 \% \mathrm{Cl}$ & $k_{\text {eff }}$ & $95 \% \mathrm{Cl}$ & $k_{\text {eff }}$ & $95 \% \mathrm{Cl}$ \\
\hline 3.00 & - & - & 0.99933 & 0.00026 & - & $\cdot$ & 1.00072 & 0.00019 \\
\hline 3.25 & - & - & 1.00073 & 0.00026 & - & $\cdot$ & 1.00219 & 0.00019 \\
\hline 3.50 & 0.99807 & 0.00055 & 1.00192 & 0.00026 & 0.99540 & 0.00016 & 1.00354 & 0.00019 \\
\hline 3.75 & 0.99965 & 0.00053 & 1.00346 & 0.00026 & 0.99663 & 0.00015 & 1.00464 & 0.00020 \\
\hline 4.00 & 1.00005 & 0.00055 & 1.00448 & 0.00026 & 0.99770 & 0.00017 & 1.00576 & 0.00019 \\
\hline 4.10 & 1.00086 & 0.00057 & 1.00480 & 0.00026 & 0.99803 & 0.00015 & 1.00632 & 0.00020 \\
\hline 4.20 & 1.00099 & 0.00057 & 1.00546 & 0.00026 & 0.99844 & 0.00018 & 1.00683 & 0.00020 \\
\hline 4.25 & 1.00059 & 0.00055 & 1.00553 & 0.00028 & 0.99866 & 0.00017 & 1.00707 & 0.00020 \\
\hline 4.50 & 1.00286 & 0.00055 & 1.00616 & 0.00026 & 0.99951 & 0.00014 & 1.00752 & 0.00020 \\
\hline 4.75 & 1.00297 & 0.00055 & 1.00688 & 0.00026 & 1.00037 & 0.00015 & 1.00844 & 0.00019 \\
\hline 5.00 & 1.00338 & 0.00055 & 1.00764 & 0.00026 & 1.00100 & 0.00013 & 1.00914 & 0.00020 \\
\hline 5.25 & 1.00409 & 0.00055 & 1.00854 & 0.00026 & 1.00161 & 0.00012 & 1.00996 & 0.00020 \\
\hline 5.50 & 1.00452 & 0.00055 & 1.00887 & 0.00026 & 1.00207 & 0.00014 & 1.01022 & 0.00019 \\
\hline
\end{tabular}


B-TM-1639

\subsubsection{Ta-2.5W-4 Experiment}

The Ta-2.5W-4 experiment is designed to simulate the average neutron spectrum of the Prometheus reactor core when flooded with water. Polyethylene is used to simulate flooding with water. A crosssectional view of the RCP01 and MCNP5 experimental configurations are shown in Figure 99 and Figure 100 , respectively, and a close-up view of the MCNP5 predicted experimental configuration is provided in Figure 101 where aluminum is yellow, polyethylene is light blue, Ta-2.5W is green, HEU is red, and stainless steel is purple (all dimensions in figures are in centimeters). Note that the lines cutting through the alignment tube in Figure 99 are a plotting artifact due to the detail of the geometry model; these features are not in the RCP01 model. The RCP01, MCNP5 with space cross sections, and RACER predicted assembly configurations, including plate layout and dimensions, are shown in Table 99, while the MCNP5 predicted assembly configuration is shown in Table 100. The RCP01 analysis predicts an assembly with 16 stacking units and a height of $6.415^{\prime \prime}$, the MCNP5 with space cross sections and RACER analyses predict an assembly with 16 stacking units and a height of 6.275 , and the MCNP5 analysis predicts an assembly with 17 stacking units and a height of 6.422 ". The assembly rests on a 3.0" thick hollow Al 6061-T6 spindle plate that has a $19^{\prime \prime}$ OD and $2.50^{\prime \prime}$ inner diameter.

The active core region of the RCP01, MCNP5 with space cross sections, and RACER predicted assembly is $3.995^{\prime \prime}$ high and contains one $0.080^{\prime \prime}$ thick polyethylene plate and 16 stacking units consisting of a $0.0246^{\prime \prime}$ thick Ta-2.5W plate, a $0.118^{\prime \prime}$ thick HEU plate, a $0.0246^{\prime \prime}$ thick Ta-2.5W plate, and a 0.080 " thick polyethylene plate. The bottom reflector consists of a $1.0^{\prime \prime}$ thick polyethylene reflector and a $0.15^{\prime \prime}$ thick Ta-2.5W reflector. The RCP01 predicted top reflector consists of a $0.15^{\prime \prime}$ thick Ta-2.5W reflector and a 1.04" thick polyethylene reflector, while the MCNP5 with space cross sections and RACER predicted top reflector consists of a $0.15^{\prime \prime}$ thick Ta-2.5W reflector and a $0.90^{\prime \prime}$ thick polyethylene reflector

The active core region of the MCNP5 predicted assembly is $4.322^{\prime \prime}$ high and contains one $0.080^{\prime \prime}$ thick polyethylene plate and 17 stacking units consisting of a $0.0246^{\prime \prime}$ thick Ta-2.5W plate, a $0.118^{\prime \prime}$ thick HEU plate, a $0.0246^{\prime \prime}$ thick Ta-2.5W plate, and a $0.080^{\prime \prime}$ thick polyethylene plate. The bottom reflector consists of a $1.0^{\prime \prime}$ thick polyethylene reflector and a $0.15^{\prime \prime}$ thick Ta-2.5W reflector. The MCNP5 predicted top reflector consists of a $0.15^{\prime \prime}$ thick Ta-2.5W reflector and a $0.80^{\prime \prime}$ thick polyethylene reflector.

In all Ta-2.5W-4 models, a hollow Al 6061-T6 alignment tube is assumed to extend from the bottom of the spindle plate to the top of the $6^{\text {th }}$ stacking unit. All other regions are modeled as void, except as noted in Section 4.0 for the RACER models. The Ta-2.5W-4 RCP01, MCNP5 with space cross sections, and RACER predicted assembly contains $194.7 \mathrm{~kg}$ of HEU and $102.4 \mathrm{~kg}$ of Ta-2.5W, while the MCNP5 predicted assembly contains $206.2 \mathrm{~kg}$ of HEU and $107.0 \mathrm{~kg}$ of Ta-2.5W. The distribution of materials in the top and bottom half of the assembly is given in Table 101 for the RCP01, MCNP5, MCNP5 with space cross sections, and RACER predicted critical configurations.

A series of analyses have been performed to predict the $k_{\text {eft }}$ of the Ta- $2.5 \mathrm{~W}-4$ assembly during the approach to critical as a function of both the number of stacking units and the polyethylene top reflector thickness. Figure 102 presents the RCP01 and MCNP5 predicted $k_{\text {eft }}$ as a function of the number of stacking units in the Ta-2.5W-4 assembly. The error bars indicate the size of the $95 \%$ confidence interval in the Monte Carlo calculations. The average difference between the MCNP5 and $\mathrm{RCP} 01$ predicted $\mathrm{k}_{\mathrm{ett}}$ is $-0.0151 \pm 0.0013 \Delta \mathrm{k}$ over the range from 8 to 28 stacking units. As discussed below, this relatively large, $-1.51 \% \Delta \mathrm{k}$, difference between the RCP01 and MCNP5 predicted $\mathrm{k}_{\text {eff }}$ is attributed to the lack of an unresolved resonance treatment in the ${ }^{181} \mathrm{Ta}$ neutron cross section used in the MCNP5 calculations. Figure 103, Table 102, and Table 103 provide a comparison of the predicted 
$k_{\text {eff }}$ of the Ta-2.5W-4 assembly with $6.005^{\prime \prime}$ ID and 10.005" ID top HEU fuel plates for both MCNP5 and RCP01 as a function of the polyethylene top reflector thickness. The experimental configurations that were predicted to achieve delayed criticality within TSR limits $(\rho<0.5 \$)$ are highlighted in green in Table Table 102 and Table 103. The Ta-2.5W-4 experiment is classified as a fast spectrum assembly with the following representative fission fractions, as predicted by MCNP5: $52.9 \%$ fast ( $\mathrm{E}>100 \mathrm{keV}$ ), $43.4 \%$ intermediate $(0.625 \mathrm{eV}<E<100 \mathrm{keV})$, and $3.7 \%$ thermal $(E<0.625 \mathrm{eV})$.

The RCP01 and MCNP5 multigroup absorption rate distributions in Ta-2.5W were compared in order to understand the relatively large $-1.5 \% \Delta k$ difference between the predicted $k_{\text {eff }}$ for the Ta- $2.5 \mathrm{~W}-4$ experiment. As illustrated in Figure 104, both the RCP01 and MCNP5 Ta-2.5W multigroup absorption rate distributions agree well in the fast energy range, however MCNP5 absorption rate distribution is significantly higher than RCP01 from $275 \mathrm{eV}$ to $5.53 \mathrm{keV}$. One of the principle differences between the RCP01 and MCNP5 models is the lack of an unresolved resonance treatment in the ${ }^{181}$ Ta neutron cross section data used in MCNP5. The RDS7 ${ }^{181}$ Ta neutron cross sections used in the RCP01 analyses have an unresolved resonance treatment between MUFT groups 34 and 29 (from $275 \mathrm{eV}$ to $5.53 \mathrm{keV}$ ). The lack of an unresolved resonance treatment in the MCNP5 ${ }^{181} \mathrm{Ta}$ cross sections is expected to result in increased Ta absorption in the unresolved resonance range and decreased assembly $k_{\text {eff }}$. This discrepancy between the RCP01 and MCNP5 predicted $k_{\text {eff }}$ highlights the value of the Ta-2.5W-4 experiment in developing an improved ${ }^{181} \mathrm{Ta}$ neutron cross section evaluation. 


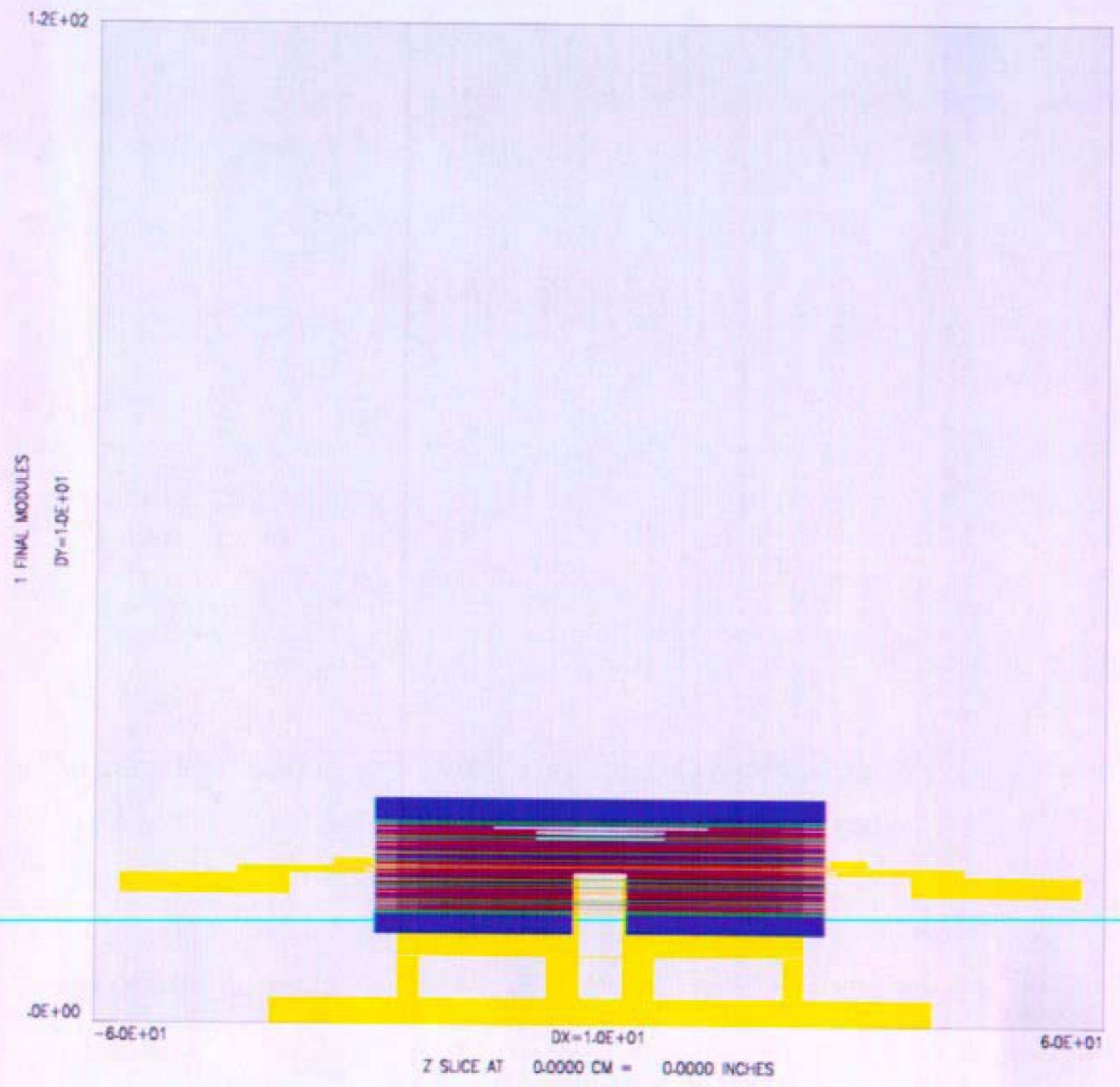

Figure 99. RCP01 Cross-sectional View of the Ta-2.5W-4 Assembly 


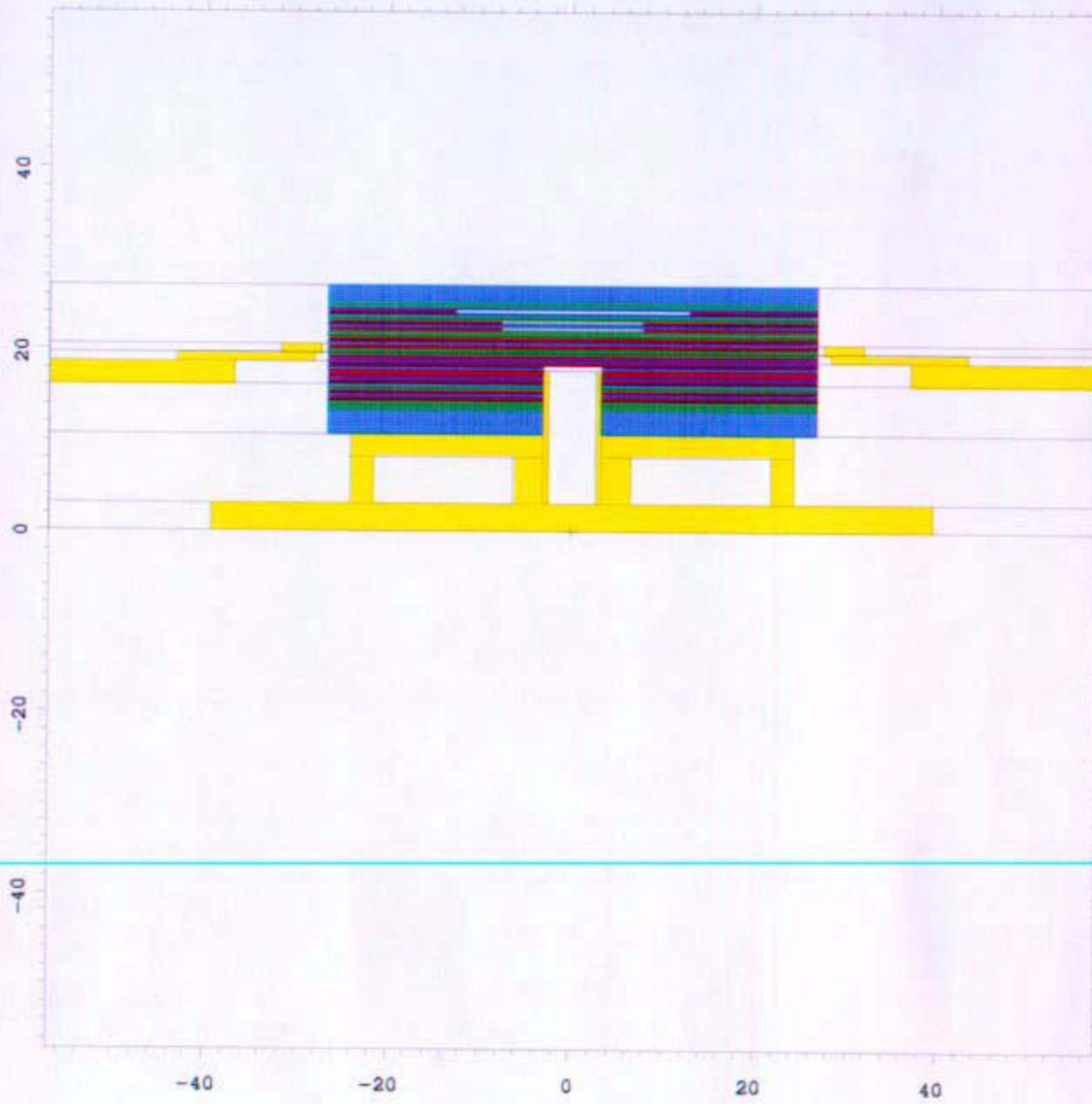

Figure 100. MCNP5 Cross-sectional View of the Ta-2.5W-4 Assembly 
$\omega$

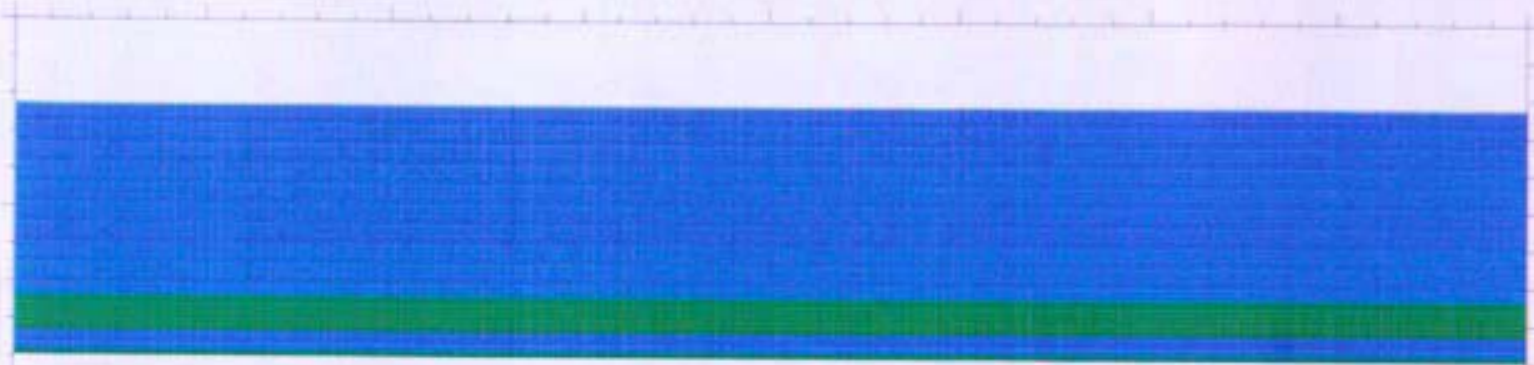

$\nabla$

o

$\uparrow$

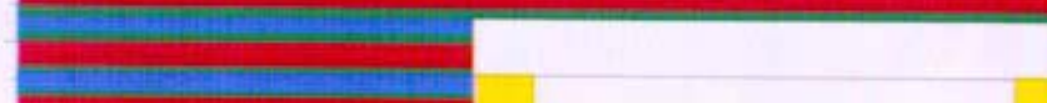

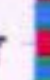

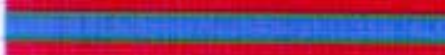

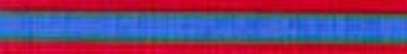

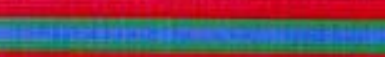

3. in

$\varphi$

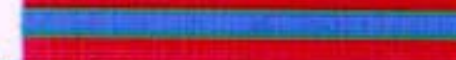

i

$-8$
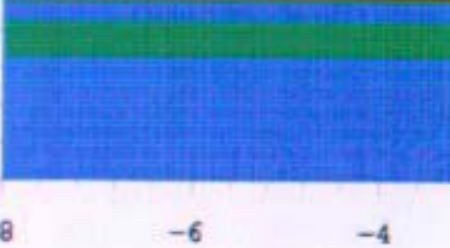

$-4$

$-2$

0

8

Figure 101. MCNP5 Cross-sectional Close-up View of the Ta-2.5W-4 Assembly 
Table 99. RCP01, MCNP5 (Space XS), and RACER Predicted Critical Configuration for the Ta-2.5W4 Assembly

\begin{tabular}{|c|c|c|c|c|c|}
\hline Unit & Material & Thickness (in) & $\begin{array}{c}\text { Inner } \\
\text { Diameter (in) }\end{array}$ & $\begin{array}{c}\text { Outer } \\
\text { Diameter (in) }\end{array}$ & $\begin{array}{l}\text { Assembly Height } \\
\text { (in) }\end{array}$ \\
\hline \multirow{3}{*}{$\begin{array}{l}\text { Bottom } \\
\text { Reflector }\end{array}$} & Poly & 1.00 & 2.51 & 21.0 & 1.0000 \\
\hline & $\mathrm{Ta}-2.5 \mathrm{~W}$ & 0.150 & 2.51 & 210 & 1.1500 \\
\hline & Poly & 0.080 & 251 & 21.0 & 1,2300 \\
\hline \multirow{4}{*}{1} & $\mathrm{Ta}-2.5 \mathrm{~W}$ & 0.0246 & 2.51 & 21.0 & 1.2546 \\
\hline & $\mathrm{HEU}$ & 0.118 & 2.51 & 21.0 & 1.3726 \\
\hline & Ta-2.5W & 0.0246 & 2.51 & 21.0 & 1.3972 \\
\hline & Poly & 0.080 & 2.51 & 21.0 & 1.4772 \\
\hline \multirow{4}{*}{2} & $\mathrm{Ta}-2.5 \mathrm{~W}$ & 0.0246 & 2.51 & 21.0 & 1.5018 \\
\hline & HEU & 0.118 & 2.51 & 21.0 & 1.6198 \\
\hline & $\mathrm{Ta}-2.5 \mathrm{~W}$ & 0.0246 & 2.51 & 21.0 & 1.6444 \\
\hline & Poly & 0.080 & 2.51 & 21.0 & 1.7244 \\
\hline \multirow{4}{*}{3} & Ta-2.5W & 0.0246 & 2.51 & 21.0 & 1.7490 \\
\hline & HEU & 0.118 & 2.51 & 21.0 & 1.8670 \\
\hline & Ta-2.5W & 0.0246 & 2.51 & 21.0 & 1.8916 \\
\hline & Poly & 0.080 & 2.51 & 21.0 & 1.9716 \\
\hline \multirow{4}{*}{4} & $\mathrm{Ta}-2.5 \mathrm{~W}$ & 0.0246 & 2.51 & 21.0 & 1.9962 \\
\hline & HEU & 0.118 & 2.51 & 21.0 & 2.1142 \\
\hline & Ta-2.5W & 0.0246 & 2.51 & 21.0 & 2.1388 \\
\hline & Poly & 0.080 & 2.51 & 21.0 & 2.2188 \\
\hline \multirow{4}{*}{5} & $\mathrm{Ta}-2.5 \mathrm{~W}$ & 0.0246 & 2.51 & 21.0 & 2.2434 \\
\hline & HEU & 0.118 & 2.51 & 21.0 & 2.3614 \\
\hline & Ta-2.5W & 0.0246 & 2.51 & 21.0 & 2.3860 \\
\hline & Poly & 0.080 & 2.51 & 21.0 & 2.4660 \\
\hline \multirow{4}{*}{6} & Ta-2.5W & 0.0246 & 2.51 & 21.0 & 2.4906 \\
\hline & HEU & 0.118 & 2.51 & 21.0 & 2.6086 \\
\hline & $\mathrm{Ta}-2.5 \mathrm{~W}$ & 0.0246 & 2.51 & 21.0 & 2.6332 \\
\hline & Poly & 0.080 & 2.51 & 21.0 & 2.7132 \\
\hline \multirow{4}{*}{7} & Ta-2.5W & 0.0246 & 2.51 & 21.0 & 2.7378 \\
\hline & HEU & 0.118 & 2.51 & 21.0 & 2.8558 \\
\hline & Ta-2.5W & 0.0246 & 2.51 & 21.0 & 2.8804 \\
\hline & Poly & 0.080 & 2.51 & 21.0 & 2.9604 \\
\hline \multirow{4}{*}{8} & $\mathrm{Ta}-2.5 \mathrm{~W}$ & 0.0246 & 0 & 21.0 & 2.9850 \\
\hline & HEU & 0.118 & 0 & 21.0 & 3.1030 \\
\hline & Ta-2.5W & 0.0246 & 0 & 21.0 & 3.1276 \\
\hline & Poly & 0.080 & 0 & 21.0 & 3.2076 \\
\hline Diaphragm & Stainless Steel & 0.040 & 0 & 24.8 & 3.4948 \\
\hline \multirow{4}{*}{.} & Ta-2.5W & 0.0246 & 0 & 21.0 & 3.2322 \\
\hline & $\mathrm{HEU}$ & 0.118 & 0 & 21.0 & 3.3502 \\
\hline & Ta-2.5W W & 0.0246 & 0 & 21.0 & 3.3748 \\
\hline & Poly & 0.080 & 0 & 21.0 & 3.4548 \\
\hline \multirow{4}{*}{10} & $\mathrm{Ta}-2.5 \mathrm{~W}$ & 0.0246 & 0 & 21.0 & 3.5194 \\
\hline & HEU & 0.118 & 0 & 21.0 & 3.6374 \\
\hline & Ta-2.5W & 0.0246 & 0 & 21.0 & 3.6620 \\
\hline & Poly & 0.080 & 0 & 21.0 & 3.7420 \\
\hline
\end{tabular}




\begin{tabular}{|c|c|c|c|c|c|}
\hline Unit & Material & Thickness (in) & $\begin{array}{c}\text { Inner } \\
\text { Diameter (in) }\end{array}$ & $\begin{array}{c}\text { Outer } \\
\text { Diameter (in) }\end{array}$ & $\begin{array}{l}\text { Assembly Height } \\
\text { (in) }\end{array}$ \\
\hline \multirow{4}{*}{11} & $\mathrm{Ta}-2.5 \mathrm{~W}$ & 0.0246 & 0 & 21.0 & 3.7666 \\
\hline & HEU & 0.118 & 0 & 21.0 & 3.8846 \\
\hline & $\mathrm{Ta}-2.5 \mathrm{~W}$ & 0.0246 & 0 & 21.0 & 3.9092 \\
\hline & Poly & 0.080 & 0 & 21.0 & 3.9892 \\
\hline \multirow{4}{*}{12} & $\mathrm{Ta}-2.5 \mathrm{~W}$ & 0.0246 & 0 & 21.0 & 4.0138 \\
\hline & HEU & 0.118 & 0 & 21.0 & 4.1318 \\
\hline & Ta-2.5W & 0.0246 & 0 & 21.0 & 4.1564 \\
\hline & Poly & 0.080 & 0 & 21.0 & 4.2364 \\
\hline \multirow{4}{*}{13} & Ta-2.5W & 0.0246 & 0 & 21.0 & 4.2610 \\
\hline & HEU & 0.118 & 0 & 21.0 & 4.3790 \\
\hline & $\mathrm{Ta}-2.5 \mathrm{~W}$ & 0.0246 & 0 & 21.0 & 4.4036 \\
\hline & Poly & 0.080 & 0 & 21.0 & 4.4836 \\
\hline \multirow{4}{*}{14} & Ta-2.5W & 0.0246 & 0 & 21.0 & 4.5082 \\
\hline & HEU & 0.118 & 6.005 & 21.0 & 4.6262 \\
\hline & $\mathrm{Ta}-2.5 \mathrm{~W}$ & 0.0246 & 0 & 21.0 & 4.6508 \\
\hline & Poly & 0.080 & 0 & 21.0 & 4.7308 \\
\hline \multirow{4}{*}{15} & Ta-2.5W & 0.0246 & 0 & 21.0 & 4.7554 \\
\hline & HEU & 0.118 & 6.005 & 21.0 & 4.8734 \\
\hline & $\mathrm{Ta}-2.5 \mathrm{~W}$ & 0.0246 & 0 & 21.0 & 4.8980 \\
\hline & Poly & 0.080 & 0 & 21.0 & 4.9780 \\
\hline \multirow{4}{*}{16} & $\mathrm{Ta}-2.5 \mathrm{~W}$ & 0.0246 & 0 & 21.0 & 5.0026 \\
\hline & HEU & 0.118 & 10.005 & 21.0 & 5.1206 \\
\hline & Ta-2.5W & 0.0246 & 0 & 21.0 & 5.1452 \\
\hline & Poly & 0.080 & 0 & 21.0 & 5.2252 \\
\hline \multirow[b]{2}{*}{$\begin{array}{c}\text { Top } \\
\text { Reflector }\end{array}$} & $\mathrm{Ta}-2.5 \mathrm{~W}$ & 0.150 & 0 & 21.0 & 5.3752 \\
\hline & Poly & $\begin{array}{c}1.04 \text { (RCP01) } \\
0.90 \text { (RACER, } \\
\text { MCNP5 Space XS) }\end{array}$ & 0 & 21.0 & $\begin{array}{l}6.4152 \text { (RCPO1) } \\
6.2752 \text { (RACER, } \\
\text { MCNP5 Space XS) }\end{array}$ \\
\hline
\end{tabular}


Table 100. MCNP5 Predicted Critical Configuration for the Ta-2.5W-4 Assembly

\begin{tabular}{|c|c|c|c|c|c|}
\hline Unit & Material & Thickness (in) & $\begin{array}{c}\text { Inner } \\
\text { Diameter (in) }\end{array}$ & $\begin{array}{c}\text { Outer } \\
\text { Diameter (in) }\end{array}$ & $\begin{array}{l}\text { Assembly Height } \\
\text { (in) }\end{array}$ \\
\hline \multirow{3}{*}{$\begin{array}{l}\text { Bottom } \\
\text { Reflector }\end{array}$} & Poly & 1.00 & 251 & 21.0 & 1,0000 \\
\hline & $\mathrm{Ta}-2,5 \mathrm{~W}$ & 0.150 & 251 & 21.0 & 1.1500 \\
\hline & Poly & 0.080 & 251 & 21.0 & 1.2300 \\
\hline \multirow{4}{*}{1} & Ta-2.5W & 0.0246 & 2.51 & 21.0 & 1.2546 \\
\hline & HEU & 0.118 & 2.51 & 21.0 & 1.3726 \\
\hline & $\mathrm{Ta}-2.5 \mathrm{~W}$ & 0.0246 & 2.51 & 21.0 & 1.3972 \\
\hline & Poly & 0.080 & 2.51 & 21.0 & 1.4772 \\
\hline \multirow{4}{*}{2} & Ta-2.5W & 0.0246 & 2.51 & 21.0 & 1.5018 \\
\hline & HEU & 0.118 & 2.51 & 21.0 & 1.6198 \\
\hline & $\mathrm{Ta}-2.5 \mathrm{~W}$ & 0.0246 & 2.51 & 21.0 & 1.6444 \\
\hline & Poly & 0.080 & 2.51 & 21.0 & 1.7244 \\
\hline \multirow{4}{*}{3} & Ta-2.5W & 0.0246 & 2.51 & 21.0 & 1.7490 \\
\hline & HEU & 0.118 & 2.51 & 21.0 & 1.8670 \\
\hline & $\mathrm{Ta}-2.5 \mathrm{~W}$ & 0.0246 & 2.51 & 21.0 & 1.8916 \\
\hline & Poly & 0.080 & 2.51 & 21.0 & 1.9716 \\
\hline \multirow{4}{*}{4} & $\mathrm{Ta}-2.5 \mathrm{~W}$ & 0.0246 & 2.51 & 21.0 & 1.9962 \\
\hline & HEU & 0.118 & 2.51 & 21.0 & 2.1142 \\
\hline & $\mathrm{Ta}-2.5 \mathrm{~W}$ & 0.0246 & 2.51 & 21.0 & 2.1388 \\
\hline & Poly & 0.080 & 2.51 & 21.0 & 2.2188 \\
\hline \multirow{4}{*}{5} & $\mathrm{Ta}-2.5 \mathrm{~W}$ & 0.0246 & 2.51 & 21.0 & 2.2434 \\
\hline & HEU & 0.118 & 2.51 & 21.0 & 2.3614 \\
\hline & $\mathrm{Ta}-2.5 \mathrm{~W}$ & 0.0246 & 2.51 & 21.0 & 2.3860 \\
\hline & Poly & 0.080 & 2.51 & 21.0 & 2.4660 \\
\hline \multirow{4}{*}{6} & $\mathrm{Ta}-2.5 \mathrm{~W}$ & 0.0246 & 2.51 & 21.0 & 2.4906 \\
\hline & HEU & 0.118 & 2.51 & 21.0 & 2.6086 \\
\hline & $\mathrm{Ta}-2.5 \mathrm{~W}$ & 0.0246 & 2.51 & 21.0 & 2.6332 \\
\hline & Poly & 0.080 & 2.51 & 21.0 & 2.7132 \\
\hline \multirow{4}{*}{7} & $\mathrm{Ta}-2.5 \mathrm{~W}$ & 0.0246 & 2.51 & 21.0 & 2.7378 \\
\hline & HEU & 0.118 & 2.51 & 21.0 & 2.8558 \\
\hline & $\mathrm{Ta}-2.5 \mathrm{~W}$ & 0.0246 & 2.51 & 21.0 & 2.8804 \\
\hline & Poly & 0.080 & 2.51 & 21.0 & 2.9604 \\
\hline \multirow{4}{*}{8} & Ta-2.5W & 0.0246 & 0 & 21.0 & 2.9850 \\
\hline & HEU & 0.118 & 0 & 21.0 & 3.1030 \\
\hline & Ta-2.5W & 0.0246 & 0 & 21.0 & 3.1276 \\
\hline & Poly & 0.080 & 0 & 21.0 & 3.2076 \\
\hline \multirow{4}{*}{9} & $\mathrm{Ta}-2.5 \mathrm{~W}$ & 0.0246 & 0 & 21.0 & 3.2322 \\
\hline & HEU & 0.118 & 0 & 21.0 & 3.3502 \\
\hline & $\mathrm{Ta}-2.5 \mathrm{~W}$ & 0.0246 & 0 & 21.0 & 3.3748 \\
\hline & Poly & 0.080 & 0 & 21.0 & 3.4548 \\
\hline Diaphragm & Stainless Steel & 0.040 & 0 & 24.8 & 3.4948 \\
\hline \multirow{4}{*}{10} & $\mathrm{Ta}-2.5 \mathrm{~W}$ & 0.0246 & 0 & 21.0 & 3.5194 \\
\hline & HEU & 0.118 & 0 & 21.0 & 3.6374 \\
\hline & $\mathrm{Ta}-2.5 \mathrm{~W}$ & 0.0246 & 0 & 21.0 & 3.6620 \\
\hline & Poly & 0.080 & 0 & 21.0 & 3.7420 \\
\hline
\end{tabular}




\begin{tabular}{|c|c|c|c|c|c|}
\hline Unit & Material & Thickness (in) & $\begin{array}{c}\text { Inner } \\
\text { Diameter (in) }\end{array}$ & \begin{tabular}{c|} 
Outer \\
Diameter (in)
\end{tabular} & $\begin{array}{l}\text { Assembly Height } \\
\text { (in) }\end{array}$ \\
\hline \multirow{4}{*}{11} & $\mathrm{Ta}-2.5 \mathrm{~W}$ & 0.0246 & 0 & 21.0 & 3.7666 \\
\hline & $\mathrm{HEU}$ & 0.118 & 0 & 21.0 & 3.8846 \\
\hline & $\mathrm{Ta}-2.5 \mathrm{~W}$ & 0.0246 & 0 & 21.0 & 3.9092 \\
\hline & Poly & 0.080 & 0 & 21.0 & 3.9892 \\
\hline \multirow{4}{*}{12} & $\mathrm{Ta}-2.5 \mathrm{~W}$ & 0.0246 & 0 & 21.0 & 4.0138 \\
\hline & HEU & 0.118 & 0 & 21.0 & 4.1318 \\
\hline & $\mathrm{Ta}-2.5 \mathrm{~W}$ & 0.0246 & 0 & 21.0 & 4.1564 \\
\hline & Poly & 0.080 & 0 & 21.0 & 4.2364 \\
\hline \multirow{4}{*}{13} & $\mathrm{Ta}-2.5 \mathrm{~W}$ & 0.0246 & 0 & 21.0 & 4.2610 \\
\hline & $\mathrm{HEU}$ & 0.118 & 0 & 21.0 & 4.3790 \\
\hline & $\mathrm{Ta}-2.5 \mathrm{~W}$ & 0.0246 & 0 & 21.0 & 4.4036 \\
\hline & Poly & 0.080 & 0 & 21.0 & 4.4836 \\
\hline \multirow{4}{*}{14} & $\mathrm{Ta}-2.5 \mathrm{~W}$ & 0.0246 & 0 & 21.0 & 4.5082 \\
\hline & HEU & 0.118 & 6.005 & 21.0 & 4.6262 \\
\hline & $\mathrm{Ta}-2.5 \mathrm{~W}$ & 0.0246 & 0 & 21.0 & 4.6508 \\
\hline & Poly & 0.080 & 0 & 21.0 & 4.7308 \\
\hline \multirow{4}{*}{15} & Ta-2.5W & 0.0246 & 0 & 21.0 & 4.7554 \\
\hline & HEU & 0.118 & 6.005 & 21.0 & 4.8734 \\
\hline & $\mathrm{Ta}-2.5 \mathrm{~W}$ & 0.0246 & 0 & 21.0 & 4.8980 \\
\hline & Poly & 0.080 & 0 & 21.0 & 4.9780 \\
\hline \multirow{4}{*}{16} & $\mathrm{Ta}-2.5 \mathrm{~W}$ & 0.0246 & 0 & 21.0 & 5.0026 \\
\hline & HEU & 0.118 & 6.005 & 21.0 & 5.1206 \\
\hline & $\mathrm{Ta}-2.5 \mathrm{~W}$ & 0.0246 & 0 & 21.0 & 5.1452 \\
\hline & Poly & 0.080 & 0 & 21.0 & 5.2252 \\
\hline \multirow{4}{*}{17} & $\mathrm{Ta}-2.5 \mathrm{~W}$ & 0.0246 & 0 & 21.0 & 5.2498 \\
\hline & HEU & 0.118 & 10.005 & 21.0 & 5.3678 \\
\hline & $\mathrm{Ta}-2.5 \mathrm{~W}$ & 0.0246 & 0 & 21.0 & 5.3924 \\
\hline & Poly & 0.080 & 0 & 21.0 & 5.4724 \\
\hline \multirow{2}{*}{$\begin{array}{l}\text { Top } \\
\text { Reflector }\end{array}$} & $\mathrm{Ta}-2.5 \mathrm{~W}$ & 0.150 & 0 & 21.0 & 5.6224 \\
\hline & Poly & 0.80 & 0 & 21.0 & 6.4224 \\
\hline
\end{tabular}

Table 101. Ta-2.5W-4 Assembly Material Mass Distribution

\begin{tabular}{|c|c|c|c|c|c|c|c|c|c|}
\hline \multirow{3}{*}{ Material } & \multicolumn{9}{|c|}{ Mass (kg) } \\
\hline & \multicolumn{3}{|c|}{ MCNP5 } & \multicolumn{3}{|c|}{ RCP01 } & \multicolumn{3}{|c|}{ MCNP5 (Space XS)/RACER } \\
\hline & $\begin{array}{l}\text { Lower } \\
\text { Assembly }\end{array}$ & $\begin{array}{c}\text { Upper } \\
\text { Assembly }\end{array}$ & Total & $\begin{array}{c}\text { Lower } \\
\text { Assembly }\end{array}$ & $\begin{array}{c}\text { Upper } \\
\text { Assembly }\end{array}$ & Total & $\begin{array}{l}\text { Lower } \\
\text { Assembly }\end{array}$ & $\begin{array}{c}\text { Upper } \\
\text { Assembly }\end{array}$ & Total \\
\hline HEU & 111.7 & 94.5 & 206.2 & 111.7 & 83.0 & 194.7 & 111.7 & 83.0 & 194.7 \\
\hline $\mathrm{Ta}-2.5 \mathrm{~W}$ & 55.5 & 51.5 & 107.0 & 55.5 & 46.9 & 102.4 & 55.5 & 46.9 & 102.4 \\
\hline Polyethylene & 9.7 & 7.8 & 17.5 & 9.7 & 8.7 & 18.3 & 9.7 & 7.9 & 17.6 \\
\hline Total & 176.9 & 153.9 & 330.8 & 176.9 & 138.5 & 315.4 & 176.9 & 137.8 & 314.7 \\
\hline
\end{tabular}




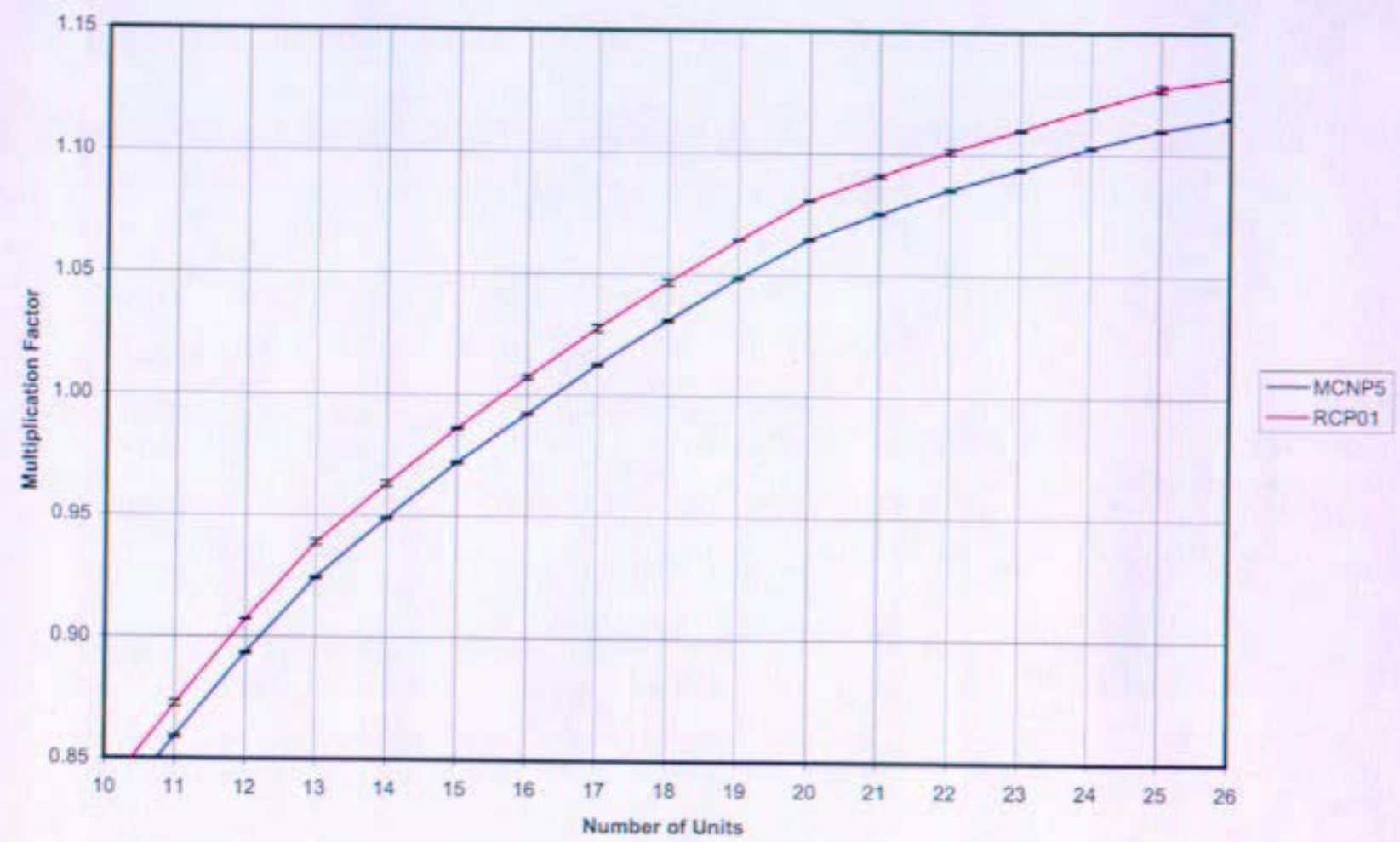

Figure 102. Ta-2.5W-4 Assembly $k_{\text {off }}$ as a Function of the Number of Stacking Units

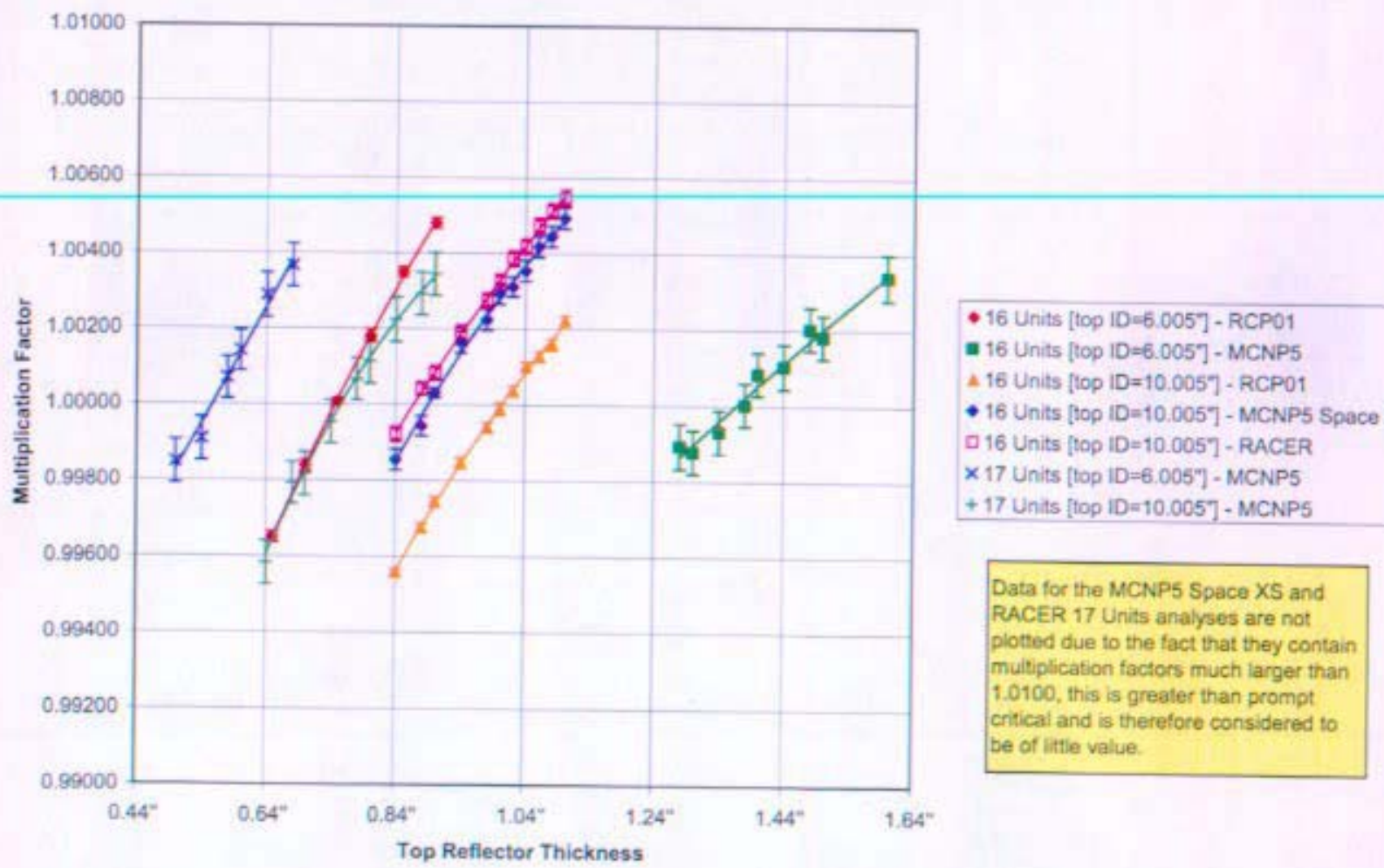

Figure 103. Ta-2.5W-4 Assembly keff as a Function of the Top Reflector Thickness 
B-TM-1639

Table 102. RCP01, MCNP5 (Space XS), and RACER Ta-2.5W-4 Assembly keff as a Function of the Top Reflector Thickness

\begin{tabular}{|c|c|c|c|c|c|c|}
\hline \multicolumn{7}{|c|}{16 Stacking Units (top HEU plate ID $=6.005^{\prime \prime}$ ) } \\
\hline \multirow{2}{*}{$\begin{array}{c}\text { Top } \\
\text { Reflector } \\
\text { Thickness } \\
\text { (in) } \\
\end{array}$} & \multicolumn{2}{|c|}{ RCP01 } & \multicolumn{2}{|c|}{ MCNP5 (Space XS) } & \multicolumn{2}{|c|}{ RACER } \\
\hline & $k_{\text {eff }}$ & $95 \% \mathrm{Cl}$ & $k_{\text {eff }}$ & $95 \% \mathrm{Cl}$ & $\mathrm{k}_{\text {eff }}$ & $95 \% \mathrm{Cl}$ \\
\hline 0.65 & 0.99651 & 0.00014 & \multirow{6}{*}{\multicolumn{2}{|c|}{$\begin{array}{l}\text { Not investigated due } \\
\text { to termination of } \\
\text { project. }\end{array}$}} & \multirow{6}{*}{\multicolumn{2}{|c|}{$\begin{array}{l}\text { Not investigated } \\
\text { due to termination } \\
\text { of project. }\end{array}$}} \\
\hline 0.70 & 0.99838 & 0.00015 & & & & \\
\hline 0.75 & 1.00008 & 0.00007 & & & & \\
\hline 0.80 & 1.00181 & 0.00017 & & & & \\
\hline 0.85 & 1.00350 & 0.00013 & & & & \\
\hline 0.90 & 1.00480 & 0.00014 & & & & \\
\hline \multicolumn{7}{|c|}{16 Stacking Units (top HEU plate ID $=10.005^{\prime \prime}$ ) } \\
\hline Top & \multicolumn{2}{|c|}{ RCP01 } & \multicolumn{2}{|c|}{ MCNP5 (Space XS) } & \multicolumn{2}{|c|}{ RACER } \\
\hline $\begin{array}{l}\text { Reflector } \\
\text { Thickness } \\
\text { (in) }\end{array}$ & $\mathbf{k}_{\text {eff }}$ & $95 \% \mathrm{Cl}$ & $\mathbf{k}_{\text {eff }}$ & $95 \% \mathrm{Cl}$ & $\mathbf{k}_{\text {eff }}$ & $95 \% \mathrm{Cl}$ \\
\hline 0.84 & 0.99558 & 0.00009 & 0.99854 & 0.00028 & 0.99921 & 0.00020 \\
\hline 0.88 & 0.99675 & 0.00013 & 0.99943 & 0.00026 & 1.00041 & 0.00018 \\
\hline 0.90 & 0.99743 & 0.00014 & 1.00030 & 0.00013 & 1.00084 & 0.00020 \\
\hline 0.94 & 0.99846 & 0.00014 & 1.00164 & 0.00028 & 1.00190 & 0.00020 \\
\hline 0.98 & 0.99940 & 0.00014 & 1.00224 & 0.00028 & 1.00275 & 0.00020 \\
\hline 1.00 & 0.99988 & 0.00016 & 1.00292 & 0.00028 & 1.00324 & 0.00021 \\
\hline 1.02 & 1.00037 & 0.00014 & 1.00311 & 0.00026 & 1.00386 & 0.00020 \\
\hline 1.04 & 1.00099 & 0.00013 & 1.00354 & 0.00028 & 1.00418 & 0.00020 \\
\hline 1.06 & 1.00128 & 0.00013 & 1.00417 & 0.00028 & 1.00473 & 0.00020 \\
\hline 1.08 & 1.00159 & 0.00015 & 1.00445 & 0.00028 & 1.00513 & 0.00020 \\
\hline 1.10 & 1.00222 & 0.00013 & 1.00493 & 0.00028 & 1.00547 & 0.00021 \\
\hline
\end{tabular}


Table 103. MCNP5, MCNP5 (Space XS), and RACER Ta-2.5W-4 Assembly keff as a Function of the Top Reflector Thickness

\begin{tabular}{|c|c|c|c|c|c|c|}
\hline \multicolumn{7}{|c|}{16 Stacking Units (top HEU plate ID=6.005") } \\
\hline \multirow{2}{*}{$\begin{array}{c}\text { Top } \\
\text { Reflector } \\
\text { Thickness } \\
\text { (in) }\end{array}$} & \multicolumn{2}{|c|}{ MCNP5 } & \multicolumn{2}{|c|}{ MCNP5 (Space XS) } & \multicolumn{2}{|c|}{ RACER } \\
\hline & $\mathbf{k}_{\text {eff }}$ & $95 \% \mathrm{Cl}$ & $\mathbf{k}_{\text {eff }}$ & $95 \% \mathrm{Cl}$ & $\mathbf{k}_{\text {eff }}$ & $95 \% \mathrm{Cl}$ \\
\hline 1.28 & 0.99892 & 0.00059 & \multirow{9}{*}{\multicolumn{2}{|c|}{$\begin{array}{l}\text { Not investigated due } \\
\text { to termination of } \\
\text { project. }\end{array}$}} & \multirow{9}{*}{\multicolumn{2}{|c|}{$\begin{array}{l}\text { Not investigated } \\
\text { due to terminatior } \\
\text { of project. }\end{array}$}} \\
\hline 1.30 & 0.99877 & 0.00057 & & & & \\
\hline 1.34 & 0.99930 & 0.00057 & & & & \\
\hline 1.38 & 1.00002 & 0.00057 & & & & \\
\hline 1.40 & 1.00083 & 0.00057 & & & & \\
\hline 1.44 & 1.00103 & 0.00059 & & & & \\
\hline 1.48 & 1.00203 & 0.00057 & & & & \\
\hline 1.50 & 1.00182 & 0.00057 & & & & \\
\hline 1.60 & 1.00339 & 0.00061 & & & & \\
\hline \multicolumn{7}{|c|}{17 Stacking Units (top HEU plate ID $=6.005^{\prime \prime}$ ) } \\
\hline Top & \multicolumn{2}{|c|}{ MCNP5 } & \multicolumn{2}{|c|}{ MCNP5 (Space XS) } & \multicolumn{2}{|c|}{ RACER } \\
\hline $\begin{array}{l}\text { Reflector } \\
\text { Thickness } \\
\text { (in) }\end{array}$ & $k_{\text {eff }}$ & $95 \% \mathrm{Cl}$ & $\mathbf{k}_{\text {eff }}$ & $95 \% \mathrm{Cl}$ & $\mathbf{k}_{\text {eff }}$ & $95 \% \mathrm{Cl}$ \\
\hline 0.50 & 0.99848 & 0.00057 & - & - & \multirow{6}{*}{\multicolumn{2}{|c|}{$\begin{array}{l}\text { Not investigated } \\
\text { due to termination } \\
\text { of project. }\end{array}$}} \\
\hline 0.54 & 0.99908 & 0.00057 & - & - & & \\
\hline 0.58 & 1.00069 & 0.00055 & - & - & & \\
\hline 0.60 & 1.00141 & 0.00053 & - & - & & \\
\hline 0.64 & 1.00287 & 0.00059 & 1.02004 & 0.00028 & & \\
\hline 0.68 & 1.00366 & 0.00057 & 1.02155 & 0.00028 & & \\
\hline \multicolumn{7}{|c|}{17 Stacking Units (top HEU plate ID $=10.005^{\prime \prime}$ ) } \\
\hline Top & \multicolumn{2}{|c|}{ MCNP5 } & \multicolumn{2}{|c|}{ MCNP5 (Space XS) } & \multicolumn{2}{|c|}{ RACER } \\
\hline $\begin{array}{l}\text { Reflector } \\
\text { Thickness }\end{array}$ & & & & & & \\
\hline $\begin{array}{l}\text { Thickness } \\
\text { (in) }\end{array}$ & $k_{\text {eff }}$ & $95 \% \mathrm{Cl}$ & $\mathbf{k}_{\text {eff }}$ & $95 \% \mathrm{Cl}$ & $k_{\text {eff }}$ & $95 \% \mathrm{Cl}$ \\
\hline 0.64 & 0.99583 & 0.00057 & 1.01367 & 0.00028 & 1.01440 & 0.00020 \\
\hline 0.68 & 0.99792 & 0.00055 & 1.01535 & 0.00028 & 1.01580 & 0.00020 \\
\hline 0.70 & 0.99816 & 0.00057 & 1.01575 & 0.00026 & 1.01626 & 0.00021 \\
\hline 0.74 & 0.99953 & 0.00057 & 1.01703 & 0.00028 & 1.01746 & 0.00019 \\
\hline 0.78 & 1.00066 & 0.00055 & 1.01826 & 0.00028 & 1.01862 & 0.00021 \\
\hline 0.80 & 1.00113 & 0.00059 & 1.01832 & 0.00026 & 1.01902 & 0.00019 \\
\hline 0.84 & 1.00223 & 0.00059 & 1.01972 & 0.00028 & 1.02017 & 0.00020 \\
\hline 0.88 & 1.00292 & 0.00057 & 1.02050 & 0.00028 & 1.02130 & 0.00021 \\
\hline 0.90 & 1.00344 & 0.00057 & 1.02121 & 0.00028 & 1.02176 & 0.00021 \\
\hline
\end{tabular}


B-TM-1639

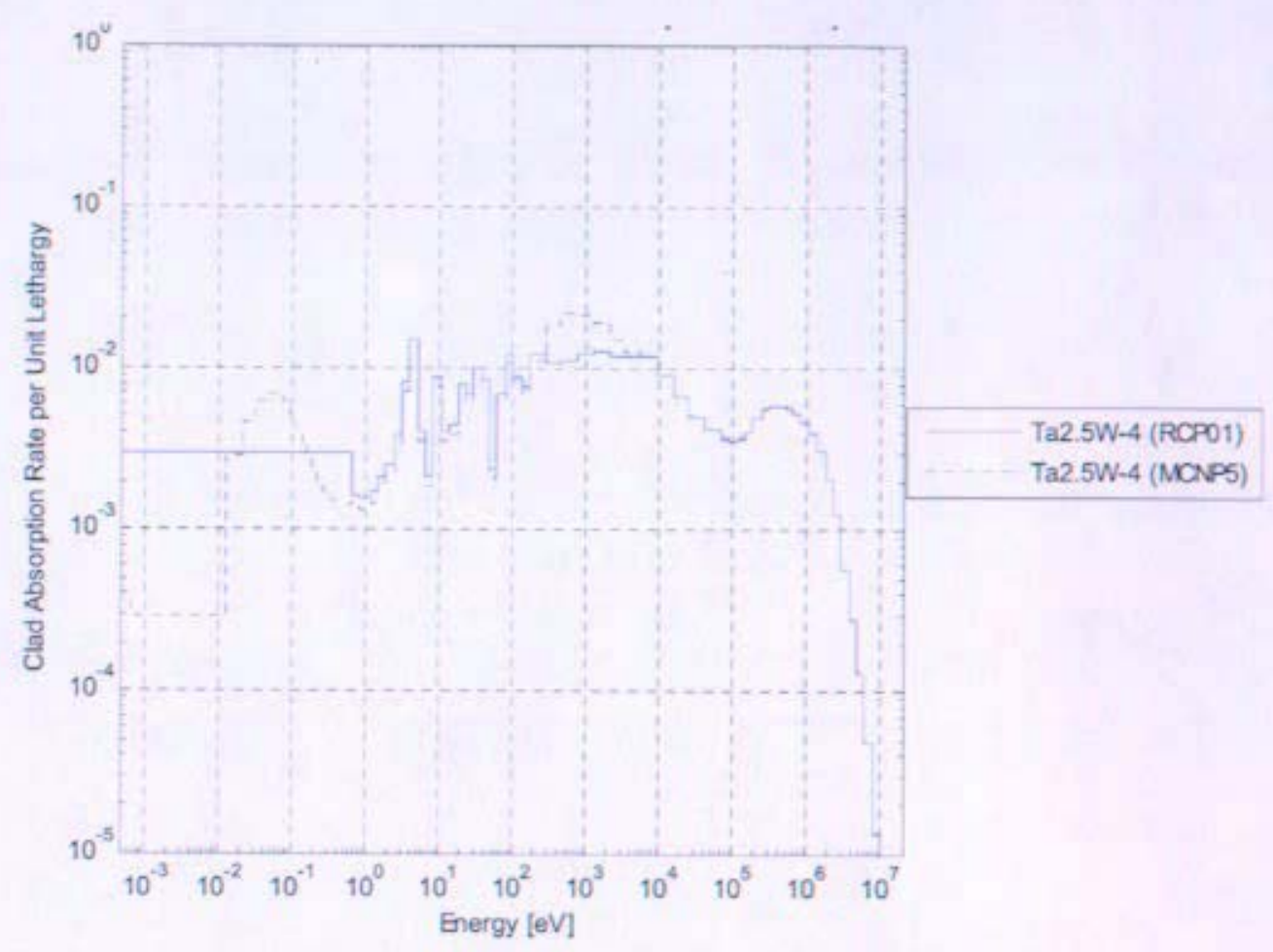

Figure 104. Comparison of Predicted RCP01 and MCNP5 Ta-2.5W Absorption Rate Spectra for the Ta-2.5W-4 Critical Experiment 


\subsubsection{Tantalum Critical Experiments Summary and Conclusions}

This document provides the pre-experimental predictions for the Ta- $2.5 \mathrm{~W}$ critical experiments including the effect of the Planet assembly machine structure. These critical experiments are being performed to:

1. determine the adequacy of the existing ${ }^{181} \mathrm{Ta}$ neutron cross section evaluations in a neutron energy spectrum characteristic of the Prometheus reactor designs under normal and accident conditions,

2. reduce the uncertainty in $k_{\text {eff }}$ for Prometheus reactor designs by performing benchmark quality critical experiments that bracket the neutron energy spectra expected under normal and accident conditions, and

3. provide benchmark critical experiments needed to develop improved ${ }^{181} \mathrm{Ta}$ neutron cross section evaluations if new evaluations are determined to be required.

The first 3 experiments are designed to bracket the neutron energy spectrum expected in the Prometheus space nuclear reactor under normal operating conditions. The Ta-2.5W-4 experiment is designed to approximate the neutron energy spectrum expected in accident conditions in which the core is flooded and surrounded by water or wet sand. A summary of the fission fraction in the thermal, intermediate, and fast energy ranges for each of the Ta-2.5W critical experiments is provided in Table 104. All of the Ta-2.5W critical experiments are classified as fast spectrum experiments. All four experiments have a significant intermediate energy range component which increases as the spectrum softens. A summary of the pre-experimental predictions for each of the Ta- $2.5 \mathrm{~W}$ critical experiments is provided in Table 105. Predictions from the RCP01, MCNP5, MCNP5 with space cross sections, and RACER analyses are provided.

Comparisons of the RCP01 and MCNP5 predicted fission reaction rate and Ta-2.5W absorption rate spectra are provided in Figure 105 and Figure 106. The lack of an unresolved resonance treatment in the MCNP5 ${ }^{181} \mathrm{Ta}$ neutron cross section data clearly results in increased absorption in Ta-2.5W between $330 \mathrm{eV}$ and $5000 \mathrm{eV}$ in all four experiments. Only the Ta-2.5W-4 experiment appears to be sensitive to differences in the unresolved resonance data. As shown in Figure 105, this is because the vast majority of the fissions occur at energies greater than $10 \mathrm{keV}$ for the other assemblies. The RCP01 predicted fission reaction rate spectrum CDFs for the Ta-2.5W experiments are provided in Figure 107.

Table 104. A Summary of the Energy Spectrum Covered in the Ta-2.5W Critical Experiments

\begin{tabular}{|c|c|c|c|}
\hline \multirow{2}{*}{ Experiment } & \multicolumn{3}{|c|}{ Percent Fissions by Energy (MCNP5 Predictions) } \\
\hline & $<0.625 \mathrm{eV}$ & $0.625 \mathrm{eV}-100 \mathrm{keV}$ & $>100 \mathrm{keV}$ \\
\hline Ta-2.5W-1 & $0.0 \%$ & $14.1 \%$ & $86.0 \%$ \\
\hline Ta-2.5W-2 & $0.0 \%$ & $20.7 \%$ & $79.3 \%$ \\
\hline Ta-2.5W-3 & $0.0 \%$ & $31.0 \%$ & $68.9 \%$ \\
\hline $\mathrm{Ta}-2.5 \mathrm{~W}-4$ & $3.7 \%$ & $43.4 \%$ & $52.9 \%$ \\
\hline
\end{tabular}


B-TM-1639

Table 105. A Summary of the Pre-Experimental Predictions for the Ta-2.5W Critical Experiments

\begin{tabular}{|c|c|c|c|c|c|c|c|c|}
\hline Experiment & $\begin{array}{c}\text { Monte } \\
\text { Carlo Code }\end{array}$ & $\begin{array}{l}\text { Stacking } \\
\text { Units }\end{array}$ & $\begin{array}{c}\text { Top } \\
\text { Reflector } \\
\text { Thickness } \\
\text { (in) }\end{array}$ & $\mathbf{k}_{\text {eff }}$ & $\begin{array}{c}95 \% \\
\text { Confidence } \\
\text { Level }\end{array}$ & $\begin{array}{c}\text { Mass } \\
\text { of HEU } \\
(\mathrm{kg})\end{array}$ & $\begin{array}{c}\text { Mass } \\
\text { of Ta- } \\
2.5 \mathrm{~W} \\
(\mathrm{~kg})\end{array}$ & $\begin{array}{c}\text { Mass of } \\
\text { Moderator } \\
\text { (graphite/ } \\
\text { polyethylene) } \\
(\mathbf{k g})\end{array}$ \\
\hline \multirow{4}{*}{$\mathrm{Ta}-2.5 \mathrm{~W}-1$} & RCP01 & 18 & 1.10 & 1.00048 & 0.00012 & 219.6 & 111.7 & 39.1 \\
\hline & MCNP5 & 18 & 1.05 & 1.00077 & 0.00057 & 219.6 & 111.7 & 38.6 \\
\hline & $\begin{array}{c}\text { MCNP5 } \\
\text { (Space XS) }\end{array}$ & 18 & 1.05 & 1.00126 & 0.00026 & 219.6 & 111.7 & 38.6 \\
\hline & RACER & 18 & 1.05 & 1.00257 & 0.00019 & 219.6 & 111.7 & 38.6 \\
\hline \multirow{4}{*}{ Ta-2.5W-2 } & RCP01 & 17 & 1.95 & 1.00162 & 0.00014 & 208.0 & 107.0 & 73.2 \\
\hline & MCNP5 & 17 & 1.75 & 1.00150 & 0.00053 & 208.0 & 107.0 & 71.2 \\
\hline & $\begin{array}{c}\text { MCNP5 } \\
\text { (Space XS) }\end{array}$ & 17 & 1.70 & 1.00055 & 0.00026 & 208.0 & 107.0 & 70.7 \\
\hline & RACER & 17 & 1.70 & 1.00219 & 0.00019 & 208.0 & 107.0 & 70.7 \\
\hline \multirow{4}{*}{ Ta-2.5W-3 } & RCP01 & 18 & 5.00 & 1.00098 & 0.00019 & 217.8 & 111.7 & 170.8 \\
\hline & MCNP5 & 18 & 4.20 & 1.00099 & 0.00057 & 217.8 & 111.7 & 162.9 \\
\hline & $\begin{array}{c}\text { MCNP5 } \\
\text { (Space XS) }\end{array}$ & 18 & 3.25 & 1.00073 & 0.00026 & 217.8 & 111.7 & 153.6 \\
\hline & RACER & 18 & 3.25 & 1.00219 & 0.00019 & 217.8 & 111.7 & 153.6 \\
\hline \multirow{4}{*}{$\mathrm{Ta}-2.5 \mathrm{~W}-4$} & RCP01 & 16 & 1.04 & 1.00099 & 0.00013 & 194.7 & 102.4 & 18.3 \\
\hline & MCNP5 & 17 & 0.80 & 1.00113 & 0.00059 & 206.2 & 107.0 & 17.5 \\
\hline & $\begin{array}{c}\text { MCNP5 } \\
\text { (Space XS) }\end{array}$ & 16 & 0.90 & 1.00030 & 0.00013 & 194.7 & 102.4 & 17.6 \\
\hline & RACER & 16 & 0.90 & 1.00084 & 0.00020 & 194.7 & 102.4 & 17.6 \\
\hline
\end{tabular}


B-TM-1639

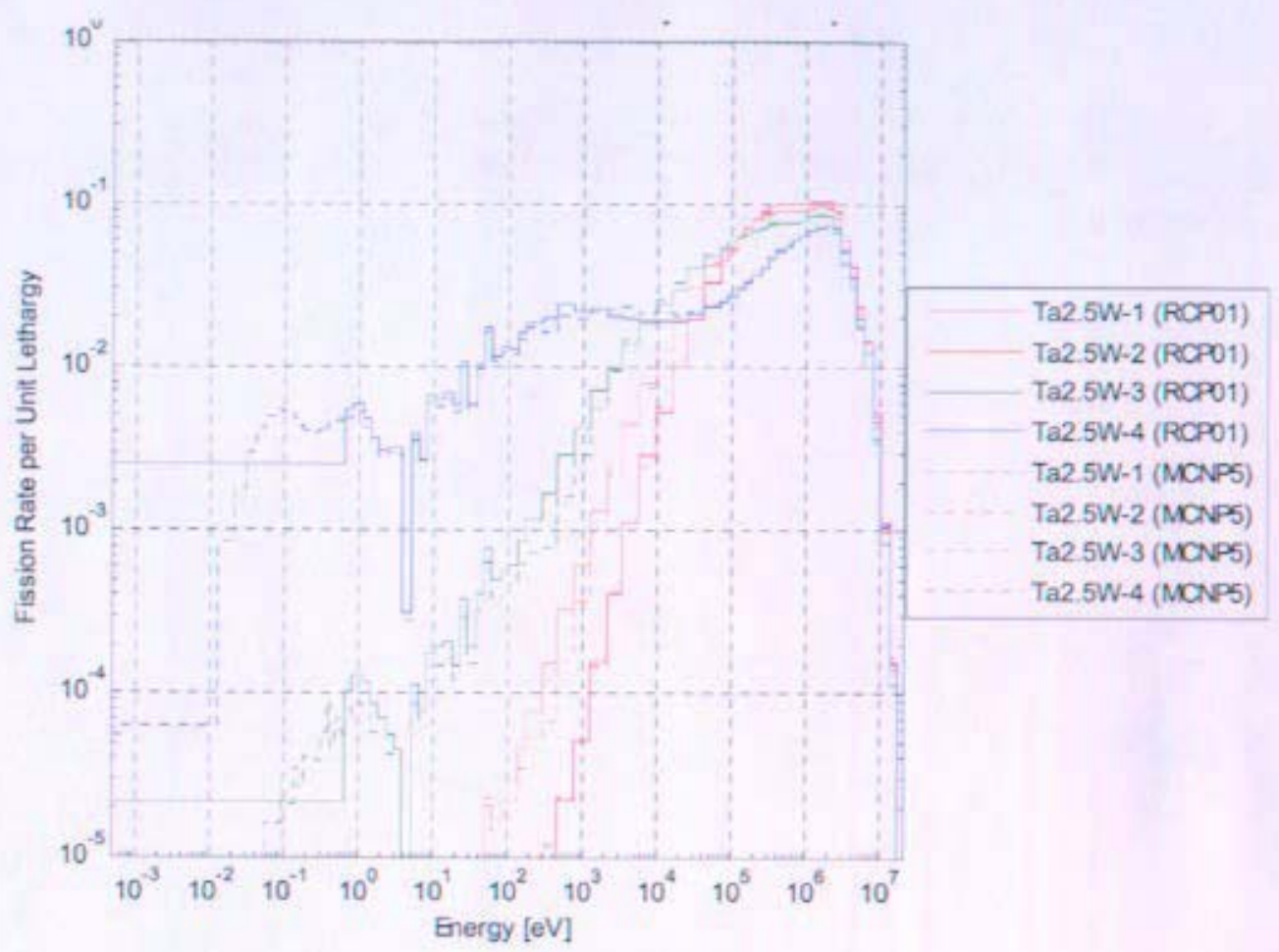

Figure 105. Comparison of RCP01 and MCNP5 Fission Rate Spectra for the Ta-2.5W Critical Experiments

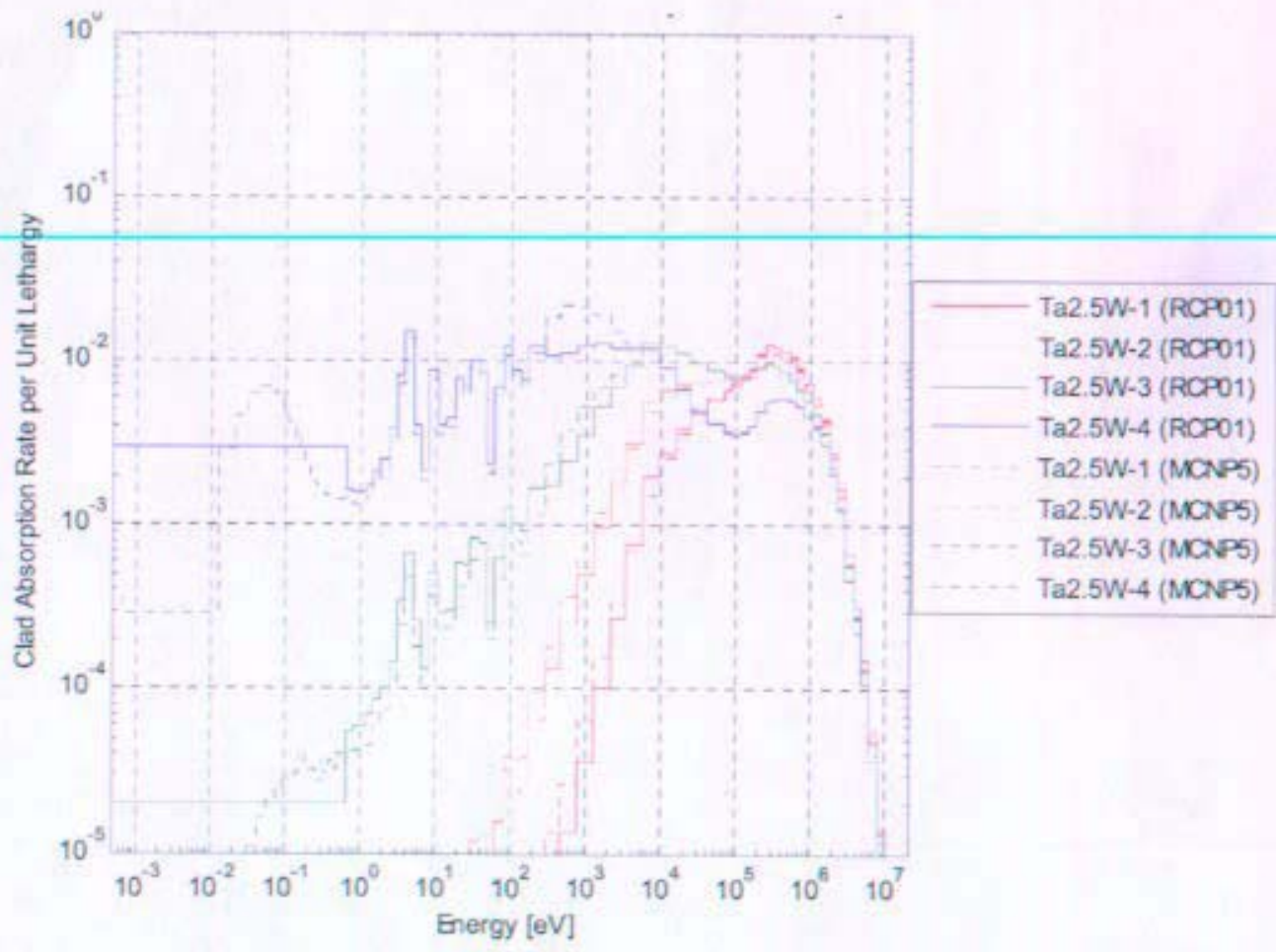

Figure 106. Comparison of RCP01 and MCNP5 Ta-2.5W Absorption Rate Spectra for the Ta-2.5W Critical Experiments 
B-TM-1639

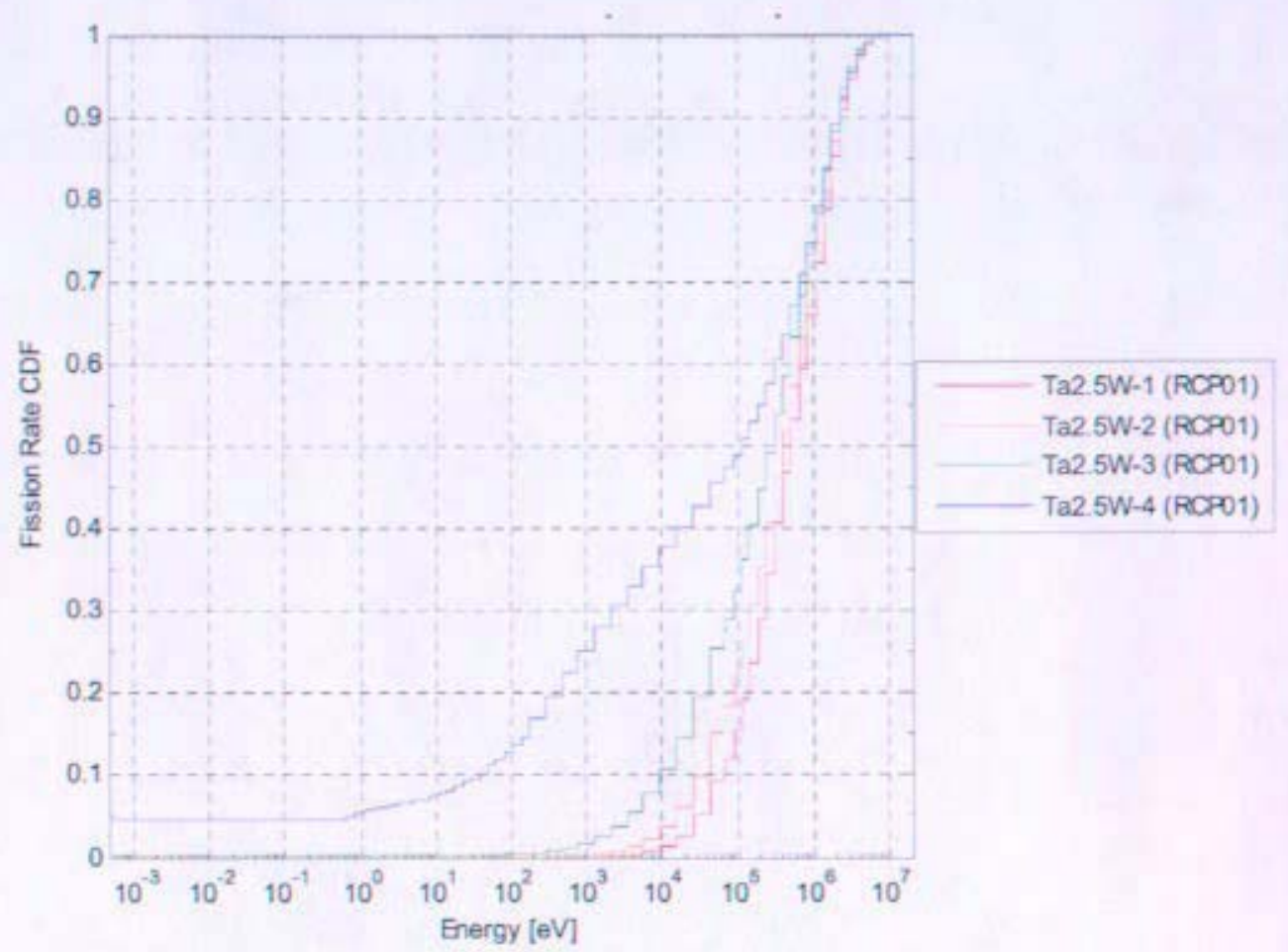

Figure 107. RCP01 Fission CDFs for the Ta-2.5W Critical Experiments 
B-TM-1639

(Intentionally Blank)

- 218 - 
B-TM-1639

\section{References}

1. International Handbook of Evaluated Criticality Safety Benchmark Experiments, OECD Nuclear Energy Agency, NEA/NSC/DOC(95)03, September 2005 Edition.

2. D. Loaiza, "Niobium - 1Zirconium Moderated by Polyethylene and Fueled with Highly Enriched Uranium," HEU-MET-FAST-047, International Handbook of Evaluated Criticality Safety Benchmark Experiments, OECD Nuclear Energy Agency, NEA/NSC/DOC(95)03, September 2006 Edition.

3. Ed. D. N. Olsen, S. G. Carpenter, J. R. Ross, and R. W. Schaefer, "Configurations and Experiments in the ZPPR-16 Power Reactor Space Benchmark Program," INL/EXT-0500555, Idaho National Laboratory and ANL-ZPR-475, Argonne National Laboratory-West, August 2005.

4. Ed. D. N. Olsen, R. W. Schaefer, J. R. Ross, and S. G. Carpenter, "Experiments for the SP-100 Space Reactor in ZPPR-20," INL/EXT-05-00556, Idaho National Laboratory and ANL-ZPR-497, Argonne National Laboratory-West, August 2005.

5. Ed. D. N. Olsen, R. W. Schaefer, S. G. Carpenter, and J. R. Ross, "Configurations for SP100 Space Reactor Experiments in ZPPR-20," INL/EXT-05-00558, Idaho National Laboratory and ANL-ZPR-498, Argonne National Laboratory-West, August 2005.

6. K. N. Grimm, R. M. Lell, R. D. McKnight, and R. W. Schaefer, "ZPPR-20 Phase C: A Cylindrical Assembly of U Metal Reflected by Beryllium Oxide," HEU-MET-FAST-075, International Handbook of Evaluated Criticality Safety Benchmark Experiments, OECD Nuclear Energy Agency, NEA/NSC/DOC(95)03, September 2005 Edition.

7. R. M. Lell, K. N. Grimm, R. D. McKnight, and R. W. Schaefer, "ZPPR-20 Phase D: A Cylindrical Assembly of Polyethylene-Moderated U Metal Reflected by Beryllium Oxide and Polyethylene," SUB-HEU-MET-MIXED-001, International Handbook of Evaluated Criticality Safety Benchmark Experiments, OECD Nuclear Energy Agency, NEA/NSC/DOC(95)03, September 2005 Edition.

8. R. W. Schaefer, K. N. Grimm, R. M. Lell, and R. D. McKnight, "ZPPR-20 Phase E: A Cylindrical Assembly of U Metal Reflected by Beryllium Oxide and Sand," SUB-HEU-METFAST-001, International Handbook of Evaluated Criticality Safety Benchmark Experiments, OECD Nuclear Energy Agency, NEA/NSC/DOC(95)03, September 2005 Edition.

9. L. A. Ondis, L. J. Tyburski, and B. S. Moskowitz, "RCP01 - A Monte Carlo Program for Solving Neutron and Photon Transport Problems in Three Dimensional Geometry with Detailed Energy Description and Depletion Capability," B-TM-1638, Bettis Atomic Power Laboratory, March 2000.

10. X-5 Monte Carlo Team, "MCNP - A General Monte Carlo N-Particle Transport Code, Version 5," LA-UR-03-1987, Los Alamos National Laboratory, April 2003.

11. T. M. Sutton, et al, "The Physical Models and Statistical Procedures Used in the RACER Monte Carlo Code," KAPL-4840, Knolls Atomic Power Laboratory, July 1999. 
12. D. Loaiza, D. Gehman, R. Sanchez, and D. Hayes, "Hand-stacking for Rhenium Critical Experiments Fueled by Highly Enriched Uranium and Moderated by Polyethylene and Various Graphite Plate Thicknesses, LA-UR-05-9236, Los Alamos National Laboratory (Draft).

13. D. Loaiza, D. Gehman, R. Sanchez, and D. Hayes, "Hand-stacking for Baseline Critical Experiments Fueled by Highly Enriched Uranium and Moderated by Polyethylene and Various Graphite Plate Thicknesses, LA-UR-05-9237, Los Alamos National Laboratory (Draft).

14. D. Loaiza, D. Gehman, R. Sanchez, and D. Hayes, "Hand-stacking for Molybdenum Critical Experiments Fueled by Highly Enriched Uranium and Moderated by Polyethylene and Various Graphite Plate Thicknesses, LA-UR-05-9238, Los Alamos National Laboratory (Draft).

15. D. Loaiza, D. Gehman, R. Sanchez, and D. Hayes, "Hand-stacking for Niobium - (1\%) Zirconium Critical Experiments Fueled by Highly Enriched Uranium and Moderated by Various Graphite Plate Thicknesses, LA-UR-05-9239, Los Alamos National Laboratory (Draft).

16. D. Loaiza, D. Gehman, R. Sanchez, and D. Hayes, "Hand-stacking for Tantalum $-2.5 w t \%$ Tungsten Critical Experiments Fueled by Highly Enriched Uranium and Moderated by Polyethylene and Various Graphite Plate Thicknesses, LA-UR-05-9240, Los Alamos National Laboratory (Draft).

17. Metals Handbook, 9th Ed., Volume 2, ASM, 115-117, 1979.

18. Metals Handbook, 9th Ed., Volume 3, ASM, 3-40, 1979.

19. ASTM B 708-01, Standard Specification for Tantalum and Tantalum Alloy Plate, Sheet, and Strip.

20. JANIS 2.1, OECD Nuclear Energy Agency, Moulineaux, France, June 2004. 
B-TM-1639

Appendix A

Specifications for the Prometheus Critical Experiments 
B-TM-1639

(Intentionally Blank)

A-2 


\section{Specifications for the Base-1 Experiment}

Starting at the bottom of the assembly $\left(z=0.0^{\prime \prime}\right)$, the experimental stack up is:

1.25" Al 6061-T6 (platen)

3.0" Al 6061-T6 (spindle plate)

$1.0^{\prime \prime}$ graphite (reflector)

17 stacking units consisting of [0.118" HEU, 0.100 " graphite]

1 stacking unit consisting of [0.118" HEU]

1.0 " graphite (reflector)

In addition:

1. All of the above cylindrical plates have a 21.0 inch outer diameter. Void extends both axially and radially beyond the assembly.

2. A 2.50 inch diameter hole extends through the center of the Al spindle plate, while a 2.51 inch diameter hole extends through the center of the assembly up to the top of the $7^{\text {th }}$ unit to accommodate an empty Al 6061-T6 alignment tube (2.0 inch inner diameter, 2.48 inch outer diameter). The alignment tube extends from the bottom of the assembly $\left(z=0.0^{\prime \prime}\right)$ to the top of the $6^{\text {th }}$ unit.

3. The nominal thickness of the graphite plates used in the central assembly is 0.100 inches.

4. The thickness of the upper graphite reflector may be adjusted to ensure that the excess reactivity of the assembly is less than $\$ 0.50$ at full closure. The tolerance on the upper reflector thickness shall be $+/-0.5$ inches. If the upper reflector thickness is outside this tolerance band, another stacking unit should be added or subtracted from the assembly or the mass of the HEU fuel plate in the last unit may be adjusted. 


\section{Specifications for the Base-2 Experiment}

Starting at the bottom of the assembly $\left(z=0.0^{\prime \prime}\right)$, the experimental stack up is:

1.25" Al 6061-T6 (platen)

3.0" Al 6061-T6 (spindle plate)

2.0 " graphite (reflector)

15 stacking units consisting of [0.118" HEU, $0.197^{\prime \prime}$ graphite]

1 stacking unit consisting of [0.118" HEU]

$2.0^{\prime \prime}$ graphite (reflector)

In addition:

1. All of the above cylindrical plates have a 21.0 inch outer diameter. Void extends both axially and radially beyond the assembly.

2. A 2.50 inch diameter hole extends through the center of the Al spindle plate, while a 2.51 inch diameter hole extends through the center of the assembly up to the top of the $7^{\text {th }}$ unit to accommodate an empty Al 6061-T6 alignment tube (2.0 inch inner diameter, 2.48 inch outer diameter). The alignment tube extends from the bottom of the assembly ( $\left.z=0.0^{\prime \prime}\right)$ to the top of the $6^{\text {th }}$ unit.

3. The nominal thickness of the graphite plates used in the central assembly is 0.197 inches.

4. The thickness of the upper graphite reflector may be adjusted to ensure that the excess reactivity of the assembly is less than $\$ 0.50$ at full closure. The tolerance on the upper reflector thickness shall be $+/-0.5$ inches. If the upper reflector thickness is outside this tolerance band, another stacking unit should be added or subtracted from the assembly or the mass of the HEU fuel plate in the last unit may be adjusted. 


\section{Specifications for the Base-3 Experiment}

Starting at the bottom of the assembly $\left(z=0.0^{\prime \prime}\right)$, the experimental stack up is:

1.25" Al 6061-T6 (platen)

3.0" Al 6061-T6 (spindle plate)

$5.0^{\prime \prime}$ graphite (reflector)

12 stacking units consisting of [0.118" HEU, 0.394" graphite]

1 stacking unit consisting of [0.118" HEU]

$5.0 "$ graphite (reflector)

In addition:

1. All of the above cylindrical plates have a 21.0 inch outer diameter. Void extends both axially and radially beyond the assembly.

2. A 2.50 inch diameter hole extends through the center of the Al spindle plate, while a 2.51 inch diameter hole extends through the center of the assembly up to the top of the $7^{\text {th }}$ unit to accommodate an empty Al 6061-T6 alignment tube (2.0 inch inner diameter, 2.48 inch outer diameter). The alignment tube extends from the bottom of the assembly ( $z=0.0$ ") to the top of the $6^{\text {th }}$ unit.

3. The nominal thickness of the graphite plates used in the central assembly is 0.394 inches.

4. The thickness of the upper graphite reflector may be adjusted to ensure that the excess reactivity of the assembly is less than $\$ 0.50$ at full closure. The tolerance on the upper reflector thickness shall be $+/-1.0$ inches. If the upper reflector thickness is outside this tolerance band, another stacking unit should be added or subtracted from the assembly or the mass of the HEU fuel plate in the last unit may be adjusted. 


\section{Specifications for the Base-4 Experiment}

Starting at the bottom of the assembly $\left(z=0.0^{\prime \prime}\right)$, the experimental stack up is:

1.25" Al 6061-T6 (platen)

3.0" Al 6061-T6 (spindle plate)

$1.0^{\prime \prime}$ polyethylene (reflector)

10 stacking units consisting of $\left[0.118^{\prime \prime} \mathrm{HEU}, 0.080^{\prime \prime}\right.$ polyethylene]

1 stacking unit consisting of [0.118" HEU]

1.0 " polyethylene (reflector)

In addition:

1. All of the above cylindrical plates have a 21.0 inch outer diameter. Void extends both axially and radially beyond the assembly.

2. A 2.50 inch diameter hole extends through the center of the Al spindle plate, while a 2.51 inch diameter hole extends through the center of the assembly up to the top of the $6^{\text {th }}$ unit to accommodate an empty Al 6061-T6 alignment tube (2.0 inch inner diameter, 2.48 inch outer diameter). The alignment tube extends from the bottom of the assembly ( $\left.z=0.0^{\prime \prime}\right)$ to the top of the $5^{\text {th }}$ unit.

3. The nominal thickness of the high density polyethylene plates used in the central assembly is 0.080 inches.

4. The thickness of the upper polyethylene reflector may be adjusted to ensure that the excess reactivity of the assembly is less than $\$ 0.50$ at full closure. The tolerance on the upper reflector thickness shall be $+/-0.50$ inches. If the upper reflector thickness is outside this tolerance band, another stacking unit should be added or subtracted from the assembly or the mass of the HEU fuel plate in the last stacking unit may be adjusted. 


\section{Specifications for the Mo-1 Experiment}

Starting at the bottom of the assembly $(z=0.0 ")$, the experimental stack up is:

1.25" Al 6061-T6 (platen)

3.0" Al 6061-T6 (spindle plate)

$1.0^{\prime \prime}$ graphite (reflector)

$0.180^{\prime \prime}$ (3@ 0.060") Mo (reflector)

0.100 " graphite

17 stacking units consisting of [0.030" Mo, 0.118" HEU, $0.030 "$ Mo, 0.100 " graphite]

$0.180^{\prime \prime}$ (3@0.060") Mo (reflector)

$1.0^{\prime \prime}$ graphite (reflector)

In addition:

1. All of the above cylindrical plates have a 21.0 inch outer diameter. Void extends both axially and radially beyond the assembly.

2. A 2.5 inch diameter hole extends through the center of the Al spindle plate, while a 2.51 inch diameter hole extends through the center of the assembly up to the top of the $7^{\text {th }}$ unit to accommodate an empty Al 6061-T6 alignment tube (2.0 inch inner diameter, 2.48 inch outer diameter). The alignment tube extends from the bottom of the assembly $\left(z=0.0^{\prime \prime}\right)$ to the top of the $6^{\text {th }}$ unit.

3. The thickness of the graphite plates used in the central assembly shall be $0.100 \pm 0.005$ inch.

4. The thickness of the upper graphite reflector may be adjusted to ensure that the excess reactivity of the assembly is less than $\$ 0.50$ at full closure. The tolerance on the upper reflector thickness shall be $+/-0.5$ inches. If the upper reflector thickness is outside this tolerance band, another stacking unit should be added or subtracted from the assembly or the mass of the HEU fuel plate in the last unit may be adjusted. 
B-TM-1639

\section{Specifications for the Mo-2 Experiment}

Starting at the bottom of the assembly $\left(z=0.0^{\prime \prime}\right)$, the experimental stack up is:

$1.25 "$ Al 6061-T6 (platen)

3.0" Al 6061-T6 (spindle plate)

$2.0 "$ graphite (reflector)

$0.180 "$ (3@0.060") Mo (reflector)

$0.197^{\prime \prime}$ graphite

15 stacking units consisting of [0.030" Mo, 0.118" HEU, $0.030^{\prime \prime}$ Mo, $0.197^{\prime \prime}$ graphite]

$0.180 "$ (3@0.060") Mo (reflector)

2.0 " graphite (reflector)

In addition:

1. All of the above cylindrical plates have a 21.0 inch outer diameter. Void extends both axially and radially beyond the assembly.

2. A 2.5 inch diameter hole extends through the center of the Al spindle plate, while a 2.51 inch diameter hole extends through the center of the assembly up to the top of the $7^{\text {th }}$ unit to accommodate an empty Al 6061-T6 alignment tube (2.0 inch inner diameter, 2.48 inch outer diameter). The alignment tube extends from the bottom of the assembly $\left(z=0.0^{\prime \prime}\right)$ to the top of the $6^{\text {th }}$ unit.

3. The thickness of the graphite plates used in the central assembly shall be $0.197 \pm 0.005$ inch.

4. The thickness of the upper graphite reflector may be adjusted to ensure that the excess reactivity of the assembly is less than $\$ 0.50$ at full closure. The tolerance on the upper reflector thickness shall be $+/-1.0$ inches. If the upper reflector thickness is outside this tolerance band, another stacking unit should be added or subtracted from the assembly or the mass of the HEU fuel plate in the last stacking unit may be adjusted. 


\section{Specifications for the Mo-3 Experiment}

Starting at the bottom of the assembly $\left(z=0.0^{\prime \prime}\right)$, the experimental stack up is:

1.25" Al 6061-T6 (platen)

3.0" Al 6061-T6 (spindle plate)

$5.0^{\prime \prime}$ graphite (reflector)

$0.180 "$ (3@0.060") Mo (reflector)

0.394 " graphite

14 stacking units consisting of [0.030" Mo, 0.118" HEU, 0.030 " Mo, 0.394 " graphite]

0.180 " (3 @ 0.060") Mo (reflector)

5.0 " graphite (reflector)

In addition:

1. All of the above cylindrical plates have a 21.0 inch outer diameter. Void extends both axially and radially beyond the assembly.

2. A 2.5 inch diameter hole extends through the center of the Al spindle plate, while a 2.51 inch diameter hole extends through the center of the assembly up to the top of the $7^{\text {th }}$ unit to accommodate an empty Al 6061-T6 alignment tube (2.0 inch inner diameter, 2.48 inch outer diameter). The alignment tube extends from the bottom of the assembly $(z=0.0$ ") to the top of the $6^{\text {th }}$ unit.

3. The thickness of the graphite plates used in the central assembly shall be $0.394 \pm 0.006$ inch.

4. The thickness of the upper graphite reflector may be adjusted to ensure that the excess reactivity of the assembly is less than $\$ 0.50$ at full closure. The tolerance on the upper reflector thickness shall be $+/-1.0$ inches. If the upper reflector thickness is outside this tolerance band, another stacking unit should be added or subtracted from the assembly or the mass of the HEU fuel plate in the last stacking unit may be adjusted. 


\section{Specifications for the Mo-4 Experiment}

Starting at the bottom of the assembly $\left(z=0.0^{\prime \prime}\right)$, the experimental stack up is:

1.25" Al 6061-T6 (platen)

3.0" Al 6061-T6 (spindle plate)

1.0 " polyethylene (reflector)

$0.180 "$ (3@0.060 in) Mo (reflector)

$0.080^{\prime \prime}$ polyethylene

11 stacking units consisting of [0.030" Mo, $0.118^{\prime \prime} \mathrm{HEU}, 0.030^{\prime \prime} \mathrm{Mo}, 0.080^{\prime \prime}$ polyethylene]

$0.180^{\prime \prime}$ (3@0.060") Mo (reflector)

$1.0 "$ polyethylene (reflector)

In addition:

1. All of the above cylindrical plates have a 21.0 inch outer diameter. Void extends both axially and radially beyond the assembly.

2. A 2.5 inch diameter hole extends through the center of the Al spindle plate, while a 2.51 inch diameter hole extends through the center of the assembly up to the top of the $6^{\text {th }}$ unit to accommodate an empty Al 6061-T6 alignment tube (2.0 inch inner diameter, 2.48 inch outer diameter). The alignment tube extends from the bottom of the assembly $\left(z=0.0^{\prime \prime}\right)$ to the top of the $5^{\text {th }}$ unit.

3. The thickness of the high density polyethylene plates used in the central assembly shall be $0.080 \pm 0.004$ inch.

4. The thickness of the upper polyethylene reflector may be adjusted to ensure that the excess reactivity of the assembly is less than $\$ 0.50$ at full closure. The tolerance on the upper reflector thickness shall be $+/-0.50$ inches. If the upper reflector thickness is outside this tolerance band, another stacking unit should be added or subtracted from the assembly or the mass of the HEU fuel plate in the last stacking unit may be adjusted. 


\section{Specifications for the Nb-1Zr-2 Experiment}

Starting at the bottom of the assembly $\left(z=0.0^{\prime \prime}\right)$, the experimental stack up is:

1.25" Al 6061-T6 (platen)

3.0" Al 6061-T6 (spindle plate)

2.0 " graphite (reflector)

$0.180 " \mathrm{Nb}-1 \mathrm{Zr}$ (reflector)

0.197 " graphite

16 stacking units consisting of [0.040" Nb-1Zr, 0.118 " HEU, $0.040 " \mathrm{Nb}-1 \mathrm{Zr}, 0.197$ " graphite]

$0.180 " \mathrm{Nb}-1 \mathrm{Zr}$ (reflector)

$2.0^{\prime \prime}$ graphite (reflector)

In addition:

1. All of the above cylindrical plates have a 21.0 inch outer diameter. Void extends both axially and radially beyond the assembly.

2. A 2.5 inch diameter hole extends through the center of the Al spindle plate, while a 2.51 inch diameter hole extends through the center of the assembly up to the top of the $7^{\text {th }}$ unit to accommodate an empty Al 6061-T6 alignment tube (2.0 inch inner diameter, 2.48 inch outer diameter). The alignment tube extends from the bottom of the assembly ( $z=0.0$ ") to the top of the $6^{\text {th }}$ unit.

3. The thickness of the graphite plates used in the central assembly shall be $0.197 \pm 0.005$ inch.

4. The thickness of the upper graphite reflector may be adjusted to ensure that the excess reactivity of the assembly is less than $\$ 0.50$ at full closure. The tolerance on the upper reflector thickness shall be +/- 1.0 inches. If the upper reflector thickness is outside this tolerance band, another stacking unit should be added or subtracted from the assembly or the mass of the HEU fuel plate in the last stacking unit may be adjusted. 
B-TM-1639

\section{Specifications for the Nb-1Zr-3 Experiment}

Starting at the bottom of the assembly $\left(z=0.0^{\prime \prime}\right)$, the experimental stack up is:

1.25" Al 6061-T6 (platen)

3.0" Al 6061-T6 (spindle plate)

5.0 " graphite (reflector)

$0.180^{\prime \prime} \mathrm{Nb}-1 \mathrm{Zr}$ (reflector)

0.394 " graphite

15 stacking units consisting of [0.040" Nb-1Zr, 0.118" HEU, 0.040" Nb-1Zr, 0.394" graphite]

$0.180^{\prime \prime} \mathrm{Nb}-1 \mathrm{Zr}$ (reflector)

$5.0^{\prime \prime}$ graphite (reflector)

In addition:

1. All of the above cylindrical plates have a 21.0 inch outer diameter. Void extends both axially and radially beyond the assembly.

2. A 2.5 inch diameter hole extends through the center of the Al spindle plate, while a 2.51 inch diameter hole extends through the center of the assembly up to the top of the $7^{\text {th }}$ unit to accommodate an empty Al 6061-T6 alignment tube (2.0 inch inner diameter, 2.48 inch outer diameter). The alignment tube extends from the bottom of the assembly $\left(z=0.0^{\prime \prime}\right)$ to the top of the $6^{\text {th }}$ unit.

3. The thickness of the graphite plates used in the central assembly shall be $0.394 \pm 0.006$ inch.

4. The thickness of the upper graphite reflector may be adjusted to ensure that the excess reactivity of the assembly is less than $\$ 0.50$ at full closure. The tolerance on the upper reflector thickness shall be $+/-1.0$ inches. If the upper reflector thickness is outside this tolerance band, another stacking unit should be added or subtracted from the assembly or the mass of the HEU fuel plate in the last stacking unit may be adjusted. 


\section{Specifications for the Re-1 Experiment}

Starting at the bottom of the assembly $\left(z=0.0^{\prime \prime}\right)$, the experimental stack up is:

$1.25 "$ Al 6061-T6 (platen)

3.0" Al 6061-T6 (spindle plate)

$1.0 "$ graphite (reflector)

18 stacking units consisting of [0.015" Re, 0.118" HEU, 0.015" Re, 0.100" graphite]

1 stacking unit consisting of [0.015" Re, 0.118" HEU, $0.015^{\prime \prime} \mathrm{Re}$ ]

$1.0^{\prime \prime}$ graphite (reflector)

In addition:

1. All of the above cylindrical plates have a 21.0 inch outer diameter. Void extends both axially and radially beyond the assembly.

2. A 2.5 inch diameter hole extends through the center of the Al spindle plate, while a 2.51 inch diameter hole extends through the center of the assembly up to the top of the $7^{\text {th }}$ unit to accommodate an empty Al 6061-T6 alignment tube (2.0 inch inner diameter, 2.48 inch outer diameter). The alignment tube extends from the bottom of the assembly $\left(z=0.0^{\prime \prime}\right)$ to the top of the $6^{\text {th }}$ unit.

3. The thickness of the graphite plates used in the central assembly shall be $0.100 \pm 0.005$ inch.

4. The thickness of the upper graphite reflector may be adjusted to ensure that the excess reactivity of the assembly is less than $\$ 0.50$ at full closure. The tolerance on the upper reflector thickness shall be $+/-0.5$ inches. If the upper reflector thickness is outside this tolerance band, another stacking unit should be added or subtracted from the assembly or the mass of the HEU fuel plate in the last unit may be adjusted. 


\section{B-TM-1639}

\section{Specifications for the Re-2 Experiment}

Starting at the bottom of the assembly $(z=0.0$ "), the experimental stack up is:

1.25" Al 6061-T6 (platen)

3.0" Al 6061-T6 (spindle plate)

$2.0^{\prime \prime}$ graphite (reflector)

16 stacking units consisting of [0.015" Re, 0.118" HEU, 0.015" Re, 0.197" graphite]

1 stacking units consisting of [0.015" Re, 0.118" HEU, 0.015" Re]

2.0 " graphite (reflector)

In addition:

1. All of the above cylindrical plates have a 21.0 inch outer diameter. Void extends both axially and radially beyond the assembly.

2. A 2.5 inch diameter hole extends through the center of the Al spindle plate, while a 2.51 inch diameter hole extends through the center of the assembly up to the top of the $7^{\text {th }}$ unit to accommodate an empty Al 6061-T6 alignment tube (2.0 inch inner diameter, 2.48 inch outer diameter). The alignment tube extends from the bottom of the assembly $\left(z=0.0^{\prime \prime}\right)$ to the top of the $6^{\text {th }}$ unit.

3. The thickness of the graphite plates used in the central assembly shall be $0.197 \pm 0.005$ inch.

4. The thickness of the upper graphite reflector may be adjusted to ensure that the excess reactivity of the assembly is less than $\$ 0.50$ at full closure. The tolerance on the upper reflector thickness shall be $+/-1.0$ inches. If the upper reflector thickness is outside this tolerance band, another unit should be added or subtracted from the assembly or the mass of the HEU fuel plate in the last stacking unit may be adjusted. 


\section{Specifications for the Re-3 Experiment}

Starting at the bottom of the assembly $\left(z=0.0^{\prime \prime}\right)$, the experimental stack up is:

1.25" Al 6061-T6 (platen)

3.0" Al 6061-T6 (spindle plate)

$5.0^{\prime \prime}$ graphite (reflector)

15 stacking units consisting of [0.015" Re, 0.118" HEU, 0.015" Re, 0.394" graphite]

1 stacking units consisting of [0.015" Re, 0.118" HEU, 0.015" Re]

5.0 " graphite (reflector)

In addition:

1. All of the above cylindrical plates have a 21.0 inch outer diameter. Void extends both axially and radially beyond the assembly.

2. A 2.5 inch diameter hole extends through the center of the Al spindle plate, while a 2.51 inch diameter hole extends through the center of the assembly up to the top of the $7^{\text {th }}$ unit to accommodate an empty Al 6061-T6 alignment tube (2.0 inch inner diameter, 2.48 inch outer diameter). The alignment tube extends from the bottom of the assembly $\left(z=0.0^{\prime \prime}\right)$ to the top of the $6^{\text {th }}$ unit.

3. The thickness of the graphite plates used in the central assembly shall be $0.394 \pm 0.006$ inch.

4. The thickness of the upper graphite reflector may be adjusted to ensure that the excess reactivity of the assembly is less than $\$ 0.50$ at full closure. The tolerance on the upper reflector thickness shall be $+/-1.0$ inches. If the upper reflector thickness is outside this tolerance band, another stacking unit should be added or subtracted from the assembly or the mass of the HEU fuel plate in the last stacking unit may be adjusted. 


\section{Specifications for the Re-4 Experiment}

Starting at the bottom of the assembly $(z=0.0$ "), the experimental stack up is:

1.25" Al 6061-T6 (platen)

3.0" Al 6061-T6 (spindle plate)

1.0 " polyethylene (reflector)

14 stacking units consisting of [0.015" Re, $0.118^{\prime \prime} \mathrm{HEU}, 0.015^{\prime \prime} \mathrm{Re}, 0.080^{\prime \prime}$ polyethylene]

1 stacking units consisting of [0.015" Re, 0.118" HEU, 0.015" Re]

$1.0^{\prime \prime}$ polyethylene (reflector)

In addition:

1. All of the above cylindrical plates have a 21.0 inch outer diameter. Void extends both axially and radially beyond the assembly.

2. A 2.5 inch diameter hole extends through the center of the Al spindle plate, while a 2.51 inch diameter hole extends through the center of the assembly up to the top of the $7^{\text {th }}$ unit to accommodate an empty Al 6061-T6 alignment tube (2.0 inch inner diameter, 2.48 inch outer diameter). The alignment tube extends from the bottom of the assembly $\left(z=0.0^{\prime \prime}\right)$ to the top of the $6^{\text {th }}$ unit.

3. The thickness of the high density polyethylene plates used in the central assembly shall be $0.080 \pm 0.004$ inch.

4. The thickness of the upper polyethylene reflector may be adjusted to ensure that the excess reactivity of the assembly is less than $\$ 0.50$ at full closure. The tolerance on the upper reflector thickness shall be $+/-0.50$ inches. If the upper reflector thickness is outside this tolerance band, another stacking unit should be added or subtracted from the assembly or the mass of the HEU fuel plate in the last stacking unit may be adjusted. 


\section{Specifications for the Ta-2.5W-1 Experiment}

Starting at the bottom of the assembly $\left(z=0.0^{\prime \prime}\right)$, the experimental stack up is:

1.25" Al 6061-T6 (platen)

3.0" Al 6061-T6 (spindle plate)

1.0 " graphite (reflector)

$0.150^{\prime \prime}$ (6@0.025") Ta-2.5W (reflector)

$0.100 "$ graphite

19 stacking units consisting of [0.025" Ta-2.5W, 0.118" HEU, 0.025" Ta-2.5W, 0.100" graphite]

0.150" (6@0.025") Ta-2.5W (reflector)

$1.0^{\prime \prime}$ graphite (reflector)

In addition:

1. All of the above cylindrical plates have a 21.0 inch outer diameter. Void extends both axially and radially beyond the assembly.

2. A 2.5 inch diameter hole extends through the center of the Al spindle plate, while a 2.51 inch diameter hole extends through the center of the assembly up to the top of the $7^{\text {th }}$ unit to accommodate an empty Al 6061-T6 alignment tube (2.0 inch inner diameter, 2.48 inch outer diameter). The alignment tube extends from the bottom of the assembly $(z=0.0$ ) to the top of the $6^{\text {th }}$ unit.

3. The Ta-2.5W plates from heat 11-19-2 shall be used to construct the bottom and center of the assembly until they are expended, then Ta-2.5W plates from heat 10-20-2 shall be used to complete the top of the assembly. Ta-2.5W plates from different heats shall not be mixed in a unit or in the top and bottom reflector. Ta-2.5W plates from heat 10-20-2 should be used to construct the top and bottom reflectors.

4. The thickness of the graphite plates used in the central assembly shall be $0.100 \pm 0.005$ inch.

5. The thickness of the upper graphite reflector may be adjusted to ensure that the excess reactivity of the assembly is less than $\$ 0.50$ at full closure. The tolerance on the upper reflector thickness shall be $+/-0.4$ inches. If the upper reflector thickness is outside this tolerance band, another stacking unit should be added or subtracted from the assembly or the mass of the HEU fuel plate in the last unit may be adjusted. 


\section{Specifications for the Ta-2.5W-2 Experiment}

Starting at the bottom of the assembly $\left(z=0.0^{\prime \prime}\right)$, the experimental stack up is:

$1.25^{\prime \prime} \mathrm{Al} 6061-\mathrm{T6}$ (platen)

3.0" Al 6061-T6 (spindle plate)

2.0 " graphite (reflector)

$0.150 "$ (6@ @ 0.025") Ta-2.5W (reflector)

0.200 " graphite

17 stacking units consisting of [0.025" Ta-2.5W, 0.118" HEU, $0.025^{\prime \prime}$ Ta-2.5W, 0.200 " graphite]

$0.150 "$ " (6@ 0.025") Ta-2.5W (reflector)

$2.0 "$ graphite (reflector)

In addition:

5. All of the above cylindrical plates have a 21.0 inch outer diameter. Void extends both axially and radially beyond the assembly.

6. A 2.5 inch diameter hole extends through the center of the Al spindle plate, while a 2.51 inch diameter hole extends through the center of the assembly up to the top of the $7^{\text {th }}$ unit to accommodate an empty Al 6061-T6 alignment tube (2.0 inch inner diameter, 2.48 inch outer diameter). The alignment tube extends from the bottom of the assembly $\left(z=0.0^{\prime \prime}\right)$ to the top of the $6^{\text {th }}$ unit.

7. The thickness of the graphite plates used in the central assembly shall be $0.200 \pm 0.005$ inch.

8. The Ta-2.5W plates from heat 11-19-2 shall be used to construct the bottom and center of the assembly until they are expended, then Ta-2.5W plates from heat 10-20-2 shall be used to complete the top of the assembly. Ta-2.5W plates from different heats shall not be mixed in a unit or in the top and bottom reflector. Ta-2.5W plates from heat $10-20-2$ should be used to construct the top and bottom reflectors.

9. The thickness of the upper graphite reflector may be adjusted to ensure that the excess reactivity of the assembly is less than $\$ 0.50$ at full closure. The tolerance on the upper reflector thickness shall be $+/-1.0$ inches. If the upper reflector thickness is outside this tolerance band, another stacking unit should be added or subtracted from the assembly or the mass of the HEU fuel plate in the last stacking unit may be adjusted. 


\section{Specifications for the Ta-2.5W-3 Experiment}

Starting at the bottom of the assembly $\left(z=0.0^{\prime \prime}\right)$, the experimental stack up is:

$$
\text { 1.25" Al 6061-T6 (platen) }
$$

3.0" Al 6061-T6 (spindle plate)

$5.0^{\prime \prime}$ graphite (reflector)

$0.150^{\prime \prime}$ (6@ @ 0.025") Ta-2.5W (reflector)

0.394 " graphite

18 stacking units consisting of [0.025" Ta-2.5W, $0.118^{\prime \prime} \mathrm{HEU}, 0.025^{\prime \prime} \mathrm{Ta}-2.5 \mathrm{~W}, 0.394$ " graphite]

$0.150 "$ (6@ 0.025") Ta-2.5W (reflector)

$5.0^{\prime \prime}$ graphite (reflector)

In addition:

5. All of the above cylindrical plates have a 21.0 inch outer diameter. Void extends both axially and radially beyond the assembly.

6. A 2.5 inch diameter hole extends through the center of the Al spindle plate, while a 2.51 inch diameter hole extends through the center of the assembly up to the top of the $7^{\text {th }}$ unit to accommodate an empty Al 6061-T6 alignment tube (2.0 inch inner diameter, 2.48 inch outer diameter). The alignment tube extends from the bottom of the assembly $\left(z=0.0^{\prime \prime}\right)$ to the top of the $6^{\text {th }}$ unit.

7. The thickness of the graphite plates used in the central assembly shall be $0.394 \pm 0.006$ inch.

8. The Ta-2.5W plates from heat 11-19-2 shall be used to construct the bottom and center of the assembly until they are expended, then Ta-2.5W plates from heat $10-20-2$ shall be used to complete the top of the assembly. Ta-2.5W plates from different heats shall not be mixed in a unit or in the top and bottom reflector. Ta-2.5W plates from heat 10-20-2 should be used to construct the top and bottom reflectors.

9. The thickness of the upper graphite reflector may be adjusted to ensure that the excess reactivity of the assembly is less than $\$ 0.50$ at full closure. The tolerance on the upper reflector thickness shall be $+/-1.0$ inches. If the upper reflector thickness is outside this tolerance band, another stacking unit should be added or subtracted from the assembly or the mass of the HEU fuel plate in the last stacking unit may be adjusted. 


\section{Specifications for the Ta-2.5W-4 Experiment}

Starting at the bottom of the assembly $\left(z=0.0^{\prime \prime}\right)$, the experimental stack up is:

1.25" Al 6061-T6 (platen)

3.0" Al 6061-T6 (spindle plate)

1.0" polyethylene (reflector)

0.150 " (6@0.025 in) Ta-2.5W (reflector)

0.080 " polyethylene

16 stacking units consisting of [0.025" Ta-2.5W, 0.118" HEU, 0.025" Ta-2.5W, 0.080" polyethylene]

$0.150^{\prime \prime}$ (6@ 0.025") Ta-2.5W (reflector)

1.0 " polyethylene (reflector)

In addition:

1. All of the above cylindrical plates have a 21.0 inch outer diameter. Void extends both axially and radially beyond the assembly.

2. A 2.5 inch diameter hole extends through the center of the Al spindle plate, while a 2.51 inch diameter hole extends through the center of the assembly up to the top of the $7^{\text {th }}$ unit to accommodate an empty Al 6061-T6 alignment tube (2.0 inch inner diameter, 2.48 inch outer diameter). The alignment tube extends from the bottom of the assembly $\left(z=0.0^{\prime \prime}\right)$ to the top of the $6^{\text {th }}$ unit.

3. The thickness of the high density polyethylene plates used in the central assembly shall be $0.080 \pm 0.005$ inch.

4. The Ta-2.5W plates from heat 11-19-2 shall be used to construct the bottom and center of the assembly until they are expended, then Ta-2.5W plates from heat $10-20-2$ shall be used to complete the top of the assembly. Ta-2.5W plates from different heats shall not be mixed in a unit or in the top and bottom reflector. Ta-2.5W plates from heat $10-20-2$ should be used to construct the top and bottom reflectors.

5. The thickness of the upper polyethylene reflector may be adjusted to ensure that the excess reactivity of the assembly is less than $\$ 0.50$ at full closure. The tolerance on the upper reflector thickness shall be $+/-0.40$ inches. If the upper reflector thickness is outside this tolerance band, another unit should be added or subtracted from the assembly or the mass of the HEU fuel plate in the last stacking unit may be adjusted. 


\section{Appendix B}

Specifications for the ORNL Nb-1Zr Critical Experiments 
B-TM-1639

(Intentionally Blank) 


\section{THE NIOBIUM EXPERIMENTS}

Description of the experimental configuration in Mexp 2J (k-eff $=0.99754+/-0.00048$ )

Starting at bottom $(y=0.0)$, one has:

$6.0372 \mathrm{~cm}$ of void, $3.81 \mathrm{~cm}$ of aluminum (the platen), $14.4274 \mathrm{~cm}$ of $\mathrm{Cu}, 1.007872 \mathrm{~cm}$ of $\mathrm{gr}$, [ 8 cells of $(0.299720 \mathrm{~cm}$ of HEU, $1.007872 \mathrm{~cm}$ of $\mathrm{gr}, 0.076200 \mathrm{~cm}$ of $\mathrm{Nb}-1 \mathrm{Zr}, 1.007872 \mathrm{~cm}$ of $\mathrm{gr})$ ], $0.299720 \mathrm{~cm}$ of HEU, $1.007872 \mathrm{~cm}$ of $\mathrm{gr}, 14.4272 \mathrm{~cm}$ of $\mathrm{Cu}$

In addition:

1. All of the above cylindrical plates extend out to a radius of $26.67 \mathrm{~cm}$, and are surrounded by a $0.127-\mathrm{cm}$ annular void, followed by a copper reflector out to $X=Z=+/-44.152 \mathrm{~cm}$. This copper reflector goes from the bottom at $Y=0.0$ to the top at $Y=60.150376 \mathrm{~cm}$.

2. A hole of radius $4.7625 \mathrm{~cm}$ extends up thru the center of the aluminum platen, while a smaller hole of radius $3.175 \mathrm{~cm}$ continues up to the top of the 5 th $\mathrm{HEU}$ plate to accommodate an empty aluminum support tube ( $\mathrm{rmin}=2.54 \mathrm{~cm}, \operatorname{rmax}=3.1496 \mathrm{~cm}$ ), which extends from the bottom of the configuration at $Y=0.0$, up to the top of the 5 th HEU plate at $Y=35.148648 \mathrm{~cm}$. 
B-TM-1639

Description of the experimental configuration in Mexp 2L $(k$-eff $=1.00454+/-0.00051)$

Starting at bottom $(y=0.0)$, one has:

$6.0372 \mathrm{~cm}$ of void, $3.81 \mathrm{~cm}$ of aluminum (the platen), $14.4274 \mathrm{~cm}$ of $\mathrm{Cu}, 0.503936 \mathrm{~cm}$ of gr, [8 cells of $(0.299720 \mathrm{~cm}$ of HEU, $0.503936 \mathrm{~cm}$ of gr, $0.076200 \mathrm{~cm}$ of $\mathrm{Nb}-1 \mathrm{Zr}, 0.503936 \mathrm{~cm}$ of $\mathrm{gr})$ ], $0.299720 \mathrm{~cm}$ of HEU, $0.503936 \mathrm{~cm}$ of $\mathrm{gr}, 14.4272 \mathrm{~cm}$ of $\mathrm{Cu}$

In addition:

1. All of the above cylindrical plates extend out to a radius of $26.67 \mathrm{~cm}$, and are surrounded by a $0.127-\mathrm{cm}$ annular void, followed by a copper reflector out to $X=Z=+/-44.152 \mathrm{~cm}$. This copper reflector goes from the bottom at $Y=0.0$ to the top at $Y=60.150376 \mathrm{~cm}$.

2. A hole of radius $4.7625 \mathrm{~cm}$ extends up thru the center of the aluminum platen, while a smaller hole of radius $3.175 \mathrm{~cm}$ continues up to the top of the 5th HEU plate to accommodate an empty aluminum support tube $(\mathrm{rmin}=2.54 \mathrm{~cm}, \mathrm{rmax}=3.1496 \mathrm{~cm})$, which extends from the bottom of the configuration at $Y=0.0$, up to the top of the 5th HEU plate at $Y=30.613224 \mathrm{~cm}$. 
Description of the experimental configuration in Mexp 4U (k-eff $=1.01212+/-0.00054)$

Starting at bottom $(y=-0.0001 \mathrm{~cm})$, one has:

$0.0001 \mathrm{~cm}$ of void, $3.81 \mathrm{~cm}$ of aluminum (the platen), $2.8575 \mathrm{~cm}$ Poly (refl), $0.279 \mathrm{~cm} \mathrm{Nb} 1 \mathrm{Zr}$ (refl), $0.0508 \mathrm{~cm}$ Poly, $0.1016 \mathrm{~cm} \mathrm{Nb} 1 \mathrm{Zr}, 0.29972 \mathrm{~cm} \mathrm{HEU,} 0.1016 \mathrm{~cm} \mathrm{Nb} 1 \mathrm{Zr}$, [12 cells of $(0.1016 \mathrm{~cm}$ Poly, $0.1016 \mathrm{~cm} \mathrm{Nb1Zr,} 0.29972 \mathrm{~cm} \mathrm{HEU,} 0.1016 \mathrm{~cm} \mathrm{Nb} 1 \mathrm{Zr})$ ], $0.0508 \mathrm{~cm}$ Poly, $0.279 \mathrm{~cm} \mathrm{Nb1Zr}$ (refl), $2.8575 \mathrm{~cm}$ Poly (refl), $0.0001 \mathrm{~cm}$ void

In addition:

1. All of the above cylindrical plates extend out to a radius of $26.67 \mathrm{~cm}$. Beyond that radially, there is nothing but void (ie, no copper reflector).

2. A hole of radius $4.7625 \mathrm{~cm}$ extends up thru the center of the aluminum platen, while a smaller hole of radius $3.175 \mathrm{~cm}$ continues up to the top of the 5th HEU plate to accommodate an empty aluminum support tube $(\mathrm{rmin}=2.54 \mathrm{~cm}, \mathrm{rmax}=3.1496 \mathrm{~cm})$, which extends from the bottom of the configuration at $Y=-0.0001$, up to the top of the 5th HEU plate at $Y=9.8167 \mathrm{~cm}$.

3. Note that this bare configuration has $13 \mathrm{HEU}$ plates, 26 of the $0.1016-\mathrm{cm} \mathrm{Nb}-1 \mathrm{Zr}$ plates, 12 of the $0.1016-\mathrm{cm}$-thk (and 2 of the $0.0508-\mathrm{cm}$-thk) polyethylene moderator sheets, two $2.8575-\mathrm{cm}$ poly (refl) plates, and two $0.279-\mathrm{cm}$-thk $\mathrm{Nb}-1 \mathrm{Zr}$ reflector plates. There is no copper reflector axially or radially.

4. The two innermost $\mathrm{Nb}-1 \mathrm{Zr}$ reflector plates have the same thickness $(0.279 \mathrm{~cm})$ as the space reactor vessel while the 2 outermost Poly reflector plates simulate the reactor reflector. These Poly reflector plates had to be somewhat thicker than in the previous cases in order to attain criticality. Above configuration extends from $Y=-0.0001$ to $Y=17.94186 \mathrm{~cm}$. 
B-TM-1639

Description of the experimental configuration in Mexp 4Y (k-eff $=1.01665+/-0.00051)$

Starting at bottom $(y=-0.0001 \mathrm{~cm})$, one has:

$0.0001 \mathrm{~cm}$ of void, $3.81 \mathrm{~cm}$ of aluminum (the platen), $0.0001 \mathrm{~cm}$ Poly, $0.279 \mathrm{~cm} \mathrm{Nb}-1 \mathrm{Zr}$ (refl), $0.003810 \mathrm{~cm}$ Poly, $0.1016 \mathrm{~cm} \mathrm{Nb}-1 \mathrm{Zr}, 0.29972 \mathrm{~cm} \mathrm{HEU}, 0.1016 \mathrm{~cm} \mathrm{Nb}-1 \mathrm{Zr}$, [20 cells of $(0.00762 \mathrm{~cm}$ Poly, $0.1016 \mathrm{~cm} \mathrm{Nb}-1 \mathrm{Zr}, 0.29972 \mathrm{~cm} \mathrm{HEU,} 0.1016 \mathrm{~cm} \mathrm{Nb}-1 \mathrm{Zr})$ ], $0.00381 \mathrm{~cm}$ Poly, $0.279 \mathrm{~cm} \mathrm{Nb}-1 \mathrm{Zr}$ (refl), $0.0001 \mathrm{~cm}$ Poly, $0.0001 \mathrm{~cm}$ void

In addition:

1. All of the above cylindrical plates extend out to a radius of $26.67 \mathrm{~cm}$. Beyond that radially, there is nothing but void (ie, no copper reflector).

2. A hole of radius $4.7625 \mathrm{~cm}$ extends up thru the center of the aluminum platen, while a smaller hole of radius $3.175 \mathrm{~cm}$ continues up to the top of the 5th HEU plate to accommodate an empty aluminum support tube $(r \min =2.54 \mathrm{~cm}, r \max =3.1496 \mathrm{~cm})$, which extends from the bottom of the configuration at $Y=-0.0001$, up to the top of the 5 th HEU plate at $Y=6.53639 \mathrm{~cm}$.

3. Note that this bare configuration has $21 \mathrm{HEU}$ plates, 42 of the $0.1016-\mathrm{cm} \mathrm{Nb-1Zr}$ plates, 20 of the $0.00762-\mathrm{cm}$-thk (and 2 of the $0.00381-\mathrm{cm}$-thk) polyethylene moderator sheets, two 0.279 -cm-thk Nb-1 $\mathrm{Zr}$ reflector plates. (The two 0.0001 -cm-thk polyethylene regions may be ignored.) There is no copper reflector axially or radially.

4. The two $\mathrm{Nb}-1 \mathrm{Zr}$ reflector plates have the same thickness $(0.279 \mathrm{~cm})$ as the space reactor vessel. Note that there is essentially no polyethylene reflector beyond the $\mathrm{Nb}-1 \mathrm{Zr}$. Criticality is achieved thru the use of a large number of HEU plates. The above configuration extends from $Y=-0.0001$ to $Y=15.08954 \mathrm{~cm}$. 


\section{Appendix C}

\section{Definition of SPACE05A Cross Section Library}

\begin{tabular}{|c|c|}
\hline Nuclide & Data Source \\
\hline $\mathrm{AC} 225$ & JENDL -3.3 \\
\hline $\mathrm{AC} 226$ & JENDL - 3.3 \\
\hline $\mathrm{AC} 227$ & JENDL - 3.3 \\
\hline AG107 & $\mathrm{ENDF} \backslash \mathrm{B}-\mathrm{VI} .0$ \\
\hline AGI09 & $\mathrm{ENDF} \backslash \mathrm{B}-\mathrm{VI}, \mathrm{O}$ \\
\hline AG110M & JENDL -3.2 \\
\hline AG111 & $\mathrm{ENDF} \backslash \mathrm{B}-\mathrm{VI} .0$ \\
\hline AL2 7 & $\mathrm{ENDF} \backslash \mathrm{B}-\mathrm{VI} .8$ \\
\hline AM2 41 & $\mathrm{ENDF} \backslash \mathrm{B}-\mathrm{VI} .3$ \\
\hline AM2 42 & $\mathrm{ENDF} \backslash \mathrm{B}-\mathrm{VI} .1$ \\
\hline AM242M & $\mathrm{ENDF} \backslash \mathrm{B}-\mathrm{VI} .1$ \\
\hline AM243 & $\mathrm{ENDF} \backslash \mathrm{B}-\mathrm{VI} .5$ \\
\hline AM2 44 & JENDL -3.2 \\
\hline AR36 & JEF -2.2 \\
\hline AR 38 & $J E F-2.2$ \\
\hline AR40 & $\mathrm{JEF}-2.2$ \\
\hline As 75 & JENDL -3.2 \\
\hline AU197 & $E N D F \backslash B-V I$. I \\
\hline B10 & $E N D F \backslash B-V I .1$ \\
\hline B11 & $E N D F \backslash B-V I .0$ \\
\hline BA130 & JENDL - 3.2 \\
\hline BA132 & JENDL - 3.2 \\
\hline BA134 & JENDL - 3.2 \\
\hline BA135 & JENDL- 3.2 \\
\hline $\mathrm{BA} 136$ & JENDL -3.2 \\
\hline BA137 & JENDL - 3.2 \\
\hline BA138 & JENDL - 3.2 \\
\hline BA140 & JENDL -3.2 \\
\hline $\mathrm{BE}-\mathrm{BEO}$ & $\mathrm{ENDF} \backslash \mathrm{B}-\mathrm{VI} .0$ \\
\hline BE-METAL & $E N D F \backslash B-V I .0$ \\
\hline $\mathrm{BE9}$ & $E N D F \backslash B-V I .8$ \\
\hline BI209 & $E N D F \backslash B-V I .7$ \\
\hline BK249 & $E N D F \backslash B-V I .0$ \\
\hline BK2 50 & JENDL - 3.2 \\
\hline BR79 & JENDL -3.2 \\
\hline BR81 & JENDL -3.2 \\
\hline $\mathrm{C}$ & $E N D F \backslash B-V I .6$ \\
\hline C-GRAPH & $\mathrm{END} F \backslash \mathrm{B}-\mathrm{VI} .6$ \\
\hline CA4O & JENDL -3.2 \\
\hline CA42 & JENDL -3.2 \\
\hline $\mathrm{CA} 43$ & JENDL -3.2 \\
\hline CA44 & JENDL -3.2 \\
\hline CA4 6 & JENDL -3.2 \\
\hline CA48 & JENDL -3.2 \\
\hline CD106 & $\mathrm{ENDF} \backslash \mathrm{B}-\mathrm{VI}$ \\
\hline
\end{tabular}




\begin{tabular}{|c|c|}
\hline Nuclide & Data Source \\
\hline CD108 & $E N D F \backslash B-V I, 4$ \\
\hline $\operatorname{CD} 110$ & $E N D F \backslash B-V I .4$ \\
\hline CD111 & $E N D F \backslash B-V I .3$ \\
\hline $\operatorname{CD} 112$ & $E N D F \backslash B-V I .4$ \\
\hline CD113 & $E N D F \backslash B-V I . O$ \\
\hline $\mathrm{CD} 114$ & $E N D F \backslash B-V I, 4$ \\
\hline CD115M & $E N D F \backslash B-V I .0$ \\
\hline $\operatorname{CD} 116$ & ENDF $\backslash B-V I .4$ \\
\hline CE140 & JENDL - 3.2 \\
\hline $\operatorname{CEI} 41$ & $E N D F \backslash B-V I .0$ \\
\hline $\operatorname{CE} 142$ & JENDL -3.2 \\
\hline $\mathrm{CE} 143$ & JEF - 2.2 \\
\hline CE144 & $E N D F \backslash B-V I .0$ \\
\hline CF249 & $E N D F \backslash B-V I, O$ \\
\hline CF250 & $E N D F \backslash B-V I, 2$ \\
\hline CF251 & $E N D F \backslash B-V I .2$ \\
\hline CF252 & $E N D F \backslash B-V I .2$ \\
\hline CF253 & $E N D F \backslash B-V I .2$ \\
\hline CF254 & JENDL - 3.2 \\
\hline CL3 5 & JENDL -3.2 \\
\hline CL37 & JENDL -3.2 \\
\hline $\mathrm{CM} 241$ & $E N D F \backslash B-V I . O$ \\
\hline $\mathrm{CM} 242$ & $E N D F \backslash B-V I .0$ \\
\hline $\mathrm{CM} 243$ & $E N D F \backslash B-V I .0$ \\
\hline $\mathrm{CM} 244$ & $E N D F \backslash B-V I .0$ \\
\hline CM245 & $E N D F \backslash B-V I .7$ \\
\hline $\mathrm{CM} 246$ & $E N D F \backslash B-V I .7$ \\
\hline $\mathrm{CM} 247$ & JENDL - 3.2 \\
\hline $\mathrm{CM} 248$ & JENDL -3.2 \\
\hline CM249 & JENDL -3.2 \\
\hline $\mathrm{CM} 250$ & JENDI - 3.2 \\
\hline $\cos 8$ & JEF-2.2 \\
\hline $\mathrm{CO} 58 \mathrm{M}$ & JEF-2. 2 \\
\hline $\cos 9$ & $E N D F \backslash B-V I .2$ \\
\hline CR50 & $E N D F \backslash B-V I .8$ \\
\hline CR52 & $E N D F \backslash B-V I .8$ \\
\hline CR53 & $E N D F \backslash B-V I .8$ \\
\hline CR.54 & $E N D F \backslash B-V I .8$ \\
\hline $\operatorname{cs} 133$ & $E N D F \backslash B-V I .0$ \\
\hline $\operatorname{cs} 134$ & $\mathrm{ENDF} \backslash \mathrm{B}-\mathrm{VI} . \mathrm{O}$ \\
\hline $\operatorname{cs} 135$ & JEF - 2.2 \\
\hline $\operatorname{CS} 136$ & $E N D F \backslash B-V I .0$ \\
\hline $\operatorname{cs} 137$ & JENDL - 3.2 \\
\hline CU63 & $E N D F \backslash B-V I .8$ \\
\hline CU65 & ENDF $\backslash B-V I .8$ \\
\hline DY 160 & $E N D F \backslash B-V I .7$ \\
\hline DY 161 & $E N D F \backslash B-V I .7$ \\
\hline DY 162 & $E N D F \backslash B-V I .7$ \\
\hline DY163 & $E N D F \backslash B-V I .7$ \\
\hline DY164 & $E N D F \backslash B-V I .7$ \\
\hline ER162 & JENDL 3.3 \\
\hline $\operatorname{ER} 164$ & JENDL 3.3 \\
\hline
\end{tabular}




\begin{tabular}{|c|c|}
\hline Nuclide & Data Source \\
\hline ER166 & JENDL 3.3 \\
\hline ER167 & JENDL 3.3 \\
\hline ERI68 & JENDL3. 3 \\
\hline ER170 & JENDL 3.3 \\
\hline ES253 & $E N D F \backslash B-V I .0$ \\
\hline EU151 & $E N D F \backslash B-V I .0$ \\
\hline EU152 & $E N D F \backslash B-V I .0$ \\
\hline EU153 & $E N D F \backslash B-V I .0$ \\
\hline EU154 & $E N D F \backslash B-V I .7$ \\
\hline EU155 & $E N D F \backslash B-V I .7$ \\
\hline EU156 & $E N D F \backslash B-V I .0$ \\
\hline EU157 & $E N D F \backslash B-V I .0$ \\
\hline F19 & $E N D F \backslash B-V I .8$ \\
\hline FE54 & $E N D F \backslash B-V I .8$ \\
\hline FE56 & $E N D F \backslash B-V I .8$ \\
\hline FE5 7 & $E N D F \backslash B-V I .8$ \\
\hline FE58 & $\mathrm{ENDF} \backslash \mathrm{B}-\mathrm{VI} .8$ \\
\hline GA 69 & JENDL - 3.2 \\
\hline GA71 & JENDL - 3.2 \\
\hline GD152 & $\mathrm{ENDF} \backslash \mathrm{B}-\mathrm{VI} .4$ \\
\hline GD154 & $\mathrm{ENDF} \backslash \mathrm{B}-\mathrm{VI} .4$ \\
\hline GD155 & $\mathrm{ENDF} \backslash \mathrm{B}-\mathrm{VI} .0$ \\
\hline GD156 & $E N D F \backslash B-V I .0$ \\
\hline GD157 & $\mathrm{ENDF} \backslash \mathrm{B}-\mathrm{VI} . \mathrm{O}$ \\
\hline GD158 & $\mathrm{ENDF} \backslash \mathrm{B}-\mathrm{VI} .0$ \\
\hline GD160 & $E N D F \backslash B-V I .0$ \\
\hline GE70 & JENDL -3.2 \\
\hline GE72 & JENDL -3.2 \\
\hline GE73 & JENDL -3.2 \\
\hline GE74 & JENDL - 3.2 \\
\hline GE76 & JENDL - 3.2 \\
\hline $\mathrm{H}-\mathrm{H} 2 \mathrm{O}$ & $E N D F \backslash B-V I .8$ \\
\hline H-POLY & $E N D F \backslash B-V I .8$ \\
\hline $\mathrm{H}-\mathrm{ZRH}$ & $E N D F \backslash B-V I .8$ \\
\hline HI & $E N D F \backslash B-V I .8$ \\
\hline $\mathrm{H} 2$ & $E N D F \backslash B-V I .6$ \\
\hline $\mathrm{H} 2-\mathrm{D} 2 \mathrm{O}$ & $E N D F \backslash B-V I .6$ \\
\hline H3 & $E N D F \backslash B-V I .0$ \\
\hline $\mathrm{HE} 3$ & $E N D F \backslash B-V I, 1$ \\
\hline HE4 & $E N D F \backslash B-V I .0$ \\
\hline HF174 & $E N D F \backslash B-V I .2$ \\
\hline HF176 & $E N D F \backslash B-V I .2$ \\
\hline HF 177 & $E N D F \backslash B-V I .2$ \\
\hline HF178 & $E N D F \backslash B-V I .2$ \\
\hline HF179 & $E N D F \backslash B-V I .2$ \\
\hline HF180 & $E N D F \backslash B-V I .2$ \\
\hline HG196 & JENDL -3.3 \\
\hline HG198 & JENDL -3.3 \\
\hline HG199 & JENDL - 3.3 \\
\hline HG & JENDL - 3.3 \\
\hline HG201 & JENDL -3.3 \\
\hline $\mathrm{HG} 2 \mathrm{O} 2$ & JENDL -3.3 \\
\hline
\end{tabular}


B-TM-1639

\begin{tabular}{|c|c|}
\hline Nuclide & Data Source \\
\hline $\mathrm{HG} 204$ & JENDL -3.3 \\
\hline $\mathrm{HO} 65$ & $E N D F \backslash B-V I .5$ \\
\hline I 127 & JENDL - 3.2 \\
\hline I129 & JENDL - 3.2 \\
\hline I130 & JEF -2.2 \\
\hline$I 131$ & $E N D F \backslash B-V I .0$ \\
\hline 1135 & $\mathrm{ENDF} \backslash \mathrm{B}-\mathrm{VI} .0$ \\
\hline IN113 & JENDL - 3.2 \\
\hline IN1 15 & JENDL - 3.2 \\
\hline IR191 & ENDF $\backslash \mathrm{B}-\mathrm{VI} .4$ \\
\hline IR193 & $E N D F \backslash B-V I .4$ \\
\hline $\mathrm{K} 39$ & JENDL - 3.2 \\
\hline K40 & JENDL -3.2 \\
\hline K4 I & JENDL -3.2 \\
\hline KR78 & JENDL -3.2 \\
\hline KR8 0 & JENDL -3.2 \\
\hline $\mathrm{KR} 82$ & JENDL -3.2 \\
\hline $\mathrm{KR} 83$ & $E N D F \backslash B-V I .0$ \\
\hline KR84 & JENDL $-3,2$ \\
\hline $\mathrm{KR} 85$ & JENDL -3.2 \\
\hline KR8 6 & JENDL -3.2 \\
\hline LAA138 & JENDL -3.2 \\
\hline LA139 & $E N D F \backslash B-V I . I$ \\
\hline LA140 & $J E F-2.2$ \\
\hline LI6 & $E N D F \backslash B-V I . I$ \\
\hline LI7 & $E N D F \backslash B-V I .0$ \\
\hline LU1 75 & $\mathrm{ENDF} \backslash \mathrm{B}-\mathrm{VI} .7$ \\
\hline LU1 76 & $E N D F \backslash B-V I .7$ \\
\hline MG24 & JENDL -3.2 \\
\hline MG2 5 & JENDL $-3 . .2$ \\
\hline MG26 & JENDL -3.2 \\
\hline MN5 5 & $E N D F \backslash B-V I .8$ \\
\hline MO100 & JENDL - 3.2 \\
\hline MO9 2 & JENDL -3.2 \\
\hline MO94 & JENDL -3.2 \\
\hline MO95 & JENDL -3.2 \\
\hline M096 & JENDL - 3.2 \\
\hline MO97 & JENDL $-3+2$ \\
\hline M098 & JENDI -3.2 \\
\hline MO99 & JENDL - 3.2 \\
\hline N14 & $E N D F \backslash B-V I .8$ \\
\hline N15 & $E N D F \backslash B-V I .0$ \\
\hline NA22 2 & JEF -2.2 \\
\hline $\mathrm{NA} 23$ & $E N D F \backslash B-V I .8$ \\
\hline NB93 & $E N D F \backslash B-V I .6$ \\
\hline NB 94 & JENDL $-3,2$ \\
\hline NB 95 & $E N D F \backslash B-V I .0$ \\
\hline ND142 & JENDL -3.2 \\
\hline $\mathrm{ND} 143$ & $E N D F \backslash B-V I .2$ \\
\hline ND144 & JENDL -3.2 \\
\hline ND 145 & $E N D F \backslash B-V I .2$ \\
\hline $\operatorname{ND} 146$ & JENDL -3.2 \\
\hline
\end{tabular}

C-4 


\begin{tabular}{|c|c|}
\hline Nuclide & Data Source \\
\hline ND1 47 & JENDL -3.2 \\
\hline ND148 & JENDL- 3.2 \\
\hline ND150 & JENDL -3.2 \\
\hline NI5 8 & $E N D F \backslash B-V I .8$ \\
\hline NI59 & $\mathrm{JEF}-2.2$ \\
\hline NI60 & $E N D F \backslash B-V I .8$ \\
\hline NI61 & $E N D F \backslash B-V I .8$ \\
\hline NI62 & $E N D F \backslash B-V I .8$ \\
\hline NI64 & $E N D F \backslash B-V I .8$ \\
\hline NP2 36 & JENDL -3.2 \\
\hline NP2 37 & $E N D F \backslash B-V I . I$ \\
\hline NP2 38 & $\mathrm{ENDF} \backslash \mathrm{B}-\mathrm{VI} .2$ \\
\hline NP239 & $E N D F \backslash B-V I .0$ \\
\hline$O-B E O$ & $E N D F \backslash B-V I .8$ \\
\hline 016 & $E N D F \backslash B-V I .8$ \\
\hline 017 & $E N D F \backslash B-V I .0$ \\
\hline OS & $\mathrm{JEF} 3.0$ \\
\hline P3.1 & $\mathrm{ENDF} \backslash \mathrm{B}-\mathrm{VI} .6$ \\
\hline PA2 31 & JENDL -3.2 \\
\hline PA2 32 & $\mathrm{ENDF} \backslash \mathrm{B}-\mathrm{VI} .8$ \\
\hline PA233 & $\mathrm{ENDF} \backslash \mathrm{B}-\mathrm{VI} .0$ \\
\hline PB204 & JENDL 3.2 \\
\hline PB206 & $E N D F \backslash B-V I .0$ \\
\hline PB207 & ENDF $\backslash \mathrm{B}-\mathrm{VI} .1$ \\
\hline PB208 & $E N D F \backslash B-V I .5$ \\
\hline PD102 & $E N D F \backslash B-V I .5$ \\
\hline PD104 & $E N D F \backslash B-V I .5$ \\
\hline PD10 5 & $E N D F \backslash B-V I .5$ \\
\hline PD106 & $E N D F \backslash B-V I .5$ \\
\hline PD107 & $E N D F \backslash B-V I .0$ \\
\hline PD108 & $\mathrm{ENDF} \backslash \mathrm{B}-\mathrm{VI}$. 5 \\
\hline PD110 & $E N D F \backslash B-V I .5$ \\
\hline PM1 47 & $E N D F \backslash B-V I .1$ \\
\hline PM14 8 & $E N D F \backslash B-V I .0$ \\
\hline PM14 8M & $E N D F \backslash B-V I, 0$ \\
\hline PM149 & $E N D F \backslash B-V I .0$ \\
\hline PM151 & $E N D F \backslash B-V I .0$ \\
\hline PR141 & $E N D F \backslash B-V I .0$ \\
\hline PR142 & $J E F-2.2$ \\
\hline PR143 & $E N D F \backslash B-V I .0$ \\
\hline PU236 & $E N D F \backslash B-V I .4$ \\
\hline PU2 37 & $E N D F \backslash B-V I .0$ \\
\hline PU238 & $E N D F \backslash B-V I .0$ \\
\hline PU239 & $E N D F \backslash B-V I .5$ \\
\hline PU240 & $E N D F \backslash B-V I, 2$ \\
\hline PU241 & $E N D F \backslash B-V I .3$ \\
\hline PU242 & $E N D F \backslash B-V I .0$ \\
\hline PU2 43 & $E N D F \backslash B-V I .2$ \\
\hline PU244 & $E N D F \backslash B-V I .0$ \\
\hline RA224 & JENDL - 3.2 \\
\hline RA226 & JENDL -3.2 \\
\hline RB85 & $E N D F \backslash B-V I .0$ \\
\hline
\end{tabular}


B-TM-1639

\begin{tabular}{|c|c|}
\hline Nuclide & Data Source \\
\hline RB 86 & $E N D F \backslash B-V I .0$ \\
\hline $\mathrm{RB} 87$ & $E N D F \backslash B-V I .0$ \\
\hline RE185 & $E N D F \backslash B-V I .0$ \\
\hline RE18 7 & $\mathrm{ENDF} \backslash \mathrm{B}-\mathrm{VI} .0$ \\
\hline $\mathrm{RH} 103$ & $E N D F \backslash B-V I .0$ \\
\hline RH105 & $E N D F \backslash B-V I .0$ \\
\hline RU100 & JENDL - 3.2 \\
\hline RU101 & $\mathrm{ENDF} \backslash \mathrm{B}-\mathrm{V} I .2$ \\
\hline RU102 & $\mathrm{ENDF} \backslash \mathrm{B}-\mathrm{VI}, 2$ \\
\hline RU103 & $E N D F \backslash B-V I .0$ \\
\hline RU104 & JENDL -3.2 \\
\hline RU105 & $\mathrm{ENDF} \backslash \mathrm{B}-\mathrm{VI} .0$ \\
\hline RU106 & $E N D F \backslash B-V I .0$ \\
\hline RU96 & $E N D F \backslash B-V I, 0$ \\
\hline RU98 & $E N D F \backslash B-V I .0$ \\
\hline RU99 & JENDL -3.2 \\
\hline S32 & JENDL -3.2 \\
\hline S33 & JENDL -3.2 \\
\hline S34 & JENDL -3.2 \\
\hline$\$ 36$ & JENDL -3.2 \\
\hline SB121 & $E N D F \backslash B-V I .0$ \\
\hline SB123 & $E N D F \backslash B-V I .0$ \\
\hline SB124 & ENDF $\backslash B-V I .0$ \\
\hline SB125 & $E N D F \backslash B-V I .0$ \\
\hline SB126 & $E N D F \backslash B-V I .0$ \\
\hline$S C 45$ & $E N D F \backslash B-V I .8$ \\
\hline SE74 & JENDL- 3.2 \\
\hline SE76 & JENDL -3.2 \\
\hline SE77 & JENDL -3.2 \\
\hline SE78 & JENDL - 3.2 \\
\hline SE79 & JENDL - 3.2 \\
\hline SE8 0 & JENDL -3.2 \\
\hline SE82 & JENDL - 3.2 \\
\hline SI28 & $E N D F \backslash B-V I .5$ \\
\hline SI29 & $E N D F \backslash B-V I .5$ \\
\hline SI30 & $E N D F \backslash B-V I .5$ \\
\hline SM1 44 & $E N D F \backslash B-V I .3$ \\
\hline SM147 & $\mathrm{ENDF} \backslash \mathrm{B}-\mathrm{VI} .0$ \\
\hline SM148 & JENDL - 3.2 \\
\hline SM149 & $E N D F \backslash B-V I .0$ \\
\hline SM150 & $E N D F \backslash B-V I .2$ \\
\hline SM151 & $\mathrm{ENDF} \backslash \mathrm{B}-\mathrm{VI} .1$ \\
\hline SM152 & $E N D F \backslash B-V I .2$ \\
\hline SM153 & $E N D F \backslash B-V I .0$ \\
\hline SM154 & $E N D F \backslash B-V I .0$ \\
\hline SN112 & $J E N D L-3.2$ \\
\hline SN114 & JENDL -3.2 \\
\hline SN115 & JENDL -3.2 \\
\hline SN116 & JENDL - 3.2 \\
\hline SN117 & JENDL -3.2 \\
\hline SN118 & JENDL -3.2 \\
\hline SN119 & JENDL $-3,2$ \\
\hline
\end{tabular}




\begin{tabular}{|c|c|}
\hline Nuclide & Data Source \\
\hline SN120 & JENDL -3.2 \\
\hline $\mathrm{SN} 122$ & JENDL -3.2 \\
\hline SN123 & $\mathrm{END} F \backslash \mathrm{B}-\mathrm{VI} .0$ \\
\hline SN124 & JENDL -3.2 \\
\hline SN125 & $E N D F \backslash B-V I .0$ \\
\hline SN126 & $E N D F \backslash B-V I .0$ \\
\hline SR86 & JENDE -3.2 \\
\hline SR87 & JENDL -3.2 \\
\hline SR8 8 & JENDL -3.2 \\
\hline SR89 & ENDF $\backslash B-V I .0$ \\
\hline SR90 & JENDL -3.2 \\
\hline TA181 & $\mathrm{END} F \backslash \mathrm{B}-\mathrm{VI} .0$ \\
\hline TA182 & $E N D F \backslash B-V I .0$ \\
\hline TB159 & JENDL -3.2 \\
\hline TB160 & $E N D F \backslash B-V I .0$ \\
\hline TC99 & JENDL -3.2 \\
\hline$T E I 20$ & $E N D F \backslash B-V I, 0$ \\
\hline TE122 & JENDL -3.2 \\
\hline TE123 & JENDL -3.2 \\
\hline TE124 & JENDL - 3.2 \\
\hline TE125 & JENDL -3.2 \\
\hline TE126 & JENDL -3.2 \\
\hline TE127M & $E N D F \backslash B-V I .0$ \\
\hline TE128 & JENDL - 3.2 \\
\hline TE129M & ENDF $\backslash B-V I .0$ \\
\hline TE130 & JENDL -3.2 \\
\hline TE132 & $E N D F \backslash B-V I .0$ \\
\hline TH2 28 & JENDL - 3.2 \\
\hline TH229 & JENDL -3.2 \\
\hline TH230 & JENDL -3.2 \\
\hline TH2 32 & $E N D F \backslash B-V I .0$ \\
\hline TH2 33 & JENDL -3.2 \\
\hline$T I$ & JENDL - 3.2 \\
\hline TI 46 & JENDI - 3.2 \\
\hline TI 47 & JENDL - 3.2 \\
\hline TI 48 & JENDL - 3.2 \\
\hline TI 49 & JENDL - 3.2 \\
\hline TI50 & JENDL -3.2 \\
\hline $\mathrm{U} 232$ & $\mathrm{JEF}-2.2$ \\
\hline U2 33 & JENDL - 3.2 \\
\hline U2 34 & $E N D F \backslash B-V I .0$ \\
\hline U235 & $E N D F \backslash B-V I .5$ \\
\hline U2 36 & $E N D F \backslash B-V I .0$ \\
\hline U2 37 & $E N D F \backslash B-V I .2$ \\
\hline U2 38 & $E N D F \backslash B-V I .5$ \\
\hline $\mathrm{V}$ & $E N D F \backslash B-V I .8$ \\
\hline W & $E N D F \backslash B-V I . I$ \\
\hline W182 & $E N D F \backslash B-V I .8$ \\
\hline W183 & $E N D F \backslash B-V I .8$ \\
\hline W1 84 & $E N D F \backslash B-V I .8$ \\
\hline W186 & $E N D F \backslash B-V I .8$ \\
\hline $\mathrm{XE} 124$ & JENDI $-3,2$ \\
\hline
\end{tabular}


B-TM-1639

Nuclide
XE126
XE128
XE129
XE130
XE131
XE132
XE133
XE134
XE135
XE136
Y89
Y90
Y91
ZN
ZR
ZR-ZRH
ZR90
ZR91
ZR92
ZR93
ZR94
ZR95
ZR96

Data source

JENDL - 3.2

JENDI -3.2

JENDI - 3.2

JENDL - 3.2

ENDF \B-VI . 0

JENDL - 3.2

$E N D F \backslash B-V I .0$

JENDL - 3.2

$E N D F \backslash B-V I, 0$

JENDL -3.2

JENDL - 3.2

$E N D F \backslash B-V I$. O

ENDF $\backslash B-V I .0$

JEF- 3.0

ENDF $\backslash B-V I$. I

ENDF \B-VI . 1

ENDF $\backslash B-V I$. 8

ENDF $\backslash B-V I .8$

$E N D F \backslash B-V I$. 8

JENDL - 3.2

ENDF $\backslash B-V I$. 8

ENDF $\backslash B-V I .0$

ENDE \B-VI . 8 
B-TM-1639

Appendix D

Material Density Measurements and Uncertainty Analysis 
B-TM-1639

(Intentionally Blank)

D-2 


\section{Introduction}

Density measurements of the $\mathrm{Ta}, \mathrm{Mo}$, and Re samples were performed by Knolls Atomic Power Laboratory using the submersion method. While this method is known to be accurate, potential sources of measurement error are the laboratory equipment, the sensitivity to water purity and quantity, and specimen handling. The following equipment was used in this series of measurements:

- Mettler AT261 calibrated balance $( \pm 0.00002 \mathrm{~g})$

- Hart Scientific 1521 Thermometer with $5627-9$ probe $\left( \pm 0.001{ }^{\circ} \mathrm{C}\right)$

- Omega $450 \mathrm{ATH}$ Thermocouple Thermometer $\left( \pm 0.1^{\circ} \mathrm{C}\right)$

- Cole Palmer Oakton 03316-72 calibrated barometer $( \pm 3 \%$ )

- Waltrous \& Company, Inc. Lufft 5033-32W calibrated hygrometer $( \pm 1 \mathrm{mmHg})$

\section{Density Analysis}

The density of the samples is calculated from measurements as shown in Equation 1:

$\rho_{\text {speeimen }}=\frac{\bar{W}_{\text {specimen }} \rho_{\text {water }}-\bar{W}_{\text {specimen }} \rho_{\text {air }}}{\bar{W}_{\text {specimen }}-\bar{W}_{\substack{\text { specimen } \\ \text { wet }}}}$

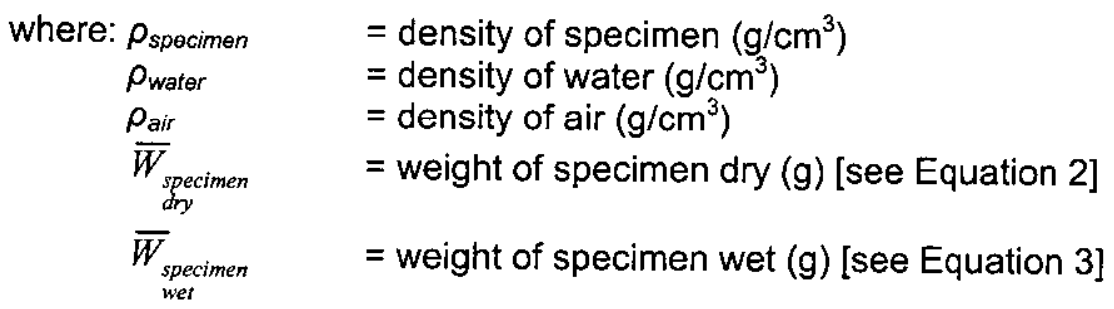

Three separate measurements of wet and dry weight were averaged according to Equations 2 and 3 :

$\bar{W}_{\substack{\text { specimen } \\ d r y}}=\frac{\left(\begin{array}{c}W_{\text {specimen }} \\ d r y\end{array}\right)_{1}+\left(\begin{array}{c}W_{\text {specimen }} \\ d r y\end{array}\right)_{2}+\left(\begin{array}{c}W_{\text {specimen }} \\ d r y\end{array}\right)_{3}}{3}$

$\bar{W}_{\substack{\text { specimen } \\ \text { wet }}}=\frac{\left(\begin{array}{c}W_{\text {specimen } / \text { saddle }}-W_{\text {saddle }} \\ \text { wet }\end{array}\right)_{1}+\left(\begin{array}{c}W_{\begin{array}{l}\text { specimen/saddle } \\ \text { wet }\end{array}}-W_{\text {saddle }} \\ \text { wet }\end{array}\right)_{2}+\left(\begin{array}{c}W_{\text {specimen/saddle }}-W_{\text {saddle }} \\ \text { wer }\end{array}\right)_{3}}{3}$

where: $W_{\substack{\text { specimen/saddle } \\ \text { wer }}}=$ combined weight of saddle \& specimen wet $(\mathrm{g})$

$W_{\text {saddle }} \quad \quad=$ weight of saddle wet $(\mathrm{g})$

The density of water is calculated as shown in Equation 4:

$$
\begin{aligned}
\rho_{\text {water }}= & (3.42935528 E-8) \bar{T}_{\text {water }}^{3}+(-7.34259259 E-6) \bar{T}_{\text {water }}^{2} \ldots \\
& +(4.62032628 E-5) \bar{T}_{\text {water }}+(9.99942302 E-1)
\end{aligned}
$$


where: $\bar{T}_{\text {water }}=$ water temperature $\left({ }^{\circ} \mathrm{C}\right)$ [see Equation 5]

Three separate measurements of water temperature were averaged according to Equation 5 :

$\bar{T}_{\text {water }}=\frac{\left(T_{\text {water }}\right)_{1}+\left(T_{\text {water }}\right)_{2}+\left(T_{\text {water }}\right)_{3}}{3}$

The density of air is calculated as shown in Equation 6:

$\rho_{\text {air }}=\frac{(0.4645540)\left(P_{b a r}-0.0037802 \cdot H_{r e l} P_{\text {yapar }}\right)}{\left(\bar{T}_{a i r}+273.15\right)(1000.027)}$

where: $P_{b a r} \quad=$ barometric pressure $(\mathrm{mmHg})$

$H_{r e l} \quad=$ relative humidity $(\%)$

$P_{\text {vapor }}=$ vapor pressure $(\mathrm{mmHg})[$ see Equation 7]

$\bar{T}_{\text {air }} \quad=$ air temperature $\left({ }^{\circ} \mathrm{C}\right)$ [see Equation 8$]$

Vapor pressure has been correlated to a function of air temperature as shown in Equation 7:

$P_{\text {vapor }}=(4.9500000 E-4) \bar{T}_{\text {air }}^{3}+(1.5080000 E-4) \bar{T}_{\text {air }}^{2}+(4.8269330 E-1) \bar{T}_{\text {air }}+(3.8535478)$

Three separate measurements of water temperature were averaged according to Equation 8 :

$\bar{T}_{a i r}=\frac{\left(T_{a i r}\right)_{1}+\left(T_{a i r}\right)_{2}+\left(T_{a i r}\right)_{3}}{3}$

\section{Error Analysis}

The error associated with the submersion method of density measurement has been calculated using an RMS (root-mean squared) approach. The governing equations follow.

The RMS error associated with the specimen density equation [Equation 1] is shown below in Equation 9:

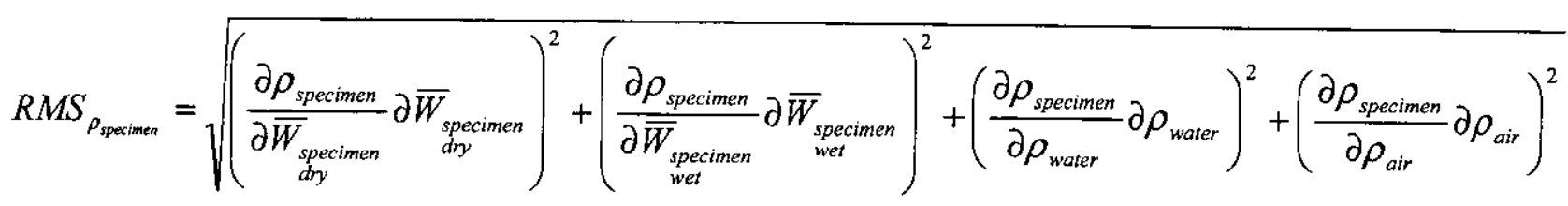

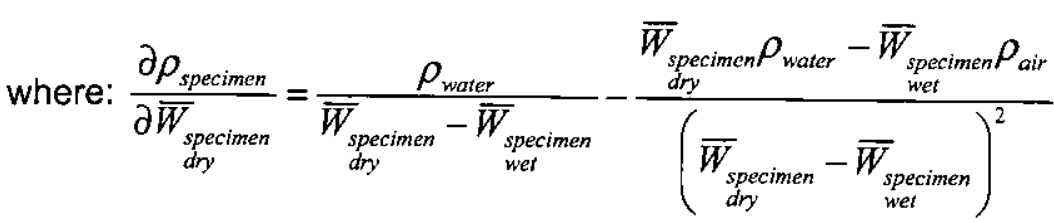

$\partial \bar{W}_{\substack{\text { specimen } \\ d r y}}=$ error associated with specimen dry weight [see Equation 10] 


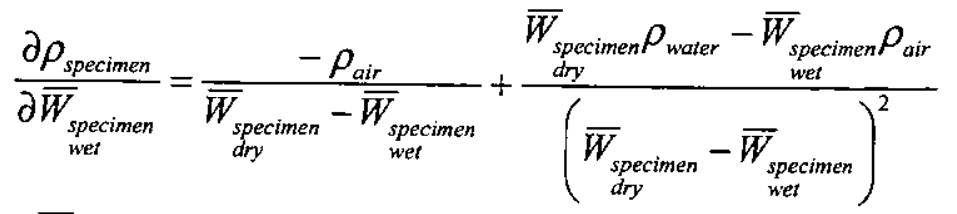

$\partial \bar{W}_{\text {specimen }}=$ error associated with specimen wet weight [see Equation 11]

$\frac{\partial \rho_{\text {specimen }}}{\partial \rho_{\text {water }}}=\frac{-\bar{W}_{\text {specimen }}}{\bar{W}_{\substack{\text { specimen } \\ \text { dry }}}-\bar{W}_{\substack{\text { specimen } \\ \text { wet }}}}$

$\partial \rho_{\text {water }} \quad=$ error associated with water density [see Equation 12]

$\frac{\partial \rho_{\text {specimen }}}{\partial \rho_{\text {air }}}=\frac{\bar{W}_{\text {specimen }}}{\partial \rho_{\substack{\text { specimen } \\ \text { dry }}}-\bar{W}_{\substack{\text { specimen } \\ \text { wet }}}}$

$\partial \rho_{\text {air }} \quad=$ error associated with air density [see Equation 13]

The error associated with specimen dry weight is calculated from the averaging equation on an RMS basis as shown in Equation 10:

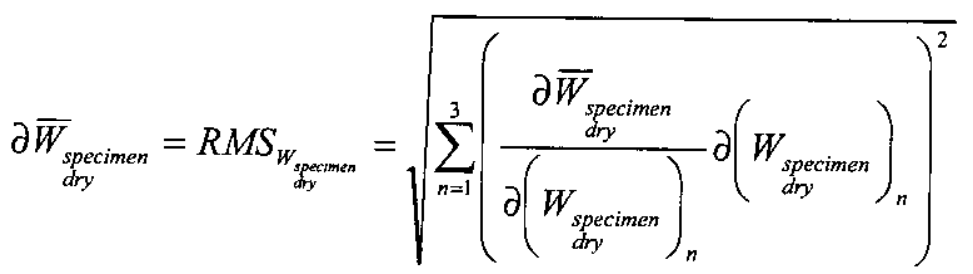

where: $\partial W_{\substack{\text { specimen } \\ d r y}}=\delta_{\text {balance }}=0.00002(\mathrm{~g})$

The error associated with specimen wet weight is calculated from the averaging equation on an RMS basis as shown in Equation 11:

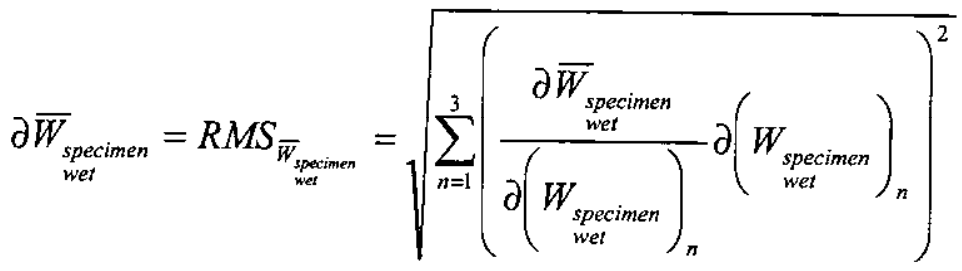

where: $\partial W_{\substack{\text { specimen } \\ \text { wet }}}=\delta_{\text {balance }}=0.00002(g)$

The error associated with the water density is calculated from the averaging equation on an RMS basis as shown in Equation 12:

$\partial \rho_{\text {wuter }}=R M S_{\rho_{\text {wate }}}=\sqrt{\left(\frac{\partial \rho_{\text {water }}}{\partial \bar{T}_{\text {water }}} \partial \bar{T}_{\text {water }}\right)^{2}}$ 
where: $\partial \bar{T}_{\text {water }}=R M S_{\bar{T}_{\text {water }}}=\sqrt{\sum_{n=1}^{3}\left(\frac{\partial \bar{T}_{\text {water }}}{\partial\left(T_{\text {water }}\right)_{n}} \partial\left(\bar{T}_{\text {water }}\right)_{n}\right)^{2}}$

where: $\partial T_{\text {water }}=\delta_{\text {water probe }}=0.001\left({ }^{\circ} \mathrm{C}\right)$

The error associated with the air density is calculated from the averaging equation on an RMS basis as shown in Equation 13:

$\partial \rho_{a i r}=R M S_{p_{a t r}}=\sqrt{\left(\frac{\partial \rho_{a i r}}{\partial P_{b a r}} \partial P_{b a r}\right)^{2}+\left(\frac{\partial \rho_{a i r}}{\partial H_{r e l}} \partial H_{r e l}\right)^{2}+\left(\frac{\partial \rho_{a i r}}{\partial \bar{T}_{a i r}} \partial \bar{T}_{a i r}\right)^{2}}$ [See Note 1]

NOTE 1: $P_{\text {vapor }}$ is solely a function of $\bar{T}_{a i r}$

$$
\text { where: } \begin{aligned}
\frac{\partial \rho_{\text {air }}}{\partial P_{\text {bar }}} & =\left(\frac{0.464554}{1000.027}\right)\left(\frac{1}{\bar{T}_{\text {air }}+273.15}\right) \\
\partial P_{\text {bar }} & =\delta_{\text {barometer }}=1(\mathrm{mmHg}) \\
\frac{\partial \rho_{\text {air }}}{\partial H_{\text {rel }}} & =\left(\frac{0.464554}{1000.027}\right)\left(\frac{-0.0037802 P_{\text {vap }}}{\bar{T}_{\text {air }}+273.15}\right) \\
\partial H_{\text {rel }} & =\delta_{\text {hygrometer }}=3 \% \\
\frac{\partial \rho_{\text {air }}}{\partial \bar{T}_{\text {air }}} & =\left(\frac{-C_{1}}{C_{3}}\right)\left\{\left[\frac{C_{2} H_{r e l}\left(C_{6}+2 C_{7} \bar{T}_{\text {air }}+3 C_{8} \bar{T}_{\text {air }}^{2}\right)}{\left(\bar{T}_{\text {air }}+C_{4}\right)}\right]+\left[\frac{P_{\text {har }}-C_{2} H_{r e l}\left(C_{5}+C_{6} \bar{T}_{a i r}+C_{7} \bar{T}_{a i r}^{2}+C_{8} \bar{T}_{a i r}^{3}\right)}{\left(\bar{T}_{a i r}+C_{4}\right)^{2}}\right]\right\}
\end{aligned}
$$

where: $C_{1}=0.464554$

$C_{2}=0.0037802$

$C_{3}=1000.027$

$C_{4}=273.15$

$C_{5}=3.8535478$

$C_{6}=0.4826933$

$C_{7}=0.0001508$

$C_{8}=0.000495$

$\partial \bar{T}_{\text {air }}=R M S_{\bar{T}_{\text {air }}}=\sqrt{\sum_{n=1}^{3}\left(\frac{\partial \bar{T}_{\text {air }}}{\partial\left(T_{\text {air }}\right)_{n}} \partial\left(T_{\text {air }}\right)_{n}\right)^{2}}$

where: $\partial T_{\text {air }}=\delta_{\text {air probe }}=0.1\left({ }^{\circ} \mathrm{C}\right)$ 


\section{Results}

Table D-1 lists the specimen densities and their measurement uncertainties as determined using the above-mentioned methods. Table D-2 provides the raw data from the specimen density measurements.

Table D-1. Specimen Density Measurements.

\begin{tabular}{|c|c|c|c|c|}
\hline Specimen ID & $\begin{array}{c}\text { Specimen } \\
\text { Density } \\
\left(g^{\prime} / \mathrm{cm}^{3}\right)\end{array}$ & $\begin{array}{c}\text { Specimen } \\
\text { Density } \\
\text { Uncertainty } \\
\left(\mathrm{g} / \mathrm{cm}^{3}\right)\end{array}$ & Operator & $\begin{array}{c}\text { Dry } \\
\text { Weight } \\
\text { Date }\end{array}$ \\
\hline \multicolumn{5}{|c|}{ Molybdenum } \\
\hline Mo-105 & 10.21828 & 0.00004 & R.Dean & $07 / 20 / 05$ \\
\hline $\mathrm{Mo}-108$ & 10.21465 & 0.00004 & R.Dean & $07 / 20 / 05$ \\
\hline Mo-107 & 10.21725 & 0.00004 & R.Dean & $07 / 20 / 05$ \\
\hline Mo-0019 & 10.21588 & 0.00008 & R.Dean & $07 / 48 / 05$ \\
\hline Mo-0015 & 10.21813 & 0.00008 & R.Dean & $07 / 18 / 05$ \\
\hline Mo-0008 & 10.21569 & 0.00009 & R.Dean & $07 / 18 / 05$ \\
\hline Mo-0007 & 10.21907 & 0.00008 & R.Dean & $07 / 18 / 05$ \\
\hline Mo-0002 & 10.21903 & 0.00008 & R.Dean & $07 / 18 / 05$ \\
\hline Mo-0017 & 10.22282 & 0.00008 & R.Dean & $07 / 18 / 05$ \\
\hline Mo-0011 & 10.21461 & 0.00008 & R.Dean & $07 / 21 / 05$ \\
\hline Mo-0012 & 10.21295 & 0.00009 & R.Dean & $07 / 21 / 05$ \\
\hline Mo-0013 & 10.22007 & 0.00008 & R.Dean & $07 / 22 / 05$ \\
\hline Mo-0016 & 10.21976 & 0.00008 & R.Dean & $07 / 22 / 05$ \\
\hline Mo-0001 & 10.22213 & 0.00008 & R.Dean & $07 / 22 / 05$ \\
\hline Mo-0021 & 10.21975 & 0.00009 & R.Dean & $07 / 22 / 05$ \\
\hline Mo-0003 & 10.21777 & 0.00008 & R.Dean & $07 / 22 / 05$ \\
\hline Mo-0006 & 10.21853 & 0.00008 & R.Dean & $07 / 22 / 05$ \\
\hline Mo-0014 & 10.22151 & 0.00008 & R.Dean & $07 / 25 / 05$ \\
\hline Mo-0009 & 10.21651 & 0.00009 & R.Dean & $07 / 25 / 05$ \\
\hline Mo-0020 & 10.21867 & 0.00008 & R.Dean & $07 / 25 / 05$ \\
\hline Mo-0022 & 10.22055 & 0.00008 & R.Dean & $07 / 25 / 05$ \\
\hline Mo 2-1 & 10.22437 & 0.00015 & R.Dean & $08 / 09 / 05$ \\
\hline Mo 2-2 & 10.21992 & 0.00016 & R.Dean & $08 / 09 / 05$ \\
\hline Mo 2-3 & 10.21806 & 0.00014 & R.Dean & $08 / 09 / 05$ \\
\hline Mo 2-4 & 10.21778 & 0.00011 & R.Dean & $08 / 09 / 05$ \\
\hline Mo 2-5 & 10.21872 & 0.00008 & R.Dean & $08 / 10 / 05$ \\
\hline Mo 2-6 & 10.22120 & 0.00013 & R.Dean & $08 / 10 / 05$ \\
\hline Mo 2-7 & 10.21821 & 0.00012 & R.Dean & $08 / 10 / 05$ \\
\hline Mo 2-8 & 10.21554 & 0.00011 & R.Dean & $08 / 10 / 05$ \\
\hline Mo 2-9 & 10.21783 & 0.00006 & R.Dean & $08 / 10 / 05$ \\
\hline Mo-051 & 10.21968 & 0.00009 & R.Dean & $09 / 08 / 05$ \\
\hline Mo-052 & 10.21635 & 0.00008 & R.Dean & $09 / 08 / 05$ \\
\hline Mo-053 & 10.21481 & 0.00008 & R.Dean & $09 / 08 / 05$ \\
\hline Mo-054 & 10.21790 & 0.00009 & R.Dean & $09 / 08 / 05$ \\
\hline Mo-055 & 10.21398 & 0.00009 & R.Dean & $09 / 08 / 05$ \\
\hline$M 0-056$ & 10.21848 & 0.00009 & R.Dean & $09 / 08 / 05$ \\
\hline \multicolumn{5}{|c|}{ Rhenium } \\
\hline $\mathrm{Re}-8$ & 21,00769 & 0.00076 & R.Dean & $07 / 25 / 05$ \\
\hline Re-9 & 21.00022 & 0.00070 & R.Dean & $07 / 25 / 05$ \\
\hline $\mathrm{Re}-10$ & 21.01982 & 0.00080 & R.Dean & $07 / 25 / 05$ \\
\hline $\operatorname{Re}-11$ & 21.01377 & 0.00075 & R.Dean & $07 / 25 / 05$ \\
\hline$R_{\theta}-12$ & 20.97726 & 0.00071 & R.Dean & $07 / 26 / 05$ \\
\hline $\operatorname{Re}-13$ & 20.98962 & 0.00073 & R.Dean & $07 / 26 / 05$ \\
\hline
\end{tabular}


B-TM-1639

\begin{tabular}{|c|c|c|c|c|}
\hline Specimen ID & $\begin{array}{c}\text { Specimen } \\
\text { Density } \\
\left(\mathrm{g} / \mathrm{cm}^{3}\right)\end{array}$ & $\begin{array}{c}\text { Specimen } \\
\text { Density } \\
\text { Uncertainty } \\
\left(\mathbf{g} / \mathrm{cm}^{3}\right)\end{array}$ & Operator & $\begin{array}{c}\text { Dry } \\
\text { Weight } \\
\text { Date }\end{array}$ \\
\hline Re-14 & 21.00555 & 0.00069 & R.Dean & $07 / 26 / 05$ \\
\hline Re-1 & 20.99868 & 0.00073 & R.Dean & $07 / 26 / 05$ \\
\hline $\operatorname{Re}-2$ & 20.99861 & 0.00078 & R.Dean & $07 / 26 / 05$ \\
\hline Re-3 & 20.97916 & 0.00072 & R.Dean & $07 / 26 / 05$ \\
\hline Re-4 & 21.00247 & 0.00073 & R.Dean & $07 / 27 / 05$ \\
\hline $\mathrm{Re}-5$ & 21.01046 & 0.00075 & R.Dean & $07 / 27 / 05$ \\
\hline $\operatorname{Re}-6$ & 21.01502 & 0.00073 & R.Dean & $07 / 27 / 05$ \\
\hline Re-7 & 20.99941 & 0.00077 & R.Dean & $07 / 27 / 05$ \\
\hline \multicolumn{5}{|c|}{ Tantalum-2.5Tungsten } \\
\hline Ta 11-19-2 \#1 & 16.71548 & 0.00017 & R.Dean & $07 / 27 / 05$ \\
\hline Ta 11-19-2 \#2 & $\$ 6.72158$ & 0.00018 & R.Dean & $07 / 27 / 05$ \\
\hline Ta 11-19-2 \#3 & 16.72443 & 0.00018 & R.Dean & $07 / 27 / 05$ \\
\hline Ta 11-19-2 \#4 & 16.71798 & 0.00016 & R.Dean & $07 / 27 / 05$ \\
\hline Ta 10-20-2 \#1 & 16.72615 & 0.00017 & R.Dean & $07 / 28 / 05$ \\
\hline Ta 10-20-2 \#2 & 16.72737 & 0.00021 & R.Dean & $07 / 28 / 05$ \\
\hline Ta $10-20-2 \# 3$ & 16.74034 & 0.00017 & R.Dean & $07 / 29 / 05$ \\
\hline Ta $10-20-2 \# 4$ & 16.72384 & 0.00017 & R.Dean & $07 / 29 / 05$ \\
\hline Ta $10-20-2 \# 5$ & 16.73094 & 0.00017 & R.Dean & $07 / 29 / 05$ \\
\hline Ta $10-20-2 \# 6$ & 16.72821 & 0,00017 & R.Dean & $07 / 29 / 05$ \\
\hline Ta $10-20-2 \# 7$ & 16.73395 & 0.00017 & R.Dean & $08 / 01 / 05$ \\
\hline $\mathrm{Ta}-11-19-2 \quad \# 7$ & 16.73555 & 0.00018 & R.Dean & $08 / 01 / 05$ \\
\hline Ta-11-19-2 \#5 & 16.71812 & 0.00017 & R.Dean & $08 / 01 / 05$ \\
\hline Ta-11-19-2 \#6 & 16.72362 & 0.00021 & R.Dean & $08 / 01 / 05$ \\
\hline
\end{tabular}




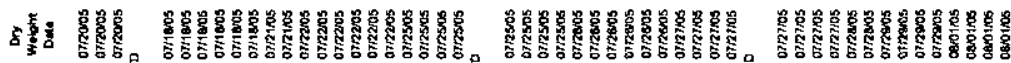

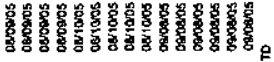

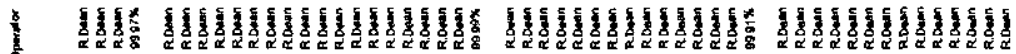

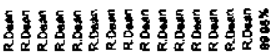

尊

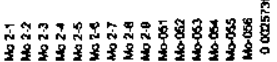

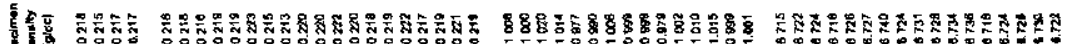

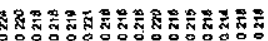

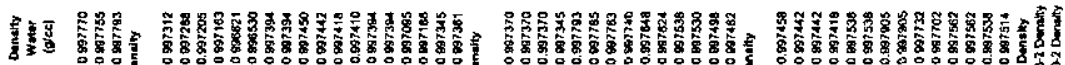

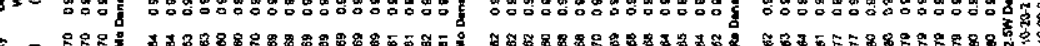

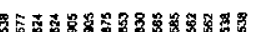

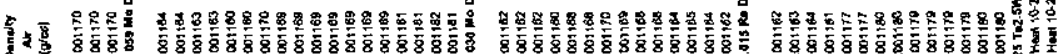

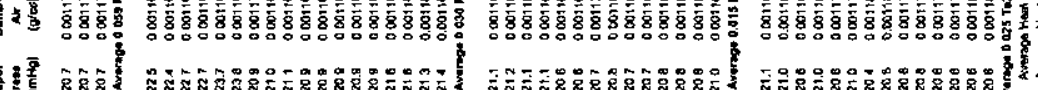
19

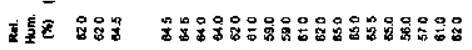

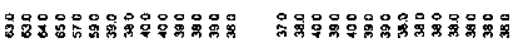

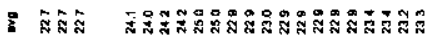

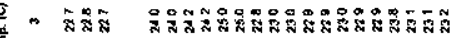

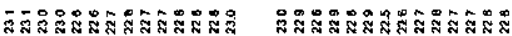

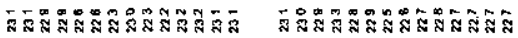

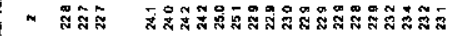

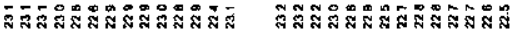

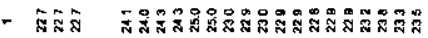
品R

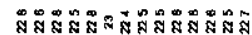

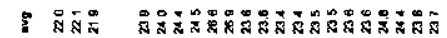

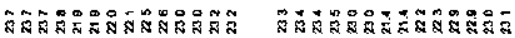

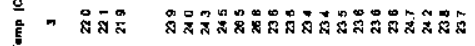

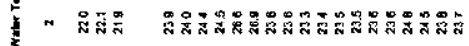

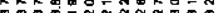
ลำลำ

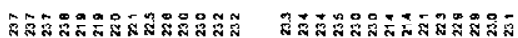

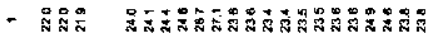

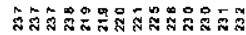
ํำ

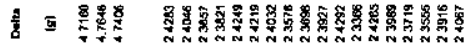

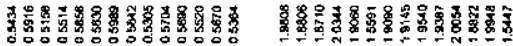

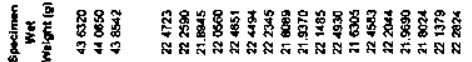

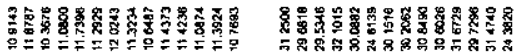

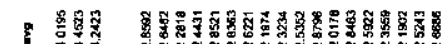

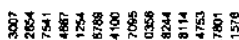

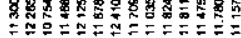

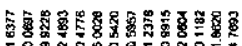

要要

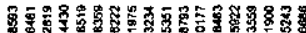

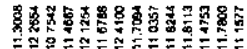

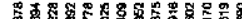

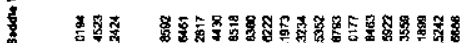

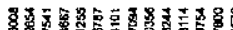

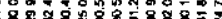

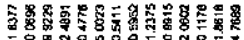

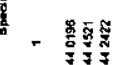

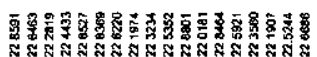

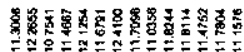

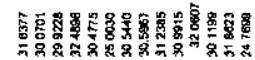

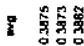

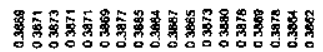

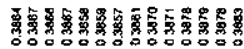

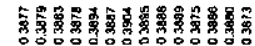

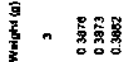

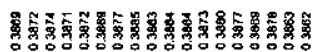

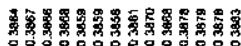

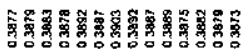

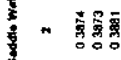

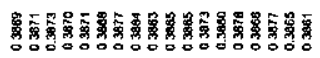

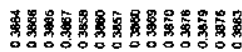

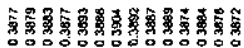

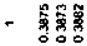

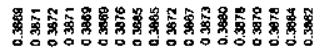

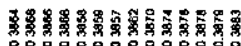

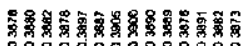

?

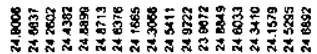

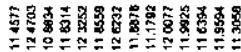

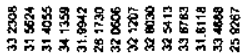

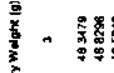

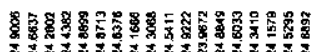

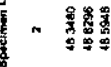

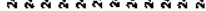

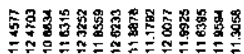

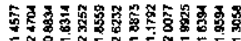

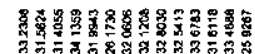

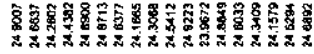

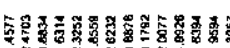

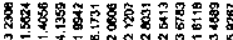

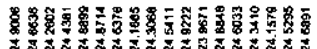

)

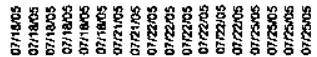

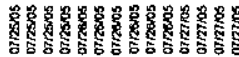

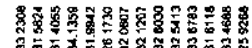

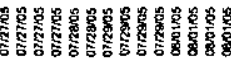

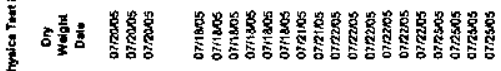
รแmmmm

memmemben

Hy

MMH!H!

MมMแมn

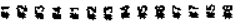
中은

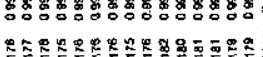

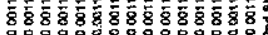

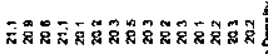

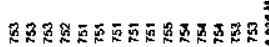

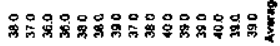

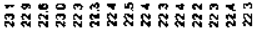
จำสสำ

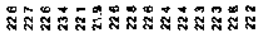

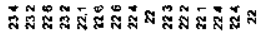
品

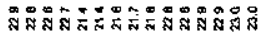
옻 สำ

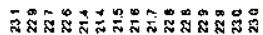

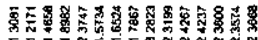

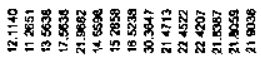

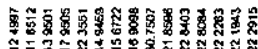

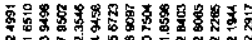

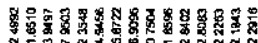

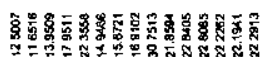

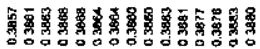

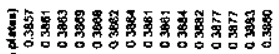

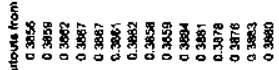

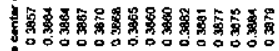

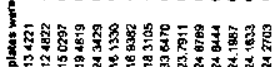

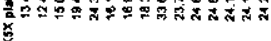

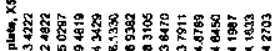

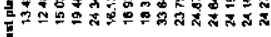

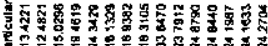

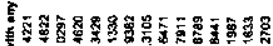

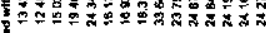

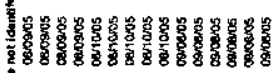
แแะแแแแกแบ1

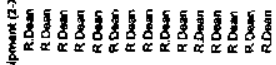
产

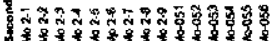




\section{Appendix E}

Impact of the Increased Diaphragm Thickness and Mass Loading Limit on the Predicted Critical Configuration of the

Prometheus Critical Experiments 
B-TM-1639

(Intentionally Blank)

E-2 


\section{Abstract}

Critical experiments were to be performed by Los Alamos National Laboratory (LANL) at the Los Alamos Critical Experiments Facility (LACEF) in Technical Area 18 (TA-18) in support of Project Prometheus. This letter provides an analysis of the impact of increasing the diaphragm thickness from $0.040^{\prime \prime}$ to $0.075^{\prime \prime}$ and implementing a $150 \mathrm{~kg}$ diaphragm mass loading limit upon the predicted critical configuration for the Re, Ta-2.5W, Baseline, and Mo critical experiments. These experiments were cancelled following the termination of the Naval Reactor Program work on Project Prometheus.

\section{Background}

The critical experiments were to be assembled on the Planet general-purpose split vertical assembly machine at LACEF. The assemblies were to consist of a cylindrical core region containing interspersed plates of highly enriched uranium (HEU) metal, various refractory metals, and graphite or polyethylene of various thicknesses. These experiments were designed to assess the adequacy of the existing neutron cross sections used in physics models for neutron energy spectra characteristic of Prometheus reactor designs under normal and accident conditions.

Three experiments were designed to bracket the neutron energy spectra expected in Prometheus reactor designs under normal operating conditions, and one experiment was designed to simulate an accident condition in which the core is flooded with water. Experiment 1 was designed to approximate the neutron energy spectrum in the center of the core. Experiments 2 and 3 were designed to bracket the upper and lower range, respectively, of the core average neutron energy spectrum. Experiment 4 was designed to simulate the average neutron energy spectrum when the core is flooded with water.

The assembly machine support structure uses a stainless steel diaphragm to support the upper core region of the critical assembly. LANL provided revised specifications for the diaphragm thickness and mass loading limit after the NRPCT pre-experimental predictions for the Re, Ta-2.5W, Baseline, and Mo critical experiments were issued. In these revised specifications the thickness of the stainless steel diaphragm used to support the upper core region of the experimental assemblies was increased from $0.040 "$ to $0.075 "$ and a $150 \mathrm{~kg}$ mass loading limit was placed on the diaphragm. This mass limit places a bound on the number of stacking units that can be in the upper core region of the assembly. The pre-experimental predictions for the Re, Ta-2.5W, Baseline, and Mo critical experiments were based on a $0.040^{\prime \prime}$ thick stainless steel diaphragm, the same diaphragm thickness used in the Nb-1 $\mathrm{Zr}$ $4 \mathrm{U}$ [2] critical experiment, and did not include a mass limit on the upper core region of the experimental assembly.

In addition, the metal reflector thickness used in the pre-experimental predictions for the Ta-2.5W critical experiments used the nominal design value of $0.150 "$. A thickness based on the average asbuilt Ta-2.5W plate thickness was not used due to the lack of as-built Ta-2.5W thicknesses at the time of analysis. The average as-built thickness for the individual Ta-2.5W plates was $0.0246^{\prime \prime}$, leading to a predicted metal reflector thickness of $0.1476^{\prime \prime}$ ( 6 @ 0.0246"). A series of analyses were performed to assess the impact of the increased, $0.075^{\prime \prime}$, diaphragm thickness, the $150 \mathrm{~kg}$ diaphragm mass loading limit, and the 0.1476 " Ta-2.5W metal reflector thickness on the pre-experimental predictions for the $\mathrm{Re}, \mathrm{Ta}-2.5 \mathrm{~W}$, Baseline, and Mo critical experiments.

\section{Summary and Conclusions}

A maximum of four different analyses were run for a given experiment and these analyses are described as cases. Case (a) is the $0.040^{\prime \prime}$ thick diaphragm, the original number of stacking units in the upper core region, and the 0.150 " thick Ta-2.5W metal reflector (for the Ta-2.5W critical experiments only). Case (b) is the $0.075^{\prime \prime}$ thick diaphragm, the original number of stacking units in the 
upper core region, and the 0.150 " thick Ta-2.5W metal reflector (for the Ta-2.5W critical experiments only). Case (c) is for the Ta-2.5W critical experiments only and includes the 0.075 " thick diaphragm, the original number of stacking units in the upper core region, and the $0.1476^{\text {" }}$ thick Ta-2.5W metal reflector. Case (d) is the updated critical configuration with the $0.075^{\prime \prime}$ thick diaphragm, the $150 \mathrm{~kg}$ mass limit put into place by adjusting the number of stacking units in the upper core region, and the 0.1476 " thick Ta-2.5W metal reflector (for the Ta-2.5W critical experiments only). These results are provided in Tables E-1 through E-4.

Note that the case (d) final predicted critical configuration is either unchanged from the original [case (a)] or has a slightly different top reflector thickness. Also note that the change in the multiplication factor $(\Delta k)$ due to the variations in the experimental configuration is calculated relative to case (a), the originally predicted critical configuration.

The $k_{\text {eff }}$ sensitivities to the changes in the experimental configuration were analyzed using both RCP01 and MCNP5. The average changes in the multiplication factor (between the two codes) due to the change in the diaphragm thickness and the number of stacking units in the upper core region of the assembly are: -0.00064 for the Re critical experiments, -0.00133 for the baseline critical experiments, and -0.00048 for the Mo critical experiments. The average change in the multiplication factor due to the change in diaphragm thickness, the number of stacking units in the upper core region of the assembly, and the change in the Ta-2.5W metal reflector thickness for the Ta-2.5W critical experiments is -0.00034 . These results indicate that the critical configuration for each of the TA-18 critical experiments is affected only slightly above the $95 \%$ confidence interval of each of the originally predicted nominal experimental configuration [case (a)] multiplication factors. The combined effect of these changes is well within the $0.40-0.50 \% \Delta \mathrm{k}$ experimental uncertainty expected for the TA18 critical experiments. Therefore, the $0.075^{\prime \prime}$ diaphragm thickness, the $150 \mathrm{~kg}$ diaphragm mass loading limit, and the change in the Ta-2.5W metal reflector thickness (for the Ta-2.5W critical experiments only) are concluded to have no significant impact on the predicted critical configuration for the TA-18 critical experiments. 


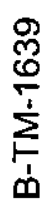

\begin{tabular}{|c|c|c|c|c|c|c|c|c|c|c|c|c|c|}
\hline \multirow{6}{*}{$\left|\begin{array}{l}\bar{\delta} \\
\mathbb{L} \\
\dot{\alpha} \\
\alpha\end{array}\right|$} & 产 & ' & 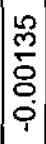 & $\mid \begin{array}{l}0 \\
8 \\
8 \\
8 \\
8 \\
0 \\
0\end{array}$ & 1 & 高 & $\begin{array}{l}3 \\
\\
8 \\
8 \\
\\
\end{array}$ & & $\left|\begin{array}{l}9 \\
0 \\
8 \\
8 \\
0 \\
0 \\
1\end{array}\right|$ & 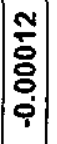 & . & 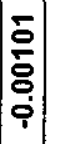 & " \\
\hline & 总导导 & $\mid \begin{array}{l}0 \\
8 \\
8 \\
0 \\
0\end{array}$ & $\begin{array}{l}\frac{0}{8} \\
8 \\
8 \\
0\end{array}$ & $\mid \begin{array}{l}8 \\
8 \\
8 \\
8 \\
\\
0\end{array}$ & $\begin{array}{l} \pm \\
8 \\
8 \\
\\
0\end{array}$ & $\begin{array}{l}\frac{7}{6} \\
8 \\
8 \\
0 \\
0\end{array}$ & $\begin{array}{l}\frac{N}{8} \\
8 \\
8 \\
0\end{array}$ & $\mid \begin{array}{l}\bar{J} \\
\vdots \\
\\
8 \\
0\end{array}$ & $\left|\begin{array}{l}\frac{\infty}{5} \\
8 \\
8 \\
0\end{array}\right|$ & $\begin{array}{l}2 \\
\dot{8} \\
8 \\
0 \\
0\end{array}$ & $\mid \begin{array}{l}0 \\
\vdots \\
\delta \\
0 \\
0\end{array}$ & $\left|\begin{array}{l}\infty \\
\delta \\
\delta \\
\delta \\
\delta\end{array}\right|$ & $\mid \begin{array}{l}m \\
\\
8 \\
\\
\end{array}$ \\
\hline & 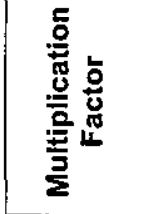 & $\mid \begin{array}{c}\frac{m}{5} \\
\\
\\
-\end{array}$ & 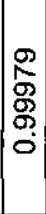 & $\mid \begin{array}{l}0 \\
\stackrel{8}{8} \\
8 \\
\end{array}$ & \% & 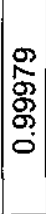 & $\begin{array}{l}\frac{9}{8} \\
\stackrel{8}{8} \\
\stackrel{8}{\circ}\end{array}$ & $\mid \begin{array}{l}0 \\
0 \\
0 \\
0 \\
-\end{array}$ & 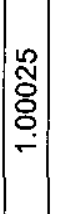 & $\mid \begin{array}{l}0 \\
8 \\
8 \\
8 \\
8 \\
- \\
-\end{array}$ & 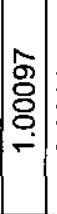 & 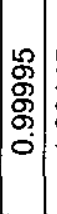 & 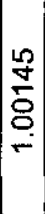 \\
\hline & 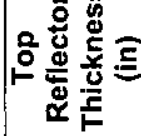 & $\stackrel{n}{\stackrel{n}{*}}$ & $\stackrel{n}{\stackrel{n}{2}}$ & $\stackrel{\sim}{\sim}$ & $\stackrel{\infty}{\infty}$ & $\stackrel{\infty}{\infty}$ & $\stackrel{\substack{\infty \\
\infty}}{-}$ & $\left|\begin{array}{l}0 \\
8 \\
6\end{array}\right|$ & $\left|\begin{array}{c}5 \\
5 \\
6\end{array}\right|$ & $\mid \begin{array}{l}0 \\
0 \\
10\end{array}$ & $\stackrel{8}{\Upsilon}$ & 冬 & $\stackrel{\Xi}{\sim}$ \\
\hline & 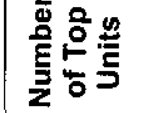 & $\sigma$ & $\sigma$ & $r$ & $\infty$ & $\infty$ & 0 & $\infty$ & $\infty$ & $\nabla$ & 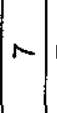 & $A \mid$ & 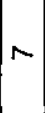 \\
\hline & 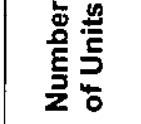 & $\stackrel{\infty}{=}$ & $\stackrel{\infty}{-}$ & $1 \%$ & 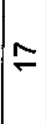 & $\mp$ & $\approx$ & $\stackrel{\circ}{\div}$ & $\stackrel{0}{=}$ & $\stackrel{0}{\circ}$ & $\stackrel{20}{-}$ & $\stackrel{10}{\square}$ & 12 \\
\hline \multirow{6}{*}{$\begin{array}{l}0 \\
\frac{2}{2} \\
0 \\
z\end{array}$} & J & 1 & $\begin{array}{l}2 \\
\frac{2}{8} \\
0 \\
0 \\
1\end{array}$ & 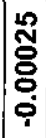 & ' & $\begin{array}{l}\frac{N}{7} \\
\frac{5}{8} \\
0 \\
0\end{array}$ & 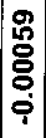 & ' & $\begin{array}{l}m \\
0 \\
0 \\
0 \\
0 \\
9\end{array}$ & $\mid \begin{array}{l}0 \\
0 \\
0 \\
\delta \\
0 \\
0 \\
0 \\
\end{array}$ & ' & 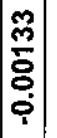 & 1. \\
\hline & 递兽 & $\mid \begin{array}{l}8 \\
8 \\
8 \\
8 \\
0 \\
0\end{array}$ & $\begin{array}{l}3 \\
8 \\
8 \\
8 \\
0 \\
0\end{array}$ & $\begin{array}{l}3 \\
8 \\
8 \\
8 \\
0\end{array}$ & $\begin{array}{l}8 \\
8 \\
8 \\
8 \\
0\end{array}$ & $\begin{array}{l}5 \\
8 \\
8 \\
8 \\
0\end{array}$ & 占 & $\mid \begin{array}{l}\overline{8} \\
8 \\
8 \\
8 \\
0\end{array}$ & $\mid \begin{array}{l}0 \\
0 \\
8 \\
8 \\
0 \\
0\end{array}$ & $\mid$ & $\mid \begin{array}{l}- \\
0 \\
8 \\
8 \\
0 \\
0\end{array}$ & $\mid \begin{array}{l}9 \\
0 \\
8 \\
8 \\
8 \\
0\end{array}$ & $\mid \begin{array}{l}\bar{\phi} \\
\mathscr{8} \\
\varnothing \\
0\end{array}$ \\
\hline & 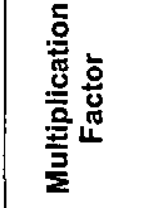 & $\mid \begin{array}{l}\frac{2}{8} \\
\\
-\end{array}$ & $\mid \begin{array}{l}0 \\
8 \\
8 \\
\\
- \\
\end{array}$ & 点 & $\frac{m}{5}$ & 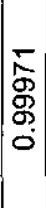 & \begin{tabular}{|} 
疋 \\
$\stackrel{8}{8}$ \\
\\
\end{tabular} & $\mid \begin{array}{l}8 \\
\frac{8}{8} \\
\\
-\end{array}$ & $\mid \begin{array}{l}\hat{g} \\
g \\
g \\
0 \\
0\end{array}$ & $\mid \begin{array}{l}\mathcal{O} \\
0 \\
8 \\
8 \\
8 \\
-\end{array}$ & 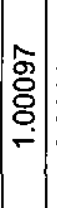 & 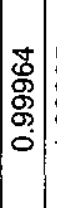 & 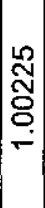 \\
\hline & 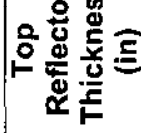 & $\stackrel{n}{\sim}$ & $\stackrel{\substack{0 \\
\sim}}{\sim}$ & $\stackrel{8}{\Omega}$ & $\stackrel{20}{2}$ & $\stackrel{20}{2}$ & $\stackrel{10}{2}$ & $\mid \begin{array}{c}8 \\
\stackrel{0}{0} \\
\dot{0}\end{array}$ & 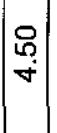 & $\left|\begin{array}{l}0 \\
0 \\
7\end{array}\right|$ & 음 & $\stackrel{\circ}{-}$ & $\frac{12}{2}$ \\
\hline & 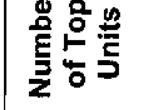 & $\sigma$ & क & 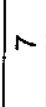 & $\infty$ & $\infty$ & $\omega$ & $\infty$ & $\infty$ & $\nabla 1$ & $N$ & $r$ & $r$ \\
\hline & 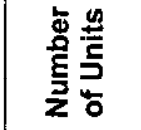 & $\infty$ & $\stackrel{\infty}{\leftarrow}$ & $\stackrel{\infty}{=}$ & $\approx$ & $\mp$ & $\neq$ & 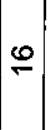 & $\stackrel{\oplus}{\circ}$ & 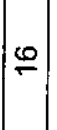 & 10 & 10 & $\stackrel{10}{-}$ \\
\hline & $\begin{array}{l}\text { 曷 } \\
\text { 怘 } \\
\end{array}$ & $+\infty$ & $\%$ & 3 & $\pi$ & 0 & 0 & $\pi$ & ـ & 0 & 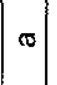 & | & 0 \\
\hline & 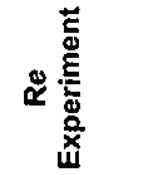 & & $\sigma$ & & & $N$ & & & $m$ & & & $\forall$ & \\
\hline
\end{tabular}




\begin{tabular}{|c|c|c|c|c|c|c|c|c|c|c|c|c|c|c|c|}
\hline & 并 & & $\frac{\sigma}{\frac{\sigma}{8}}$ & 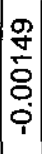 & $\mid$ & & $\begin{array}{l}\frac{2}{5} \\
\frac{5}{8} \\
\vdots \\
\vdots\end{array}$ & 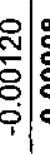 & & 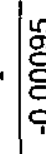 & $\begin{array}{l}0 \\
8 \\
\end{array}$ & 象 & & 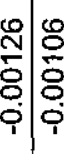 & 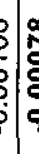 \\
\hline & 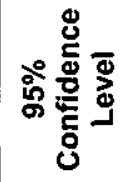 & 票 & $\begin{array}{l}0 \\
8 \\
8 \\
8 \\
\end{array}$ & $\mid \begin{array}{l}0 \\
\\
0 \\
0 \\
0\end{array}$ & $\mid \begin{array}{c}\infty \\
0 \\
8 \\
8 \\
0 \\
0\end{array}$ & $\begin{array}{l}\frac{\pi}{8} \\
8 \\
\\
\end{array}$ & & 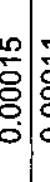 & & 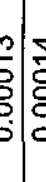 & 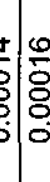 & $\begin{array}{l}10 \\
8 \\
8 \\
0\end{array}$ & & & \\
\hline$\left|\begin{array}{l}\overline{\mathbf{0}} \\
\mathbf{0} \\
\overline{\mathbf{x}}\end{array}\right|$ & 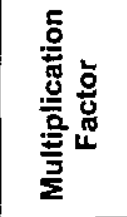 & . & 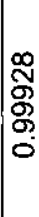 & $\mid \begin{array}{l}\text { g } \\
\text { o. } \\
\text { o } \\
0 \\
0\end{array}$ & $\mid$ & 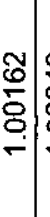 & 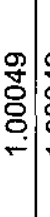 & 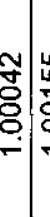 & & 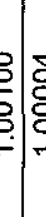 & : & 量 & 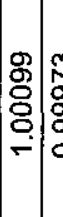 & $\begin{array}{l}3 \\
5 \\
5 \\
\\
0 \\
0 \\
0\end{array}$ & \\
\hline & 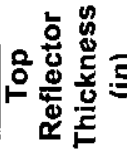 & $\frac{9}{\square}$ & $\stackrel{\circ}{=}$ & 움 & $\frac{0}{\div}$ & 兽 & $\stackrel{8}{8}$ & 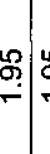 & & S. & $\int_{10}^{8}$ & $\begin{array}{l}8 \\
1 \\
15\end{array}$ & 志 & & \\
\hline & 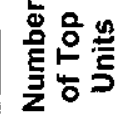 & 10 & $\sigma$ & 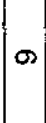 & $\infty$ & $\infty$ & $\infty$ & $\infty$ & & $\Rightarrow \sigma$ & 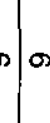 & $m$ & 100 & $\infty \mid \infty$ & 011 \\
\hline & 总总 & $\stackrel{\infty}{-}$ & $\stackrel{\infty}{-}$ & $\stackrel{\infty}{\leftarrow}$ & $\infty$ & $=$ & $=$ & $F$ & & $2:$ & $\stackrel{0}{2} \infty$ & $\stackrel{\infty}{-\infty}$ & $\infty$ & 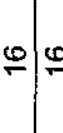 & 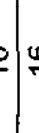 \\
\hline & 弟 & & 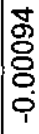 & $\mid$ & $\mid$ & & 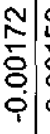 & $\begin{array}{l}8 \\
8 \\
8 \\
8\end{array}$ & 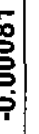 & 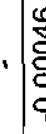 & $\begin{array}{l}0 \\
\end{array}$ & 戀 & & 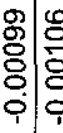 & 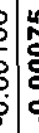 \\
\hline & 总离 & 存 & 隽 & $\begin{array}{l}\text { 告 } \\
\text { 员 } \\
0 \\
0\end{array}$ & $\left|\begin{array}{l}0 \\
0 \\
0 \\
0 \\
0 \\
0\end{array}\right|$ & \begin{tabular}{l}
3 \\
\hdashline \\
0 \\
0
\end{tabular} & 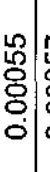 & $\begin{array}{l}5 \\
8 \\
8 \\
8 \\
0\end{array}$ & & s. & $\begin{array}{l}5 \\
3 \\
5\end{array}$ & $\begin{array}{l}1 \\
0 \\
0 \\
0 \\
0 \\
0\end{array}$ & $\mid \begin{array}{l}0 \\
0 \\
0 \\
0 \\
0 \\
0 \\
0\end{array}$ & \begin{tabular}{l|l}
0 \\
0
\end{tabular} & : \\
\hline 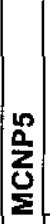 & 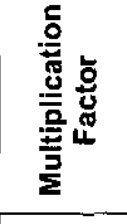 & 沯 & 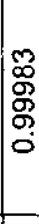 & $\begin{array}{l}3 \\
0 \\
0 \\
8 \\
0 \\
0\end{array}$ & $\mid \begin{array}{l}1 \\
0 \\
0 \\
0 \\
0 \\
-1\end{array}$ & $\stackrel{8}{8}$ & 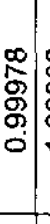 & 㝵 & 8 & 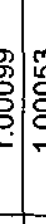 & $\mid \begin{array}{l}\square \\
\vdots \\
0 \\
0 \\
0\end{array}$ & 咅 & 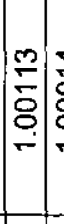 & $\begin{array}{l}\overrightarrow{8} \\
\overline{8}\end{array}$ & 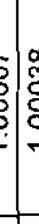 \\
\hline & 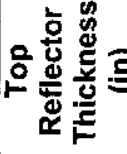 & . & $\stackrel{\mathscr{8}}{\stackrel{8}{\circ}}$ & $\stackrel{8}{\circ}$ & \begin{tabular}{|l|} 
\\
0
\end{tabular} & $\stackrel{20}{\square}$ & $\stackrel{0}{?}$ & \begin{tabular}{l}
$n$ \\
-2 \\
\hdashline
\end{tabular} & & จุ & \begin{tabular}{l}
8 \\
\hdashline \\
4
\end{tabular} & 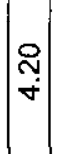 & $\begin{array}{l}\infty \\
\vdots \\
0\end{array}$ & $\begin{array}{l}\infty \\
\vdots \\
0\end{array}$ & 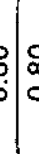 \\
\hline & 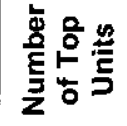 & $\infty$ & $\infty$ & $\infty$ & 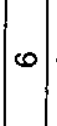 & $\infty$ & $\infty$ & $\infty$ & $\Omega$ & $\sigma 0$ & $\Rightarrow 0$ & $m$ & $\infty$ & $\infty \mid \alpha$ & 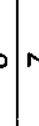 \\
\hline & 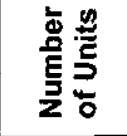 & $\stackrel{\infty}{\simeq}$ & $\stackrel{\infty}{=}$ & $\stackrel{\infty}{=}$ & $\infty$ & $=$ & $\approx$ & $=1:$ & & $2:$ & $0, \infty$ & $\mathbb{\infty}$ & $1=$ & $=1$ & 7 \\
\hline & 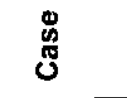 & $\pi$ & Do & ro & 嗐 & $\pi$ & مـ & & 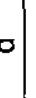 & $\pi$ & 0.0 & 0 & $\approx$ & o & 7 \\
\hline & 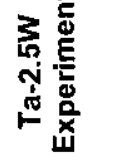 & & & $r$ & & & $N$ & & & & $m$ & & & v & \\
\hline
\end{tabular}

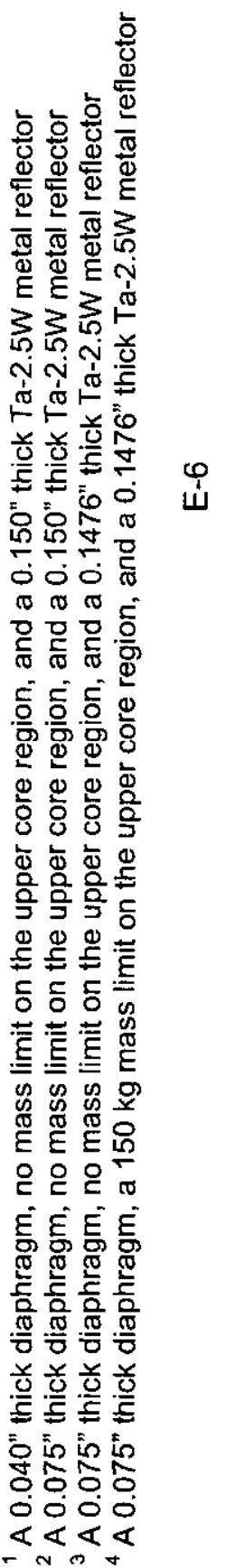


$\sum_{\substack{\frac{\sigma}{6} \\ \text { ஸे }}}^{\frac{1}{1}}$

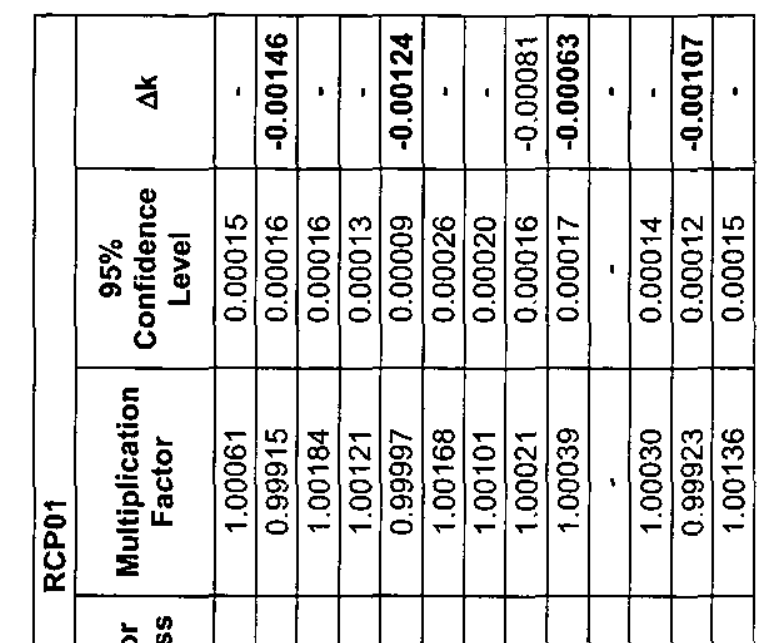

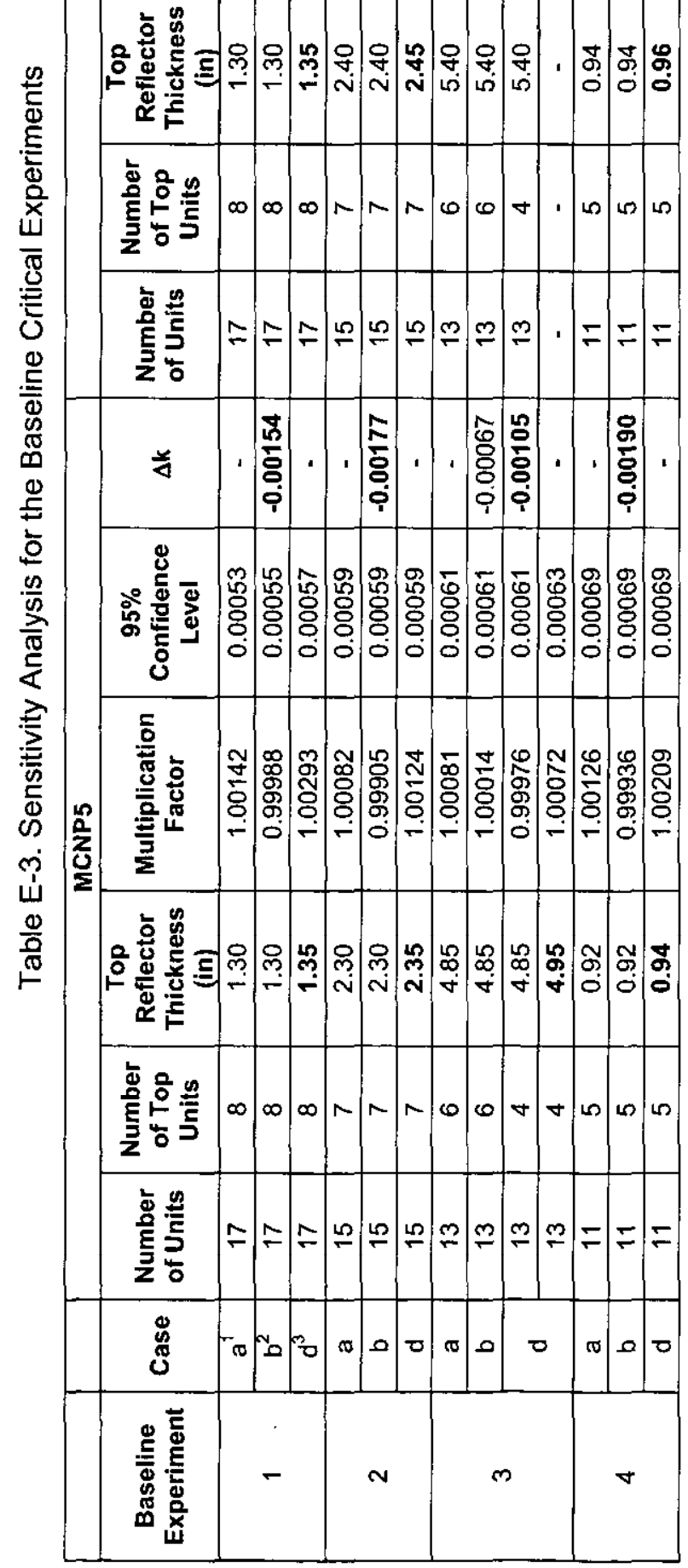

高市号 윽윽등 送农 동ㄷㅇ음 है

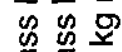
总 胥员 을웅 물묻ㅁ $\varepsilon E \varepsilon$ 홍 등도 需 总总总 ㅇํㅇ 눙응 000 $14<4$ 


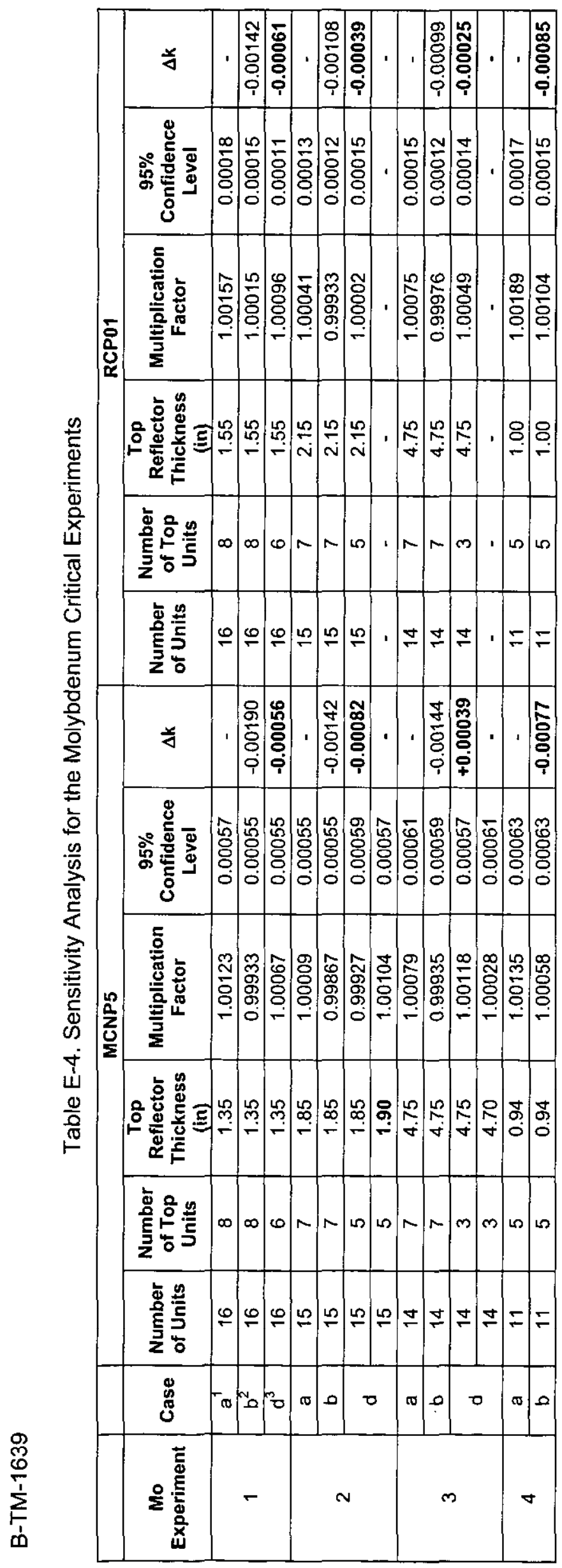

w

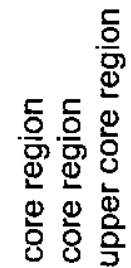

起告

옥윽음

$\stackrel{\text { 巳巳g }}{\underline{5}}$

ธㄷㅇㅇㅡ

를 흘

of

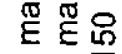

웅

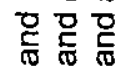

동 통

흥등흥

줗 $\frac{\pi}{7}$

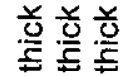

운

응ㅇ

운

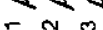


Appendix F

Mo Plate Dimension and Chemistry Reports 
B-TM-1639

(Intentionally Blank) 

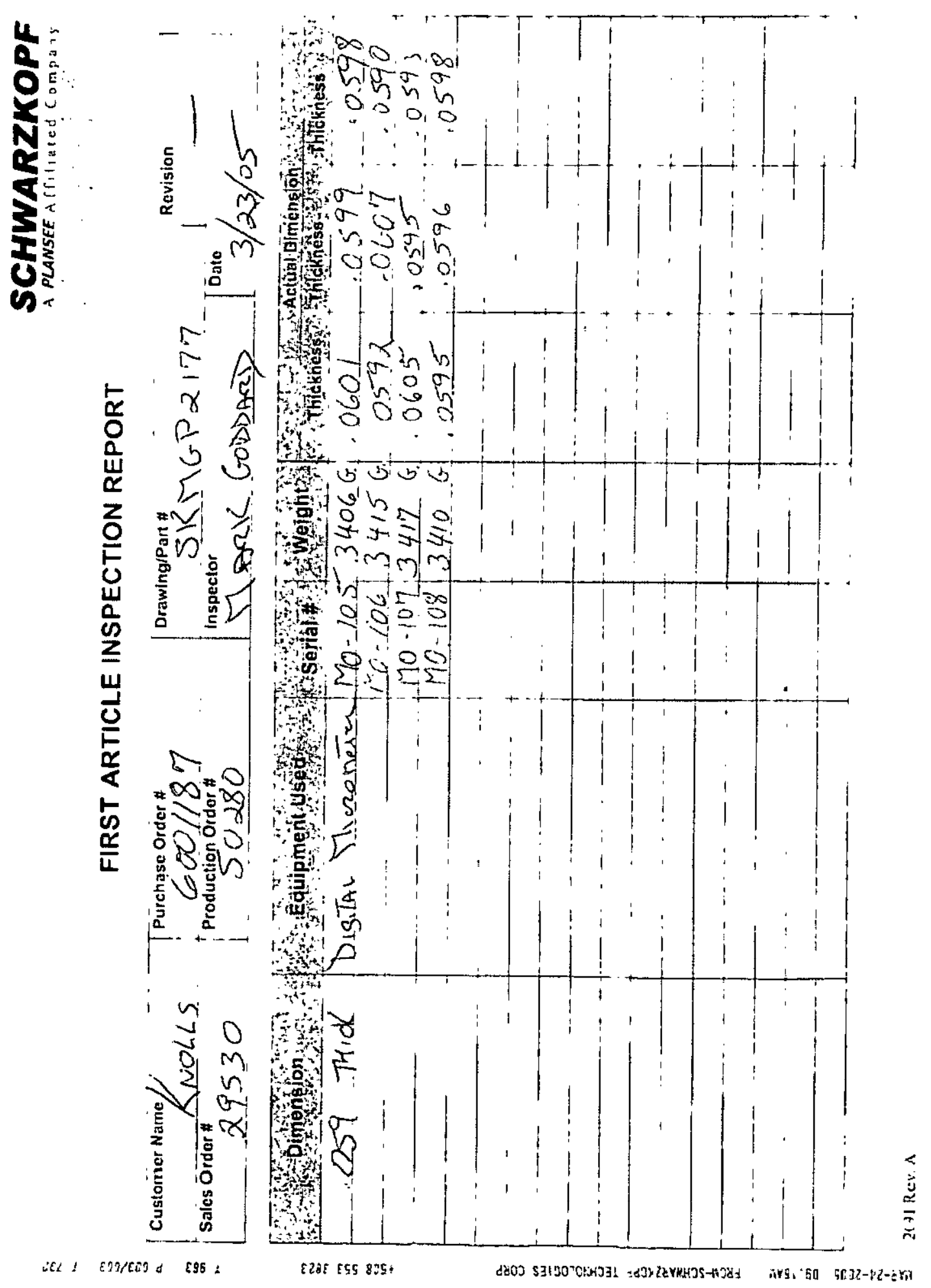


\section{B-TM-1639}

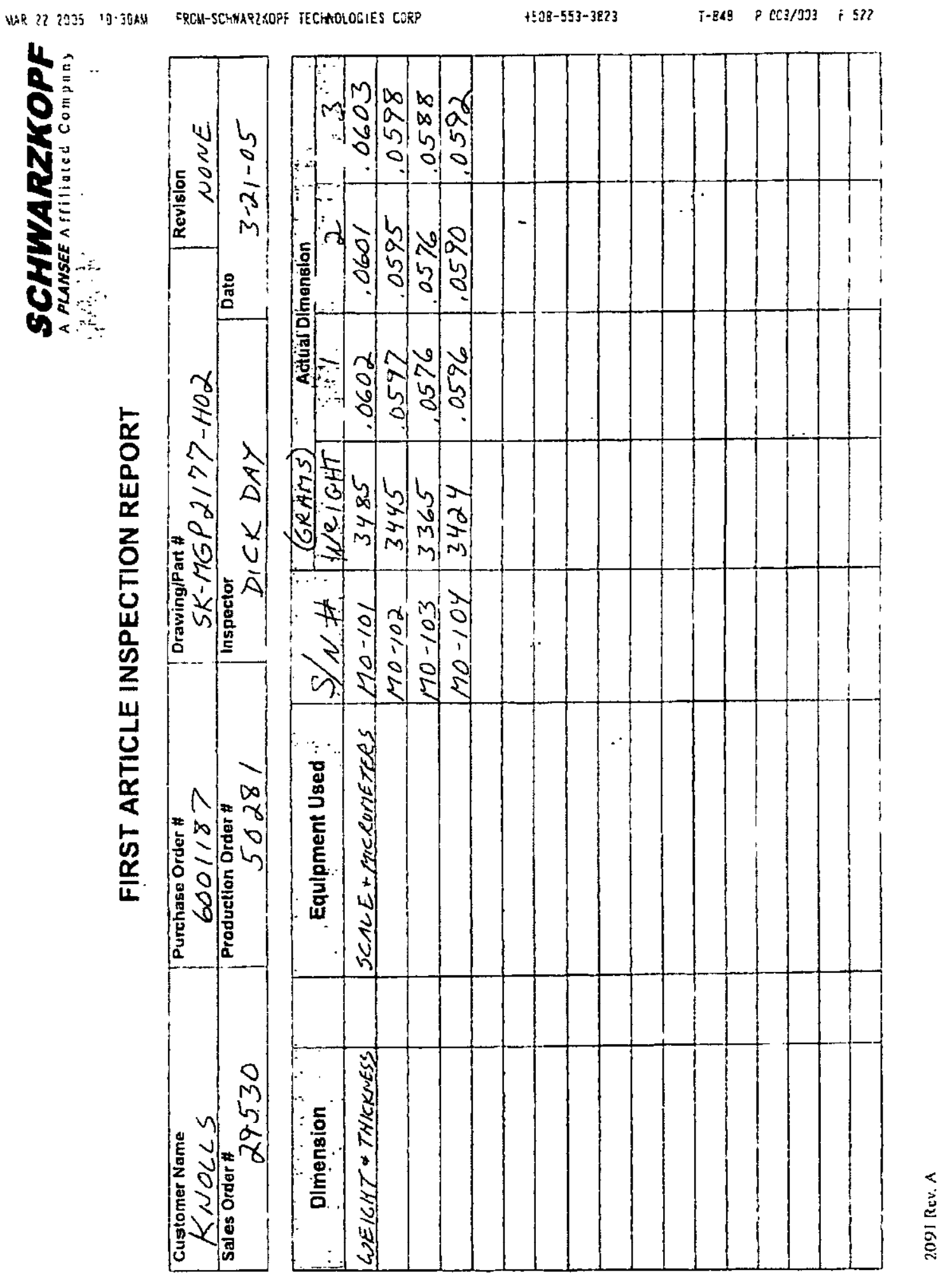


B-TM-1639

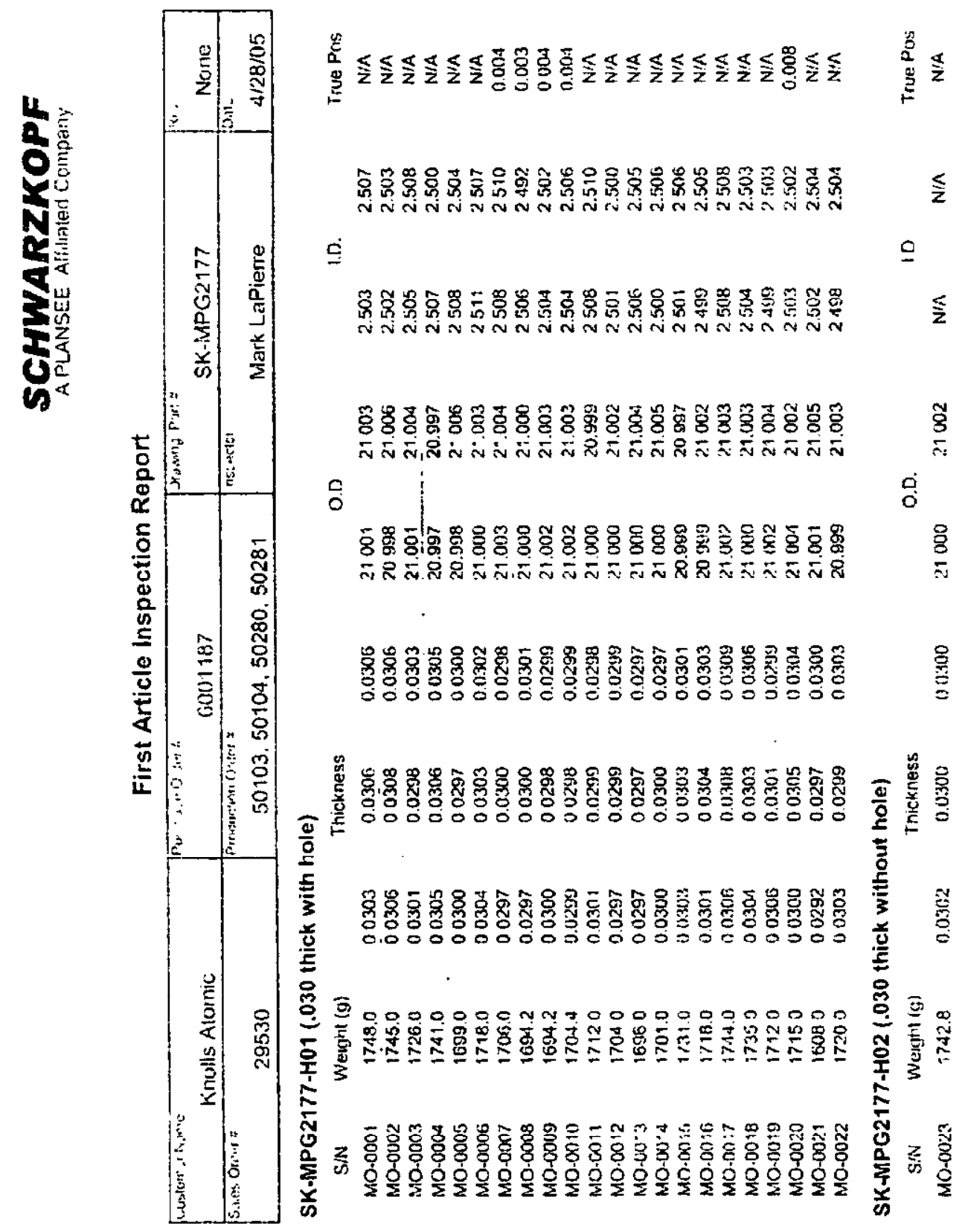




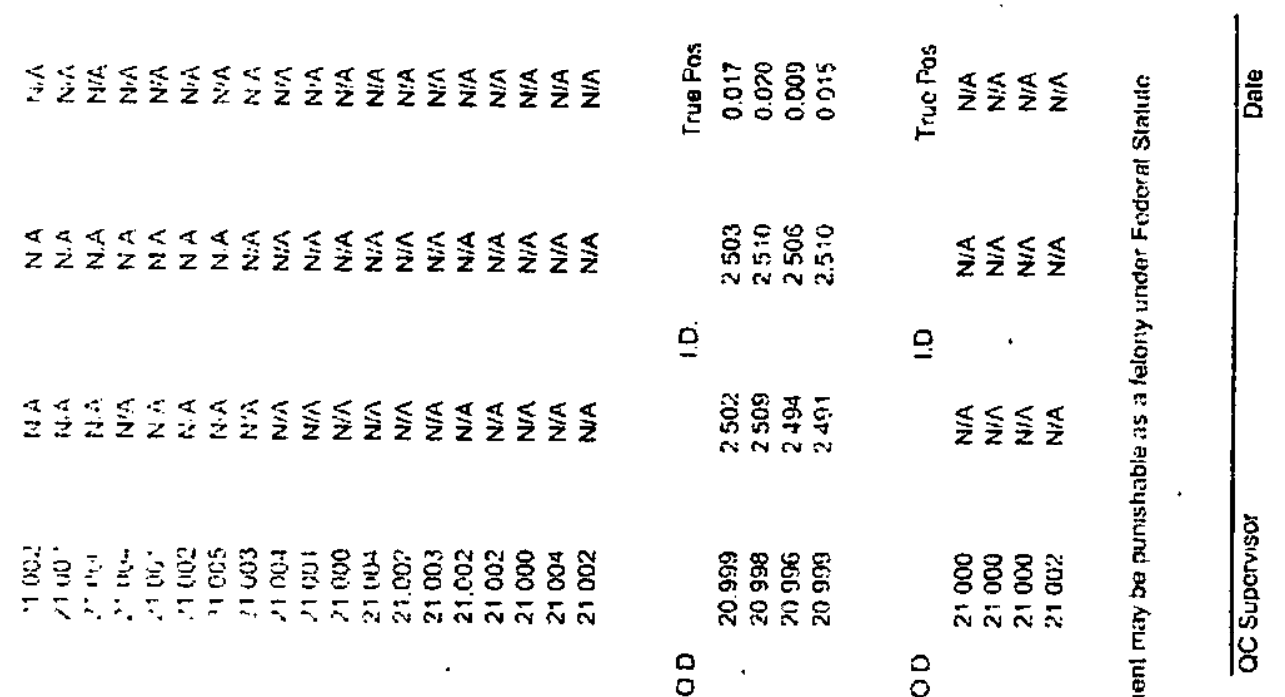

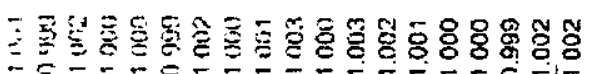

8

路骂骂器

กำ

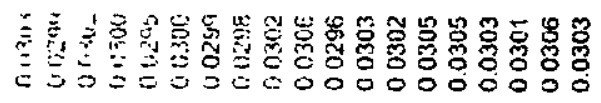

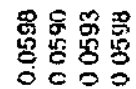

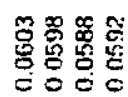

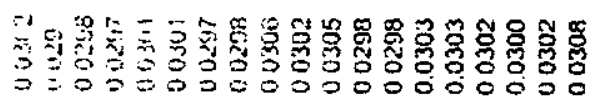

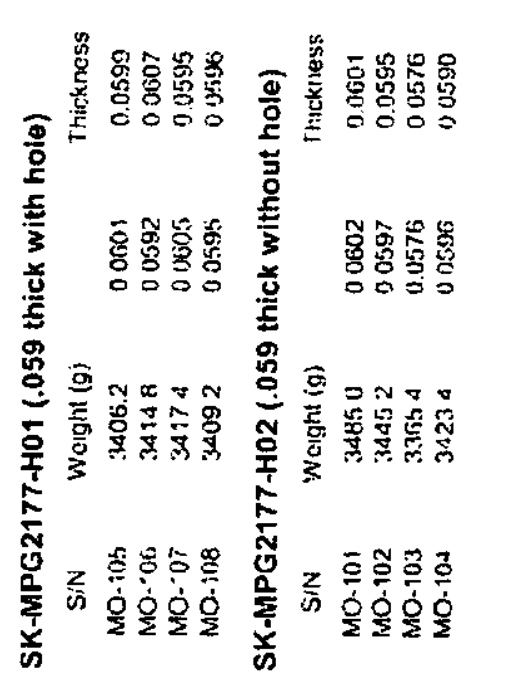

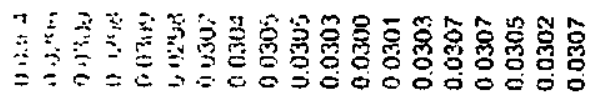

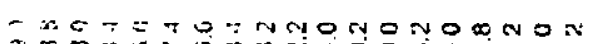

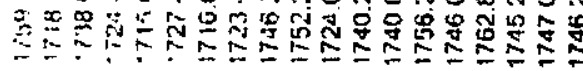

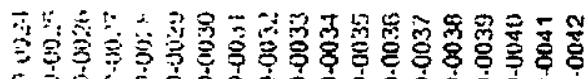

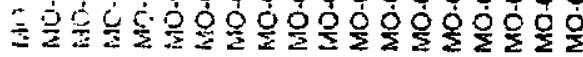


B-TM-1639

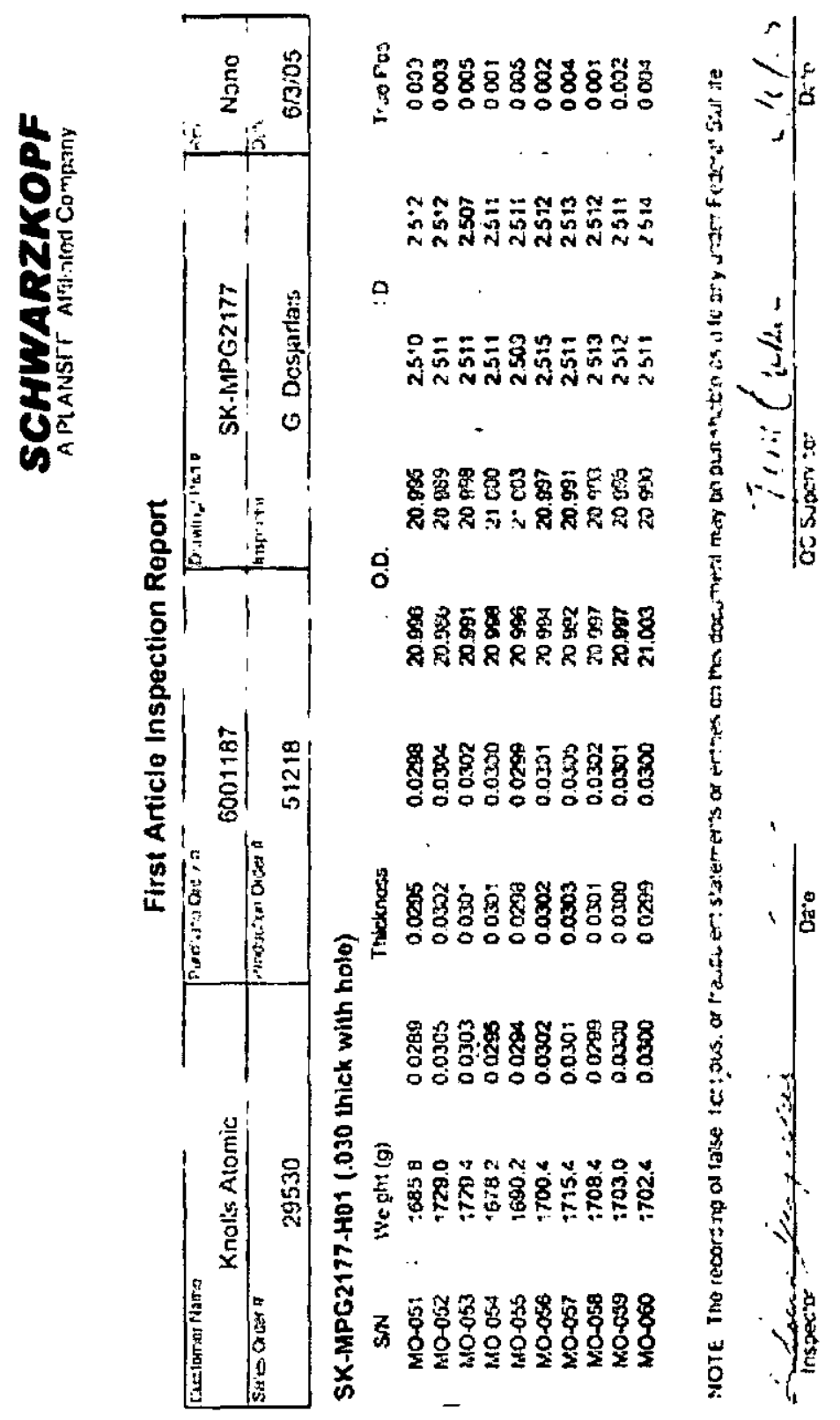


B-TM-1639

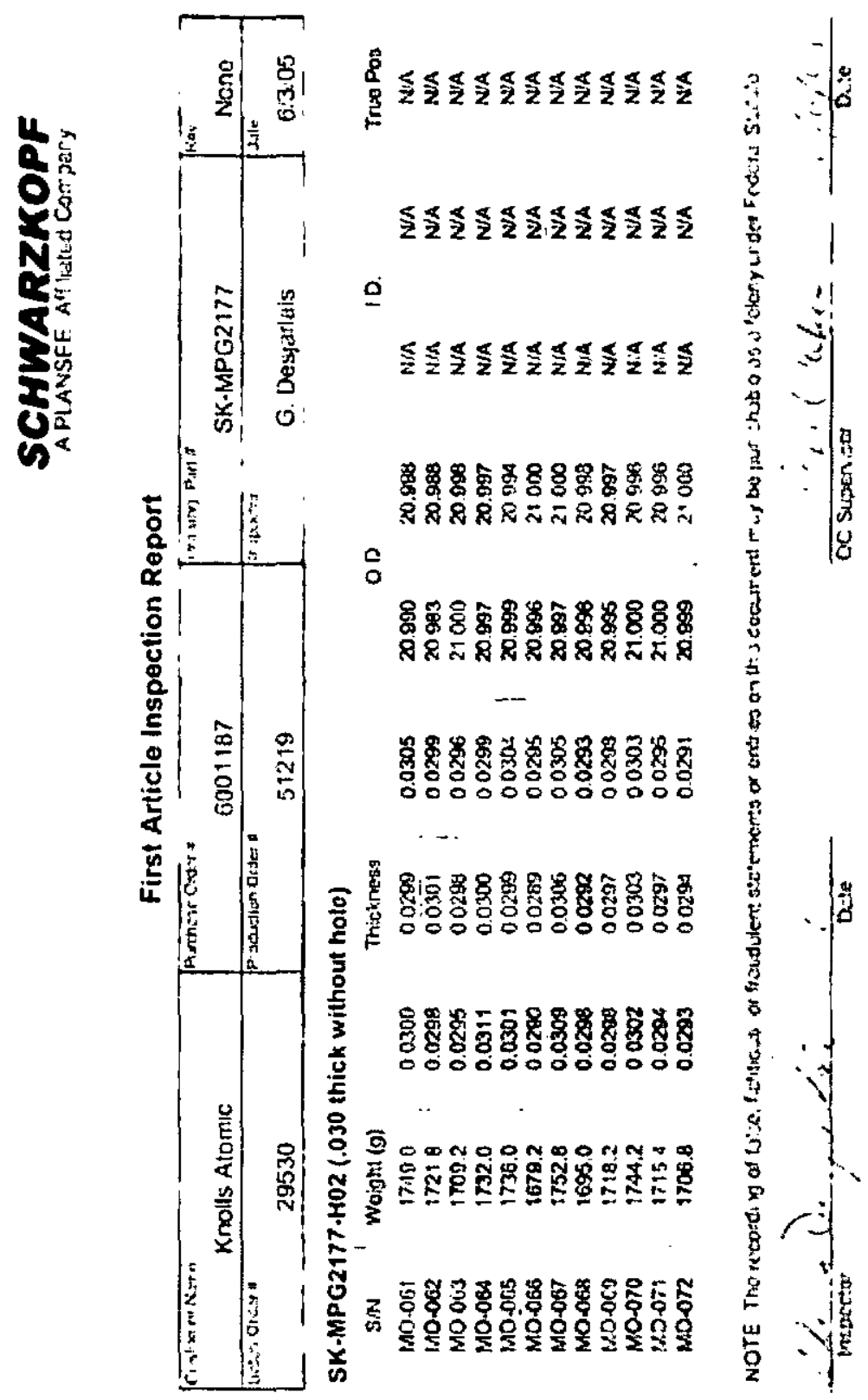




\section{SCHWARZKOPF TECHNOLOGIES CORPORATION}

II 5 Constitution Blvd./Franklin. MA 02038

\section{CERTIFICATE OF CONFORMANCE}

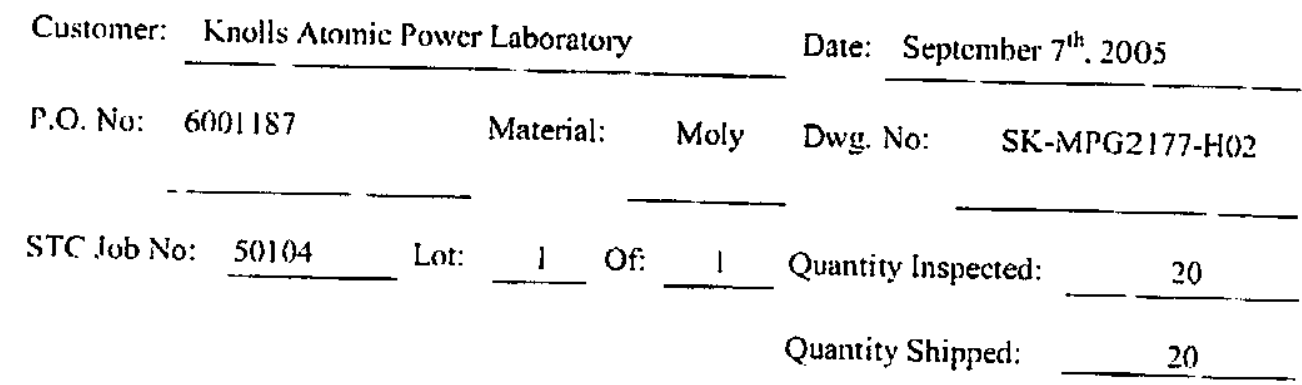

Remarks: Stc Ar! No 50025138

Material report: 81839875000010

Bittel \#: 0090232160

This is to certify that this shipment is in conformance with the Drawings and/or

Specifications listed on this order, and that we have performed the required physical tests and inspections on the materials.

The liability of Schuarzkopf Technologies hereunder is limited to the cost of the materials in question.

Certified

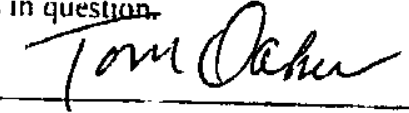

Certified

Certified

Certified

$2120 \mathrm{Rev} . \mathrm{E}$

Title

Title

Title

Title

115 Constitution Blvd. Franklin, MA 02038 Phone 508.553.3800 Fax 508.553.3823 


\section{SCHWARZKOPF TECHNOLOGIES CORPORATION}

115 Constitution Blvd./Eranklin. MA 02038

\section{CERTIFICATE OF CONFORMANCE}

\begin{tabular}{|c|c|c|c|c|c|c|c|c|}
\hline Customer: & Knolls A & Powe & Laboratol & & & Date: & September & $7^{\text {1h }}, 2005$ \\
\hline P.O. No: & 6001187 & & Material: & & Moly & Dwg. & SK- & -MPG $2177-\mathrm{H} 02$ \\
\hline STC Job N & 51219 & Lot: & 1 & of: & 1 & Quanti & ity Inspected: & 12 \\
\hline & & & & & & Quentit & ty Shippcd: & 12 \\
\hline
\end{tabular}

Remarks: Stc An No 50025136

Muterial report: 82493034000010

Botcl it: 0090273793

This is to certify that this shipment is in confurmance with the Drawings and/or Specifications listed on this order, and that we have performed the required physical tesis and inspections on the matcrials.

The liability of Schwarzopf Technologies hereunder is limited to the cost of the malerials in question.

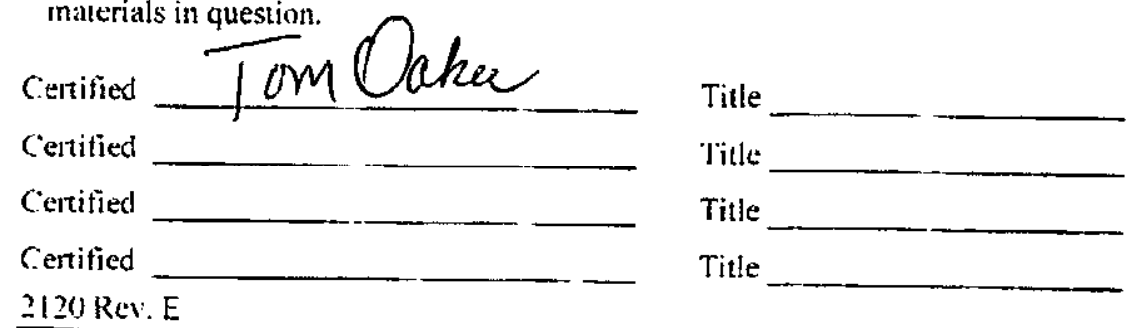

2120 Rev. E

115 Constitution Blvd. Franklin, MA 02038 Phone 508.553.3800 Fax 508.553.3823 


\section{SCHWARZKOPF TECHNOLOGIES CORPORATION}

115 Constitution Bivd./Franklin. MA 02038

\section{CERTIFICATE OF CONFORMANCE}

\begin{tabular}{|c|c|c|c|c|c|c|c|c|}
\hline Customer: & Knolls At & Powe & Laborator & & & Date: & September 7 & $7^{\text {th }} .2005$ \\
\hline P.O. No: & 6001187 & & Material: & & Moly & Dwg. 1 & SK-I & $-M P G 2177-\mathrm{HO} 1$ \\
\hline STC Iob No & $0: 50103$ & Lot: & 1 & Of: & 1 & Quantity & ty Inspecied: & 22 \\
\hline & & & & & & Quantity & y Shipped: & $\underline{2}$ \\
\hline
\end{tabular}

Remarks: Stc Ar No 50025136

Matcrial repon: 81839875000010

Batch \#: 00902.32160

This is to certify that this shipment is in confornance with the Drawings and/or

Specitications listed on this order, and that we have perforned the required plysical tcsts and inspections on the materials.

The liability of Selwwarzkopl Technologies hereunder is limited to the cost of the matcrials in question.

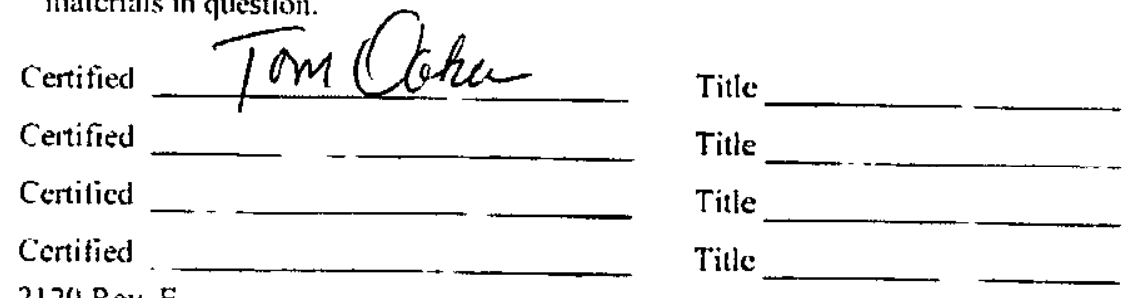

2120 Rev. E 


\section{SCHWARZKOPF TECHNOLOGIES CORPORATION}

115 Constitution B]vd./Franklin. MA 02038

\section{CERTIFICATE OF CONFORMANCE}

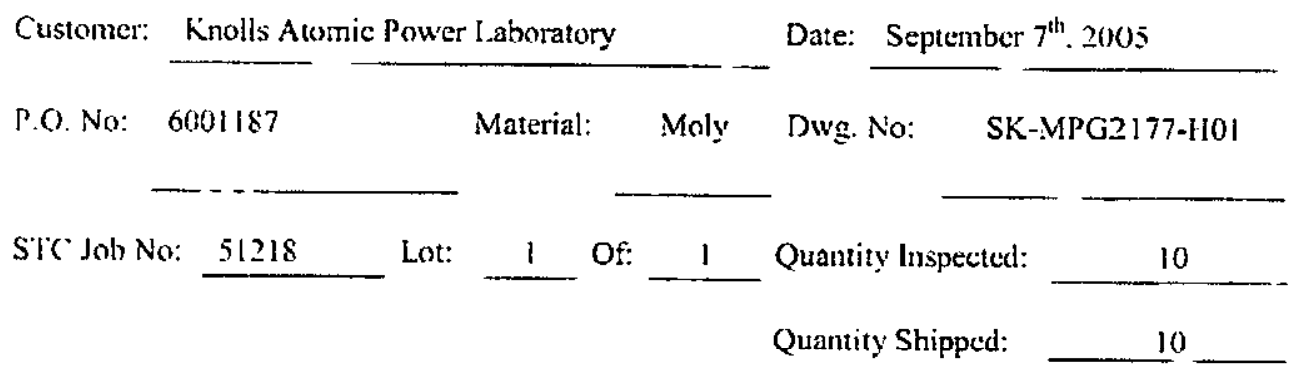

Remarks: Sic Art No 50025136

Material report: 82493034000010

Batch it: 0090273793

This is to certily that this shipment is in confornance with the Drawings and/or Specifications listed on this order. and that we have perforned the required physical tests and inspections on the muterials.

The liability of Schwarzkopf Technologies hereunder is limited to the cost of the matcrials in question.

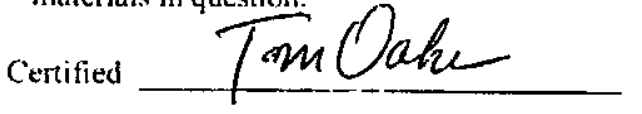

Cortificd

Certifice

Cortificd 2I 20 Rev. E

Tïle

Titte

Title

Title

115 Constitution Blvd. Franklin, MA 02038 Phone 508.553.3800 Fax 508.553.3823 


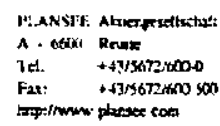

TEST-REPORT

acc. to EN $10204-2.2$

\section{PLANSEe}

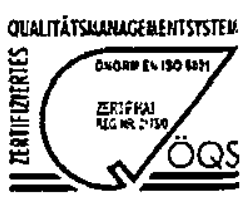

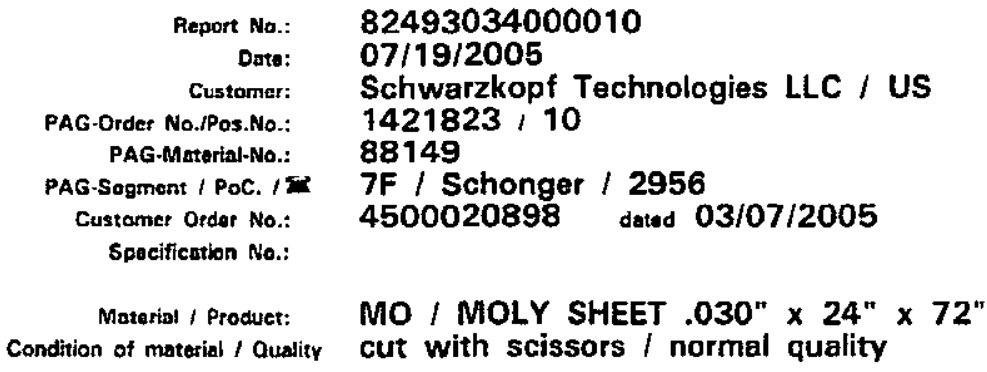

Dimensions:

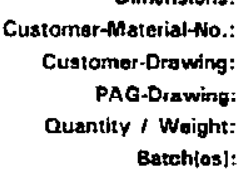

$$
11
$$

0090273793

\subsection{KG / KG}

$43.010 \mathrm{kG}$

GUARANTEED CHEMICAL ANALYSIS: ecc. to PAG-Spec. AOOT

Mo min. $99,97 \%$ *

Ag $\max .10 \mu g / g$

Ba $\max .5 \mu g / g$

Co max. $10 \mu g / 9$

Fe $\max .60 \mu g / g$

Mn $\max .2 \quad \mu g / g$

$\mathrm{Ni} \max .10 \mu g / g$

Ti $\max , 10 \quad \mu g / g$

W $\max .250 \mu g / g$

$C \max 30 \mu g / g$

$0 \quad \max .40 \mu g / g$

Si $\max .30 \mu g / g$

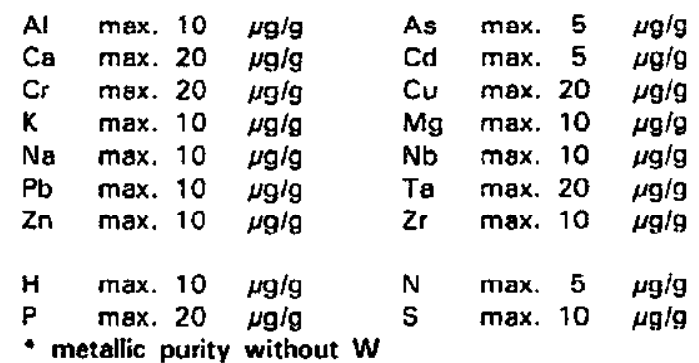

Certified that the supplies/survices dntailent hereon have been inspecied and tested in accondanco with thet conditions and requirements of the contract or purchase order and unless ollerwise noted below, conform in all respocts to the syatecificationis\}, drowingisi relevant therato.

This cortificate has been generated by computur and nagd not to be signed for validity according to EN $1020 \mathrm{~A}$.

PLAMSEe Aktiongestallschaft -

High Performance Matoriats

onssz - Cartificates 


\section{SCHWARLKOPF TECHNOLOGIES CORPORATION}

115 Constitution Blvd./Franklin. MA 02038

\section{CERTIIICATE OF CONFORMANCE}

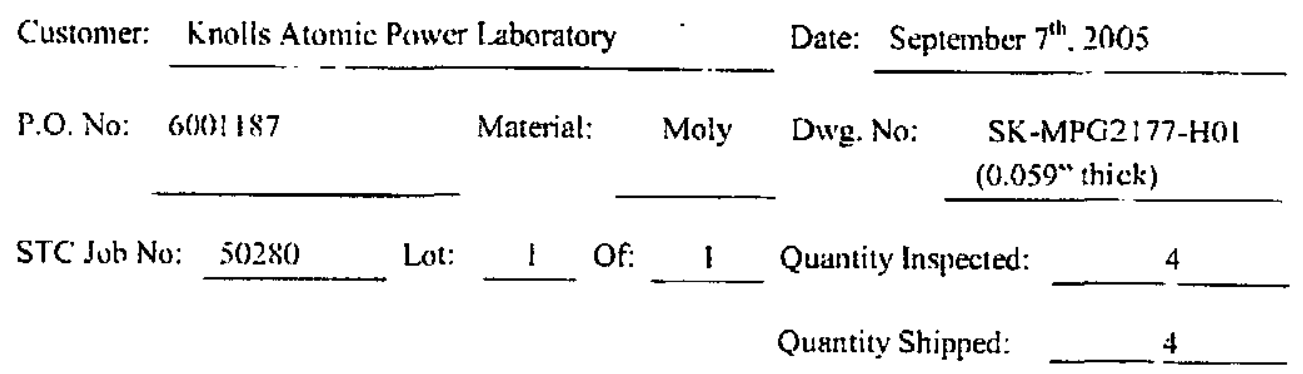

Remarks: Stc Art No 50025306

Material report: 82052337000010

Batcli : : 0090242449

This is to centify that this shipment is in conformance with the Drawings and/or

Spevifications listed on this order. and that we have performed the required physical tests and inspections on the materials.

The liability of Schwarzkop I Techologies hercunder is limited to the cost of the materials in question.

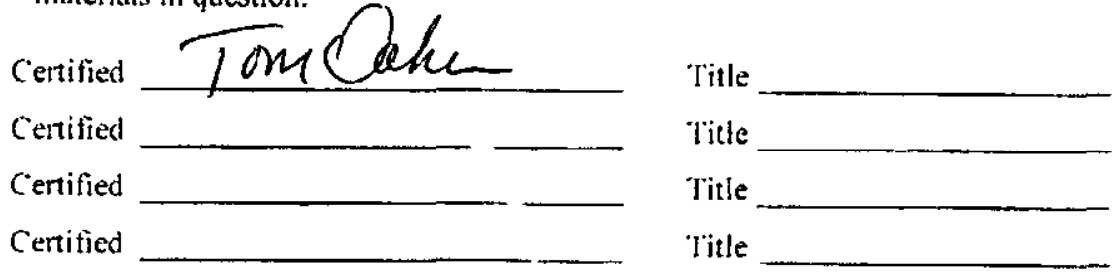

?) 20 R(r. E

115 Constitution Blvd. Franklin, MA 02038 Phone 508.553.3800 Fax 508.553.3823 


\section{SCHWARZKOPF TECHNOLOGIES CORPORATION}

115 Constitution Blvd./Franklin. MA 02038

\section{CERTIFICATE OF CONFORMANCE}

\begin{tabular}{|c|c|c|c|c|c|}
\hline Custumer: & Kunlls AI & Laborator & & Date: & September $7^{\text {th }} .2005$ \\
\hline P.O. No: & 6001187 & Material: & Moly & Dwog & $\begin{array}{l}\text { SK-MPG2 } 177-\mathrm{H} 02 \\
\left(0.059^{\prime \prime} \text { thick }\right)\end{array}$ \\
\hline
\end{tabular}

STC Job No: 50281 Lot: 1 of: 1 Quantity Inspected: 4

Quantity Shipped:

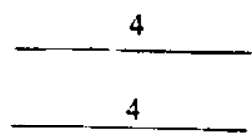

Remarks: Stc Art No 50025307

Matterial report: 82052337000010

Batch H: 00190242449

This is to certify that this shipment is in conformance with the Drawings and/or Specifications listed on this order. and that we have performed the required physical tests and inspections on the matcrials.

The liability of Schwarzkopf Technologies hereunder is limited to the cost of the materials in question.

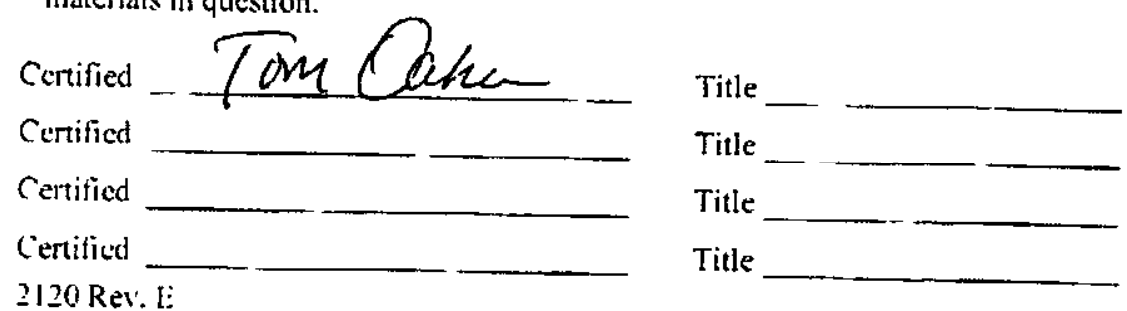
2I20 Rev' I: 


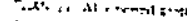

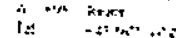

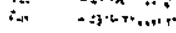

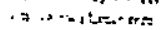

\section{INSPECTION CERTIFICATE asn. 60 DIN EN 10204 - 3.18}

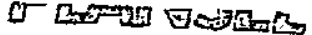

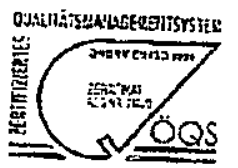

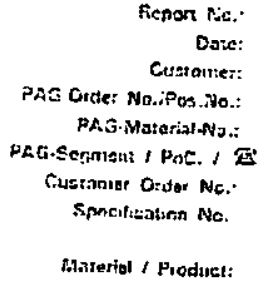

Ficpor Nic. Dore:

Custanter:

PAL Orde: No.Pos. PAG MaterialtNo. PAG.Seqmiti I PAE. I G Gustanigr Ordor Ne. spmeitivatiras No

Harterial / Pioduct: Sandition hì material : Guglity.
82052337000010

09.12 .2004

Schwarzkopf Technologies / US

1261929 , 60

257308

7F / Kerber / 2952

4500020152

detod 04.11 .2004

MO / MOLY SHEET .059" $\times 23.6^{\prime \prime} \times 78.7 "$ cut with scissors / normal quality

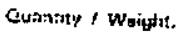

$$
\begin{aligned}
& \text { Entehilosi. } \\
& 009 \pi 242449 \\
& 147.650 \mathrm{KG} / \mathrm{KG} \\
& 747.650 \mathrm{ko}
\end{aligned}
$$

GUARANTEED CHEMICAL ANALYSIS: acc. to PAG-SpEc. AOO1
Mo min. 90.97

Ac m.2x. 13 uglo

Zi mas. 3 .

Co max. 10 pgro

itg max. 60 Hg/o

Min max. 2 mog

แ। max. 10 watg

mix $10 \mu g / g$

$$
\begin{array}{lll}
\text { Al } & \text { max. 10 } & \mu g / g \\
\text { Ca } & \text { max. 20 } & \mu / g \\
C_{F} & \max .20 & \mu g / g \\
X & m a x .10 & \mu g / c \\
\text { Na } & \max .10 & \mu g / g \\
\text { Pb } & \max .10 & \mu g / g \\
Z n & \max .10 & \mu g / g
\end{array}
$$

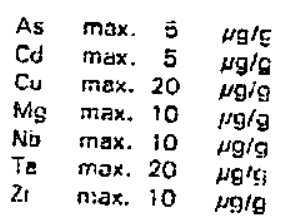

W 1 m. $250 \quad \mu g / 9$

max. $30 \mathrm{\mu g} / \mathrm{g}$

mex. 40 pora

max. $30 \mu g / G$

$\mathrm{H} \quad \operatorname{mox} .10 \quad \mu g / g$

$F$ inax. $20 \quad \mu g / g$

N max. $5 \quad \mu g / g$

- metallic purity without $w$

max. 10

rgig]

Horanose Hy

EN 1506507.1

$250-254$

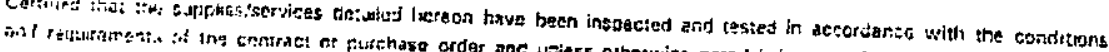

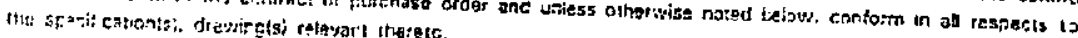

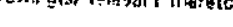

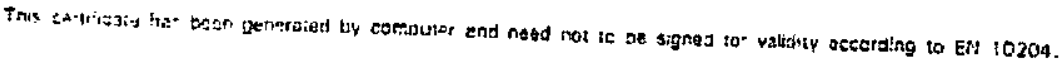

Whate thenaston

(b) 7 haเมn!I

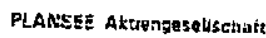

High Parformmon s.jisterials

ingaction Deparumone atasz

(Fardier)

[Kuroer) 
B-TM-1639

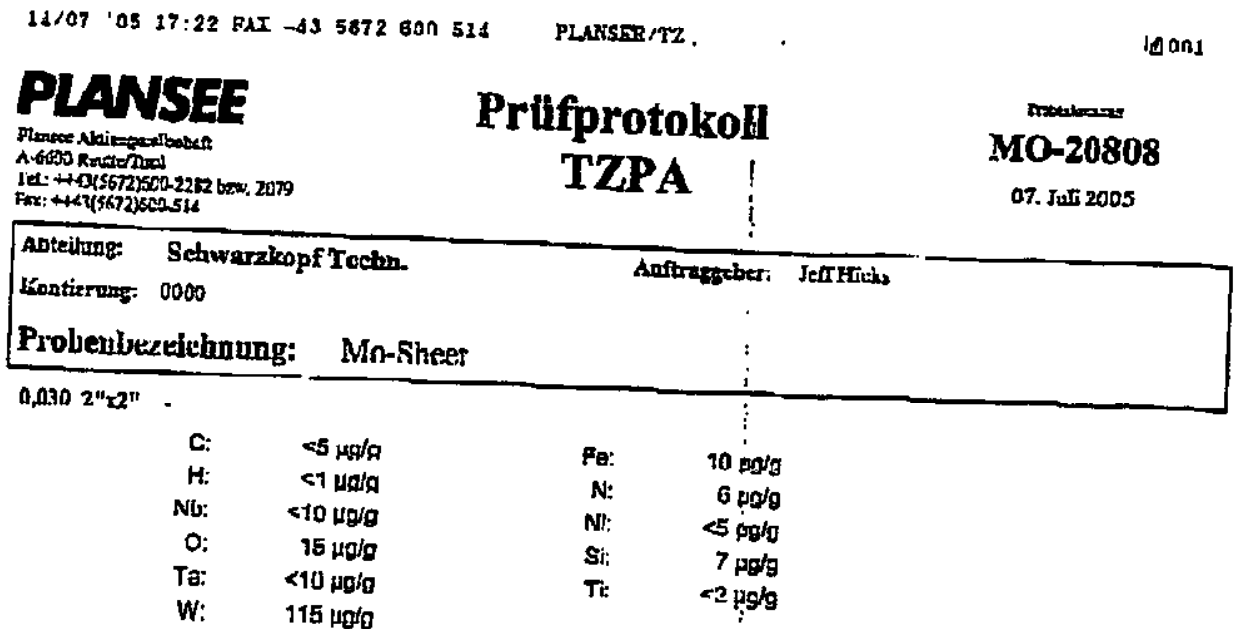

......Batch: 0090273793

Report No. 82493034000n10

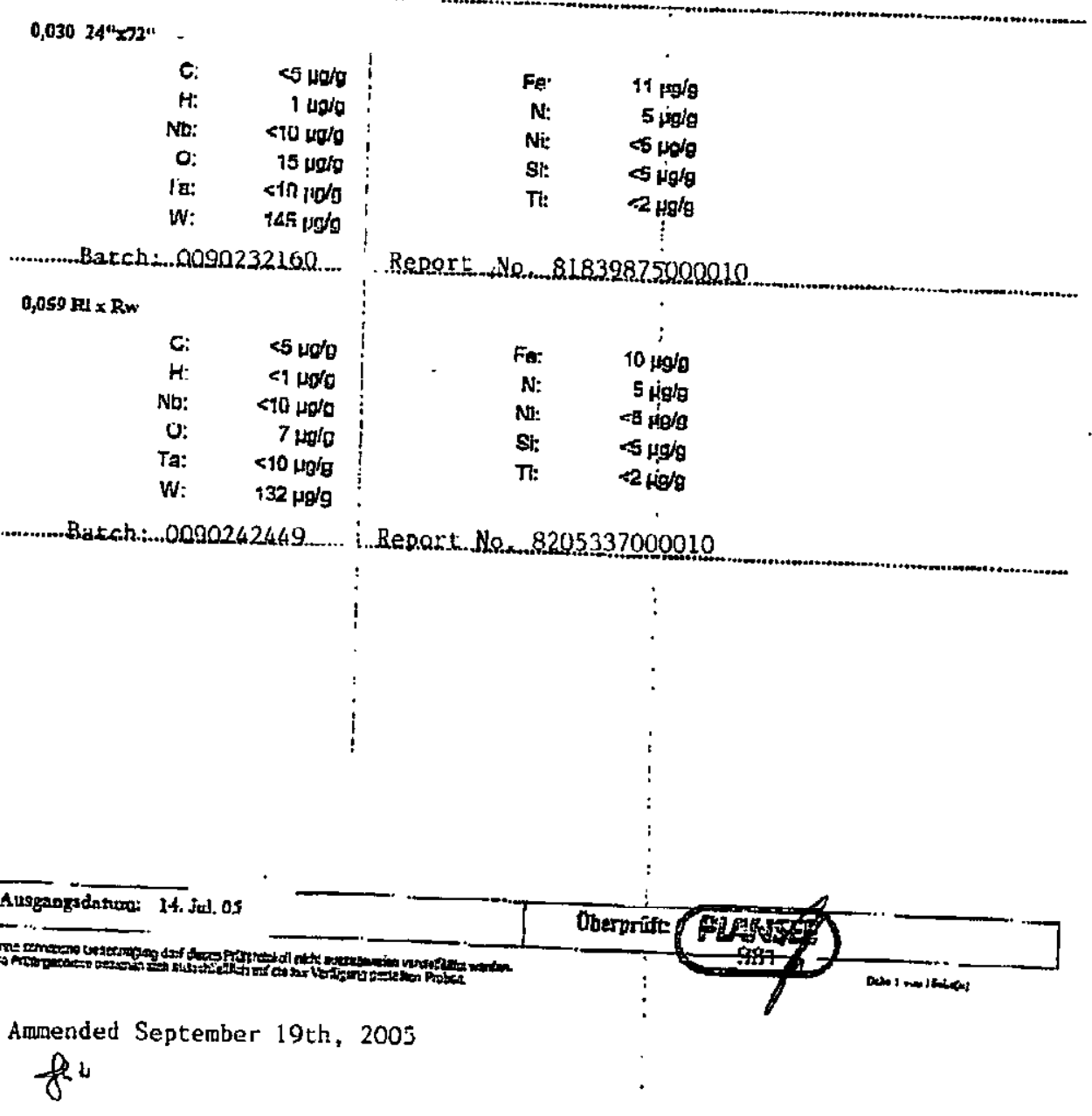


B-TM-1639

(Intentionally Blank)

\section{F-20}


B-TM-1639

Appendix G

Re Plate Dimension and Chemistry Reports 
B-TM-1639

(Intentionally Blank) 


\title{
KAPL Inspection Sheet \\ Per Bechtel Bettis Inc. \\ Drawing \#SK-MGP2177 Rev. -
}

\author{
Solid Disk \\ (Re-01 - Re-22)
}

Part number:_Re-01____ Lot Number: R-1478/1481

Gage serial numbers:

24" Caliper: 06749_1" Micrometer:_9052740_Scale:_1343

Weight of disk:_1929.1g

Temperature of disk at time of measurement: $\_22.78^{\circ} \mathrm{C}$

Thickness measurements $(.015 \pm .0015)$

$\# 1$ _.0165"_ \#2_.0160"_\#3_.0155"

Outside diameter $(\varnothing 21.000 \pm 0.010)$

$\# 1 \_21.000 "$ \#2_21.000"

Cliff Guthman

Quality Control Engineer 
KAPL Inspection Sheet

Per Bechtel Bettis Inc.

Drawing \#SK-MGP2177 Rev. -

$$
\begin{gathered}
\text { Solid Disk } \\
(\operatorname{Re}-01-\operatorname{Re}-22)
\end{gathered}
$$

Part number:_Re-02

Lot Number: R-1478

Gage serial numbers:

24" Caliper:06749_1" Micrometer:_9052740_Scale:_1343

Weight of disk:_1969.3g

Temperature of disk at time of measurement: $\_22.22^{\circ} \mathrm{C}$

Thickness measurements $(.015 \pm .0015)$

$\# 1$ _.0165"__ \#2 _.0168"_\#3 _.0170"

Outside diameter $(\varnothing 21.000 \pm 0.010)$

\#1_20.997"_\#2_21.000"

Cliff Guthman

Quality Control Engineer 
KAPL Inspection Sheet

Per Bechtel Bettis Inc.

Drawing \#SK-MGP2177 Rev. -

\author{
Solid Disk \\ (Re-01 - Re-22)
}

Part number:_Re-03___ Lot Number: R-1478

Gage serial numbers:

24" Caliper: 06749_1" Micrometer:_9052740_Scale:_1343

Weight of disk:_1970.9g

Temperature of disk at time of measurement: $\_21.94^{\circ} \mathrm{C}$

Thickness measurements $(.015 \pm .0015)$

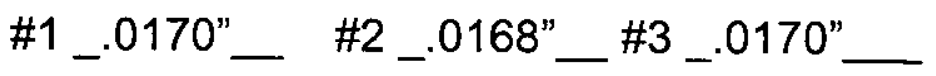

Outside diameter $(\varnothing 21.000 \pm 0.010)$

\#1_20.998" \#2_20.999"

Cliff Guthman

Quality Control Engineer 
KAPL Inspection Sheet

Per Bechtel Bettis Inc.

Drawing \#SK-MGP2177 Rev. -

\author{
Solid Disk \\ (Re-01 - Re-22)
}

Part number:_Re-04___ Lot Number: R-1478

Gage serial numbers:

24" Caliper: 06749_1" Micrometer:_9052740_Scale:_1343

Weight of disk:_1981.6g

Temperature of disk at time of measurement: $\_22.22^{\circ} \mathrm{C}$

Thickness measurements $(.015 \pm .0015)$

\#1_.0160"__ \#2_.0168"_\#3_.0150"

Outside diameter $(\varnothing 21.000 \pm 0.010)$

\#1_21.000"_\#2_20.998"

Cliff Guthman

Quality Control Engineer 


\title{
KAPL Inspection Sheet \\ Per Bechtel Bettis Inc. \\ Drawing \#SK-MGP2177 Rev. -
}

\author{
Solid Disk \\ (Re-01 - Re-22)
}

Part number:_Re-05___ Lot Number: R-1478

Gage serial numbers:

24" Caliper: 06749_ 1" Micrometer:_9052740_Scale:_1343

Weight of disk: _1976.3g

Temperature of disk at time of measurement: $\_22.5^{\circ} \mathrm{C}$

Thickness measurements $(.015 \pm .0015)$

$\# 1$ _.0165"__ \#2_.0165"_\#3_.0164" __

Outside diameter $(\varnothing 21.000 \pm 0.010)$

\#1_20.996"_\#2_20.994"

Cliff Guthman

Quality Control Engineer 


\section{Re RHENIUM

1329 Taylor St.

P.O. Box 245

Elyria, Oh 44036-0245

Voice (440) 365-7388

Fax (440) 366-9831

KAPL Inspection Sheet

Per Bechtel Bettis Inc.

Drawing \#SK-MGP2177 Rev. -

$$
\begin{gathered}
\text { Solid Disk } \\
(\operatorname{Re}-01-\operatorname{Re}-22)
\end{gathered}
$$

Part number:_Re-06____ Lot Number: R-1478

Gage serial numbers:

24" Caliper: 06749_1" Micrometer:_9052740_Scale:_1343

Weight of disk: _1966.9g

Temperature of disk at time of measurement: $\_21.94^{\circ} \mathrm{C}$

Thickness measurements $(.015 \pm .0015)$

\#1_.0164"_ \#2_.0158"_\#3 _.0163"

Outside diameter $(\varnothing 21.000 \pm 0.010)$

\#1_20.999"_\#2_20.997"

Cliff Guthman

Quality Control Engineer 


\title{
Re RHENIUM
}

KAPL Inspection Sheet

Per Bechtel Bettis Inc.

Drawing \#SK-MGP2177 Rev. -

\author{
Solid Disk \\ (Re-01 - Re-22)
}

Part number:_Re-07

Lot Number: R-1478

Gage serial numbers:

24" Caliper: 06749_1" Micrometer:_9052740_Scale:_1343

Weight of disk: _1965.7g

Temperature of disk at time of measurement: $\_22.5^{\circ} \mathrm{C}$

Thickness measurements $(.015 \pm .0015)$

$\# 1$ _.0165"_ \#2_.0161"_ \#3_.0163"

Outside diameter $(\varnothing 21.000 \pm 0.010)$

\#1_20.998"_\#2_20.999"

Cliff Guthman

Quality Control Engineer 


\section{Re RHENIUM}

1329 Taylor St.

P.O. Box 245

M.I. () Y. $1.10^{\circ}$

Elyria, Oh 44036-0245

Voice (440) 365-7388

Fax (440) 366-9831

\section{KAPL Inspection Sheet}

Per Bechtel Bettis Inc.

Drawing \#SK-MGP2177 Rev. -

$$
\begin{gathered}
\text { Solid Disk } \\
\text { (Re-01-Re-22) }
\end{gathered}
$$

Part number:_Re-08___ Lot Number: R-1481

Gage serial numbers:

24" Caliper: 06749_1" Micrometer:_9052740_Scale:_1343

Weight of disk:_1969.9g

Temperature of disk at time of measurement: $\_22.5^{\circ} \mathrm{C}$

Thickness measurements $(.015 \pm .0015)$

\#1_.0170"_ \#2_.0165"_\#3_.0165"

Outside diameter $(\varnothing 21.000 \pm 0.010)$

\#1_20.997"_\#2_20.996"

Cliff Guthman

Quality Control Engineer 


\title{
KAPL Inspection Sheet
}

Per Bechtel Bettis Inc.

Drawing \#SK-MGP2177 Rev. -

\author{
Solid Disk \\ (Re-01-Re-22)
}

Part number:_Re-09___ Lot Number: R-1481

Gage serial numbers:

24" Caliper: 06749_ 1" Micrometer:_9052740__Scale:_1343

Weight of disk:_1953.8g

Temperature of disk at time of measurement: $\_22.5^{\circ} \mathrm{C}$

Thickness measurements $(.015 \pm .0015)$

$\# 1 \_.0170 "$ _ \#2_.0160"_ \#3_.0162"

Outside diameter $(\varnothing 21.000 \pm 0.010)$

\#1_21.000"_\#2_20.995"

Cliff Guthman

Quality Control Engineer 


\title{
$\operatorname{Re} \mathrm{RHENIUM}$

\section{KAPL Inspection Sheet}

Per Bechtel Bettis Inc.

Drawing \#SK-MGP2177 Rev. -

\author{
Solid Disk \\ $(\operatorname{Re}-01-\operatorname{Re}-22)$
}

Part number:_Re-10____ Lot Number: R-1481

Gage serial numbers:

24" Caliper:06749_1" Micrometer:_9052740_Scale:_1343

Weight of disk:_1944.3g

Temperature of disk at time of measurement: $\_22.22^{\circ} \mathrm{C}$

Thickness measurements $(.015 \pm .0015)$

\#1_.0165"_ \#2_.0163"_\#3 _.0164"

Outside diameter $(\varnothing 21.000 \pm 0.010)$

\#1_20.999"_\#2_20.995"

Cliff Guthman

Quality Control Engineer 


\title{
KAPL Inspection Sheet
}

Per Bechtel Bettis Inc.

Drawing \#SK-MGP2177 Rev. -

\author{
Solid Disk \\ (Re-01 - Re-22)
}

Part number:_Re-11

Lot Number: R-1481

Gage serial numbers:

24" Caliper: 06749_ 1" Micrometer:_9052740__ Scale:_1343

Weight of disk:_1981.6g

Temperature of disk at time of measurement: $\_22.5^{\circ} \mathrm{C}$

Thickness measurements $(.015 \pm .0015)$

$\# 1$ _.0163"__ \#2 _.0165"_ \#3 _.0158"

Outside diameter $(\varnothing 21.000 \pm 0.010)$

\#1_20.999"_\#2_20.997"

Cliff Guthman

Quality Control Engineer 
Re RHENIUM

AI.IOYS.INC
1329 Taylor St.

P.O. Box 245

Elyria, Oh 44036-0245

Voice (440) 365-7388

Fax (440) 366-9831

KAPL Inspection Sheet

Per Bechtel Bettis Inc.

Drawing \#SK-MGP2177 Rev. -

\author{
Solid Disk \\ (Re-01 - Re-22)
}

Part number:_Re-12

Lot Number: R-1481

Gage serial numbers:

24" Caliper: 06749_ 1" Micrometer:_9052740_Scale:_1343

Weight of disk:_1992.8g

Temperature of disk at time of measurement: $\_22.78^{\circ} \mathrm{C}$

Thickness measurements $(.015 \pm .0015)$

$\# 1$ _.0161"_ \#2_.0164"_\#3_.0159"

Outside diameter $(\varnothing 21.000 \pm 0.010)$

\#1_20.999"_\#2_20.998"

Cliff Guthman

Quality Control Engineer 


\section{KAPL Inspection Sheet \\ Per Bechtel Bettis Inc.}

Drawing \#SK-MGP2177 Rev. -

\section{Annular Disk \\ (Re-23 - Re-44)}

Part number:__Re-23____ Lot Number: R-1481

Gage serial numbers:

24" Caliper:_06749

Scale: 1343
1" Micrometer:

6" Caliper:
9052740

Rec-005

Weight of disk:_1936.7g

Temperature of disk at time of measurement: $\_21.94^{\circ} \mathrm{C}$

Thickness measurements $(.015 \pm .0015)$

$\# 1$ _. 0158"

$\# 2$ $.0160 "$

\#3 $.0156 "$

Outside diameter $(\varnothing 21.000 \pm 0.010)$

\#1_20.997"_ \#2_20.997"

Inside diameter $(\varnothing 2.510 \pm 0.010)$

$\# 1$ 2.508"_ \#2_ $2.507 "$ 


\section{Re RHENIUM}

KAPL Inspection Sheet

Per Bechtel Bettis Inc.

Drawing \#SK-MGP2177 Rev. -

$$
\begin{gathered}
\text { Annular Disk } \\
(\operatorname{Re}-23-\operatorname{Re}-44)
\end{gathered}
$$

Part number: _ $R e-24$

Lot Number: R-1481

Gage serial numbers:

24" Caliper:_06749

Scale: 1343

1" Micrometer: $\quad 9052740$

6" Caliper: Rec-005

Weight of disk:_1957.2g

Temperature of disk at time of measurement: $\_22.5^{\circ} \mathrm{C}$

Thickness measurements $(.015 \pm .0015)$

$\# 1$ _.0161"

\#2

$0165 "$

\#3_.0160"

Outside diameter $(\varnothing 21.000 \pm 0.010)$

\#1_20.998" _ \#2 _ 20.999"

Inside diameter $(\varnothing 2.510 \pm 0.010)$

$\# 1 \_2.511^{\prime \prime}$

\#2 2.511"

Cliff Guthman

Quality Control Engineer 


\section{Re RHENIUM}

1329 Taylor St.

ALCOS. INC

P.O. Box 245

Elyria, Oh 44036-0245

Voice (440) 365-7388

Fax (440) 366-9831

KAPL Inspection Sheet

Per Bechtel Bettis Inc.

Drawing \#SK-MGP2177 Rev. -

$$
\begin{gathered}
\text { Annular Disk } \\
(\mathrm{Re}-23-\mathrm{Re}-44)
\end{gathered}
$$

Part number: _ Re-25

Lot Number: R-1481

Gage serial numbers:

24" Caliper:_06749

Scale: 1343

1" Micrometer:__9052740_

6" Caliper: Rec-005

Weight of disk:_1917.4g

Temperature of disk at time of measurement: $\_22.22^{\circ} \mathrm{C}$

Thickness measurements $(.015 \pm .0015)$

\#1_.0157" _ \#2_.0153"

\#3_.0163"

Outside diameter $(\varnothing 21.000 \pm 0.010)$

\#1_20.999" _ \#2 _20.997"

Inside diameter $(\varnothing 2.510 \pm 0.010)$

\#1 _ 2.509" _ \#2 $2.501^{\prime \prime}$ 


\title{
$\operatorname{Re}$ RHENIUM

\section{KAPL Inspection Sheet \\ Per Bechtel Bettis Inc. \\ Drawing \#SK-MGP2177 Rev. -}

\author{
Annular Disk \\ (Re-23 - Re-44)
}

Part number:

$\operatorname{Re}-26$

Lot Number: R-1481

Gage serial numbers:

24" Caliper:_06749

1" Micrometer: _ 9052740

Scale: 1343

6" Caliper: Rec-005

Weight of disk:_1927.8g

Temperature of disk at time of measurement: $\_22.5^{\circ} \mathrm{C}$

Thickness measurements $(.015 \pm .0015)$

$\# 1$ $.0157^{\prime \prime}$ \#2 .0151" \#3 $.0156 "$

Outside diameter $(\varnothing 21.000 \pm 0.010)$

\#1__20.998"

\#2 _20.997"

Inside diameter $(\varnothing 2.510 \pm 0.010)$

$\# 1 \quad 2.509 "$

\#2 2. 2.508"

Cliff Guthman

Quality Control Engineer

Rhenium Alloys, Inc

Email: rhenium@rhenium.com

Web site: http://www.rhenium.com 
Re RHENIUM

dilors IXC.
1329 Taylor St.

P.O. Box 245

Elyria, Oh 44036-0245

Voice (440) 365-7388

Fax (440) 366-9831

\title{
KAPL Inspection Sheet
}

Per Bechtel Bettis Inc.

Drawing \#SK-MGP2177 Rev. -

\author{
Annular Disk \\ $(\operatorname{Re}-23-\operatorname{Re}-44)$
}

Part number:

$\operatorname{Re}-27$

Lot Number: R-1481

Gage serial numbers:

24" Caljper:_06749

Scale: 1343

1" Micrometer: _ 9052740

6' Caliper: _Rec-005

Weight of disk:_1920.2g

Temperature of disk at time of measurement: $\_22.5^{\circ} \mathrm{C}$

Thickness measurements $(.015 \pm .0015)$

\#1 0161" \#2 0158" \#3 _..0157"

Outside diameter $(\varnothing 21.000 \pm 0.010)$

\#1__20.995"__ \#2__20.998"

Inside diameter $(\varnothing 2.510 \pm 0.010)$

\#1 _2.508" _ \#2 _ 2.502" _ 


\section{Re RHENIUM}

1329 Taylor St.

P.O. Box 245

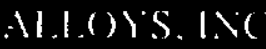

Elyria, Oh 44036-0245

Voice (440) 365-7388

Fax (440) 366-9831

\section{KAPL Inspection Sheet}

Per Bechtel Bettis Inc.

Drawing \#SK-MGP2177 Rev. -

\section{Annular Disk \\ (Re-23 - Re-44)}

Part number:

$\operatorname{Re}-28$

Lot Number: R-1481

Gage serial numbers:

24" Caliper:_06749

Scale: 1343

1" Micrometer: _9052740_

6" Caliper: Rec-005

Weight of disk: _1902.8g

Temperature of disk at time of measurement: $\_22.78^{\circ} \mathrm{C}$

Thickness measurements $(.015 \pm .0015)$

$\# 1$ _.0163" _ \#2_.0162"

\#3

Outside diameter $(\varnothing 21.000 \pm 0.010)$

\#1_20.996" _ \#2 20.998"

Inside diameter $(\varnothing 2.510 \pm 0.010)$

$\# 1$ _ 2.509"

\#2 $2.511^{\prime \prime}$

Cliff Guthman

Quality Control Engineer

Rhenium Alloys, Inc

Email: rhenium@rhenium.com

Web site: htto://www.rhenium.com 
KAPL Inspection Sheet

Per Bechtel Bettis Inc.

Drawing \#SK-MGP2177 Rev. -

Annular Disk
$(\operatorname{Re}-23-\operatorname{Re}-44)$

Part number: _ Re-29___ Lot Number: R-1481

Gage serial numbers:

24" Caliper:_06749

Scale: 1343
1" Micrometer: 9052740

6" Caliper: Rec-005

Weight of disk:_1926.3g

Temperature of disk at time of measurement: $\_21.94^{\circ} \mathrm{C}$

Thickness measurements $(.015 \pm .0015)$

\#1_..0150" _ \#2 . \#3 _..0162"

Outside diameter $(\varnothing 21.000 \pm 0.010)$

\#1_20.999"_ \#2 _20.994"

Inside diameter $(\varnothing 2.510 \pm 0.010)$

\#1 _ 2.510" _ \#2 $2.511^{\prime \prime}$ 
$\operatorname{Re}$ RHENIUM

Al. ())S.ISC.
1329 Taylor St.

P.O. Box 245

Elyria, Oh 44036-0245

Voice (440) 365-7388

Fax (440) 366-9831

\section{KAPL Inspection Sheet}

Per Bechtel Bettis Inc.

Drawing \#SK-MGP2177 Rev. -

\section{Annular Disk}

(Re-23 - Re-44)

Part number: _ Re-30

Gage serial numbers:

24" Caliper:_06749

Scale: 1343

1"Micrometer: _ 9052740

6" Caliper: Rec-005

Weight of disk: _1920.1g

Temperature of disk at time of measurement: $-22.22^{\circ} \mathrm{C}$

Thickness measurements $(.015 \pm .0015)$

$\# 1$ _.0151"

\#2 $.0150 "$

\#3 $.0154 "$

Outside diameter $(\varnothing 21.000 \pm 0.010)$

\#1_20.999" _ \#2 _20.995"

Inside diameter $(\varnothing 2.510 \pm 0.010)$

\#1_2.511"

\#2 _2.509"

Cliff Guthman

Quality Control Engineer 


\section{KAPL Inspection Sheet}

Per Bechtel Bettis Inc.

Drawing \#SK-MGP2177 Rev. -

\section{Annular Disk \\ (Re-23 - Re-44)}

Part number: $\operatorname{Re}-31$

Lot Number: R-1481

Gage serial numbers:

24" Caliper:_06749

Scale: 1343

1" Micrometer: _ 9052740

6" Caliper: Rec-005

Weight of disk:_1950.5g

Temperature of disk at time of measurement:

$22.5^{\circ} \mathrm{C}$

Thickness measurements $(.015 \pm .0015)$

\#1 $.0162 "$

\#2 $.0160 "$ \#3

Outside diameter $(\varnothing 21.000 \pm 0.010)$

$\#$ $20.995^{\prime \prime} \ldots$ \#2 $20.997^{\prime \prime}$

Inside diameter $(\varnothing 2.510 \pm 0.010)$

\#1 _2.510" \#2 _ 2.510"

Cliff Guthman

Quality Control Engineer 
KAPL Inspection Sheet

Per Bechtel Bettis Inc.

Drawing \#SK-MGP2177 Rev. -

\author{
Annular Disk \\ (Re-23 - Re-44)
}

Part number

_ $\operatorname{Re}-32$

Lot Number: R-1481

Gage serial numbers:

24" Caliper:_06749

Scale: 1343

1" Micrometer: _ 9052740

6" Caliper: Rec-005

Weight of disk: _1910.6g

Temperature of disk at time of measurement: $\ldots 22.22^{\circ} \mathrm{C}$

Thickness measurements $(.015 \pm .0015)$

$\# 1$ _. $0164 "$

\#2 _.0165"

\#3 0165"

Outside diameter $(\varnothing 21.000 \pm 0.010)$

\#1 _20.995" _ \#2 _20.994"

Inside diameter $(\varnothing 2.510 \pm 0.010)$

\#1 _2.509"__ \#2 _ 2.510" 


\section{RHENIUM}

NIOCYS, INC.
1329 Taylor St.

P.O. Box 245

Elyria, Oh 44036-0245

Voice (440) 365-7388

Fax (440) 366-9831

\title{
KAPL Inspection Sheet
}

Per Bechtel Bettis Inc.

Drawing \#SK-MGP2177 Rev. -

\author{
Annular Disk \\ (Re-23 - Re-44)
}

Part number:

$\operatorname{Re}-33$

Lot Number: R-1481

Gage serial numbers:

24" Caliper:_06749

Scale: 1343

1" Micrometer: _ 9052740

6" Caliper: Rec-005

Weight of disk:_1945.8g

Temperature of disk at time of measurement: $\_22.5^{\circ} \mathrm{C}$

Thickness measurements $(.015 \pm .0015)$

\#1 $.0163^{\prime \prime}$

\#2 $.0164 "$ \#3 $.0164 "$

Outside diameter $(\varnothing 21.000 \pm 0.010)$

\#1__20.997"

\#2 _20.992"

Inside diameter $(\varnothing 2.510 \pm 0.010)$

\#1_2.510"

\#2 2.509"

Cliff Guthman

Quality Control Engineer

Rhenium Alloys, Inc

Email: rhenium@rhenium.com

Web site: http://www.rhenium.com

G-25 


\section{Re RHENIUM}

AI.IOSS. IN

1329 Taylor St.

P.O. Box 245

Elyria, Oh 44036-0245

Voice (440) 365-7388

Fax (440) 366-9831

KAPL Inspection Sheet

Per Bechtel Bettis Inc.

Drawing \#SK-MGP2177 Rev. -

$$
\begin{gathered}
\text { Annular Disk } \\
(\mathrm{Re}-23-\mathrm{Re}-44)
\end{gathered}
$$

Part number: $\quad \operatorname{Re}-34$

Lot Number: R-1481

Gage serial numbers:

24" Caliper:_06749

Scale: 1343

1" Micrometer: _ 9052740

6 " Caliper: Rec-005

Weight of disk:_1924.6g

Temperature of disk at time of measurement: $\_22.5^{\circ} \mathrm{C}$

Thickness measurements $(.015 \pm .0015)$

$\# 1$ _. $0164 ”$

\#2

$.0163 "$

\#3 $.0161 "$

Outside diameter $(\varnothing 21.000 \pm 0.010)$

\#1_20.999"

\#2

$20.996^{\prime \prime}$

Inside diameter $(\varnothing 2.510 \pm 0.010)$

$\# 1 \_$2.510"

\#2 2 2.509"

Cliff Guthman

Quality Control Engineer

Rhenium Alloys, Inc

Email: rhenium@rhenium.com

Web site: http://www.rhenium.com 
B-TM-1639

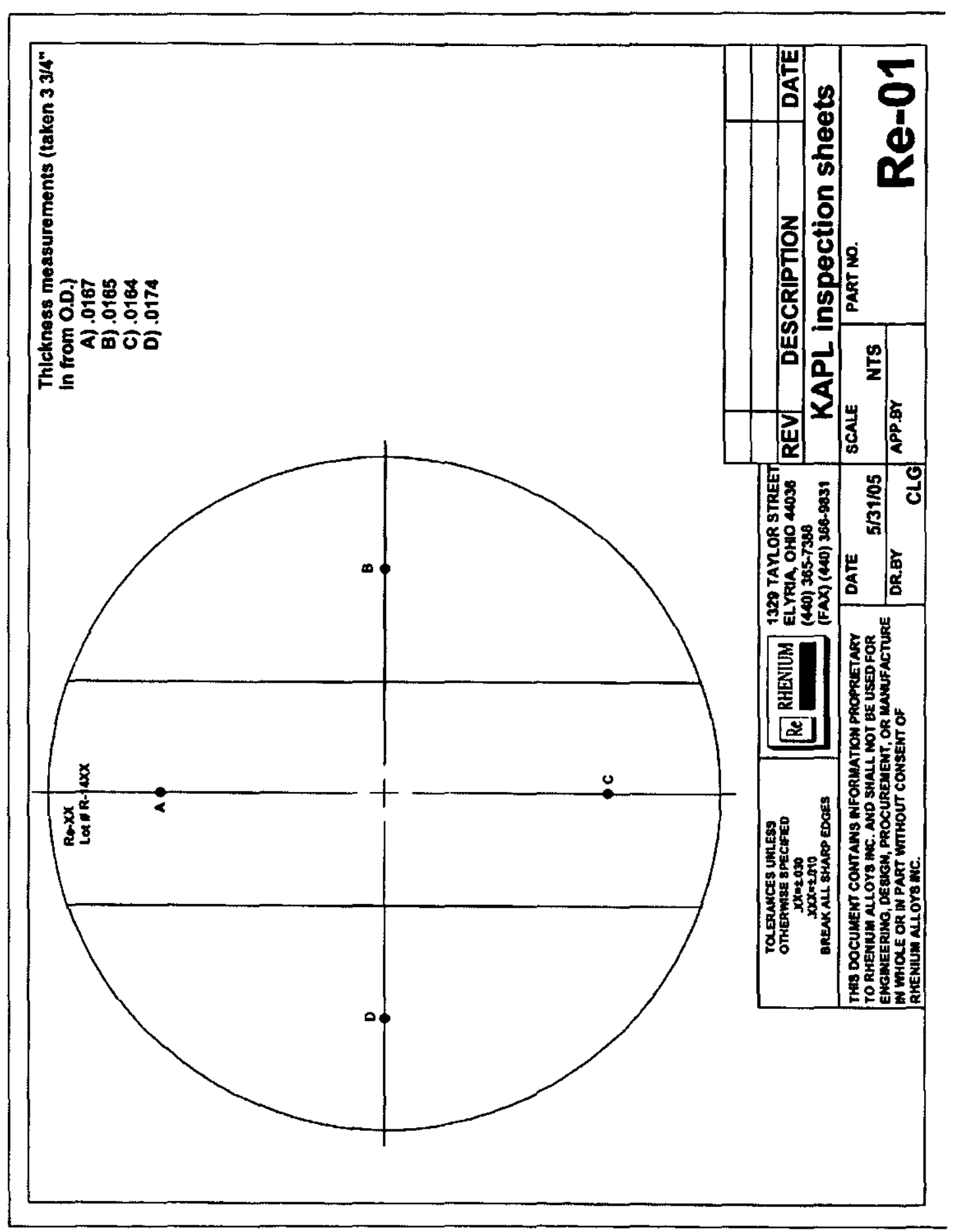




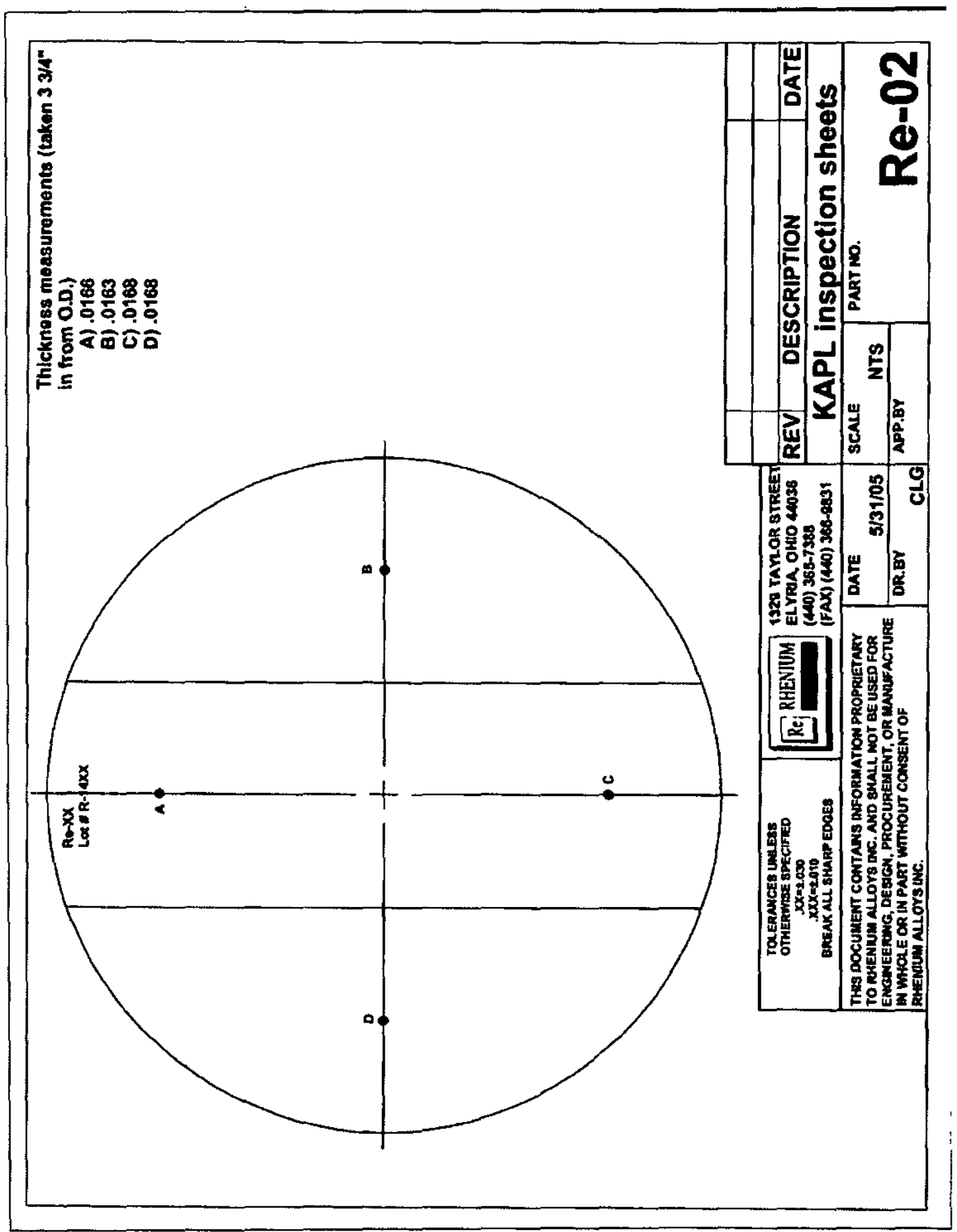


B-TM-1639

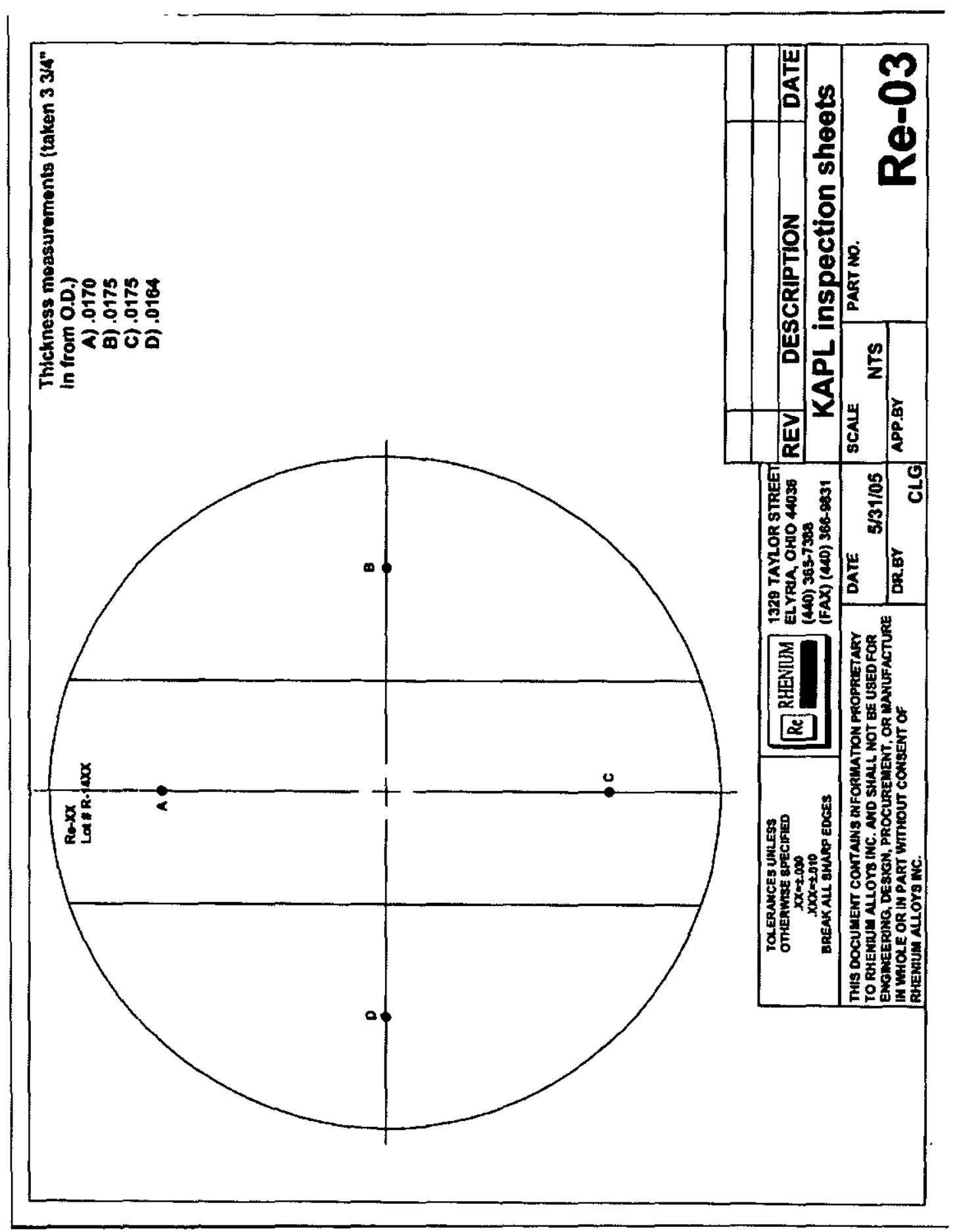




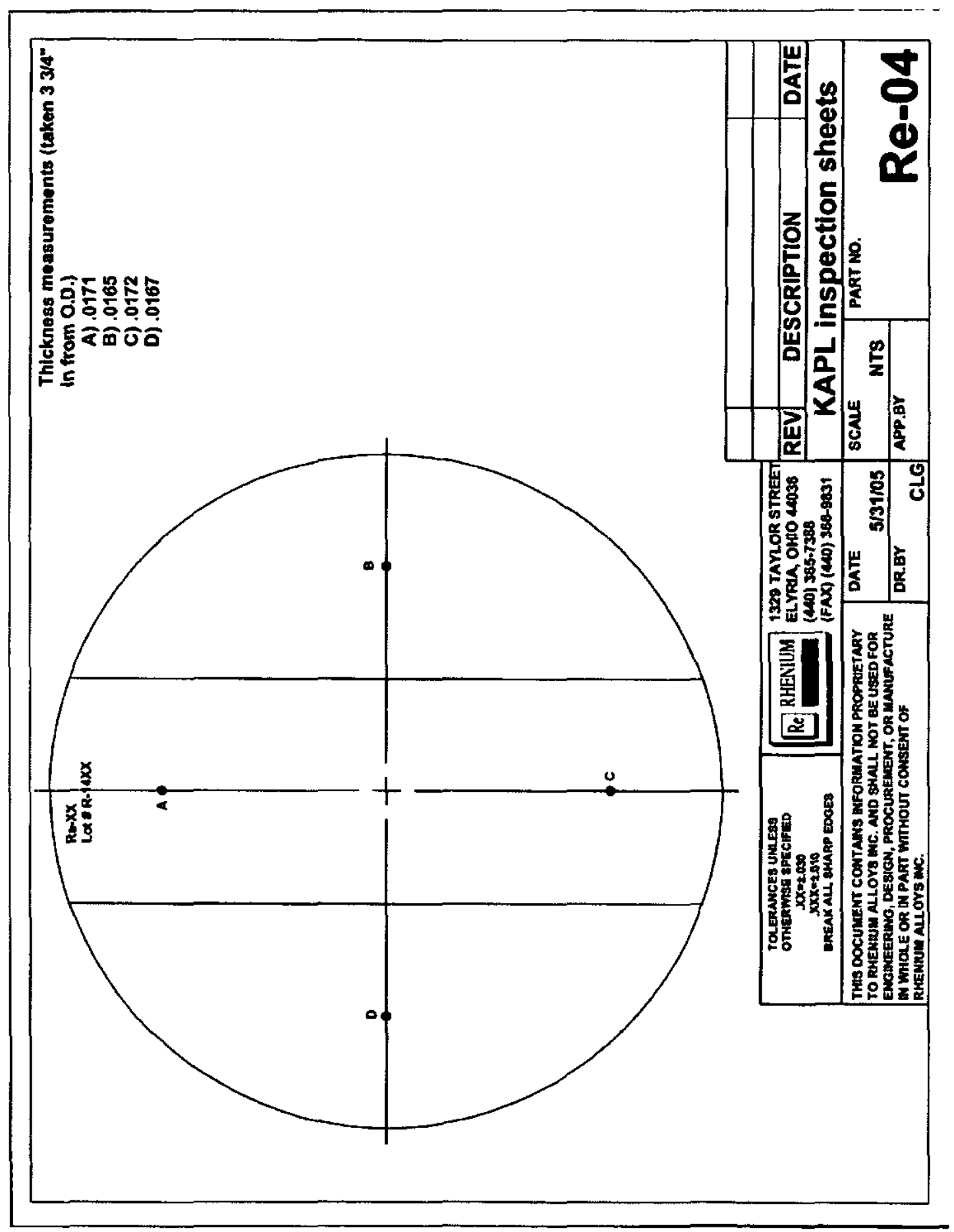


B-TM-1639

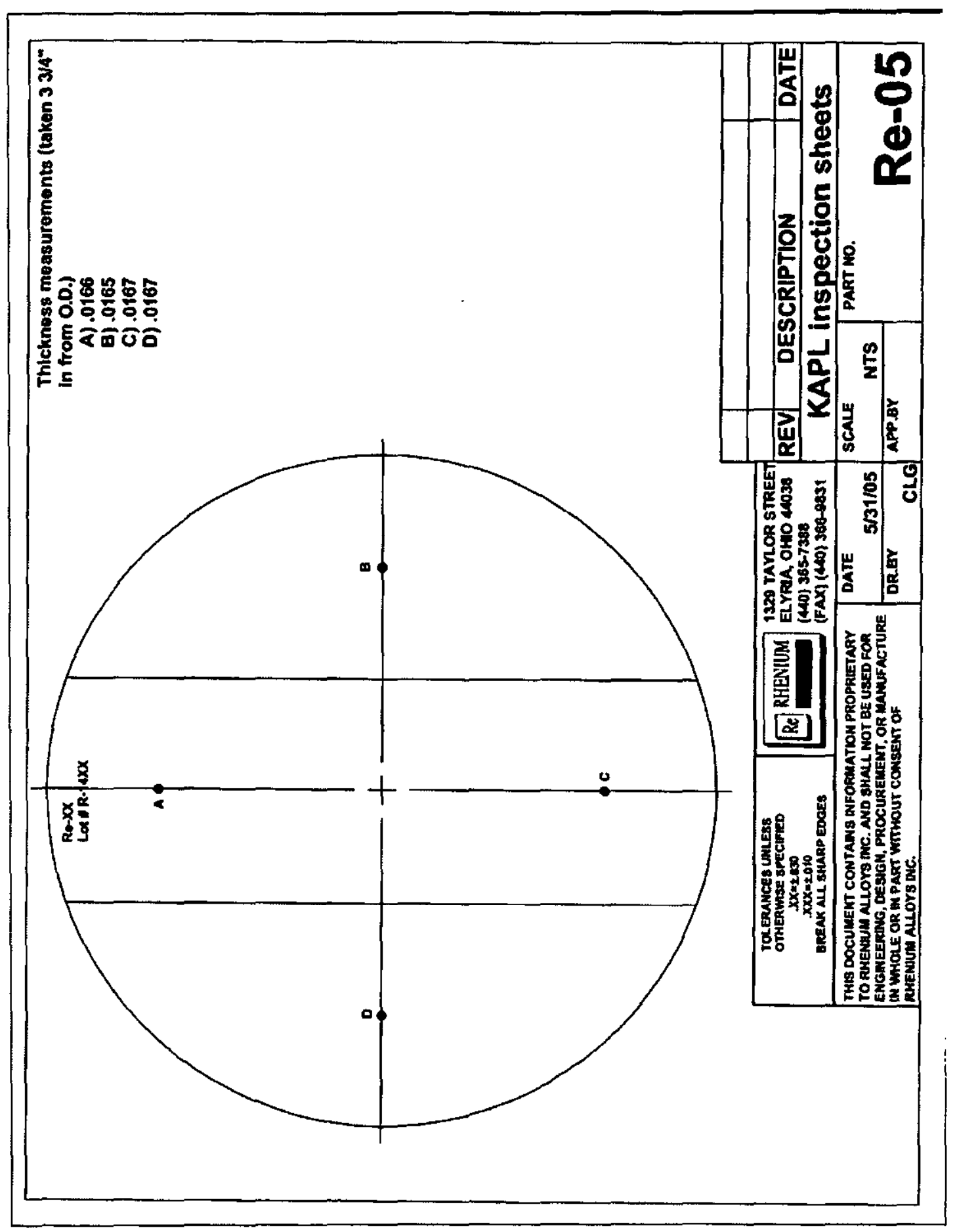


B-TM-1639

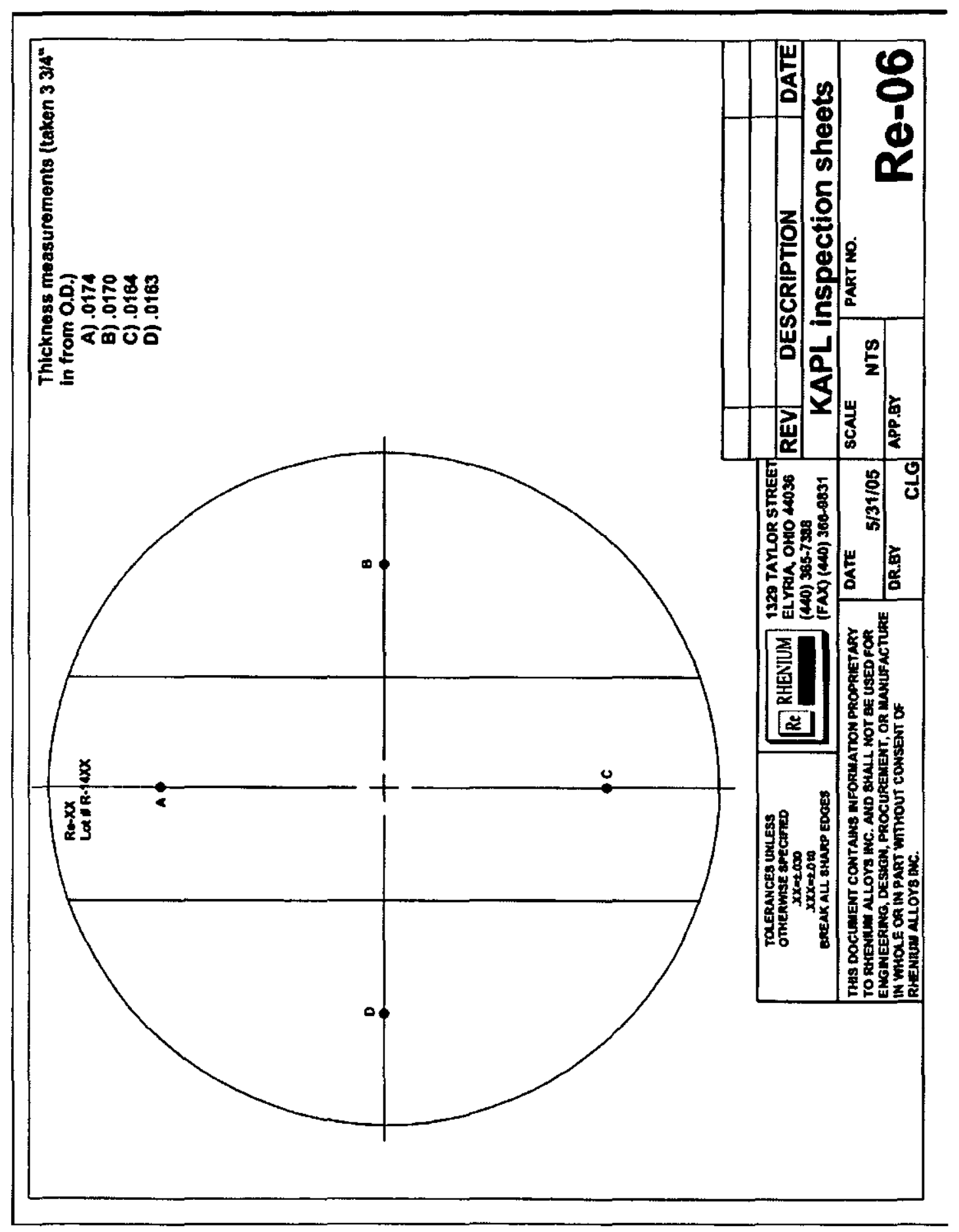


B-TM-1639

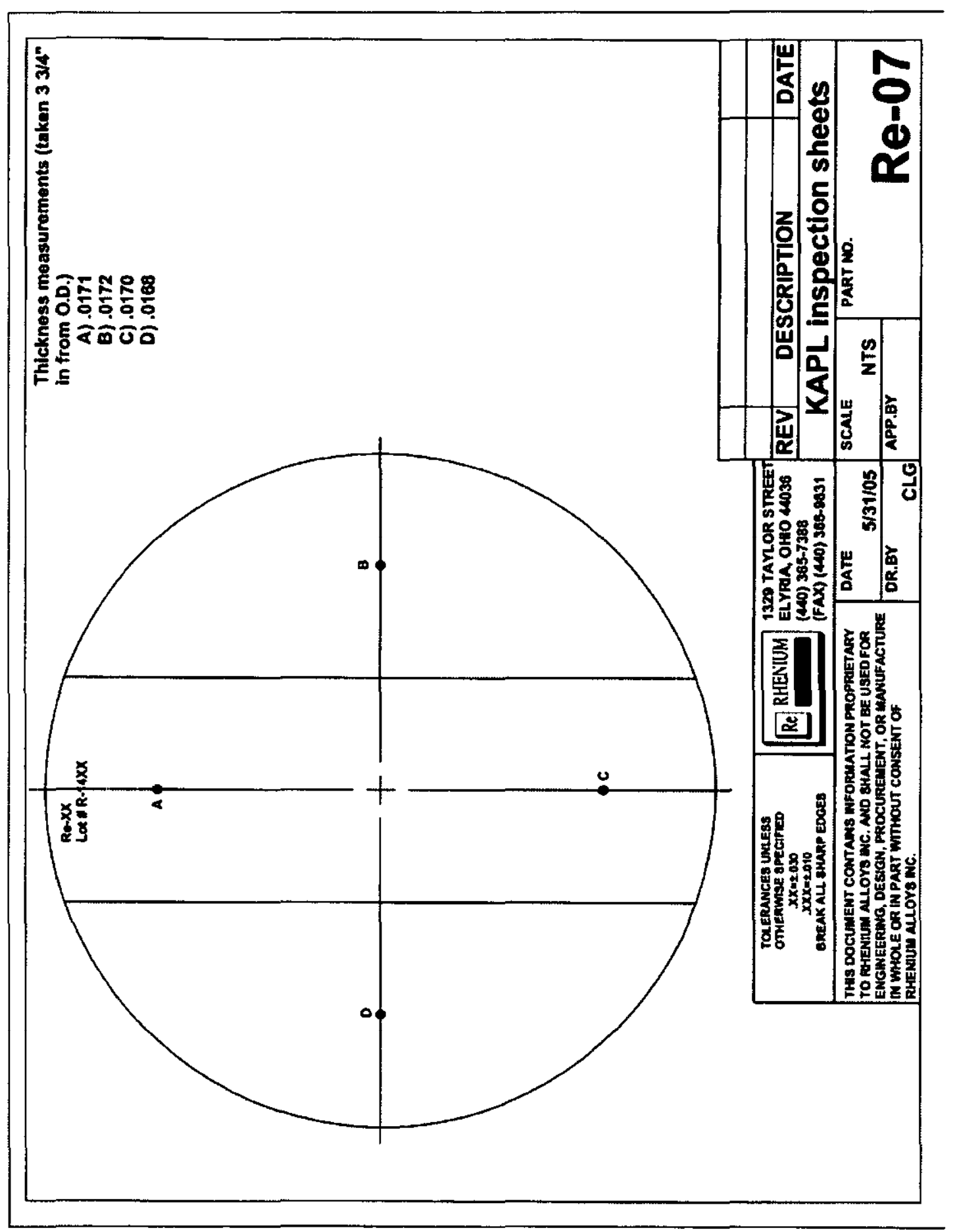


B-TM-1639

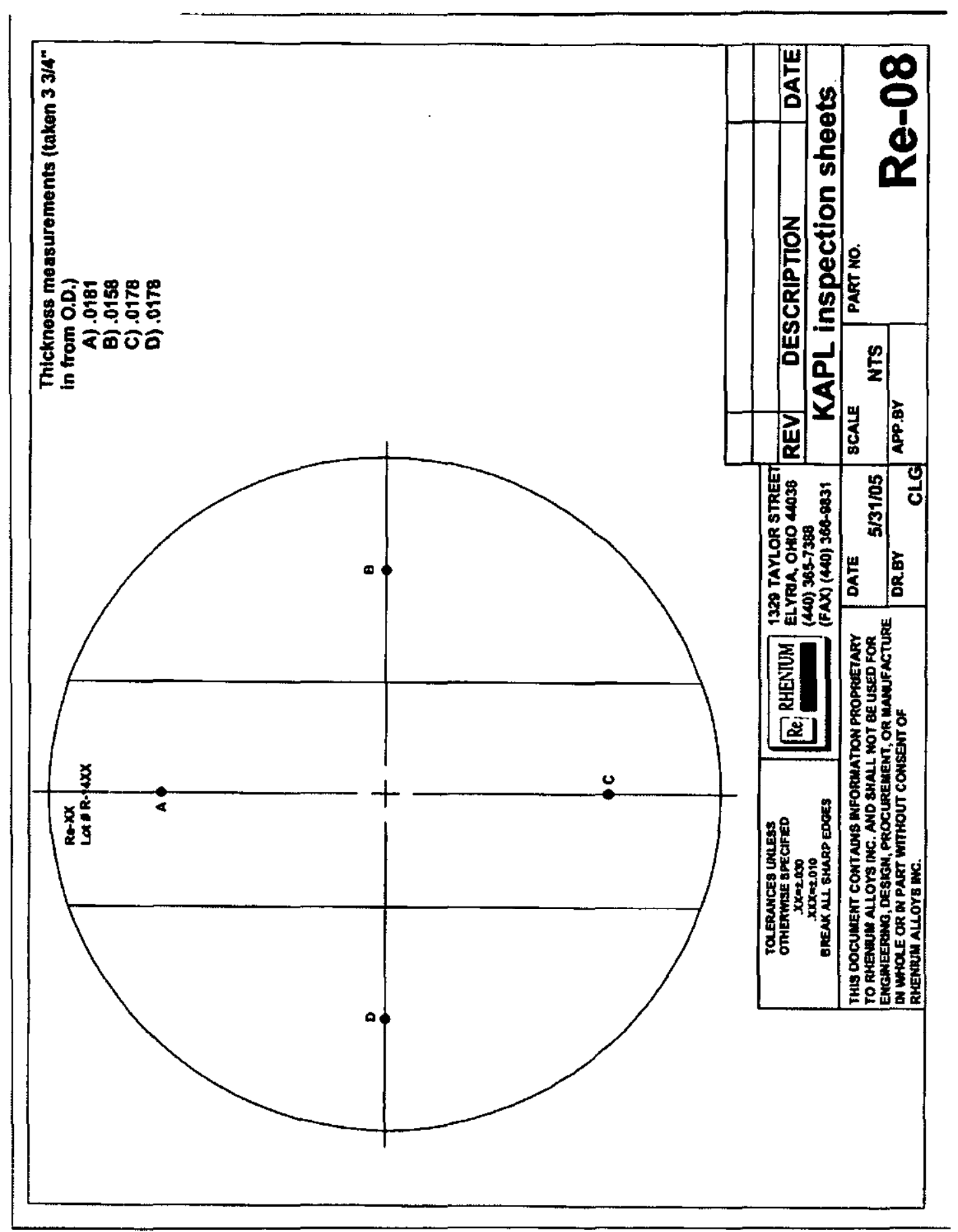


B-TM-1639

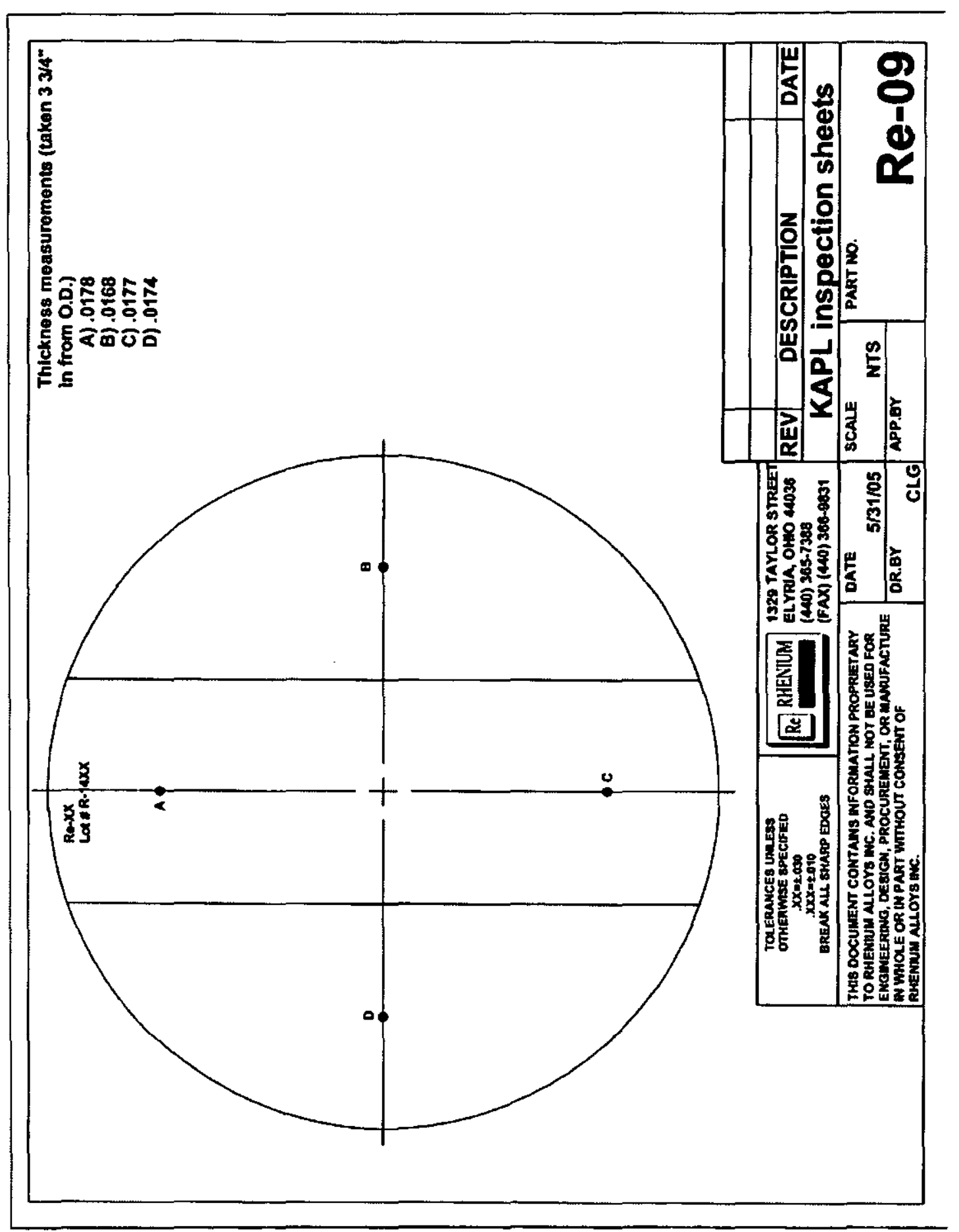




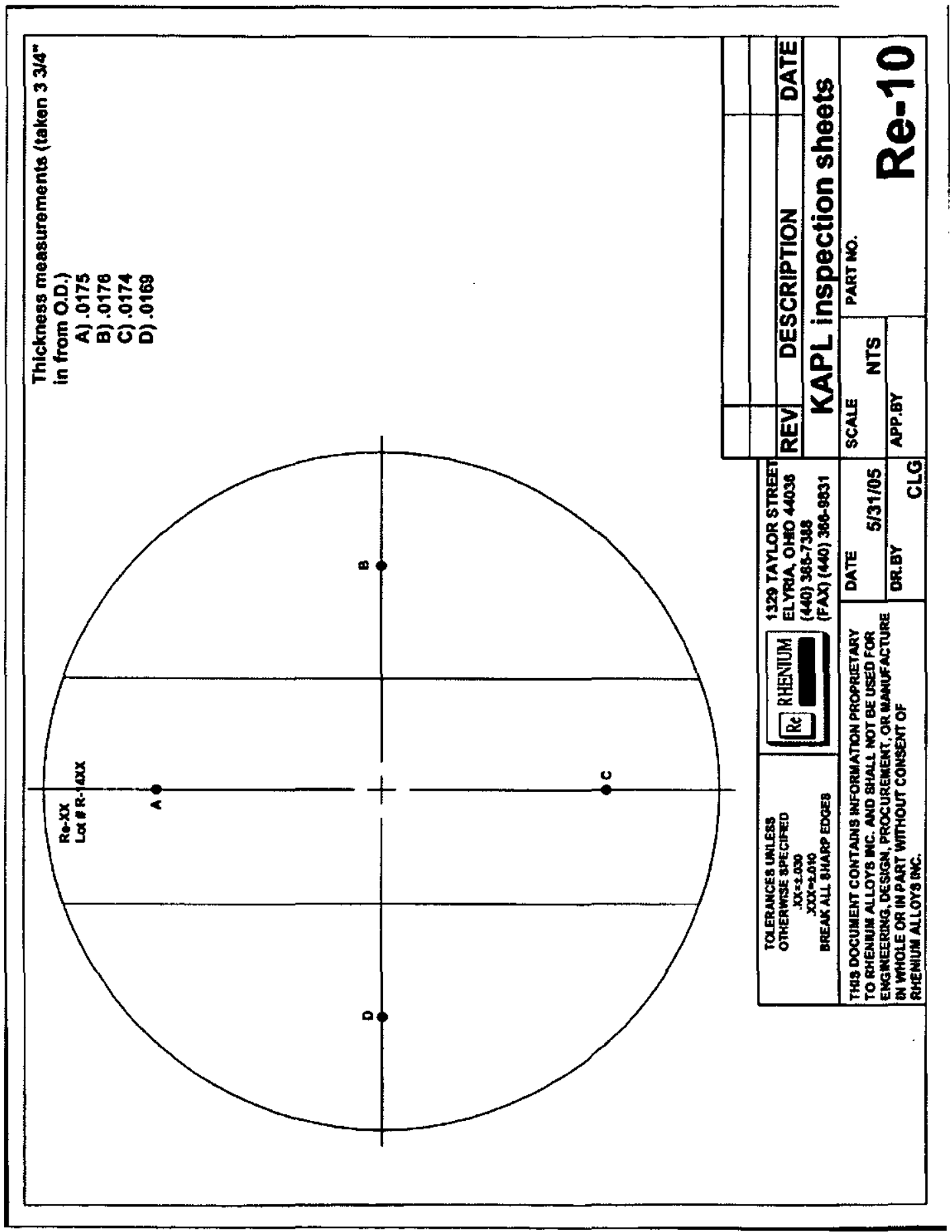


B-TM-1639

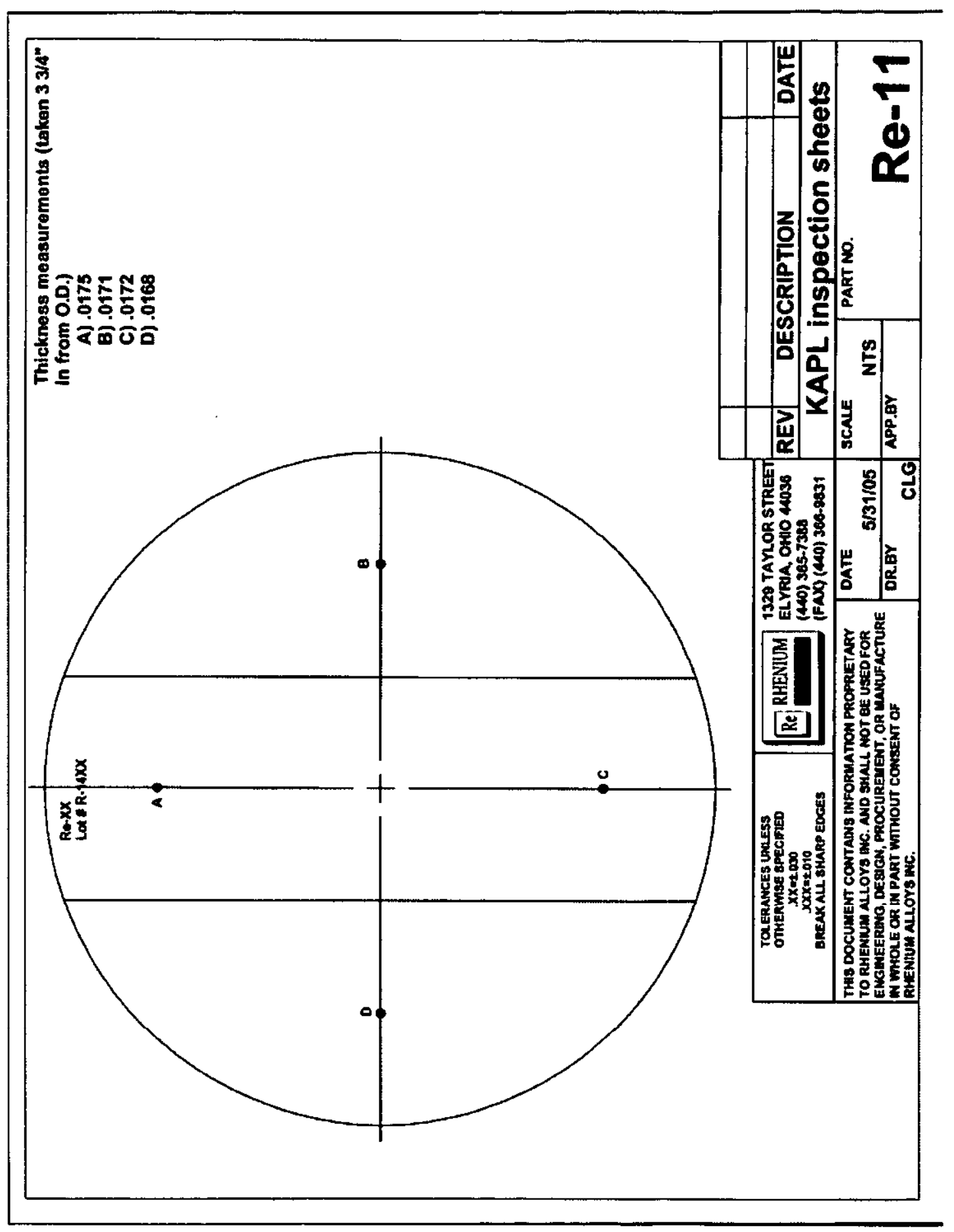


B-TM-1639

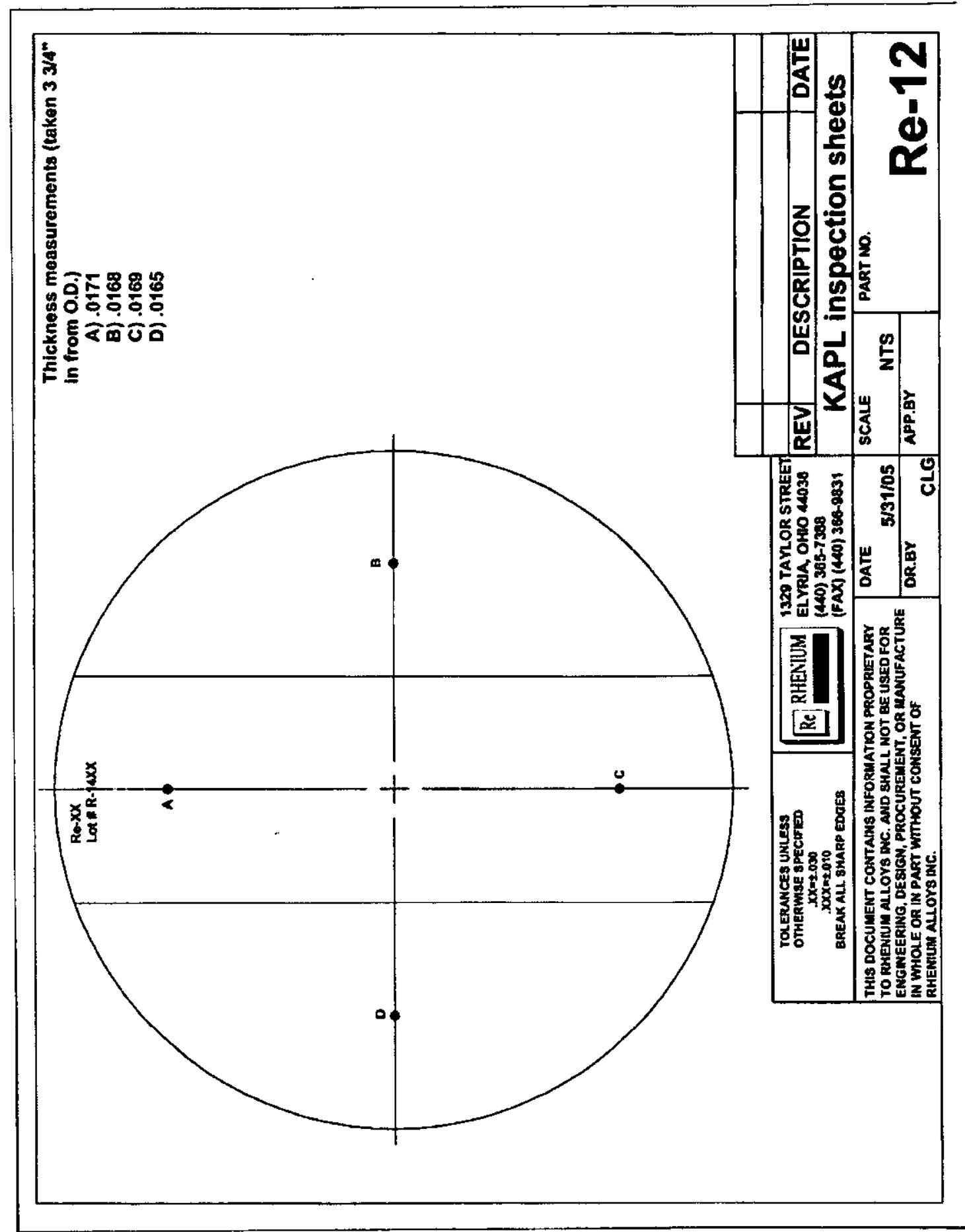


B-TM-1639

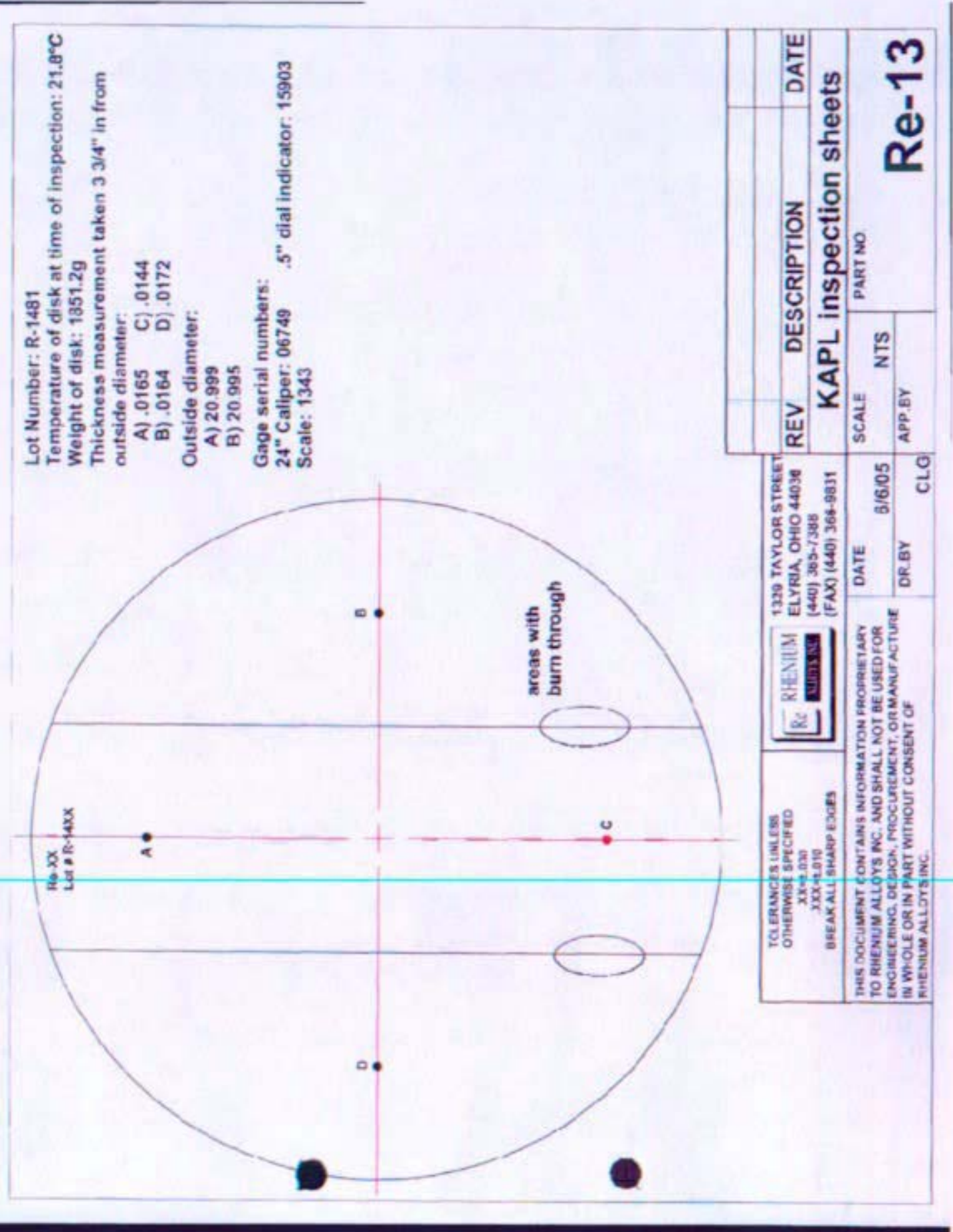




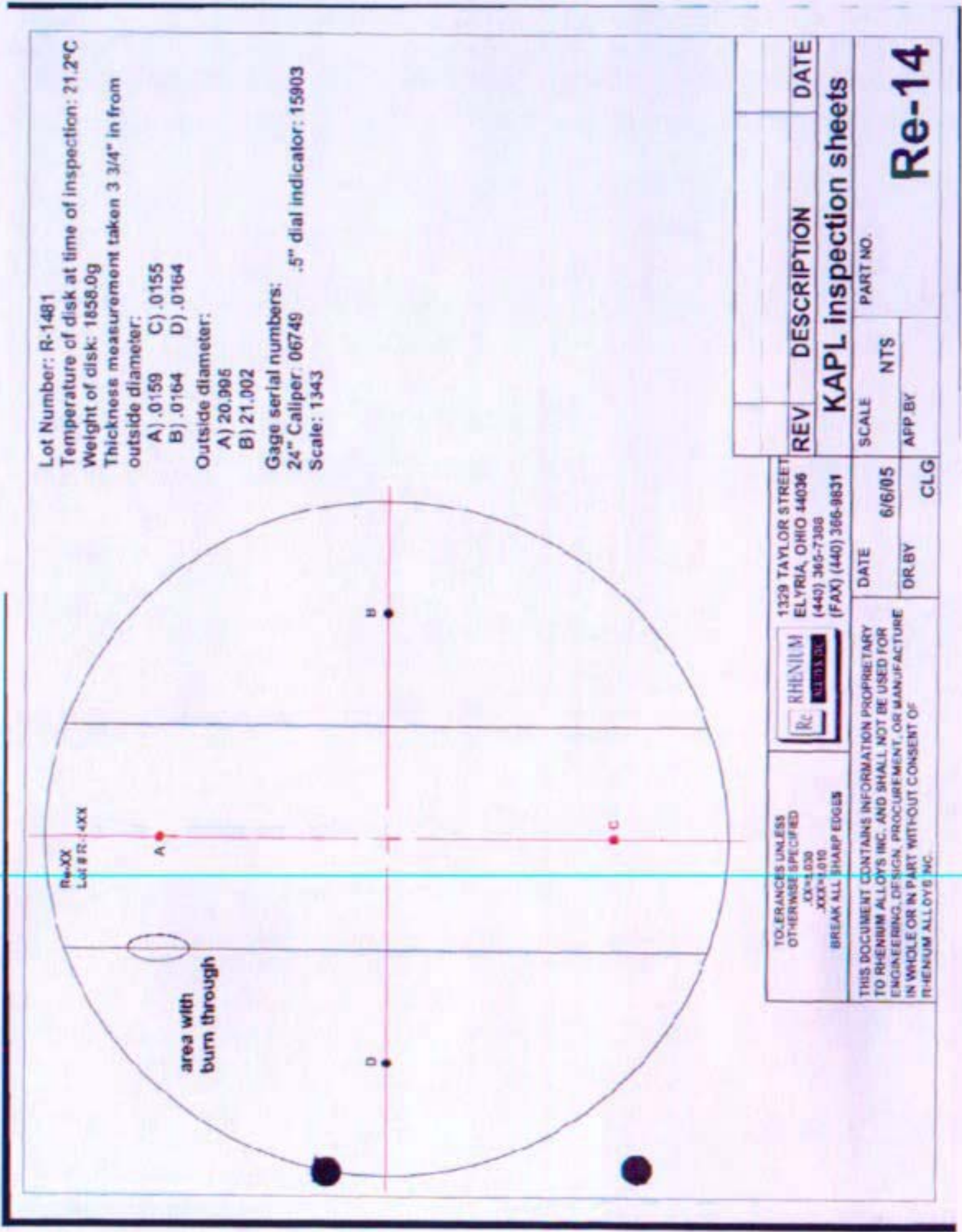


B-TM-1639

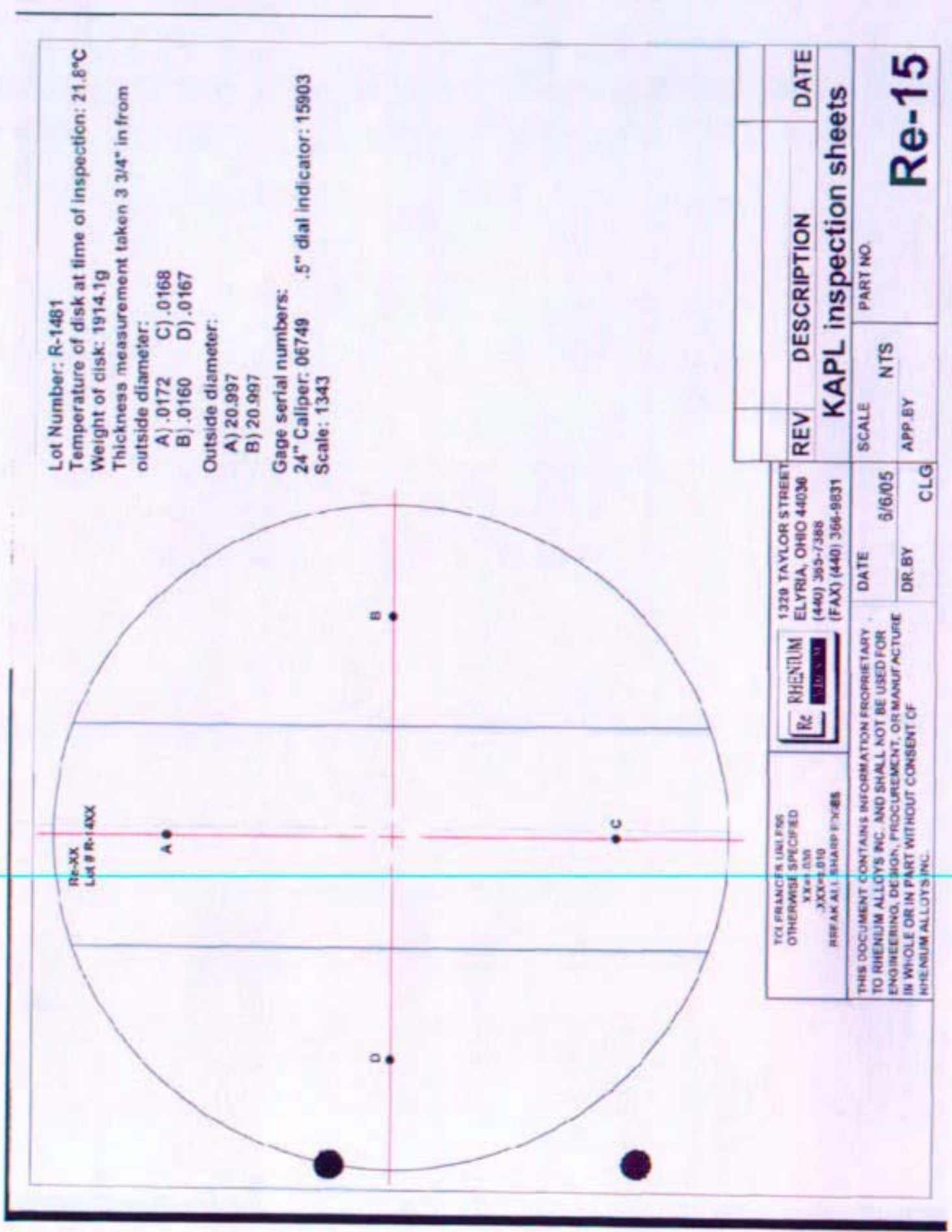




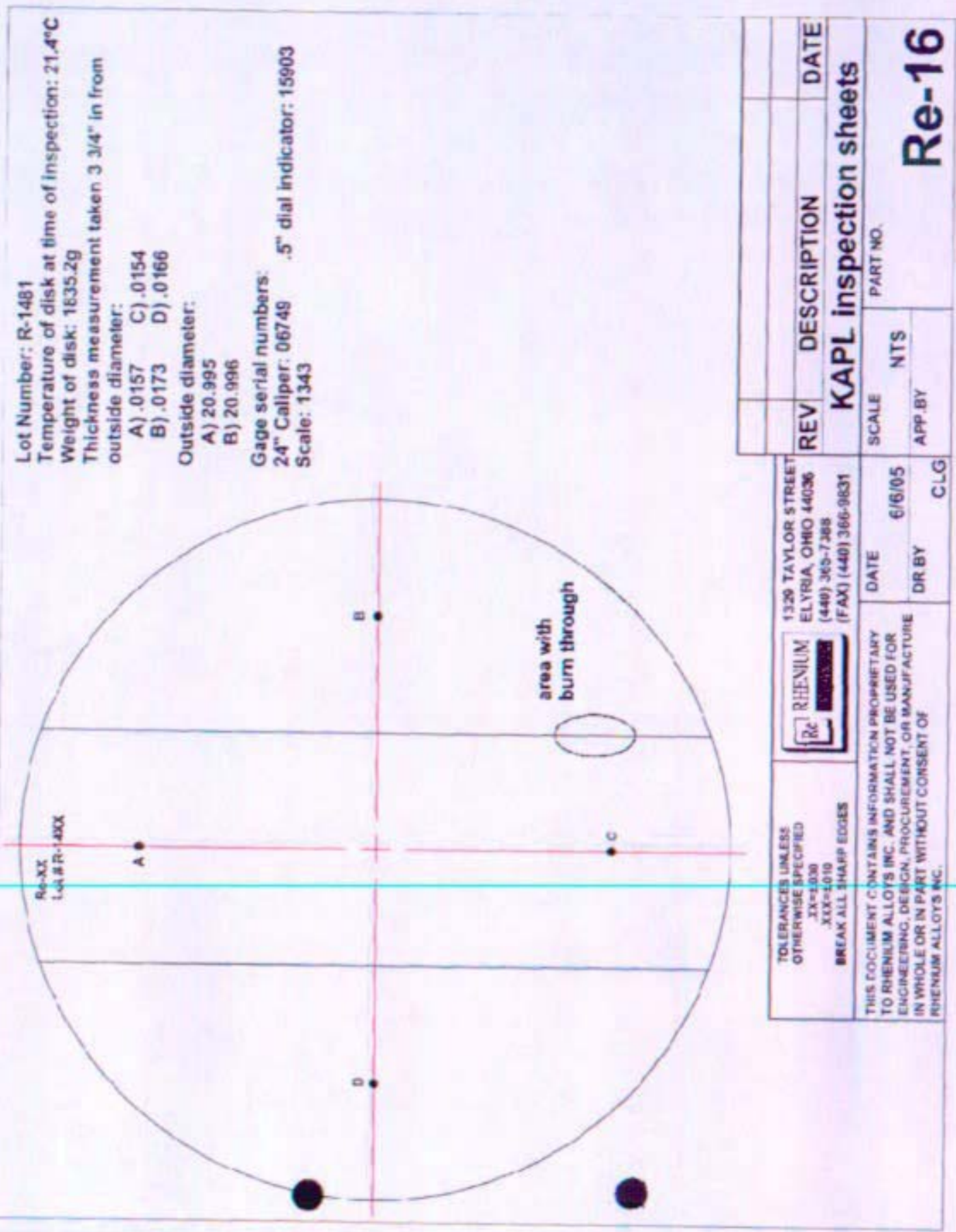


B-TM-1639

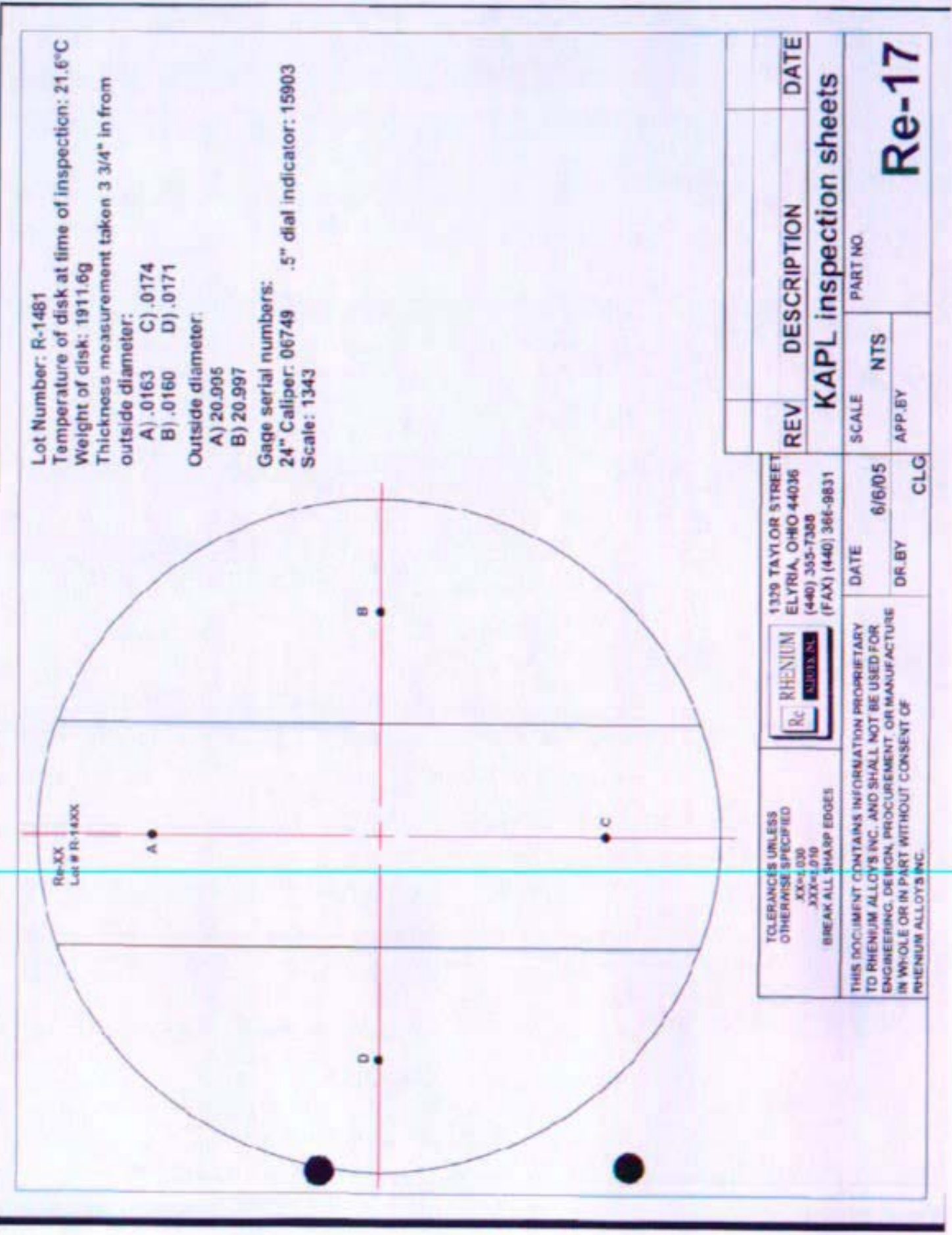




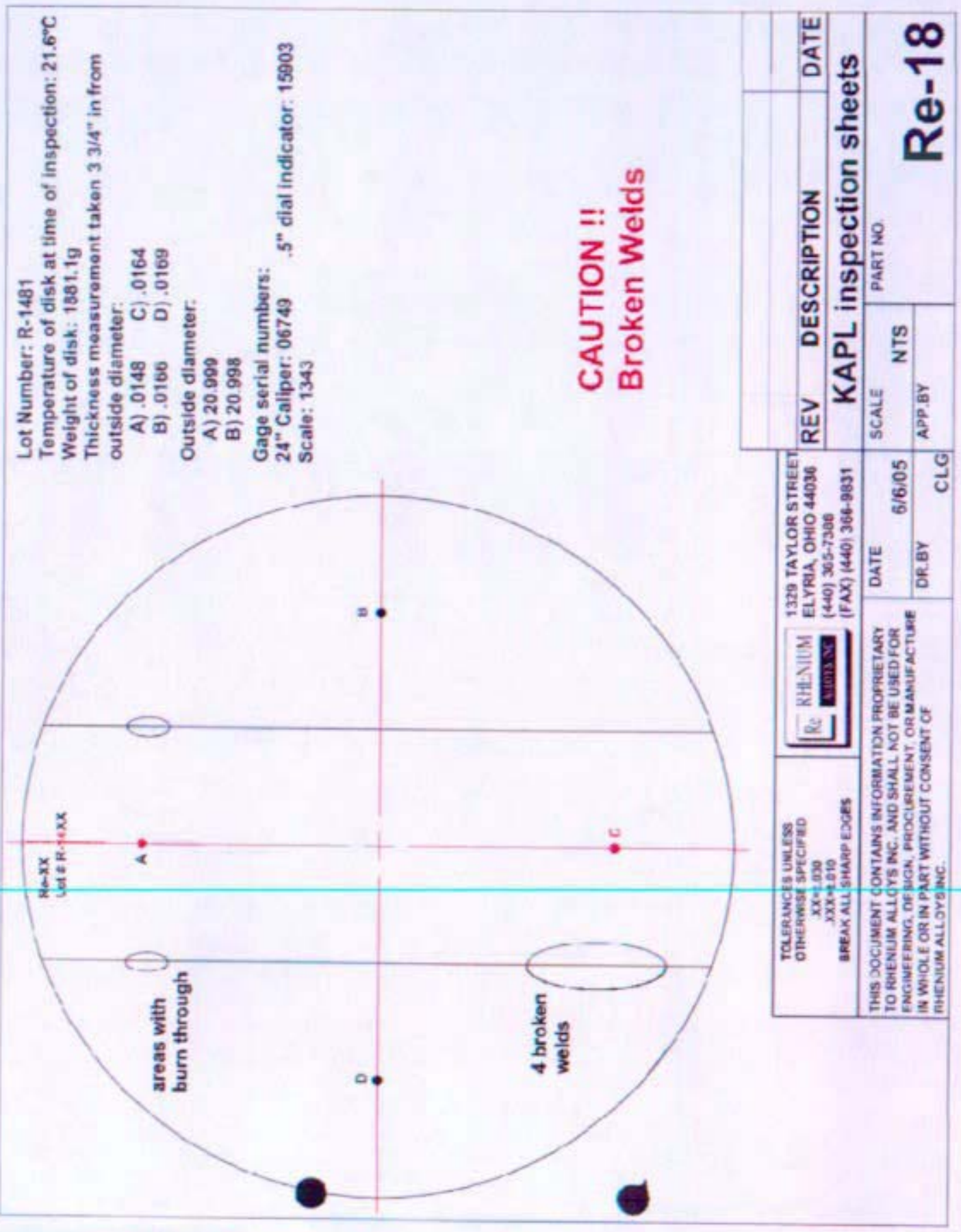


B-TM-1639

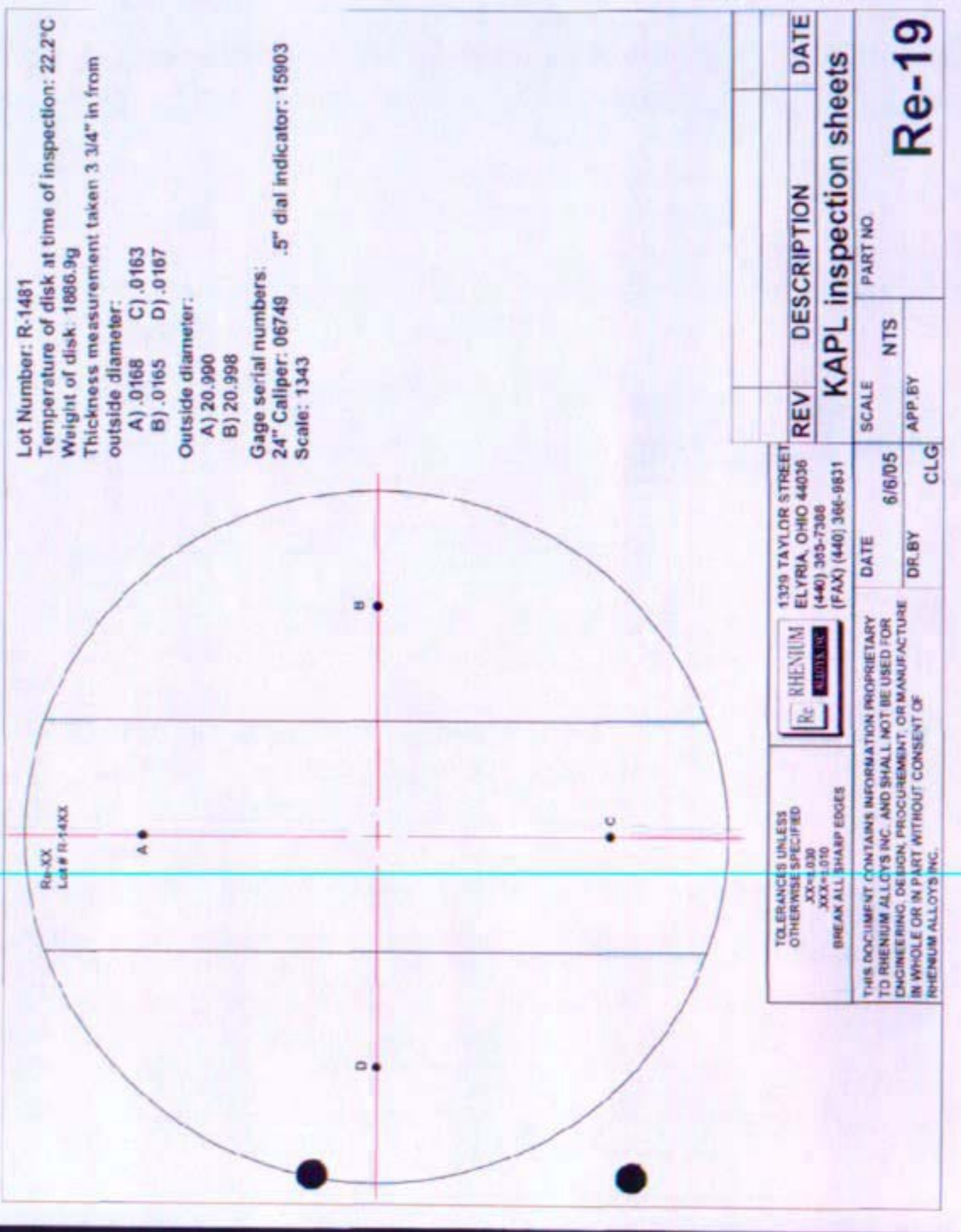




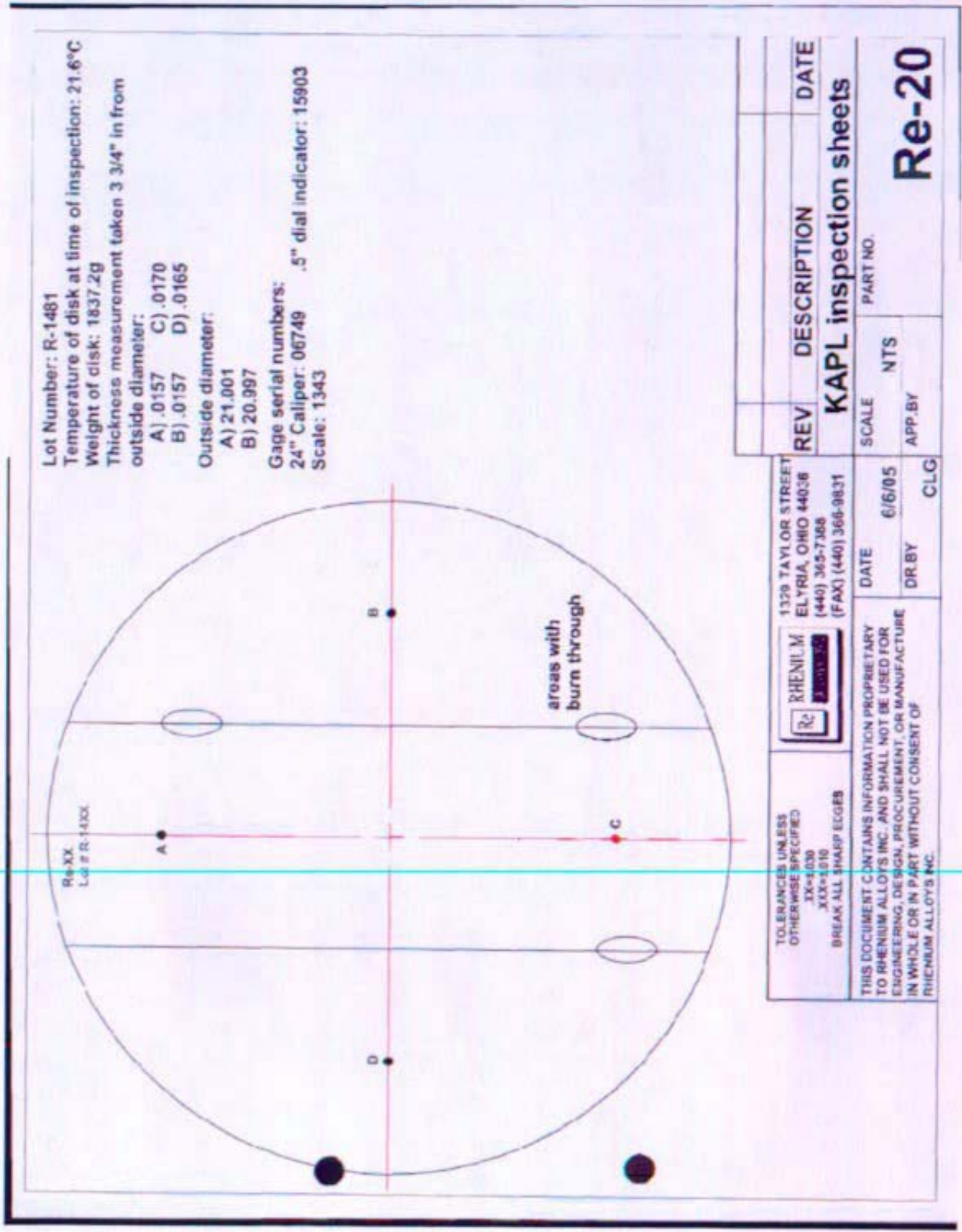


B-TM-1639

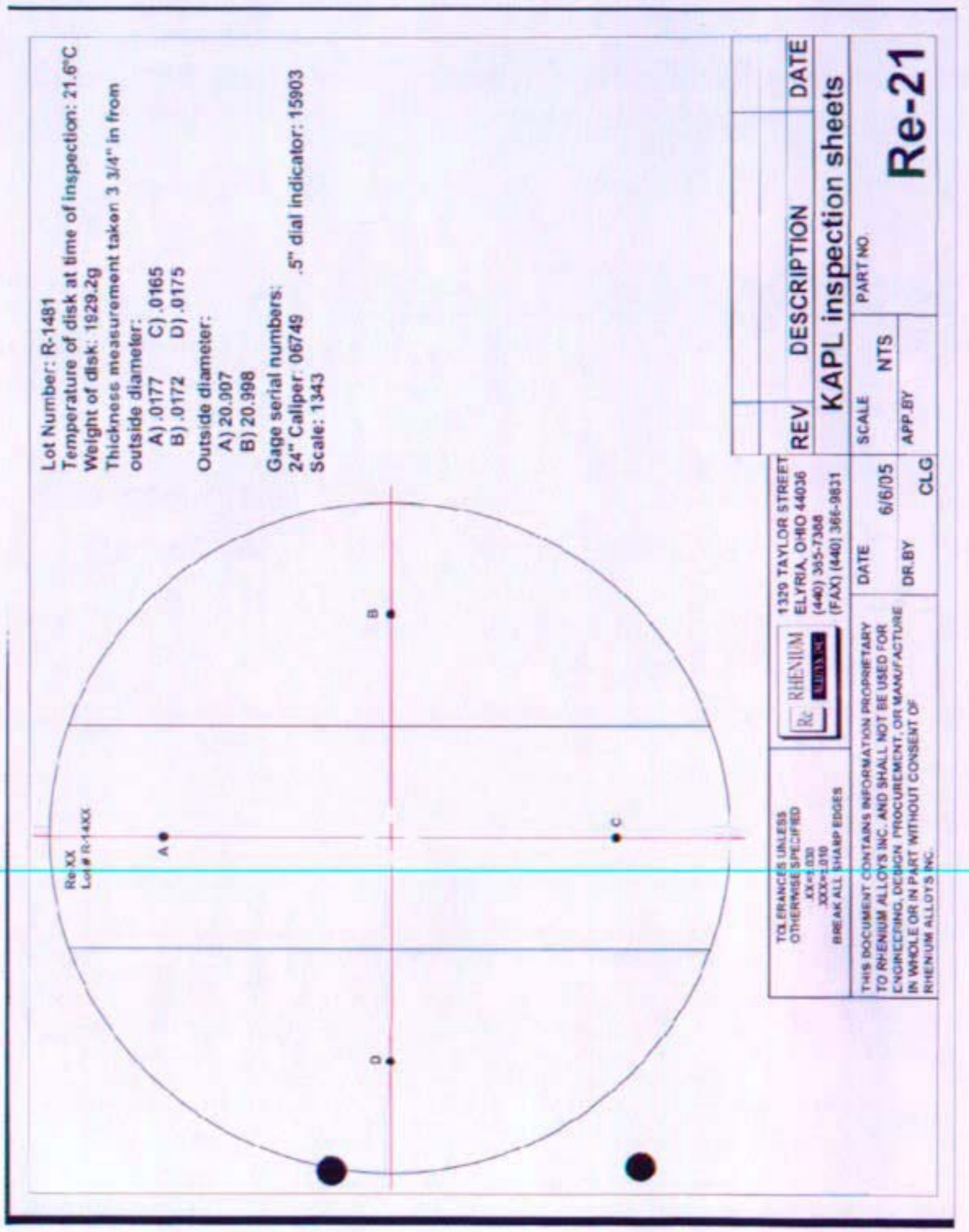




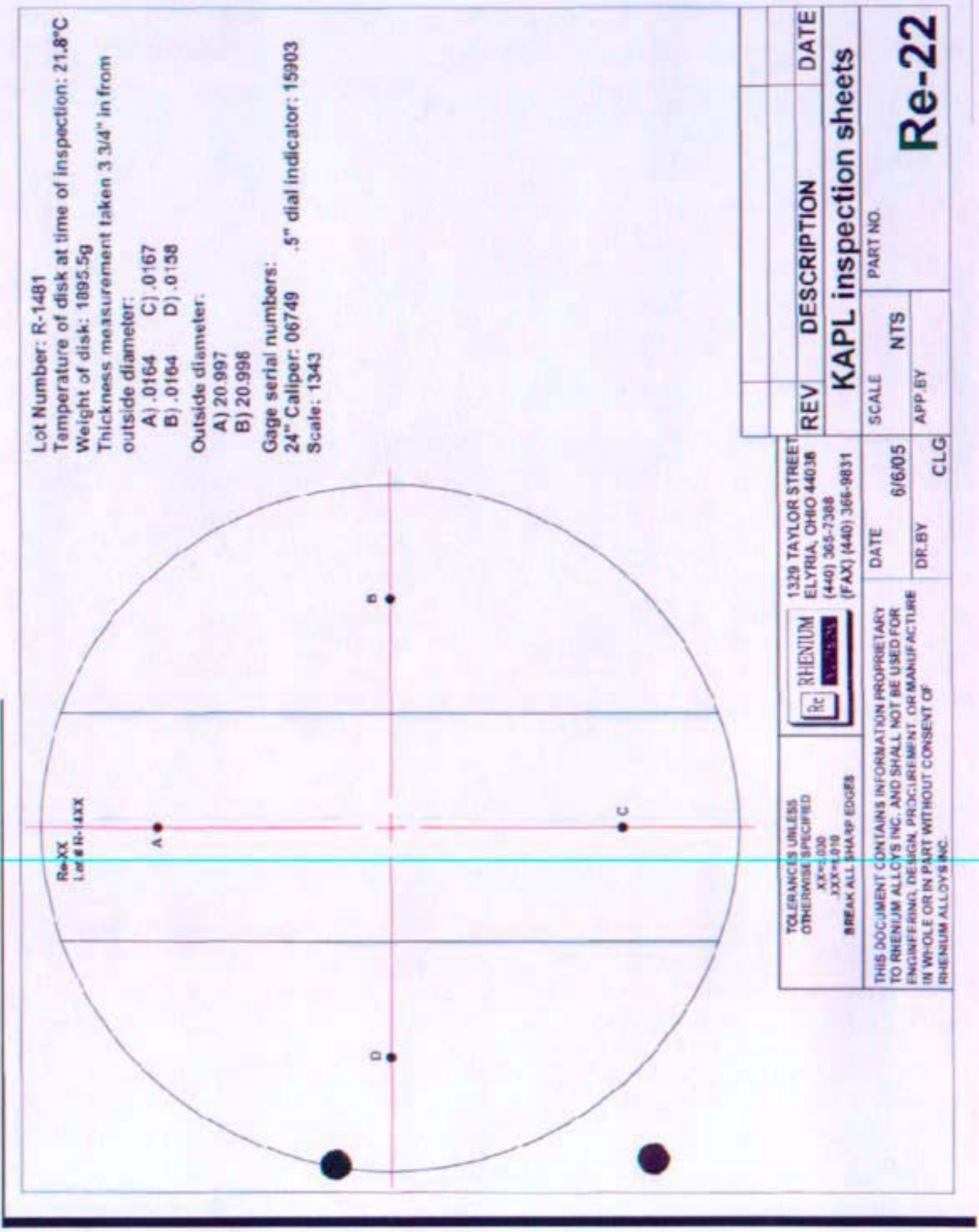




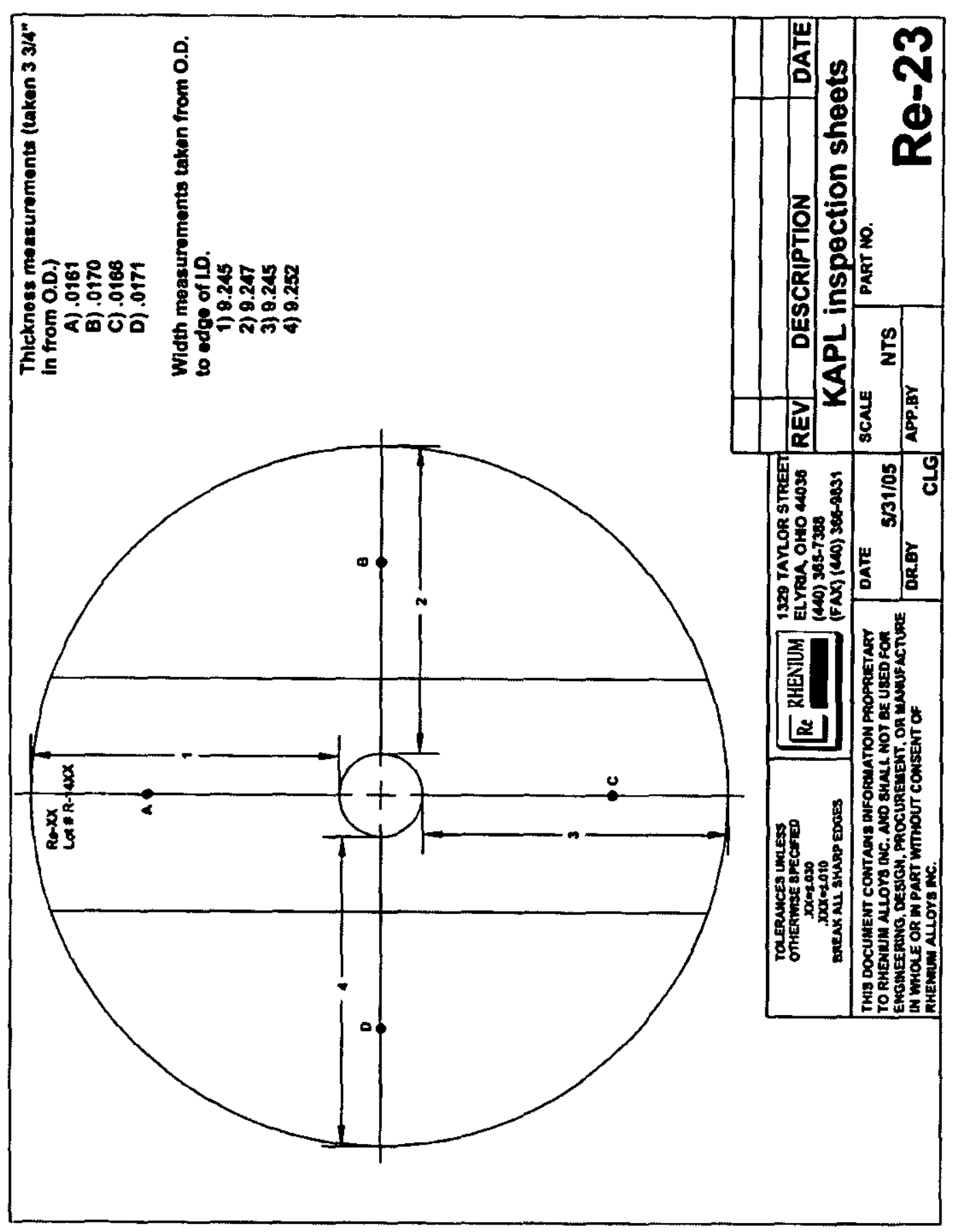




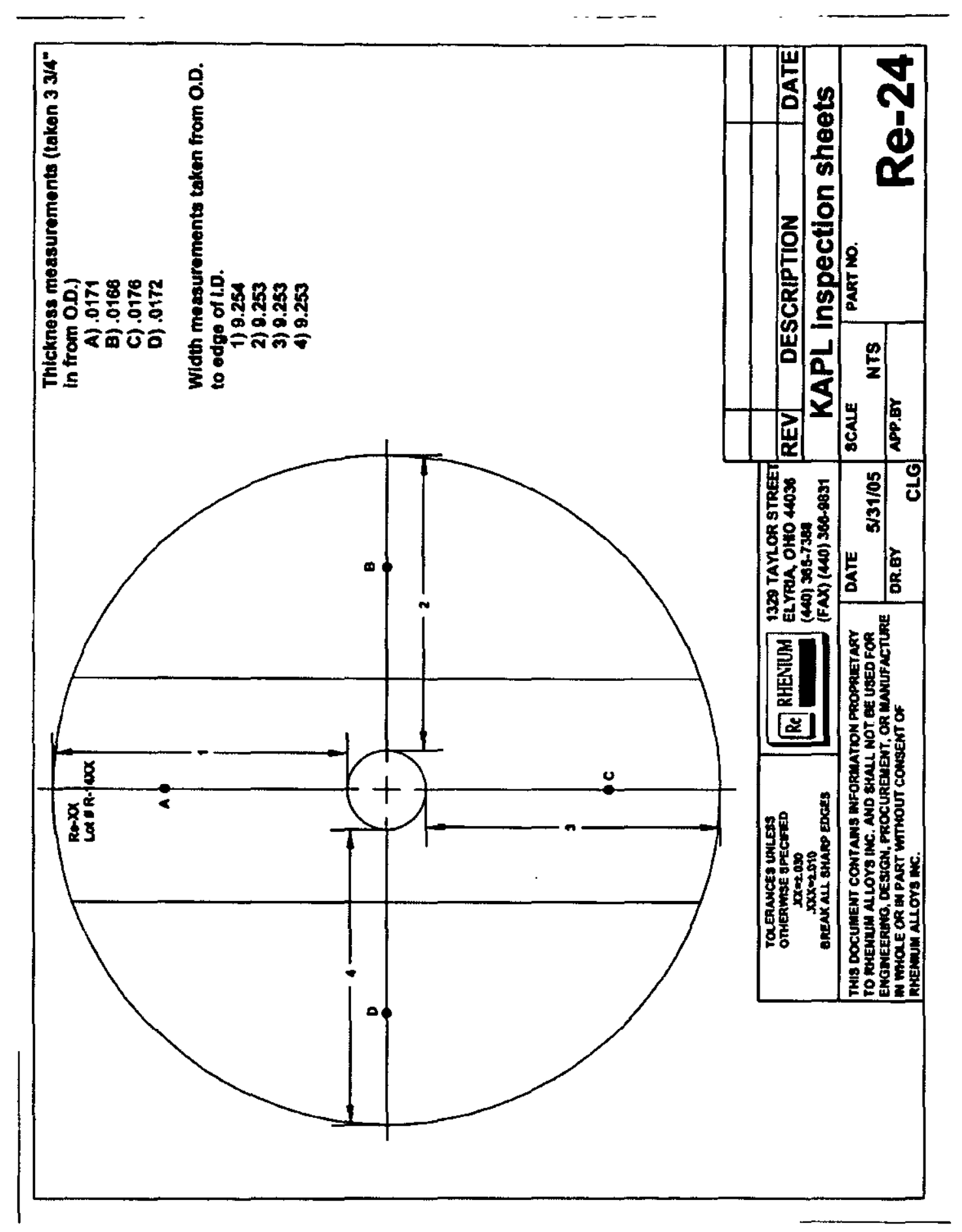


B-TM-1639

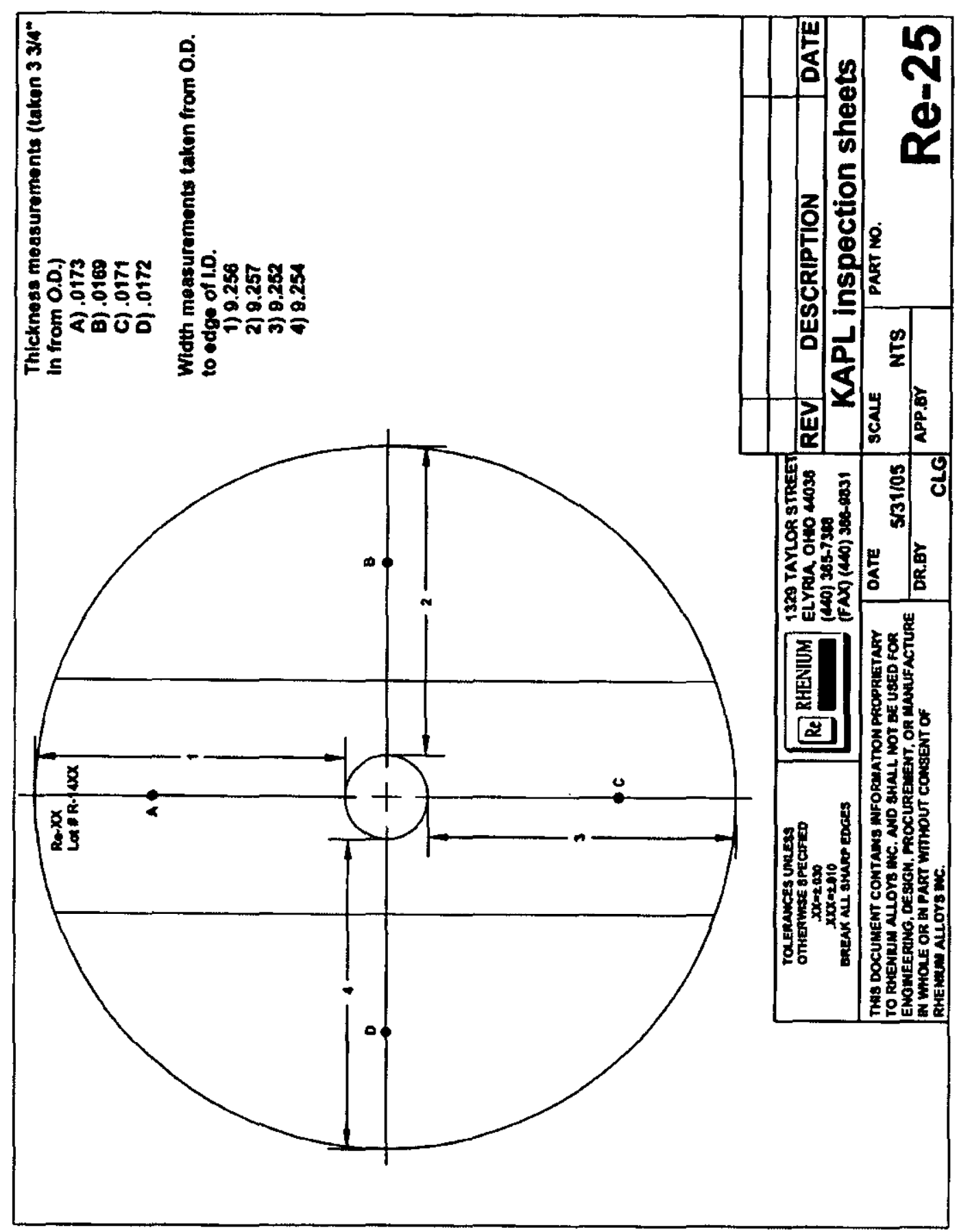


B-TM-1639

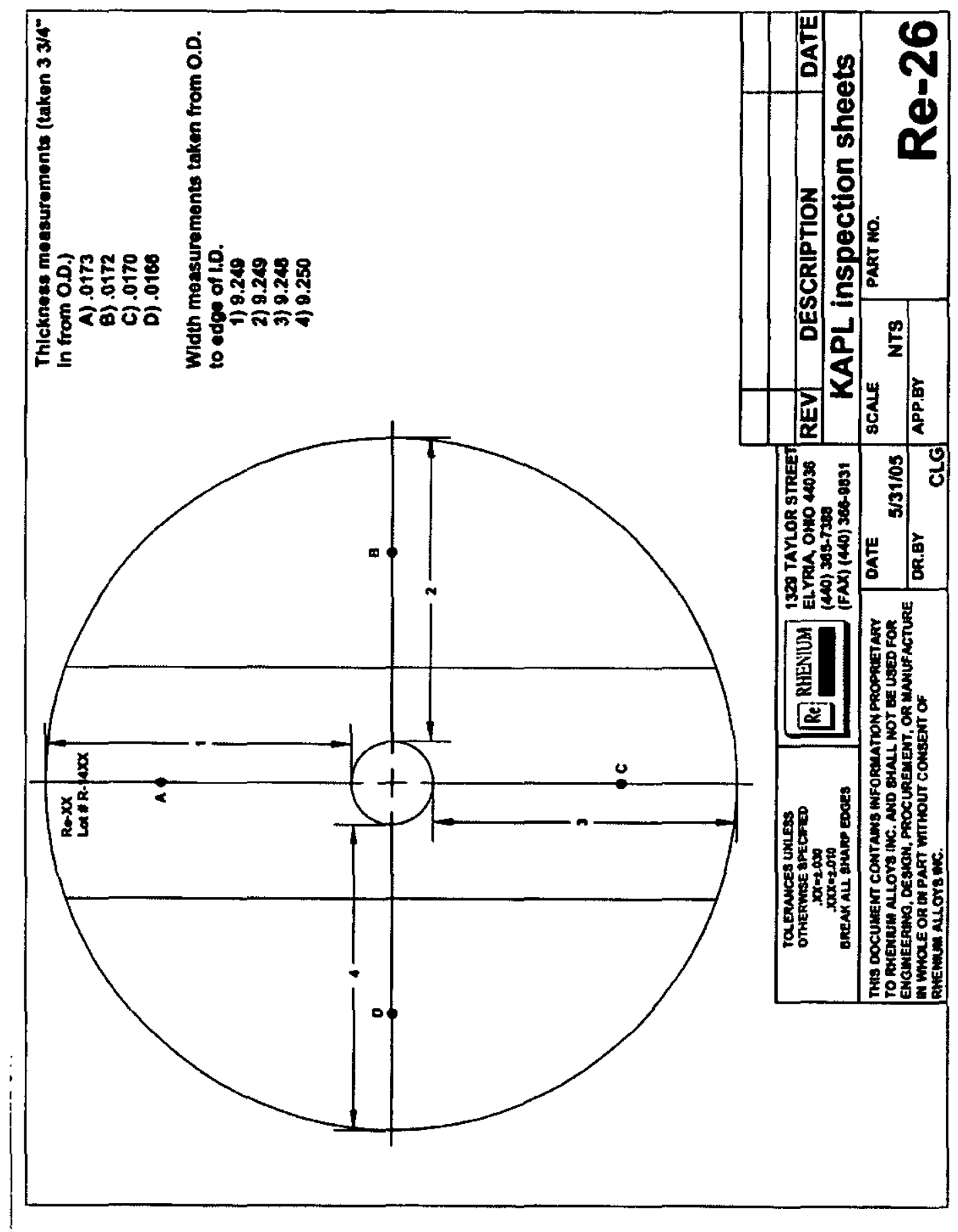


B-TM-1639

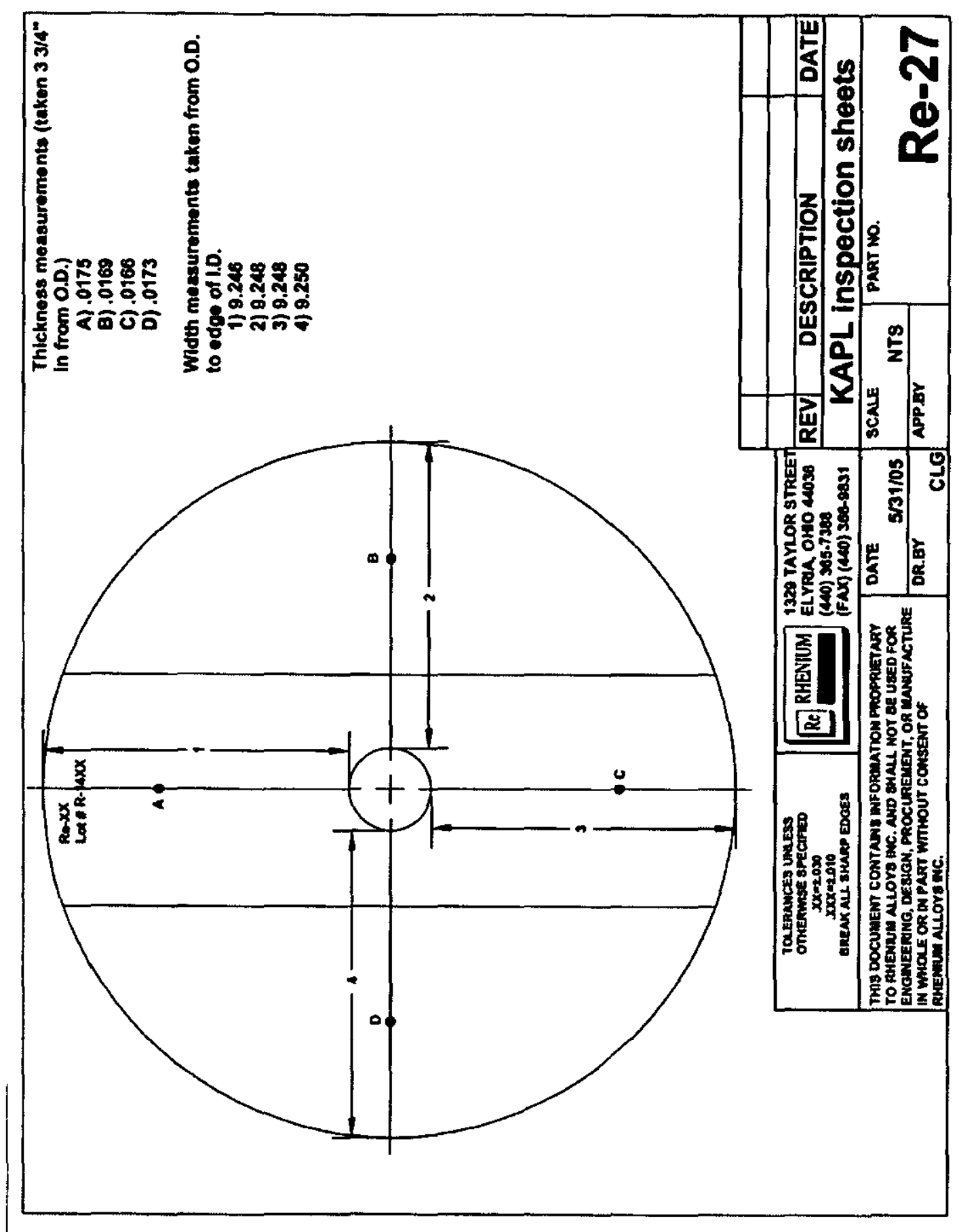




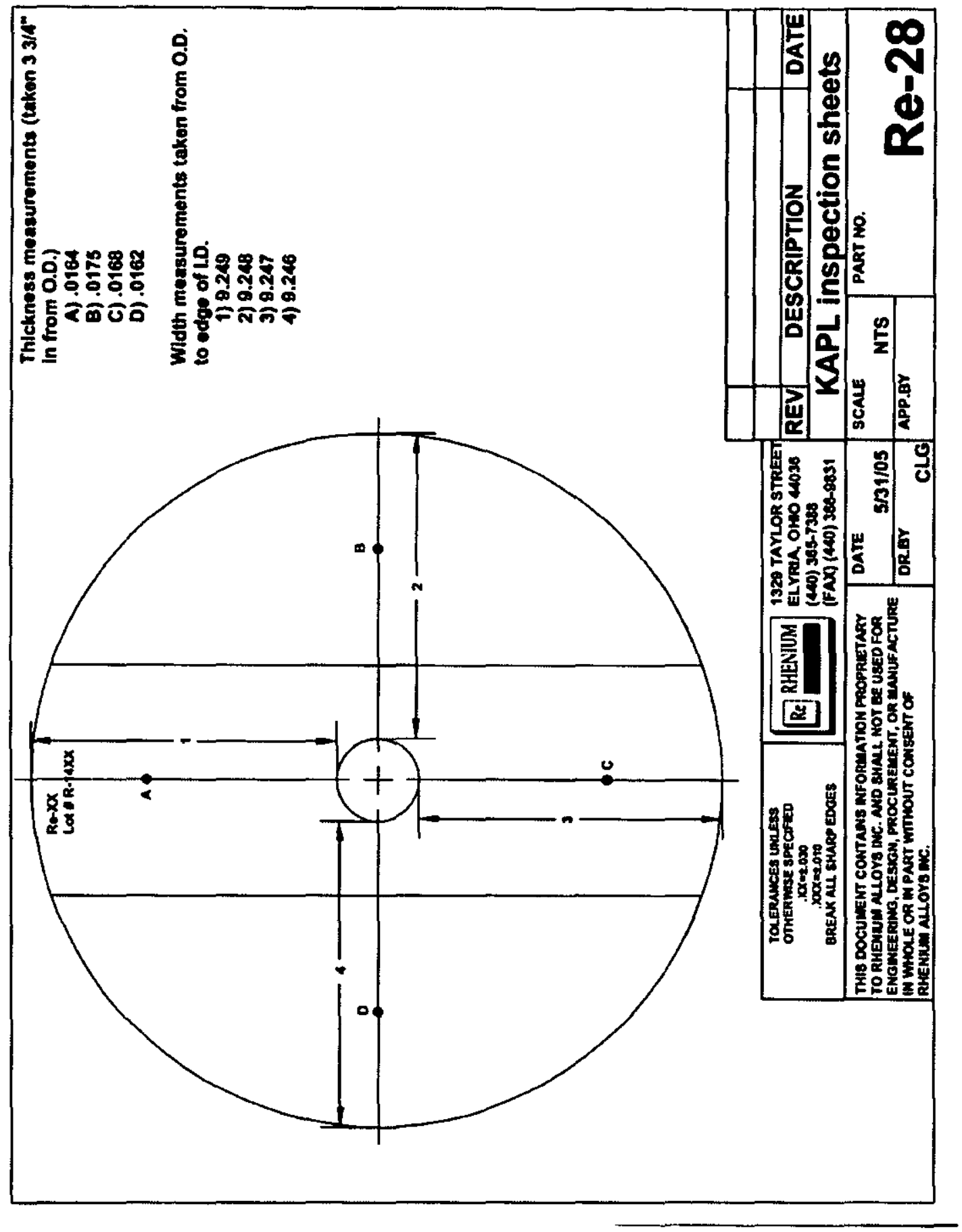


B-TM-1639

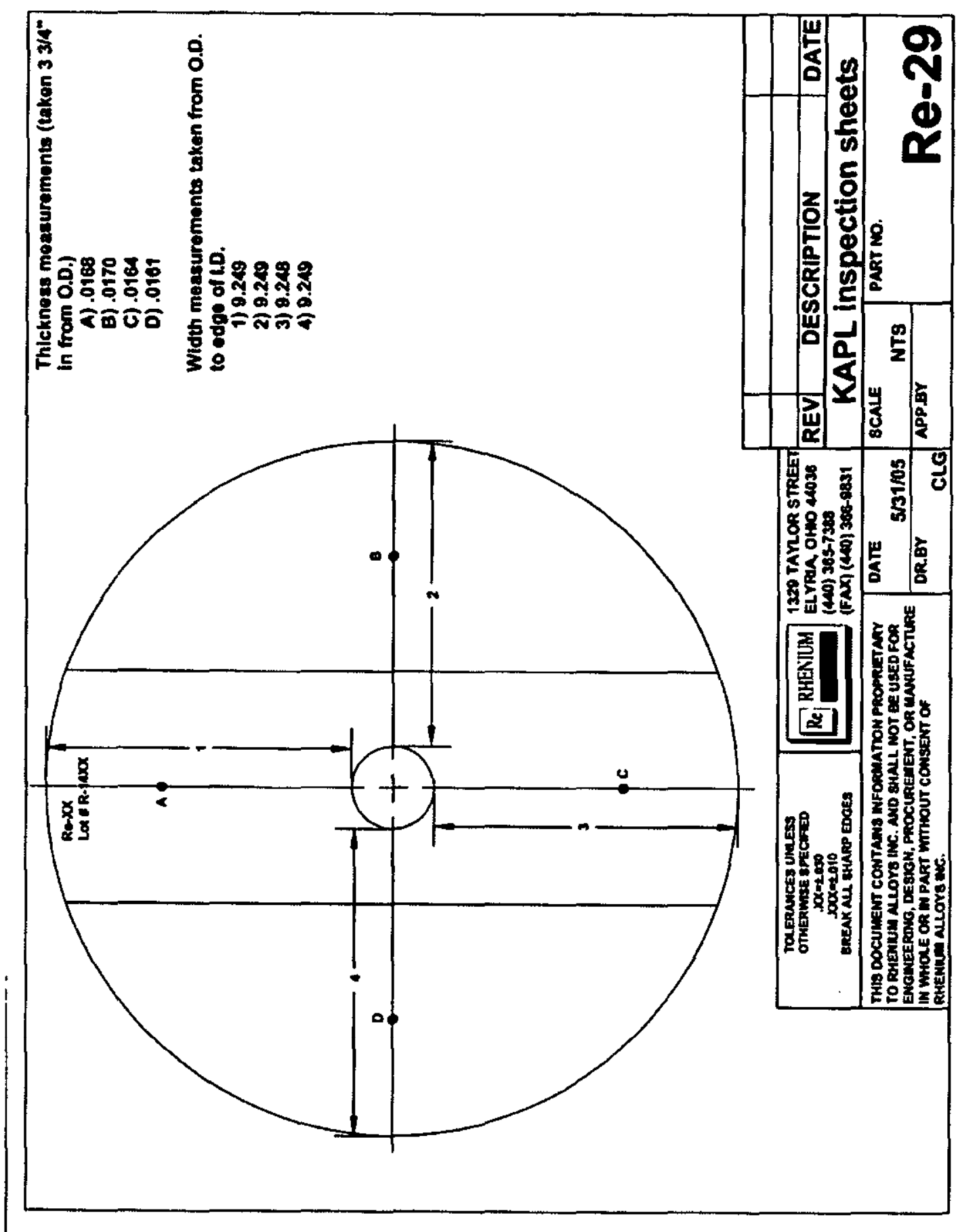




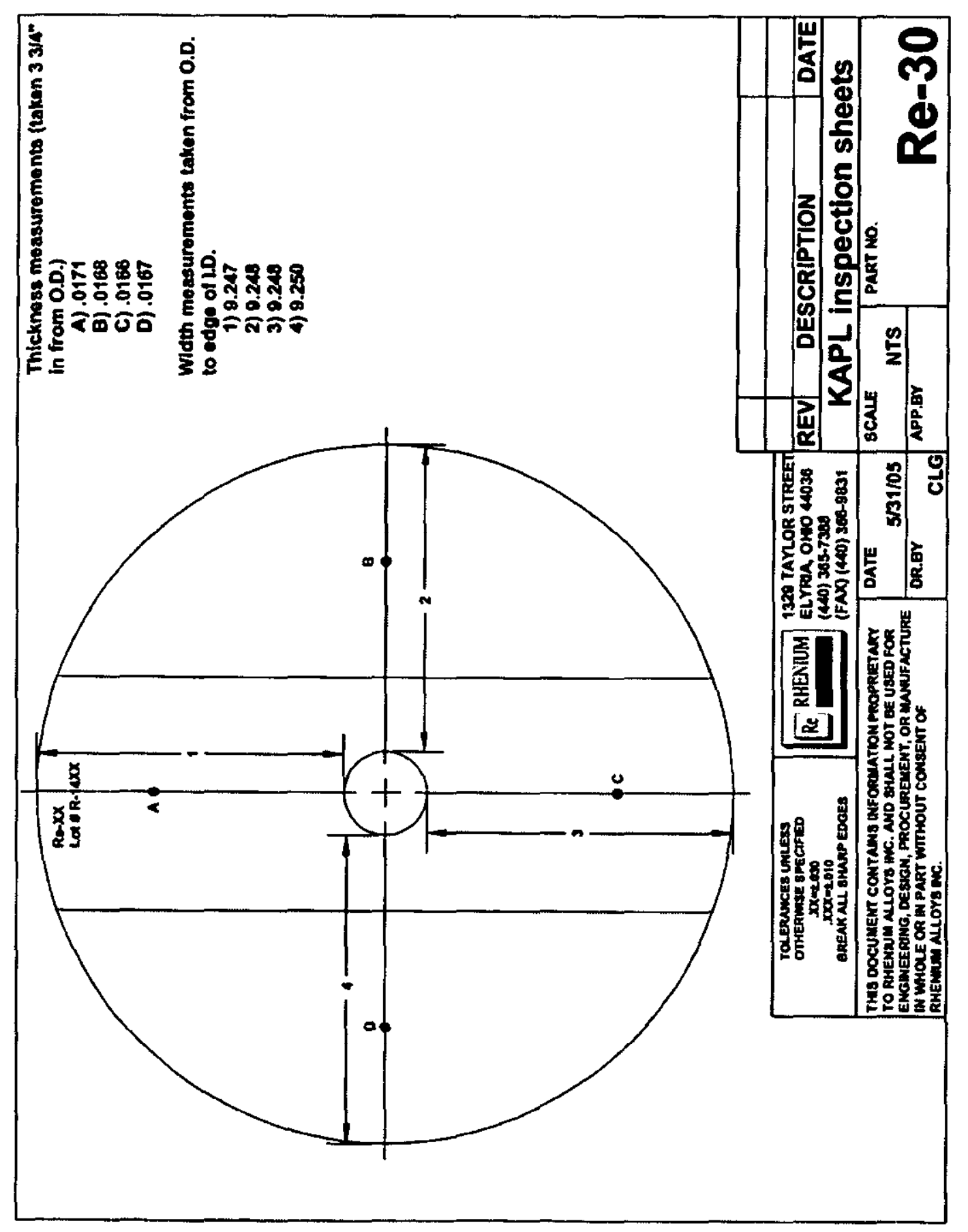


B-TM-1639

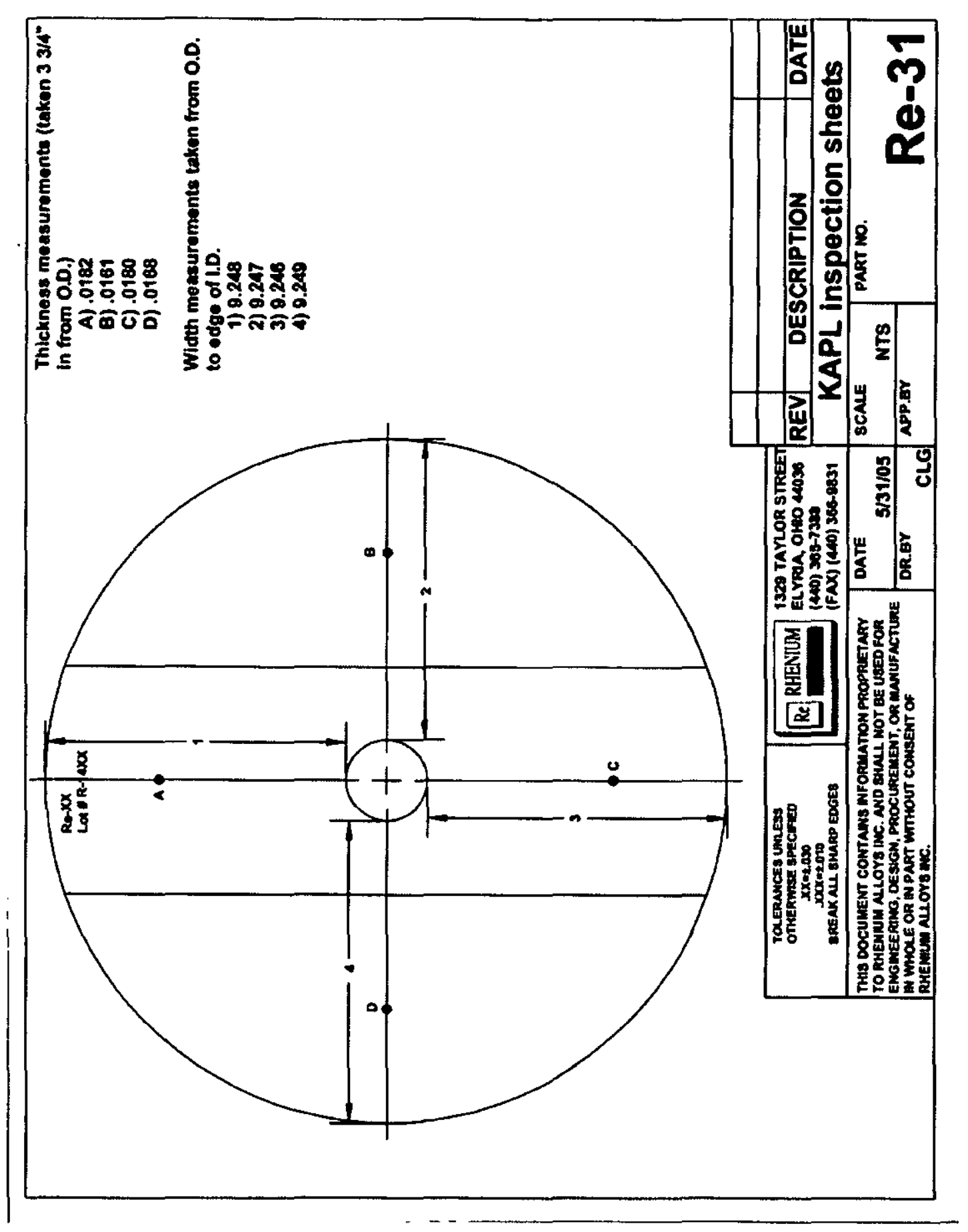




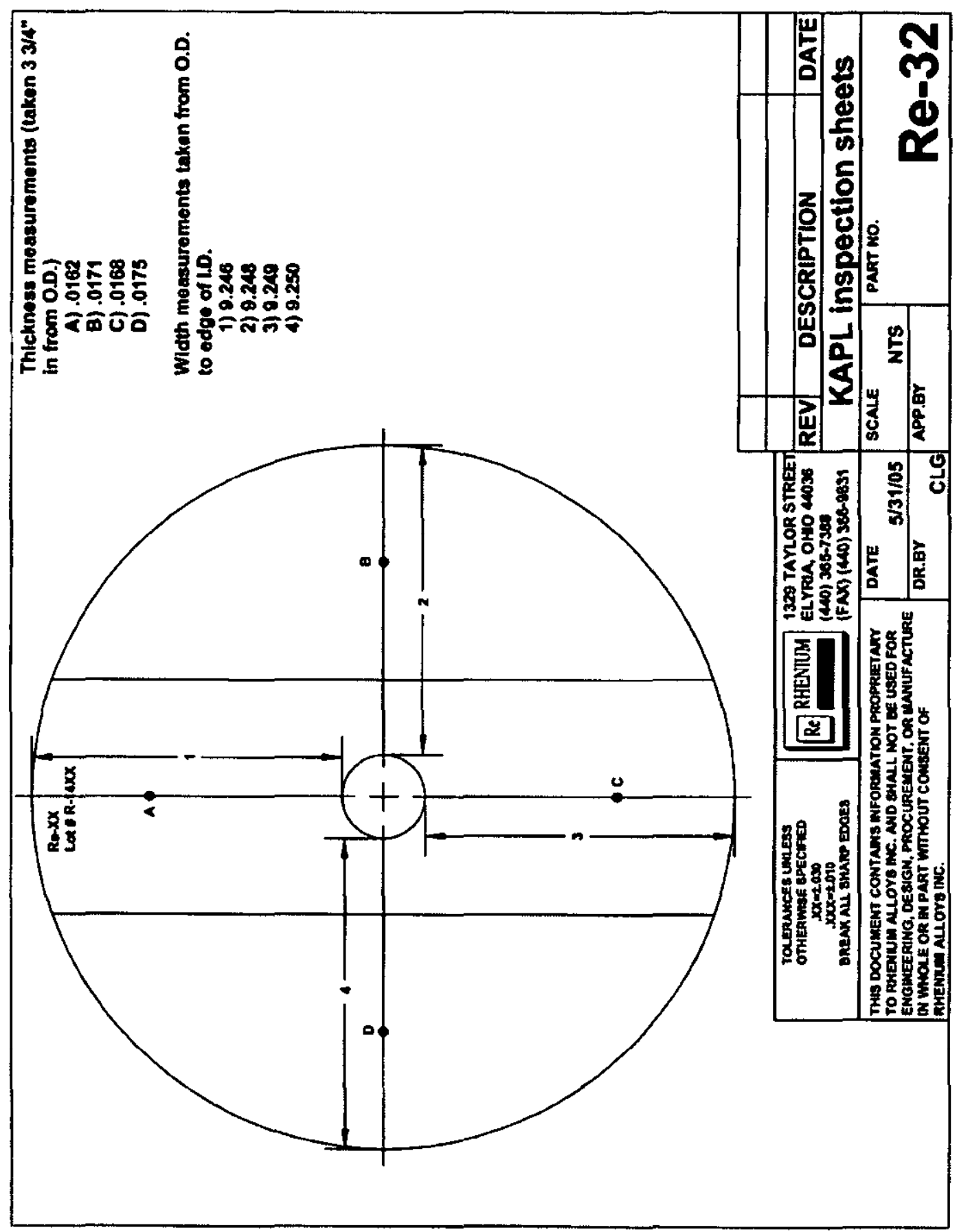




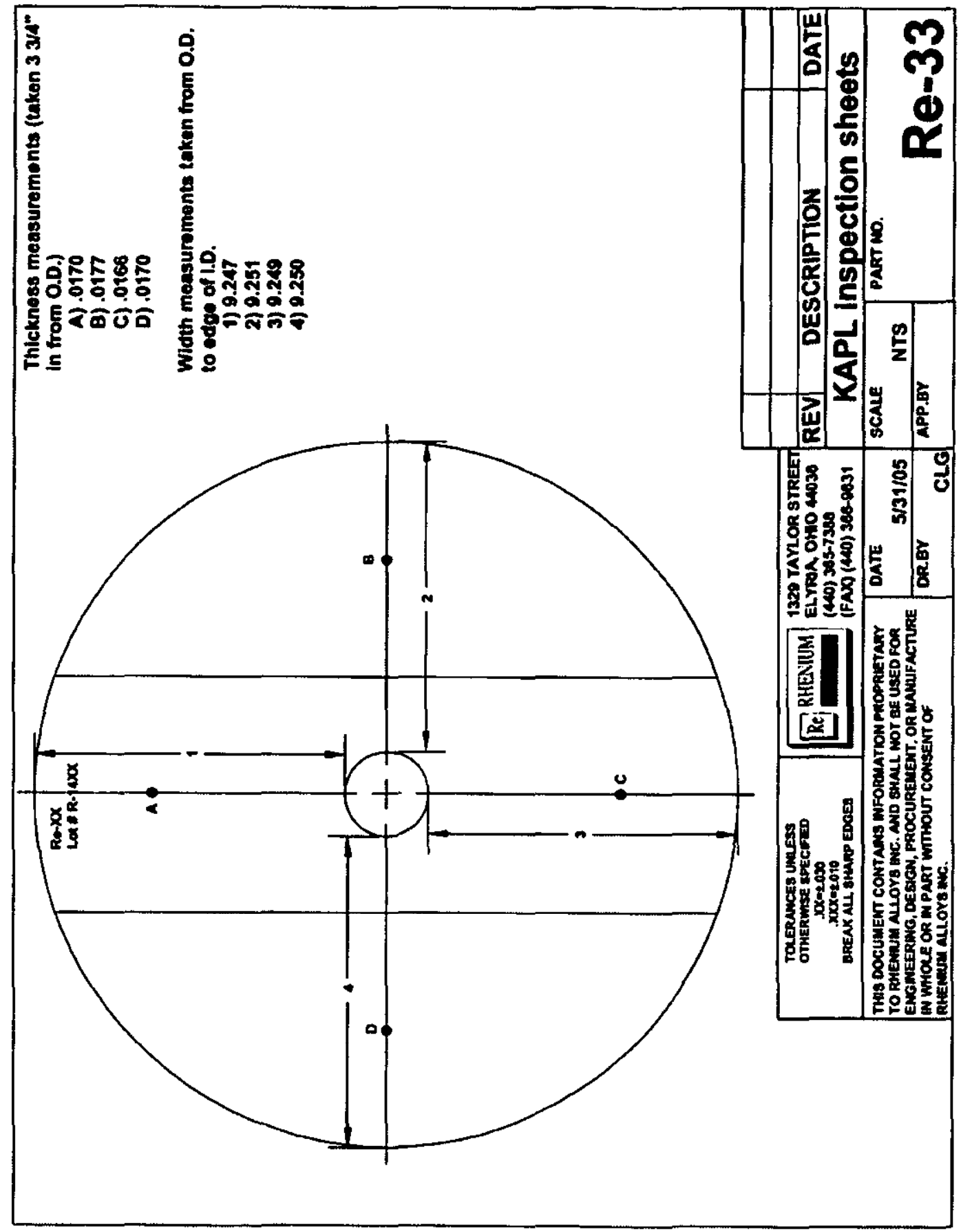




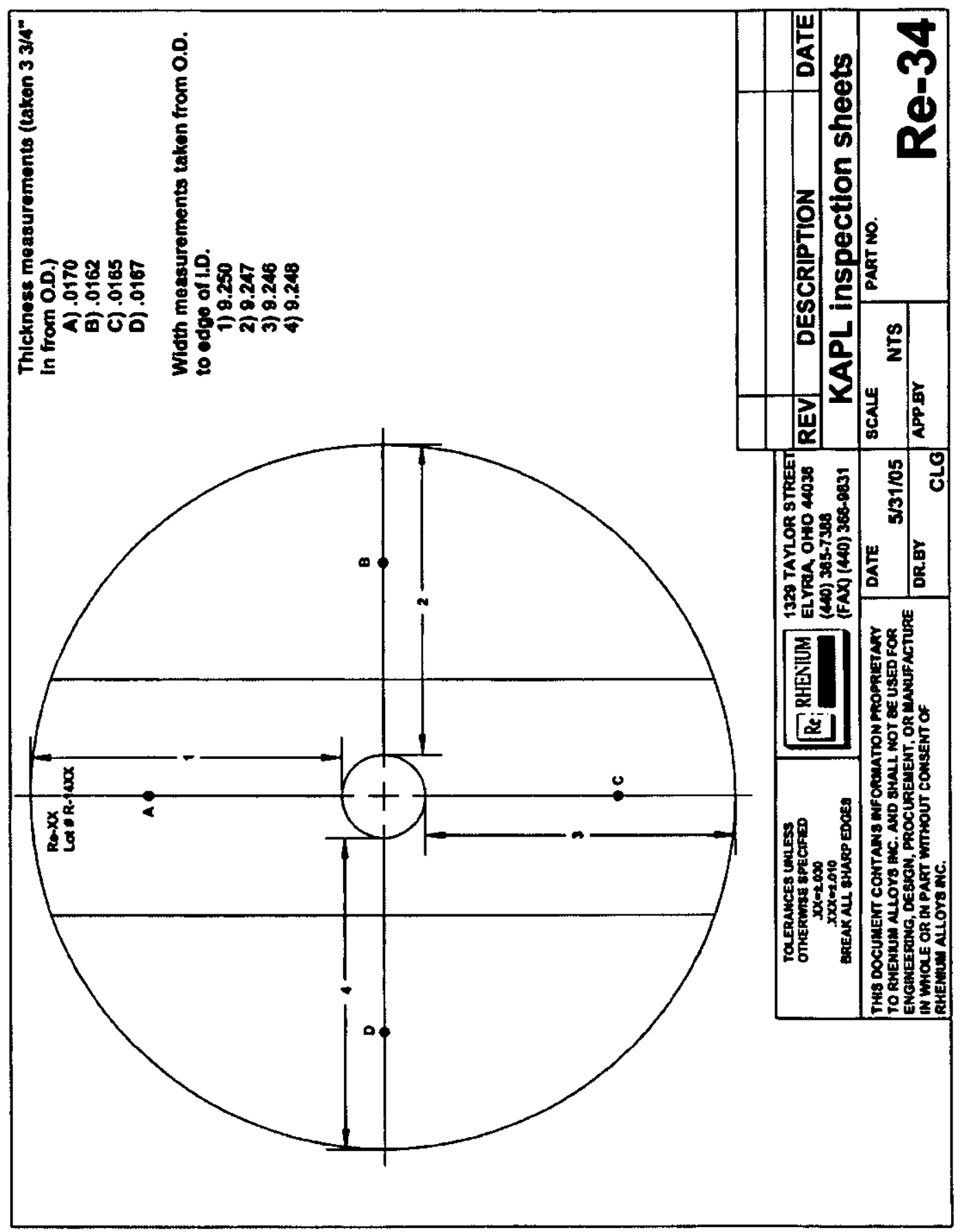


B-TM-1639

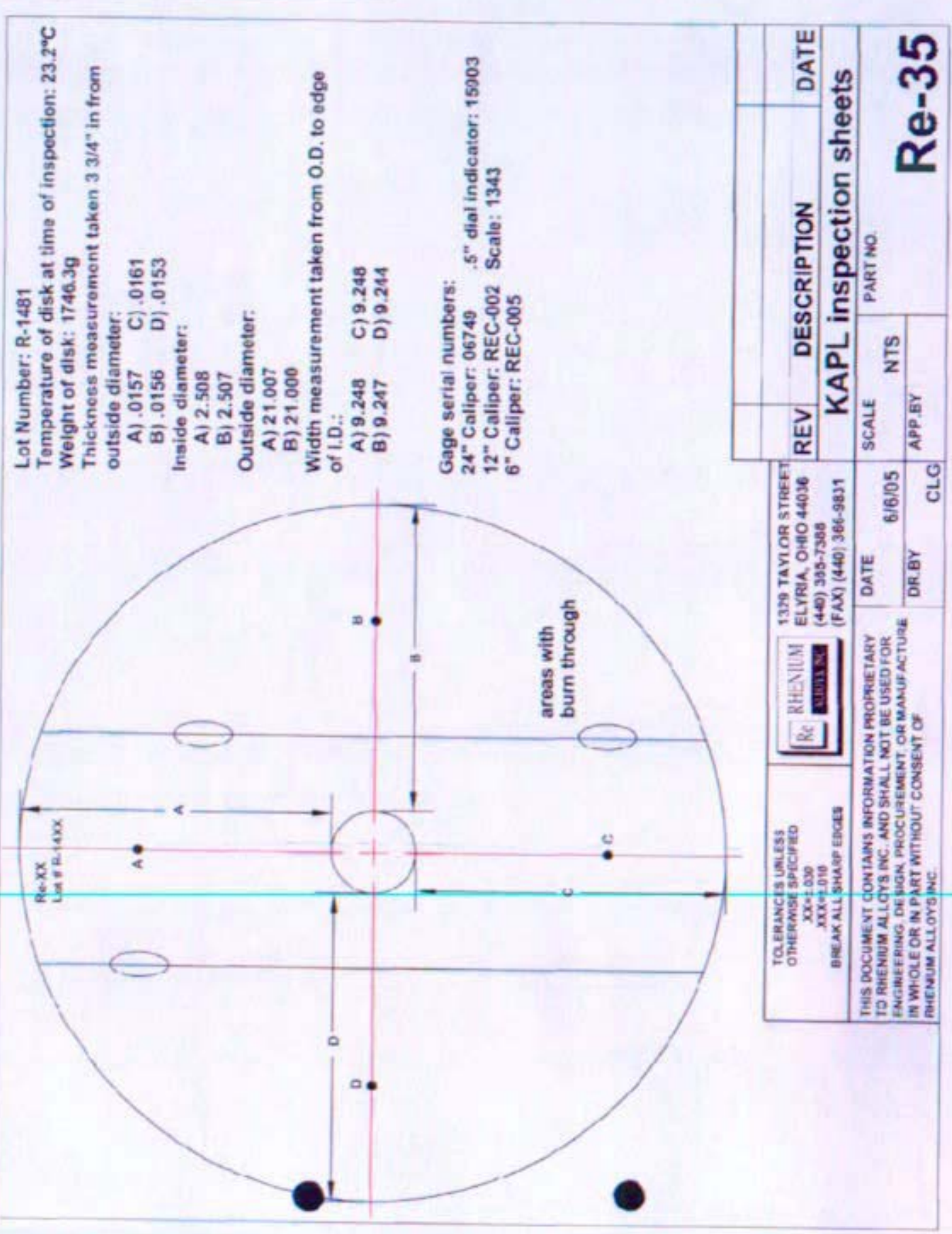



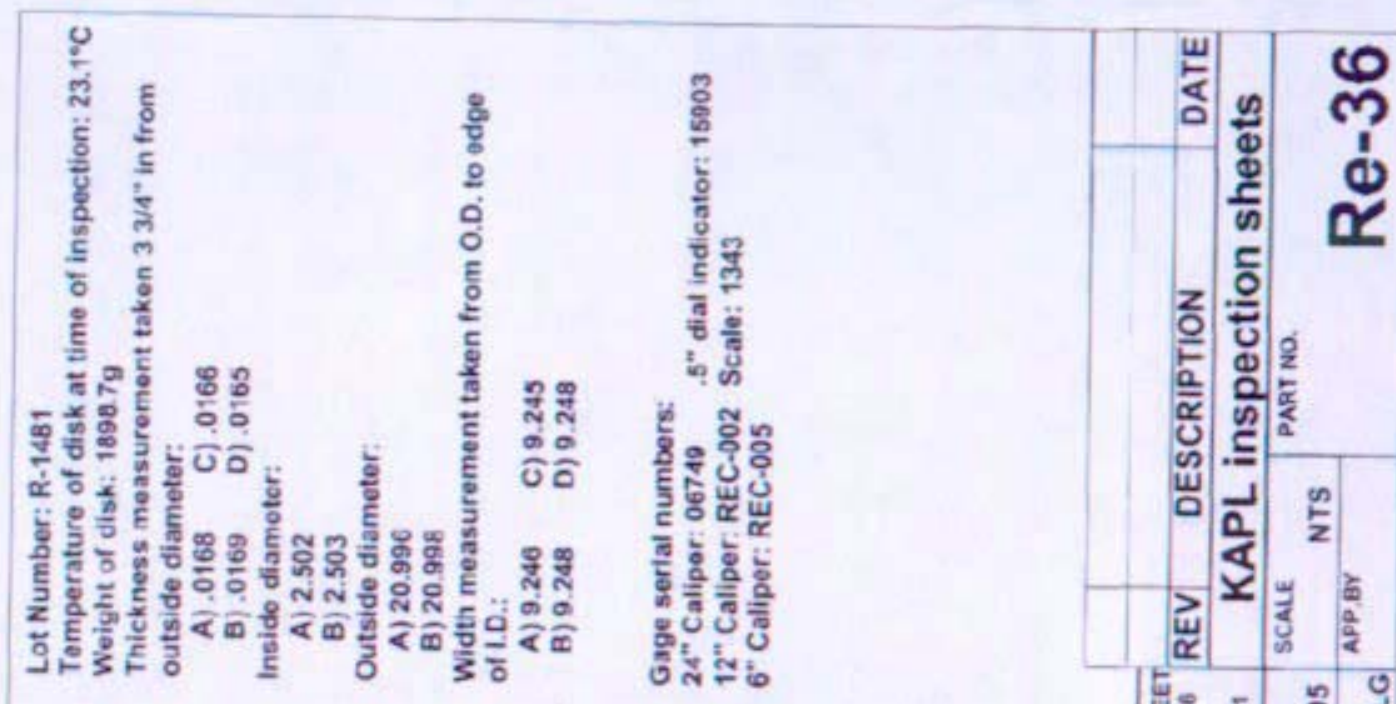

동

동웅하유

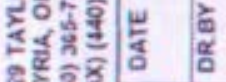

द्विर्वर

즐 질
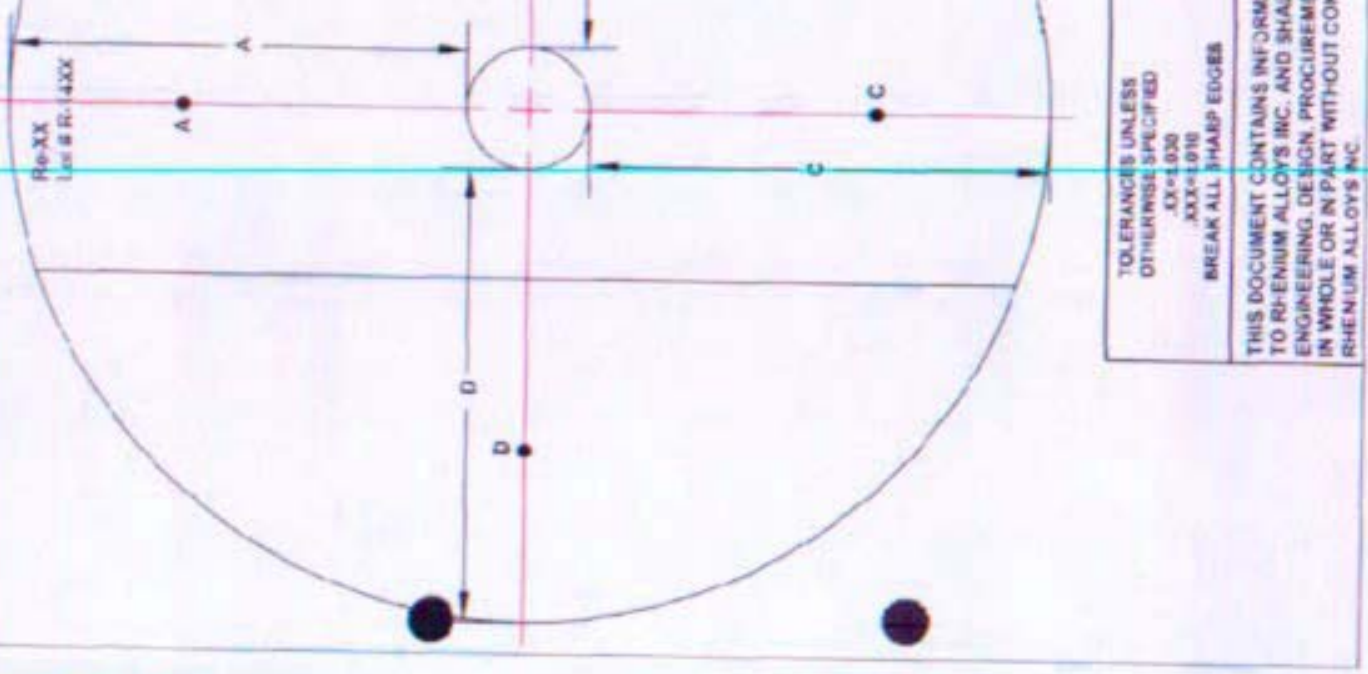


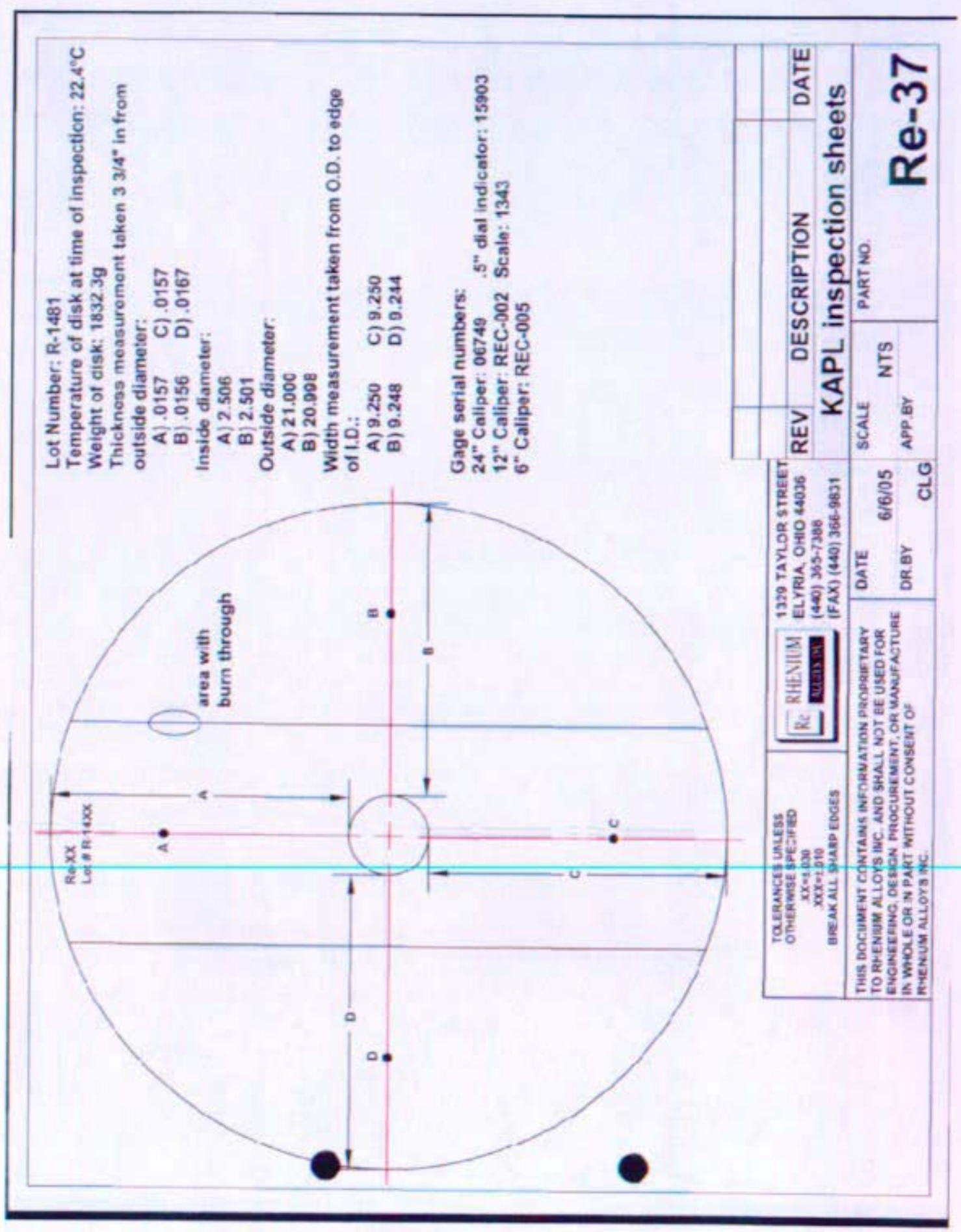




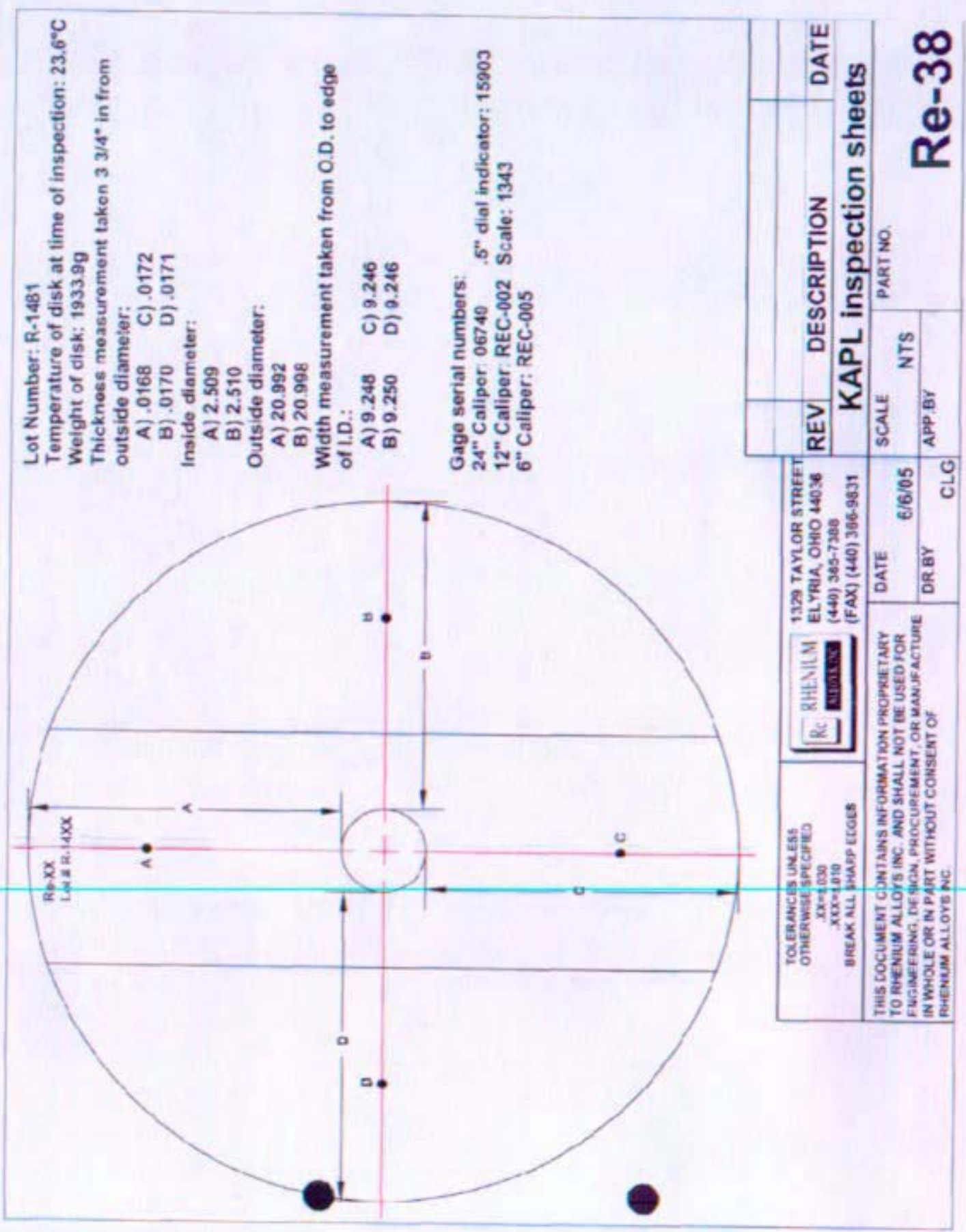




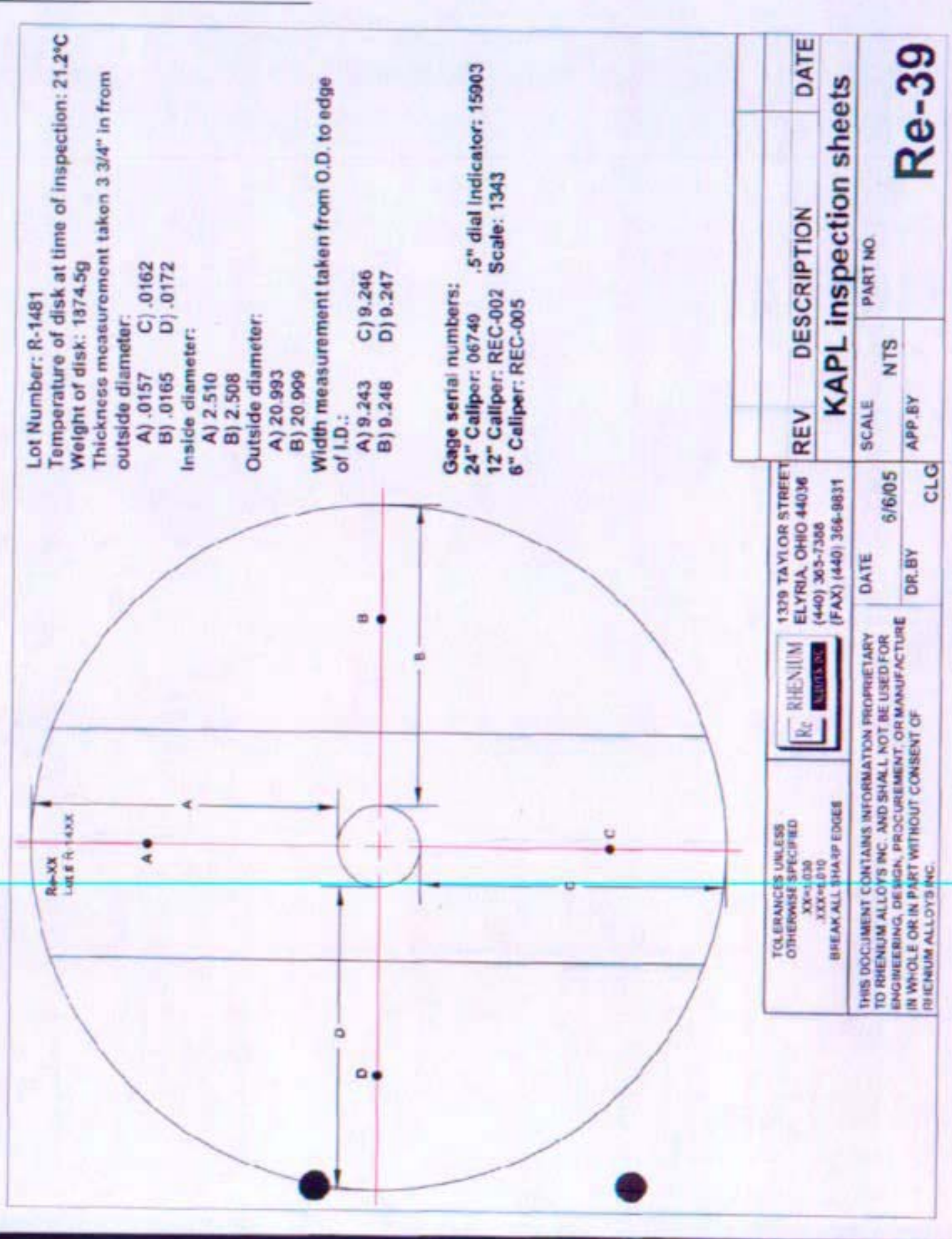




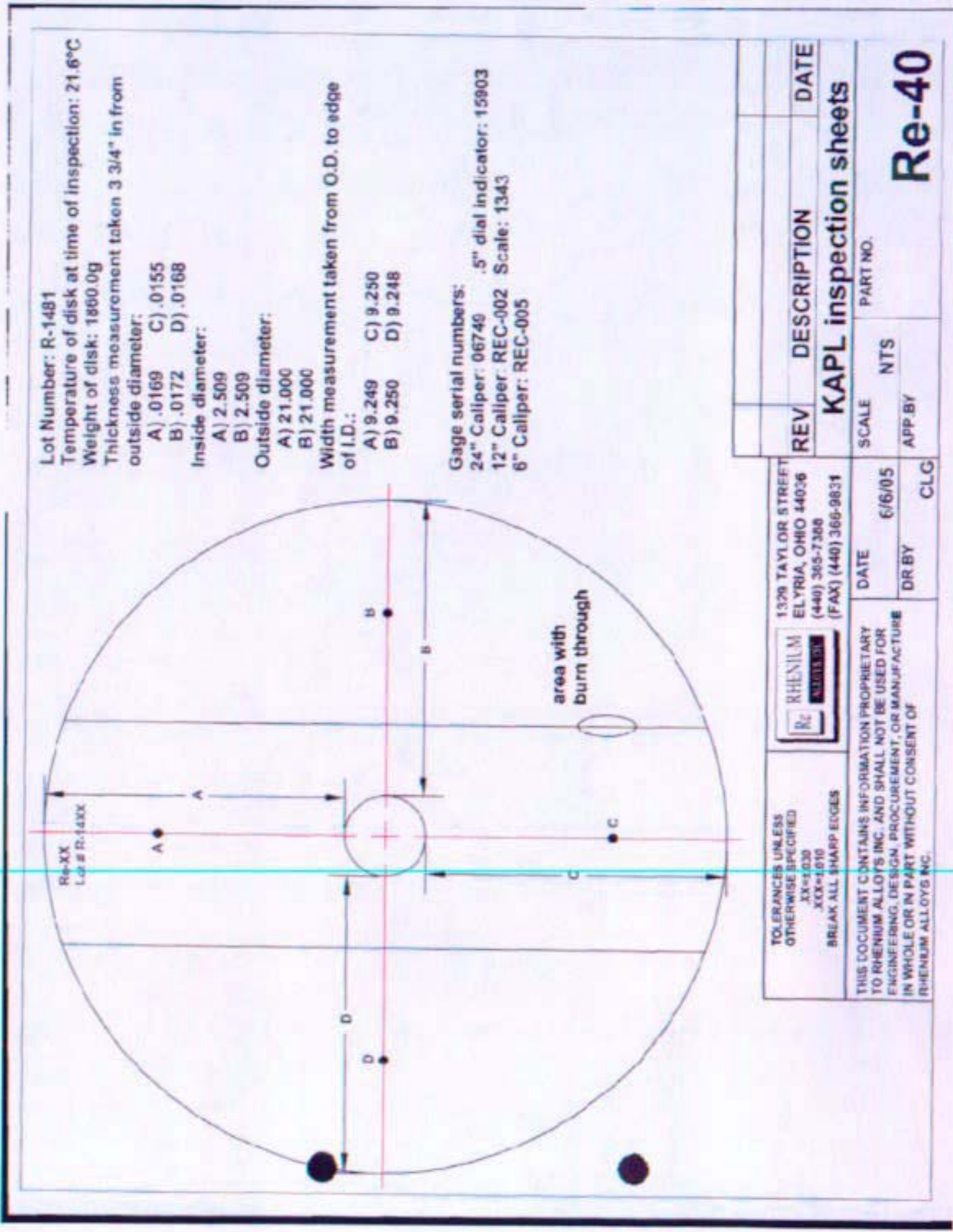


B-TM-1639

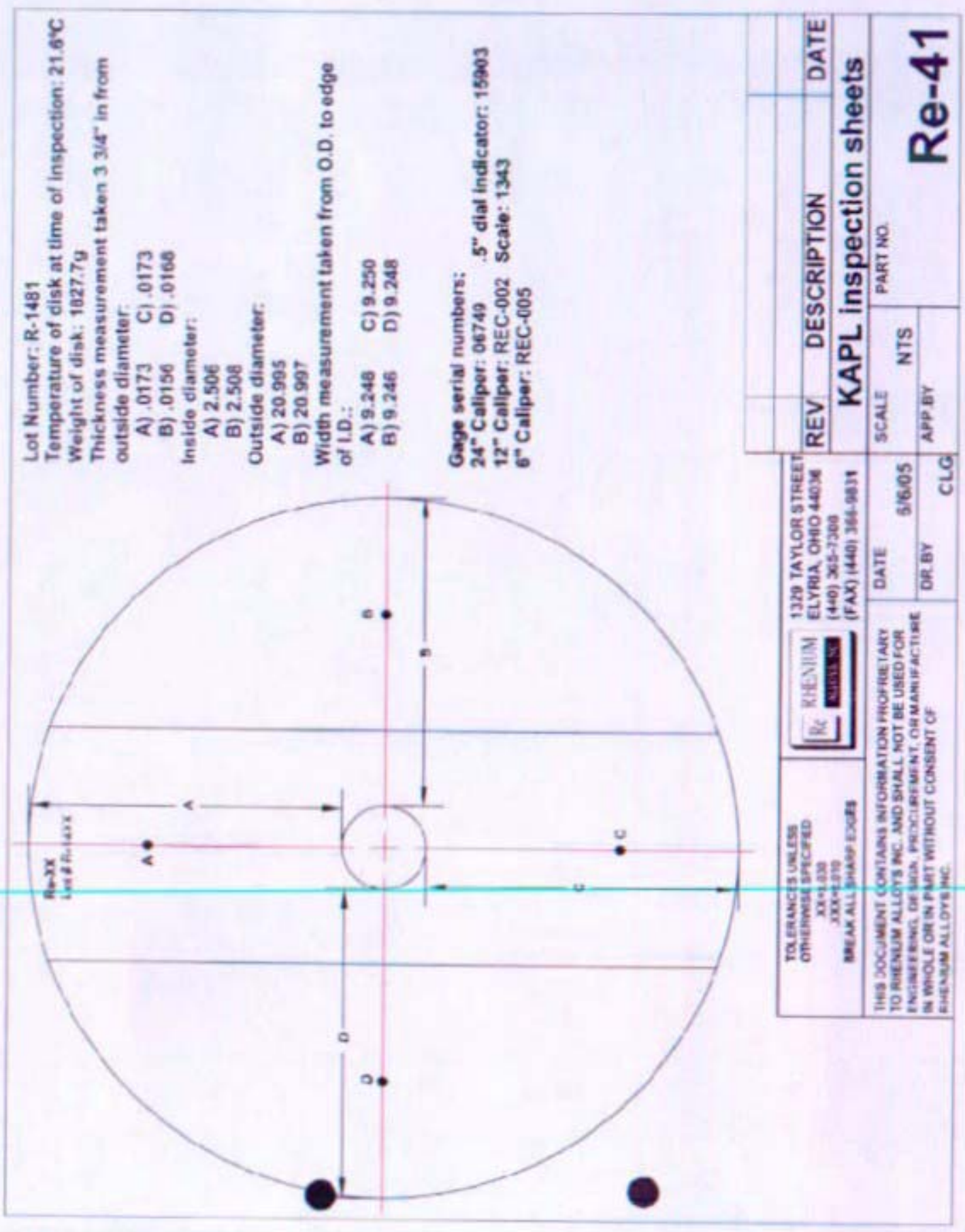




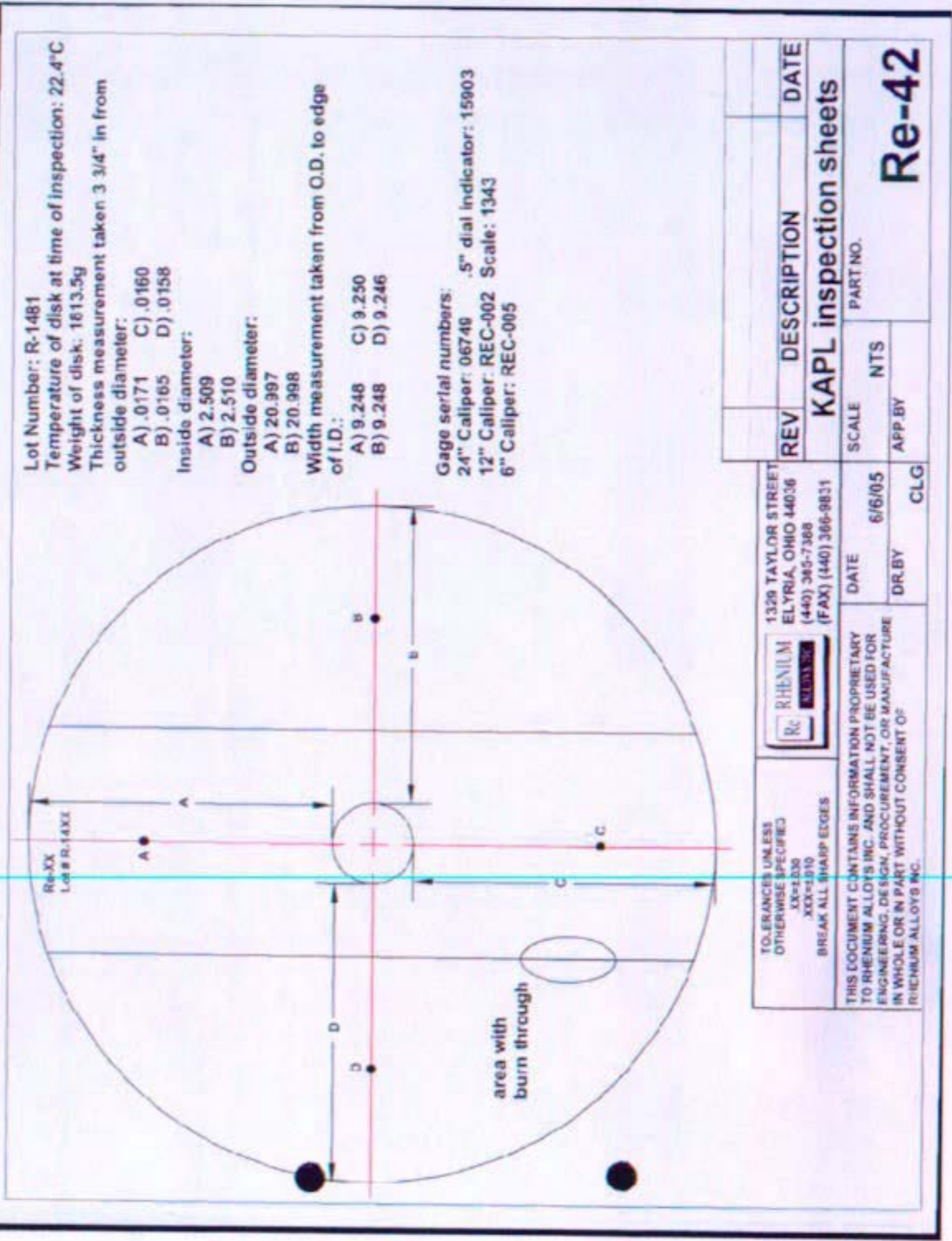




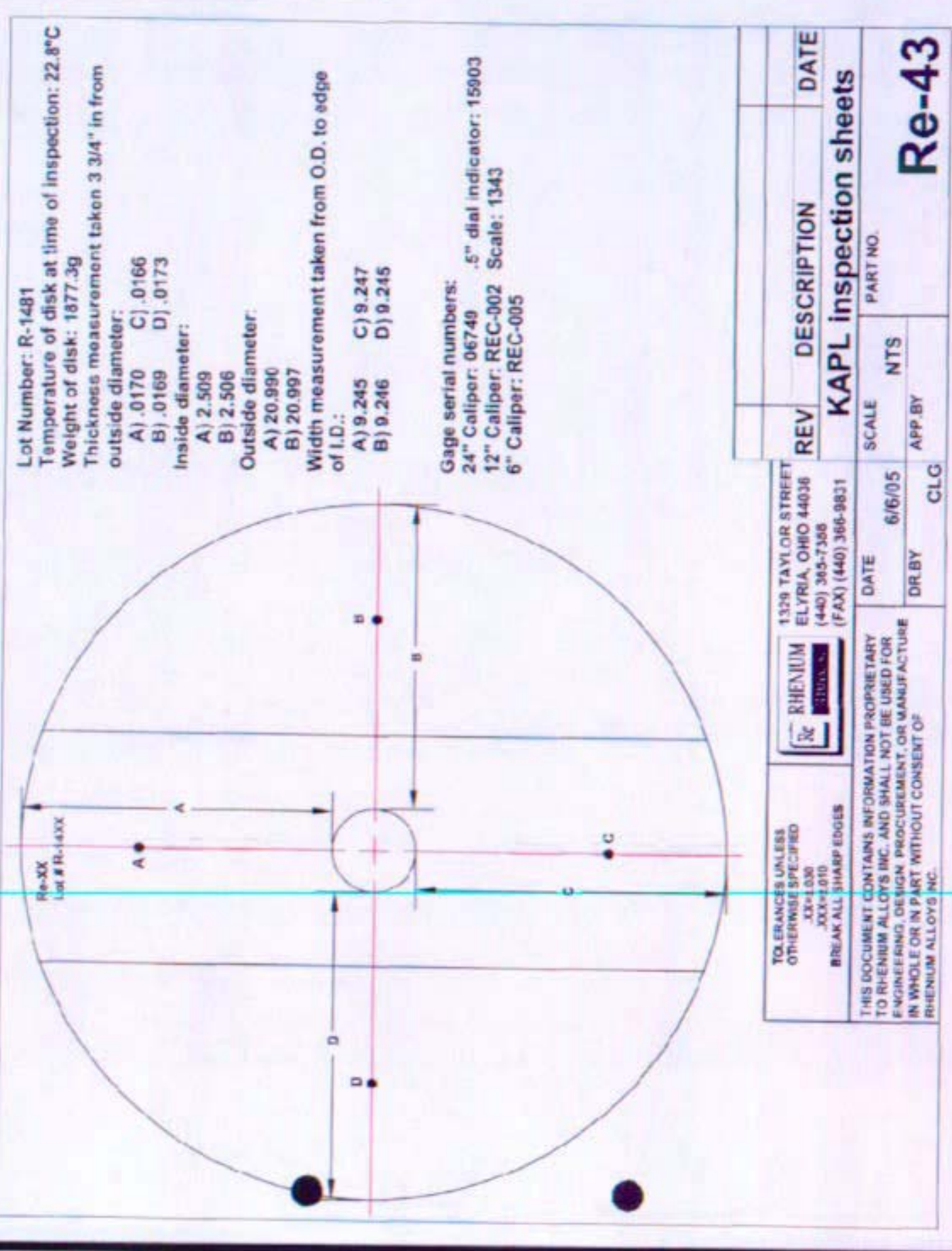




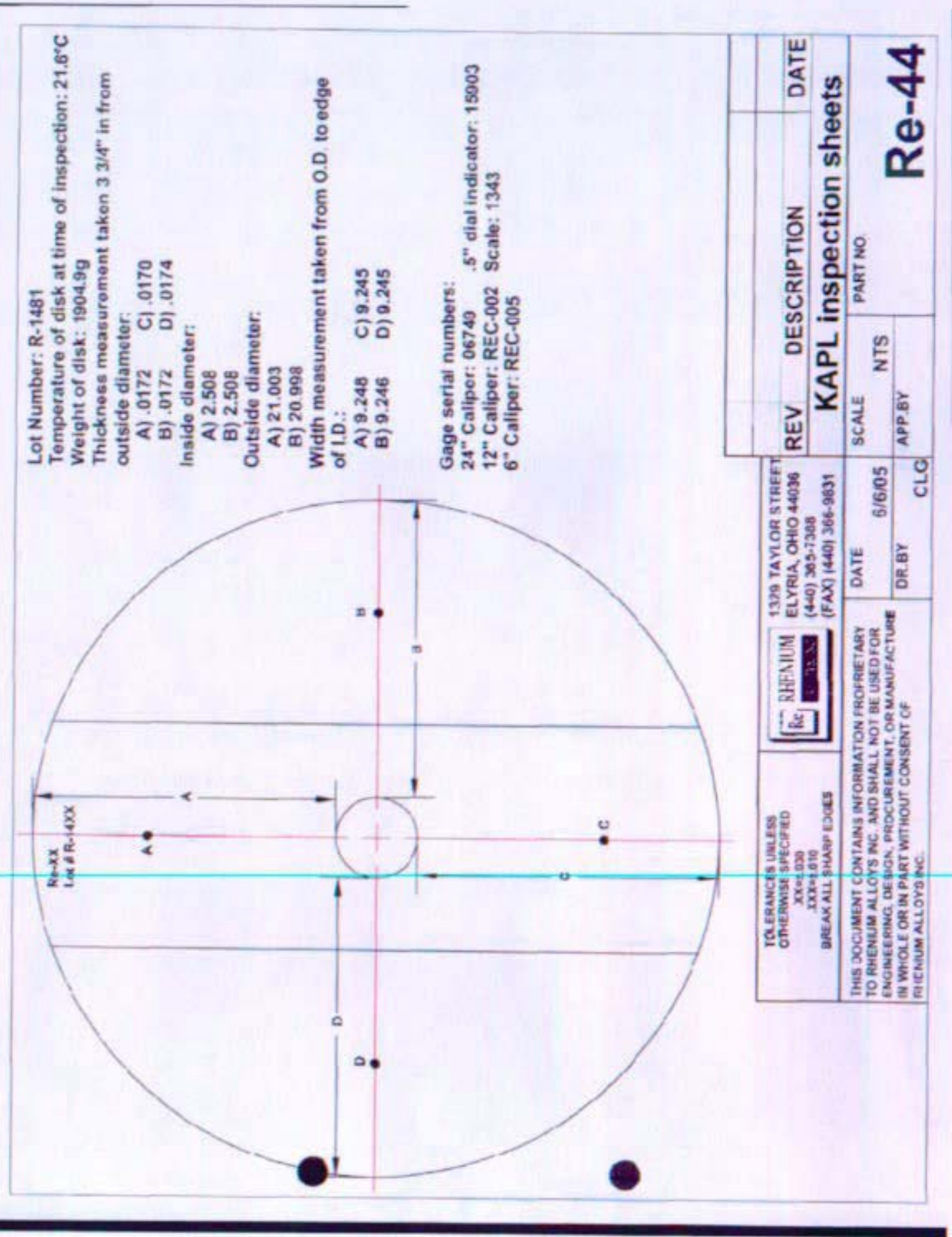



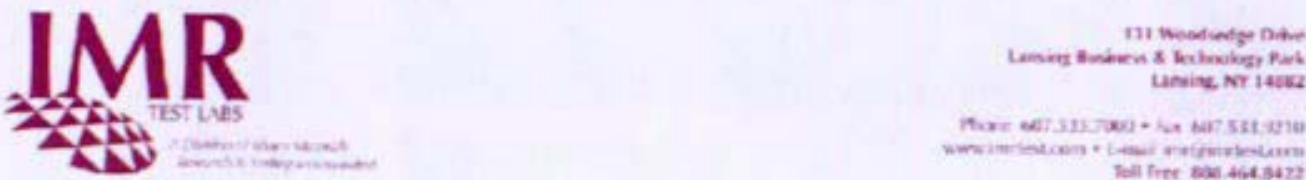

\begin{abstract}
Original Date
May 9, 2005

Revised Date

May 10, 2005
\end{abstract}

Oiff Guthman

Rivenium Allows inc

1329 Tayloe Strret

PO Bow 245

Elyria, OH 44036-0245

USA

FONumiter

12176

Daserewed

May 3,2005

Senple"

R-1478

Marrial

Khenium Strips

\section{CERTIFIED MATERIAL ANALYSIS}

IMR Report Number 200504066-Revision 1 (corrected sample * on chemistry table per customer request)

\section{SUMMARY}

The sample was received for chemical analysis. The GDMS portion of the analysis was outsouroed by IMR to a qualified outside facility (non-A2LA accredited). Per customer request the sample was analyned by combustion for hydrogen, oxygen, nitrogen and carbon. Note that the combustion methods used for hydrogen, oxygen, nitrogen and carbon are the referee methods of analysis.

The results are given on the following page.

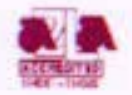

\section{Nadcap}

Reviewed by

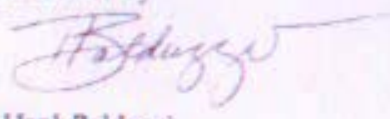

Hank Balduzzi

Chemist
Reviewed by<smiles>CCCCCCCCCCC</smiles>

Peter Damian

Chemistry Dept. Manager

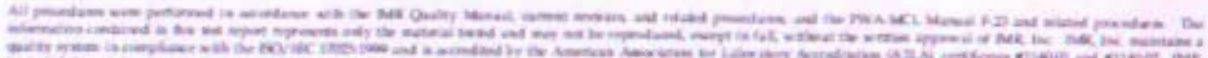

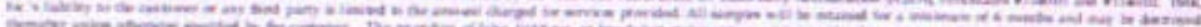

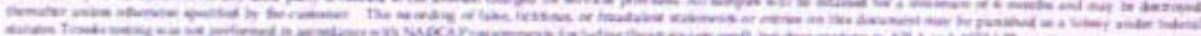

Rimiiam Nhops it

Fune i at 3

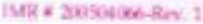


BMR Teat Lat, - In Woodeedge Driwe + Laming NY ake

\section{CHEMISTRY}

\begin{tabular}{|c|c|}
\hline Element & R-1478 \\
\hline $\mathrm{H}^{i}$ & 6.6 \\
\hline $\mathrm{Li}$ & $<0.005$ \\
\hline Be & $<0.005$ \\
\hline$B$ & $<0005$ \\
\hline $\mathrm{C}^{2}$ & 19 \\
\hline $\mathrm{Ni}$ & 1 \\
\hline $\mathrm{O}^{2}$ & 28 \\
\hline F & $<0.05$ \\
\hline $\mathrm{Na}$ & 0.36 \\
\hline $\mathrm{Mg}_{8}$ & 0.03 \\
\hline Al & 12 \\
\hline $\mathrm{Si}$ & 1.7 \\
\hline $\mathrm{P}$ & 0.12 \\
\hline$S^{2}$ & 82 \\
\hline a & 0.13 \\
\hline $\mathrm{K}$ & 0.09 \\
\hline $\mathrm{Ca}$ & 0.44 \\
\hline Sc & $<0.005$ \\
\hline Ti & 0.11 \\
\hline $\mathrm{V}$ & 0.008 \\
\hline $\mathrm{Cr}$ & 23 \\
\hline Mn & 0.14 \\
\hline $\mathrm{Fe}$ & 5,1 \\
\hline Co & 0.01 \\
\hline $\mathrm{Ni}$ & 22 \\
\hline $\mathrm{Cu}$ & 0.07 \\
\hline $\mathrm{Zn}$ & 0.09 \\
\hline Ga & $<0.05$ \\
\hline $\mathrm{Ce}$ & $<0.05$ \\
\hline As & $<0.05$ \\
\hline Se & $<0.05$ \\
\hline $\mathrm{Br}$ & $<0.05$ \\
\hline $\mathrm{Rb}$ & $<0.01$ \\
\hline St & $<0.01$ \\
\hline $\mathbf{Y}$ & $<0.005$ \\
\hline $\mathrm{Zr}$ & 0.11 \\
\hline $\mathrm{Nb}$ & 0.01 \\
\hline Mo & 0,58 \\
\hline $\mathrm{Ru}$ & $<0.01$ \\
\hline Rh & $<0.01$ \\
\hline Pd & $<0.01$ \\
\hline $\mathrm{Ag}$ & $<0.01$ \\
\hline $\mathrm{Cd}$ & $<0.1$ \\
\hline
\end{tabular}




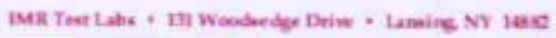

\begin{tabular}{|c|c|}
\hline In & $<0.1$ \\
\hline Sn & 007 \\
\hline $\mathrm{Sb}$ & $<001$ \\
\hline $\mathrm{Te}$ & $<0.01$ \\
\hline 1 & $<0.01$ \\
\hline Cs & $<0.5$ \\
\hline $\mathrm{Ba}$ & $<0.01$ \\
\hline La & $<0.01$ \\
\hline $\mathrm{Ce}$ & $<0.01$ \\
\hline $\mathrm{Pr}$ & $<0,01$ \\
\hline $\mathrm{Nd}$ & $<0.01$ \\
\hline $5 \mathrm{~m}$ & $<0.01$ \\
\hline $\mathrm{Eu}$ & $<0.01$ \\
\hline Gd & $<0.01$ \\
\hline Tb & $<0.01$ \\
\hline Dy & $<0.01$ \\
\hline Ho & $<0.01$ \\
\hline $\mathrm{Er}$ & $<0.01$ \\
\hline $\mathrm{Tm}$ & $<0.01$ \\
\hline $\mathrm{Yb}$ & $<001$ \\
\hline $\mathrm{Lu}$ & $<0.01$ \\
\hline $\mathrm{Hf}$ & $<0.01$ \\
\hline $\mathrm{Ta}$ & $<5$ \\
\hline$W$ & $<0.2$ \\
\hline Re & Matrix \\
\hline Os & $<0.01$ \\
\hline Ir & $<0.01$ \\
\hline $\mathrm{Pl}$ & $<0.05$ \\
\hline $\mathrm{Au}$ & $<0.5$ \\
\hline $\mathrm{Hg}_{\mathrm{g}}$ & $<0.05$ \\
\hline$\pi$ & $<0.01$ \\
\hline $\mathrm{Pb}$ & $<0.01$ \\
\hline $\mathrm{Bi}$ & $<0.01$ \\
\hline $\mathrm{Th}$ & $<0001$ \\
\hline $\mathrm{U}$ & $<0001$ \\
\hline
\end{tabular}

IDetermined by inert gas fusion-thermal conductivity.

2Determined by combustion-infrared absorbance.

Unless othenvise indicated, elements were analyzed by CDMS.

Results in ppm (ppm = parts per million $=\mathrm{mg} / \mathrm{Kg}) ; 0.1000 \mathrm{x}$ by $w \mathrm{t}=1000 \mathrm{ppm}$ unless otherwise indicated.

Methods: ASTM E 1019-03, CAP-032.A (Hydrogen), and GDMS 


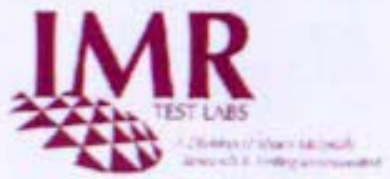

May 10, 2005

Ciff Guthman

Rherium Alloys inc

1329 Taylor Street

PO Blox 245

Flyria, OH 40\%-1045

USA

rONunter

12175

Dase Recuived

May 3,2005

Sencted

R-1461

Matral

Wherium Rectangle

\section{CERTIFIED MATERIAL ANALYSIS}

IMR Report Number 200504068

\section{SUMMARY}

The sample was received for chemical analysis. The GDMS portion of the analysis was outsourced by IMR to a qualified outside facility (non-A2LA accredited). Per customer request the sample was analyzed by combustion for hydrogen, oxygen, nitrogen and carbon. Note that the combustion methods used for hydrogen, oxygen, nitrogen and carbon are the referee methods of analysis.

The results are given on the following page.
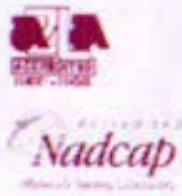

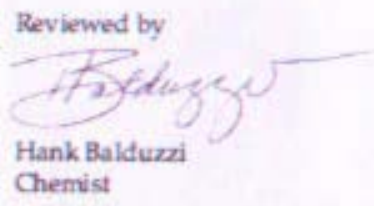

Chemist
Reviewed by

Ter

Peter Damian

Chemistry Dept. Manager

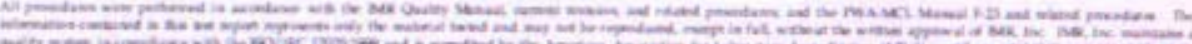
Ix.

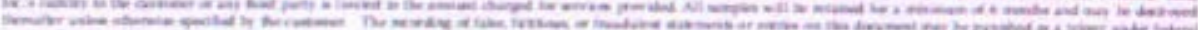

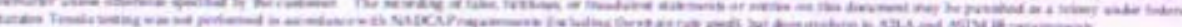




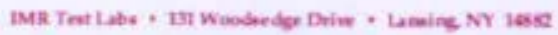

\section{CHEMISTRY}

\begin{tabular}{|c|c|}
\hline Element & $R-1481$ \\
\hline $\mathrm{H}^{\mathrm{i}}$ & 8.3 \\
\hline $\mathrm{Li}$ & $<0.005$ \\
\hline Be & $<0,005$ \\
\hline B & $<0,005$ \\
\hline $\mathrm{C}^{2}$ & 6 \\
\hline $\mathbf{N}^{1}$ & 2 \\
\hline $\mathrm{O}^{2}$ & 41 \\
\hline $\mathrm{F}$ & $<0.05$ \\
\hline $\mathrm{Na}$ & 0.24 \\
\hline $\mathrm{Mg}_{\mathrm{g}}$ & $<0.01$ \\
\hline Al & 1.1 \\
\hline Sì & 27 \\
\hline $\mathrm{P}$ & 0.21 \\
\hline 5 & 0.14 \\
\hline $\mathrm{a}$ & 0.22 \\
\hline K & 0.09 \\
\hline $\mathrm{Ca}$ & 0.09 \\
\hline $5 c$ & $<0.005$ \\
\hline$\pi$ & 0.08 \\
\hline $\bar{v}$ & 0.01 \\
\hline $\mathrm{Cr}$ & 4.4 \\
\hline Mn & 0.34 \\
\hline $\mathrm{Fe}$ & 11 \\
\hline Co & 0.04 \\
\hline $\mathrm{Ni}$ & 35 \\
\hline $\mathrm{Cu}$ & 0.12 \\
\hline $\mathrm{Zn}$ & $<0.05$ \\
\hline Ga & $<0.05$ \\
\hline Ge & $<005$ \\
\hline As & $<0.05$ \\
\hline $\mathrm{Se}$ & $<0.05$ \\
\hline $\mathrm{Br}$ & $<0.05$ \\
\hline $\mathrm{Rb}$ & $<0.01$ \\
\hline Sr & $<0.01$ \\
\hline $\mathbf{Y}$ & $<0.005$ \\
\hline $\mathrm{Zr}$ & 0.05 \\
\hline $\mathrm{Nb}$ & 0.01 \\
\hline Mo & 0.65 \\
\hline $\mathrm{Ru}$ & $<0.01$ \\
\hline $\mathrm{Rh}$ & $<001$ \\
\hline Pd & $<0.01$ \\
\hline Ag & $<0.01$ \\
\hline $\mathrm{Cd}$ & $<0.1$ \\
\hline
\end{tabular}


BMT Teit Labs + 13 Wooderder Drive + Luteing NY lase

\begin{tabular}{|c|c|}
\hline In & $<0.1$ \\
\hline $5 n$ & $<0.01$ \\
\hline $\mathrm{Sb}$ & $<0.01$ \\
\hline Te & $<0.01$ \\
\hline I & $<0.01$ \\
\hline $\mathrm{C}_{5}$ & $<0.5$ \\
\hline $\mathrm{Ba}$ & 0.02 \\
\hline La & $<0.01$ \\
\hline $\mathrm{Ce}$ & $<0.01$ \\
\hline $\mathrm{Pr}$ & $<0.01$ \\
\hline Nd & $<0.01$ \\
\hline $\mathrm{Sm}$ & $<0.01$ \\
\hline Eu & $<0.01$ \\
\hline Gd & $<0.01$ \\
\hline $\mathrm{Tb}$ & $<0.01$ \\
\hline Dy & $<0.01$ \\
\hline Ho & $<0.01$ \\
\hline Er & $<0.01$ \\
\hline $\mathrm{Tm}$ & $<0.01$ \\
\hline $\mathrm{Yb}$ & $<0.01$ \\
\hline $\mathrm{Lu}$ & $<0.01$ \\
\hline $\mathrm{Hf}$ & $<0.01$ \\
\hline $\mathrm{Ta}$ & $<5$ \\
\hline$W$ & $<0.2$ \\
\hline Re & Matrix \\
\hline Os & $<0.01$ \\
\hline Ir & $<0.01$ \\
\hline $\mathrm{Pt}$ & $<0.05$ \\
\hline $\mathrm{Au}$ & $<0.5$ \\
\hline $\mathrm{Hg}_{\mathrm{g}}$ & $<0.05$ \\
\hline$\pi$ & $<0.01$ \\
\hline $\mathrm{Pb}$ & 0.01 \\
\hline $\mathrm{Bi}$ & $<0.01$ \\
\hline Th & $<0001$ \\
\hline U & $<0.001$ \\
\hline
\end{tabular}

IDetermined by inert gas fusion-thermal conductivity.

IDetermined by combustion-infrared absorbance.

Unless otherwise indicated, elements were analyzed by GDMS.

Results in ppm (ppm = parts per million $=\mathrm{mg} / \mathrm{Kg}) ; 0.1000 \mathrm{k}$ by $w t=1000 \mathrm{ppm}$ unless otherwise indicated.

Methods: ASTM E 1019-03, CAP-a32A (Hydrogen), and CDMS 
B-TM-1639

\section{Appendix $\mathrm{H}$}

\section{Ta-2.5W Plate Dimension and Chemistry Reports}


B-TM-1639

(Intentionally Blank)

$\mathrm{H}-2$ 
B-TM-1639

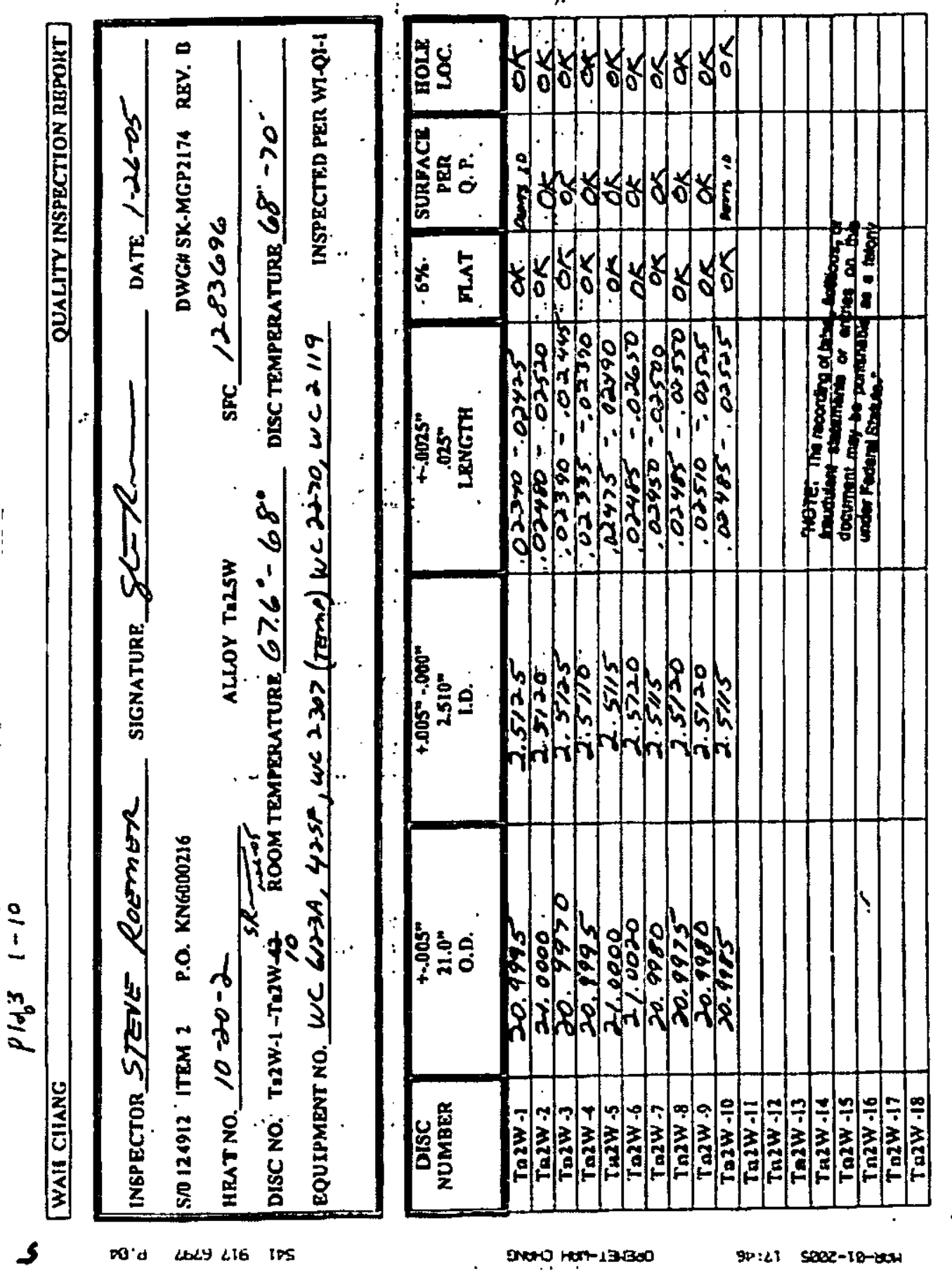



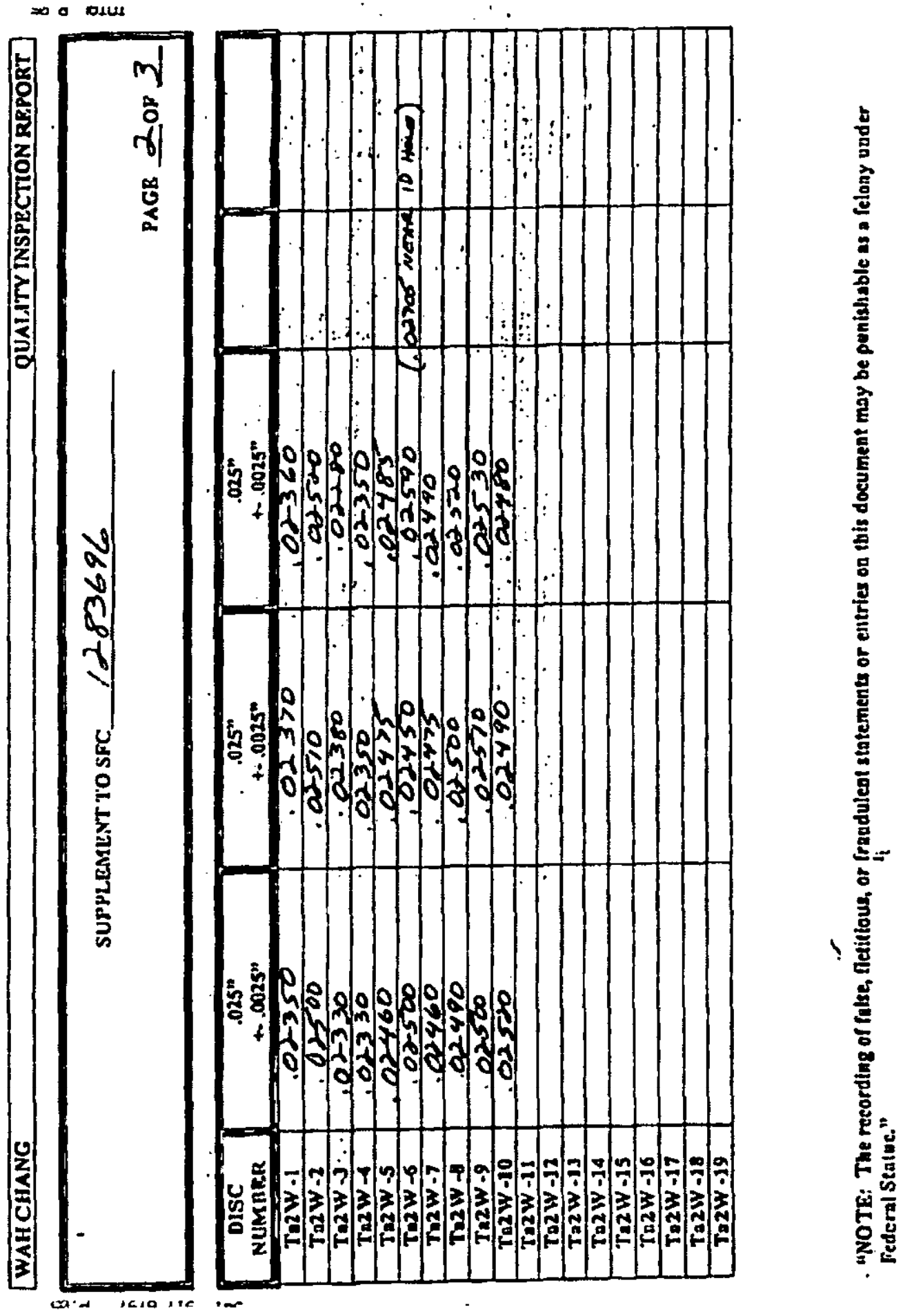


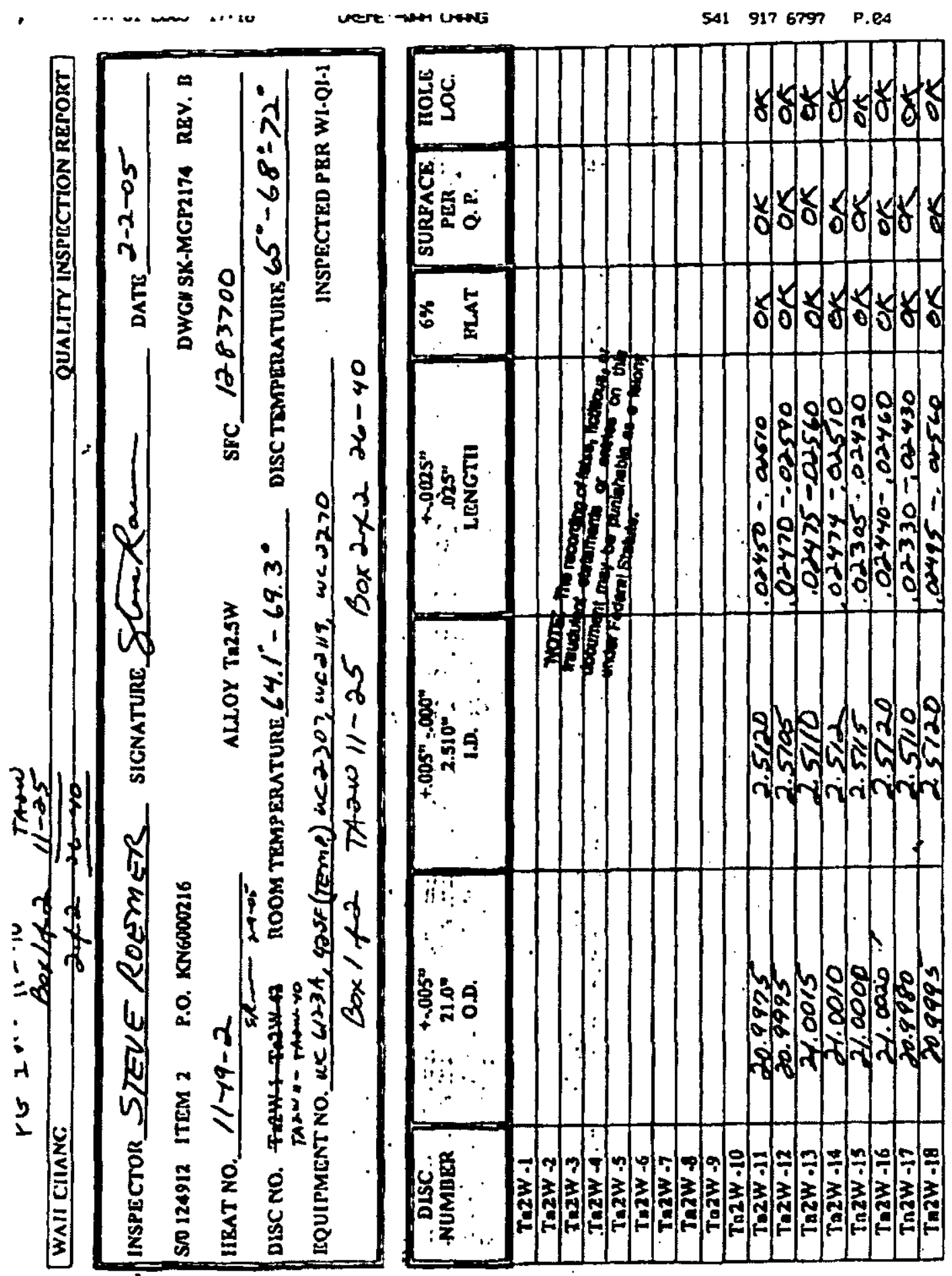




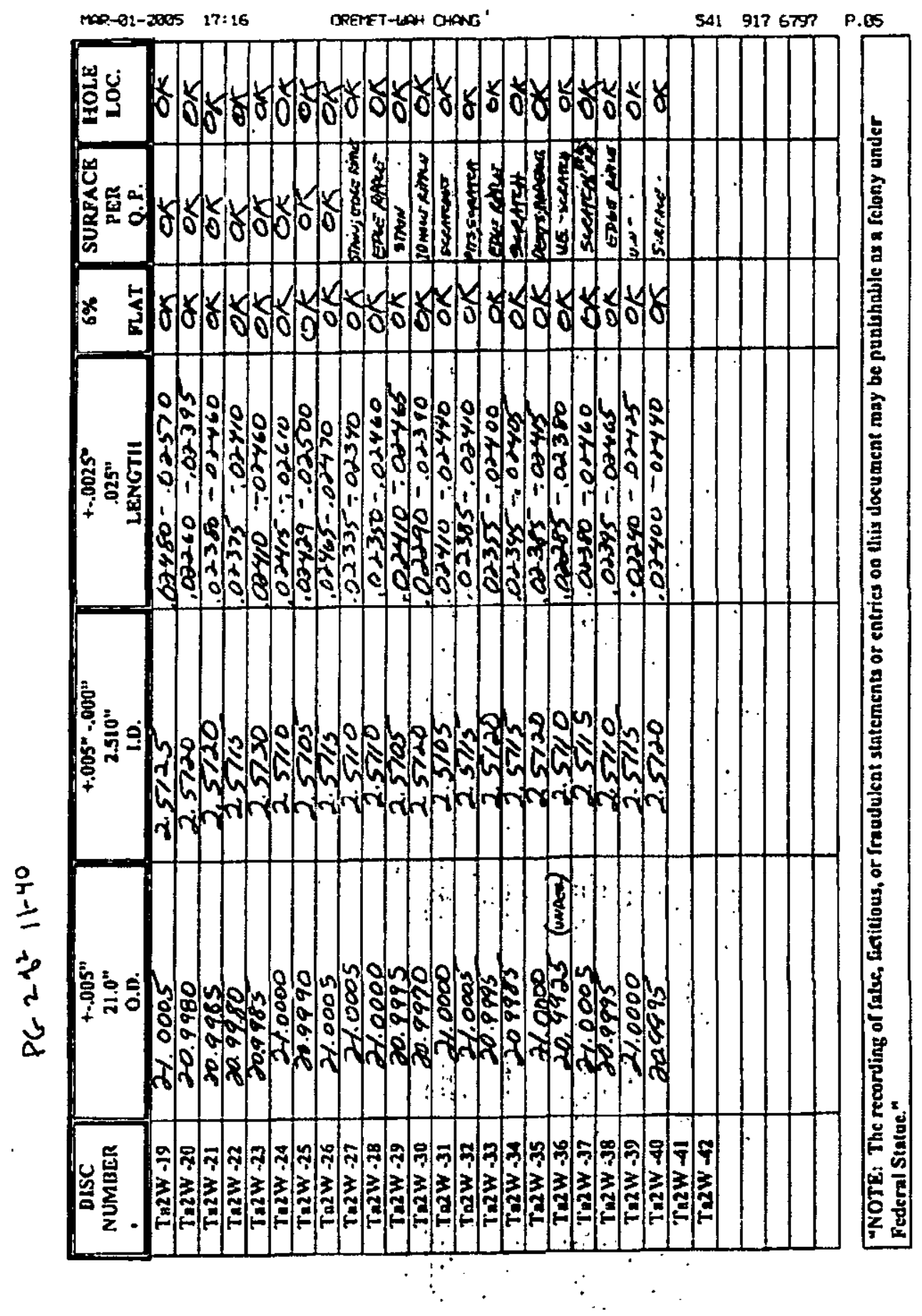




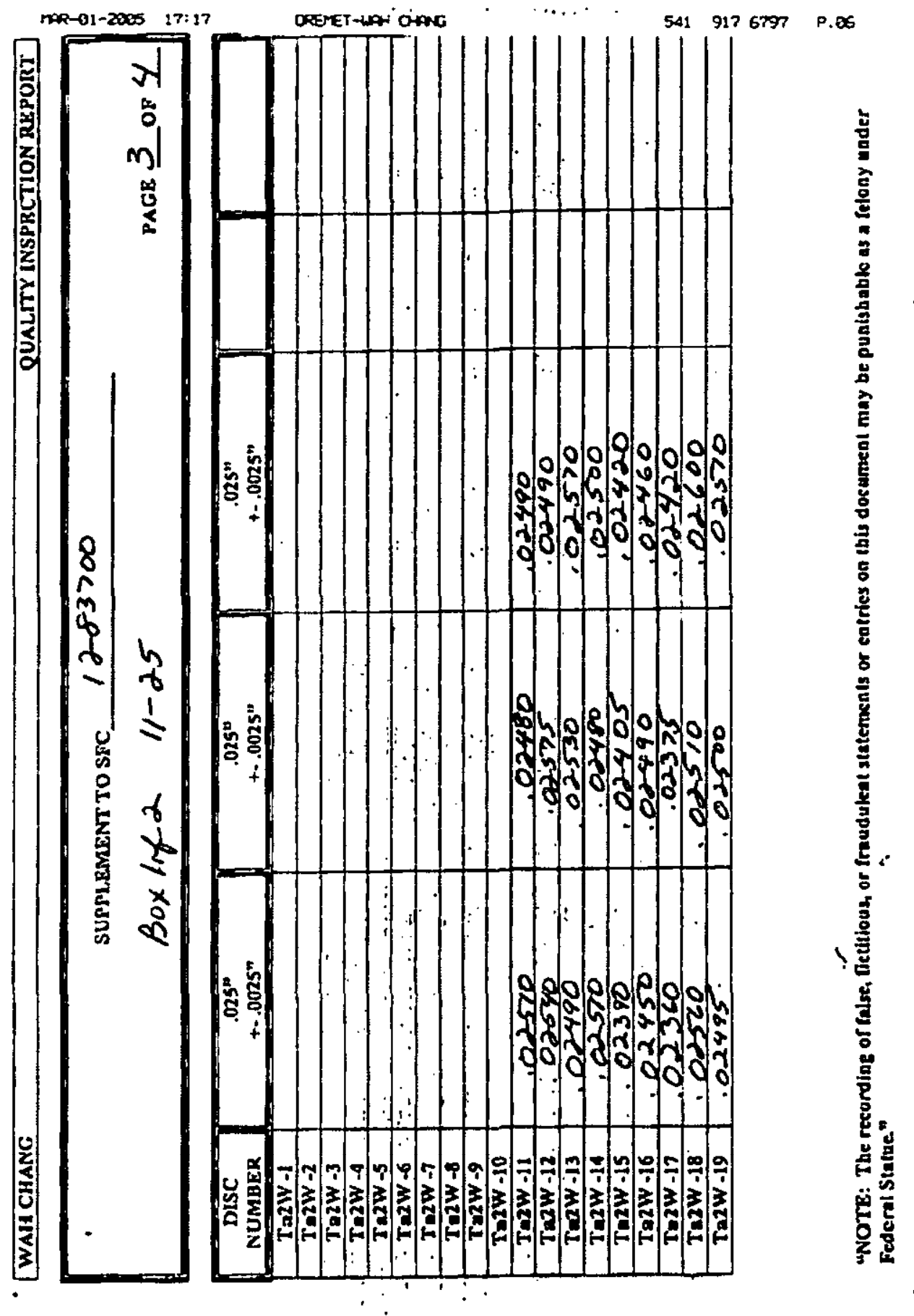




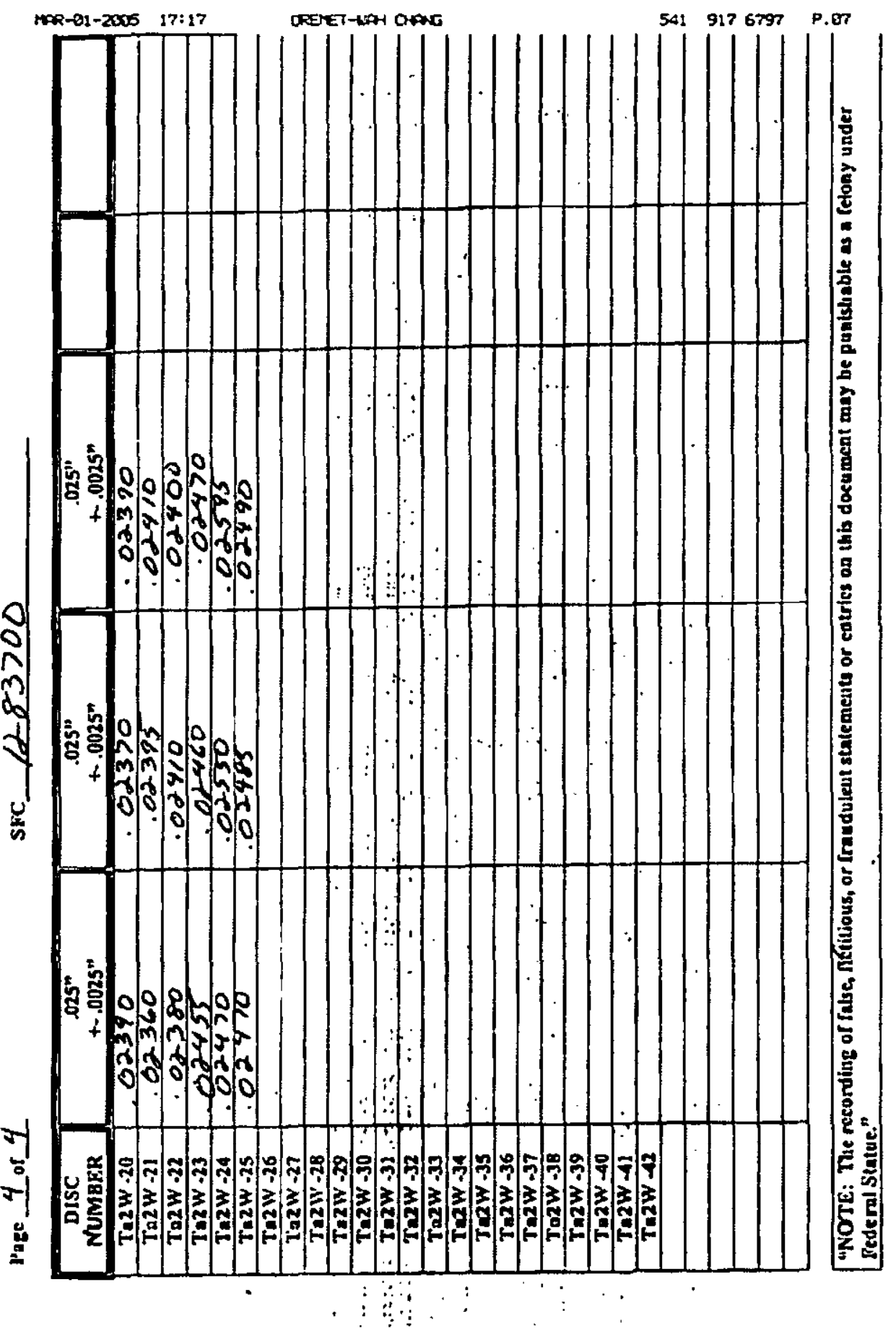


B-TM-1639

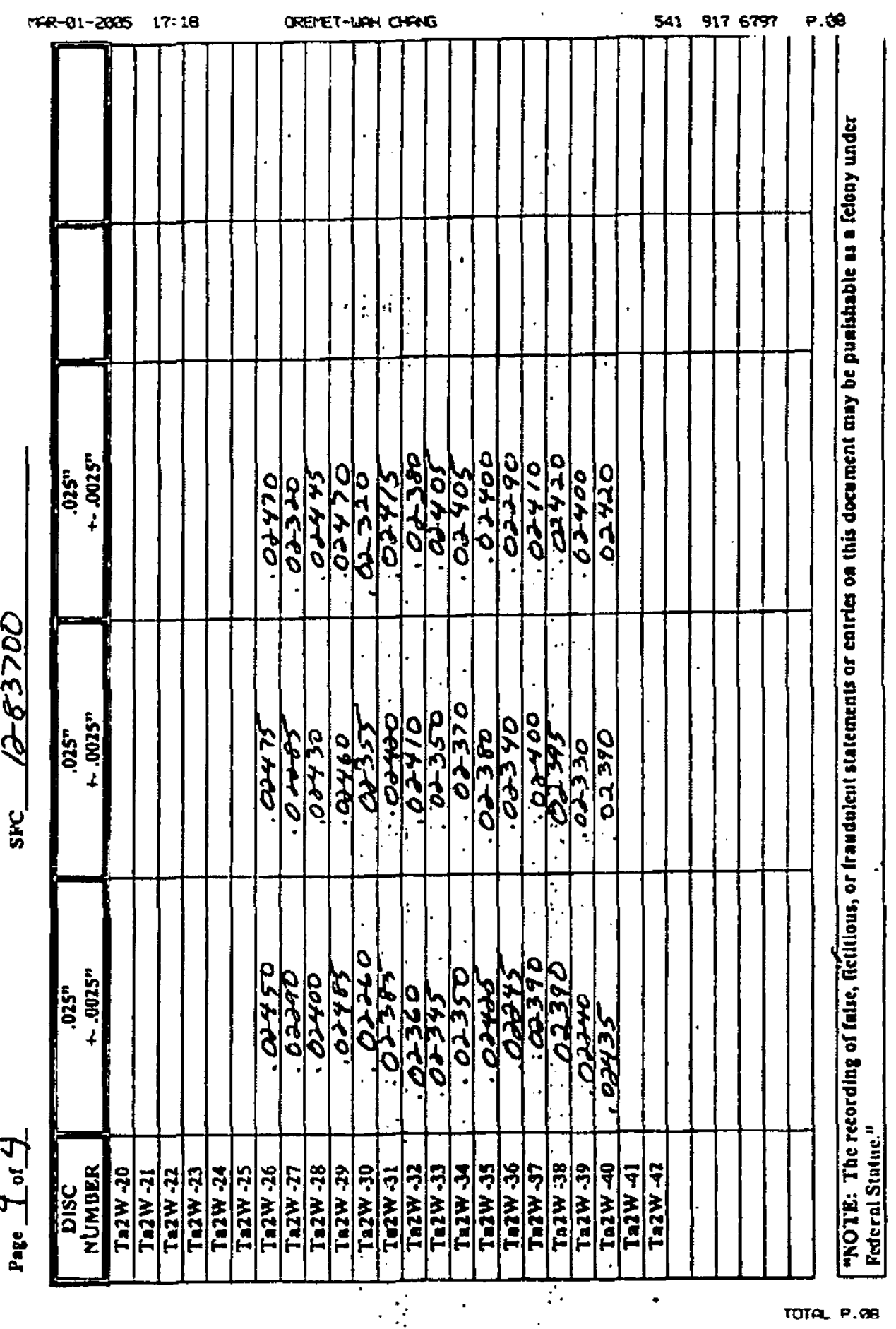


B-TM-1639

(Intentionally Blank)

$\mathrm{H}-10$ 
B-TM-1639

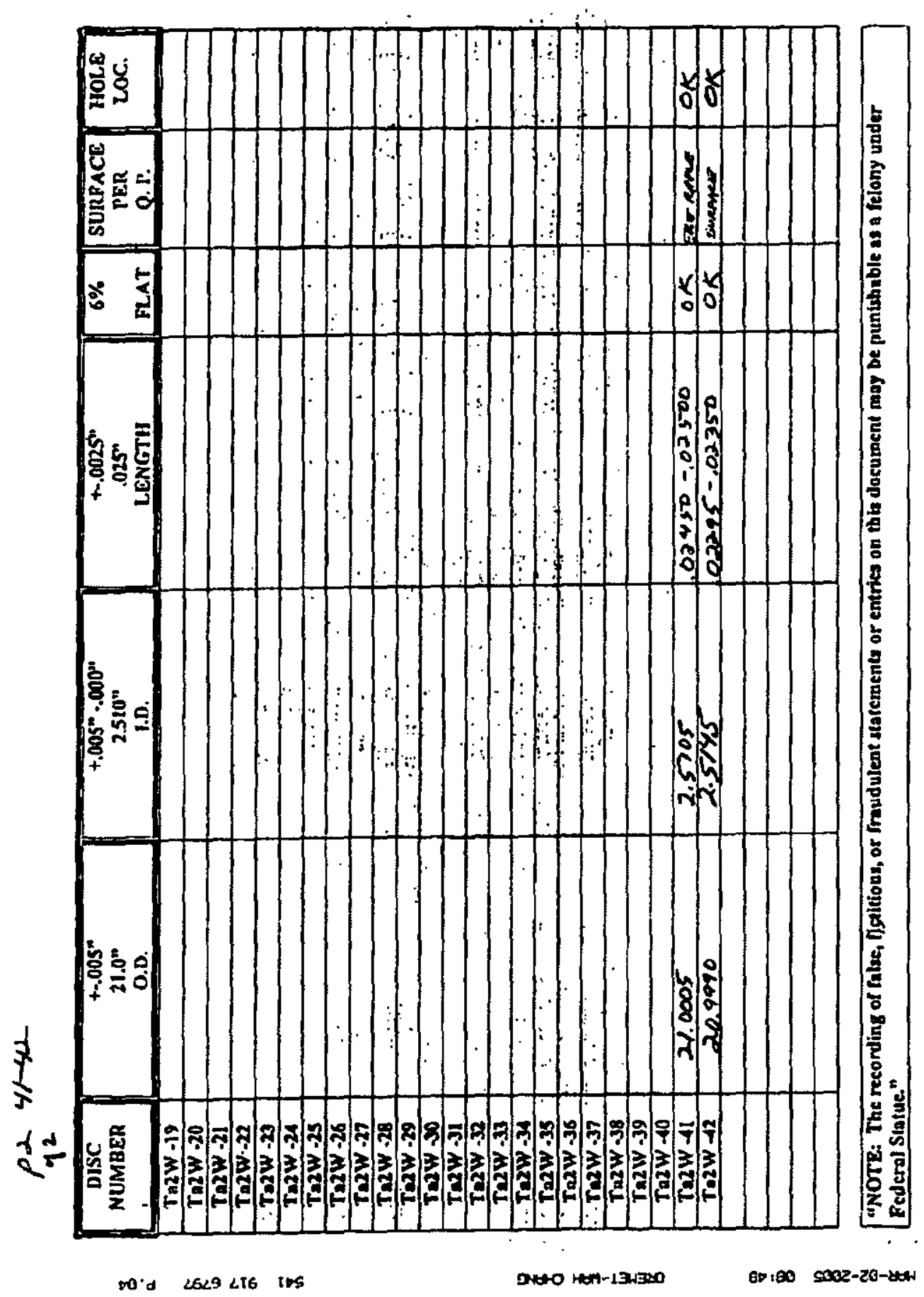


B-TM-1639

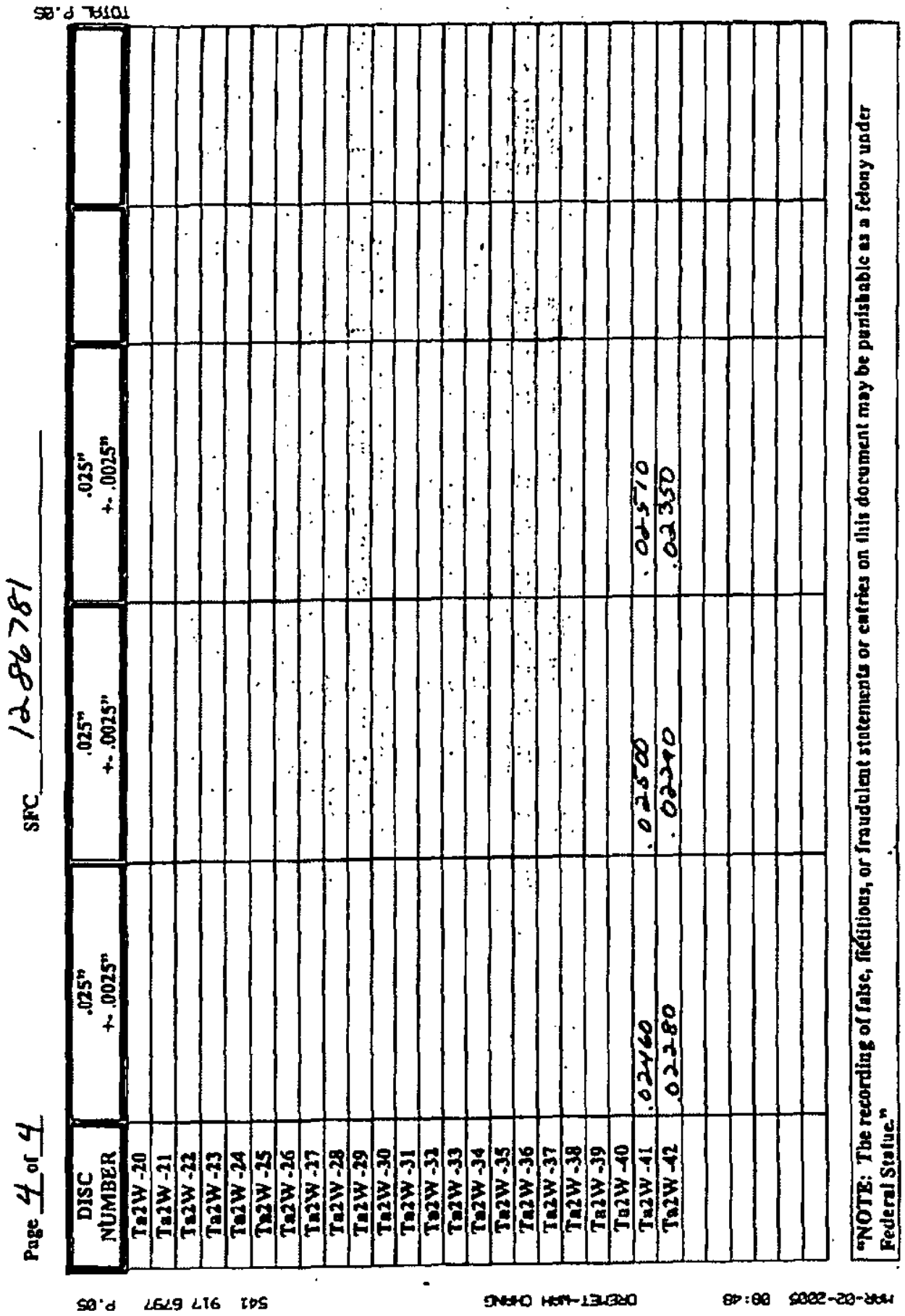


B-TM-1639

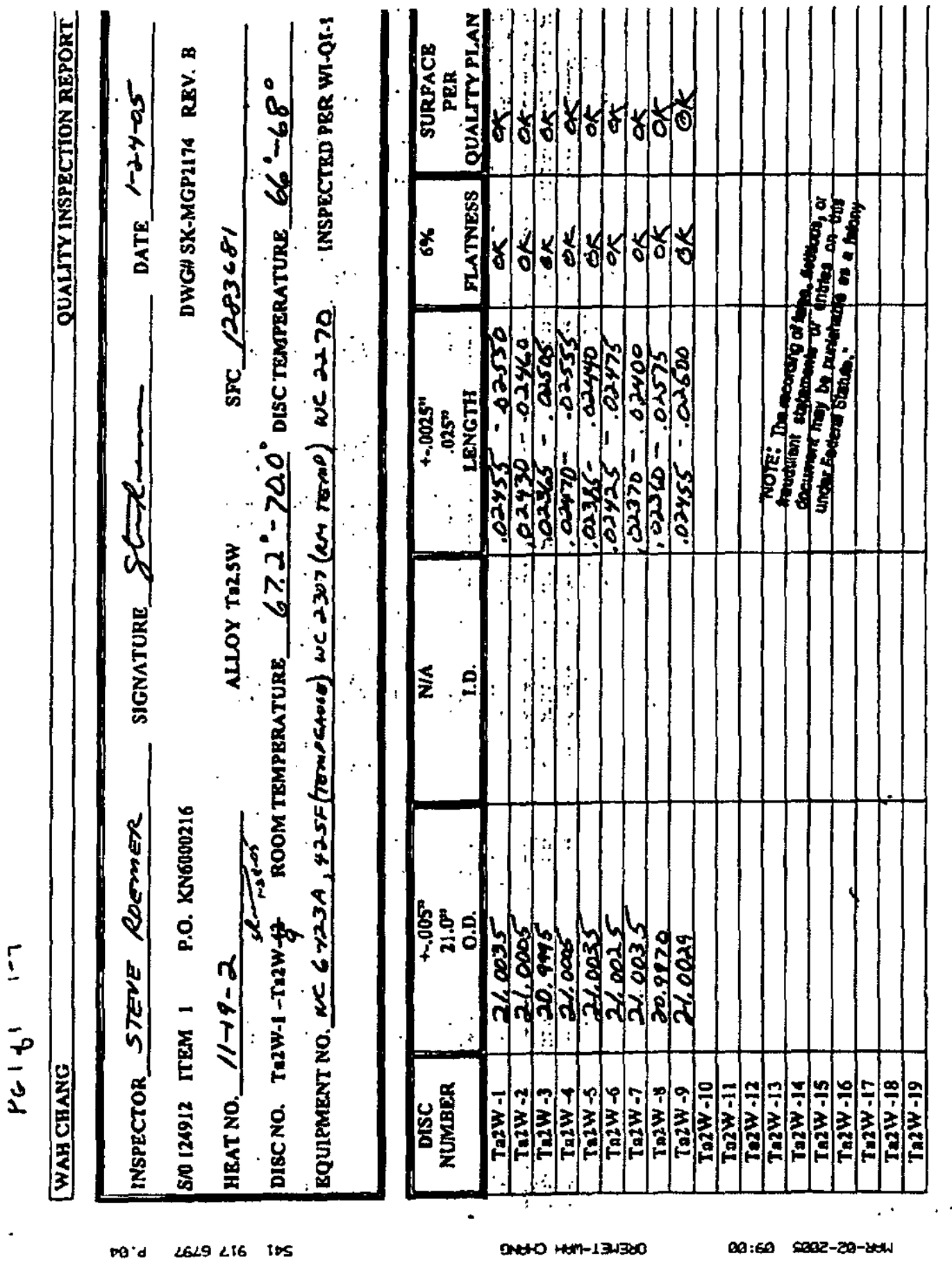


B-TM-1639

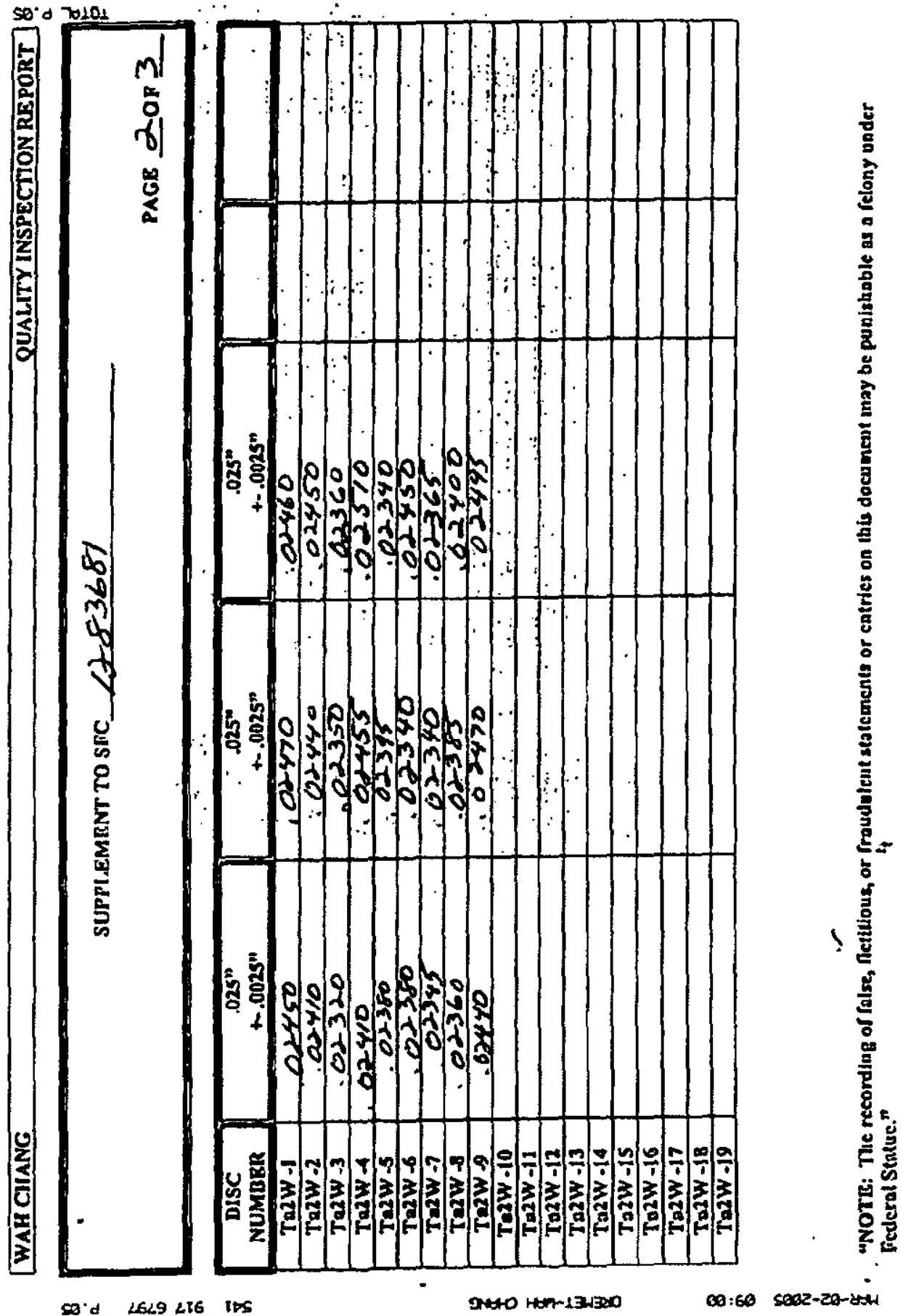




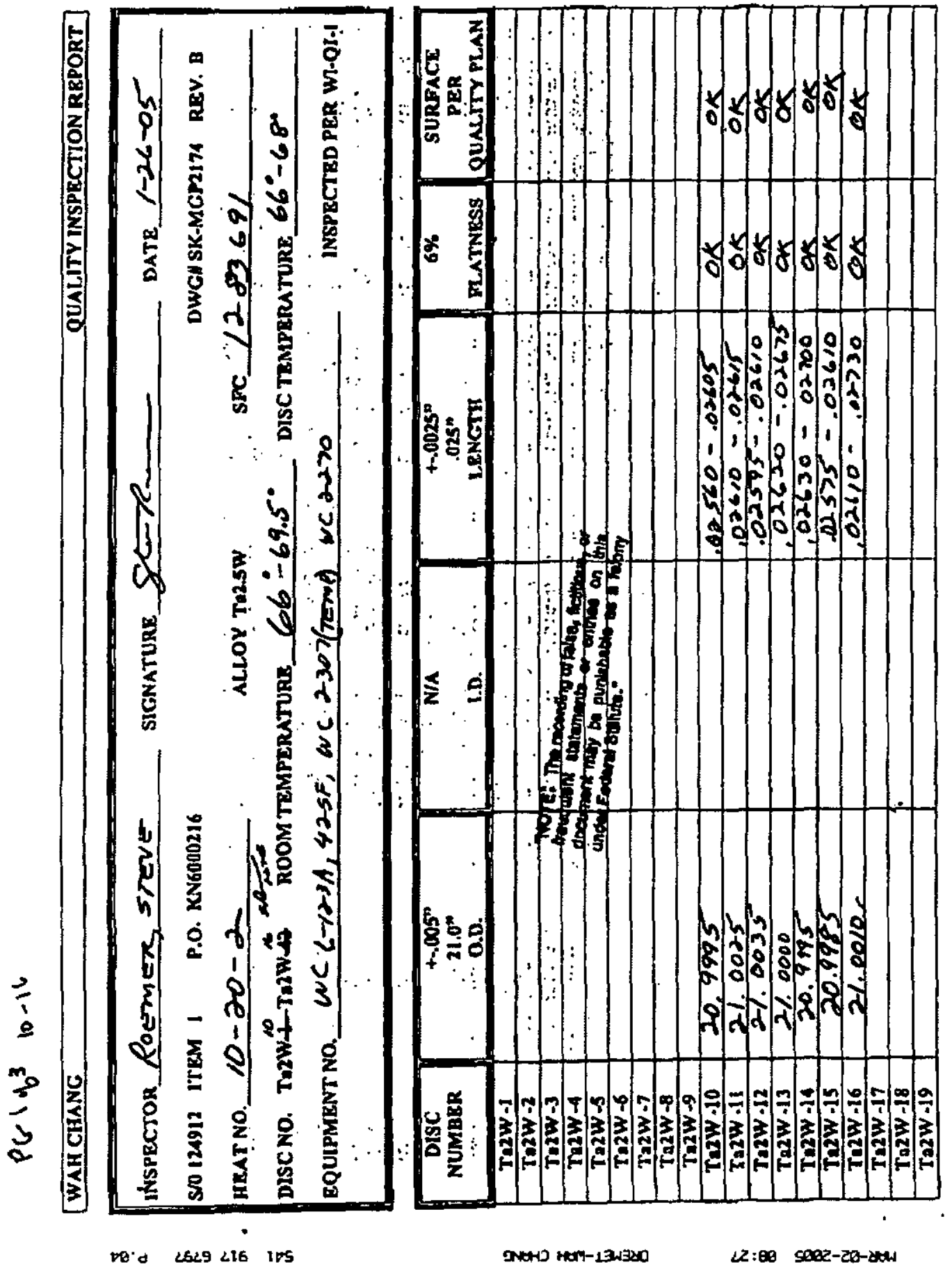




\section{B-TM-1639}

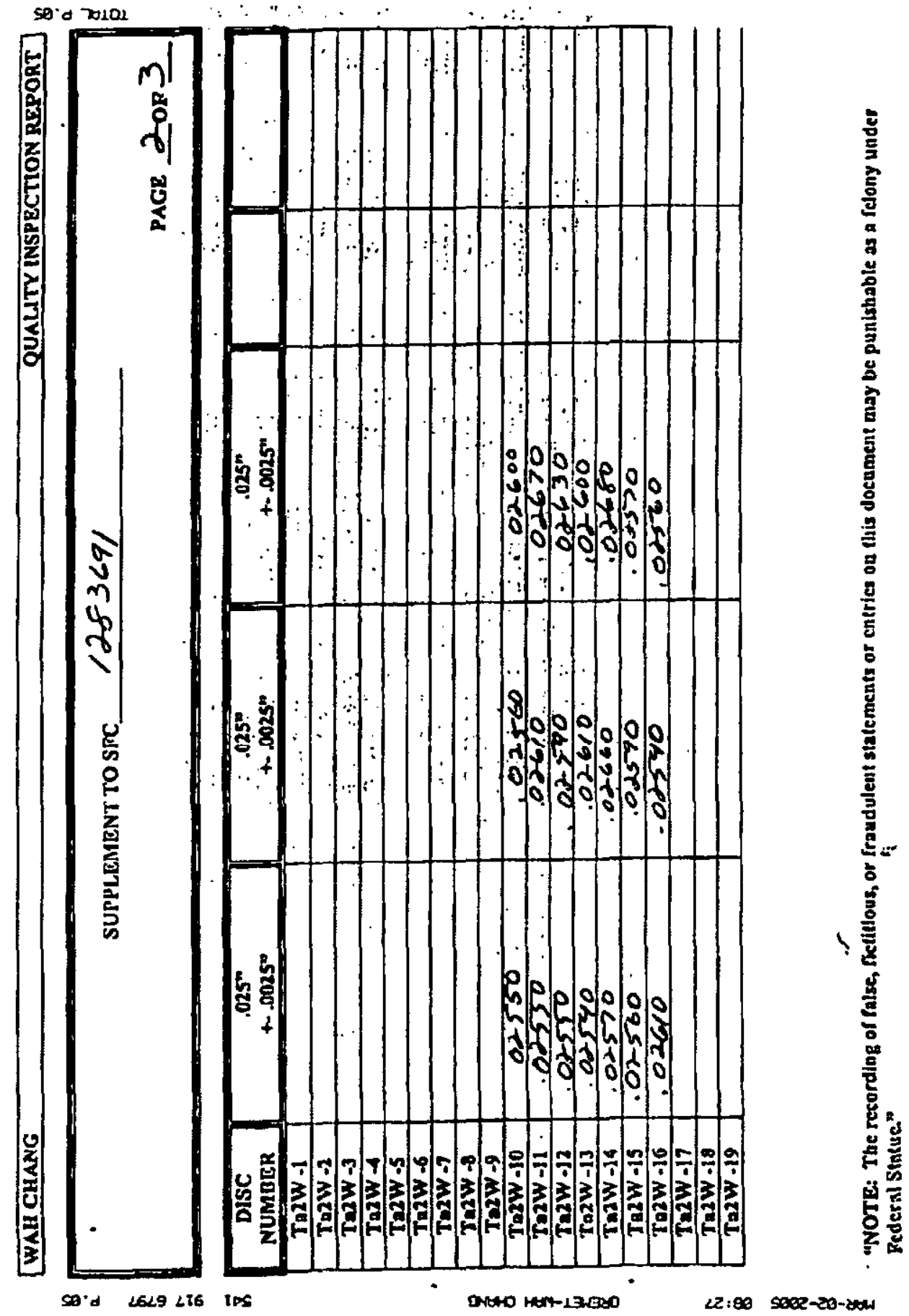




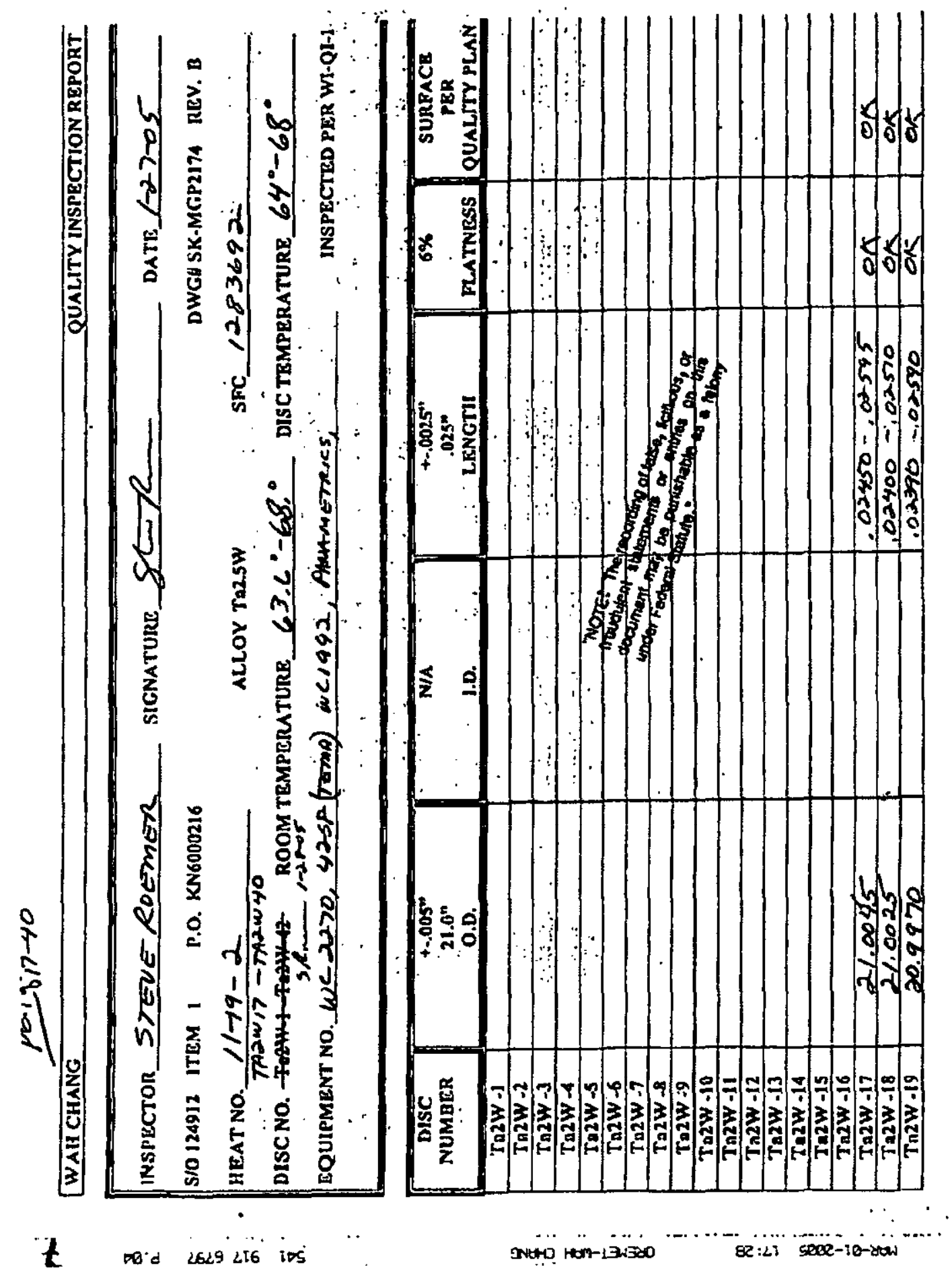




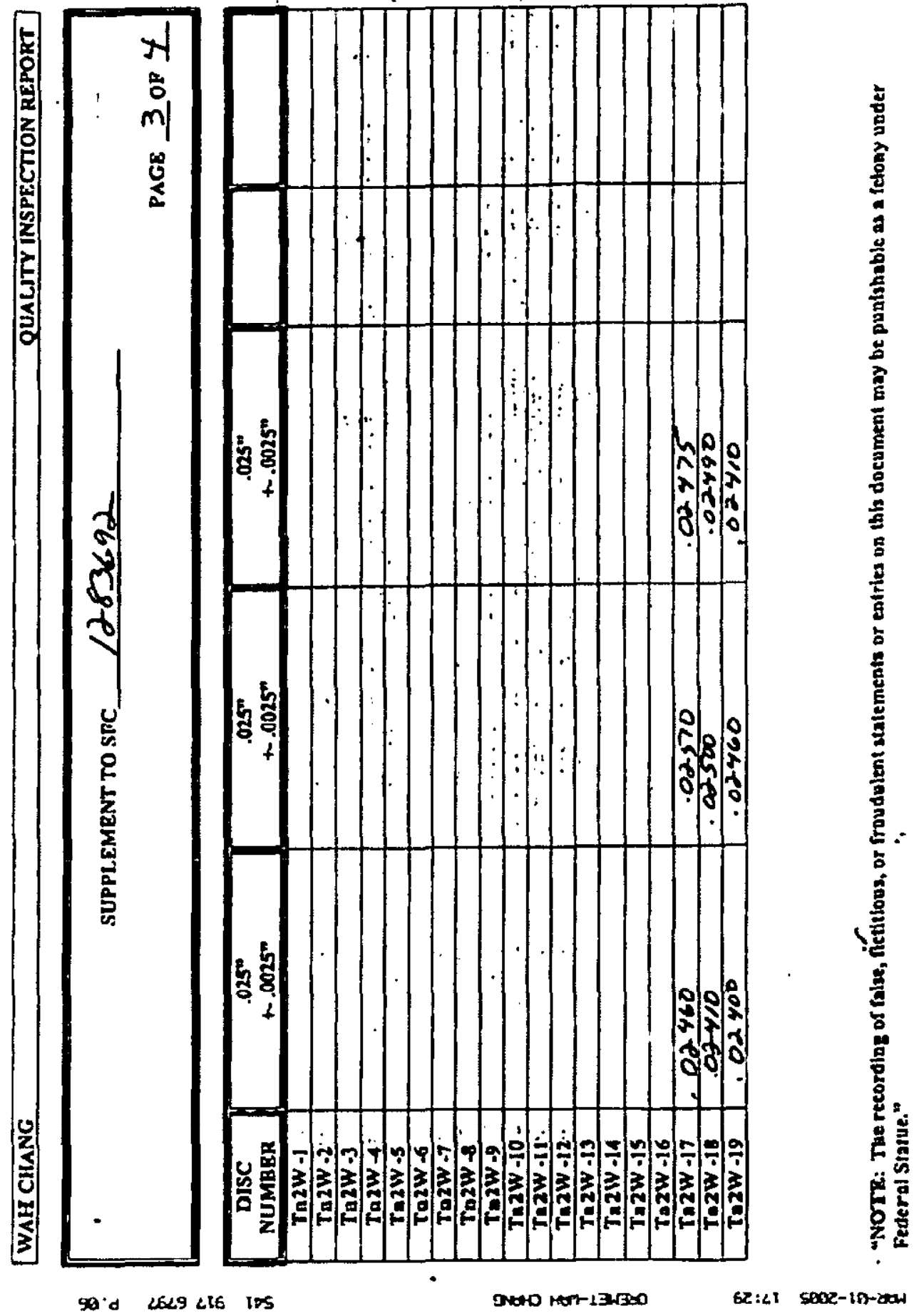




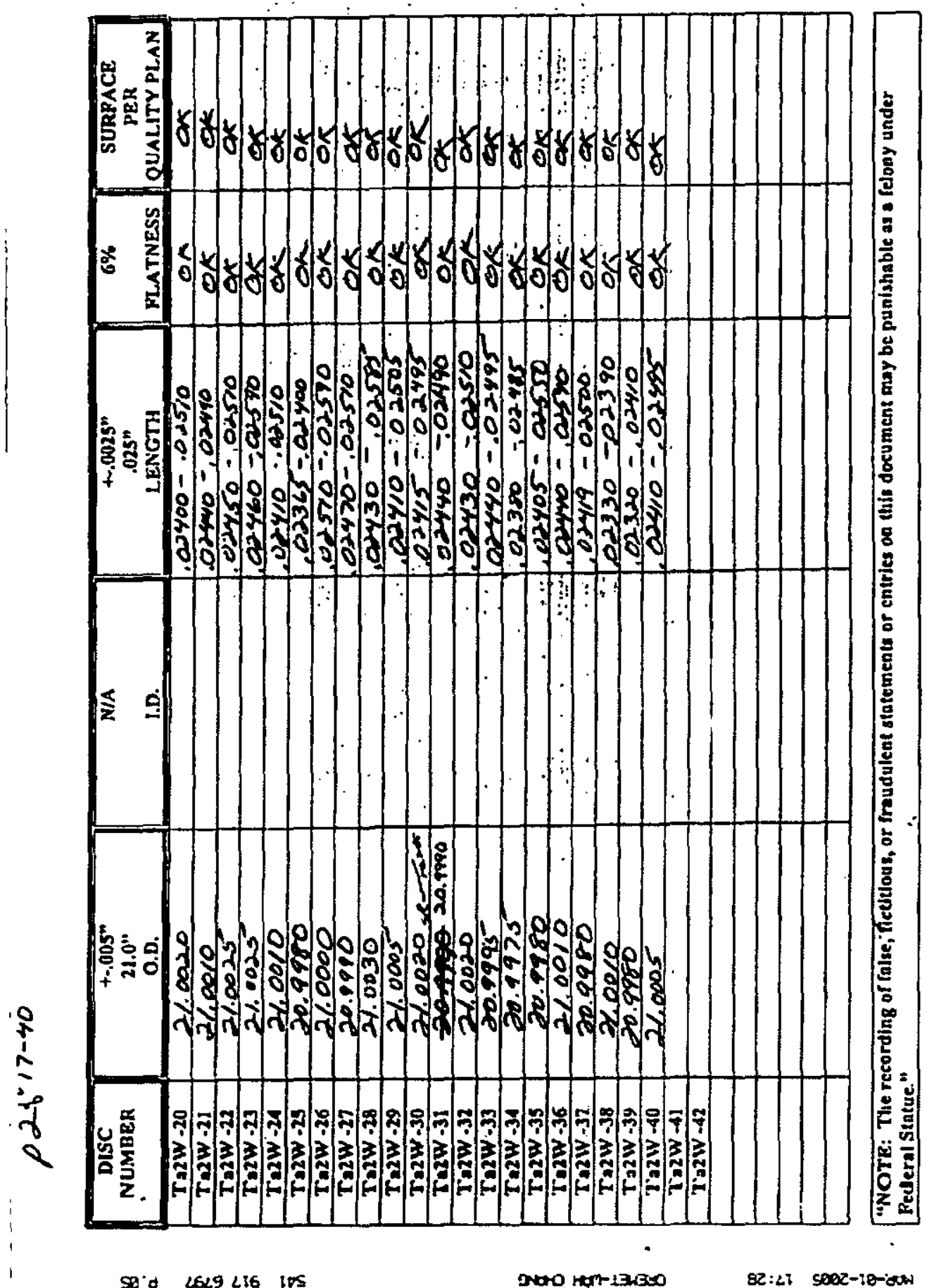


B-TM-1639

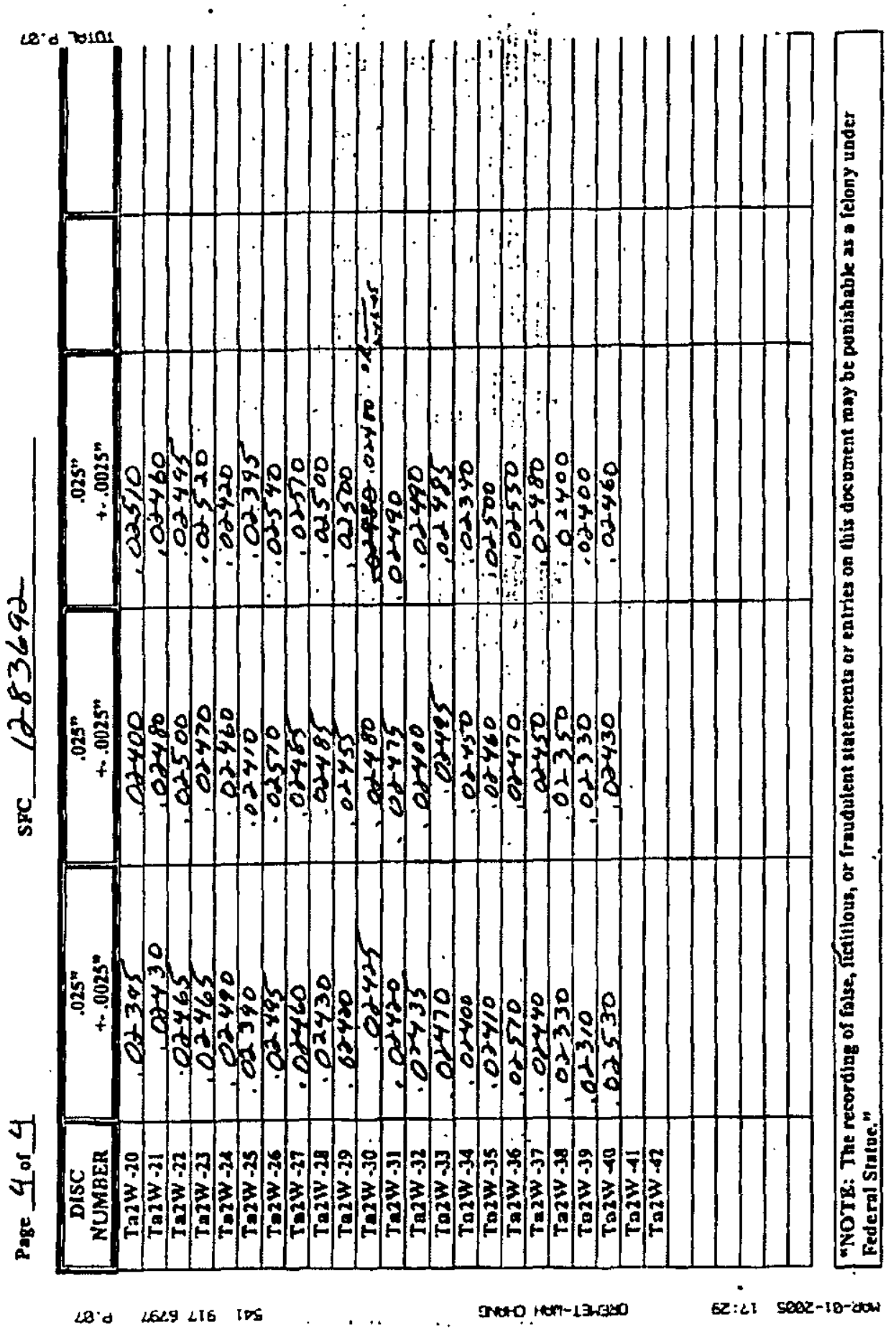


B-TM-1639

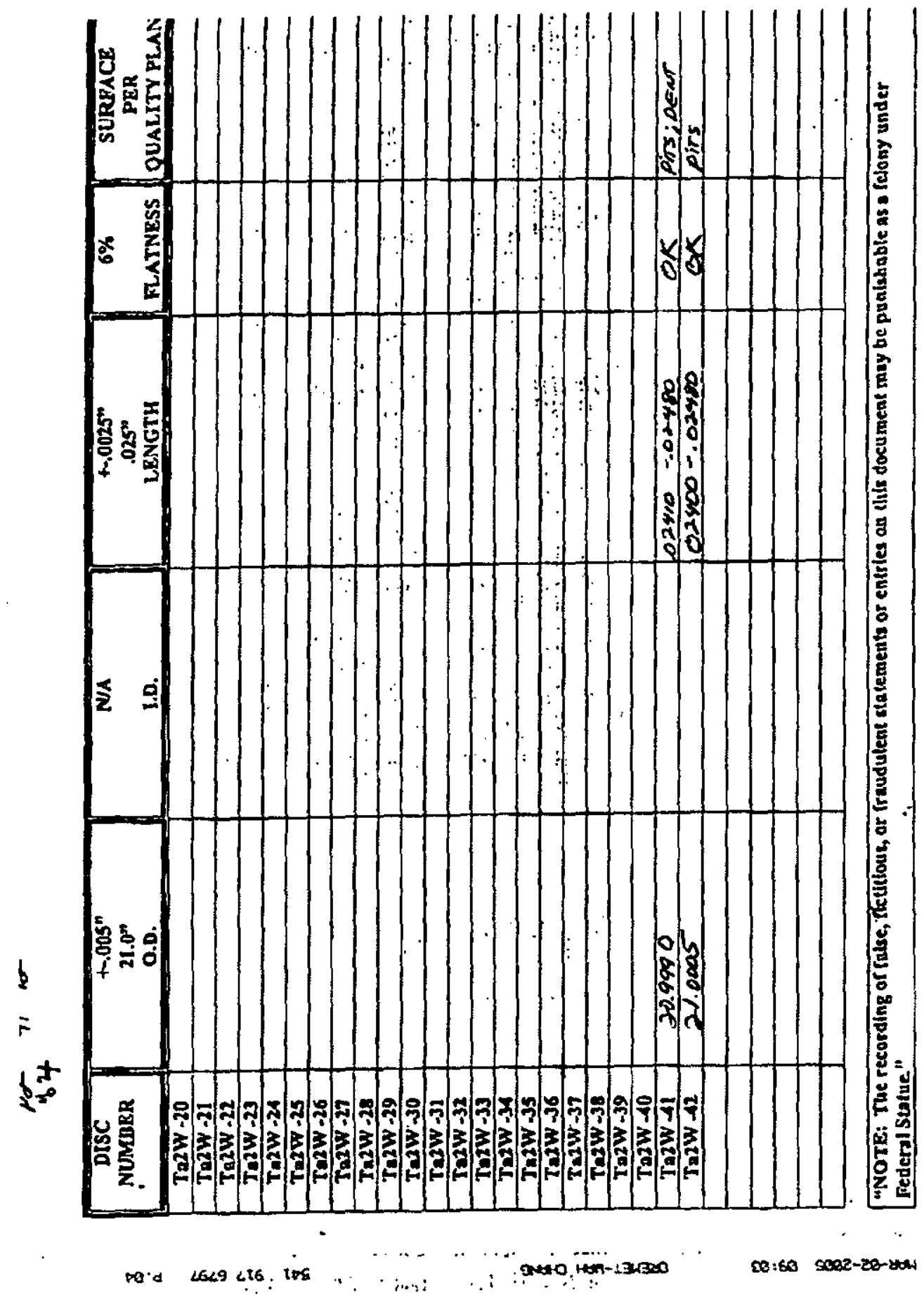


B-TM-1639

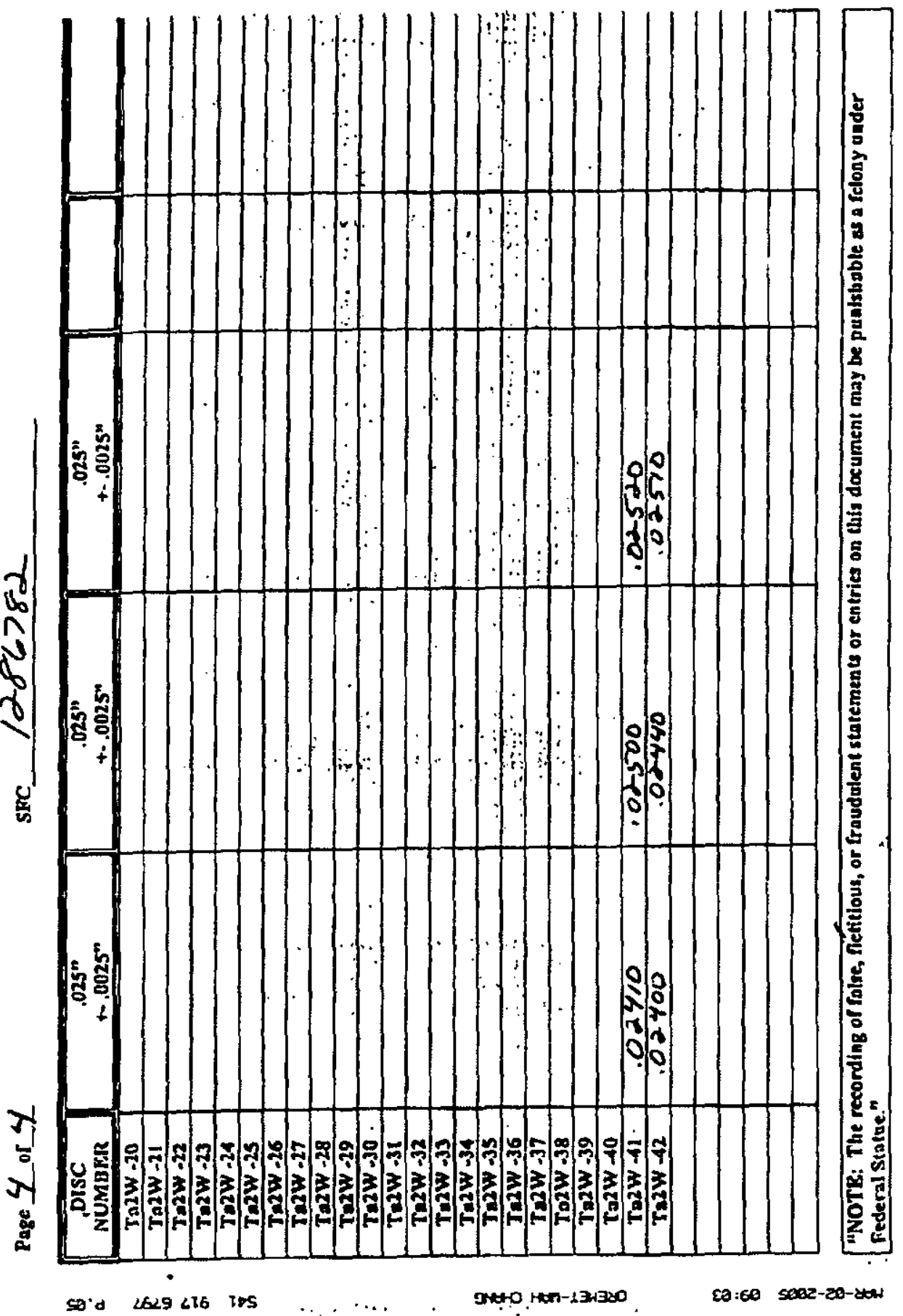


To:

Address:

KNOLLS ATOMC POWER LAB

POSOX 1072

Schenectady. NY 12301

Attention of. Accounts Payable
Doc. 210510 ver. 2 APPROVED. Page 1 of 2

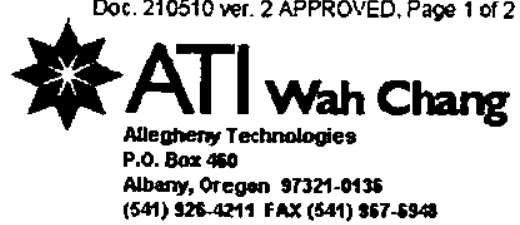

\section{PRODUCT CERTIFICATION}

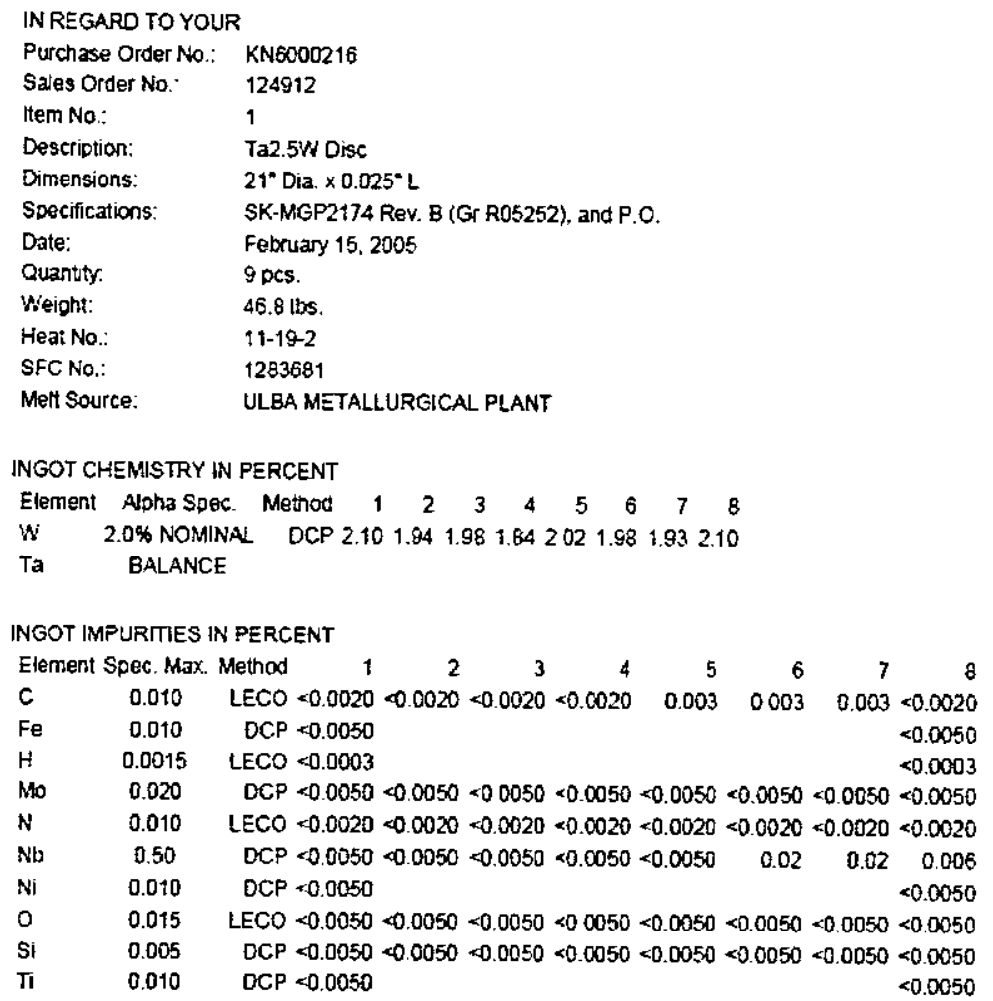

Cetriled BY: R Louie, QA Supervisor les 02/15/05

Wah Chang 1s A Registered / Certified ISO 9004:2000 Company. 
Purchase Oreer No: KN6000216

Sales Order No., $\quad 124912$

Item No:: 1

Heat No: $\quad 11-19-2$

SFC. No.: $\quad 1283681$

Doc. 210510 ver. 2 APPROVED. Page 2 of 2

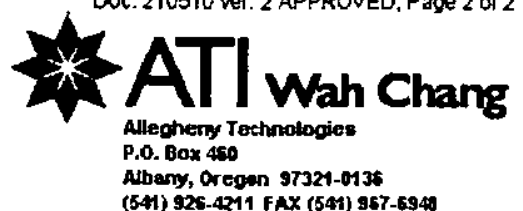

PRODUCT CHEMISTRY IN PERCENT

Element Alpha Spec. Top Top Middle Bottorn

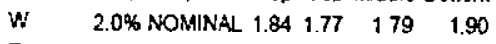

Ta GALANCE

PROCUCT IMPURITIES IN PERCENT

Element Spec. Max. Top

C $\quad 0.010 \quad 0.003$

Fe $\quad 0.010<0.0050$

$\mathrm{H} \quad 0.0015 \quad 0.0003$

tho $0.020 \quad 0.0050$

$N \quad 0.010 \quad 00020$

$\mathrm{Nb} \quad 0.50 \quad 0.02$

Ni $\quad 0.010 \quad 4.0050$

$0.015 \quad 0.0050$

Si $\quad 0.005<0.0050$

Ti $\quad 0.010 \quad 40.0050$

METALLOGRAPHY TEST (FOR INFO ONLY)

Tesi Units Results

Recrystallization: 100

MERCURY FREE STATEMENT

Wan Chang certfes that the product associated with this certification did not come in drect contact with mercury or any of its compounds during mansfacturing, testing, inspection, and packaging.

"Knowingly or willfulby recording of false, ficttious or fraudulent statements or entries on this document may be punished as a felany under Federal Statu*es induding Foderal Low. Title 18, Chapter 47." 
To:

Address:

NOLLS ATOMIC POWER LAE

PO BOX 1072

Schenectact. NY 12301

Aftention Of. Accounts Payable
Doc. 210504 ver 2 APPROVED Page i of 2

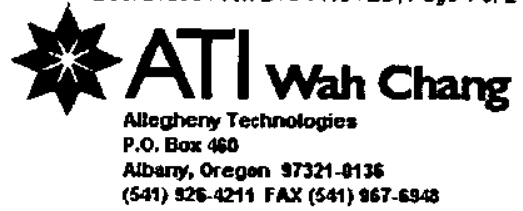

\section{PRODUCT CERTIFICATION}

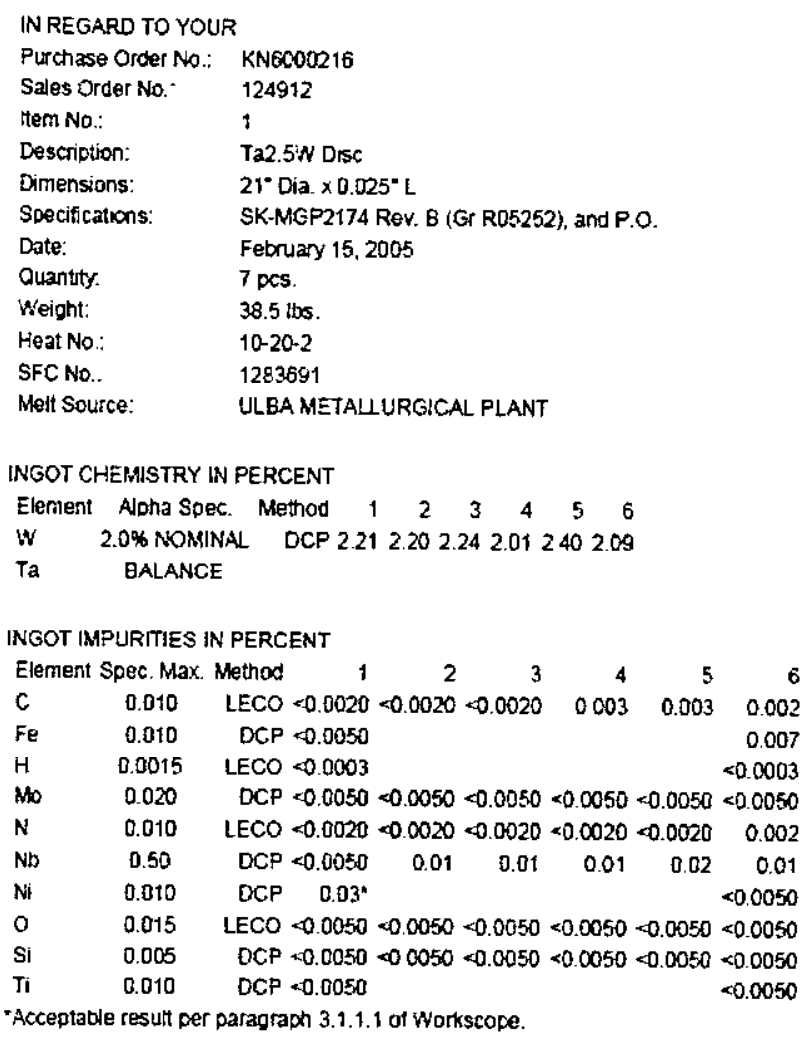

Wah Chang Is A Registered / Certitied I\$O 9001:2000 Company. 
Purchase Order No: KNGOOO216

Sales Order No.. $\quad 124912$

Itern No: 1

Heat No: $\quad 10-20-2$

SFC NO: $\quad 1283691$

Doc. 210504 ver 2 APPROVED, Page 2 of 2

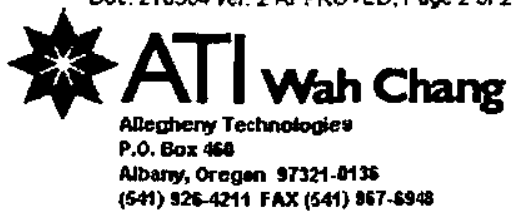

PRODUCT CHENISTRY IN PERCENT

Element Alpha Spec. Fop Too Midde Bottom

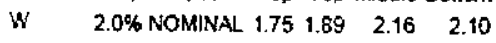

Ta BALANCE

PRODUCT IMPURITIES IN PERCENT

Element Spec. Max. Top

C. $\quad 0.010 \quad 0.003$

Fe $\quad 0.010 \quad 00050$

H. $\quad 0.0015 \quad 0.0003$

Mo $\quad 0.020<0.0050$

$N \quad 0.010 \quad \$ 0.0020$

$\mathrm{Nb} \quad 0.50 \quad 0.02$

Ni $\quad 0.010 \quad 20.0050$

$0 \quad 0.015 \quad 00.0050$

SI $\quad 0.005 \quad 40.0050$

$\mathrm{TI} \quad 0.910 \quad 0.0050$

METALLOGRAPHY TEST (FOR INFO ONLY)

Test Units Results

Recrystalization: $\quad \% \quad 100$

MERCURY FREE STATEMENT

Wal chang certfes that the product associated with this certification did not come in direct contact with mercury or any of th compounds during manufacturing, testing, inspection, and packaging

"Knowingly or willfully recording of false, fictitious or fraudulent statements pr entres on this document may be punished as a felony under Foderal Statutes including Federal La*, Tite 18, Chapter $47^{\circ}$ 
To:

Address:

KNOLLS ATOMC POWER LAB

POE BOX 1072

Sehenectady. NY 12301

Altention of. Accounts Payable
Doc. 210557 vet 3 APPROVED Page 1 of 2

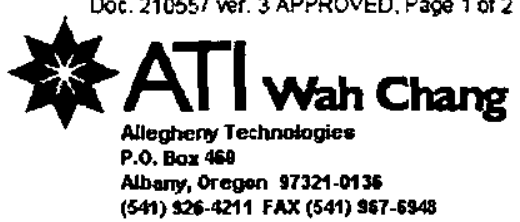

\section{PRODUCT CERTIFICATION}

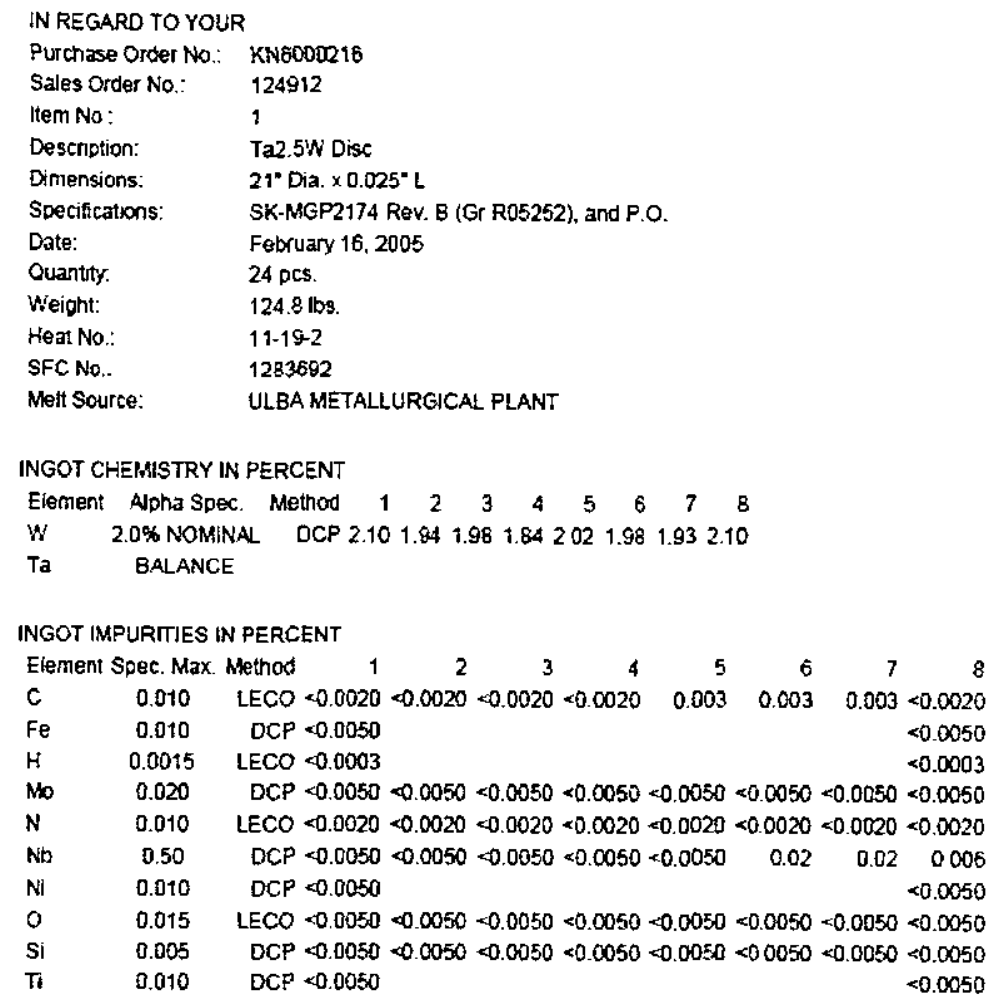

Certified By: R Louie, OA Supervisor les 02/16105

Wah Chang Is A Registered / Certified ISO 9001:2000 Company. 
Purchase Order No.: KN6000216

Sales Order No. $\quad 124912$

Item No: 1

Heat No:: 11-19-2

SFC No: $\quad 1283692$

Dot. 210557 ver. 3 APPROVED, Page 2 of 2

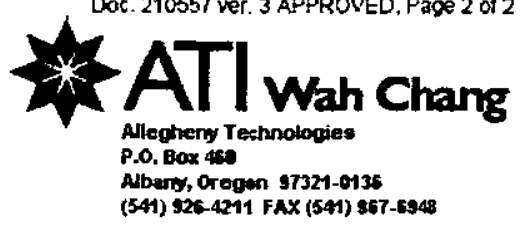

PRODUCT CHENISTRY IN PERCENT

Elemen: Apha Spec Top Top Middle Botion

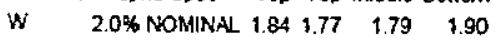

Ta GALANCE

PRODUCT IMPURIEIES IN PERCENT

Element Spec. Max. Top

$\begin{array}{lll}C & 0.010 & 0.003\end{array}$

Fe $\quad 0.010 \quad 40.0050$

H $\quad 0.00 \% 5 \quad 0.0003$

tho $\quad 0.020 \quad 0.0050$

$N \quad 0.010<0.0020$

Nb $\quad 0.50 \quad 0.02$

Ni $\quad 0.010<0.0050$

$0 \quad 0.015 \quad \$ 0.0050$

si $\quad 0.005 \quad 0.0050$

Ti $\quad 0.010 \quad 00.0050$

METALLOGRAPHY TEST (FOR INFO ONLY)

Test Units Results

Recrystalization: 100

MERCURY FREE STATEMENT

Wah Chang centries that the product associated with this certification dud not come in direct contact with mercury or any of its compounds during nuanufacturing, testing, inspection, and packaging.

"Knowingly or wilfully recording of false, fictitious of fraudulent statements or entries on this document may be punished as a fellony under Foderal Statutes ineluding Federal Law. Tite 18, Chapter 47." 
Attention Of. Accounts Payable
Doc. 210477 ver. 2 APPROVED, Page 1 of 2

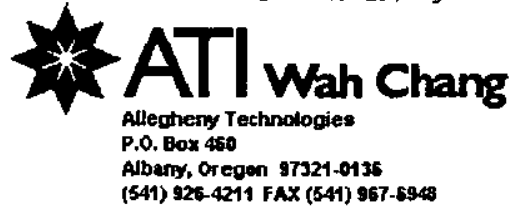

\section{PRODUCT CERTIFICATION}

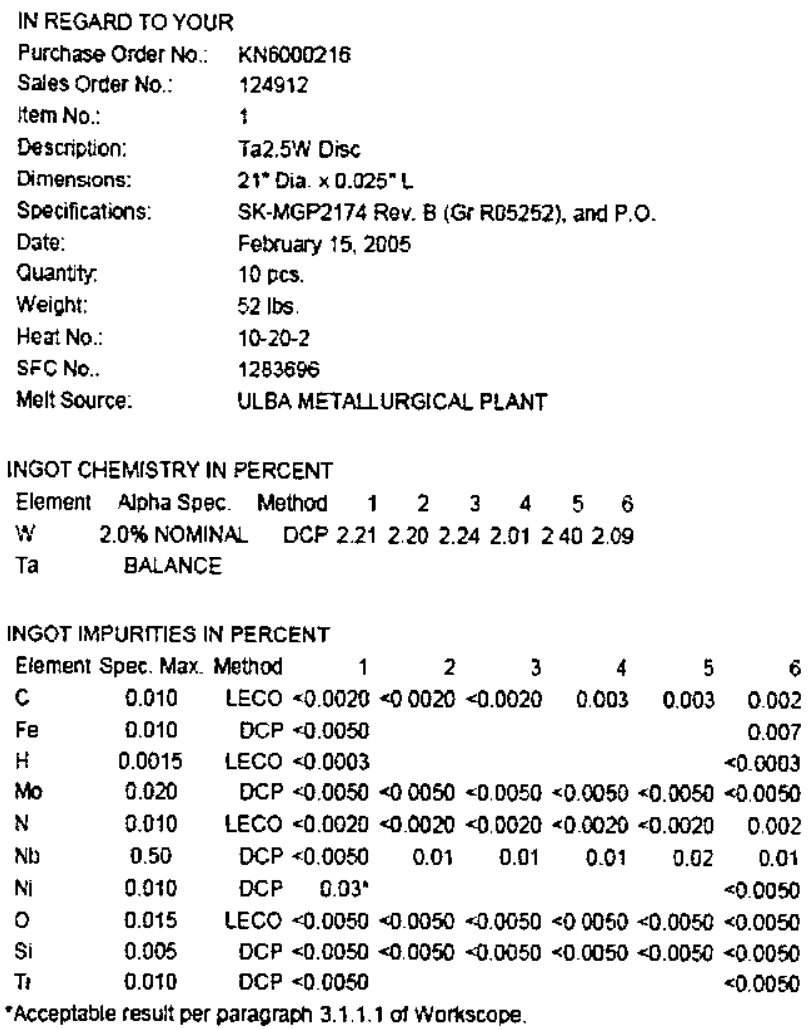

Wah Chang is A Registered / Certified IS0 9001:2000 Company. 


\section{B-TM-1639}

Purchase Orcer No: KN6000216

Sales Order Ho. $\quad 124912$

Iten No: $\quad 1$

Heat No: $\quad 10-20-2$

SFC NO: $\quad 1283696$

DOC. 210477 ver. 2 APPROVED. Page 2 of 2

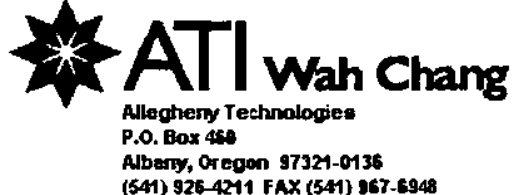

PRODUCT CHEMLSTRY IN PERCENT

Element Aloha Spec Jop Top Middle Botion

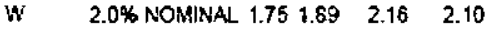

Ta BALANCE

PRODUCT IMPURITIES IN PERCENT

Element Spec. Max Top

C $\quad 0.010 \quad 0.003$

Fe $\quad 0.010 \quad 00050$

H $\quad 0.0015 \quad 0.0003$

Mo $\quad 0.020<00050$

N $\quad 0.010 \quad 80020$

N.2 $\quad 0.50 \quad 0.02$

Ni) $\quad 0.010 \quad 00050$

$0 \quad 0.015<0.0050$

Si $\quad 0.005<00050$

$\mathrm{T} \quad 0.010 \quad 0.0050$

METALLOGRAPHY TEST (FOR INFO ONLY)

Test Units Results

Recrystallization: * 100

MERCURY FREE STATEMENT

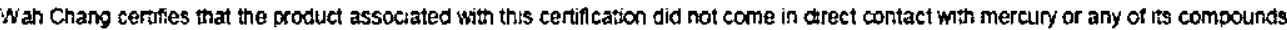
during manufacturing, testing, inspection, and packaging.

"Krowingty or wilfully recorcing of false, ficttious or fraudulent statements or entnes on this document may be punished as a telony under Federal Sta:ures including Federal Law, Tilie 18, Cnapter 47." 
To:

Address:

KNOLLS ATOMC POWER LAE

POBOX 1072

Schenectady. NY 12301

Attention Of Accounts Payable
Doc. 210544 ver. 3 APPROVED. Page 1 of 2

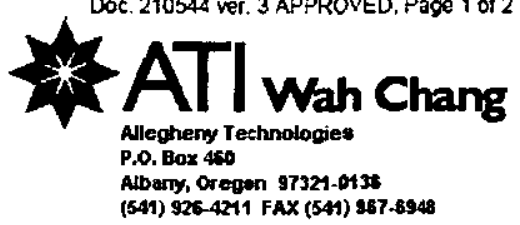

\section{PRODUCT CERTIFICATION}

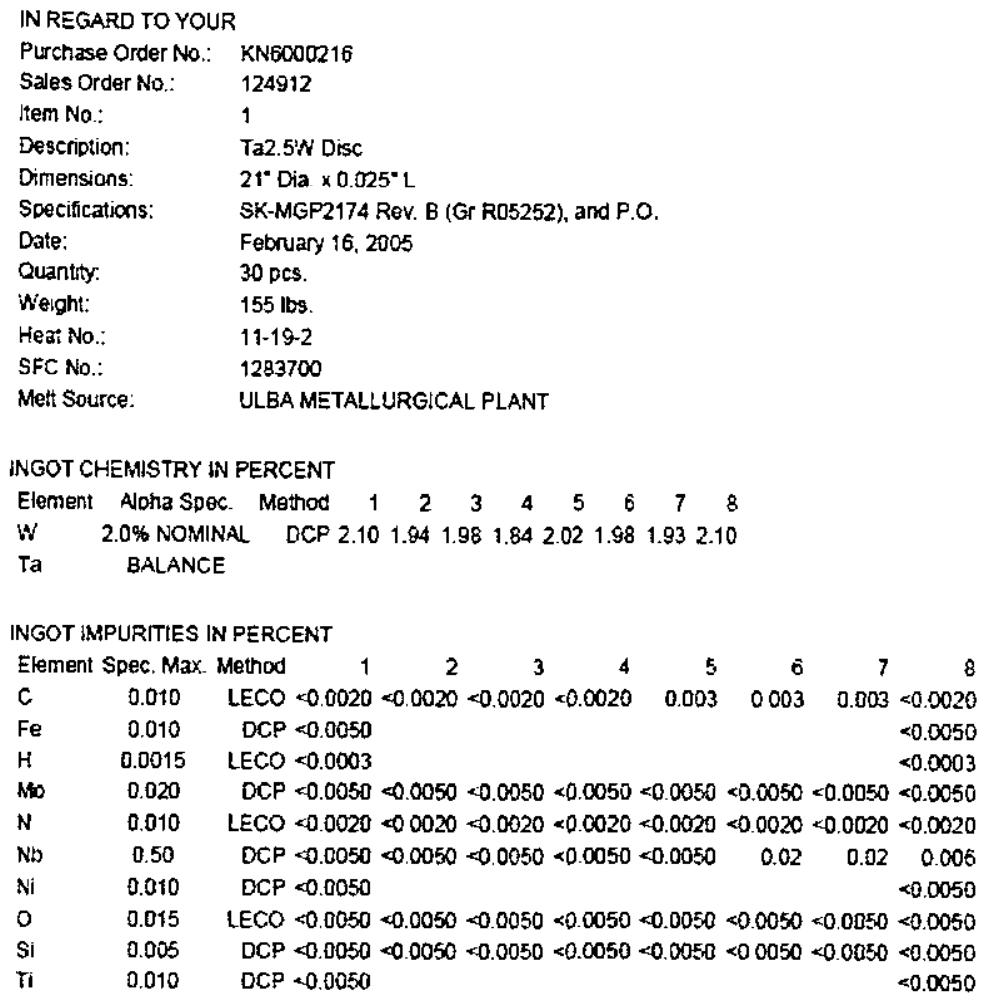

Certifled By: R Loule, OA Supervsor los 02/16ros

Wah Chang is A Registered r Certified Iso g004:2000 Company. 
Purchase Order No.: KNG000216

Sales Ordel No. $\quad 124912$

Iten No: $\quad 1$

Heat No: $\quad$ 11-19-2

SFC NO: $\quad 1283700$

Jac. 210544 ver. 3 APPROVED, Page 2 of 2

CHEMISTRY IN PERCENT

Etement Alpha Spec. Top Top Middle Botion

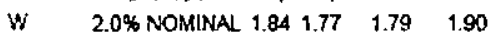

Ta BALANCE

PRODUCT IMPURITIES IN PERCENT

Element Spec. Max. Top

C $\quad 0.010 \quad 0.003$

Fe $\quad 0.010 \quad 0.0050$

H. $\quad 0.0015 \quad 0.0003$

no $\quad 0.020 \quad 0.0050$

$N \quad 0.010 \quad 0.0020$

Nh $\quad 0.50 \quad 0.02$

Ni $\quad 0.070 \quad 00050$

$0 \quad 0.015 \quad \$ .0050$

S1 $\quad 0.005 \quad 00.0050$

TI $\quad 0.010 \quad 00050$

METALLOGRAPHY TEST (FOR INFO ONLY)

Test Units Results

Recrystallization; \% 100

MERCURY FREE STATEMENT

Wah chang ceraties that the product associated with this certifleation did not come in direct contact with mercury or any of its compounds during mantficturing, testing, inspection, and packaging.

"Knowingty or willuly recording of false, fictitious or traudulent statements or entries on this document may be punished as a fekany under Federal Statures induding Federal Law, Titte 18, Chapter 47. 
To

KNOLLS ATOWLC POWER LAB

Address: POBOX 1072

Schenectady, NY 12301

Attention ot. Accounts Payable
Dor 210505 wer 2 ApPROVED Page 1 of 2

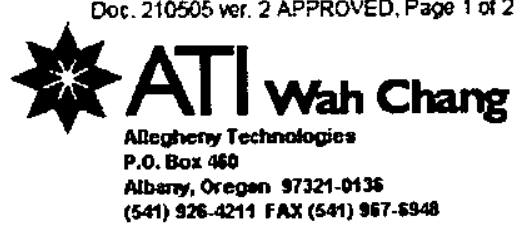

\section{PRODUCT CERTIFICATION}

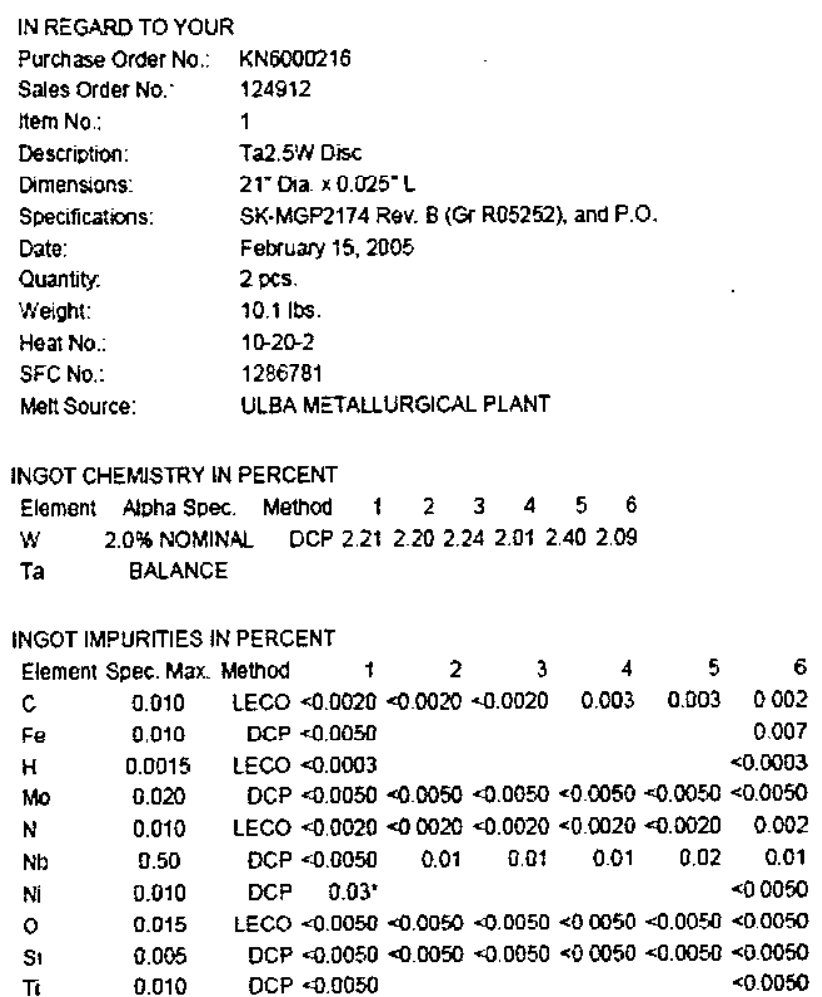

Wah Chang is A Registered / Certified 1\$0 9001:2000 Company. 
Purchase Order NO: KN6000216

Sades Order No. $\quad 124912$

Iterm No.: 1

Heat No.: $\quad 10-20-2$

SFC NO: $\quad 1285761$

Doc. 210505 ver. 2 APPROVED. Page 2 of 2

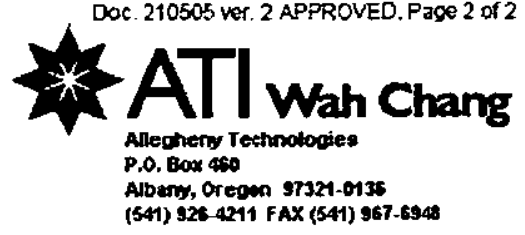

PROOUCT CHEMISTRY WN PERCENT

Element Aloha Spec. ToO ToD Middle Botiom

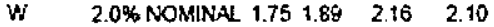

Ta GALANCE

PRODUCT IMPURITIES IN PERCENT

Element Spec. Max. Top

$\begin{array}{lll}C & 0.010 \quad 0.003\end{array}$

$\mathrm{Fe} \quad 0.010 \quad 000050$

H $\quad 0.0015 \quad \$ 0.0003$

No $\quad 0.020 \quad 0.0050$

$N \quad 0.010 \quad 0.0020$

$\mathrm{Nab} \quad 0.50 \quad 0.02$

Ni $\quad 0.010 \quad 0.0050$

$0 \quad 0.015 \quad \$ 0.0050$

Si $\quad 0.005<00050$

$\mathrm{TI} \quad 0.010 \quad 0.0050$

METALIOGRAPHY TEST (FOR INFO ONLY)

Tes: Units Results

Recrystallization: *6 100

MERGURY FREE STATEMENT

Wan chang certhes that the product associated with this certification did not come in difect contact with mercury or any of its compounds curing manufacturing, testing, inspection, and packaging.

-Knowingly or wilfully recording of false, fletitious or iraudulent statements or entries on this document may be putnished as a felpny under Federal Stziutes including Federal Lay. Tita 19, Chacter 47. 
To:

Address:

KNOLLS ATOWIC POWER LAB

POBOX 1072

Schenectady, NY 12301

Aftention Ot: Accounts Payabla
COC. 210503 ver 2 APPRONED Page 1 of 2

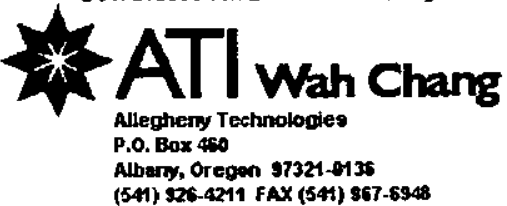

\section{PRODUCT CERTIFICATION}

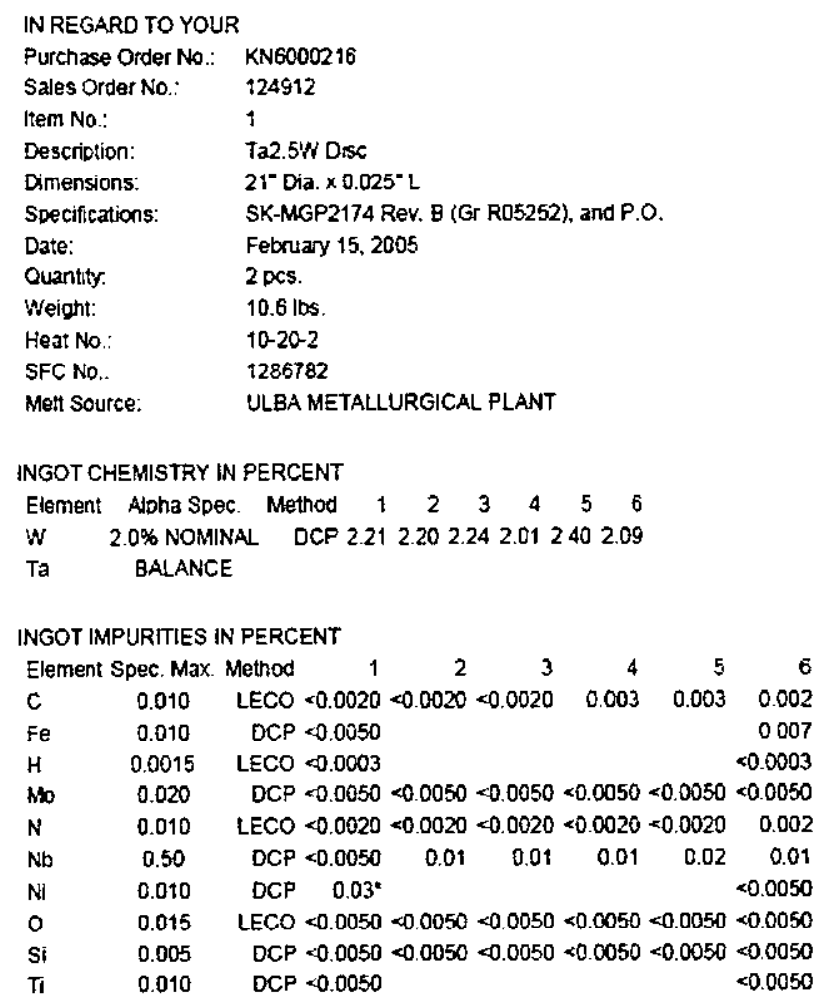

Wah Chang is A Registered / Certified Iso 9009:2000 Company. 
Purchase Order No:: KNG000216

Sales Order No.. $\quad 124912$

Item No: 1

Heat No: $\quad 10-20-2$

SFC No.: $\quad 1286782$

Doc. 210503 ver. 2 APPROVED. Page 2 of 2

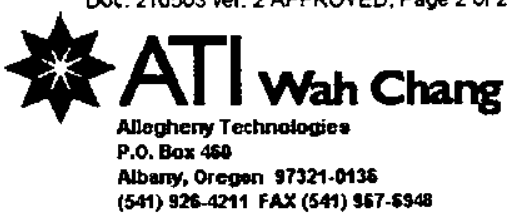

PRODUCT CHEMISTRY IN PERCENT

Element Aloha Spec Top ToD Middle Botion

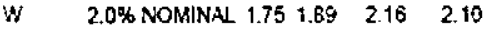

Ta BALANCE

PRODUCT IMPLRITIES IN PERCENT

Element Spec. Max. Top

$\begin{array}{lll}\text { C } & 0.010 \quad 0.003\end{array}$

Fe $\quad 0.010 \quad \$ .0050$

H. $\quad 0.0015 \quad 00.0003$

Mo $\quad 0.020 \quad 40.0050$

$N \quad 0.010 \quad 0.0020$

$\begin{array}{lll}\mathrm{Nb} & 0.50 \quad 0.02\end{array}$

$\mathrm{Ni} \quad 0.010 \quad 0.0050$

$\begin{array}{lll}0 & 0.015<0.0050\end{array}$

Si $\quad 0.005 \quad 00050$

TI $\quad 0.010 \quad 0.0050$

METALLOGRAPHY TEST (FOR INFO ONLY)

Tesi Units Resuts

Recjystalization: \% 100

MERCLRY FREE STATEMENT

Wah Chang certifies that the product associated with this certucason did not come in direct contact with mercury or any of its compounds during manufacturing, testing, inspection, and packaging.

"Knowingly or willfuly recording of false, fictitious or fraudulent statemems or enties on this docurnent may be punished as a felony under Foderal Siatures including Feceral Law, Tíle 18, Chapter 47." 


\section{Appendix I}

\section{1" Thick Graphite Plate Inspection Reports}


B-TM-1639

(Intentionally Blank) 
SalesOrder. Boops A 1

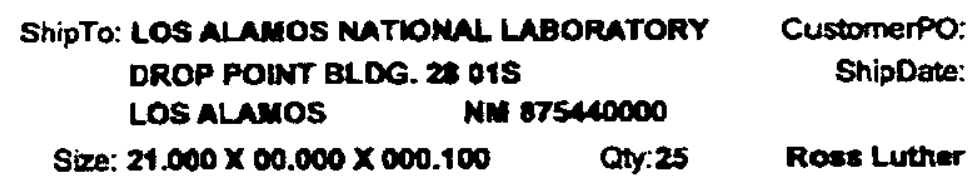

This is to cortify that the material thiond en the above numberd order Is UCAR orophitegrate PGX

BD: Bulk density (GKC)

SR: Specific Resistance (Micno-OHM-Meters)

$\begin{array}{lllll}\text { FO } & \text { BD } & \text { SR } & \text { Fumaco } & \text { Run } \\ \text { TRS17HMo01 } & 1.732 & 11.172 & 55 & 274 \\ \text { FO } & \text { Thickness } & \text { Width } & \text { Length } & \\ \text { TRS17M4001 } & 20.870 & 0 & 78.268 & \end{array}$


2-Fob-05

CERTIFICATE OF QUAUTY CONFORMTTY

SalesOrder. BOoo4 A 2

\author{
ShipTo: LOS ALAMOS NATIONAL LABORATORY \\ DROP POAT BLDG. 28019 \\ CustomerPo: 300476: \\ LOS ALAMOS NM 87540000 \\ Size: $21.000 \times 02510 \times 000.100 \quad$ Oty:25 Ross Luther
}

This is to certily that the matorial shiped on the sbove numbercd ordar la UCAR grophlende PGX

\begin{tabular}{|c|c|c|c|c|}
\hline \multicolumn{5}{|c|}{$\begin{array}{l}\text { BD: Bulk density (G/CC) } \\
\text { SR: Specific Resistanoe (Micro-OHM-Meters) }\end{array}$} \\
\hline $\begin{array}{l}\text { FO } \\
\text { TRS17H4001 }\end{array}$ & $\begin{array}{l}\text { BD } \\
1.732\end{array}$ & $\begin{array}{l}\text { SR } \\
11.172\end{array}$ & $\begin{array}{l}\text { Fumace } \\
\mathbf{5 s}\end{array}$ & $\begin{array}{l}\text { Run } \\
\mathbf{2 7 4}\end{array}$ \\
\hline Fo & Thickness & Width & Length & \\
\hline TRS17H4004 & 30.870 & 0 & 70.208 & \\
\hline
\end{tabular}


B-TM-1639

Appendix J

Polyethylene Plate Inspection Reports 


\section{B-TM-1639}

(Intentionally Blank) 
B-TM-1639

plastic rupply mo.

340 Gind $N$

Abuandon. M 67107

Cos 090007

PAx $600-\sec 0 \mathrm{cos}$

CERTIRICATE OP CONFORHITY

cuatomar Mamo STANDAR MACH

Addros: 2933 Ranchites Loep N.E

Customer P.0.*15867

Material HO Poly

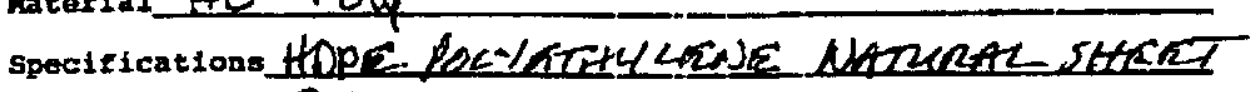
Manufacturor Poly $-H_{1}$

Dascription $1 \frac{1 / 2}{2}$ Theak $-3 / 4$ THerk $-1 / 8$ THICk

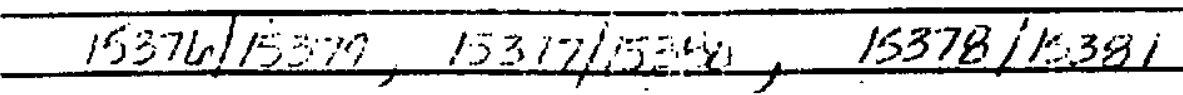

Supplied on Involco $\leqslant 106185$

Date $8-17-05$

signed

Plastic Supply Ine.

Anet

J-3 
B-TM-1639

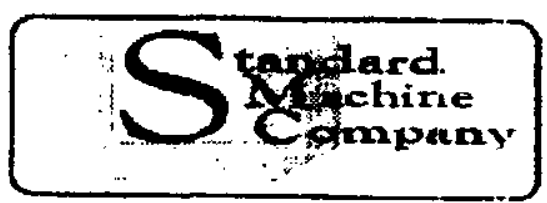

Form " SMClO1?

7933 Ranchitos Loop $\mathrm{NE}$

Alboquerqde, NM 87113

Fi: (\$0s) $890-2124$

Fax (505) 890-1126

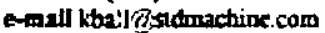

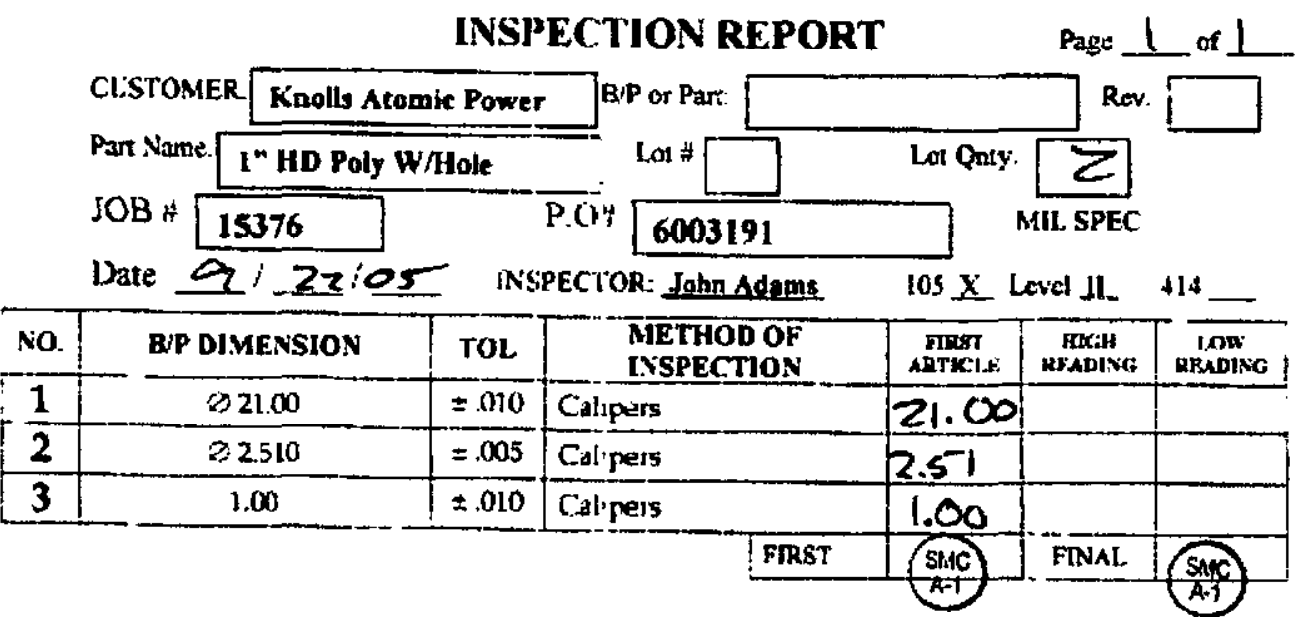


B-TM-1639

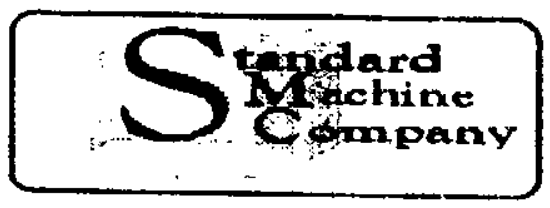

Form * SuC1012

2933 Ranclicos Loop NE

Abuquerque NM 8311.3

PH: (sis) $\times 90-1131$

$\operatorname{Tax}(505)$ 490-1126

e-matil kbail $\tilde{g}$ dd mach ine.com

INSPECTION REPORT

Page

CUSTUMER: Knodls Alomic Power Bre or Pan:

Part Nane: .50" HD Poly W/Hole

IOB \# 15377 P.O

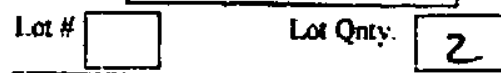

Rev.

Date 9122105

6003191

MIL SPEC

\begin{tabular}{|c|c|c|c|c|c|c|c|}
\hline & $912 \geq$ & & PECIOR: & dame & $105 X_{-}$ & vel II. & 414 \\
\hline NO & BP DIMENSION & TOL & $\begin{array}{l}\mathrm{ME} \\
\text { UN }\end{array}$ & $\begin{array}{l}\text { OF } \\
\text { ION }\end{array}$ & $\begin{array}{c}\text { FIRST } \\
\text { ARTICLE }\end{array}$ & $\begin{array}{c}\text { Hugh } \\
\text { RENDLe }\end{array}$ & $\begin{array}{c}\text { Lok: } \\
\text { READNA: }\end{array}$ \\
\hline 1 & 021.00 & \pm .010 & Calipers & & 21.0 & & \\
\hline 2 & 02.510 & \pm .005 & Caipers & & 2.51 & & \\
\hline 3 & .50 & $: \pm .010$ & Calipers & & 5 & & \\
\hline & & & & FIRST & & FNAL & \\
\hline
\end{tabular}


B-TM-1639

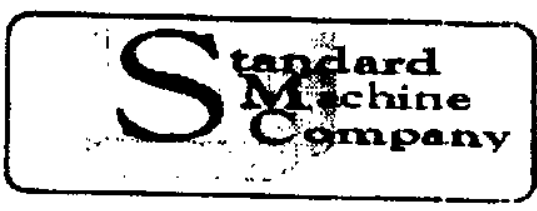

Form * SMchalz

7933 Ranctiolos Loop NE Altuguerque, NM 87113

PH: (s0s) 890-1124

Pux (505) $890-1126$

c-mail kballatistenachine com

\section{INSPECTION REPORT}

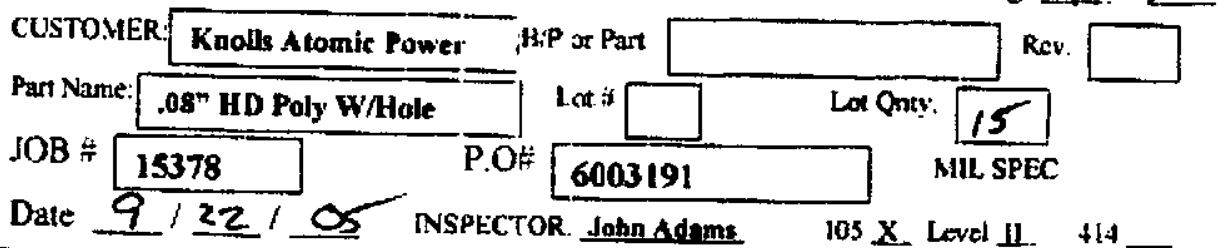

Date $9 / 22 /$ OS INSPECTOR John Adnm:

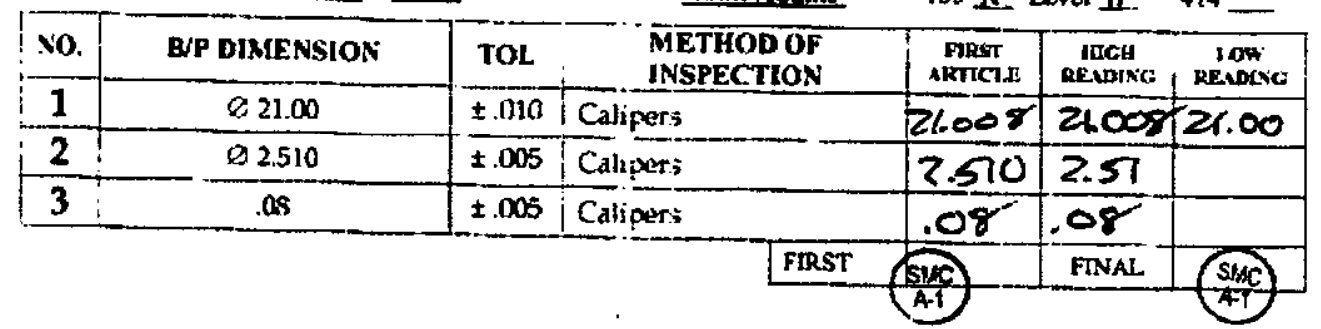




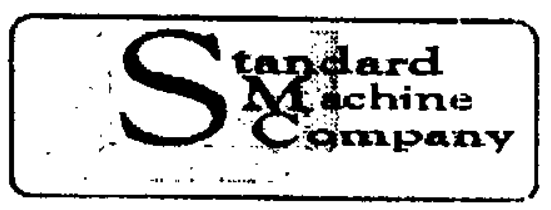

Form $\$ \underline{\text { SMCLOL1 }}$

7933 Ranfiticos Loog NE

Albuxquerque. WM 8711 ?

PH: (505) 890-1124

Fax (305) 89i-1 126

enail thallg grturachine.com

INSPECIION REPORT

Page $\leq$ of 1

CUSTOMER: Knolls Atomic Power
Part Name: I- HD Poły
JOR $\$: 1539$

15379

P.OH

6003191 MIL SPEC

Date 9 /222' OS INS'ECTOR John Adam

$105 \times$ Level $11 \quad 414$

\begin{tabular}{|c|c|c|c|c|c|c|}
\hline No. & B'P DIMENSION & TOL & $\begin{array}{l}\text { METHOO OF } \\
\text { IXSPECTION }\end{array}$ & $\begin{array}{c}\text { FTROT } \\
\text { AMTICLE }\end{array}$ & $\begin{array}{c}\text { Hach } \\
\text { KEADING }\end{array}$ & $\begin{array}{c}\text { LOW } \\
\text { RENOING } \\
\end{array}$ \\
\hline 1 & 021.00 & \pm .010 & Calupers & 21.00 & & \\
\hline 2 & 1.00 & \pm .010 & Calpers & 1.00 & & \\
\hline & & & $F 1 R$ & & FINAL. & \\
\hline
\end{tabular}




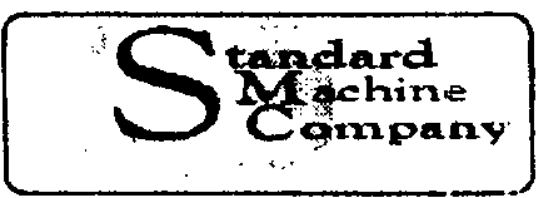

Fara * SNC1012

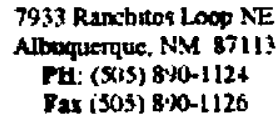

INSPECTION REPORT

Page _ I of 6

CUSTOMER Knoth Atomic Pawer rof in Part. Lot $\quad$ Lat Qunts. 2

Part Name.

$.50^{\text {* HD Poly }}$

P.O:

6003191

MIL SPEC

$\mathrm{JOB} \neq 15380$

Date 9 22 o5 NSIECCTOR Eohnddams

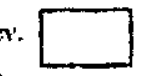

\begin{tabular}{|c|c|c|c|c|c|c|}
\hline No. & B/P DIMENSION & TOL. & $\begin{array}{l}\text { METHOD OF } \\
\text { IASPECIION }\end{array}$ & $\begin{array}{l}\text { suss } \\
\text { ARTice }\end{array}$ & $\begin{array}{c}\text { mugt } \\
\text { Heferd } \mathrm{AC}\end{array}$ & 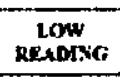 \\
\hline 1 & 221.00 & \pm 0.010 & Calipers & 21.0 & 21.00 & \\
\hline 2 & .50 & $\$ .010$ & Cali 1 kers & 50 & .50 & \\
\hline & & & $\overline{\text { FIRST }}$ & 4 & $\overline{\text { FINAL }}$ & 5 \\
\hline
\end{tabular}




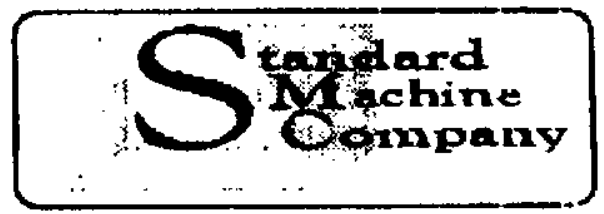

farm \# SNClon?

7933 Ranzhitos Loop NE

Albuquerque. NM 87) (3

P1i. (505) 890-1 124

$\operatorname{Fax}(505) 890.1126$

e-mati kbilliâstumachine.com

INSPECTION REPORT

Page 1 of 1 -

CUSTOMER: Knolls Atomic Power

Part Nane:

.08" HD Poly

$\mathrm{JOB}=15381$

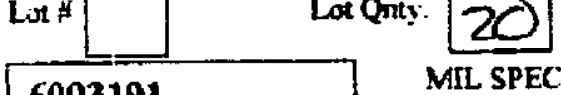

Date $9 / 2 z / Q S$ INS.ECTOR Johnddums

$105 x$ Level II $\quad 414$

\begin{tabular}{|c|c|c|c|c|c|c|c|}
\hline No. & BAP DIMENSION & TCIL & \multicolumn{2}{|c|}{$\begin{array}{l}\text { METHODOF } \\
\text { IMSPECTION }\end{array}$} & $\begin{array}{c}\text { Frnst } \\
\text { Anticte } \\
\end{array}$ & $\begin{array}{c}\text { ILOA } \\
\text { REAbINC: }\end{array}$ & $\begin{array}{c}\text { Low } \\
\text { READINC }\end{array}$ \\
\hline 1 & 021.00 & \pm .0110 & Calipers & & 7.00 & $210 x$ & \\
\hline 2 & .08 & \pm .105 & Calipers: & & & .08 & \\
\hline & & & & FIRST & & FDNAL & \\
\hline
\end{tabular}


B-TM-1639

(Intentionally Blank) 